\title{
URBAN MICROCLIMATE ANALYSIS FOR HIGH PERFORMANCE OFFICE BUILDINGS
}

\author{
BY \\ JING LI
}

\begin{abstract}
A thesis
Submitted to Victoria University of Wellington

in fulfilment of the requirements for the degree

Doctor of Philosophy

in

Architecture
\end{abstract}

Victoria University of Wellington 


\section{ACKNOWLEDGEMENTS}

During my PhD, I got lots of help from many nice and important people. I would like to express my deepest gratitude to them.

I would like to thank my academic supervisor, Prof. Michael Donn for his expertise, guidance and support. I am very lucky to have you as my supervisor. Without your help I wouldn't finish my research. When I go in the wrong direction, you always remind me what the most important thing is in my research. Also, huge thanks to Dr. Geoff Thomas for his assistance, patience and help. Thanks for your time to read and correct my writings. Your detailed and rigorous corrections inspire me to work hard.

I also would like to my colleges, Riley Willis, Aymeric Delmas, James Sullivan and Negin Imani. Thanks for your helpful and generous suggestions. I would like to give special thanks to Lu Qiu and Linda Lee. You have made my time in Victoria University of Wellington more positive and enjoyable. Thanks to Rose Lu for correcting my English. Thanks to all my friends in New Zealand. I also would like to thank all the examiners. Thanks for your valuable time to read and evaluate my thesis. Thanks for the UCL (University College London) Energy Institute for sharing GIS data of the City of London.

In addition, I would like to express my gratitude to my parents. Thanks for your love and support. You always do your best to support me. Also huge thanks to my partner Hao Chen. Thank you for accompanying me for so many years. When I feel depressed, you always cheer me up. I appreciate it very much that we could support each other to finish our PhD studies in New Zealand. Thank you for all the great memories in the past nine years. 


\section{ABSTRACT}

This research explored whether urban microclimate analysis has significant impacts on high-performance office buildings. It studied the effects of detailed three-dimensional urban microclimate modelling on building performance simulation. The feasibility and necessity of developing an urban microclimate simulation system were explored.

Currently, individual parameters of urban microclimate are modelled by individual programs. However, there was no individual software that could model airflow, Urban Heat Island (UHI) effects and building energy performance at the same time. A simulation system made it possible to model these features of urban microclimate together. Apart from the reliability of programs, accessibility and compatibility were also important for building a simulation system. The goal of this research was to determine the relative scale of the likely microclimate impacts on energy performance, not to present a system that made a precise estimate of these effects in combination. The scale of the variations of results due to changes of urban microclimate parameters were more significant than the values of the results themselves. This is because the focus of the research was on determining to what degree each parameter made a difference in the building performance. The goal was to determine whether it is necessary to model every urban microclimate parameter when their individual effects are combined.

The parameters of urban microclimates included horizontal parameters like urban wind and UHI, and vertical parameters like lapse rate, urban boundary layer. In this research, the urban microclimate was modelled in three dimensions, but the process of urban microclimate modelling was time-consuming. This leaded to one of the central questions of the thesis: is there value in the time spent? How big is the scale of the influence of urban microclimate detailed modelling on the prediction of building performance? Is it worthwhile to model three-dimensional urban microclimates? When there is not enough time to calibrate all parameters, what are the parameters' priorities? A prototypical high-rise office building was modelled based on the data about high-rise office buildings in London. Firstly, the effects of the horizontal parameters were explored. The UHI has larger effects than urban wind. Secondly, the significance of vertical parameters was also explored. At a lower floor, the influence of the wind speed 
exponent and the boundary layer thickness on building performance simulation is bigger than that of the air temperature gradient coefficient. However, at a higher floor, the influence of the air temperature gradient coefficient is bigger. Finally, a multilayer modelling method was developed to explore the inconsistent vertical variations. The multilayer model consists of the portion in the Urban Canopy Layer (UCL) and the portion in the Urban Boundary Layer (UBL). The effects of vertical variations increase with the distance between the studied height and the UCL height.

The feasibility and necessity of developing the simulation system of urban microclimate detailed modelling were demonstrated in the climate of London. In different climates, is it still necessary? The effects of urban microclimate detailed modelling on windy, continental, and tropical climates were also studied.

The necessity of urban microclimate detailed modelling has been demonstrated because the combined effects produced around $-25 \%$ change in London's climate and Wellington' climate at most. In Beijing's climate the change was around $-6 \%$ and in Singapore's climate was $2.2 \%$ at most. The UHI has a big impact in moderate and continental climates. In a continental climate, there is a big difference in the monthly thermal load prediction. It helps engineers optimize the design of heating in winter and cooling in summer. The effects of urban wind in a windy climate are bigger than those in other cities. The precision of vertical variations has very limited influence, especially in the tropical climate. The air temperature gradient in a tropical climate changed thermal load prediction a lot. The parameters' priorities in different climates are different. There is no consistent pattern of one factor being less important than the others across all these climates. Therefore, to model the thermal performance of tall buildings in dense urban environments it is necessary to develop a simulation system that can model the Urban Heat Island, and the differences in 3D of variations of temperature, sun and wind within and above the Urban Canopy Layer. Finally, from the one case study examined, modelling urban microclimate in detail is more important for natural ventilation systems than for HVAC systems.

Overall, the simulation system of urban microclimate modelling was developed gradually. It is necessary to develop the simulation system to approach a real urban circumstance. The accuracy of the detailed urban microclimate model depends on the engineers' requirements. The priority of urban microclimate parameters depends on climatic features. 


\section{TABLE OF CONTENTS}

ACKNOWLEDGEMENTS

$\begin{array}{ll}\text { ABSTRACT } & \text { ii }\end{array}$

LIST OF TABLES - xi

LIST OF FIGURES X xiii

LIST OF SYMBOLS AND ABBREVIATIONS xxiii

CHAPTER 1. INTRODUCTION 1

1.1 Problem Statement - current building performance evaluation 2

1.1.1 Current simulation tools and method 3

1.1.2 Quality assurance and level of precision 4

1.2 Research Question, Objective and Scope 5

$\begin{array}{lll}\text { 1.2.1 High-rise office buildings } & 6\end{array}$

$\begin{array}{lll}\text { 1.2.2 Urban microclimates } & 7\end{array}$

$\begin{array}{lll}\text { 1.2.3 Building performance } & 8\end{array}$

$\begin{array}{ll}\text { 1.3 Significance of the Research } & 8\end{array}$

1.3.1 Benefits of detailed urban microclimate modelling 9

1.3.2 Benefits of high-performance office buildings 11

$\begin{array}{lll}1.4 & \text { Thesis Structure and Chapter Summary } & 12\end{array}$

CHAPTER 2. URBAN MICROCLIMATE, MODELLING TECHNIQUE, $\begin{array}{ll}\text { BUILDING PERFORMANCE } & 14\end{array}$

$\begin{array}{lll}2.1 & \text { Chapter Intent } & 14\end{array}$

$\begin{array}{lll}2.2 & \text { Urban Microclimate } & 14\end{array}$

$\begin{array}{lll}\text { 2.2.1 Wind flow and Boundary Layer } & 15\end{array}$

$\begin{array}{ll}\text { 2.2.2 Urban Heat Island } & 17\end{array}$

$\begin{array}{lll}2.2 .3 & \text { Lapse Rate } & 19\end{array}$

$\begin{array}{lll}2.3 & \text { Modelling Technique } & 20\end{array}$ 
2.3.2 Urban Weather Generator and Dragonfly plugins

2.3.3 EnergyPlus and Ladybug and Honeybee plugin

2.4 High-Performance Office Building 24

2.4.1 Energy performance 25

$\begin{array}{lll}\text { 2.4.2 Thermal comfort } & 25\end{array}$

$\begin{array}{lll}2.4 .3 & \text { Natural ventilation } & 26\end{array}$

$\begin{array}{lll}2.5 & \text { Systematic Literature Review } & 27\end{array}$

$\begin{array}{lll}\text { 2.5.1 Methodology } & 28\end{array}$

$\begin{array}{lll}\text { 2.5.2 Search process } & 29\end{array}$

$\begin{array}{lll}\text { 2.5.3 Data extraction } & 30\end{array}$

$\begin{array}{llr}2.5 .4 & \text { Results } & 30\end{array}$

$\begin{array}{lll}\text { 2.5.5 Discussion } & 37\end{array}$

$\begin{array}{lll}2.6 & \text { Chapter Summary } & 38\end{array}$

$\begin{array}{lll}\text { CHAPTER 3. METHODOLOGY } & 39\end{array}$

$3.1 \quad$ Chapter Intent 39

3.2 Refined Research Question, Objective and Scope 39

3.2.1 Research question, objective and framework 39

3.2.2 Urban microclimate parameters 41

3.2.3 High-performance buildings and performance metric 42

3.2.4 High-rise office buildings 43

3.2.5 Vertical variation 43

3.2.6 Accuracy, sensitivity and reliability 44

3.3 Overarching Methodology: Real City, Prototypical High-rise Office Building 46

3.3.1 Modelling technique and reliability validation 
3.3.2 Simulation system establishment

3.3.3 Impact analysis of urban microclimate on high-rise office buildings $\quad 60$

3.4 Chapter Summary

CHAPTER 4. INDIVIDUAL MODELLING PROGRAMS RELIABILITY VERIFICATION63

4.1 Chapter Intent $\quad 63$

4.2 Verification of Wind Speed Prediction with OpenFOAM 63

4.2.1 Methodology $\quad 63$

$\begin{array}{lll}\text { 4.2.2 Model description } & 64\end{array}$

$\begin{array}{lll}\text { 4.2.3 The comparison of analysis results } & 68\end{array}$

4.2.4 Summary of the analysis of flow around a high-rise building in a multi-block model 74

4.3 Verification of Wind Pressure Coefficient Prediction with OpenFOAM 76

$\begin{array}{lll}\text { 4.3.1 Methodology } & 76\end{array}$

$\begin{array}{lll}\text { 4.3.2 } & \text { Model description } & 78\end{array}$

$\begin{array}{lll}\text { 4.3.3 The comparison of analysis results } & 82\end{array}$

4.4 Verification of Urban Heat Island Effects Modelling with Urban Weather Generator

$\begin{array}{lll}\text { 4.4.1 Methodology } & 85\end{array}$

$\begin{array}{lll}\text { 4.4.2 } & \text { Model description } & 87\end{array}$

4.4.3 The comparison of analysis results $\quad 88$

4.5 Verification of Building Performance with EnergyPlus 90

$\begin{array}{lll}\text { 4.5.1 Methodology } & 90\end{array}$

$\begin{array}{lll}\text { 4.5.2 Model description } & 90\end{array}$

4.5.3 The comparison of analysis results 91

$\begin{array}{lll}4.6 & \text { Chapter Summary } & 93\end{array}$ 
CHAPTER 5. A REPRESENTATIVE SAMPLE OF PROTOTYPICAL OFFICE BUILDING IN A REAL CITY 95

$\begin{array}{lll}5.1 & \text { Chapter Intent } & 95\end{array}$

$\begin{array}{ll}5.2 & \text { Real City - London }\end{array}$

5.2.1 Real city or ideal city? 95

5.2.2 Why London? 96

$\begin{array}{lll}5.3 & \text { Prototypical Office Building } & 97\end{array}$

5.3.1 Why office buildings? 97

5.3.2 Why high-rise office buildings? 98

5.3.3 Prototypical office building based on highest office buildings in London 98

5.4 Weather Data in Urban Areas Calibration 102

$\begin{array}{lll}\text { 5.4.1 Urban Heat Island weather data } & 102\end{array}$

$\begin{array}{ll}\text { 5.4.2 Urban wind weather data } & 103\end{array}$

$\begin{array}{lll}\text { 5.4.3 Four kinds of weather data } & 103\end{array}$

5.5 Analysis of the Prototypical Office Building Performance 104

$\begin{array}{lll}\text { 5.5.1 Urban microclimate weather data } & 105\end{array}$

$\begin{array}{llr}\text { 5.5.2 Height } & 108\end{array}$

$\begin{array}{lll}\text { 5.5.3 Natural ventilation } & 112\end{array}$

$\begin{array}{lll}\text { 5.5.4 Vertical variation } & 114\end{array}$

$\begin{array}{lll}\text { 5.6 Chapter Summary } & 117\end{array}$

CHAPTER 6. VERTICAL VARIATION EFFECTS ON BUILDING

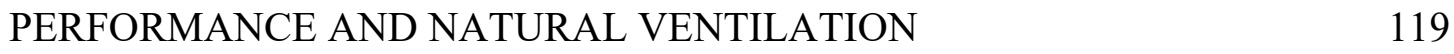

$\begin{array}{lll}\text { 6.1 Chapter Intent } & 119\end{array}$

$\begin{array}{lll}\text { 6.2 Urban Microclimate Profile } & 119\end{array}$

$\begin{array}{lll}\text { 6.2.1 Urban wind profile } & 120\end{array}$

$\begin{array}{ll}\text { 6.2.2 Urban atmospheric boundary layer height/thickness } & 121\end{array}$

$\begin{array}{lll}\text { 6.2.3 Urban temperature profile } & 122\end{array}$ 
6.3 Urban Microclimate Profile of London

6.3.1 Urban wind profile of London

6.3.2 Urban atmospheric boundary layer thickness of London

6.3.3 Urban temperature profile of London

6.3.4 Vertical variation Settings of London microclimate

6.4 Urban Microclimate Vertical Variation Effects

6.4.1 Vertical variations effects on thermal loads in rural and urban areas

6.4.2 Effects of wind speed profile parameters on thermal loads in urban areas 132

6.4.3 Effects of temperature gradient coefficient on thermal loads in urban areas 135

6.4.4 Effects of vertical variation on different ventilation systems in urban areas 136

6.5 Conclusions

CHAPTER 7. SIMULATION SYSTEM

7.1 Chapter Intent

7.2 Methodology

7.2.1 Modelling two layers of urban microclimate and prototypical building 140

7.2.2 Urban wind speed and wind pressure coefficients

7.2.3 Ventilation system

7.3 Urban Microclimate Modelling

7.3.1 Urban-rural wind speed ratio of London

7.3.2 Wind pressure coefficients at different height

7.3.3 Vertical variations of two layers respectively

7.4 Necessity of Modelling Wind Pressure Coefficients

7.4.1 Wind pressure coefficients at the $1^{\text {st }}, 17^{\text {th }}$ and $33^{\text {rd }}$ floors

7.4.2 Wind pressure coefficients effects on natural ventilation 
7.4.3 Effects of urban microclimate parameters on detailed natural ventilation system 154

7.5 Urban Microclimate Multilayer Modelling Method 156

7.5.1 Wind pressure coefficients in the UCL and UBL 156

7.5.2 Urban microclimate setting in the UCL and UBL 157

$\begin{array}{lll}\text { 7.5.3 Analysis and results } & 158\end{array}$

$\begin{array}{lll}7.6 & \text { Conclusion } & 171\end{array}$

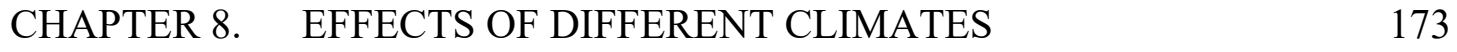

$\begin{array}{lll}8.1 & \text { Chapter Intent } & 173\end{array}$

$\begin{array}{lll}\text { 8.2 Methodology } & 173\end{array}$

$\begin{array}{lll}\text { 8.3 Urban Microclimate Parameters } & 178\end{array}$

$\begin{array}{lll}\text { 8.3.1 Urban microclimate modelling precision } & 178\end{array}$

$\begin{array}{lll}\text { 8.3.2 Height variation precision for cities } & 187\end{array}$

$\begin{array}{lll}\text { 8.3.3 Height variations of terrain } & 192\end{array}$

8.4 Effects of Urban Microclimate Detailed Modelling on Cities with Different Climate

8.4.1 Effects of Urban microclimate modelling precision

8.4.2 Height variation precision and terrain

8.4.3 Effects of Height variation precision and terrain at different height 204

8.5 Priority of Urban Microclimate Parameters in Different Climates 209

$\begin{array}{lll}\text { CHAPTER 9. CONCLUSIONS } & 214\end{array}$

$\begin{array}{lll}9.1 & \text { Research Conclusions } & 214\end{array}$

$\begin{array}{lll}9.2 & \text { Limitations and Future Studies } & 223\end{array}$

$\begin{array}{lll}\text { CHAPTER 10. BIBLIOGRAPHY } & 224\end{array}$

$\begin{array}{ll}\text { APPENDIX A. WORKFLOW } & 248\end{array}$

$\begin{array}{lll}\text { A.1 Building Thermal Loads Simulation } & 248\end{array}$

$\begin{array}{lll}\text { A.1.1 Geometry and thermal zones } & 248\end{array}$ 
A.1.2 Loads, Schedule and Constructions

$\begin{array}{lr}\text { A.1.3 Thermal Loads } & 250\end{array}$

$\begin{array}{ll}\text { A.2 Urban Microclimate Simulation } & 251\end{array}$

$\begin{array}{lll}\text { A.2.1 Urban wind } & 251\end{array}$

A.2.2 Urban Heat Island 253

$\begin{array}{ll}\text { A.3 Detailed natural ventilation system } & 254\end{array}$

A.4 Versions of programs and plugins used in the simulation system 255 


\section{LIST OF TABLES}

Table 1: Comparison between urban microclimate and rural environments (Nagle \& Cooke, 2017) 15

Table 2: Search terms within databases (Date of last search:13 November 2016) .....29

Table 3: Search results quantity from databases (13 November 2016 and 11 Januray 2019)

Table 4: Results of eligible studies (until 13 November 2016). .34

Table 5: Title-Abs-Key: "Lapse rate of temperature" and "in dense area" (until 26 October 2016) .35

Table 6: Title-Abs-Key: UHI, rural, air temperature and height (until 26 October 2016)

Table 7: Title-Abs-Key: Urban Heat Island, wind, temperature gradient and height (until 26 October 2016) .36

Table 8: Title-Abs-Key: Urban Heat Island, wind and lapse rate (until 26 October 2016)

Table 9: Modelling and simulation parameters of 3 CFD programs .50

Table 10: Comparing modelling tools and selecting appropriate tools (J. Li, Delmas, et al., 2018) .55

Table 11: Verification of programs . .56

Table 12: Environment conditions from AIJ model .64

Table 13: Basic parameters of the simulation condition for wind speed model. .66

Table 14: Parameters of original model and comparison model .68

Table 15: Basic parameters of the simulation condition for wind pressure coefficients model .79

Table 16: Geometric information of R0198 .91

Table 17: Top 32 tallest office building in London in 2016 ('List of Tallest Buildings and Structures in London', n.d.) .99 
Table 18: The percentage of each zone

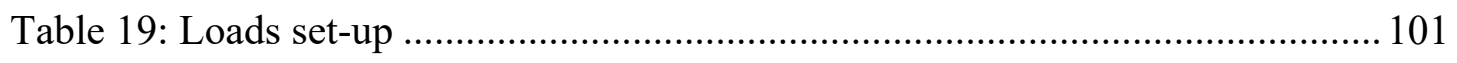

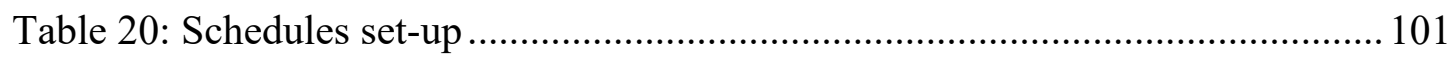

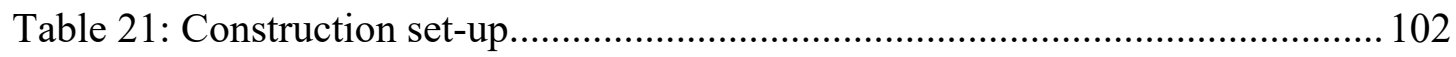

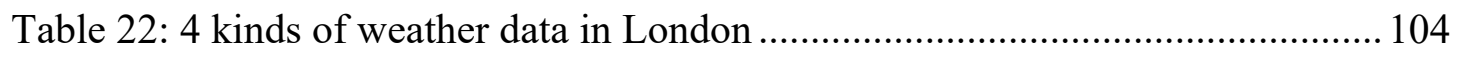

Table 23: Modelling flow for heights, weather data, ventilation systems and height

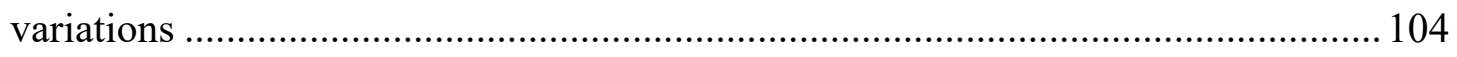

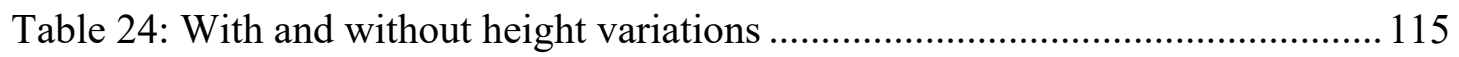

Table 25: Wind Speed Profile Coefficients (Handbook-Fundamentals, 2009)......... 125

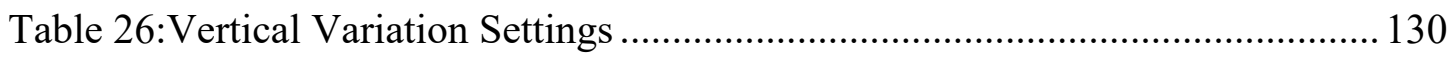

Table 27: Original and adjusted height variations for the City of London................ 152

Table 28: Vertical Variation Settings of detailed natural ventilation system............ 155

Table 29: Height variations of multilayer model.................................................. 158

Table 30: Weather data and height variations of single-layer and multilayer model 166

Table 31: 4 climate regions, 3 ventilation systems and 15 urban microclimate

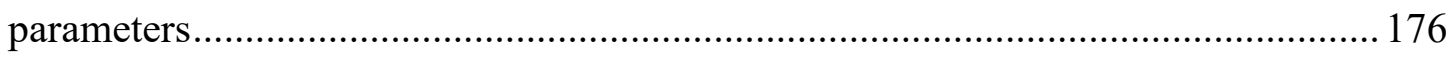




\section{LIST OF FIGURES}

Figure 1: Number of completions of 200-meter-plus and 300-meter-plus tall buildings during the preceding year (2020 data is provisional) (2019 Tall Building Year in Review, 2019).

Figure 2: Height Incremental Changes in the Development of the World's Tallest Buildings Historically (CTBUH Journal Tall Buildings in Numbers, 2018)..... 7

Figure 3: Diagram of Urban Boundary Layer and Urban Canopy (Oke, 1976)........ 16

Figure 4: Schematic of Heat island magnitudes in urban, suburban and rural areas for Vancouver in $4^{\text {th }}$ November 1999 (Stewart et al., 2014) .......................................... 19

Figure 5: Diagram of lapse rate (Real Climate Science, n.d.) .................................20

Figure 6: Flow diagram for the research .......................................................... 22

Figure 7: Overview of OpenFOAM structure (OpenFOAM Introduction, 2018).......22

Figure 8: Diagram of the urban weather generator (UWG) scheme (Bruno et al., 2012)

Figure 9: Acceptable range of operative temperature and air speeds at humidity ratio 0.010 (Standard, 2010) .26

Figure 10: Problems for urban wind prediction. 27

Figure 11: Interaction of urban microclimate features: Urban wind, Boundary Layer, Urban Heat Island and Lapse Rate .28

Figure 12: Simulation framework of the research .41

Figure 13: Velocity and Temperature boundary layer (Vijek, 2013)..... .44

Figure 14: Methodology flow diagram. 47

Figure 15: Model of AIJ wind tunnel experiment (Tominaga \& Mochida, 2016) ......50

Figure 16: $0^{\circ}$ Wind Tunnel, Autodesk CFD, OpenFOAM and UrbaWind results comparison. .53

Figure 17: $22.5^{\circ}$ Wind Tunnel, OpenFOAM and UrbaWind results comparison .54 
Figure 18: $45^{\circ}$ Wind Tunnel, Autodesk CFD, OpenFOAM and UrbaWind results comparison

Figure 19: Outline of the multi-block model for AIJ wind tunnel experiment (Tominaga

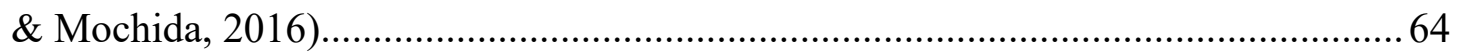

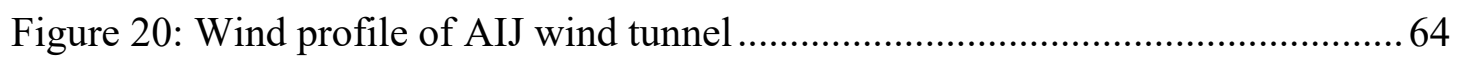

Figure 21: (a) 78 measurement points for AIJ wind tunnel experiment (b) Modified version of 66 measurement points without points besides the central building .......... 65

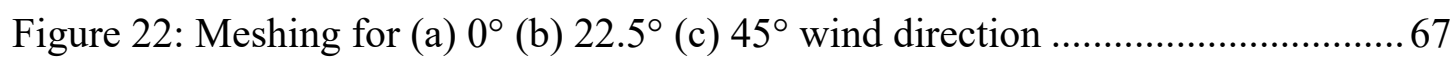

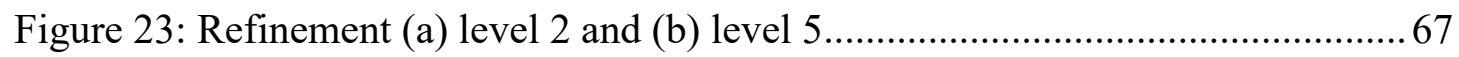

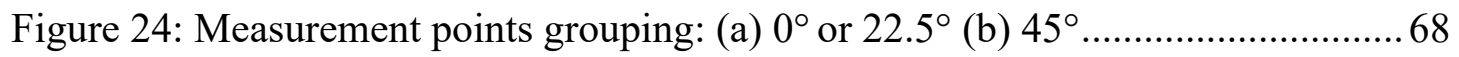

Figure 25: Comparison of wind speed ratios at different wind direction ...................69

Figure 26: Comparison of wind speed ratios between OpenFOAM and Wind Tunnel .70

Figure 27: Comparison of OpenFOAM and Wind Tunnel in non-wake areas (test points $1-44)$. .70

Figure 28: Comparison of OpenFOAM and Wind Tunnel in wake areas (test points 4566) .71

Figure 29: Comparison of wind speed ratios for different refinement levels .72

Figure 30: Comparison of wind speed ratios for different roughness lengths. .73

Figure 31: Comparison of wind speed ratios for different turbulence models .74

Figure 32: Measurement points around central building: (a) $0^{\circ}$ or $22.5^{\circ}$ with $31-50$ and (b) $45^{\circ}$ with $31 *-50 *$ .75

Figure 33: Comparison of wind speed ratio predictions around the central block...... 75

Figure 34: Comparison of test points around the central block. .76

Figure 35: CAAR stand tall building: full-scale dimensions, dynamic properties and pressure tap location (Melbourne, 1980). .79

Figure 36: Meshing of the numerical wind tunnel of CAAR stand tall building using OpenFOAM .80 
Figure 37: Meshing of CAARC standard tall building and 20 test points .81

Figure 38: Pressure coefficient calculation strings for the function object .82

Figure 39: Comparison of wind pressure coefficients at different wind direction .83

Figure 40: Wind pressure coefficients comparison between OpenFOAM and Wind Tunnel. 84

Figure 41: City of London (red area) in Greater London (TUBS, 2011)..... .86

Figure 42: three-dimensional City of London from Google map (Google Maps, 2019)

Figure 43: City of London from GIS model .87

Figure 44: Average air temperature and UHI of London ..... .88

Figure 45: Maximum, minimum and average London UHI in August $\left({ }^{\circ} \mathrm{C}\right)$ .89

Figure 46: Air temperature of London suburb and city as well as UHI on Aug-4 and Aug-17 .89

Figure 47: Weekday Average Hourly Loads .92

Figure 48: Weekend Average Hourly Loads .92

Figure 49: Map of London and Gatwick Airport (Google Maps, 2019) .96

Figure 50: (a)London 'heat island' (minimum temperatures in ${ }^{\circ} \mathrm{C}$ ) (mid-May: clear skies and light winds) (b) Temperature profile of London (Jebson, 2008) .... 97

Figure 51: a) World population growth (Roser et al., 2013) b) Total number of 200meter-plus buildings (blue) and 300-meter-plus (yellow) at the end of each decade (2018 Tall Building Year in Review, 2018) .98

Figure 52: 3 floors of the prototypical high-rise office building. 100

Figure 53: Daily averaged Dry Bulb Temperature and UHI 103

Figure 54: Thermal loads of the high-rise office building for 4 different weather data 106

Figure 55: Cooling of the high-rise office building for 4 different weather data .... 107

Figure 56: Heating of high-rise office building for 4 different weather data 107 
Figure 57: Thermal loads at the $1^{\text {st }}, 17^{\text {th }}$ and $33^{\text {rd }}$ floors for rural and urban weather files

Figure 58: Cooling at the $1^{\text {st }}, 17^{\text {th }}$ and $33^{\text {rd }}$ floors for rural and urban weather files 109 Figure 59: Heating at the $1^{\text {st }}, 17^{\text {th }}$ and $33^{\text {rd }}$ floors for rural and urban weather files 109 Figure 60: Thermal load percentage changes at the $1^{\text {st }}, 17^{\text {th }}$ and $33^{\text {rd }}$ floors for UHI and urban winds. 110

Figure 61: Cooling percentage changes at the $1^{\text {st }}, 17^{\text {th }}$ and $33^{\text {rd }}$ floors for UHI and urban winds (from May to October)

Figure 62: Heating percentage changes at the $1^{\text {st }}, 17^{\text {th }}$ and $33^{\text {rd }}$ floors for UHI and urban winds (from November to April).

Figure 63: Thermal loads for 4 weather data with an HVAC system and with a natural ventilation system $(\mathrm{NV})$.

Figure 64: Thermal loads of urban weather data at the $1^{\text {st }}, 17^{\text {th }}$ and $33^{\text {rd }}$ floors with an HVAC system and with a natural ventilation system (NV)

Figure 65: Cooling changes for 4 weather data at the $1^{\text {st }}, 17^{\text {th }}$ and $33^{\text {rd }}$ floors between an HVAC system and a natural ventilation system (HVAC-NV).

Figure 66: Thermal load percentage changes at the $1^{\text {st }}, 17^{\text {th }}$ and $33^{\text {rd }}$ floors of the UHI and urban winds with a natural ventilation system (NV) over an HVAC system..... 114 Figure 67: Thermal load percentage changes for 4 different weather data with height variations (HV) over without height variations for an HVAC system.

Figure 68: Thermal load percentage changes of 4 weather data with height variations (HV) over without height variations for a natural ventilation system (NV) 116

Figure 69: Thermal load changes of 4 weather data with height variations (HV) over without height variations for a natural ventilation system $(\mathrm{NV})$ at the $1^{\text {st }}, 17^{\text {th }}$ and $33^{\text {rd }}$ floors.

Figure 70: The mean wind speed profile averaged within 4578 h (Drew et al., 2013) and data sorted out.

Figure 71: Modified mean wind speed profile for the height of $1500 \mathrm{~m}, 1000 \mathrm{~m}$ and 500 $\mathrm{m}$ 
Figure 72:Potential temperature profile measured from Larkhill and Herstmonceux (Barlow et al., 2015)

Figure 73: Absolute temperature profile converted from potential temperature profile

Figure 74: Upward trend part and downward trend part of the absolute temperature profile.

Figure 75: Predicted temperature profiles of LWC (Kukkonen et al., 2005). 128

Figure 76: Temperature changes with the height of LWC

Figure 77: Air temperature gradient coefficient minimum value of EnergyPlus

Figure 78: For an HVAC system thermal load percentage changes with vertical variations over without at the $1^{\text {st }}, 17^{\text {th }}$ and $33^{\text {rd }}$ floors in rural and urban areas of London.

Figure 79: For the natural ventilation (NV) system thermal load changes with vertical variations over without at the $1^{\text {st }}, 17^{\text {th }}$ and $33^{\text {rd }}$ floors in rural and urban areas of London.

Figure 80: For an HVAC system effects of the wind speed profile exponent and relative boundary layer thickness on thermal load changes at the $1^{\text {st }}, 17^{\text {th }}$ and $33^{\text {rd }}$ floors. ... 132 Figure 81: For the natural ventilation (NV) system effects of the wind speed exponent and relative boundary layer thicknesses on thermal load changes at the $1^{\text {st }}, 17^{\text {th }}$ and $33^{\text {rd }}$ floors.

Figure 82: For an HVAC system effects of the boundary layer thickness on thermal load changes at the $1^{\text {st }}, 17^{\text {th }}$ and $33^{\text {rd }}$ floors.

Figure 83: For the natural ventilation (NV) system effects of boundary layer thickness on thermal load changes at the $1^{\text {st }}, 17^{\text {th }}$ and $33^{\text {rd }}$ floors.

Figure 84: For an HVAC system effects of the temperature gradient coefficient on thermal load changes at the $1^{\text {st }}, 17^{\text {th }}$ and $33^{\text {rd }}$ floors.

Figure 85: For the natural ventilation (NV) system effects of the temperature gradient coefficient on thermal load changes at the $1^{\text {st }}, 17^{\text {th }}$ and $33^{\text {rd }}$ floors. 136 
Figure 86: Effects of vertical variations on thermal load changes with an HVAC system and a natural ventilation system.

Figure 87: The urban microclimate and the building in the UCL and in the UBL ... 140

Figure 88: Distribution of building height in the City of London

Figure 89: Outline of the City of London from Google map (Google Maps, 2019) 145

Figure 90: Building blocks and test points in City of London (a) blocks (b) test points 145

Figure 91: Prototypical building with surroundings 146

Figure 92: Rotated blocks according to wind directions 146

Figure 93: Test points around the prototypical building and its wind tunnel meshing 147

Figure 94: Urban wind speed profile of London (simulated by OpenFOAM) 147

Figure 95: Urban wind speed profile of London in the UBL (simulated by OpenFOAM) 148

Figure 96: Urban wind speed profile of London in the UCL layer (simulated by OpenFOAM). 148

Figure 97: Trendlines of the predicted temperature of London Weather Centre (LWC) (Kukkonen et al., 2005) 149

Figure 98: Predicted temperature profile in the UBL (Kukkonen et al., 2005)......... 150

Figure 99: Predicted temperature profile in the UCL (Kukkonen et al., 2005)......... 150

Figure 100: Wind pressure coefficients from 12 directions at the $1^{\text {st }}, 17^{\text {th }}$ and $33^{\text {rd }}$ floors 151

Figure 101: Thermal load ratio of detailed natural ventilation, HVAC system over simplified natural ventilation a) with original height variations b) with adjusted height variations $(\mathrm{HV})$

Figure 102 Thermal load percentage change with adjusted height variations (HV) over original height variations for simplified natural ventilation, HVAC system and detailed natural ventilation 153 
Figure 103: Thermal loads for detailed natural ventilation with four kinds of weather data.

Figure 104: Thermal load percentage change for detailed natural ventilation with different height variations (HV) over control group (HV0.4_500_0.002) at the $1^{\text {st }}, 17^{\text {th }}$ and $33^{\text {rd }}$ floors

Figure 105: Wind pressure coefficients from 12 directions at the $1^{\text {st }}, 4^{\text {th }}$ and $7^{\text {th }}$ floors

Figure 106: Wind pressure coefficients from 12 directions at the $10^{\text {th }}, 22^{\text {nd }}$ and $33^{\text {rd }}$ floors

Figure 107: Thermal loads of six floors in the UCL and UBL for simplified natural ventilation a) with original height variations b) with adjusted height variations (HV)

Figure 108: Thermal load percentage change with adjusted height variations (HV) over original height variations for simplified natural ventilation of six floors in the UCL and UBL 160

Figure 109: Thermal loads of six floors in the UCL and UBL for an HVAC system 161

Figure 110: Thermal load percentage change with adjusted height variations (HV) over original height variations for an HVAC system of six floors in the UCL and UBL. 162 Figure 111: Thermal loads of six floors in the UCL and UBL for detailed natural ventilation..... 163

Figure 112: Thermal load percentage change with adjusted height variations (HV) over original height variations for detailed natural ventilation of six floors in the UCL and UBL 163

Figure 113: Effects of adjusted height variations (HV) on simplified natural ventilation, HVAC system, and detailed natural ventilation of six floors in the UCL and UBL. 164 Figure 114: Thermal load percentage change of simplified natural ventilation and detailed natural ventilation over an HVAC system of six floors a) with original height variations b) with adjusted height variations (HV) 165 
Figure 115: Thermal load percentage change of multilayer model over single-layer model for simplified natural ventilation, an HVAC system and detailed natural ventilation with original height variations and adjusted height variations (HV) ...... 167

Figure 116: Thermal loads of multilayer model and single-layer model for simplified natural ventilation, an HVAC system and detailed natural ventilation at a) $1^{\text {st }}$ floor b) $17^{\text {th }}$ floor c) $33^{\text {rd }}$ floor, and percentage change of multilayer model over single-layer model at d) $1^{\text {st }}, 17^{\text {th }}$ and $33^{\text {rd }}$ floors with original height variations

Figure 117: Thermal loads of multilayer model and single-layer model for simplified natural ventilation, an HVAC system and detailed natural ventilation at a) $1^{\text {st }}$ floor b) $17^{\text {th }}$ floor c) $33^{\text {rd }}$ floor, and percentage change of multilayer model over single-layer model at d) $1^{\text {st }}, 17^{\text {th }}$ and $33^{\text {rd }}$ floors with adjusted height variations (HV) 170

Figure 118: Annual total thermal load percentage change of multilayer model over single-layer model for simplified natural ventilation, an HVAC system and detailed natural ventilation model at the $1^{\text {st }}, 17^{\text {th }}$ and $33^{\text {rd }}$ floors with adjusted height variations (HV). 171

Figure 119: London, Beijing Singapore and Wellington four different climates (Kottek et al., 2006) . 174

Figure 120: Heating Degree Days (HDD) base $18^{\circ} \mathrm{C}$ and Cooling Degree Hours (CDH) base $27^{\circ} \mathrm{C}$ in different cities

Figure 121: Size and outlines of cities (Google Maps, 2019).....

Figure 122: a) thermal load percentage change b) thermal load change of urban wind over rural weather file with different ventilation systems in the climate of different cities. 180

Figure 123: a) thermal load percentage change b) thermal load change of UHI over rural weather file with different ventilation systems in the climate of different cities 181

Figure 124: a) thermal load percentage change b) thermal load change of UHI and urban wind over rural weather file with different ventilation systems in the climate of different cities.

Figure 125: a) thermal load percentage change b) thermal load change of UHI, urban wind and adjusted height variations over rural weather file with different ventilation systems in the climate of different cities 185 
Figure 126: a) thermal load percentage change b) thermal load change of UHI, urban wind, adjusted height variations and multilayer modelling method over rural weather file with different ventilation systems in the climate of different cities. 187

Figure 127: a) thermal load percentage change b) thermal load change of wind speed profile exponent 0.33 over 0.4 with different ventilation systems in the climate of different cities

Figure 128: a) thermal load percentage change b) thermal load change of wind speed profile boundary layer thickness $400 \mathrm{~m}$ over $500 \mathrm{~m}$ with different ventilation systems in the climate of different cities 190

Figure 129: a) thermal load percentage change b) thermal load change of air temperature gradient coefficient $0.004 \mathrm{~K} / \mathrm{m}$ over $0.002 \mathrm{~K} / \mathrm{m}$ with different ventilation systems in the climate of different cities

Figure 130: a) thermal load percentage change b) thermal load change of wind speed profile exponent 0.22 over 0.4 with different ventilation systems in the climate of different cities 194

Figure 131: a) thermal load percentage change b) thermal load change of wind speed profile boundary layer thickness $370 \mathrm{~m}$ over $500 \mathrm{~m}$ with different ventilation systems in the climate of different cities....

Figure 132: a) thermal load percentage change b) thermal load change of air temperature gradient coefficient $0.0065 \mathrm{~K} / \mathrm{m}$ over $0.002 \mathrm{~K} / \mathrm{m}$ with different ventilation systems in the climate of different cities 197

Figure 133: a) thermal load percentage change b) thermal load change of suburban height variations $(0.22370 \mathrm{~m} 0.0065 \mathrm{~K} / \mathrm{m})$ over urban height variations $(0.4500 \mathrm{~m}$ $0.004 \mathrm{~K} / \mathrm{m}$ ) with different ventilation systems in the climate of different cities 198

Figure 134: Monthly percentage changes due to urban microclimate modelling precision in four cities with three ventilation systems 200

Figure 135: Annual absolute changes of thermal load due to urban microclimate parameters in four cities with three ventilation systems. 201

Figure 136: Monthly percentage changes due to height variation precision and terrain in four cities with three ventilation systems 203 
Figure 137: Annual absolute changes due to (a) height variation precision and (b) height variation of terrain in four cities with three ventilation systems 204

Figure 138: Monthly percentage changes at the $1^{\text {st }}$ Floor due to height variation precision and terrain in four cities with three ventilation systems 205

Figure 139: Monthly percentage changes at the 17th Floor due to height variation precision and terrain in four cities with three ventilation systems 206

Figure 140: Monthly percentage changes at the $33^{\text {rd }}$ Floor due to height variation precision and terrain in four cities with three ventilation systems 207

Figure 141: Annual absolute changes at the $1^{\text {st }}$ floor due to (a) height variation precision and (b) height variation of terrain in four cities with three ventilation systems. 208 Figure 142: Annual absolute changes at the $17^{\text {th }}$ floor due to (a) height variation precision and (b) height variation of terrain in four cities with three ventilation systems 208

Figure 143: Annual absolute changes at the $33^{\text {rd }}$ floor due to (a) height variation precision and (b) height variation of terrain in four cities with three ventilation systems

Figure 144: Annual thermal load changes due to urban microclimate parameters and relative climates $\mathrm{HDD}$ and $\mathrm{CDH}$ 210 Figure 145: a) annual thermal load absolute changes b) annual thermal load percentage changes in different climate regions due to individual urban microclimate parameters

Figure 146: a) annual thermal load absolute changes b) annual thermal load percentage changes in different climate regions due to combined effects. 212 


\section{LIST OF SYMBOLS AND ABBREVIATIONS}

\begin{tabular}{|c|c|}
\hline o & Degrees \\
\hline${ }^{\circ} \mathrm{C}$ & Degrees Celsius \\
\hline AIJ & Architectural Institute of Japan \\
\hline $\mathrm{CDH}$ & Cooling Degree Hours \\
\hline CFD & Computational fluid dynamics \\
\hline GIS & Geographic Information Systems \\
\hline GUI & Graphical User Interface \\
\hline HDD & Heating Degree Days \\
\hline HV & Height variations \\
\hline HVAC & Heating, Ventilation and Air-conditioning \\
\hline $\mathrm{H} / \mathrm{W}$ & Height-to-width ratio \\
\hline K & Degree Kelvin \\
\hline $\mathrm{K} / \mathrm{m}$ & Degree Kelvin change per metre \\
\hline $\mathrm{kg} / \mathrm{m}^{3}$ & Kilograms per cubic meter \\
\hline $\mathrm{km}$ & Kilometre \\
\hline $\mathrm{km}^{2}$ & Square Kilometre \\
\hline $\mathrm{kWh}$ & kiloWatt-hours \\
\hline $\mathrm{kWh} / \mathrm{m}^{2}$ & kiloWatt-hours per square metre \\
\hline
\end{tabular}




$\begin{array}{ll}\mathrm{m}^{2} & \text { Square Metre } \\ \mathrm{m}^{3} & \text { Cubic meter } \\ \mathrm{m}^{3} / \mathrm{s} & \text { Metres cubed per second } \\ \mathrm{mm} & \text { Millimetre } \\ \mathrm{m} / \mathrm{s} & \text { Metre per second } \\ \mathrm{NV} & \text { Natural Ventilation } \\ \mathrm{UBL} & \text { Urban boundary-layer } \\ \mathrm{UCL} & \text { Urban canopy-layer } \\ \mathrm{UHI} & \text { Urban heat island } \\ \mathrm{WWH} & \text { Urban Weather Generator } \\ \mathrm{UW} & \text { Window to Wall Ratio } \\ \mathrm{VAV} & \text { Variable Air Volume } \\ \mathrm{VPL} & \text { Visual Programming Language } \\ & \end{array}$




\section{CHAPTER 1. INTRODUCTION}

Urban microclimates may or may not have significant impacts on high-performance office buildings (Rohinton Emmanuel \& Steemers, 2018). In exploring the relationship between the urban environment and its potential to affect the performance of office buildings, it is necessary to examine whether the effect of microclimates is significant. This thesis addressed how to develop a simulation system to explore this question. It examined the impacts of microclimates in urban areas on the performance of high-rise office buildings. It investigated whether or not the impacts could make a significant change to the energy use and indoor thermal comfort of high performance office buildings. In addition, according to the change brought by urban microclimate, technical solutions for building performance optimization were proposed. The research had three Phases:

Phase A - Review urban microclimates and modelling techniques.

Phase B - Develop a trustworthy simulation system to model the effect of urban microclimates on building performance.

Phase $\mathrm{C}$ - Analyse the impacts of urban microclimates on high-rise office buildings

The first Phase (A) studied the features of urban microclimates, which might impact the energy consumption and thermal comfort of office buildings. This study focused on not only horizontal differences between urban and rural microclimates but also vertical variations of urban microclimates. Several simulation tools were used to model threedimensional urban microclimates individually (Gracik et al., 2015). A range of urban microclimate modelling tools were evaluated and validated.

The second Phase (B) developed a simulation system, using simulation tools to model the features urban microclimates in Phase A. The effects of urban microclimate detailed modelling on building performance simulation were analysed. In this study, a typical high-rise office building was used as a case study. This was based on data from the tallest office buildings in London. Several features of urban microclimate effects on building performance simulation were also explored.

The third Phase (C) was the application of the system to test the significance of urban microclimate modelling and assess its impacts on building performance simulation. A 
series of simulations were conducted to verify the impacts of urban microclimate modelling in different climates. It concluded with an assessment of the necessity of urban microclimate detailed modelling for building performance simulation.

\subsection{Problem Statement - current building performance evaluation}

"Building performance simulation in urban areas mostly relies on regional climate data which were typically collected from suburban or rural areas such as nearby airports" (Wilcox \& Marion, 2008).

Simulation of building thermal performance using a digital computer has been an active area of investigation since the 1960s, with much of the early work focusing on energy analysis. Over time, the simulation domain has grown more productive and more integrated, with tools available for integrating simulation of heat and mass transfer in the building fabric, airflow in and through the building, daylighting, and a vast array of system types and components (Hensen \& Lamberts, 2012).

Building performance simulation in urban areas mostly relies on regional climate data, which is typically collected from suburban or rural areas such as nearby airports (Wilcox \& Marion, 2008). That is mostly a result of the requirements in climate record standards for a large grass area under the climate measurement station and operational requirements for airports. There have been numerous studies confirming the general suspicion that the modelled performance of buildings is not accurate when it is based on weather data from somewhere else other than their actual dense urban location (Kotthaus \& Grimmond, 2014; Wong et al., 2016).

However, urban weather data was not as readily available as rural weather data. Measured urban weather data could only ever represent the particular combination of roads, buildings, trees and plants of its specific neighbourhood. Therefore, for generality, it is necessary to look to model the effects of these parameters starting from the generalisable open country data.

Currently, Computational Fluid Dynamics (CFD) programs could model urban winds and other programs could model Urban Heat Island (UHI) effects. However, all these programs were independent. Information about urban microclimates was fragmented and incomplete. There was very little research linking up individual programs for 
building an urban microclimate simulation system. No research was found modelling the features of urban microclimates together.

Only reliable input gives a reliable output. It is crucial to model urban microclimates in detail. Some previous research modelled two-dimensional urban microclimate but not three-dimensional. They focused on the microclimate differences in the horizontal direction, between urban and rural areas (R. Emmanuel et al., 2007; Street et al., 2013). Vertical variations of urban microclimates and the effects of vertical variations were not included. As temperature and wind speeds are known to vary with height in the open country (Lawrence C. Nkemdirim, 1979) and large buildings create complex three-dimensional airflows when interacting with the wind, it is important to understand how the vertical variations of urban microclimates affect building performance simulation. Is the influence significant enough to be worth modelling? When taking it into detail, the influence of the surrounding microclimate caused by building height variation is not evident as well. Is it significant enough to affect the accuracy of the simulation? Is it significant enough to affect its HVAC system or natural ventilation design? Hence, the problem is the feasibility and necessity of developing a simulation system to model the three-dimensional urban microclimate in detail.

\subsubsection{Current simulation tools and method}

In general, it could be assumed that the closer urban microclimate modelling is to reality, the more likely it is that building performance simulation results will be accurate. However, currently no individual program could model all urban microclimate features at the same time. Compatibility between programs that model urban environments and those that model buildings was also an issue. Hence, the first and most crucial problem was taking appropriate tools to model urban microclimates and build a simulation system.

Currently, urban wind is generally modelled by Computational Fluid Dynamics (CFD) programs, and there are several CFD programs that focus on modelling the built environment, like OpenFOAM, Autodesk CFD and UrbaWind (Section 3.3.1.1.2). In different industries, people use different CFD programs. There are several programs focused on the built environment that can model Urban Heat Island (UHI) effect as well, like Urban Weather Generator (UWG) and ENVI-met (Section 3.3.1.1.1). There are many individual programs available for urban microclimate modelling (Bueno et al., 
2013; J. Li, Delmas, et al., 2018; Nazarian \& Kleissl, 2015; Subramania Pillai \& Yoshie, 2012; Y. Wang et al., 2015). The problems are which modelling program is appropriate and how to put the individual programs together and develop a reliable urban microclimate simulation system.

In this research, developing the urban microclimate simulation system consisted of two parts. The first part was the urban microclimate modelling, and the second part was the building performance simulation. Urban microclimate modelling mainly consisted of CFD simulation and UHI simulation. Some of the CFD programs could do very complex simulation. However, the research was not looking for the most potent functional CFD program in this research. What the research was looking for was a compatible and functional one which could be connected with other programs. This research was not about individual modelling. It was about establishing a simulation system to model three-dimensional urban microclimate in detail. Also, the compatibility of UHI modelling programs with building performance calculations got priority in this research.

The feature of compatibility was a special request for this simulation system. Apart from the compatibility, other standard features like availability, operability and reliability were also crucial for the simulation system development. To develop a reliable simulation system for exploring the significance of urban microclimate detailed modelling, it is necessary initially to verify the reliability of relevant individual programs. Only appropriate and reliable individual programs can be linked up by a platform for building an urban microclimate simulation system.

\subsubsection{Quality assurance and level of precision}

Quality assurance and accuracy of results are very significant and ongoing issues for simulation. Simulation results are not based on real data collected from the operating buildings. They come from the simulation algorithm. The reliability of the outputs is determined by the reliability of modelling inputs and simulation tools.

In Satwiko et al.'s paper, a question about the accuracy and precision of CFD simulation "how close is close enough?" is proposed (Satwiko et al., 1998). The answer to this question is significant for all CFD related research. If the simulation results match with reality $100 \%$, there is no doubt that the modelling is successful. However, if the results 
don't match with reality, how big of a difference would mean failure? What is the acceptable deviation?

According to some research, a relative error within $10 \%$ is "acceptable" for the majority of studies (Calis et al., 2001; Gowreesunker \& Tassou, 2013; Gromke \& Blocken, 2015; Montazeri et al., 2015; Yoshie et al., 2007). Some of them may be bigger than this value, and some of them may be smaller than this value. A smaller relative error means better agreement. However, it is unrealistic to expect a full match of simulation results with experimental data. A minor deviation between simulation predictions and the measurement data may be accepted (Satwiko et al., 1998). A minor deviation is acceptable if it does not affect design strategies, but unacceptable if it does.

This research explored how to model urban microclimate in detail and predict building performance. Several parameters of urban microclimates were modelled, but the importance of each parameter was different. The precision of urban microclimate detailed modelling depended on how big differences it made in the building performance prediction.

\subsection{Research Question, Objective and Scope}

This research aimed to develop a simulation system to model urban microclimate in detail and explore whether urban microclimate detailed modelling has significant impacts on high-performance office buildings.

In order to address this research question, two goals needed to be achieved:

1) Build a simulation system that can be used to report the likely impact of microclimates;

2) Make an estimate of the likely scale of the microclimate effects, based on annual simulations and accounting for the three-dimensional effects of urban environments on wind and temperature.

The feasibility and necessity of developing a simulation system was discussed. This research also explored the relationship between urban microclimates and highperformance office buildings taking height variations into account. The following works represented the research scope of this research.

- High-rise Office Buildings. 
- Wind Flow, Boundary Layer, Urban Heat Island, Lapse Rate (temperature gradient).

- Energy Consumption, Thermal Comfort, Natural Ventilation.

"The evidence suggests it is likely - although not proven - that much of the increase in energy use with height is due to the greater exposure of taller buildings to lower temperatures, stronger winds and more solar gains" (Godoy-Shimizu et al., 2018). The intensity of the urban microclimates in a large-scale city is larger. Therefore, the simulation results are clearer. The same goes for a high-rise office building. Only if the building is high enough can vertical variations of urban microclimates be revealed. The scope of the project is nearly zero-energy office buildings in large-scale cities.

\subsubsection{High-rise office buildings}

The increasing rate of urbanisation in recent decades has accelerated the construction of high-rise buildings all over the world. According to the annual review of tall buildings by the Council on Tall Buildings and Urban Habitat (CTBUH), 128 buildings taller than 200 m lower than 300 m were completed in 2016, with $84 \%$ of completions being in Asia and 66\% in China (CTBUH Journal Tall Buildings in Numbers, 2018). The 2019 Tall Building Year in Review shows 126 buildings of at least 200 meters were completed in 2019 (2019 Tall Building Year in Review, 2019). In Figure 1, the year of 2019 recorded 26 "supertall" buildings of 300 meters or greater height, more than any year previously.

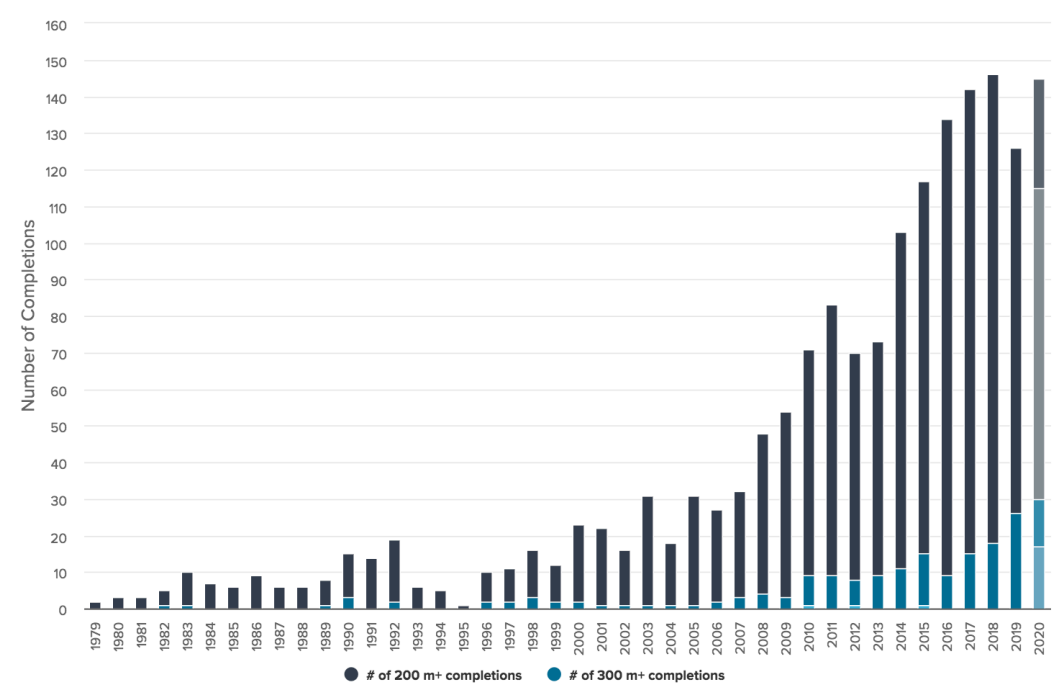

Figure 1: Number of completions of 200-meter-plus and 300-meter-plus tall buildings during the preceding year (2020 data is provisional) (2019 Tall Building Year in Review, 2019) 
In the past two decades or so, the race for constructing the tallest has been extended to include the contest for constructing the most iconic and spectacular high-rise buildings. They were often characterised by complex geometries and leaning/twisting forms (Tall Buildings Past and Present Trends, 2018). Figure 2, a graph of the timeline and height of tall buildings, shows the increase of tall buildings' height over time.

The scope of this project is tall buildings, in particular high-rise office buildings, because empirical data suggests tall leads to worse energy performance (GodoyShimizu et al., 2018). Therefore, the wind's turbulent boundary layer and the lapse rate decrease of temperature with height become important to model. For low-rise buildings, the increase of wind speeds and the decrease of temperature from elevation are too small to be significant. When a building is tall enough, it is possible to explore the effects of vertical variations of urban microclimates on building performance.

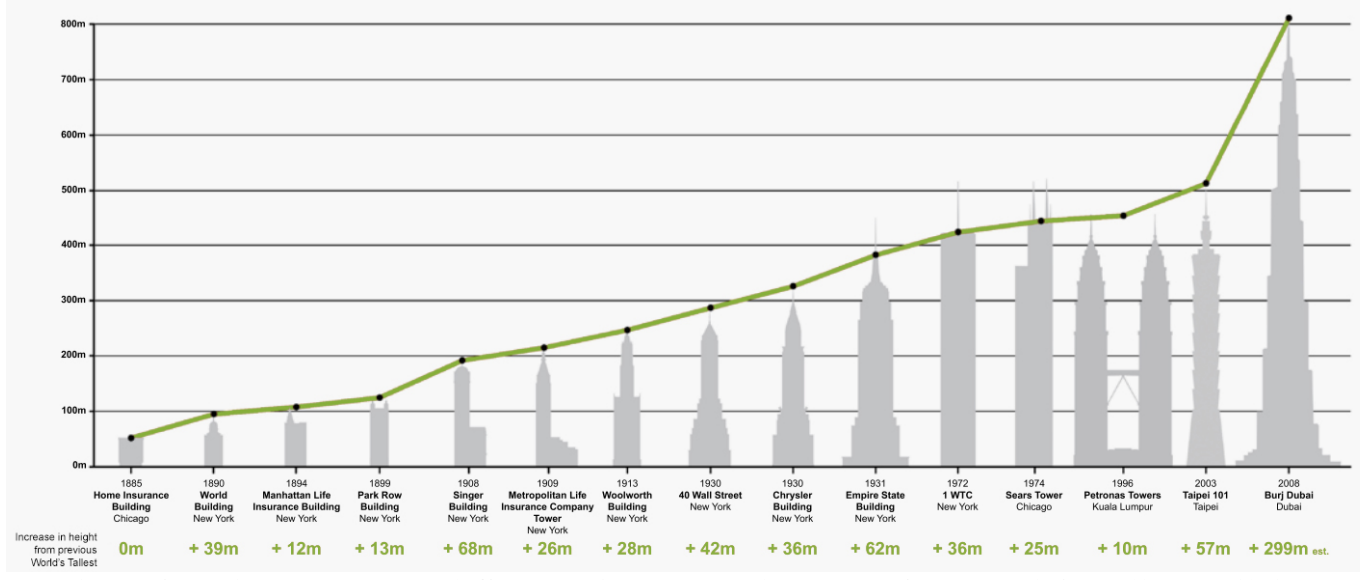

Figure 2: Height Incremental Changes in the Development of the World's Tallest Buildings Historically (CTBUH Journal Tall Buildings in Numbers, 2018)

\subsubsection{Urban microclimates}

Currently, most urban building performance simulations are based on rural weather data. While simulation programs can predict the building performance in rural microclimates, whether or not they are capable to model the complex urban microclimates needs to be demonstrated. The main features of the urban microclimate discussed in this study were the Urban Heat Island (UHI) effects and Lapse Rate, urban winds and the Urban Boundary Layer (UBL), because these temperature and wind related features affect the building performance simulation. These urban features change with height. Wind pressure coefficients and temperature on the façade of the high-rise office buildings on different floors lead to different natural ventilation performance. 


\subsubsection{Building performance}

Urban life gives citizens a convenient way of living. However, citizens have to face the problem of disconnection with the natural world, which UNDESA argues is likely to lead to various physical and mental disorders (Modak et al., 2012). The disconnection with the natural world is much more obvious in office buildings with air conditioning systems. Natural ventilation can weaken the disconnection, reduce building energy consumption and improve indoor air quality and thermal comfort level (B. Wang \& Malkawi, 2019). The focus on recommendations for increased fresh outdoor air delivery resulting from the COVID-19 pandemic, is likely to lead to a greater interest in future in developing natural ventilation options for tall buildings. This project looked to build on simulation data to explore how to develop natural ventilation by utilizing a prototypical high-rise office building model. The reason for modelling an office building is that currently office buildings rely on air conditioning, while natural ventilation can improve internal comfort and save energy for office buildings (B. Wang \& Malkawi, 2019).

\subsection{Significance of the Research}

Currently, individual parameters of urban microclimate are studied in some papers. No research was found modelling the features of urban microclimates together. The principal goal of this research is to quantify the magnitude of the difference in building thermal performance simulations when the urban microclimate is modelled as threedimensional compared to the conventional two-dimensional model. Three-dimensional urban microclimate is more complex and closer to reality. The simulation system makes it possible to model urban microclimate more accurately. Modelling urban microclimate in detail influences the prediction of building performance, and the prediction of building performance influences the capacity design of building equipment. Underestimated building performance results in undersized building equipment and a lack of thermal comfort. Overestimated building performance leads to financial waste. A more accurate prediction of building performance for a high-rise office building is helpful for engineers to optimize design and improve performance.

The standard two-dimensional climate model associated with UHI is ground-level information. The climate data include the temperatures, relative humidity and solar radiation measured at $2 \mathrm{~m}$ from the ground, and wind speed recorded at $10 \mathrm{~m}$ height 
every hour in a year (LBNL, 2018). The climate data is based on a typical meteorological year.

Wind speeds increase with height, so the wind speed at the top of a high-rise building is much higher than that at the bottom. This growth rate of the wind speed is much bigger in the open country than in the city due to the drag from taller buildings. Besides, the complex interaction between buildings and urban winds, leads to downdraughts into the street and channelling between buildings, making the simplistic general equations relating to height and wind speed inaccurate. This imprecision in our understanding of the variation of wind speed with height has a direct effect on a) surface heat transfer coefficients; b) wind pressures affecting infiltration; c) wind pressures affecting the potential for natural ventilation.

In dense urban areas, the maximum temperature difference between the rural temperatures and those in the centre of a UHI could be as much as 6 to $12^{\circ} \mathrm{C}$, depending on the density and size of a city (Oke, 1973). UHI is traditionally identified from the air temperatures which are at height of $2 \mathrm{~m}$ above the ground surface (Hafner \& Kidder, 1999). This research examines the effect of height on temperatures, and hence on the performance of buildings subjected to the temperature variations. Does the conventional lapse rate of a decrease in temperature of $0.65^{\circ} \mathrm{C}$ per $100 \mathrm{~m}$ elevation experienced in the open country (Brunt, 1933) apply in the middle of a dense urban environment?

It is important to understand how the increase of wind speed and decrease of temperature with height influence the building performance prediction at different height. According to the influence of vertical variations of urban microclimate, engineers can take different strategies at different floors.

\subsubsection{Benefits of detailed urban microclimate modelling}

From 1950 to 2018, the proportion of the world population living in urban areas increased from around $30 \%$ to $55 \%$. By 2050 , the proportion of the world population living in urban areas is predicted to rise to $68 \%$ (United Nations Department of Economic and Social Affairs, 2018). The revision also shows there will be another 2.5 billion people moving from rural to urban areas, taking the overall growth of the world's population into account. 
Because of the Urban Heat Island (UHI) phenomenon, urban microclimates are different from rural microclimates. The phenomenon of higher temperatures in urban areas than in rural areas relates to dense urban development over a wide area, including massive high-rise buildings in cities. At the same time, the convenient way of living costs lots of energy, and the enormous energy gives out heat. Given the number of highrise buildings has increased dramatically during the last 20 years (Figure 1), it is essential to better understand the urbanization impacts on urban microclimates and predict high-rise building performance. If thermal comfort and energy consumption can be predicted before the urban building construction has been completed, the thermal discomfort and waste of energy caused by poorly designed buildings can be avoided effectively. Accurate urban microclimate modelling makes it feasible to propose technical solutions for building performance optimization.

\subsubsection{Urban microclimate modelling}

Knowledge about urban microclimate modelling is the essence of accurate microclimate data. Furthermore, accurate microclimate data is significant for building performance simulation. Also, urban microclimate data is beneficial for indoor and outdoor thermal comfort assessment. However, urban microclimate measurement data is not readily available. Rural climate data from weather stations are accessible. Urban microclimate data can be estimated by numerical urban microclimate simulation. The more important thing is that numerical simulation can give three-dimensional climate data. The use of vertical climate data makes it feasible to study the impact of height on building performance in urban areas.

\subsubsection{Definition of accurate - how close is close enough}

A simulation system was developed to model urban microclimate, which was based on rural weather data. From rural areas to urban areas, the urban microclimate model is getting close to reality. At first urban winds were taken into account, then UHI, wind speed profile, lapse rate and Urban Canopy Layer. The process of system improvement was advanced gradually. Hence, the effects of each element could be evaluated, and the significance of each element could be compared as well.

Without routinely performing calibration of modelling programs, it would always possible to doubt the simulation results (Satwiko et al., 1998). Even though getting closer to reality means getting closer to real results, it is not necessary to model a $100 \%$ 
perfect urban microclimate, because the last $10 \%$ maybe produces only $1 \%$ difference. For example, the urban wind and UHI may have significant impacts on building performance simulation. However, the height of Urban Canopy Layer may not. Hence, the matter of how close is close enough was discussed. ASHRAE Guideline 14 explained the determination of uncertainty. Extensive information was provided regarding the calculation of uncertainty, such as model prediction uncertainty. Generally, there are two ways to improve the accuracy of simulation. One is by reducing biases and the other is by reducing random errors. Better information, like measured values not assumed or stipulated values, can reduce biases (Guideline, 2002). Consideration should be given to control the factors creating uncertainty, and the level of precision can be improved.

This research used a real city, London, as a case study. The simulation system was developed based on the climatic condition in London. Then it examined whether the case might be specific to that climate. Can the simulation system be applied to other climates? If detailed modelling of urban microclimates in different climates is worthwhile, then it is feasible to give engineers suggestions to improve the building performance. If the parameters of the urban microclimate model have different priority under different climatic conditions, it is feasible to adjust the model accuracy and optimize the model according to the requirements of the engineer.

\subsubsection{Benefits of high-performance office buildings}

\subsubsection{Definition of high-performance}

"High performance buildings are defined as those that minimize resource consumption during construction, and over their life, and provide healthy and productive environments for occupants through the application of "sustainable" or "green" principles" (Riley et al., 2004).

The attributes of high-performance buildings include energy efficiency, durability, lifecycle performance, and occupant productivity (Act, 2005). The operation cost of the lifecycle of a building is approximate $60 \%$ to $85 \%$ of the total lifecycle cost (Christian $\&$ Pandeya, 1997). As the operation phase of a building is cost intensive, Angela Lewis, David Riley and Abbas Elmualim defined high performance buildings by their operation and maintenance (Lewis et al., 2010). They defined operation as services to keep systems and equipment operating as designed, and maintenance as services to 
restore systems and equipment to design conditions. The building systems and equipment include Heating, Ventilating and Air-Conditioning (HVAC) systems, Building Automation Systems (BAS), lighting, renewable energy technologies and software that support these systems (Lewis et al., 2010).

In this research, the fundamental question is what is the scale of the effect of microclimates on the likely performance of buildings. The buildings were designed to be nearly zero-energy while delivering the highest quality indoor environment. The attributes of high-performance buildings that can be influenced by surrounding microclimates are the operation phase of lifecycle performance, which is related to HVAC systems and natural ventilation systems. Utilization of natural ventilation systems and coordination with HVAC systems can reduce energy consumption and improve building performance. A simplified natural and a detailed natural ventilation were explored. How these two natural ventilation systems improve the building performance would be discussed.

\subsection{Thesis Structure and Chapter Summary}

Chapter 1: Introduction

Chapter 1 introduces the topic and the reason why the research is essential. It outlines the research question, objective and scope.

Chapter 2: Urban Microclimate, Modelling Technique, Building performance

Chapter 2 outlines the context of high-performance office buildings, urban microclimate features, and modelling techniques. It also presents what has been done and what needs to be done based on a literature review.

Chapter 3: Methodology

Chapter 3 addresses the methodology of this research. It explains the 3 stages of the research methodology, the preparation stage, the system development stage and analysis stage. It also describes in detail each step of the method and outlines the following research processes.

Chapter 4: Individual modelling programs reliability verification 
Chapter 4 demonstrates the simulation programs reliability and prepares for chapter 5 . In this chapter, Urban Weather Generator, OpenFOAM and EnergyPlus are tested through comparing predictions with experimental data.

Chapter 5: A representative sample of a prototypical office building in a real city

Chapter 5 begins with developing a prototypical office building and modelling it in the urban microclimate of London. From this case study, this chapter presents the process of gathering individual programs.

Chapter 6: Vertical variation effects on building performance and natural ventilation

Chapter 6 develops the urban microclimate detailed model based on chapter 5. It explores vertical variations of urban microclimate features effects on building performance. The significance of each parameter at different heights is discussed, and the necessity of vertical urban microclimate modelling is demonstrated.

Chapter 7: Simulation system

According to chapter 6, vertical variations of urban microclimates are not constant. Chapter 7 develops a multilayer modelling method. The necessity of wind pressure coefficients modelling is demonstrated. The natural ventilation system with detailed wind pressure data relates to the microclimate around the prototypical building. The urban microclimate effects on ventilation systems using a multilayer modelling method are explored. The simulation system of urban microclimate detailed modelling is developed gradually in Chapter 5, Chapter 6 and Chapter 7.

Chapter 8: Effects of different climates

Chapter 8 demonstrates that urban microclimate detailed modelling has significant impacts on building performance. The necessity of developing a simulation system in different climates is explored. The impacts of different urban microclimate features in different climates are compared with each other. The priority of those features in different climates are also explored. This proves the necessity of developing a simulation system in different climates.

Chapter 9: Conclusions

Chapter 9 summarises the conclusions of the research and determines whether the research question and objectives have been met. 


\section{CHAPTER 2. URBAN MICROCLIMATE, MODELLING TECHNIQUE, BUILDING PERFORMANCE}

\subsection{Chapter Intent}

"The quality of life of millions of people living in cities can be improved if the factors that affect the urban microclimate are understood and the form of the built environment responds to them in an appropriate way" (Erell et al., 2012).

This chapter provides an overview of the characteristics of urban microclimate and the modelling techniques for urban microclimate and building performance. It is based on a systematic literature review. It helps to understand the interaction of urban microclimate and high-rise office buildings. A systematic literature review was conducted to establish the level of documented evidence for the relationship between UHI depth, temperature lapse rates and building interaction with the turbulent wind boundary layer (J. Li \& Donn, 2017). The goal is to establish a basis upon which naturally ventilated tall buildings within dense urban environments might be modelled in detail. If a new large-scale tower is placed amongst a large city of low-rise buildings, the effect of the new building on the surrounding microclimate is problematic. This chapter explores what the literature can tell us on this subject. The problem for the simulationist is establishing the appropriate microclimate 'correction'. The height of the new building affects urban wind flow significantly. The temperature lapse rate can be significant in buildings of 30 storeys or more. The effect of the significant lapse rate and the altered wind flows on the building performance are less well-known (J. Li, Donn, et al., 2018).

\subsection{Urban Microclimate}

When simulating the energy performance of a building in urban areas, understanding how urban microclimates affect building performance simulation is critical. In general, an urban microclimate is different from a rural environment. The urban area modifies the climate because of the effects of urban structures and layout. In dense urban areas, the temperature is usually warmer and the winds slower than those in rural areas. Larger urban areas respond with a bigger modification. Compared with rural areas, Table 1 
shows that urban areas have less radiation, higher temperature, slower wind speed, less humidity, more precipitation and more cloudiness.

\begin{tabular}{|c|c|c|}
\hline Factor & & $\begin{array}{l}\text { Comparison with } \\
\text { rural environments }\end{array}$ \\
\hline \multirow[t]{4}{*}{ Radiation } & Global & $2-10 \%$ less \\
\hline & Ultraviolet, winter & $30 \%$ less \\
\hline & Ultraviolet, summer & $5 \%$ less \\
\hline & Sunshine duration & $5-15 \%$ less \\
\hline \multirow[t]{5}{*}{ Temperature } & Annual mean & $1^{\circ} \mathrm{C}$ more \\
\hline & Sunshine days & $2-6^{\circ} \mathrm{C}$ more \\
\hline & Greatest difference at night & $11^{\circ} \mathrm{C}$ more \\
\hline & Winter maximum & $1.5^{\circ} \mathrm{C}$ more \\
\hline & Frost-free season & $2-3$ weeks more \\
\hline \multirow[t]{3}{*}{ Wind speed } & Annual mean & $10-20 \%$ less \\
\hline & Gusts & $10-20 \%$ less \\
\hline & Calms & $5-20 \%$ more \\
\hline \multirow[t]{2}{*}{ Relative humidity } & Winter & $2 \%$ less \\
\hline & Summer & $8-10 \%$ less \\
\hline \multirow[t]{3}{*}{ Precipitation } & Total & $5-30 \%$ more \\
\hline & Number of rain days & $10 \%$ more \\
\hline & Snow days & $14 \%$ less \\
\hline \multirow[t]{5}{*}{ Cloudiness } & Cover & $5-10 \%$ more \\
\hline & Fog, winter & $100 \%$ more \\
\hline & Fog, summer & $30 \%$ more \\
\hline & Condensation nuclei & 10 times more \\
\hline & Gases & $5-25$ times more \\
\hline
\end{tabular}

Table 1: Comparison between urban microclimate and rural environments (Nagle \& Cooke, 2017)

\subsubsection{Wind flow and Boundary Layer}

Because there are fewer barriers on the ground, wind speeds are higher in rural areas at ground level. However, at low altitudes, buildings in urban areas produce more friction and slow down winds. That means at the same height below the urban canopy urban areas have slower wind speeds than their surrounding rural areas. At a higher altitude, wind speeds are the same no matter in urban areas or rural areas, because there are no barriers and no impacts from the barriers in both urban areas and rural areas at a high enough height. In the Urban Canopy Layer, the shape and array of buildings affect the airflow movement, which makes urban winds different from rural winds. The increase 
of the site coverage ratio decreases the pedestrian-level natural ventilation performance (Yuan, 2018).

Figure 3 shows that in the atmospheric boundary layer, wind speed increases with height. Because the roughness value in urban areas is much higher than that in rural areas, the thickness of the boundary layer in urban areas, also known as the Urban Boundary Layer (UBL), is higher than that in rural areas. The dashed line means the same wind speed.

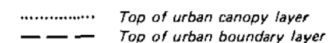

$\begin{array}{ll}\text {-二.- } & \text { Top of urban boundary layer } \\ \text { Top of dowrwind rural boundary layer }\end{array}$

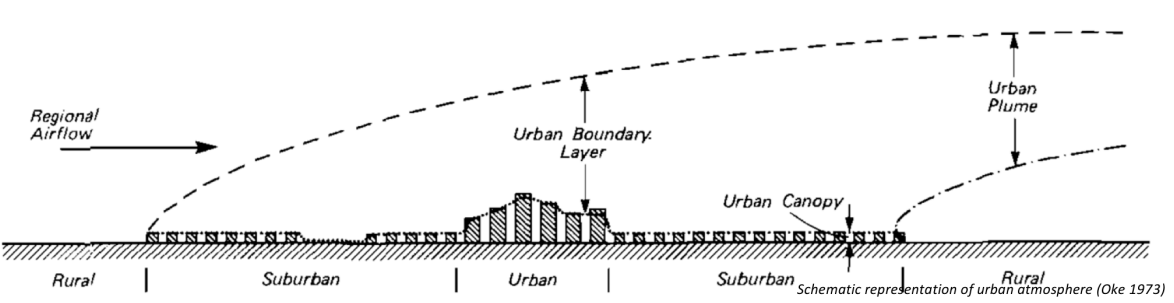

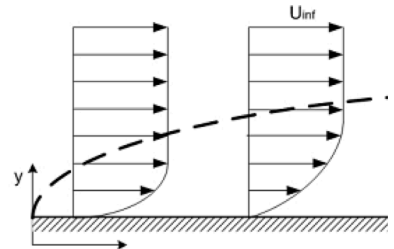

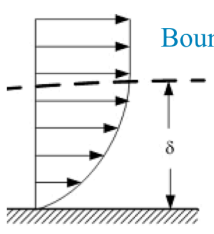

Figure 3: Diagram of Urban Boundary Layer and Urban Canopy (Oke, 1976)

The UBL relates to the height of buildings in the city. Varying heights of buildings makes the urban canopy uneven. From the ground level to the top of buildings is the lowest part of the urban atmosphere, Urban Canopy Layer (UCL) (Erell et al., 2012). UCL is a surface assembled by all roofs of urban buildings (Figure 3). Under the UCL, there is a unique urban microclimate. On a small scale, from point to point within the UCL, the shape and spacing of buildings or groups of buildings vary widely, which means a relatively high level of the inherent heterogeneity of UCL. Due to the heterogeneity of UCL, the winds around buildings in urban areas are highly variable.

In a central area of a city, the behaviour of wind is far more complex and variable. An individual high-rise building affects the movement of air radically. From the windward side, the airflow streams down from the surface of buildings and over the top. Behind the building, the reverse flow leads to turbulence. The behaviour of winds around a single block is relatively independent, and winds behave similarly where buildings are widely spaced. However, when buildings are close together, airflow from multiple buildings can interfere with each other. When buildings are packed close enough, the wind blows over the top of buildings and there is less turbulence between buildings. 
When high-rise buildings line a straight street, the airflow is squeezed, resulting in higher wind speeds.

The microclimate surrounding buildings in the UCL is extremely important for energy performance and thermal comfort. The building blocks also influence the airflow moving over and around. Modelling studies with smoke streams have shown that highrise buildings have a strong effect on the intensity and direction of airflow (Erell et al., 2012). A high-rise building, located in lower-level blocks, generates airflow disturbance. Higher wind speeds and forces occur on the windward wall, and the wake area is near the leeward wall. The sharp corners of the building separate the airflow to form suction zones. The wind in the leeward zone near the ground is weaker and has lower velocities but higher turbulence. These airflow disturbances caused by the highrise buildings also change the wind environment around them at different heights.

As the airflow passes through the city, the wind from rural areas changes the behaviour by contacting with the urban buildings. The wind in the Urban Boundary Layer (UBL) is significantly different from that at the same height in rural areas. The thickness of UBL increases with the increase of Urban Canopy Layer (UCL) height. Even in the same city, in different areas, the height of urban surface depends on the height of buildings in a particular area. If a new high-rise building is built, the surrounding UCL will also rise and the UBL in this location will change as well. There may be significant differences between urban-scale winds and regional winds.

\subsubsection{Urban Heat Island}

"The urban heat island is one of the most important manifestations of the urban climate, and has been the subject of much research since it was first described for the city of London by Luke Howard in 1818” (Erell et al., 2012).

Urban Heat Islands (UHI) have been associated with urbanization. It is a phenomenon that there is a substantial temperature difference between urban and rural areas of a city. The formation of the temperature difference between urban and rural areas reflects the effects of human activities. The rise of high-rise buildings in cities makes the topography of urban areas very different from that of rural areas. Besides, the leading cause of the urban heat island effect is from the modification of land surfaces (Solecki et al., 2005; US EPA, 2014). The air temperature increase is mainly from the heat storage in the building mass and urban ground surface (Yuan et al., 2020). In high- 
density urban environments, as urban population grows, the wasted heat generated by energy usage also contributes to the temperature increase.

The maximum value of UHI is usually located near the densest area of a city. When the city is quite big and has more than one dense area, the values of a measurement location can only represent the corresponding UHI at that site. Besides, the definition of rural is rough, and which measurement location can accurately represent the rural area? In general, the conventional test sites for rural weather data are beside the airport, which is usually located far away from the urban core. The measured data is not only beneficial for the study of urban weather, but also useful for the operation of the airport. Data collected from urban and rural measurement sites are used to calculate the temperature difference, which is the UHI.

UHI is mainly caused by human activities. The intensity is related to the sum effect of human released energy, also solar heating in paved areas, such as lack of heat loss from evapotranspiration by plants. This means the size of the city and the population also affect the maximum temperature difference. The phenomenon is also affected by seasons and time of day. As cities have so many buildings that can store energy, the heating rate in the morning and cooling rate in the late afternoon are usually lower in urban areas than in rural areas. As a result, the temperature difference peaks two to three hours after sunset (Hewitt \& Jackson, 2020). The increase of temperature difference is more correlated to cooling rates in rural areas than that in urban areas (Yang et al., 2019). The cooling rate of rural areas varies from one to the other because of geographic location and weather. Figure 4 shows the magnitudes of heat island at a different place of a city which is between $-1 \mathrm{~K}$ and $6 \mathrm{~K}$.

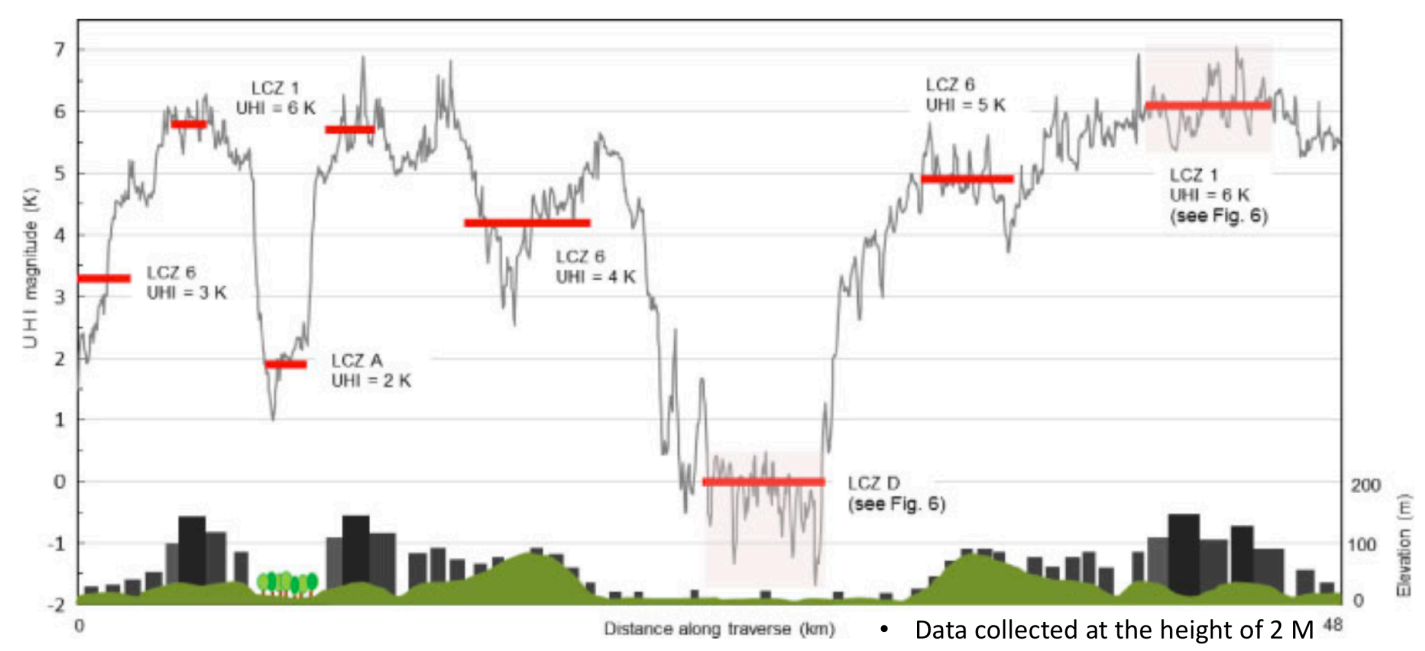


Figure 4: Schematic of Heat island magnitudes in urban, suburban and rural areas for Vancouver in $4^{\text {th }}$ November 1999 (Stewart et al., 2014)

In densely populated urban areas, the maximum temperature difference between rural areas and the UHI central area can be as much as 6 to $12^{\circ} \mathrm{C}$, depending on the size of the city (Oke, 1973). UHI is usually determined by the surface air temperatures of 2 meters high (Hafner \& Kidder, 1999). But is the temperature difference between urban and rural regions at the height of 2 meters equal to the difference at 100 meters?

The intensity of UHI decreases with altitude. Taking the city of Calgary as an example, the intensity of UHI at the height of $10 \mathrm{~m}$ is $0.57{ }^{\circ} \mathrm{C}$ and decreases to $0.04{ }^{\circ} \mathrm{C}$ at the height of $300 \mathrm{~m}$ (Lawrence C. Nkemdirim, 1979).

The Urban Heat Island (UHI) effect, as a phenomenon of air temperature increase caused by urbanization, is not often considered in current building energy simulations (Bruno et al., 2012). One reason is that current thermal simulation practices are based on typical meteorological year (TMY) data or actual meteorological year (AMY) data. TMY data is not available for centre city locations because it is very difficult to establish a representative location in the complex heterogeneous environment of a city. The widely used TMY and AMY files originate from long-term weather data stations outside the urban area, usually at airports (Wilcox \& Marion, 2008). Since building sites tend to be urban, the use of rural weather data causes deviations in performance metrics due to the UHI phenomenon (Arnfield, 2003).

\subsubsection{Lapse Rate}

Lapse Rate is the atmospheric phenomenon of vertical variation of temperature in the troposphere. It varies from day to day, from place to place. The vertical temperature difference is related to the atmosphere pressure distribution (Hummel \& Kuhn, 1981). The tropospheric pressure decreases with height, and atmospheric expansion cooling occurs with a decrease of pressure. So, the temperature decreases with height as well. In addition, the air is not completely dry, and condensation occurs in moist air. As the air rises from expansion cooling, the condensation releases some heat, thereby reducing the intensity of expansion cooling. When air expansion cooling dominates the temperature change, the temperature decreases with height.

Bokwa studied the differences in lapse rates of the near-ground air layer of 0.5-2 $\mathrm{m}$ in urban and non-urban areas (Bokwa, 2015). The temperature near the ground sometimes 
decreases with height and sometimes rises with height. The lapse rate is much higher in urban areas than in the non-urban areas, especially in summer.

Unlike wind speed which increases with height, the lapse rate generally decreases with height. For example, in Lawrence's study, the lapse rates at the edge of Calgary city decrease from $0.034^{\circ} \mathrm{C} \mathrm{m}-1$ at $10 \mathrm{~m}$ to only $0.003^{\circ} \mathrm{C} \mathrm{m}-1$ at $300 \mathrm{~m}$ (Lawrence C. Nkemdirim, 1979).

According to previous observations, the average Lapse Rate is close to $0.65^{\circ} \mathrm{C} / 100 \mathrm{~m}$ (Figure 5). Thus, the temperature outside the top floor of a $100 \mathrm{~m}$ high building is $0.65^{\circ} \mathrm{C}$ lower than that at the bottom. This decrease is the normal lapse rate. The Lapse Rate in densely populated urban areas is different from that in rural areas.
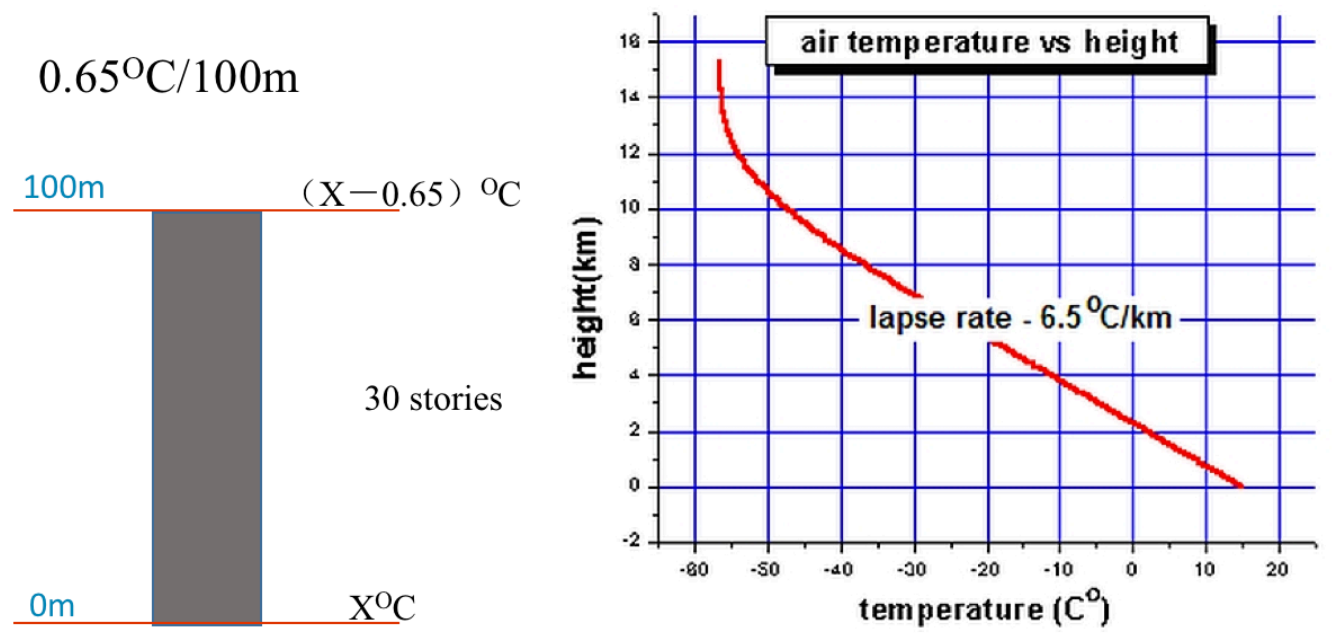

Figure 5: Diagram of lapse rate (Real Climate Science, n.d.)

\subsection{Modelling Technique}

This study aims to find a method for modelling three-dimensional urban microclimates, considering the phenomena of urban wind, Boundary Layer, Urban Heat Islands (UHI) and Lapse Rate. To achieve this main goal, this research proposes a method of using individual simulation programs for different purposes and reorganizing them through a platform to establish a simulation system.

The selected tools for modelling urban microclimate and assessing building performance need to:

- Be extensively used and available for users, such as researchers and design analysts, yet sufficiently comprehensive enough to get useful results 
- Be extensible and alterable to meet the needs of a specific situation, and flexible enough to compile like open-source programs

- Be compatible so that they can be united with each other in the same operating environment and have the results linked to other programs

OpenFOAM (Section 2.3.1) is used for urban wind environment simulation, Urban Weather Generator (UWG) (Section 2.3.2) is used for the Urban Heat Island simulation, and EnergyPlus (Section 2.3.3) is used for building performance simulation.

- Verification of CFD prediction of urban winds with OpenFOAM Comparison with wind tunnel experiment

- Verification of Urban Heat Island effect prediction with Urban Weather Generator

Comparison with real UHI of a city

- Verification of building performance prediction with EnergyPlus

Comparison with real performance of a building

OpenFOAM, Urban Weather Generator (UWG) and EnergyPlus are the basic programs for developing an urban microclimate simulation system. These three programs have their corresponding plugins: Butterfly (Section 2.3.1), Dragonfly (Section 2.3.2), Ladybug and Honeybee (Section 2.3.3). Rhino is used for modelling three-dimensional buildings and it has a plugin named Grasshopper. Grasshopper is a Visual Programming Language (VPL) for the 3D modelling program Rhino. Butterfly, Dragonfly, Ladybug and Honeybee are user interfaces written in the VPL of grasshopper. Their biggest advantage is that they have a consistent interface style and modelling concept, making inter-operability easier (Figure 6). 


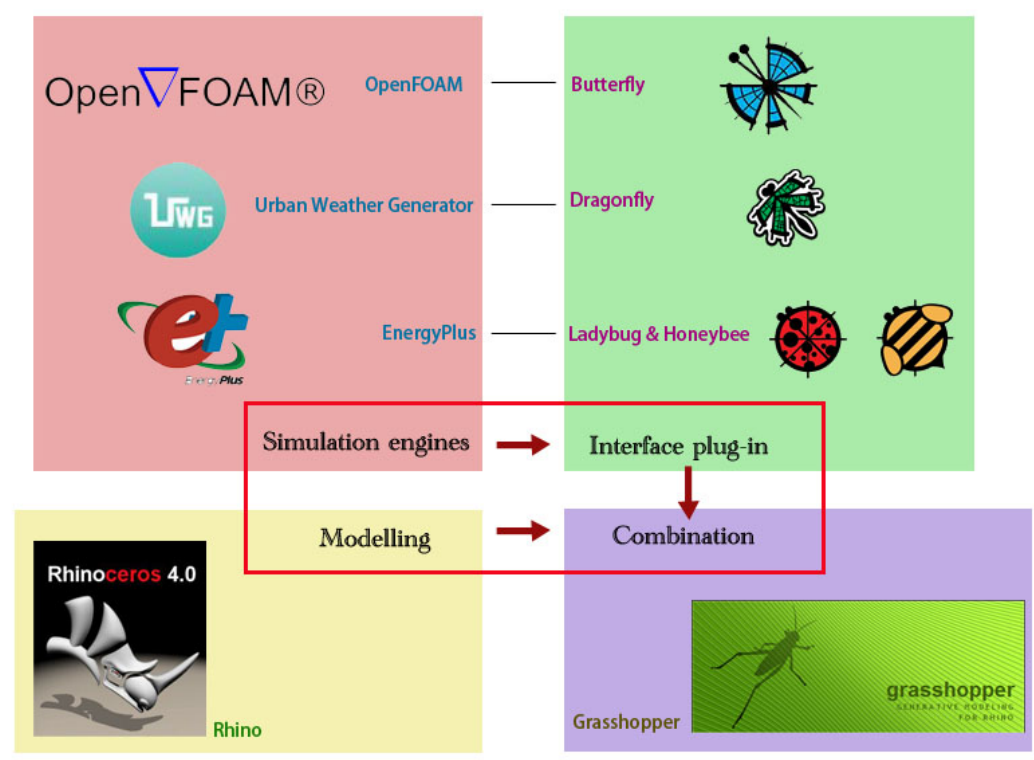

Figure 6: Flow diagram for the research

\subsubsection{OpenFOAM and Butterfly plugin}

OpenFOAM is an open-source Computational Fluid Dynamic (CFD) computer program. OpenFOAM is developed for the Linux operating system and uses virtualization to imitate a Linux compile environment on Windows and Mac. Therefore, it is necessary to install a virtual box such as Docker Hub before using OpenFOAM. The OpenFOAM has no Graphical User Interface (GUI) and requires an additional GUI program. In this research, Butterfly is the GUI for OpenFOAM and the plugin of Grasshopper. Figure 7 shows the structure of the OpenFOAM program which consists of three parts: pre-processing, solving and post-processing.

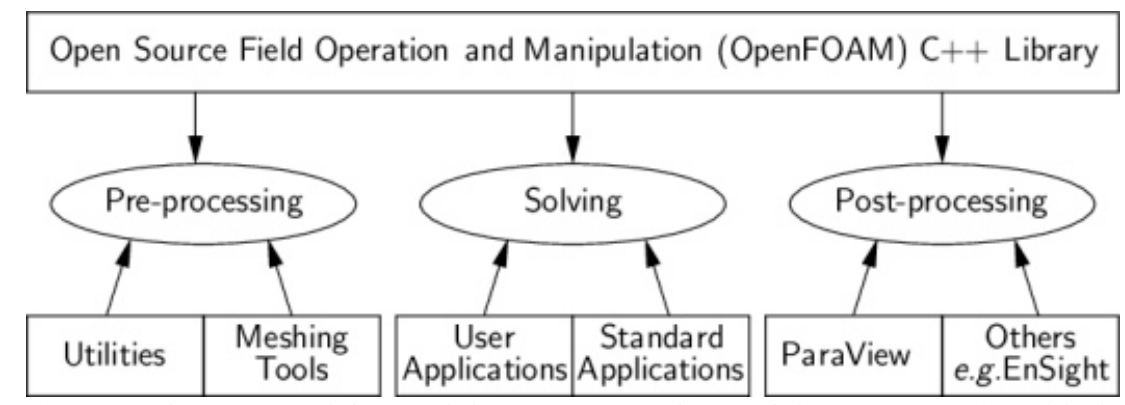

Figure 7: Overview of OpenFOAM structure (OpenFOAM Introduction, 2018)

Most of the simulations in this research used a Linux version of OpenFoam running in a virtual machine on a Windows operating system computer. More recently, a native Windows version of OpenFoam has become available. The new version of OpenFOAM for the Windows 10 operating system is called blueCFD (The BlueCFD-Core Project, n.d.). 


\subsubsection{Urban Weather Generator and Dragonfly plugins}

Urban Weather Generator (UWG) is an Urban Heat Island (UHI) effect modelling program. To estimate the UHI effects, UWG requires two pieces of information. One is a weather file (EPW format), and the other is a description of the urban configuration. Weather data is usually from a rural weather station. The description of urban configuration includes the shape and size of the building, the proportion of the landscape and the asphalt pavement, and so on. Building materials and urban composition influence the heat transfer in urban areas. The following figure shows the workflow of UWG. The output of UWG is an urban weather file in EPW format.

"UWG is composed of four modules: the Rural Station Model (RSM), the Vertical Diffusion Model (VDM), the Urban Boundary-Layer (UBL) model and the Urban Canopy and Building Energy Model (UC-BEM). Thermal networks indicate the main heat transfer processes included in the RSM and UC-BEM. $T_{r u r}, T_{u b l}$ and $T_{u r b}$ represent the air temperature measured at the weather station, calculated at the urban boundary layer and calculated at the urban site. The RSM provides rural sensible heat fluxes $\left(H_{\text {rur }}\right)$ to the VDM and the UBL model. The UC-BEM provides urban sensible heat fluxes $\left(H_{u r b}\right)$ to the UBL model (Figure 8)" (Bueno et al., 2013).

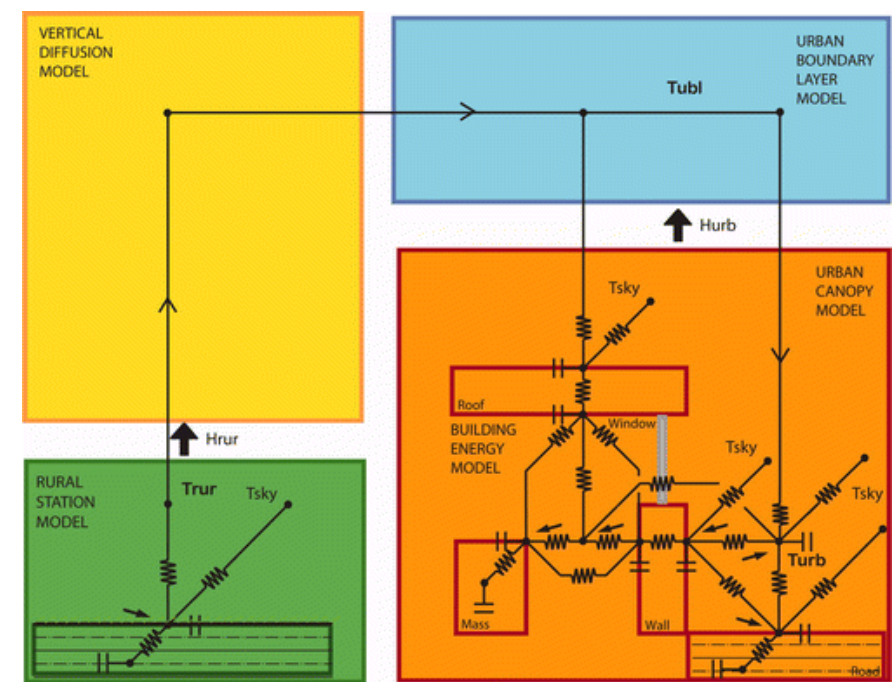

Figure 8: Diagram of the urban weather generator (UWG) scheme (Bruno et al., 2012)

Dragonfly is the GUI between Grasshopper (plugin of 3D modelling software Rhino) and UWG. Dragonfly is used to input urban parameters, and then UWG is responsible for the calculation. Modelling with the grasshopper plugin is convenient because it shares information with other programs. Users do not need to learn the interface to 
UWG because the Dragonfly interface provides a way to enter the correct input data and obtain the outputs that follows the same user experience paradigm as the other simulation software used. The Dragonfly interface replaces the set-up process and simplifies the operation. UWG is only used for calculation and runs in the background.

\subsubsection{EnergyPlus and Ladybug and Honeybee plugin}

Over the past few decades, a wide variety of building energy simulation programs have been developed, improved and used throughout the building energy community (Crawley et al., 2008). When assessing those programs, comprehensive modelling capability is the first and foremost criteria, such as daylighting, ventilation, electrical systems, HVAC systems, and so on. In addition, compatibility with other programs is also important. Due to its comprehensiveness, compatibility, wide application in research and multiple publicly available validation reports, EnergyPlus was selected in this research as the building performance simulation tool (Boyano et al., 2013; Fumo et al., 2010; L. Wang et al., 2012).

"EnergyPlus is an energy analysis and thermal loads simulation program. Based on a user's description of a building from the perspective of the building's physical make-up, associated mechanical systems, etc., EnergyPlus will calculate the heating and cooling loads necessary to maintain thermal control setpoints, conditions throughout an secondary HVAC system and coil loads, and the energy consumption of primary plant equipment as well as many other simulation details that are necessary to verify that the simulation is performing as the actual building would" (LBNL, 2018).

Like OpenFOAM, EnergyPlus is also a free, open-source program. Unlike OpenFOAM, EnergyPlus can run on Windows, Mac and Linux operating systems without virtualization tools.

\subsection{High-Performance Office Building}

The reason for studying office buildings is that they perhaps are the most critical building type of the 20th century (Kleiven, 2003). The number and height of high-rise office buildings are increasing. Another reason for studying high-rise office buildings is that the vertical variations of urban microclimates are associated with heights. For 
low-rise buildings, the increase in wind speed and the decrease in temperature with height are too small to be significant.

Just as the factory was a symbol of industrialization in the early 19th century, the office building is a symbol of the post-industrial era. There are office buildings all around us. They dominate contemporary cities, they accommodate more than half the working population of the western world, and they represent a large proportion of the total energy use in buildings.

\subsubsection{Energy performance}

Energy performance is measured and compared by the amount of energy consumed. A convenient unit of measurement for energy use in buildings is the kilowatt-hour (kWh). However, for the comparison of energy consumption efficiency of buildings of different sizes, this method is too general and potentially misleading. Therefore, the energy consumption metric used in this research was $\mathrm{kWh} / \mathrm{m}^{2} /$ year. It eliminated the effects of the operation period and building size.

\subsubsection{Thermal comfort}

"A human being's thermal sensation is mainly related to the thermal balance of his or her body as a whole. This balance is influenced by physical activity and clothing, as well as the environmental parameters: air temperature, mean radiant temperature, air velocity and air humidity” (ISO, 2005).

ASHRAE Standard 55 is a thermal comfort standard, which is published by American Society of Heating, Refrigerating and Air-Conditioning Engineers. ASHRAE Standard 55 takes personal and environmental factors into account: metabolic rate (met), clothing insulation (clo), air temperature, radiant temperature, air velocity, and relative humidity (Standard, 2010). The acceptable range of temperature and its relationship with air speed are shown in Figure 9. When the air speed is low, the acceptable temperature is low. When the air speed is high, the acceptable temperature is high. When the air speed is $0.1 \mathrm{~m} / \mathrm{s}$, the acceptable temperature range is from $20^{\circ} \mathrm{C}$ to $27^{\circ} \mathrm{C}$. 


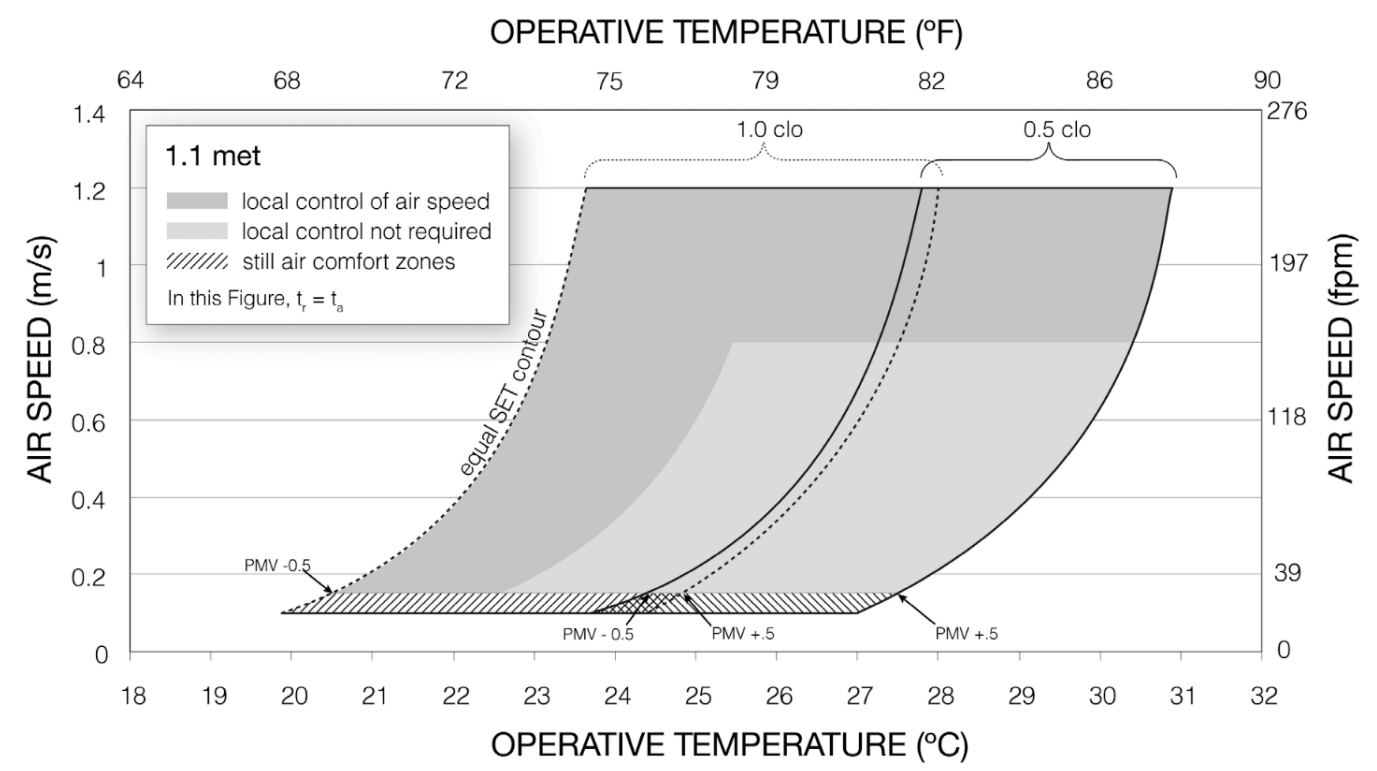

Figure 9: Acceptable range of operative temperature and air speeds at humidity ratio 0.010 (Standard, 2010)

\subsubsection{Natural ventilation}

Natural ventilation offers the opportunity to achieve a high reduction in energy consumption while improving indoor air quality (Kolokotroni \& Aronis, 1999). With more cities looking to remove cars away from the city centre and vehicle fleets electrifying, it is conceivable that occupants in office buildings in dense urban areas might have fresh outdoor air to help maintain high-quality thermal comfort.

Due to the crowding of buildings, wind flow in the city changes. The situation is much more complicated. Wind is brought down into the street by large scale buildings. Wind speeds increase with height. It makes urban winds complex and turbulent. The problems caused by urban winds are shown in Figure 10. As the wind speed increases, the air pressure also increases, which increases the possibility of air infiltration heat loss at the upper floors of tall buildings. So, should the opening at a higher place be smaller than that at a lower place? Should the openings at the top of large-scale buildings be banned because the wind is blowing too fast? 
Problems for prediction

- Urban wind is complex

- Buildings out of scale bring wind down into the street

- Should the windows be different sizes at different heights

- Are the winds at the top of tall buildings too fast for opening windows

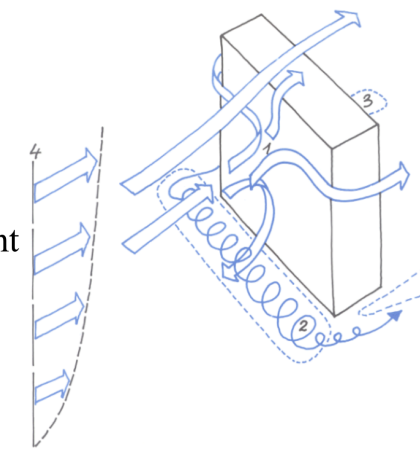

Figure 10: Problems for urban wind prediction

Natural ventilation efficiency is affected by variable factors such as wind speed and wind direction, especially the wind movement around the building. The urban form, especially the height of individual buildings, influences the wind movement in urban areas, leading to microclimate change. This research focused on identifying the height of buildings as a parameter which influences wind movement, on the increase of wind speed with height in the Urban Boundary Layer, and also on temperature stratification in the atmosphere. In this research, simplified natural ventilation systems and detailed natural ventilation systems were studied.

\subsection{Systematic Literature Review}

The Urban Boundary Layer (UBL) and Lapse Rate change the microclimate with height in urban areas (Figure 11). Each of these phenomena interrelates with all the others. However, it is not clear how changing microclimates affect the natural ventilation of buildings at different heights. These well-known phenomena can be modelled in software such as EnergyPlus. It can model the increase of wind speed with height using a power-law, and the decrease of temperature of $0.65^{\circ} \mathrm{C}$ for each $100 \mathrm{~m}$ height increase. What is less known is the interaction of these parameters with Urban Heat Island. Is city-scale CFD (Ai \& Mak, 2013) an essential part of every building model study? 


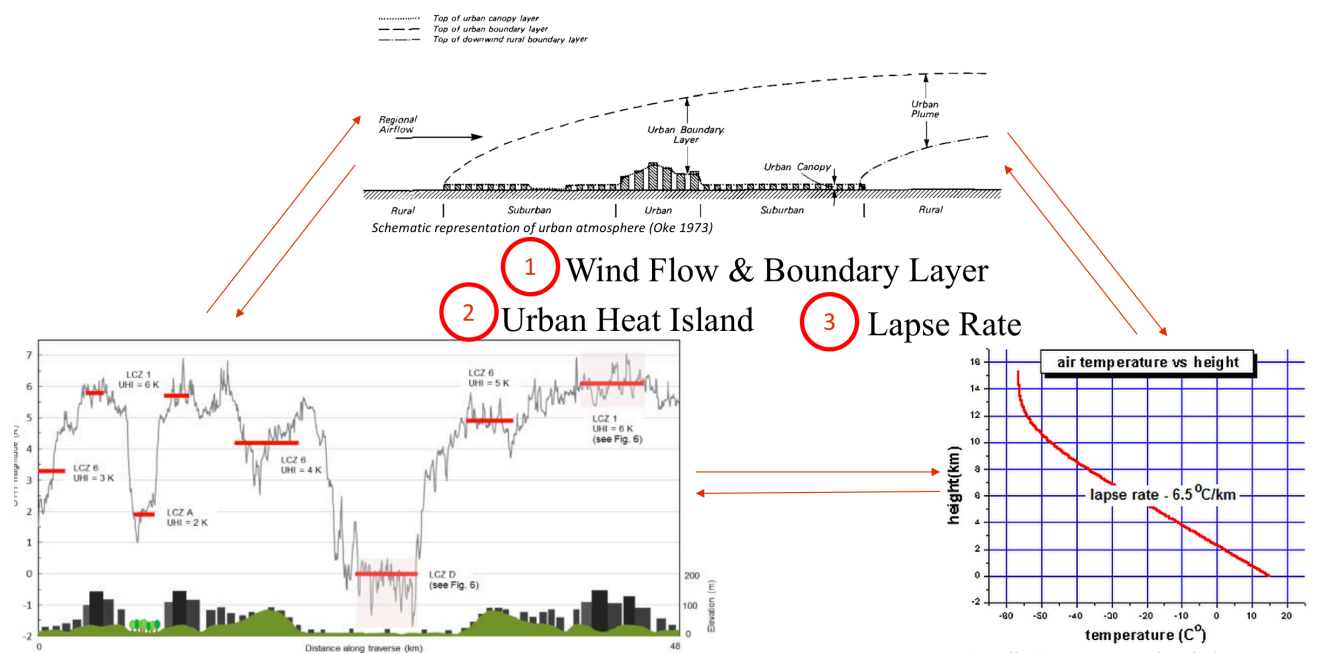

Figure 11: Interaction of urban microclimate features: Urban wind, Boundary Layer, Urban Heat Island and Lapse Rate

The purpose of this literature review is to find evidence for accurate modelling of wind and temperature in dense urban areas affected by Urban Heat Island (UHI) issues. The goal is to establish evidence to manage the models of buildings and neighbourhood heights in order to obtain better natural ventilation in dense urban areas.

\subsubsection{Methodology}

This section systematically reviews the theme of urban microclimate, focusing on the interactions between Urban Heat Island, vertical temperature lapse rates and the influence of tall buildings on urban winds. The review examined over 200 relevant articles.

In the atmospheric boundary layer, the wind speed increases with height. As wind speeds increase, so does the air pressure, which has the potential to increase heat loss from upper storeys of tall buildings, and then the air temperature decreases with height. If a new high-rise building is placed among low-rise buildings in dense urban areas, the problem is what kind of effect the new building has on the UHI, the urban wind in the street and the Lapse Rate. A systematic review was conducted on the influence of building height. The issue of the height or depth of UHI when a large-scale tower penetrates the Urban Canopy Layer (UCL) was explored. The impact of these parameters on the potential for openable windows to provide adequate natural ventilation for cooling in summer was investigated. 


\subsubsection{Search process}

The search process identified papers across five English language literature databases: ScienceDirect, Scopus, ProQuest, Engineering Village and SAGE journals. These five databases are the most popular databases for building science, and they cover the vast majority of relevant research. In ScienceDirect, Scopus and Engineering Village, the initial search terms in the article title, abstract or keywords were: 'Urban Heat Island', 'height or depth', 'temperature', 'simulation', 'building' and 'wind'. In Engineering Village, WN means searching within a specific field and KY relates to "subject/title/abstract" (Table 2).

This study mainly focused on the influence of building height on the depth of UHI, wind flow and temperature gradients, so, the limitation key words were restricted to "UHI", "height or depth", "temperature" and "building" when searching the related papers. Since simulation is also an efficient method, simulation was added as a search limitation. In ProQuest, the search terms were searched everywhere except full text, which is the same as title-abstract-keywords. The search area for SAGE journals was all over the field because search results were rare when restricted to title- abstractkeywords. Then in SAGE journal, the initial search terms in all fields were: 'Urban Heat Island', 'height or depth' and 'temperature'. The search terms in the abstract were: 'simulation', 'building' and 'wind'. Air pollution is out of this study and therefore it does not include the results of pollution or pollutant. The exact search terms used show in Table 2.

Table 2: Search terms within databases (Date of last search:13 November 2016)

\begin{tabular}{l|l}
\hline Database & Search terms \\
\hline \multirow{3}{*}{ ScienceDirect } & TITLE-ABSTR-KEY(urban heat island) AND \\
& TITLE-ABSTR-KEY(height or depth) AND \\
& TITLE-ABSTR-KEY(simulation) AND \\
& TITLE-ABSTR-KEY(building) AND TITLE-ABSTR-KEY(wind) \\
\hline \multirow{3}{*}{ Scopus } & TITLE-ABS-KEY ( urban heat island ) AND \\
& TITLE-ABS-KEY ( height OR depth ) AND \\
& TITLE-ABS-KEY ( temperature ) AND \\
& TITLE-ABS-KEY ( simulation ) AND \\
\hline
\end{tabular}




\begin{tabular}{l|l}
\hline & \multicolumn{3}{l}{ TITLE-ABS-KEY ( building ) AND TITLE-ABS-KEY ( wind ) } \\
\hline \multirow{3}{*}{ ProQuest } & $\begin{array}{l}\text { all(urban heat island) AND all((height OR depth)) AND } \\
\text { all(temperature) AND all(simulation) AND all(building) AND } \\
\text { all(wind) }\end{array}$ \\
\hline Engineering & $\begin{array}{l}((((((\text { urban heat island) WN KY) AND ((height or depth) WN KY)) } \\
\text { AND ((temperature) WN KY)) AND ((simulation) WN KY)) AND } \\
((\text { building) WN KY) }) \text { AND ((wind) WN KY)) }\end{array}$ \\
\hline SAGE & $\begin{array}{l}\text { urban in all fields and heat in all fields and island in all fields and height } \\
\text { or depth in all fields and temperature in all fields and simulation in } \\
\text { journals }\end{array}$ \\
\hline
\end{tabular}

\subsubsection{Data extraction}

The following data was searched for in the studies found by the search strategy: (1) temperature gradient (2) difference between Urban Canopy and Urban Boundary Layer temperature or wind (3) type of building (4) measured simulation data (5) 3D or 2D (6) season or diurnal (7) climate type. Papers which were associated with air pollution were excluded.

\subsubsection{Results}

The scoping search revealed that there were thousands of papers on the topic of the Urban Heat Island. In these studies, it was challenging to find papers that answered the research question directly.

This section outlines the interaction of Urban Heat Island, vertical temperature lapse rates and the influence of tall buildings on urban wind flows. In the beginning, there were several thousand of papers about UHI in each database. After comparing and screening the literature search results (Table 3), based on an in-depth abstract selection, 13 unique studies from literature databases seemed to be eligible and were further analyzed. The results of additional studies and limitations are then discussed.

\subsubsection{Step 1: Databases}

Table 3 shows the results from the five search databases: ScienceDirect, Scopus, ProQuest, Engineering Village and SAGE journals. Three of the 13 studies (data of 13 November 2016) showed information about temperature gradient, which is not many, but quite useful for understanding temperature differences in a vertical direction. 
Table 3: Search results quantity from databases (13 November 2016 and 11 Januray 2019)

\begin{tabular}{|c|c|c|c|}
\hline \multirow[t]{2}{*}{ Database } & \multirow[t]{2}{*}{ Search limitation } & \multicolumn{2}{|l|}{ Quantity } \\
\hline & & 13/11/2016 & $11 / 01 / 2019$ \\
\hline \multirow{7}{*}{$\begin{array}{l}\text { Science } \\
\text { Direct }\end{array}$} & Urban heat island(title-abstr-key) & 1091 & 1637 \\
\hline & Height or depth(title-abstr-key) & 117 & 159 \\
\hline & Temperature(title-abstr-key) & 80 & 107 \\
\hline & Simulation(title-abstr-key) & 25 & 37 \\
\hline & Building(title-abstr-key) & 17 & 24 \\
\hline & wind(title-abstr-key) & 5 & 9 \\
\hline & Research relevant (air quality exclude) & 4 & \\
\hline \multirow[t]{7}{*}{ Scopus } & Urban heat island(title-abs-key) & 3886 & 5999 \\
\hline & Height or depth(title-abs-key) & 339 & 506 \\
\hline & Temperature(title-abs-key) & 239 & 365 \\
\hline & Simulation(title-abs-key) & 71 & 102 \\
\hline & Building(title-abs-key) & 32 & 47 \\
\hline & Wind(title-abs-key) & 11(duplicates 5) & 18(9) \\
\hline & Research relevant (air quality exclude) & 5 & \\
\hline \multirow[t]{7}{*}{ ProQuest } & $\begin{array}{l}\text { Urban heat island(anywhere except full } \\
\text { text) }\end{array}$ & 4017 & 10804 \\
\hline & Height or depth(anywhere except full text) & 375 & 872 \\
\hline & Temperature(anywhere except full text) & 258 & 610 \\
\hline & Simulation(anywhere except full text) & 64 & 173 \\
\hline & Building(anywhere except full text) & 17 & 86 \\
\hline & Wind(anywhere) & 6(duplicates 3) & $23(8)$ \\
\hline & Research relevant (air quality exclude) & 2 & \\
\hline \multirow{7}{*}{$\begin{array}{l}\text { Engineeri } \\
\text { ng Village }\end{array}$} & Urban heat island(subject/title/abstract) & 2299 & 3438 \\
\hline & Height or depth(subject/title/abstract) & 200 & 300 \\
\hline & Temperature(subject/title/abstract) & 141 & 229 \\
\hline & Simulation(subject/title/abstract) & 56 & 85 \\
\hline & Building(subject/title/abstract) & 30 & 48 \\
\hline & Wind(subject/title/abstract) & 9(duplicates 8) & $16(13)$ \\
\hline & Research relevant & 1 & \\
\hline \multirow{7}{*}{$\begin{array}{l}\text { SAGE } \\
\text { journals }\end{array}$} & Urban heat island(all fields) & 2293 & 4219 \\
\hline & Height or depth(all fields) & 1259 & 2355 \\
\hline & Temperature(all fields) & 723 & 1280 \\
\hline & Simulation(abstract) & 34 & 59 \\
\hline & Building(abstract) & 19 & 30 \\
\hline & Wind(abstract) & 3 & 6 \\
\hline & Research relevant & 1 & \\
\hline
\end{tabular}

Table 4 shows the content and conclusions of 13 eligible studies. Two studies mentioned the difference in temperature or wind speed between Urban Canopy and Urban Boundary Layer. In Pillai's study, uniform height and non-uniform height buildings induced different urban canopy configurations and these were investigated by experimental and numerical simulation. Boundary layer height temperature above the canopy was taken as the roof surface temperature, and the centre point temperature of the canopy was chosen as the reference temperature for buildings' surfaces (Subramania Pillai \& Yoshie, 2012). The detailed relationships or differences between the temperature of the urban canopy and boundary layer were not compared. In Li's 
study, the typical winter urban boundary layer over Beijing was investigated (X. Li et al., 2005). The effects of variables on Urban Boundary Layer structure were indicated in that paper, and the Urban Canopy Layer was considered as a factor. It does not explain the relationship or temperature difference between the boundary layer and Urban Canopy Layer.

In these studies, only three papers discussed building typology. It is not because study areas played a specific role in urban heat island studies, but perhaps because the study area is the most accessible area for authors as researchers (Table 4).

All of these studies adopted a numerical simulation methodology, and a few of them also picked up measured data, mainly for verification. Fluent was the most common numerical simulation software, which was used in these studies, then ENVI-met followed as the second most popular simulation method. Most of these studies chose 3D modelling, and only a few of them used a 2D model. In the CFD simulation of Nazarian's study, a street-scale urban environment was investigated, and it also explored the average temperature of all four walls of a building (Nazarian \& Kleissl, 2015). According to this information, it is possible to get the temperature of building walls at different height through Fluent simulation. Also, mean air temperature at 1.5 m height was achieved in Cao's study on Guangzhou city, which indicated air temperature at different height could also be obtained through Fluent (Cao et al., 2015).

7 papers mentioned research season, and 6 were about summer. Only one of them studied winter, which considered air pollution as well.

Some of these studies gave the research location, and others did not. The given locations included different climate types, but all of them were in dense areas.

When investigating height, some research investigated height-to-width ratio (Bourbia \& Boucheriba, 2010; Oleson et al., 2008), or it investigated city areas with same height different density (Stewart et al., 2014). 5 cases were concerned about the effect of Height/Width ratio for the streets on the surrounding environment (P.J.C et al., 2015). In Pillai's study, uniform height buildings and mixed arranged non-uniform height buildings with different building coverage ratio were investigated (Subramania Pillai \& Yoshie, 2012), but no studies worked on the structure of the temperature or wind gradient. The Height/Width ratio was about how dense the city was, and hence how hot the $2 \mathrm{~m}$ height UHI might be. It was not about how the UHI changes with height. 
Urban form and function as building performance parameters were studied (Mohammed A. \& Jae D., 2015). 10 local climate regions with different city forms, compact high-rise, mid-rise, low-rise and open high-rise, mid-rise, low-rise, and so on, were estimated. These results addressed the building height influence on the UHI. The model formulation is associated with surface emissivity, albedo, roughness length, building height, vegetation fraction, anthropogenic heat, initial boundary-layer height. According to these parameters, the estimation was found from the calculation (Theeuwes et al., 2015). In Wang's study, three types of areas, high-rise, middle-rise and detached house area, are investigated using software ENVI-met (Y. Wang et al., 2015). It is possible to do the same simulation according to detailed input parameters, and that makes it possible to use a similar simulation method to investigate building height's effect on UHI. Additionally, 3 different building coverage ratios, coupled with 2 categories of uniform height building and non-uniform height building, totalling 6 city models were investigated. With the same building coverage ratio, the temperature contour for the non-uniform height case was quite different from that of the uniform height case. In this research, CFD was used for simulation, and this method has been verified through comparing with experiment results (Sivaraja Subramania \& Ryuichiro, 2012). The non-uniform height buildings are arranged regularly, not a high-rise building penetrating the UCL. 
Table 3: Results of eligible studies (until 13 November 2016)

\begin{tabular}{|c|c|c|c|c|c|c|c|c|}
\hline Study & $\begin{array}{c}\text { Temperature } \\
\text { Gradient }\end{array}$ & $\begin{array}{l}\text { Difference } \\
\text { between Urban } \\
\text { Canopy and } \\
\text { Urban Boundary } \\
\text { Layer Temp / } \\
\text { Wind }\end{array}$ & $\begin{array}{l}\text { Type of } \\
\text { building/ } \\
\text { Office or } \\
\text { Apartment }\end{array}$ & Measured or simulated data & $\begin{array}{l}\text { 3D or } \\
\text { 2D }\end{array}$ & $\begin{array}{l}\text { Season } \\
\text { Day / } \\
\text { Night }\end{array}$ & $\begin{array}{c}\text { Climate } \\
\text { Type/ } \\
\text { Location }\end{array}$ & Conclusion \\
\hline $\begin{array}{l}\text { (Nazarian \& } \\
\text { Kleissl, 2015) }\end{array}$ & Not reported & Not reported & Not reported & $\begin{array}{l}\text { Numerical simulation: } \\
\text { ANSYS/FLUENT }\end{array}$ & $3 \mathrm{D}$ & $\begin{array}{c}\text { Summer } \\
\text { Diurnal }\end{array}$ & $\begin{array}{l}\text { Southern } \\
\text { California, } \\
\text { USA }\end{array}$ & $\begin{array}{l}\text { The ground and wall temperature increase with canopy height-to-width ratio. Land cover } \\
\text { modification with urbanization, larger aspect ratio, and smaller reflectance from ground surface, all } \\
\text { promote UHI. }\end{array}$ \\
\hline $\begin{array}{l}\text { (Cao et al., } \\
\text { 2015) }\end{array}$ & Not reported & Not reported & Not reported & $\begin{array}{l}\text { Numerical simulation: } \\
\text { FLUENT }\end{array}$ & $3 \mathrm{D}$ & Summer & $\begin{array}{l}\text { Guangzho } \\
\text { u zhujiang } \\
\text { New } \\
\text { Town, } \\
\text { China }\end{array}$ & $\begin{array}{l}\text { Roads and wind direction should be arranged in a specific angle to increase the wind speed and } \\
\text { reduce temperature as roads provide the broad path for urban ventilation. }\end{array}$ \\
\hline $\begin{array}{l}\text { (Kong et al., } \\
\text { 2016) }\end{array}$ & $\begin{array}{l}\text { Vertical } \\
\text { section of air } \\
\text { temperature }\end{array}$ & Not reported & Study area & $\begin{array}{l}\text { Numerical simulation: } \\
\text { ENVI-met }\end{array}$ & $3 \mathrm{D}$ & Summer & $\begin{array}{l}\text { Nanjing, } \\
\text { China }\end{array}$ & $\begin{array}{l}\text { In the vertical direction, the effect of the removal of green spaces on near-surface wind field is rare; } \\
\text { above the surface, there is significant increase on the turbulence perpendicular to the main wind } \\
\text { direction. }\end{array}$ \\
\hline $\begin{array}{l}\text { (Subramania } \\
\text { Pillai \& } \\
\text { Yoshie, 2012) }\end{array}$ & $\begin{array}{l}\text { Temperature } \\
\text { contour }\end{array}$ & $\begin{array}{l}\text { Temperature in } \\
\text { urban canopy and } \\
\text { boundary layer } \\
\text { height }\end{array}$ & Not reported & $\begin{array}{l}\text { Measured: wind tunnel } \\
\text { Numerical simulation: } \\
\text { FLUENT }\end{array}$ & $3 \mathrm{D}$ & $\begin{array}{c}\text { Not } \\
\text { reported }\end{array}$ & $\begin{array}{c}\text { Not } \\
\text { reported }\end{array}$ & $\begin{array}{l}\text { No matter for uniform or non-uniform building heights cases, the convective heat flux from canopy } \\
\text { surfaces decreases with the increase of building cover ratio; the effects of building height variation } \\
\text { are not remarkable. }\end{array}$ \\
\hline $\begin{array}{l}\text { (Zhang et al., } \\
\text { 2012) }\end{array}$ & Not reported & Not reported & Study area & $\begin{array}{l}\text { Numerical simulation: } \\
\text { FLUENT }\end{array}$ & $3 \mathrm{D}$ & $\begin{array}{c}\text { Not } \\
\text { reported }\end{array}$ & $\begin{array}{l}\text { Hong } \\
\text { Kong }\end{array}$ & $\begin{array}{l}\text { A new building at the HK PolyU Campus under eight prevailing wind directions was modeled by } \\
\text { CFD and the new building would change the environment which is more comfortable in winter } \\
\text { with Velocity Ratio decrease and less uncomfortable in summer with Velocity Ratio increase. }\end{array}$ \\
\hline $\begin{array}{l}\text { (Bozonnet et } \\
\text { al., 2015) }\end{array}$ & Not reported & Not reported & Not reported & $\begin{array}{l}\text { Measured: data acquired by } \\
\text { LEEA laboratory } \\
\text { Numerical simulation: ENVI- } \\
\text { met, SOLENE-microclimate }\end{array}$ & $3 \mathrm{D}$ & Summer & $\begin{array}{c}\text { Not } \\
\text { reported }\end{array}$ & $\begin{array}{l}\text { From street to district scale design issues of UHI mitigation techniques are highlighted; at the urban } \\
\text { scale large-scale modeling of physical processes are required for assessing UHI mitigation. }\end{array}$ \\
\hline $\begin{array}{l}\text { (Park et al., } \\
\text { 2013) }\end{array}$ & Not reported & Not reported & Not reported & $\begin{array}{l}\text { Numerical simulation: } \\
\text { Urban Micro-climate } \\
\text { Management System }\end{array}$ & $2 \mathrm{D}$ & $\begin{array}{c}\text { Not } \\
\text { reported }\end{array}$ & $\begin{array}{c}\text { Not } \\
\text { reported }\end{array}$ & $\begin{array}{l}\text { Green urban regeneration improved the urban environment of wind and temperature at ground level } \\
\text { with wind thickness increase and reduce the urban heat island as well as mitigate the energy } \\
\text { consumption. }\end{array}$ \\
\hline $\begin{array}{l}\text { (X. Li et al., } \\
\text { 2005) }\end{array}$ & $\begin{array}{l}\text { Vertical cross- } \\
\text { section of } \\
\text { temperature }\end{array}$ & $\begin{array}{c}\text { Thermal structure } \\
\text { of Urban } \\
\text { Boundary Layer }\end{array}$ & Not reported & $\begin{array}{l}\text { Numerical simulation: } \\
\text { MM5-CUP }\end{array}$ & $2 \mathrm{D}$ & $\begin{array}{l}\text { Daytime, } \\
\text { night } \\
\text { time } \\
\text { winter }\end{array}$ & $\begin{array}{c}\text { Beijing, } \\
\text { China }\end{array}$ & $\begin{array}{l}\text { Different extent urbanization experiment addresses that wind speed would decrease and turbulent } \\
\text { kinetic energy increase with the increase in the density and height of buildings. At the same time, } \\
\text { the bottom of nocturnal elevated inversion would increase in city area, and the intensity of urban } \\
\text { heat island would strengthen. }\end{array}$ \\
\hline $\begin{array}{c}\text { (Holt \& } \\
\text { Pullen, 2007) }\end{array}$ & Not reported & Not reported & Not reported & $\begin{array}{c}\text { Numerical simulation: } \\
\text { Coupled Ocean-Atmosphere } \\
\text { Mesoscale Prediction System } \\
\text { (COAMPS) }\end{array}$ & $2 \mathrm{D}$ & $\begin{array}{l}\text { Daytime, } \\
\text { night } \\
\text { time } \\
\text { summer }\end{array}$ & $\begin{array}{l}\text { New York } \\
\text { City, USA }\end{array}$ & $\begin{array}{l}\text { Due to wall and road effects, Weather Research Forecasting-Urban Canopy Model better maintains } \\
\text { UHI through increased nocturnal warming. For Brown and Williams Urban Canopy Model, urban } \\
\text { wind speed decrease significantly, with daytime decrease generally over tallest building heights } \\
\text { region. The surface layer warms much more during night than in the daytime with the depth } \\
\text { increase of urban canopy. }\end{array}$ \\
\hline $\begin{array}{c}\text { (Qaid \& } \\
\text { Ossen, 2015) }\end{array}$ & $\begin{array}{l}\text { Vertical air } \\
\text { temperature }\end{array}$ & Not reported & Not reported & $\begin{array}{l}\text { Numerical simulation: } \\
\text { ENVI-met }\end{array}$ & $3 \mathrm{D}$ & $\begin{array}{c}\text { Daytime, } \\
\text { night } \\
\text { time }\end{array}$ & $\begin{array}{l}\text { Putrajaya } \\
\text { Boukevard } \\
\text {, Malaysia }\end{array}$ & $\begin{array}{l}\text { Asymmetrical streets enhance more wind flow than low symmetrical streets and block more solar } \\
\text { radiation, when tall buildings face wind direction or solar altitude. }\end{array}$ \\
\hline $\begin{array}{l}\text { (Memon et al., } \\
\text { 2010) }\end{array}$ & $\begin{array}{l}\text { Temperature } \\
\text { contour }\end{array}$ & Not reported & Not reported & $\begin{array}{l}\text { Numerical simulation: } \\
\text { RNG k-epsilon turbulence } \\
\text { model }\end{array}$ & $2 \mathrm{D}$ & $\begin{array}{l}\text { Daytime, } \\
\text { night } \\
\text { time }\end{array}$ & $\begin{array}{c}\text { Not } \\
\text { reported }\end{array}$ & $\begin{array}{l}\text { There is an air temperature difference between high and low aspect ratio street canyon, and the } \\
\text { difference was highest during the night time. Meanwhile air temperature increased when ambient } \\
\text { wind speed reduced. }\end{array}$ \\
\hline $\begin{array}{l}\text { (Gutiérrez et } \\
\text { al., 2015) }\end{array}$ & Not reported & Not reported & Not reported & $\begin{array}{l}\text { Measured: Observations } \\
\text { Numerical simulation: } \\
\text { Weather Research } \\
\text { Forecasting(WRF) model, } \\
\text { Urban Canopy Model(UCM) } \\
\end{array}$ & $\begin{array}{c}\text { Not } \\
\text { reported }\end{array}$ & summer & $\begin{array}{l}\text { New York } \\
\text { City, USA }\end{array}$ & $\begin{array}{l}\text { In the most complex urban scheme, the temperature vertical profiles at the location of the highest } \\
\text { building were characterized by steep lapse rate and the absence of a nocturnal elevated inversion. }\end{array}$ \\
\hline $\begin{array}{l}\text { (Rafieian et } \\
\text { al., 2014) }\end{array}$ & Not reported & Not reported & Study area & $\begin{array}{l}\text { Numerical simulation: ENVI- } \\
\text { met }\end{array}$ & $\begin{array}{c}\text { Not } \\
\text { reported }\end{array}$ & $\begin{array}{c}\text { Not } \\
\text { reported }\end{array}$ & $\begin{array}{c}\text { Tehran, } \\
\text { Iran }\end{array}$ & A significant relationship exists between Sky View Factor and the intensity of Urban Heat. \\
\hline
\end{tabular}




\subsubsection{Step 2: Specific kevwords}

The initial search terms in the article title, abstract or keywords were: 'Urban Heat Island', 'height or depth', 'temperature', 'simulation', 'building' and 'wind', as each of them was an aspect of this study. Articles most relevant to the research topic were after searching these 6 terms. Apart from papers containing all of the 6 terms, some others which only had 2, 3 or 4 terms were also explored.

First of all, "Lapse rate of temperature" and "in dense area" as two limitations were searched in Title-Abs-Key with different search tools to figure out the temperature profile in dense areas (Table 5).

Table 5: Title-Abs-Key: "Lapse rate of temperature" and "in dense area" (until 26 October 2016)

\begin{tabular}{l|l}
\hline Searching Tool & Quantity \\
\hline ScienceDirect & 5 \\
\hline Scopus & 9 (duplicates 3) \\
\hline ProQuest & 6 (duplicates 4) \\
\hline Engineering Village & 3 (duplicates 3) \\
\hline SAGE journals & 0 \\
\hline
\end{tabular}

Secondly, UHI, rural, air temperature and height as four limitations were searched in Title-Abs-Key with different search tools to investigate the height of UHI differences between urban and rural area (Table 6).

Table 6: Title-Abs-Key: UHI, rural, air temperature and height (until 26 October 2016)

\begin{tabular}{l|l}
\hline Searching Tool & Quantity \\
\hline ScienceDirect & 12 \\
\hline Scopus & $10($ duplicates 6) \\
\hline ProQuest & 19 (duplicates 12) \\
\hline Engineering Village & $11($ duplicates 8$)$ \\
\hline SAGE journals & 0 \\
\hline
\end{tabular}

Wind speeds increase in the boundary layer, so wind speeds governing air leakage (infiltration) and surface heat loss is twice at the top than that at the bottom.

In general, the temperature of urban areas should be $\mathrm{TU}=\mathrm{TR}+\Delta \mathrm{T}$, where $\mathrm{TU}$ is the temperature of urban, $\mathrm{TR}$ is the temperature of rural areas, and $\Delta \mathrm{T}$ is the UHI temperature difference. But what is the temperature profile like when wind flows happen, and the atmosphere is not stable? Will the urban temperature contour change in vertical and horizontal directions? To explore these questions, the next search was limited to wind and lapse rate in height. 
Thirdly, Urban Heat Island, wind, temperature gradient and height as four limitations were searched in Title-Abs-Key with different searching tools to study temperature gradient of UHI, taking wind into consideration (Table 7).

Table 7: Title-Abs-Key: Urban Heat Island, wind, temperature gradient and height (until 26 October 2016)

\begin{tabular}{l|l}
\hline Searching Tool & Quantity \\
\hline ScienceDirect & $2($ duplicates 2$)$ \\
\hline Scopus & $3($ duplicates 1$)$ \\
\hline ProQuest(all fields) & $5($ duplicates 4$)$ \\
\hline Engineering Village & $5($ duplicates 4$)$ \\
\hline SAGE journals & 0 \\
\hline
\end{tabular}

Finally, Urban Heat Island, wind and lapse rate as three limitations were searched in Title-Abs-Key with different searching tools, as lapse rate had similar meaning to temperature gradient with height (Table 8).

Table 8: Title-Abs-Key: Urban Heat Island, wind and lapse rate (until 26 October 2016)

\begin{tabular}{l|l}
\hline Searching Tool & Quantity \\
\hline ScienceDirect & 0 \\
\hline Scopus & 5 \\
\hline ProQuest(all fields) & $2($ duplicates 1$)$ \\
\hline Engineering Village & $2($ duplicates 1$)$ \\
\hline SAGE journals & 0 \\
\hline
\end{tabular}

In Bornstein's study, when the average height of the base of the urban area is elevated to $310 \mathrm{~m}$, urban-rural temperature differences became zero (Bornstein, 1968). In S.Pal's study based on Paris, because of the effect of UHI, the mean nocturnal boundary layer depth over the urban area on average is $74 \mathrm{~m}$ higher than its adjacent suburban areas, and if the UHI effects are excluded, the number should be $63 \mathrm{~m}$ (Pal et al., 2012). UBL depends on the amount of surface energy. Because of warming and heat storage, turbulent processes are induced above cities. Daily UBL becomes unstable, and its depth changes from daytime to night time (Aude \& Valery, 2001). In Paris, daytime well-mixed convective boundary layer showed higher entrainment zone thickness(326 $\mathrm{m})$ over urban areas than over suburban $(234 \mathrm{~m})$ and rural $(200 \mathrm{~m})$ areas (Pal et al., 2012). Also, it is confirmed that wind speed and lapse rate could affect the urban heat island intensity (L.C. Nkemdirim, 1980). In Giovanini's study, Trento of Italy was investigated, and the UHI intensity tends to be slightly stronger during dry months, which are influenced by seasonal lapse rate changes. Furthermore, stronger winds make weaker UHI intensity (Giovannini et al., 2011). 


\subsubsection{Discussion}

The interaction of UHI, wind speed and lapse rates in dense urban areas is not clear. The analysis shows that urban heat island intensity is related to the city size, which is measured by population (Oke, 1973). In Oke's later study, an empirical model incorporating wind speed and city size were proved to be able to describe urban heat island (Oke, 1976). Padmanabhamurty and Hirt made a study about the relationship between lapse rate $(\mathrm{x})$ and UHI intensity $(\Delta \theta)$ as $\Delta \theta_{0}=3.81+0.88 x$ (Padmanabhamurty \& Hirt, 1974). A significant heat island increases with the heightto-width ratio for the canyon which is the average cross section dimensions of the streets (Oleson et al., 2008). When a new tall building, much taller than neighbouring buildings, is built, the effects of height-to-width increase on urban heat island intensity around its surrounding area were explored (Oleson et al., 2008). Simultaneously, airflow environment around the new building would be changed. The importance of street canyon aspect ratio and wind speed on urban heating have been highlighted (Memon et al., 2010). In Stewart's study, urban and rural landscapes were divided into 17 standard classes, and buildings intensity is relevant to urban heat island magnitude (Stewart et al., 2014). The building height topology has a minimal influence on the mean air temperatures, but affects the local air temperature and the size of local heat islands (Allegrini \& Carmeliet, 2017).

The studies from the literature review focused more on the uniform, or the non-uniform but regular arranged urban form impact on UHI, rarely on individual building height impact on UHI. The scenario of an individual tall building surrounded by low-rise buildings hasn't been investigated, as well as a high-rise building breaking through the urban canopy. What the lapse rate is like above the original urban canopy before the new large-scale tower is placed is still a knowledge gap.

Currently, simulating energy consumption of urban buildings needs site-specific microclimate data. Site-specific weather data relies on calculations based of operational weather stations from rural areas. Some relative models have been investigated, like Local-Scale Urban Meteorological Parameterization Scheme (LUMPS), which are based on the urban canopy model (Grimmond \& Oke, 2002), the canyon air temperature (CAT) model, which is a rural-to-urban weather transformation, as well as incorporating vertical diffusion model and urban boundary layer model (VDM-UBL) (Bueno et al., 2012). The Urban Weather Generator (UWG) is composed of four 
coupled modules: the rural station model (RSM), the vertical diffusion model (VDM), the urban boundary layer (UBL) model and the urban canopy and building energy model (UC-BEM) (Bueno et al., 2013). It can be used alone or integrated into existing programs. According to the literature review, Fluent, ENVI-met as well as UWG did well in its simulation scenario. In order to explore the impact of UHI, lapse rate and wind speed on the natural ventilation, energy consumption of an office building surrounded by a complex set of urban buildings will be calculated. Whether or not the data from Fluent, ENVI-met and UWG could be exported into EnergyPlus or similar energy simulation software needs to be explored in the next practical stage.

\subsection{Chapter Summary}

This chapter reviews and evaluates the relevant papers to see whether they answer the research question about three-dimensional model of urban microclimate such as the interaction between the height of a building and its surrounding microclimate. Currently, the interaction of UHI, wind speed and lapse rates in dense urban areas have not been studied, nor have the microclimate of a new tall building surrounded by low-rise buildings.

Some research documents the influence of temperature lapse rates in dense urban areas. The temperature lapse rates profile in urban areas differ from that in rural areas. The influence of wind speed on the intensity of urban heat island was quantified. It could be concluded that UHI influences the lapse rate in urban areas and the lapse rate reflects UHI intensity. Individual high-rise buildings change their surrounding microclimate, especially the airflow. The rising wind speed may increase the temperature. As a result, UHI intensity decreased. At the same time, the temperature profile changed. According to previous studies, the relationship between two of these three parameters could be addressed, but there is still a knowledge gap on the impact of the three parameters.

In addition, the measurement method and the variable simulation method were compared and investigated. Therefore, in the following chapters, the influence of building height on its microclimate is simulated, considering lapse rate, wind speed as well as UHI. Finally, the potential of natural ventilation system for high-rise buildings could be investigated according to the analysis of urban microclimate threedimensional model. 


\section{CHAPTER 3. METHODOLOGY}

\subsection{Chapter Intent}

Chapter 3 presents the refined research question, objectives and scope as well as the research methodology. The objectives and scope were refined to help understand the methodology of this research. A research flow diagram was provided to explain the structure of this thesis and display each step of the methodolgy.

\subsection{Refined Research Question, Objective and Scope}

\subsubsection{Research question, objective and framework}

The research question was whether it is worthwhile developing a simulation system to model urban microclimate in detail.

Two objectives needed to be achieved to outline the specific steps and address this research question.

1) Build a simulation system that can be used to report the likely impact of microclimate;

2) Make an estimate of the likely scale of the microclimate effect, based on annual simulations, accounting for the three-dimensional effects of urban environments on wind and temperature.

The first objective was to explore the feasibility of developing an urban microclimate simulation system. The second objective was to explore the necessity of developing the simulation system.

Urban microclimate modelling allows architects and urban planners to understand how the surrounding climate affects building performance. At the same time, it also provides a basis for design decisions. Urban microclimate modelling is based on the rural weather data collected from official stations. However, due to the disturbance of building blocks, the airflow and heat transfer in the city are much more complicated. In addition, the wind profile and temperature profile in urban areas are quite different from those in rural areas. In general, urban microclimate modelling might consider the UHI and urban winds and reports two-dimensional differences. In this research, the 
influence of vertical variations of urban microclimates were also analysed. Hence, urban microclimates were modelled in three dimensions.

The aim of developing a simulation system was to predict the effects of urban microclimates on building performance. In the former part of this research, before the system developed, the modelling programmes were tested separately to verify their credibility. The development of an urban microclimate simulation system was a stepby-step process. The related parameters of urban microclimate modelling were tested, and the importance of each parameter was evaluated. A detailed urban microclimate model was established to verify its impacts on building performance simulation, and that the results could be useful and meaningful for the design of ventilation systems.

This research was designed to answer the question of whether it is necessary to account for urban microclimate in detail during the design process. The theoretical framework of this research was that it proposed a sufficient test of the hypothesis. In order to create a testable proposal, it was hypothesised that it is not necessary to account for urban microclimate. It was assumed that a sufficient test of the hypothesis is to model the performance of a single high-rise building in a complex urban environment. Should that single case demonstrate that urban microclimate parameters cannot be ignored, then it will have been demonstrated that the hypothesis is not true for this case. If not true for this case, it cannot be assumed that microclimate can be ignored. Further, the framework proposes that the applicability of the approach can be demonstrated more broadly than for a single case through examination of the case in several different climates. The reason for using several climates rather than several high-rise office buildings to verify the approach is that this study is about the effects of urban microclimates and testing different urban microclimates enables generalization to a broader range of urban environments. The theoretical building physics foundations of this study would argue that studying a range of different building scales would only reveal the same issues, but to a lesser or greater degree depending on the building scale. If it has been proved that detailed modelling of urban microclimate parameters is not negligible in one or more cases, then the hypothesis is not true. Therefore, the answer to the research question is that it is necessary to account for urban microclimate in detail during the design process.

This research also proposed a simulation framework (Figure 12). It began with a comprehensive understanding of 3-dimensional urban microclimates and modelling 
tools, including how a detailed simulation system could be developed. A comprehensive understanding of urban microclimate detailed modelling, based on the optimization of design strategies and the building performance refining consequences, provided the basis for why urban microclimates should be modelled in detail. In other words, engineers require detailed information to adjust design strategies, and a simulation system of this type can provide the opportunities to understand the scale of the impact of 3-dimensional detailed modelling can have, and then engage in deliberate simulation.

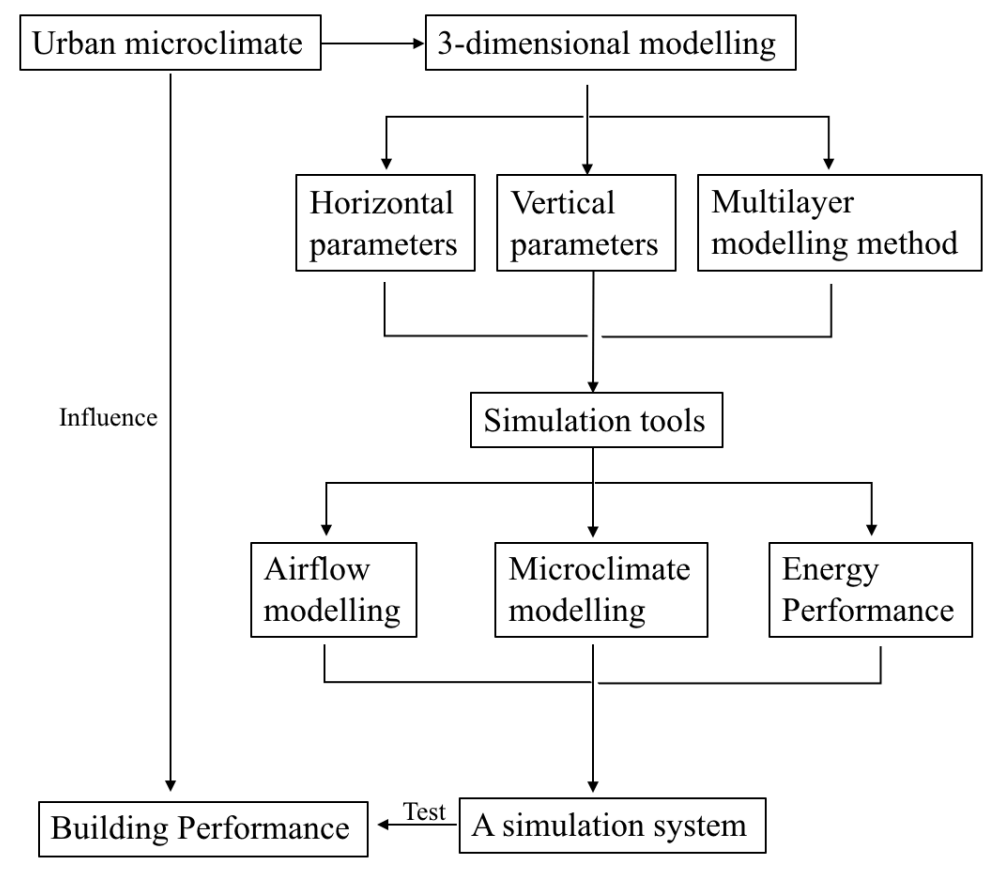

Figure 12: Simulation framework of the research

\subsubsection{Urban microclimate parameters}

The urbanization process has dramatically influenced the heat balance of urban space, the convective heat exchange between the ground and buildings, the air flow above the urban area and the heat generation within the city (Dimoudi et al., 2013). The parameters of urban microclimates discussed in this research were about the climate characteristics, not the urban features. Urban parameters such as sky view factor, floor area ratio, site coverage ratio and building storeys determine the urban morphology (Wei et al., 2016), and these parameters were not included in urban microclimate parameters of this research. The modelling of urban microclimatic conditions mainly focused on the airflow and air temperature distribution in cities. The investigation of wind profile and thermal profile in dense urban areas is mainly due to the difference 
between urban and rural climatic conditions. Additionally, these parameters are tightly related to the performance of building blocks, which are captured in the urban microclimatic conditions. Phenomena related to the urban wind and temperature distribution such as Urban Heat Island, Lapse Rate, and Urban Boundary Layer were addressed.

In general, the rural areas are the low dense area and the buildings in these areas are low-rise buildings. Even though the rural climate changes with height, the influence of vertical climate variations on building performance is trivial, because the heights of buildings are too low to generate vertical climate differences. However, in dense cities, there are plenty of high-rise buildings which are high enough to experience vertical climate variations. At the same time, vertical variations of urban microclimates such as the wind speed and direction as well as the temperature, affect the performance of highrise buildings and even the feasibility of natural ventilation at different floors. Hence, the vertical distributions and variations of urban microclimate parameters were explored.

\subsubsection{High-performance buildings and performance metric}

It is not easy to define a high-performance building, because different functions and demands dominate different buildings. High performance includes environmental, societal and economic aspects. Users are concerned about the thermal comfort, and owners are concerned about the economic efficiency. For the society, energy efficiency is of great significance for energy source finiteness. The term "high performance" in this research mainly refers to energy efficiency and thermal comfort because they are dramatically influenced by urban microclimates. Urban winds cause pressure changes on the surfaces of buildings. These effects on the air change rates and ventilation methods are important for improving thermal comfort. The cooling and heating costs of buildings are mainly determined by the temperature distribution in urban areas, which is associated with the energy consumption.

Hence, the performance metrics in this research indicated the energy performance metric and the thermal comfort performance metric. 


\subsubsection{High-rise office buildings}

A high-rise office building, as the term suggests, is a tall building and its function is an office. A high-rise building is the antithesis of a low-rise building. However, what exact height is the boundary line of a high-rise building? Since different regions have different definitions of height for a high-rise building, there is no uniform answer. For example, in China, residential buildings with height over 27 meters and non-residential buildings with height over 24 meters height are classified as high-rise buildings (Code for Fire Protection Design of Buildings, 2014). In Japan, high-rise buildings are over 31 meters, or more than 8 storeys ('Building Height Restrictions', 2017). According to Emporis Standards, the definition of a high-rise is between 35-100 meters tall or 12-39 floors (EMPORIS, n.d.). In America, high-rise means higher than 23 meters or about 7 storeys. The exact height which is deemed high-rise may be specified by fire and building codes of the country, region, state or city where the building is located (Craighead, 2009). In general, when a fire breaks out in a high-rise building, the people inside cannot rely on external rescue because it is too high to be reached by pressurized hoses and ladders. The simulation system developed in this research is intended to be used in any city around the world. It has no geographical restriction. The height definition of high-rise buildings in this research is correlated with vertical variations of urban microclimates. It is high enough to capture the great microclimate differences between the bottom and the top of high-rise buildings.

High-rise buildings have a variety of functions, such as residential and commercial. High-rise office buildings are commercial buildings, as well as hotels and retail. Sometimes, a high-rise building consists of several functions, such as a commercial building with retail at the bottom, office in the middle and hotel on the top part of the building.

The office building is the most representative type of buildings in the last century. An office building should provide users with a safe and comfortable working environment. In this research, the elements which are associated with the improvement of thermal comfort were explored, especially those affected by urban microclimates.

\subsubsection{Vertical variation}

The vertical variation in this research is reflected in two aspects. One is the variation of urban microclimate with height. The other is the difference in building performance 
between different floors. The vertical variations of urban microclimates are the reason for the difference in building performance at different heights. The vertical variations of urban microclimates have two aspects. The wind speed increases with height and the air temperature decreases with height (Figure 13).

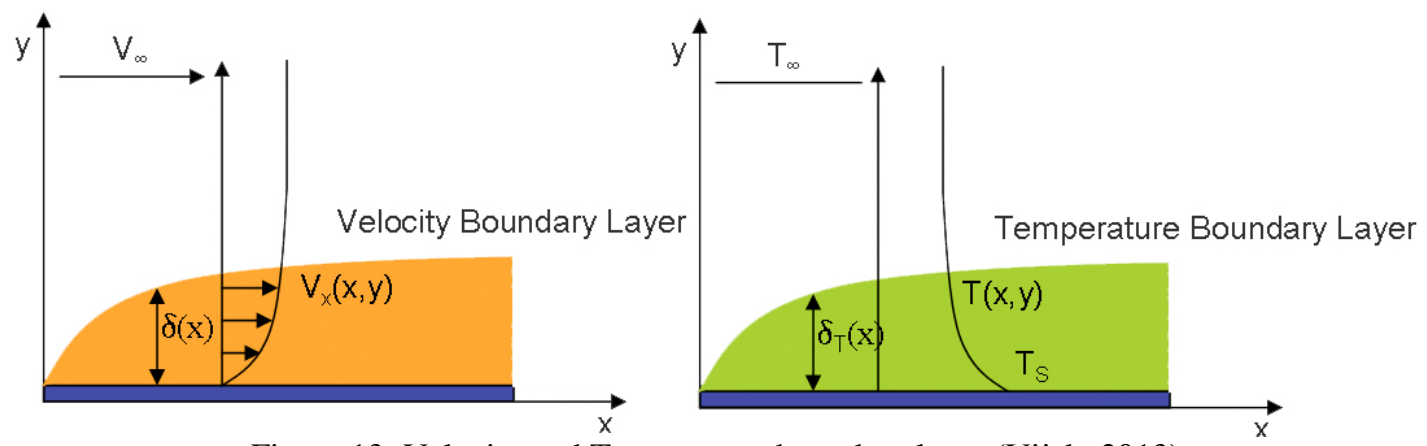

Figure 13: Velocity and Temperature boundary layer (Vijek, 2013)

The wind speed and wind direction affect the wind pressure around buildings and the natural ventilation of buildings. The widely used wind boundary condition is addressed by a power-law distribution (Chang \& Meroney, 2001; Irwin, 1979; Theurer et al., 1992).

$$
v_{z}=v_{0}\left(\frac{z}{z_{0}}\right)^{\alpha}
$$

where $v_{z}$ is the wind speed $(\mathrm{m} / \mathrm{s})$ at height $\mathrm{Z}(\mathrm{m})$, and $v_{0}$ is the measured wind speed $(\mathrm{m} / \mathrm{s})$ at a reference height $Z_{0}(\mathrm{~m})$. The exponent $(\alpha)$ is an empirical constant and is dependent on atmosphere stability.

\subsubsection{Accuracy, sensitivity and reliability}

In this research, several programs were used to analyse urban microclimate parameters such as wind speeds, boundary layer and Urban Heat Island (UHI). However, urban weather data are rarely collected from weather stations and it is based on real information from a rural weather station. So how do we know that the urban microclimate data is accurate and reliable? If the environment inputs don't match the reality, then the building performance prediction lacks credibility. Incorrect inputs lead to unreliable simulation results.

In order to develop a reliable simulation system, both the inputs and outputs should be reliable. Accuracy or reliability is concerned with matching real data with simulation results. In general, the real data cannot always match the predictions of simulation 
$100 \%$, so how big a difference is acceptable? What scale of difference between real and simulated data is acceptable and how close is close enough (Satwiko et al., 1998)?

In Varga et al.'s research, the average error between CFD and experimental primary flow rate was $8 \%$ and it was considered as a good agreement (Varga et al., 2011). In Hemidi et al.'s research, the CFD prediction was reported as a good accuracy $(<10 \%)$ (Hemidi et al., 2009). In Rusly et al.'s research, the prediction by CFD is very close to the experimental results, with a difference of less than $10 \%$ (Rusly et al., 2005).

In Calis et al.'s research, it was shown that a commercial CFD code (CFX-5.3) could be used for prediction with an average error of around $10 \%$ and an error of $10 \%$ by CFD is acceptable for design purposes (Calis et al., 2001). However, Gowreesunker and Tassou's study considered that the models based with a relative error less than $30 \%$ as valid models (Gowreesunker \& Tassou, 2013). With most of the studies, Yoshie et al.'s research took relative errors within $10 \%$ of the CFD analysis results as criteria, compared with experimental results in the active wind region (Yoshie et al., 2007). While it was considered as not a good match when the calculated results were $15 \%$ lower than the experimental results (Yoshie et al., 2007). Gromke and Blocken contemplated relative differences smaller than $10 \%$ as a good agreement with field data (Gromke \& Blocken, 2015). In Montazeri et al.'s research, it was believed that the evaporation process is accurately predicted when the local deviations from the windtunnel measurements are within $10 \%$ for dry bulb temperature, 5\% for wet bulb temperature and 7\% for the specific enthalpy (Montazeri et al., 2015).

There is no absolute answer to this question of accuracy and reliability. The scale of acceptable differences is related to the criteria which always varies with the situation. That's why the answer to the question of how close is close enough is always problematic (Satwiko et al., 1998). When a cost of a 2\% error is very high, $2 \%$ error is not close enough, and the criteria in these circumstances is much more rigorous. When even a $15 \%$ error doesn't make a remarkable difference to the results, then the $15 \%$ error is acceptable. That means there is no equivalent measure and criterion. In different studies, there is an individual acceptable scale of difference that is appropriate to its specific situation.

Apart from accuracy, it is also important to know whether accurate inputs significantly affect the outputs. The sensitivity of the urban microclimate modelling influences the 
necessity of detailed simulation. Sensitivity is a general concept, but the sensitivity can be measured by quantitatively comparing the changes in output with the changes in input (Lam \& Hui, 1996). From rural weather data, to the Urban Heat Island (UHI) effects, then wind, and the accuracy of vertical variation, the parameters change step by step. How these parameters influence building performance determines the significance of modelling urban microclimate in detail.

In this research, more than $10 \%$ changes in building performance prediction mean a significant impact, between $5 \%$ and $10 \%$ changes mean a medium impact and less than $5 \%$ changes mean a small impact.

\subsection{Overarching Methodology: Real City, Prototypical High-rise Office Building}

This section presents the overall methodology of this study. The first goal was to develop a simulation system to model the urban microclimate and the building performance in urban areas. The second one was to assess the necessity of this system.

To model the urban microclimate, the initial weather data was real and collected from weather stations located in rural areas. Therefore, weather data was based on a real city. Besides, the simulation system for urban microclimate modelling was intended to be used in real circumstances, and modelling microclimate of a real city laid the foundation for further study. In contrast, the high-rise office building in this research was not a real building but a prototypical building. Because a prototypical building could be prescribed to be representative of the majority of the high-rise buildings, but detailed real buildings are often constrained by site, finance, planning laws and are thus very specific to a situation.

Figure 14 gives the flow diagram of methodology, and there are 3 phases as following:

- Phase A - Review urban microclimates and modelling techniques.

- Phase B - Develop a trustworthy simulation system to model the effect of urban microclimates on building performance.

- Phase C - Analyse the impacts of urban microclimates on high-rise office buildings 
Phase A was the preparatory phase. The $1^{\text {st }}$ step addressed the features of urban microclimates. The $2^{\text {nd }}$ step indicated modelling techniques and validates the reliability of modelling programs individually.

Phase B used a case study to develop the simulation system. The $3^{\text {rd }}$ step modeled a prototypical high-rise office building in a real city. The $4^{\text {th }}$ and $5^{\text {th }}$ steps explored horizontal and vertical urban microclimate parameter effects on building performance. The $6^{\text {th }}$ step explored the effects of urban microclimates on detailed natural ventilation systems and the $7^{\text {th }}$ step compared a multilayer modelling method with single-layer modelling method.

Phase C used the simulation system developed in Phase B to analyse the impacts of modelling urban microclimate in detail on different climate regions in the $8^{\text {th }}$ step. It tested whether the urban microclimate parameters identified as important in the case study are also important in other climates. The necessity of developing a simulation system in different climates was explored in Phase C.

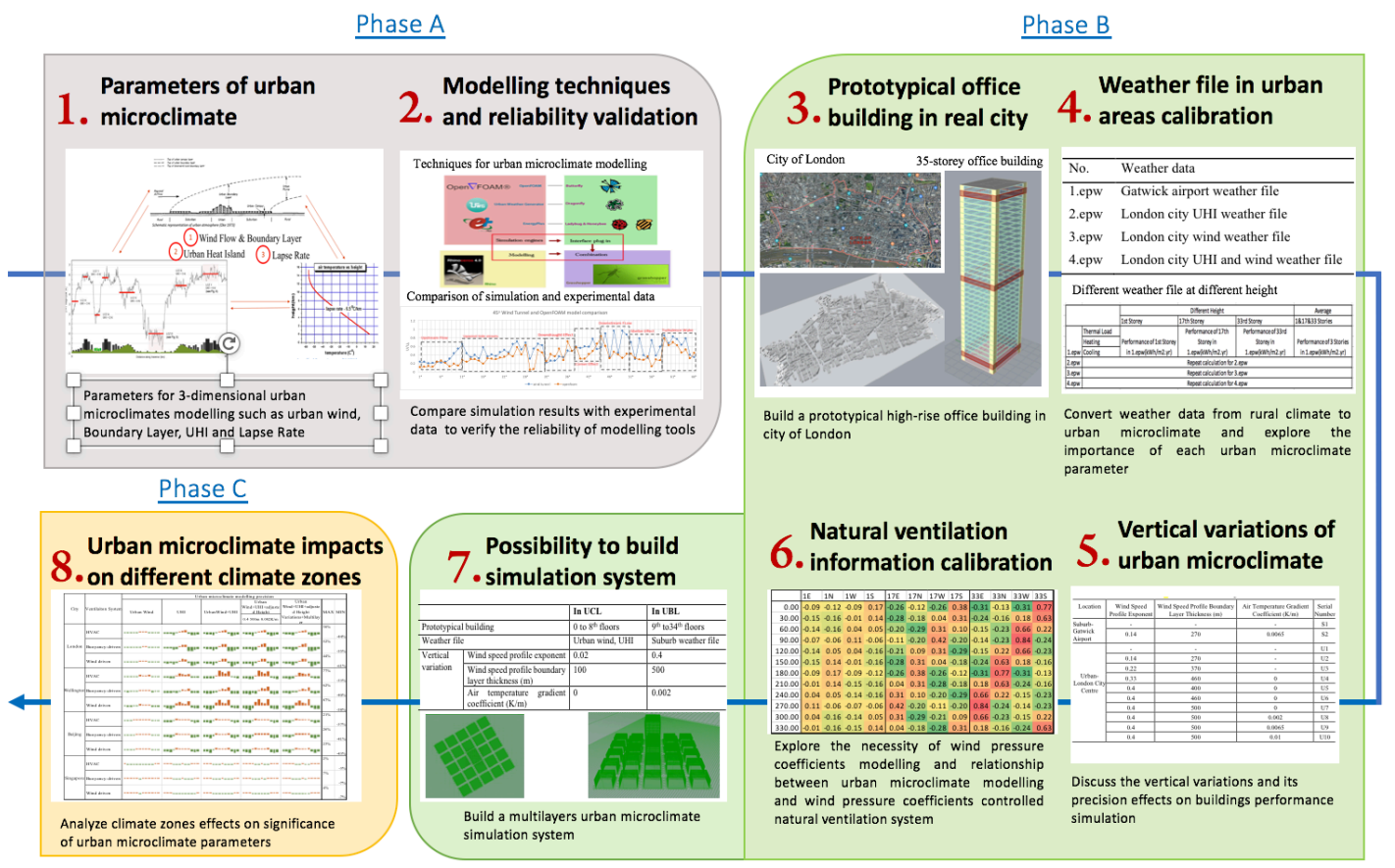

Figure 14: Methodology flow diagram

\subsubsection{Modelling technique and reliability validation}

The first phase of the research methodology was the background of urban microclimates and modelling techniques. To develop the simulation system to study the effects of urban microclimate on building performance, appropriate modelling techniques were required. Whether or not the modelling programs are capable of 
predicting the microclimate in the city centre was assessed at this stage. The reliability of the modelling programs was determined by comparing the real data and the simulation results. The simulation tools could be used as components of the simulation system only if the tools are trustworthy.

\subsubsection{Techniques for modelling}

In this research, programs for Urban Heat Island modelling, urban wind modelling and building performance simulation are necessary. Individual programs are essential for developing a simulation system. In chapter 2, reasons related to the selection of modelling techniques were addressed, such as Urban Weather Generator (UWG) is used for the Urban Heat Island modelling, OpenFOAM for urban winds and EnergyPlus for building performance (Section 2.3). UWG and OpenFOAM are tools for urban microclimate modelling, and EnergyPlus is an energy analysis tool. When selecting computer programs, the validation of simulation tools was considered, as it was associated with the reliability of the prediction results.

There are good reasons such as accessibility and compatibility to select OpenFOAM as urban wind modelling program. However, there are so many Computational Fluid Dynamics (CFD) programs for urban wind modelling, such as Autodesk CFD and UrbaWind. Cannot they model urban wind for this research? A comparison of 3 CFD programs was made to make sure that OpenFOAM is the most appropriate CFD program in this research.

\subsection{Selecting the appropriate UHI modelling program}

Using urban density data or empirical data for a specific city, regional climate data can be modified to better represent of the temperature range experienced by the city.

ENVI-met is an urban microclimate simulation program that includes air-flow calculation, heat exchange, and vegetation as well as pavement factors (Bruse \& Fleer, 1998). Numerous studies use three-dimensional climate data provided by ENVI-met to simulate urban microclimates. One of the advantages of ENVI-met is the convenience to use. This advantage is also a disadvantage of ENVI-met, as its convenience sacrifices the details of the inputs and the accuracy of the results. In Ali's study, the effects of aspect ratio and orientation of an urban street canyon on outdoor thermal comfort in hot and dry climates have been discussed using ENVI-met (Ali-Toudert \& Mayer, 2006). Perini and Magliocco studied the effects of vegetation, urban density, building height, 
and atmospheric conditions on local temperatures and thermal comfort using ENVImet (Perini \& Magliocco, 2014). ENVI-met is often used in a street level of scale simulation. In this research, relatively detailed buildings and large-scale cities were both involved. Therefore, ENVI-met did not meet the requirements of this research.

Urban Weather Generator (UWG) imports rural weather data and exports an urban weather file. It only changes temperature and humility. One of the advantages of UWG is that it can predict UHI for a whole year. The output is continuous data. That means it can be compatible with other programs, especially building performance modelling programs, as programs of building performance simulation generally give a year-round prediction. The results of the prediction are based on hourly weather data. Besides, UWG is free and comes with a plugin version for Grasshopper. That makes it possible to link up UWG with other programs and build a system. Therefore, compared with ENVI-met, UWG was much more suitable for this study.

\subsection{Selecting the appropriate CFD program}

With the increasing availability of Computational Fluid Dynamics (CFD) programs, CFD simulation is becoming more feasible for general urban design practice. There are several CFD programs that can simulate the urban wind environment. To explore which CFD programs can be used in this study, my colleagues, Riley Willis, Aymeric Delmas and I compared CFD simulation results with experimental wind tunnel data, using Autodesk CFD, OpenFOAM and UrbaWind respectively (J. Li, Delmas, et al., 2018). The standard, high-quality experimental wind tunnel dataset, was provided by the Architectural Institute of Japan (AIJ) (Tominaga \& Mochida, 2016).

This section reports a comparison between simulation results of three CFD programs and experimental wind tunnel data. Also, it reports the urban flow areas where the CFD programs agree with each other, areas where they agree with the wind tunnel data, and areas where they disagree. The influence of these agreement on the reliability of CFDbased design decisions were discussed.

In the guidebook of Architectural Institute of Japan (AIJ), 7 cases and 4 city configurations are presented (Tominaga \& Mochida, 2016). The case of a central highrise building surrounded by a grid of city blocks was selected for its consistency in the exploration of the urban wind environment. This research explored the urban microclimate of a high-rise office building surrounded by low-rise buildings. At the 
same time, this simplified model made the validation much more targeted and efficient. In this case, the AIJ wind tunnel model consisted of 82 low-rise blocks (40m x 40m x $10 \mathrm{~m})$ and 1 high-rise block $(25 \mathrm{~m} \times 25 \mathrm{~m} \times 100 \mathrm{~m})$ in the centre. The initial physical experiment was conducted at the Niigata Institute of Technology with a scale of 1:400, as shown in Figure 15. The inflow velocity at the height of $100 \mathrm{~m}$ was $6.65 \mathrm{~m} / \mathrm{s} .66$ measurement points around the central building and between the surrounding blocks were set up for the experiment.

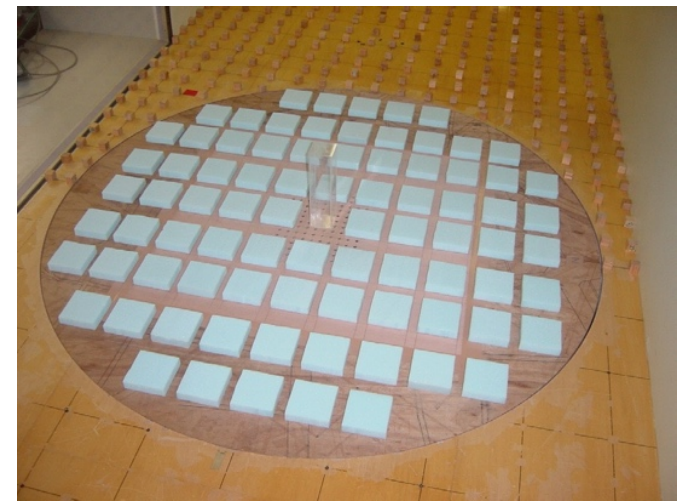

Figure 15: Model of AIJ wind tunnel experiment (Tominaga \& Mochida, 2016)

Table 9 shows detailed information of the model parameters used by three different CFD programs. According to relevant data of AIJ wind tunnel experiment, wind flowed from $0^{\circ}, 22.5^{\circ}, 45^{\circ}$ and the roughness length is $0.043 \mathrm{~m}$. There was no unified modelling method for these three programs. Autodesk CFD could not model the wind flowing from $22.5^{\circ}$. To model the wind profile, Autodesk CFD inputed different speeds at different heights, while OpenFOAM and UrbaWind only imported a roughness length $\left(z_{0}\right)$ to show the vertical variations of wind speeds. Autodesk CFD and OpenFOAM had Standard k-Epsilon model and RNG k-Epsilon model to describe turbulence flow conditions. Autodesk CFD could set up turbulence intensity, and OpenFOAM could increase the meshing density of a specific site. The computational domain modelled by UrbaWind extended the same scale for each direction.

Table 9: Modelling and simulation parameters of 3 CFD programs

\begin{tabular}{c|c|c|c}
\hline Condition & Autodesk CFD & OpenFOAM & UrbaWind \\
\hline Wind direction & $0^{\circ}, 45^{\circ}$ & $0^{\circ}, 22.5^{\circ}, 45^{\circ}$ & $0^{\circ}, 22.5^{\circ}, 45^{\circ}$ \\
\hline Inlet Wind Profile & $\begin{array}{c}\text { Velocity at a different } \\
\text { height (from AIJ) }\end{array}$ & $\begin{array}{c}\text { Roughness length }\left(\mathrm{z}_{0}\right): \\
0.043 \mathrm{~m}(\text { From AIJ) }\end{array}$ & $\begin{array}{c}\text { Roughness } \\
\text { length }\left(\mathrm{z}_{0}\right): 0.043 \mathrm{~m} \\
\text { (From AIJ) }\end{array}$ \\
\hline Turbulence model & $\begin{array}{c}\text { k-Epsilon model } \\
\text { SST k-w } \\
\text { RNG k-Epsilon model }\end{array}$ & $\begin{array}{c}\text { Standard k-Epsilon } \\
\text { model }\end{array}$ & kNG k-Epsilon model \\
\hline Turbulence intensity & $1 \%, 5 \%, 50 \%$ & ---- & ---- \\
\hline
\end{tabular}


Table 9: Modelling and simulation parameters of 3 CFD programs

\begin{tabular}{|c|c|c|c|c|}
\hline \multicolumn{2}{|c|}{ Condition } & Autodesk CFD & OpenFOAM & UrbaWind \\
\hline \multirow{4}{*}{$\begin{array}{c}\text { Meshin } \\
\mathrm{g}\end{array}$} & & $\begin{array}{c}\text { Unstructured tetrahedral } \\
\text { mesh }\end{array}$ & Rectangula & $\begin{array}{c}\text { Unstructured } \\
\text { Cartesian mesh }\end{array}$ \\
\hline & Cell type & & & \\
\hline & $\begin{array}{c}\text { Density } \\
\text { distributio } \\
n\end{array}$ & Gradual change & $\begin{array}{l}X \text { axis: percentage length } \\
(10 \%, 30 \%, 60 \%) \text { cells } \\
(10 \%, 70 \%, 20 \%) \\
Y \text { axis: percentage length } \\
(50 \%, 50 \%) \text { cells }(50 \% \text {, } \\
50 \%) \\
Z \text { axis: percentage length } \\
(50 \%, 50 \%) \text { cells ( } 70 \% \text {, } \\
30 \%)\end{array}$ & $\begin{array}{l}\text { Automatic } \\
\text { refinement near } \\
\text { ground, obstacles } \\
\text { and result points. } \\
\text { One face of a cell } \\
\text { can be in contact } \\
\text { with a maximum of } \\
\text { two different faces }\end{array}$ \\
\hline & Cell size & $\begin{array}{c}\text { Autosized-- } 360,000 \\
0.5-2,900,000 \\
0.25-19,000,000 \\
0.2-32,000,000 \\
0.15-83,000,000\end{array}$ & $\begin{array}{l}\text { Cell size: }(100,50,30) \\
\text { Refinement level 2- } \\
260,000 \\
\text { Refinement level 5- } \\
\text { 1,070,000 } \\
\text { Cell size: }(20,10,6) \\
\text { Refinement level 2- } \\
\text { 2,300,000 } \\
\text { Refinement level 5- } \\
\text { 2,310,000 }\end{array}$ & $\begin{array}{l}\text { Thinnest cell size: } 1 \\
\mathrm{~m} \\
\text { Refinement level } 1 \\
\text { ( } 2 \text { layers of thinnest } \\
\text { cells) }-2,712,800 \\
\text { Refinement level } 2 \\
\text { (4 layers of thinnest } \\
\text { cells) - 2,710,500 } \\
\text { Thinnest cell size: } 2 \\
\text { m } \\
\text { Refinement level } \\
1-4,903,100 \\
\text { Refinement level } 2 \\
-4,849,200\end{array}$ \\
\hline \multicolumn{2}{|c|}{$\begin{array}{l}\text { Computational } \\
\text { domain }\end{array}$} & $\begin{array}{c}1720 \mathrm{~m} \times 1500 \mathrm{~m} \times \\
300 \mathrm{~m}\end{array}$ & $\begin{array}{l}2360 \mathrm{~m} \times 1340 \mathrm{~m} \times 300 \mathrm{~m} \\
\text { (Windward extension: } 3 \\
\text { times } \\
\text { Leeward extension: } 3 \\
\text { times } \\
\text { Sides extension: } 4 \text { times } \\
\text { Top extension: } 15 \text { times) }\end{array}$ & $\begin{array}{l}\text { Automatic } \\
\text { rectangular box } \\
\text { (based on the size of } \\
\text { the studied } \\
\text { geometry) } \\
800 \mathrm{~m} \times 800 \mathrm{~m} \mathrm{x} \\
800 \mathrm{~m} \text { (aligned with } \\
\text { the wind } \\
\text { flow for each } \\
\text { direction) }\end{array}$ \\
\hline
\end{tabular}

The selected configuration was modeled in Autodesk CFD at full scale. The computational domain was $1720 \mathrm{~m} \times 1500 \mathrm{~m} \times 300 \mathrm{~m}$. The boundary conditions, the meshing settings, as well as the turbulence parameters are shown in Table 9.

In the OpenFOAM simulation, the model was at full scale. The prototype model was based on the experiment conditions of the wind tunnel. The inlet wind profile used for the wind tunnel experiment was given by the AIJ (Tominaga \& Mochida, 2016), and it was reproduced in the OpenFOAM by corresponding roughness length of terrain which is shown by the option of landscapes in the software. 
In the UrbaWind simulation, the configuration was modelled at full scale as well. In UrbaWind, considering the structure of the atmospheric boundary layer, the inlet boundary condition was vertically divided into three regions. The first region, from the ground to hs (the surface heat flux), corresponded to the surface layer (Caniot et al., 2011). The inlet wind profile was given by the logarithmic law which takes the inlet roughness defined by the user into account. The transition region, from hs to hbl (height of boundary layer), corresponded to the Ekman layer. In the upper region, geostrophic wind was applied to the upper boundary condition. Turbulent kinetic energy is constant. It was evaluated through the roughness length of the inlet which is the only input parameter of the inlet.

The meshing of the model in Autodesk CFD was gradually changed. It is unstructured tetrahedral mesh and its density could not be defined according to requirements of the target calculation areas. Besides, it was hard to locate the test points which were based on uniform grids. While, OpenFOAM could define the density of meshing. It even could define it in different methods with $\mathrm{X}, \mathrm{Y}$ and $\mathrm{Z}$ axis. For example, the blocks in the middle area of the computational domain took $30 \%$ length of $\mathrm{X}$ axis, while $70 \%$ cells of $\mathrm{X}$ axis, which means the density in the middle area is much higher than the other areas. On the $\mathrm{Z}$ axis, the lower half part had $70 \%$ cells and the higher half part only had $30 \%$. It is because blocks are in the lower portion. UrbaWind could define the density of meshing through changing the refinement level and the cell size of meshing (Table 9).

The biggest weakness of Autodesk CFD was the placement of the measurement points. In the Autodesk CFD program, the only method of exporting the wind speed results was via a uniform grid across the entire domain. The modeller could not independently control the location of the grid but can control its resolution. The major disadvantage of UrbaWind was that it cannot set up wind speeds and turbulence profiles of the inlet, while that is crucial in the case of calibration against experimental wind tunnel data. OpenFOAM does not have that weakness. The roughness length setting did not match AIJ quite well, but the roughness length, when tested, has a minimal effect on the prediction of wind speeds.

Compared with Autodesk CFD and UrbaWind, OpenFOAM matched the tendency of the wind tunnel well at $0^{\circ}$ (Figure 16) and $22.5^{\circ}$ (Figure 17). At $0^{\circ}$, the predictions of OpenFOAM are almost the same as the wind tunnel measurements, and only a small 
gap can be found in the wake area. In the wake area, the predictions of OpenFOAM are less inaccurate than those of Autodesk CFD. At $22.5^{\circ}$, UrbaWind overestimates the predictions. The OpenFOAM graph at $45^{\circ}$ (Figure 18) is not as good as at $0^{\circ}$ (Figure 16) and $22.5^{\circ}$ (Figure 17), but its main tendency matched well with the wind tunnel one, with only a few points under-predicted in the Corner Effect and Downstream Flow areas.

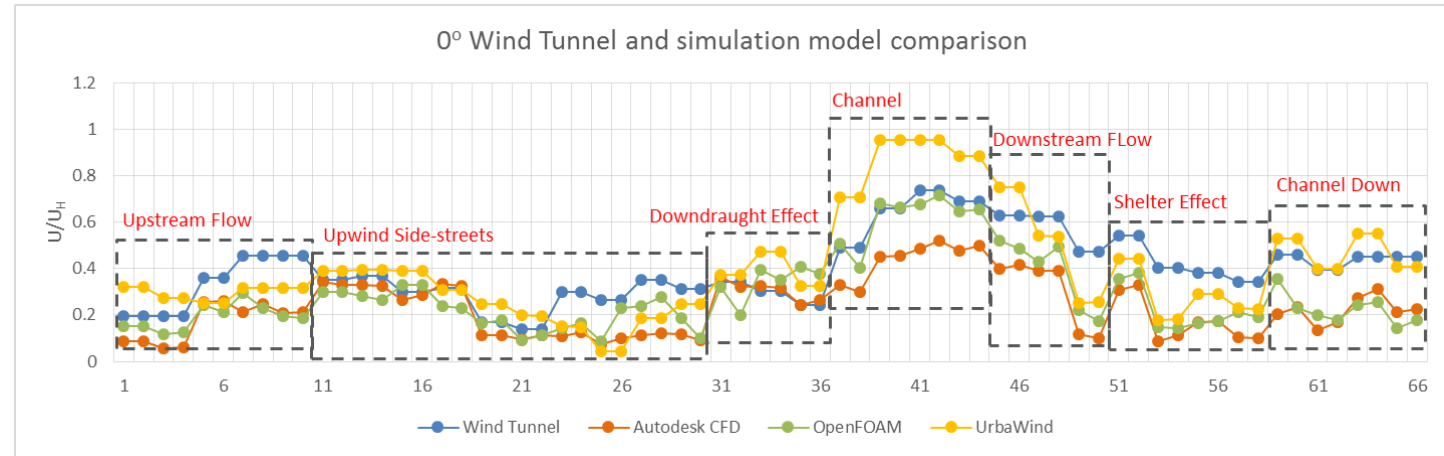

(a)

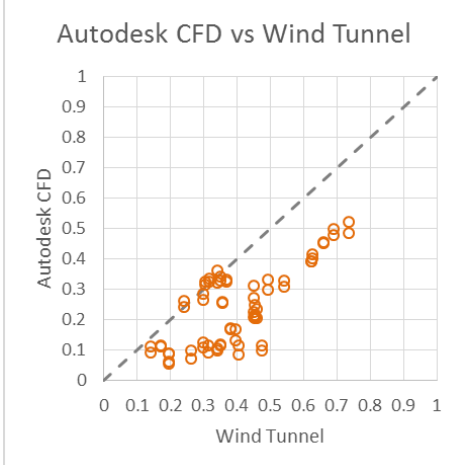

(b)

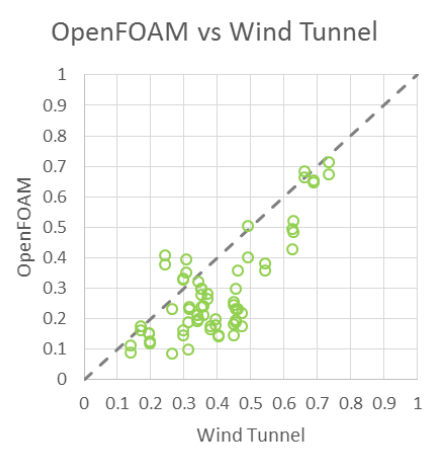

(c)

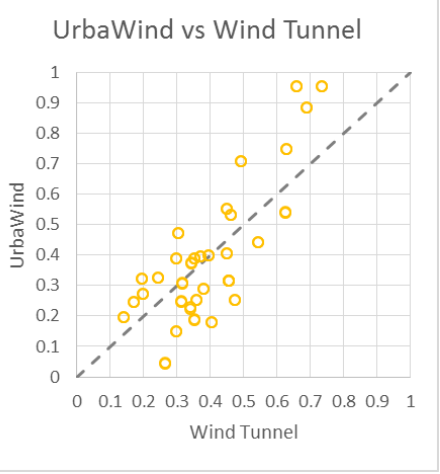

(d)

Figure 16: $0^{\circ}$ Wind Tunnel, Autodesk CFD, OpenFOAM and UrbaWind results comparison

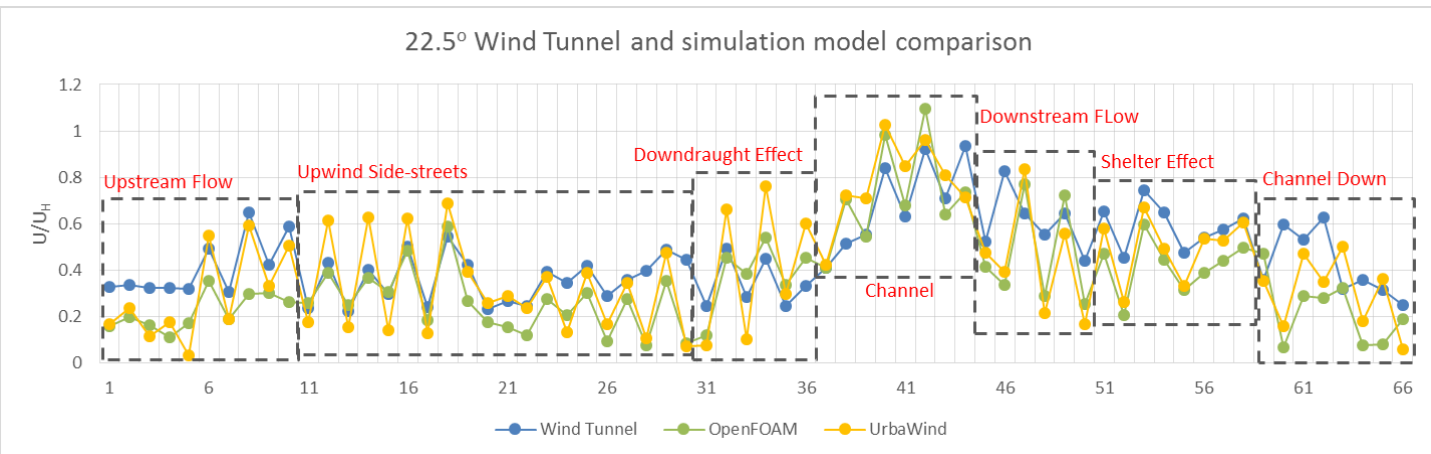

(a) 


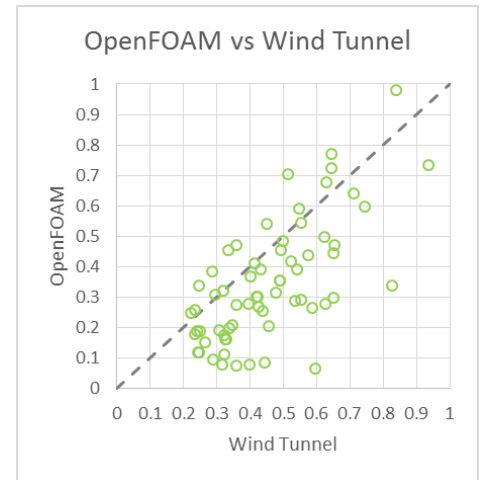

(b)

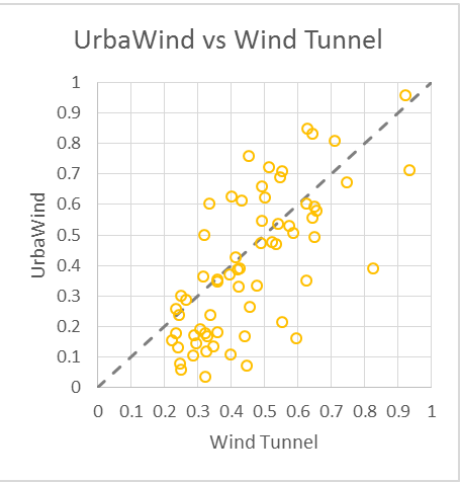

(c)

Figure 17: 22.5 Wind Tunnel, OpenFOAM and UrbaWind results comparison

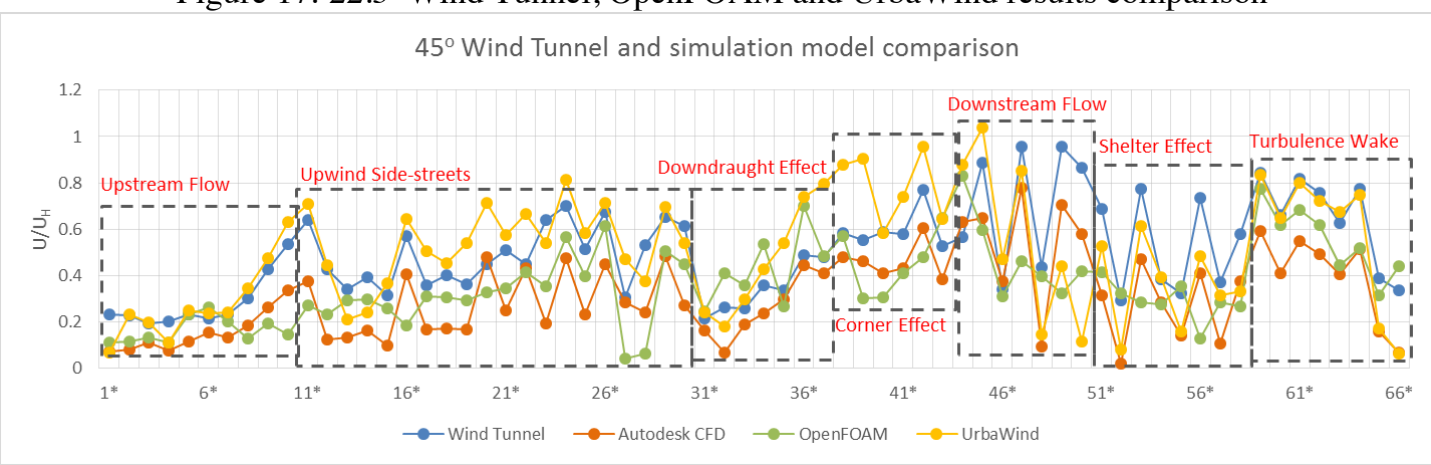

(a)

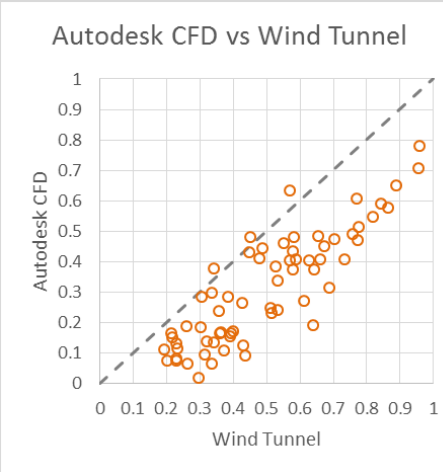

(b)

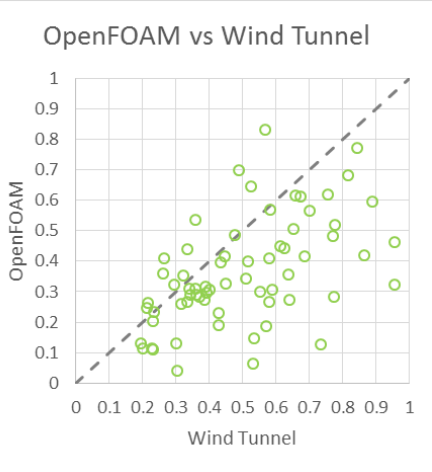

(c)

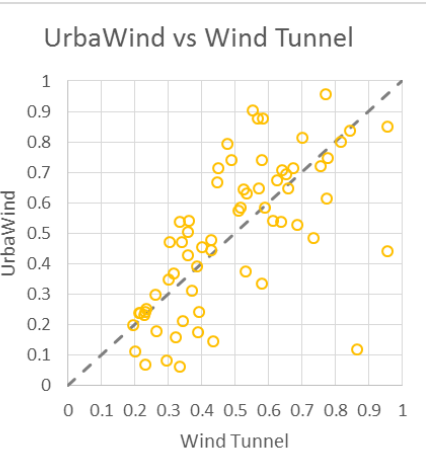

(d)

Figure 18: $45^{\circ}$ Wind Tunnel, Autodesk CFD, OpenFOAM and UrbaWind results comparison.

The results of three CFD programs were compared with the AIJ wind tunnel data to verify their accuracy and reliability.

1) OpenFOAM can adjust meshing density and improve the efficiency of calculation.

2) At $0^{\circ}$ and $22.5^{\circ}$ the prediction of the CFD programs matches better than at $45^{\circ}$.

3) The simulation results of Autodesk CFD and OpenFOAM at measurement points around central building are consistent with the AIJ dataset.

4) The predictions of air flow at the wake area is not quite consistent with the AIJ data set. At $0^{\circ}$ OpenFOAM predicts better, and at $45^{\circ}$ UrbaWind is better. 
Autodesk CFD could not define the location of measurement points. UrbaWind could not set up the wind speed and turbulence of the inlet. Compared with Autodesk CFD and UrbaWind, OpenFOAM could define the meshing methodology and turbulence model. Overall, OpenFOAM is appropriate for this research. The reliability of OpenFOAM would be tested and verified in the next chapter.

\subsection{Comparison of modelling tools}

The research looked for appropriate tools to build a system, rather than the most functional tools which covered almost all urban microclimate parameters. The tools had to be interoperable, alterable and available, because the outputs of weather data were to be used for building performance simulation. One full year of weather data is useful for energy calculation, user-defined test points are necessary for the simulation of wind pressure on windows; and the set-up of wind speed and turbulence is important for urban wind modelling. Some of the tools could not meet these requirements and some were not free. For example, ENVI-met could not predict the UHI for a whole year, Autodesk CFD could not define the location of measurement points, and UrbaWind could not set up the wind speed and turbulence of the inlet. They were not sufficiently extensible or alterable. The appropriate tools had to be compatible. Urban Weather Generator and OpenFoam were selected as the appropriate tools for this research, because their outputs could be the inputs of building performance simulation, and they have relevant grasshopper plugins (Section 2.3) to link them up. The comparison of the tools is shown in Table 10 .

Table 10: Comparing modelling tools and selecting appropriate tools (J. Li, Delmas, et al.,

2018)

\begin{tabular}{l|l|c|c|c}
\hline & $\begin{array}{l}\text { Available for } \\
\text { users }\end{array}$ & $\begin{array}{l}\text { Extensible and } \\
\text { alterable }\end{array}$ & Compatible & $\begin{array}{l}\text { Available } \\
\text { for } \begin{array}{l}\text { the } \\
\text { research }\end{array}\end{array}$ \\
\hline Urban Weather Generator & Free & Yes & Yes & Yes \\
\hline ENVI-met & With costs & No & Yes & No \\
\hline OpenFoam & Free & Yes & Yes & Yes \\
\hline Autodesk CFD & $\begin{array}{l}\text { Free for students; } \\
\text { with costs for } \\
\text { professionals }\end{array}$ & No & No & No \\
\hline UrbaWind & With costs & No & No & No \\
\hline
\end{tabular}




\subsubsection{Verify the reliability of modelling programs individually}

There were two objectives in this research: the first one was the feasibility of developing a simulation system to model effects of the urban microclimate on building performance; the second one was the necessity of the simulation system. Before developing the system, the validation of independent programs of which the system consists of, laid the foundation for consistent inputs of system parameters. When the inputs are truthful, the outputs are reliable.

In this section, the accuracy of several programs' prediction is demonstrated. To verify the programs' prediction, real data and simulation results had to be compared (Table 11). Urban Weather Generator (UWG), an Urban Heat Island (UHI) effects modelling program, could predict the temperature difference between urban and rural areas. The verification of UWG reliability was to match the UHI of a city with its prediction. In this research, the real data of London UHI, which was collected from numerous literatures, was compared with the UWG simulation results. The wind speed outputs of OpenFOAM were compared with the wind tunnel data of AIJ (Architectural Institute of Japan) benchmarks (Tominaga \& Mochida, 2016). Taking a high-rise building in city blocks as a model, AIJ wind tunnel data was used to model the shape of buildings and wind speed profile parameters. The wind pressure coefficient outputs of OpenFOAM were compared with the wind tunnel experiment results of CAARC Standard Tall Building Model (Melbourne, 1980). Thermal loads of the EnergyPlus model were compared with real measurement data of a high-rise commercial building in Auckland, which is from Cory's $\mathrm{PhD}$ research (Cory, 2016).

Table 11: Verification of programs

\begin{tabular}{l|l|l|l}
\hline Content & Programs & Against & Reference \\
\hline UHI & UWG & London UHI & $\begin{array}{l}\text { (Kolokotroni } \\
\text { Giridharan, 2008) } \\
\text { (Watkins et al., 2002) }\end{array}$ \\
\hline Wind speed & OpenFOAM & Wind tunnel data of AIJ & $\begin{array}{l}\text { (Tominaga \& Mochida, } \\
\text { 2016) }\end{array}$ \\
\hline $\begin{array}{l}\text { Wind } \\
\text { pressure } \\
\text { coefficient }\end{array}$ & OpenFOAM & Wind tunnel data of CAARC & (Melbourne, 1980) \\
\hline $\begin{array}{l}\text { Building } \\
\text { performance }\end{array}$ & EnergyPlus & $\begin{array}{l}\text { Measurement data of a high- } \\
\text { rise commercial building in } \\
\text { Auckland }\end{array}$ & (Cory, 2016) \\
\hline
\end{tabular}




\subsubsection{Simulation system establishment}

In the first phase, appropriate programs were selected. Then, the second phase of the methodology in this study was to develop the simulation system. This phase combines those programs and establishes a system that reorganizes the independent simulation tools. The variable phenomena of urban microclimate were modelled step by step through the simulation system. For different urban climate phenomenon, there are different corresponding modelling programs, and these programs operate individually. While, Grasshopper, a Visual Programming Language (VPL) interface for 3D modelling program Rhino, provides a platform which can put the urban microclimate modelling programs and building performance modelling programs together. The urban microclimate was calculated by Urban Weather Generator (UWG) and OpenFOAM, and building performance was calculated by EnergyPlus. The calculations were operated by corresponding plugins Dragonfly, Butterfly, Ladybug and Honeybee. Grasshopper provides the opportunity to reorganize these algorithm plugins systemically, and then link them up to develop the simulation system.

Firstly, the horizontal parameters of urban microclimates were modelled. Secondly, the impacts of vertical variations of urban microclimates on building performance simulation were explored. At last a multilayer modelling method of urban microclimate modelling was developed. These three steps were the process of the simulation system development. The simulation system makes it much more convenient and reliable to evaluate the urban microclimate comprehensively.

\subsubsection{Build a sample of a prototypical office building in a real city}

A case study was built to string all the programs together. A prototypical office building was used as the case to string all the plugins together and develop the urban microclimate simulation system. The corresponding plugins of modelling programs were reorganized and strung together on the grasshopper visual programming language platform. Rhino is used for three-dimensional modelling, and Grasshopper is a Visual Programming Language (VPL) platform where many plugins, algorithms and interfaces can be built not only for Rhino, but also for external analysis engines. The "Ladybug Tools" suite of programs has taken advantage of the Grasshopper VPL to build a set of interoperable interfaces to a range of Daylighting, Energy, Airflow, and Microclimate modelling engines (Roudsari, n.d.). This made it possible to string 
together a range of programs to enable the consistent exchange of information between programs to assist the reliable simulation of prototypical office buildings.

The sample took a typical high-rise office building in a typical Urban Heat Island (UHI) city as an example. The reason for picking high-rise office buildings was explained in Section 3.2.4. London was the typical UHI case study city in this research as its urban weather data and its buildings GIS (geographic information system) data is accessible. The shape and size of the prototypical high-rise office building was based on published data of the 32 tallest office buildings in London ('List of Tallest Buildings and Structures in London', 2018) and Pacific Northwest National Laboratory (PNNL) prototype office large (Commercial Prototype Building Models, 2016). The prototypical high-rise office building was $72 \mathrm{~m}$ x 50m x $154 \mathrm{~m}$ high and 35 storeys tall. Each floor of the prototypical high-rise office building was split into 5 zones, 4 perimeter zones and 1 core zone. The perimeter zone depth was $5 \mathrm{~m}$ and occupied $31.1 \%$ of the floor area, which were set according to PNNL prototype office large and large office studies of Lawrence Berkeley National Laboratory (Huang et al., 1991).

\subsubsection{Calibrate the urban weather file}

The prototypical office building performance was modelled in the city centre of London. The urban microclimate situation is significant for building performance modelling. At first, the weather data of London was collected from the weather station located at Gatwick airport, which is approximately $45 \mathrm{~km}$ away from the city centre of London. This rural weather data, as the initial version, was the foundation of urban microclimate data of London. CIBSE recommended this data is to be used for urban (London) site energy performance simulation (CIBSE - Weather Data, 2019). A second version of weather file which took Urban Heat Island (UHI) effects into account was generated by Urban Weather Generator (UWG). Its temperature was significantly different from the initial version. Then a third version was generated by using OpenFOAM to predict urban wind changes. The second version only considered the temperature differences between urban weather data and rural weather data, and the third one only calibrated the air-flow variations. A fourth one combined the second and third version, and a complete version of urban microclimate weather data was achieved. Based on the fourth version, the vertical variation of urban microclimates was taken into account to explore the effects of wind speeds and temperatures at different heights on the building performance. Lastly, additional algorithms about vertical variations of wind speeds and 
temperatures were added on the modelling process. This was intended to calibrate urban weather file to make it much closer to reality.

\subsubsection{Calibrate the natural ventilation information around the office building}

The detailed natural ventilation of a prototypical office building located in urban London was explored. The feasibility of detailed natural ventilation was related to the urban wind, especially the wind pressure coefficients $(\mathrm{Cp})$ around the building facades. The first step was to get wind pressure coefficients using OpenFOAM. An electronic wind tunnel was built with OpenFOAM to simulate the wind in 12 directions and predict the corresponding $\mathrm{Cp}$ of each facade. The second step used Airflow Network template of EnergyPlus to model a detailed natural ventilation system and evaluate the performance of the sample office building, especially on different floors.

\subsubsection{Combine individual programs as a workflow to build the simulation system}

The workflow of a comprehensive simulation system was set up. The reliability of individual tools was the cornerstone of the system. Although there could be no guarantee that the combination of all the tools precisely predicts reality, the goal was to determine the potential scale of the tools' interactions. The relative scale of the effect of each parameter would then determine whether each Urban Microclimate parameter had a sufficiently large effect on the overall energy performance that it must be incorporated into any future urban microclimate simulation. Two branches of urban microclimate modelling, the temperature branch and wind branch, were gathered together. The urban microclimate modelling outcomes were the inputs of building performance simulation. The plugins of individual programs made it possible for them to collaborate on a single on one platform. The modelling of urban microclimate was divided into two layers. The lower portion was the Urban Canopy Layer (UCL) and the upper portion was the Urban Boundary Layer (UBL). This same division was applied to the prototypical high-rise office building. Thus, the methodology was to work with a multilayer modelling approach that dealt separately with the effects of the UCL and the UBL on the building.

By modelling the horizontal and vertical parameters of urban microclimate modelling and using the multilayer modelling method, an urban microclimate simulation system was established. The simulation system consisted of a three-dimensional modelling template, Urban Heat Island modelling template, wind tunnel modelling template, 
natural ventilation modelling template and building performance template. The simulation system took account of most of the parameters that potentially affect the urban microclimate and explored their impacts on energy performance predictions.

\subsubsection{Impact analysis of urban microclimate on high-rise office buildings}

The third phase of the methodology was to explore the necessity of the simulation system by estimating the likely scale of the microclimate effects on building performance simulation. Whether or not the impacts of urban microclimate detailed modelling are significant is the most crucial part of this research.

\subsubsection{Assess the influence of each parameter of urban microclimates on building performance}

The cumulative effects of urban microclimates parameters, the likely scale of impacts of height variation precision of a city and the effects of height variations of suburban terrain were explored. The combined effects included urban wind, UHI, adjusted urban height variations (HV) and using multilayer modelling method. Urban wind here was the wind speed reduction due to urban blocks. Adjusted urban height variations were specific for London, while the original height variations were rough for cities. Accurate height variation data of urban microclimates was unavailable, especially temperature lapse rate and wind speed profile exponents inside the Urban Canopy Layer (Section 7.3.3). Hence, the likely scale of impacts of height variation precision determined the necessity of getting a specific urban height variation. Besides, exploring importance of suburban terrain was because the air flow over rough urban terrain does not represent well the air flow over large parks. The comparison made it clear which parameter has a big effect. The scale of the combined effects of the parameters indicated the necessity of developing a simulation system for accurate prediction. Then according to the prediction of the simulation system, building performance on different floors with different ventilation systems was assessed to explore the effects of height and ventilation systems on building performance.

\subsubsection{Analyse the impacts of urban microclimate detailed modelling in different climates}

The thesis also explored how the urban microclimate parameters influence building performance predictions in other climates. The reason for using several climates to verify the simulation system was that this study is about the effects of urban 
microclimates and testing different urban microclimates enables generalization to a broader range of urban environments. Not all types of climates, but several typical and different climates were explored, such as a moderate climate, a windy climate, a continental climate and a tropical climate. The case study in previous sections was based on the climate of London which is a moderate climate. If the effects in moderate climates have been demonstrated, it is possible to model the case study in other climates and test how the effects are different in different climates. Apart from a moderate climate, a moderate but windy climate was studied to explore whether wind plays a more important role in a windy climate. Wellington is one of most windy cities in the world and it is also moderate. The climate of Wellington was compared with London to explore the influence of wind. The research also studied an extremely hot and cold climate and a hot and wet climate. Beijing has a continental climate which is cold in winter and hot in summer. Singapore is another kind of extreme. Singapore is close to the equator and has a tropical climate. Singapore is hot all year round. When the outdoor weather is not suitable for natural ventilation for most of the year, whether the urban microclimate parameters play a less important role was discussed. The effects of moderate, windy, continental, and tropical climates were explored and compared. In different climates, the most critical parameter might be different. If detailed urban microclimate modelling has significant impacts on building performance simulation in not only a moderate climate but also other climates, then these parameters should not be ignored, and the necessity of urban microclimate simulation system development has been demonstrated.

\subsection{Chapter Summary}

This chapter outlines the overall methodology of this research. The methodology outlined the detail to be expanded on in the next few chapters. To explore the feasibility to develop a simulation system and the necessity of developing the system, the methodology of this research consisted of three phases: the first phase was the preparation part (refer to CHAPTER 4); the second phase demonstrated the feasibility (refer to CHAPTER 5 CHAPTER 6 and CHAPTER 7); the third phase demonstrated the necessity (refer to CHAPTER 8).

This research was about the relationship between urban microclimate and the performance of office buildings. The research methodology was mainly based on 
numerical simulation, which related to urban wind environment, temperature variation, building performance, natural ventilation, and so on. 


\section{CHAPTER 4. INDIVIDUAL MODELLING PROGRAMS RELIABILITY VERIFICATION}

\subsection{Chapter Intent}

Chapter 4 is the preparation stage for the following three chapters of modelling. This purpose of this study is to explore how to model the urban climate in detail to provide information about the microclimate around buildings and thus affect the energy performance simulation. The reliability of the simulation tools used in this research is of fundamental importance for all modelling, calculation and simulation. This Chapter tests and verifies the reliability of related programs such as OpenFOAM, Urban Weather Generator, and EnergyPlus. Only when these tools are reliable, will the modelling of a high-rise building in an urban climate in the next chapter make sense.

\subsection{Verification of Wind Speed Prediction with OpenFOAM}

\subsubsection{Methodology}

To verify the reliability of wind speed modelling with OpenFOAM, the simulation results were compared with experimental wind tunnel data from the Architectural Institute of Japan (AIJ) (Tominaga \& Mochida, 2016). AIJ provided a benchmark for the validation of CFD simulation. The prediction of the simulation results was compared with the experimental data to verify the agreement. How the OpenFOAM parameters, such as meshing size, influence the agreement is discussed.

This research studied high-rise office buildings in urban microclimates. The air flow around a high-rise building surrounded by blocks was one part of this research. In the AIJ research, there are 7 benchmark tests, from group A to group G. Among them, group D, which is "A high-rise building in a multi-block" model, is consistent with this research. Group D is a simplified urban configuration. The simplified urban configuration from group D is modelled and its relative urban wind is predicted. In the verification stage, the model should be neither too simple nor too complex. If it is too simple, the results are not reliable. If it is too complicated, it takes lots of time and is not necessary. Group D consists of 83 blocks, which can represent an appropriately sized urban environment. 


\subsubsection{Model description}

\subsubsection{The wind tunnel model}

In the AIJ's documents, detailed information about the wind tunnel model is provided (Tominaga \& Mochida, 2016). It contains the size and layout of the buildings, the wind environment and the location of the test points.

The wind tunnel model was made up of 82 low-rise blocks (40m x 40m x 10m) and 1 high-rise block $(25 \times 25 \times 100 \mathrm{~m})$ in the centre (Figure 19). The experiment was conducted at the Niigata Institute of Technology at a scale of 1:400 (Tominaga and Mochida 2016).

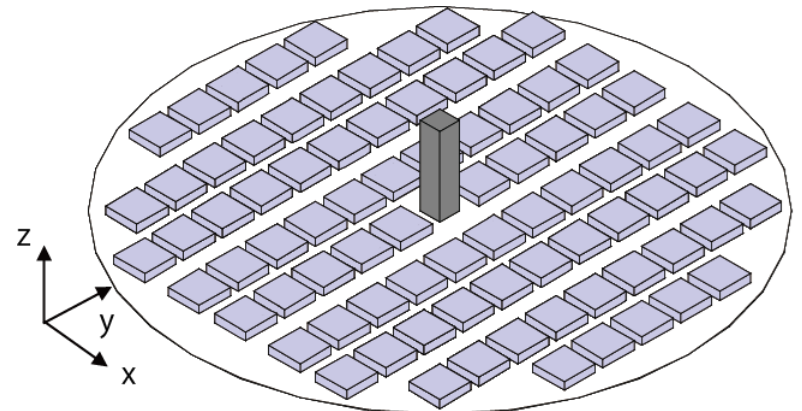

Figure 19: Outline of the multi-block model for AIJ wind tunnel experiment (Tominaga \& Mochida, 2016)

The vertical distribution of wind from AIJ wind tunnel is shown in Figure 20. In practice, the inflow velocity at the height of $100 \mathrm{~m}$ was $6.65 \mathrm{~m} / \mathrm{s}$. In the case of the scaled wind tunnel, the wind speed was $6.65 \mathrm{~m} / \mathrm{s}$ at the height of $250 \mathrm{~mm}$.

\begin{tabular}{|c|c|c|c|c|c|}
\hline $\mathrm{z}(\mathrm{mm})$ & $\mathrm{z} / \mathrm{H}$ & $\mathrm{U}(\mathrm{m} / \mathrm{s})$ & $\mathrm{U} / \mathrm{U}_{\mathrm{H}}$ & $\mathrm{k}$ & $\mathrm{k} / \mathrm{U}^{{ }_{\mathrm{H}} 2}$ \\
\hline 5 & 0.02 & 3.833 & 0.576 & 0.529 & 0.012 \\
\hline 10 & 0.04 & 4.121 & 0.620 & 0.606 & 0.014 \\
\hline 20 & 0.08 & 4.321 & 0.650 & 0.667 & 0.015 \\
\hline 30 & 0.12 & 4.476 & 0.673 & 0.666 & 0.015 \\
\hline 50 & 0.20 & 4.740 & 0.713 & 0.730 & 0.017 \\
\hline 100 & 0.40 & 5.320 & 0.800 & 0.750 & 0.017 \\
\hline 200 & 0.80 & 6.282 & 0.945 & 0.744 & 0.017 \\
\hline 300 & 1.20 & 6.982 & 1.050 & 0.694 & 0.016 \\
\hline 400 & 1.60 & 7.550 & 1.135 & 0.635 & 0.014 \\
\hline 600 & 2.40 & 8.678 & 1.305 & 0.456 & 0.010 \\
\hline 800 & 3.20 & 9.525 & 1.432 & 0.281 & 0.006 \\
\hline 1000 & 4.00 & 10.024 & 1.507 & 0.126 & 0.003 \\
\hline 1200 & 4.80 & 10.071 & 1.514 & 0.068 & 0.002 \\
\hline
\end{tabular}
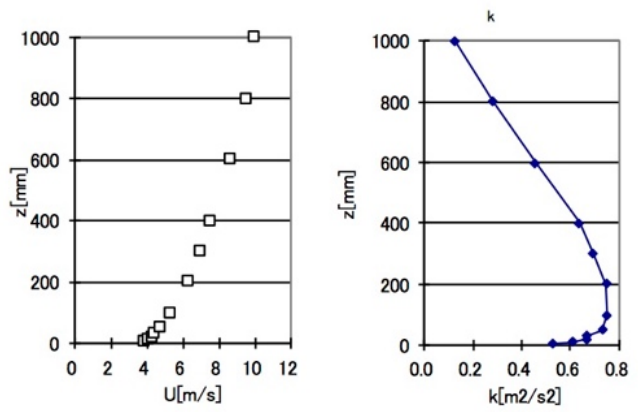

Figure 20: Wind profile of AIJ wind tunnel

Table 12 shows the environmental parameters in the real circumstances and in a scaleddown condition. Since the wind tunnel model was 400 times smaller than the real size building, the roughness length of inlet airflow and the height of the measurement points were scaled down (Table 12). The wind speed was the same as the real circumstance.

Table 12: Environment conditions from AIJ model 


\begin{tabular}{|c|c|c|c|}
\hline Condition & Real & $\begin{array}{l}\text { Scaled (Normalized } \\
\text { by } \mathrm{H} \text { and } \mathrm{U}_{\mathrm{H}} \text { ) }\end{array}$ & Scaled 1:400 \\
\hline Height of central building $(\mathrm{H})$ & $100 \mathrm{~m}$ & 1 & $0.25 \mathrm{~m}$ \\
\hline $\begin{array}{l}\text { Inflow velocity at the central } \\
\text { building height }\left(\mathrm{U}_{\mathrm{H}}\right)\end{array}$ & $6.65 \mathrm{~m} / \mathrm{s}$ & 1 & $6.65 \mathrm{~m} / \mathrm{s}$ \\
\hline Wind direction & $0^{\circ}, 22.5^{\circ}, 45^{\circ}$ & $0^{\circ}, 22.5^{\circ}, 45^{\circ}$ & $0^{\circ}, 22.5^{\circ}, 45^{\circ}$ \\
\hline Measurement points height (z) & $2 \mathrm{~m}$ & 0.02 & $0.005 \mathrm{~m}$ \\
\hline Roughness length $\left(\mathrm{z}_{0}\right)$ & $0.043 \mathrm{~m}$ & $4.3 \times 10^{-4}$ & $1.075 \times 10^{-4} \mathrm{~m}$ \\
\hline
\end{tabular}

In this wind tunnel experiment, the wind speeds around the central high-rise building were collected. Figure 21 (a) shows 78 test points arranged in the grid. However, the results of 12 measurement points next to the central building could not be tested. Hence, the data of points 26, 27, 28, 29, 32, 33, 36, 37, 40, 41, 42, 43 in AIJ tunnel wind model were empty. After ignoring the points in the yellow area, the series number of the measurement points was rearranged (Figure 21b).

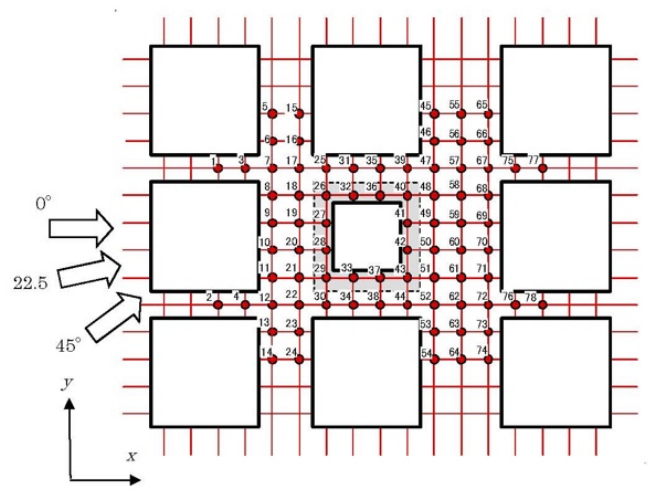

(a)

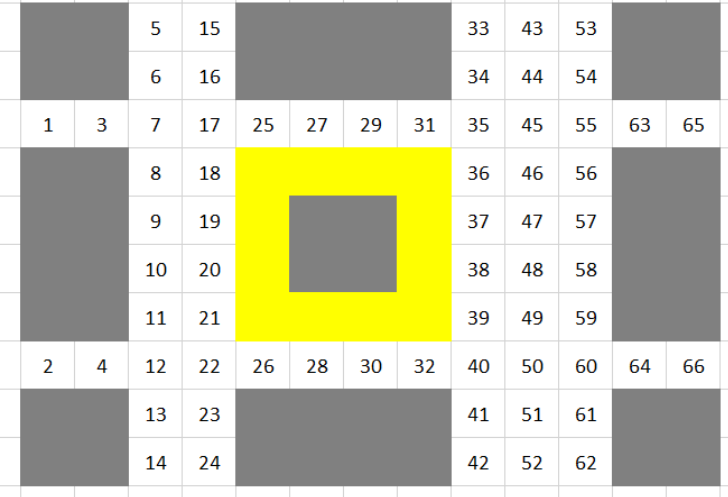

(b)

Figure 21: (a) 78 measurement points for AIJ wind tunnel experiment (b) Modified version of 66 measurement points without points besides the central building

\subsubsection{The numerical model}

The numerical model was developed by OpenFOAM. Whether or not the simulation results match with the wind tunnel results can reflect the trustworthiness of OpenFOAM. In this simulation, the model is of real-life size. According to the data of AIJ experimental conditions, the wind speed at $100 \mathrm{~m}$ height was set as $6.65 \mathrm{~m}$, the wind flowed from $0^{\circ}, 22.5^{\circ}$ and $45^{\circ}$, the measurement height was $2 \mathrm{~m}$ and the roughness length is $0.043 \mathrm{~m}$ (Table 13). OpenFoam represents the world in full scale measurements, but the wind tunnel represents a scaled building. At different heights, inlet flow velocities of the wind tunnel were different. In OpenFOAM, the vertical variation of the inlet flow profile was adjusted through different roughness lengths of various landscapes (Hammond et al., 2012). The roughness length of $0.43 \mathrm{~m}$ was bigger 
than $0.03 \mathrm{~m}$ and it corresponded to the landscape of "open" in the OpenFOAM model. The meshing method and size were based on Section 3.3.1.1.2.

Table 13: Basic parameters of the simulation condition for wind speed model

\begin{tabular}{|c|c|}
\hline $\begin{array}{l}\text { Basic condition for prototype } \\
\text { model }\end{array}$ & Values \\
\hline Inflow velocity at $100 \mathrm{~m}$ height & $6.65 \mathrm{~m} / \mathrm{s}$ \\
\hline Wind direction & $0^{\circ}, 22.5^{\circ}, 45^{\circ}$ \\
\hline Measurement points height (z) & $2 \mathrm{~m}$ \\
\hline Roughness length $\left(\mathrm{z}_{0}\right)$ & $0.043 \mathrm{~m}$ \\
\hline $\begin{array}{l}\text { Landscape } \quad \text { (Based } \\
\text { OpenFOAM standard) }\end{array}$ & $\begin{array}{l}2>\text { ' } 0.03 \text { ' \# open. Level country with low vegetation (e.g. } \\
\text { grass) and isolated obstacles with separations of at least } \\
50 \text { obstacle heights; e.g. grazing land without } \\
\text { windbreaks, heather, moor and tundra, runway area of } \\
\text { airports. Ice with ridges across-wind. }\end{array}$ \\
\hline Turbulence model & k-Epsilon model \\
\hline Meshing & $\begin{array}{l}\mathrm{X} \text { axis percentage length }(10 \%, 30 \%, 60 \%) \\
\text { percentage cells }(10 \%, 70 \%, 20 \%) \\
\mathrm{Y} \text { axis percentage length }(50 \%, 50 \%) \\
\text { percentage cells }(50 \%, 50 \%) \\
\mathrm{Z} \text { axis percentage length }(50 \%, 50 \%) \\
\text { percentage cells }(70 \%, 30 \%)\end{array}$ \\
\hline The cell size & $(100,50,30)$ \\
\hline Refinement level & 2 \\
\hline Computational domain & $\begin{array}{l}\text { Windward extension: } 3 \text { times } \\
\text { Top extension: } 3 \text { times } \\
\text { Sides extension: } 4 \text { times } \\
\text { Leeward extension: } 15 \text { times }\end{array}$ \\
\hline
\end{tabular}

The computational domain of the model was initially set by default. The recommendations were 3 times the height, 3 times the width, 3 times windward and 15 times leeward (Table 13). It worked well when the wind blows from $0^{\circ}$ direction. However, when the wind flow direction changed to $22.5^{\circ}$ or $45^{\circ}$, the diagonal of building block group exceeded the meshing width range. The 3 times width was not big enough because the diagonal was longer than the width. Therefore, it was modified to 4 times which worked well. The meshing models in different directions are shown in Figure 22. 


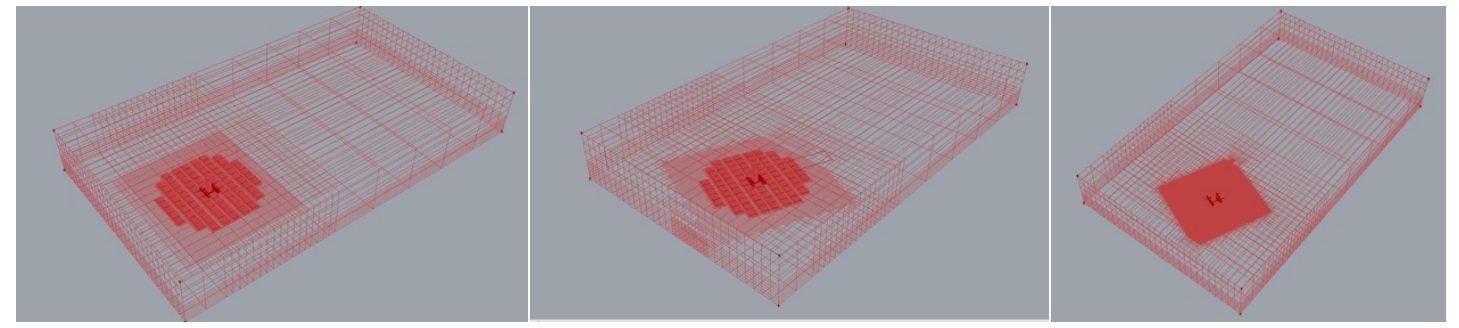

(a)

(b)

Figure 22: Meshing for (a) $0^{\circ}$ (b) $22.5^{\circ}$ (c) $45^{\circ}$ wind direction

(c)

In CFD simulations, meshing is always a significant step. The refinement level represents the density of meshing, the lower-level means fewer and bigger grids (Figure 23a) and the higher-level means denser and smaller grids (Figure 23b). The higher density of meshing gives a more accurate result; however, it also means a longer calculation period.

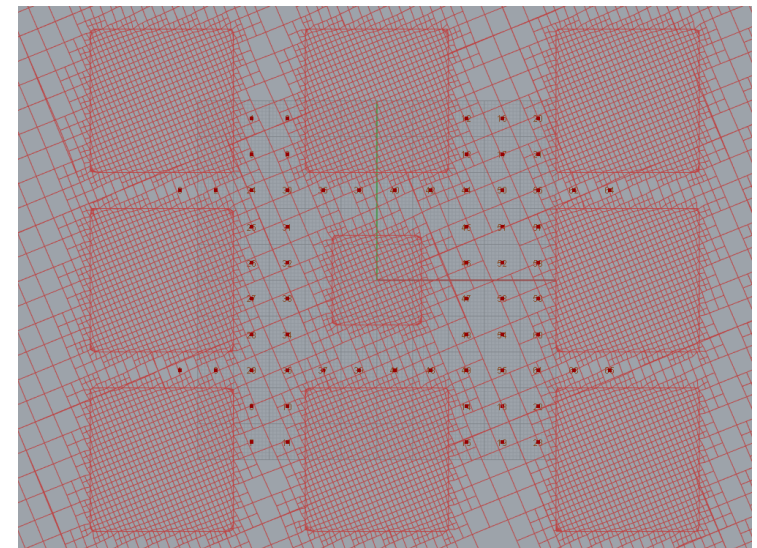

(a)

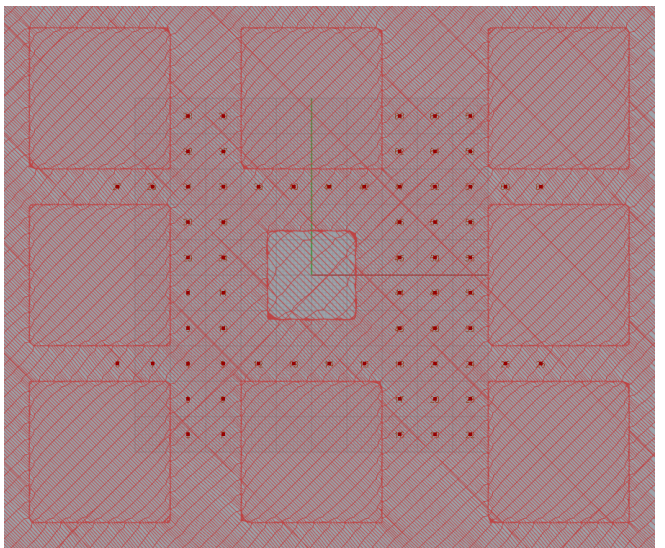

(b)

Figure 23: Refinement (a) level 2 and (b) level 5

\subsubsection{Analysis cases}

To understand the role of each parameter in the modelling process, a prototype model and several comparison models were generated. The original model was based on the AIJ wind tunnel model, and the comparison models had different conditions. How the change of condition parameters influence the results is discussed in this section (Table 14).

The impacts of mesh refinement level, roughness length and turbulence model can show which parameters are closer to the wind tunnel experiment data and indicate how to model wind environments using OpenFOAM. For example, is it worthwhile to mesh in a high level, is the accuracy of roughness length important, and does the turbulence model make a significant difference? 
Table 14: Parameters of original model and comparison model

\begin{tabular}{l|l|l}
\hline Condition & Original Model & Comparison Model \\
\hline Mesh refinement level & 5 & 2 \\
\hline Wind direction & $0^{\circ}$ & $22.5^{\circ}, 45^{\circ}$ \\
\hline roughness length & $2>^{\prime} 0.03^{\prime} \quad \#$ open & $4>^{\prime} 0.25^{\prime} \quad \#$ rough \\
\hline Turbulence model & k-Epsilon model & RNG k-Epsilon model \\
\hline
\end{tabular}

\subsubsection{Grouping measurement points}

The grouping of measurement points is helpful to identify different flow features and to compare the simulation data. A set of sorting rules was proposed to ensure the consistency of test point numbering in a different direction. The grouping of points was based on the effects of different expected winds. The effect areas of the $0^{\circ}$ and $22.5^{\circ}$ winds were considered similar, but the grouping of the measurement points at $45^{\circ}$ was different from that in the previous two directions. The grouping of three directions is shown in Figure 24. The measurement points were separated into 6 groups: Upstream Flow, Upwind Side Streets, Flow Down Side Streets, Downdraught Effect, Channelling Down streets, Corner Effect and Downstream Flow and Shelter Effect area.

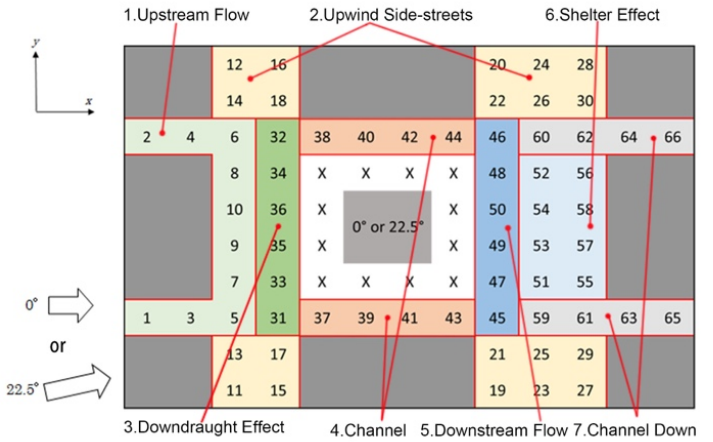

(a)

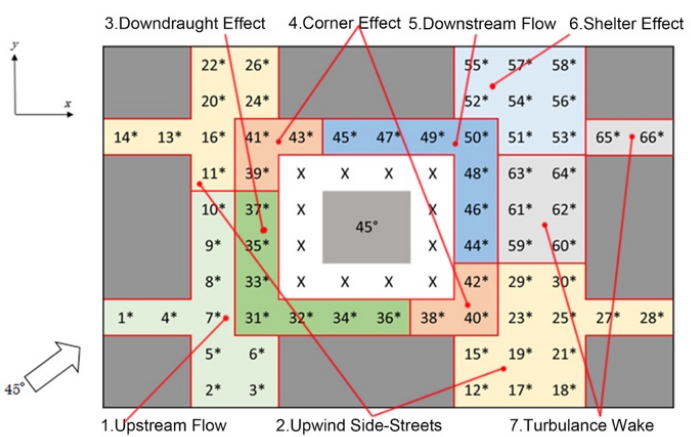

(b)

Figure 24: Measurement points grouping: (a) $0^{\circ}$ or $22.5^{\circ}$ (b) $45^{\circ}$

\subsubsection{The comparison of analysis results}

\subsubsection{Effects of wind direction}

Figure 25 shows the effect of different wind direction on the AIJ configuration. The graphs show a comparison between wind predictions by OpenFOAM and wind tunnel measurements recorded by the AIJ.

At $0^{\circ}$, the wind tunnel measurement data and CFD simulation results have good consistency in Upstream Flow area, the left part of Upwind Side streets, and the left part of Corner Effect and Channel area (Figure 25a). There is a distinct gap between 
the measurement data and the predicted results in the Downstream Flow, Shelter Effect and Channel Down area. This shows that the CFD model under-predicts the wind speed in the wake area of flow. The line graph at $22.5^{\circ}$ has a similar situation at $0^{\circ}$. The agreement at Upstream area is better than in the wake area (Figure 25b). At $45^{\circ}$, the graphs of Upstream Flow area, Upwind Side Streets area and Shelter Effect match the shape of the wind tunnel graph. Graphs of Channelling Down streets, Corner Effect and Downstream Flow on the whole match the wind tunnel graph, but there is a large gap between the two lines (Figure 25c). OpenFOAM predicts the tendency well but underestimates the values.

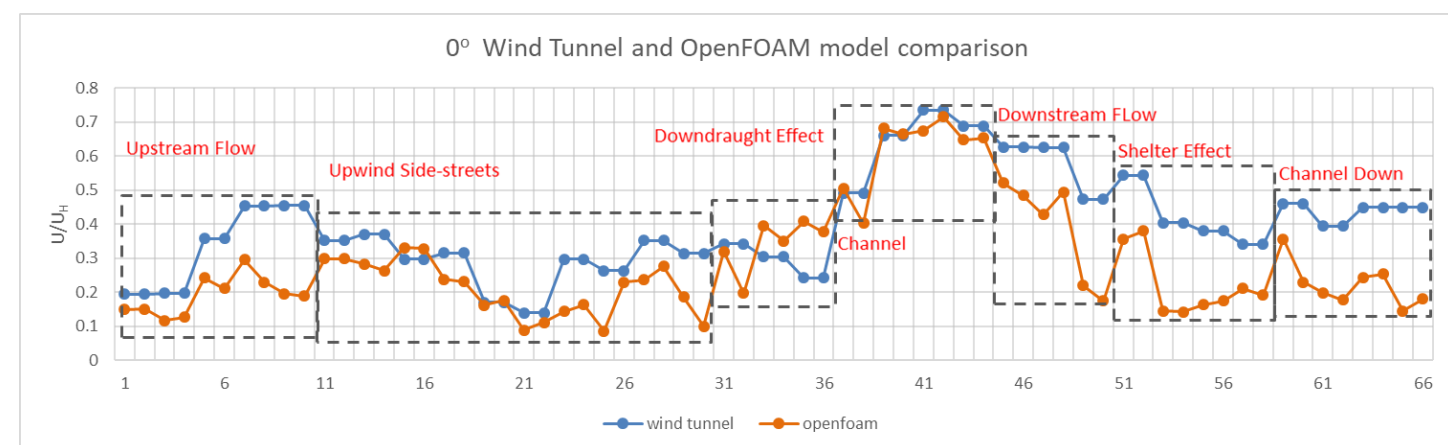

(a)

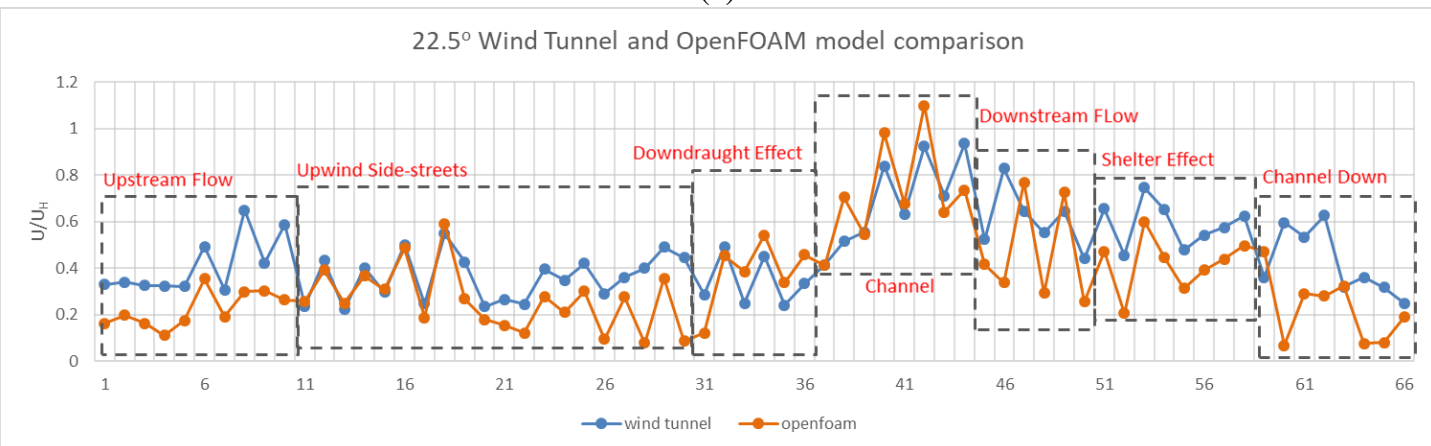

(b)

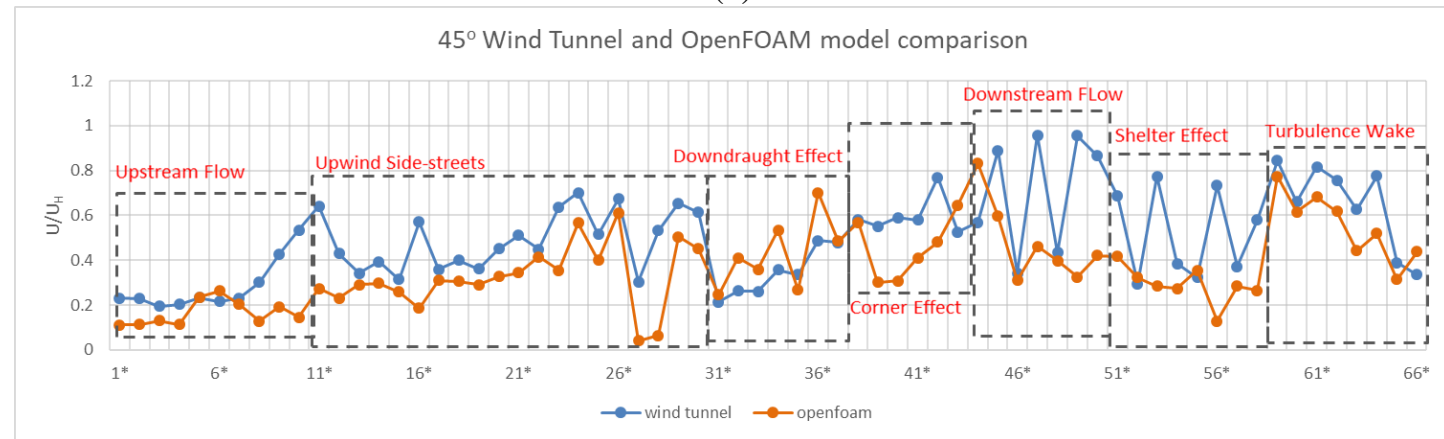

(c)

Figure 25: Comparison of wind speed ratios at different wind direction

Compared (a) (b) and (c) of Figure 26, it can be seen that red spots are less scattered than green spots and blue spots. Less scattered means more consistent. The equation shows OpenFOAM is closer to wind tunnel at $0^{\circ}(84.0 \%)$ and $22.5^{\circ}(89.2 \%)$ than at $45^{\circ}$ 
(45.7\%). That means that OpenFOAM matches with Wind Tunnel at $0^{\circ}$ and $22.5^{\circ}$ better than at $45^{\circ}$.

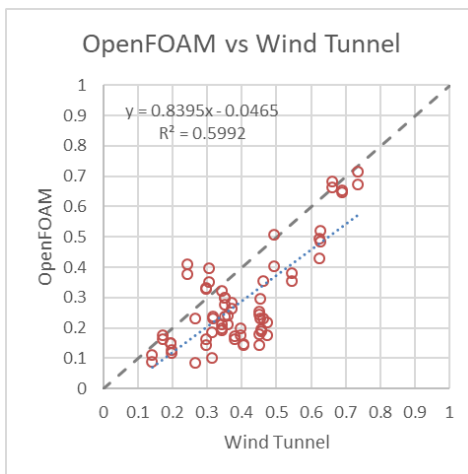

(a) $0^{\circ}$

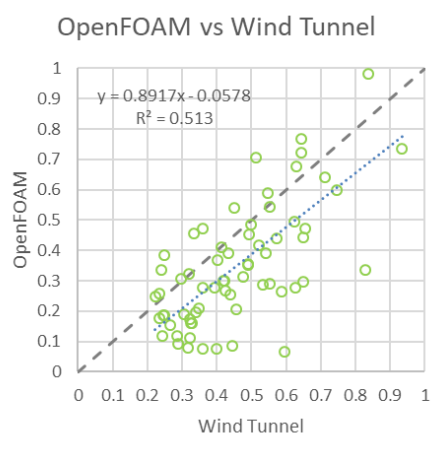

(b) $22.5^{\circ}$

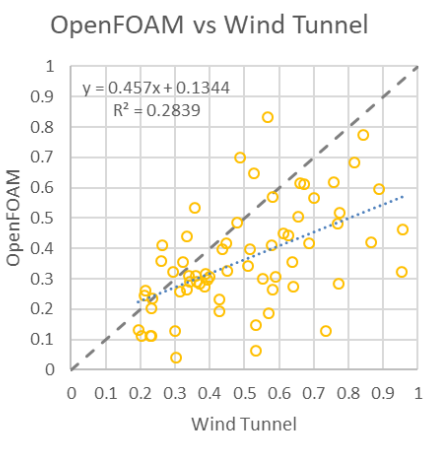

(c) $45^{\circ}$

Figure 26: Comparison of wind speed ratios between OpenFOAM and Wind Tunnel

Figure 25 shows the comparison of OpenFOAM and wind tunnel for 7 groups of flow features. Figure 26 shows the agreement of all 66 test points between OpenFOAM and wind tunnel. If the 66 test points of Figure 26 are divided into 7 groups, the number of test points is too small to get a trustworthy trend line. The 66 test points are divided into 2 groups, 1-44 (non-wake areas) and 45-66 (wake areas).

In the non-wake area, OpenFOAM is $94.7 \%$ (Figure $27 \mathrm{a}$ ) of wind tunnel at $0^{\circ}$, and $106 \%$ (Figure $27 \mathrm{~b}$ ) at $22.5^{\circ}$. The difference between OpenFOAM and wind tunnel is less than $10 \%$. At $45 \%$ OpenFOAM reaches $60.8 \%$ (Figure $27 \mathrm{c}$ ) of wind tunnel, which is much better than $45.7 \%$ (Figure 26c). The agreement between OpenFOAM and wind tunnel in the non-wake area is better than that of all test points.

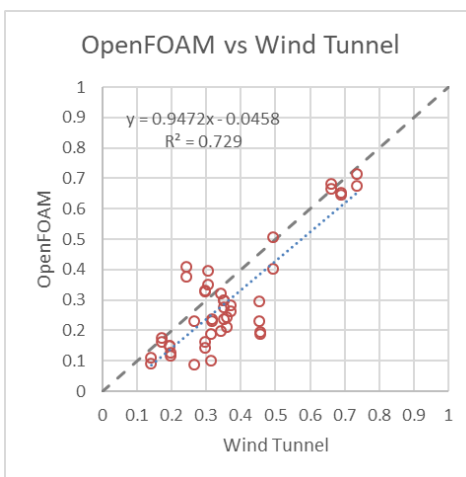

(a) $0^{\circ}$

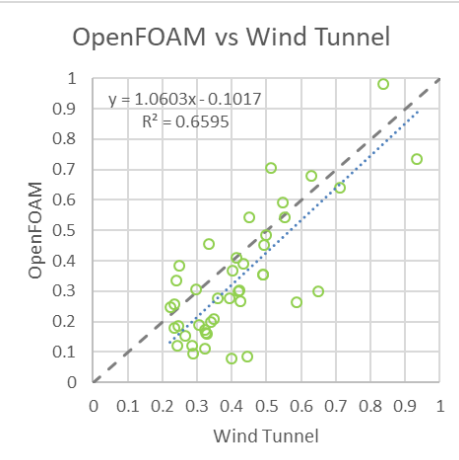

(b) $22.5^{\circ}$

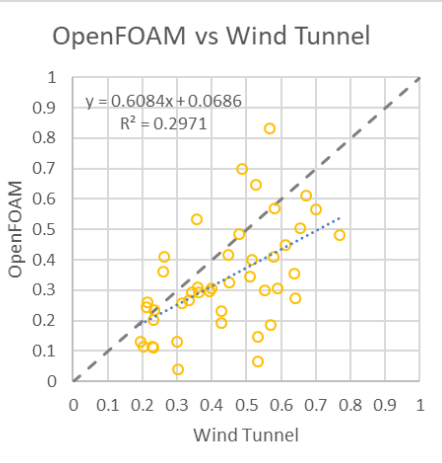

(c) $45^{\circ}$

Figure 27: Comparison of OpenFOAM and Wind Tunnel in non-wake areas (test points 1-44)

In contrast to in the non-wake area and all test points, the agreement between OpenFOAM and wind tunnel in the wake area is the worst. In Figure 28, OpenFOAM is $120.3 \%$ of wind tunnel at $0^{\circ}$ and $68.1 \%$ at $22.5^{\circ}$. At $45^{\circ}$, OpenFOAM is only $30.9 \%$ (Figure 28c) of wind tunnel. 


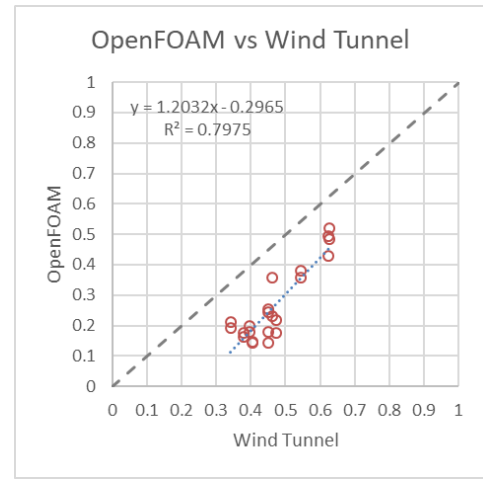

(a) $0^{\circ}$

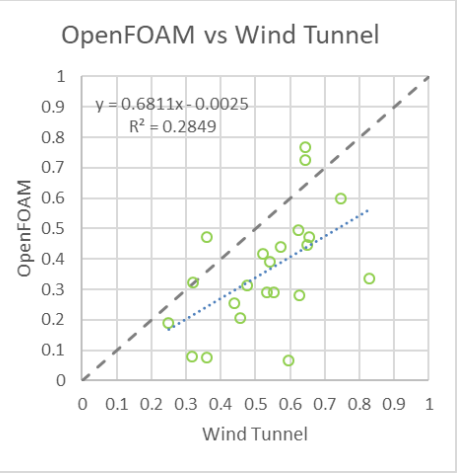

(b) $22.5^{\circ}$

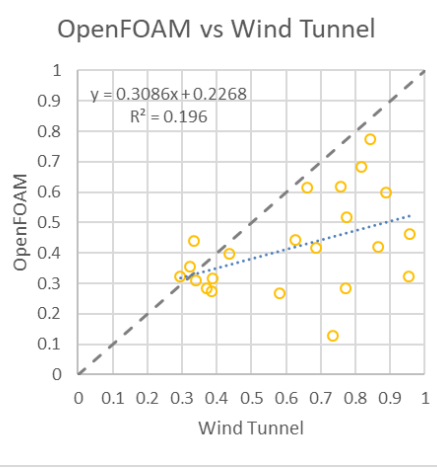

(c) $45^{\circ}$

Figure 28: Comparison of OpenFOAM and Wind Tunnel in wake areas (test points 45-66)

Overall, the agreement between OpenFOAM and wind tunnel at $0^{\circ}$ and $22.5^{\circ}$ is better than at $45^{\circ}$, and the agreement in the non-wake areas is better than the wake area.

\subsubsection{Effects of mesh refinement}

The purpose of exploring the effects of mesh refinement level is to evaluate the necessity of intensive meshing. Figure 29 shows the effect of mesh refinement which is related to grid density, and high level means high density.

The graphs show that the wind predictions by OpenFOAM with two levels of refinement compared to wind tunnel measurements recorded by the AIJ. The agreement between the graph of refinement level 5 and the wind tunnel is not as good as the agreement of refinement level 2 and the wind tunnel. Besides, the gap between level 5 and the wind tunnel is larger than the gap between level 2 and wind tunnel, especially at $45^{\circ}$ in the Corner Effect and Downstream Flow area and Shelter Effect areas. The CFD model of level 2 under-predicts the wind speeds, in particular the right part of Upwind Side streets, and the right part of Corner Effect and Downstream Flow areas. The predictions of level 5 enlarge the gap because the gaps between level 5 and wind tunnel are bigger than that between level 2 and wind tunnel.

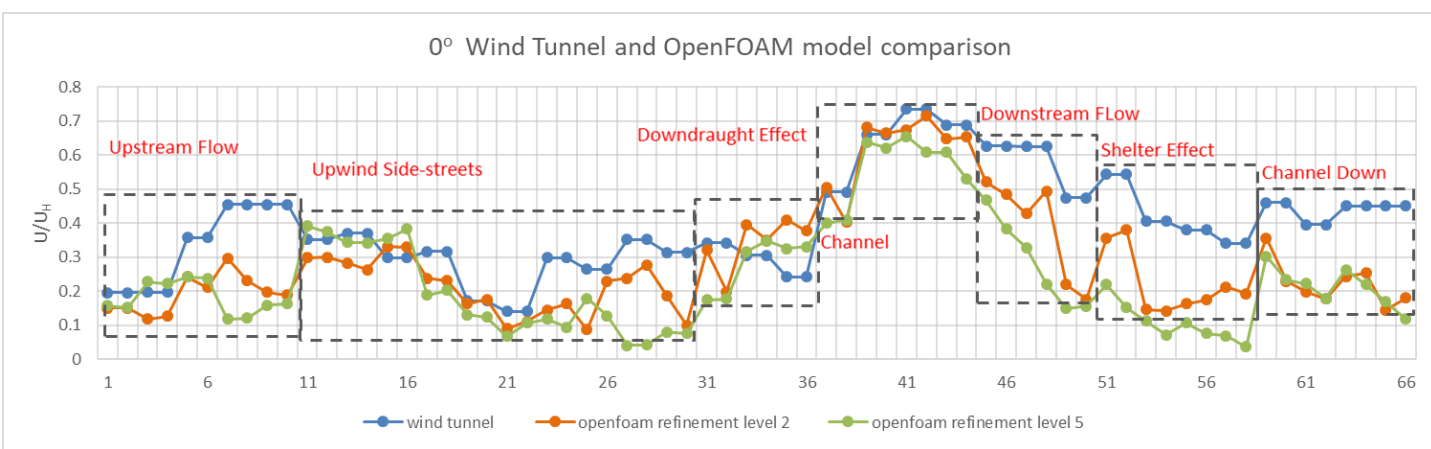

(a) 


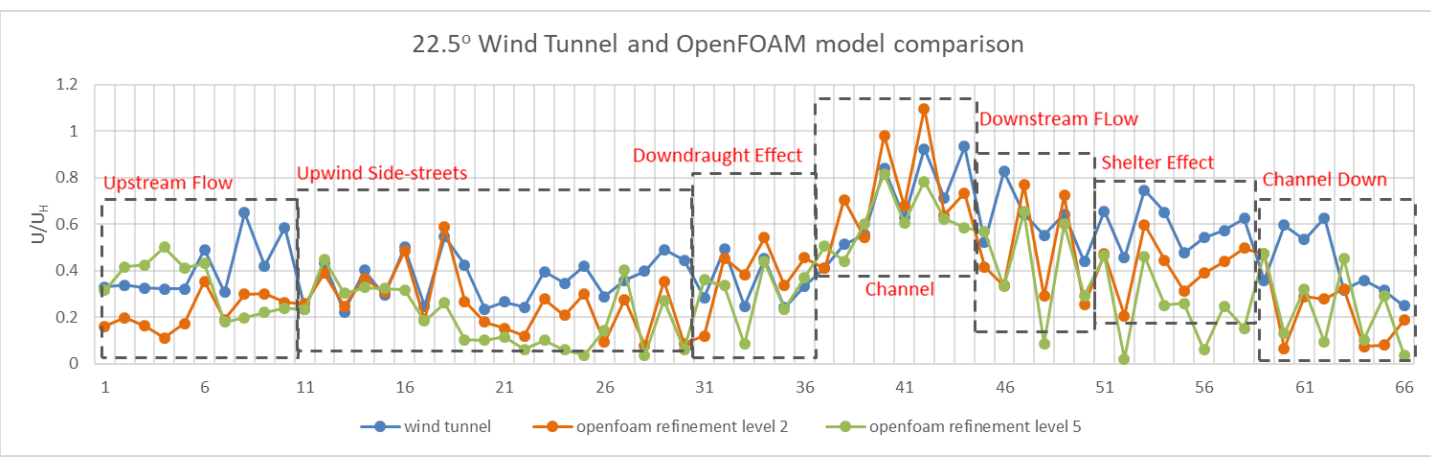

(b)

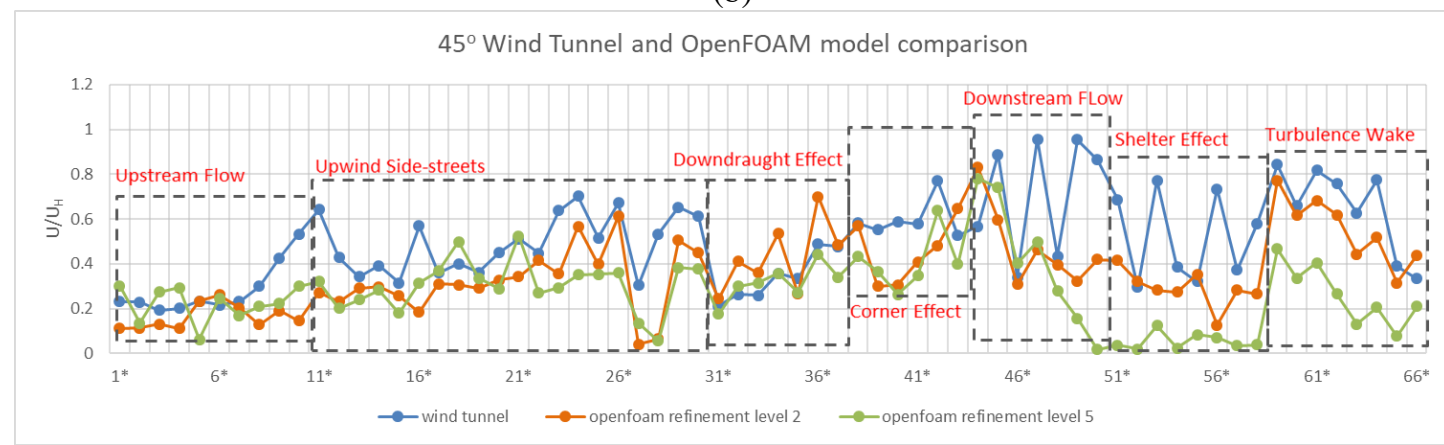

(c)

Figure 29: Comparison of wind speed ratios for different refinement levels

Hence, it is unnecessary to mesh in level 5. Mesh refinement of level 2 is recommended for the following models using OpenFOAM.

\subsubsection{Effects of roughness length}

The purpose of exploring the effects of roughness length is to evaluate the importance of roughness length accuracy. Figure 30 shows the effect of roughness length, which is related to ground surface condition and landscape style. The graphs show the comparison between wind predictions by OpenFOAM with two kinds of roughness lengths and wind tunnel measurements recorded by the AIJ. At $22.5^{\circ}$ and $45^{\circ}$ the agreement between roughness 0.03 and 0.25 is quite good, they are almost the same. At $0^{\circ}$, the agreement is also quite good in the non-wake area. In the wake area, the predictions of roughness 0.03 are higher than those of roughness 0.25 .

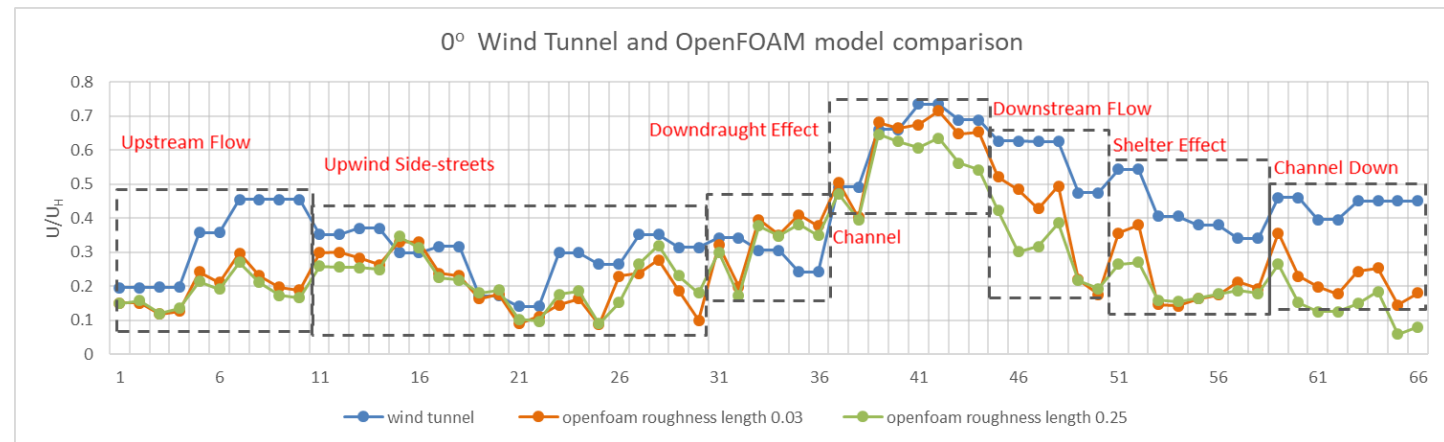

(a) 


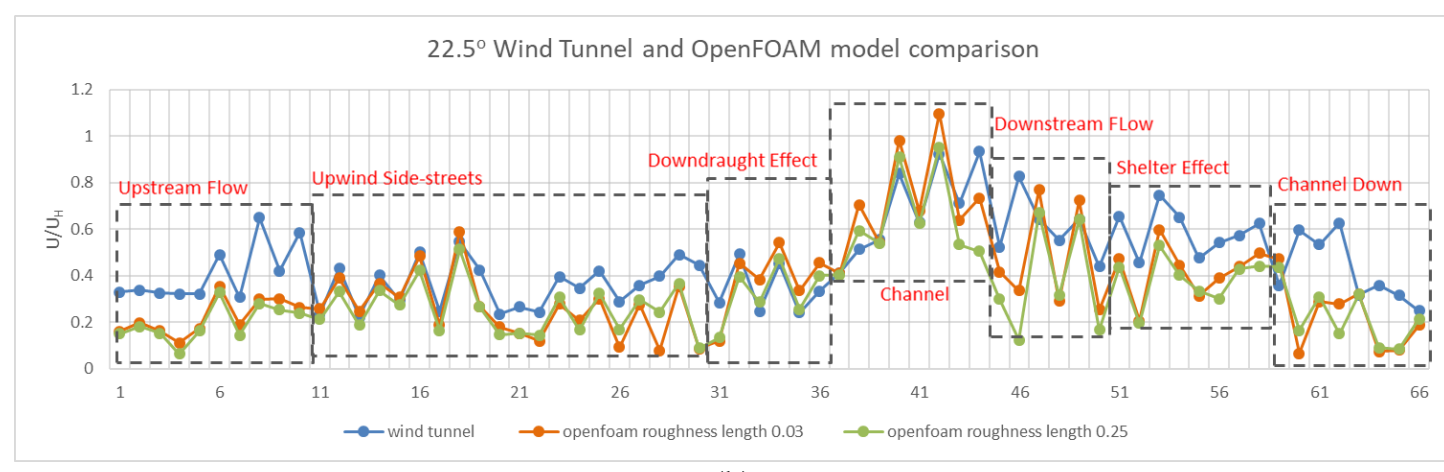

(b)

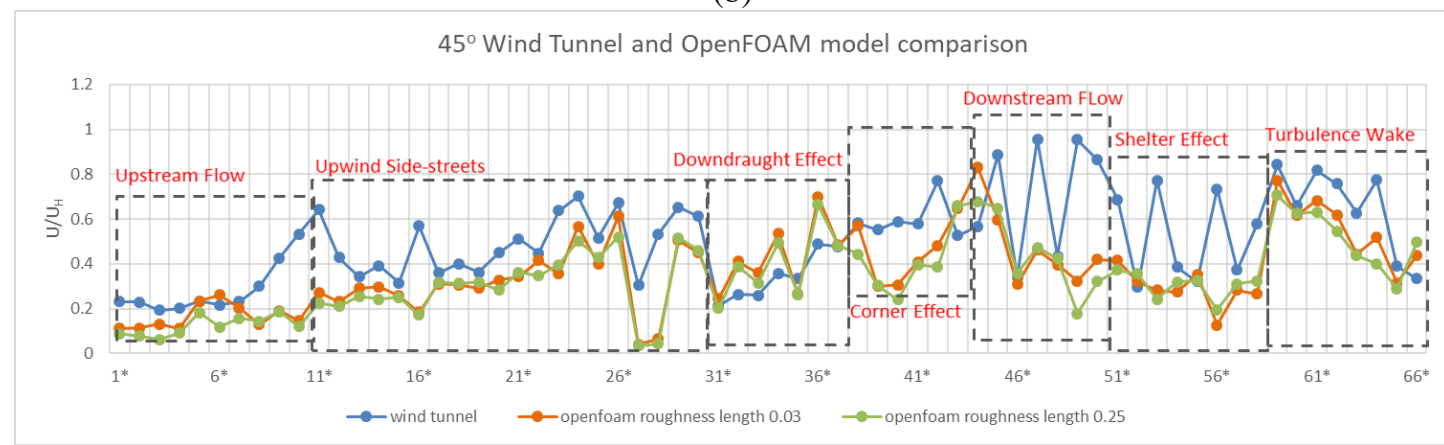

(c)

Figure 30: Comparison of wind speed ratios for different roughness lengths

Hence, the roughness length has a minimal effect on the prediction of wind speed. That is probably because the influence of roughness length is related to the height and the height of measurement points is too low to give a difference.

\subsubsection{Effects of turbulence model}

The purpose of exploring the effects of turbulence models is to identify the recommended model. Figure 31 shows the effect of turbulence models. The graphs show the comparison between wind predictions by OpenFOAM with two kinds of turbulence models and wind tunnel measurements recorded by the AIJ. The agreement between graphs of RNG k-Epsilon turbulence model and the wind tunnel is not as good as the graphs of k-Epsilon turbulence model with the wind tunnel. The trends of kEpsilon turbulence model and RNG k-Epsilon turbulence model match each other quite well, but RNG k-Epsilon turbulence model enlarges the peak data. The k-Epsilon turbulence model under-predicts the wind speed. Compared with k-Epsilon turbulence, the RNG k-Epsilon turbulence model under-predicts the wind speeds, while, in some areas over-predicts the wind speed, such as in No.3 Downdraught Effect area at $0^{\circ}$ and $22.5^{\circ}$, and in No.1 Upstream Flow area at $45^{\circ}$. The RNG k-Epsilon turbulence model enlarges the wind speed in some areas. Turbulence model has different effect on wind speed prediction in different flow feature areas. The k-Epsilon turbulence model 
matches better than the RNG k-Epsilon turbulence model. Hence, the k-Epsilon turbulence model is recommended.

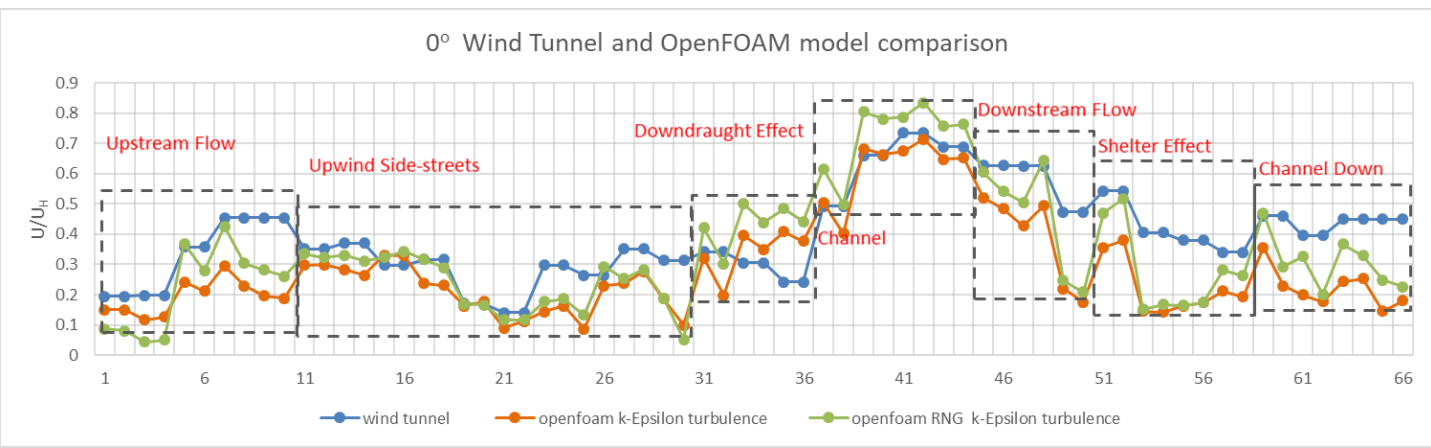

(a)

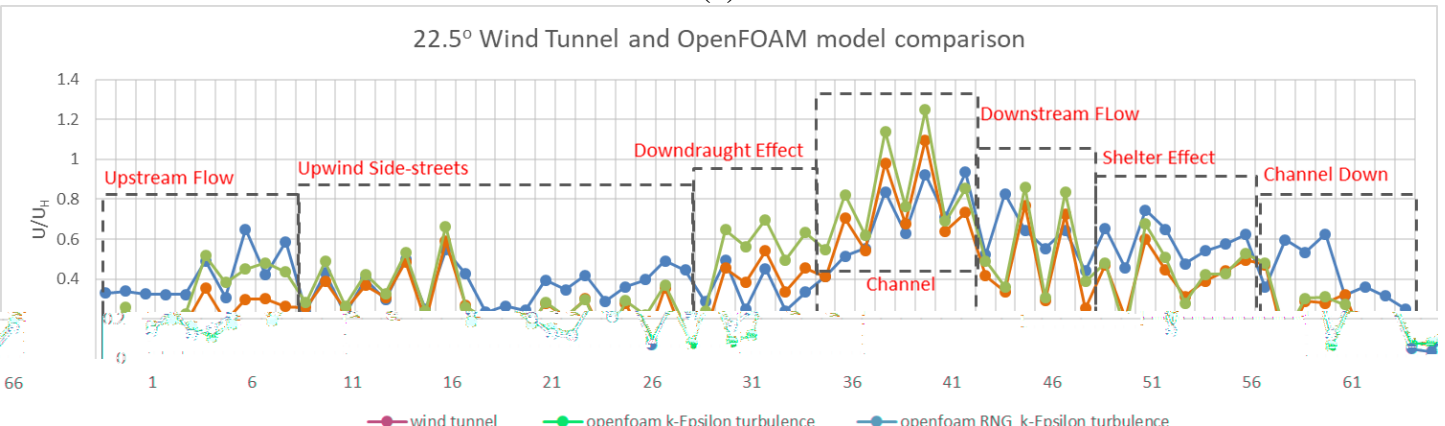

(b)

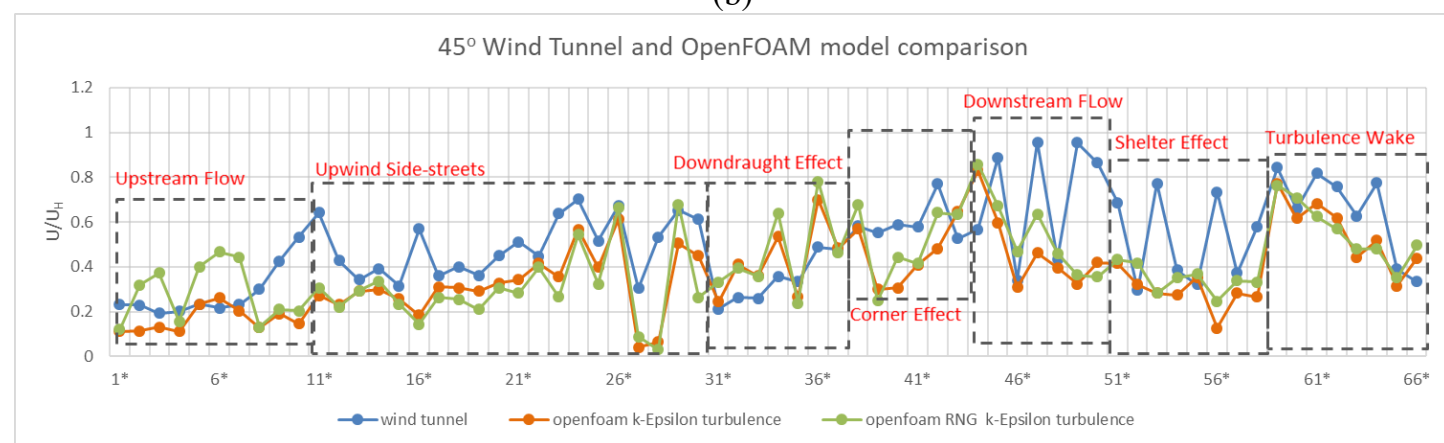

(c)

Figure 31: Comparison of wind speed ratios for different turbulence models

\subsubsection{Summary of the analysis of flow around a high-rise building in a multi- block model}

20 measurement points around a high-rise building and their serial number at $0^{\circ}, 22.5^{\circ}$ and $45^{\circ}$ are shown in Figure 32. The predictions of measurement points just around the building were analysed because it reflects the small scale of the wind environment. This thesis was about the influence of microclimate on building performance. The simulation of wind environment around buildings is an important part of this research. At $0^{\circ}$ or $22.5^{\circ}$, the measurement points around the high-rise building were $31-50$, and at $45^{\circ}$, the measurement points were $31 *-50 *$. 


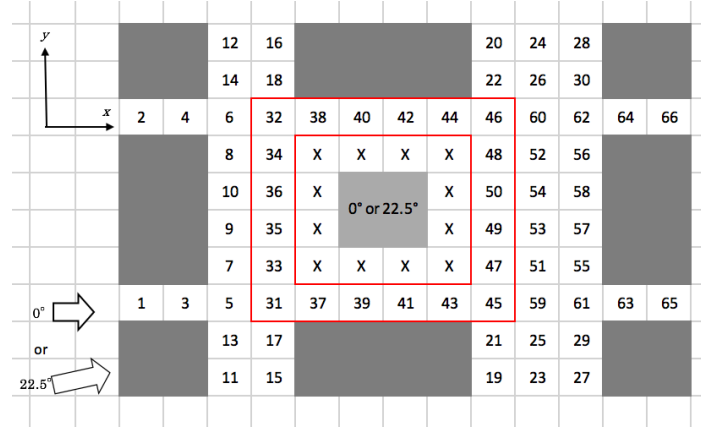

(a)

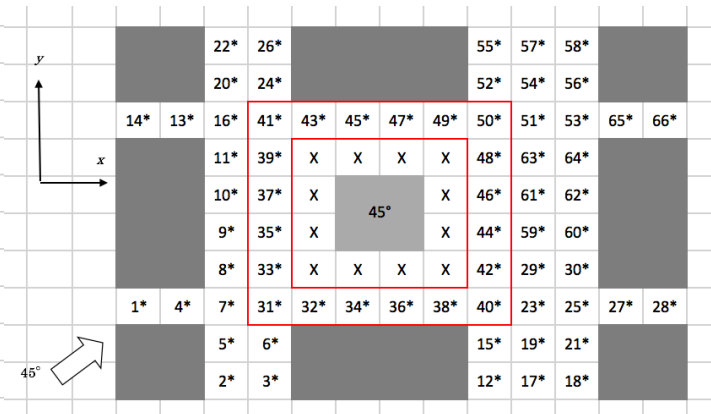

(b)

Figure 32: Measurement points around central building: (a) $0^{\circ}$ or $22.5^{\circ}$ with $31-50$ and (b) $45^{\circ}$ with $31 *_{-}-50 *$

In Figure 33, the CFD graphs mostly match the shape of the wind tunnel graph in the windward direction. It suggests that the right flow features are modelled. In the wake area, the gap between the graphs becomes larger.

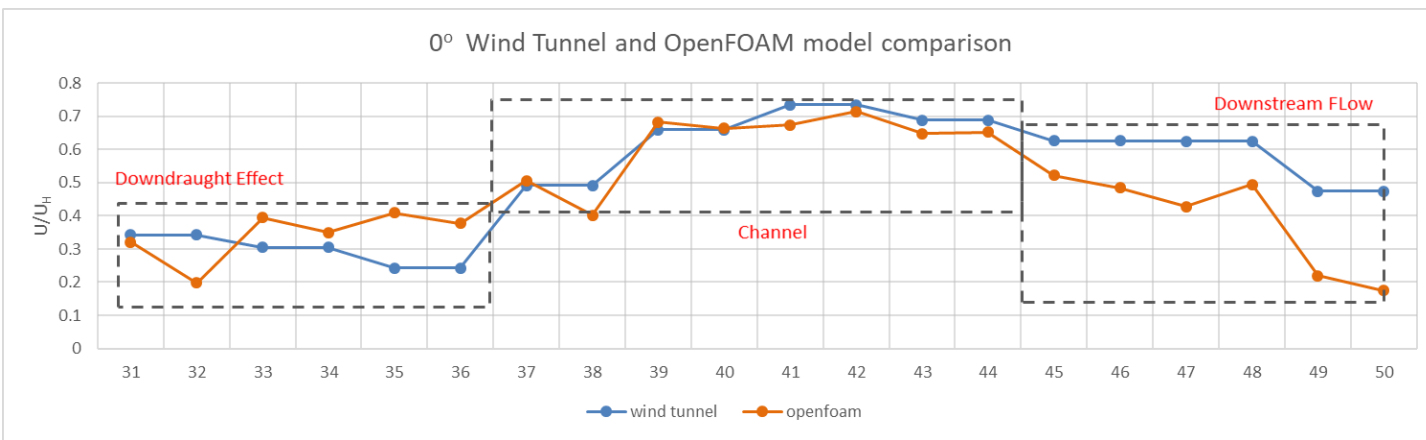

(a)

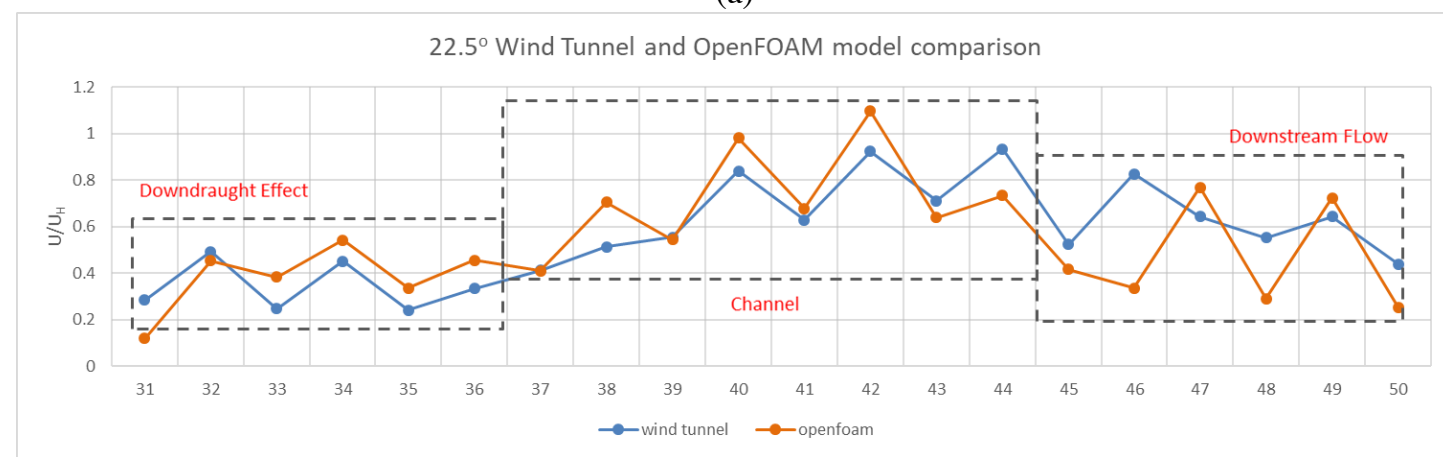

(b)

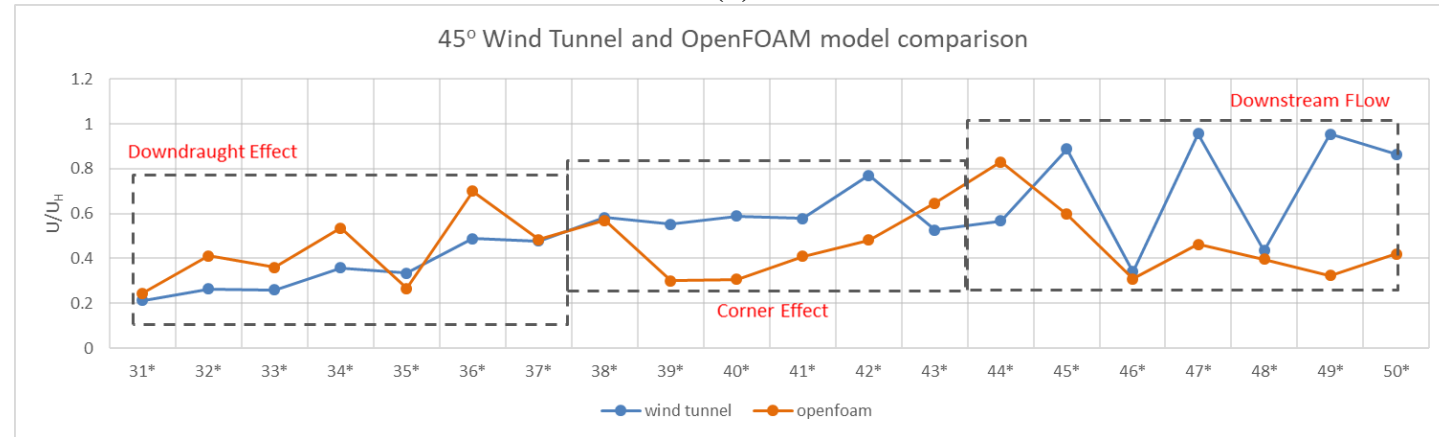

(c)

Figure 33: Comparison of wind speed ratio predictions around the central block

The CFD graph (Figure 33) matches the shape of the wind tunnel graph quite well at $0^{\circ}$ and $22.5^{\circ}$. The predictions are smaller than wind tunnel results in the Downstream Flow 
area. The CFD graph at $45^{\circ}$ is not as perfect as at $0^{\circ}$ and $22.5^{\circ}$, but the main tendency matches except a few under-predicted points. Figure 34 shows a similar conclusion as Figure 33, because the red spots are less scattered than the green spots, and the green spots are less scattered than the yellow spots. When the spots are closer to the dashed line, it means values from OpenFOAM match with values from Wind Tunnel. The equation shows that at $0^{\circ}$ OpenFOAM is $73.7 \%$ of wind tunnel, at $22.5^{\circ} 83.9 \%$, and at $45^{\circ}$ only $14.4 \%$. The red and green spots match better than yellow spots. That means OpenFOAM matches wind tunnel at $0^{\circ}$ and $22.5^{\circ}$ much better than $45^{\circ}$.

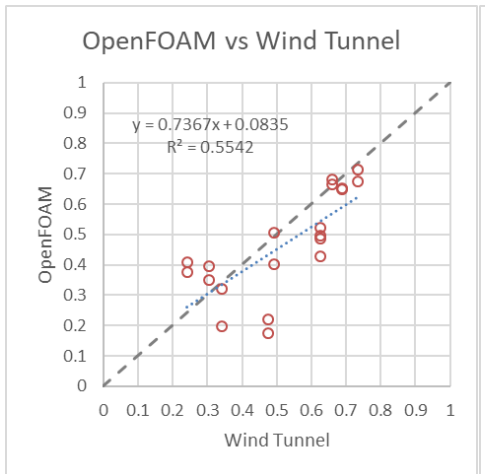

(a) $0^{\circ}$

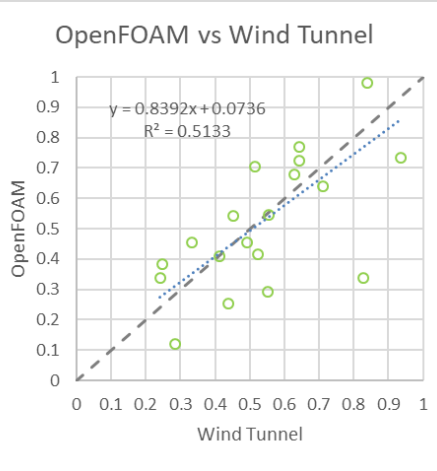

(b) $22.5^{\circ}$

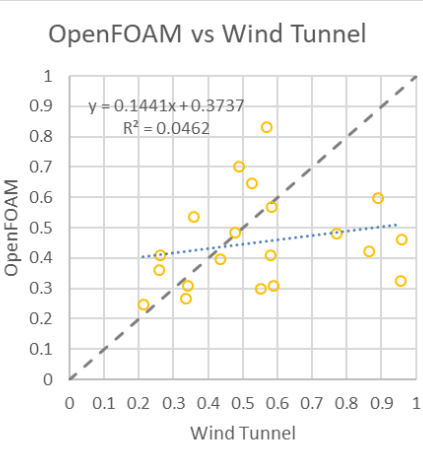

(c) $45^{\circ}$

Figure 34: Comparison of test points around the central block

In summary, the wind speed calculated by OpenFOAM matches well with wind tunnel results in the non-wake areas, not well in the wake area. OpenFOAM predicts the wind speed at $0^{\circ}$ and $22.5^{\circ}$ better than at $45^{\circ}$. Meshing of refinement level 2 and the k-Epsilon turbulence model are highly recommended because their simulations are less inaccurate. The roughness length has a minimal effect on the prediction of wind speed at a low height, because the effect only apparent when the height is sufficient. Overall, the wind speed modelled by OpenFOAM can be trust, except the simulation in the wake area.

\subsection{Verification of Wind Pressure Coefficient Prediction with OpenFOAM}

\subsubsection{Methodology}

The verification of wind speed prediction is for urban wind simulation. In this section, the wind pressure coefficient perdition is verified. The wind pressure coefficients are the inputs for the detailed natural ventilation modelling. The wind pressure coefficients around the high-rise office building can address the surrounding environment.

The verification of the wind pressure coefficient model was similar to that of the wind speed model. The simulation results of wind pressure coefficient from OpenFOAM 
were compared with the experiment data of wind tunnel. Experimental data is from the paper "Comparison of Measurements on the CAARC Standard Tall Building Model In Simulated Model Wind Flows" (Melbourne, 1980).

That paper provided six sets of experimental information made by six establishments. Only two of them did the experiment in seven directions. The six groups of values were compared with each other, and the maximum and minimum values were taken. Comparing those two experimental results, the results of the National Aeronautical Establishment are less extreme. Therefore, the experimental model of National Aeronautical Establishment was taken as the comparative model. The simulation model was set with its parameters and their results were compared with each other.

OpenFOAM can directly output wind speed, wind pressure and wind pressure coefficient and other information. However, the default outputs from the butterfly plugin are only wind speed and wind pressure without wind pressure coefficient. If the wind pressure coefficient is required, additional inputs of the Function Objects are added before simulation.

The additional Function Objects inputs for wind pressure coefficients was based on the OpenFOAM. According to the OpenFOAM Code Guide, the pressure function object provides several calculation methods (OpenFOAM Introduction, 2018), including:

- $\quad$ static pressure, $p$ :

$$
p=\rho p_{k}
$$

- $\quad$ total pressure, $p_{0}$ :

$$
p_{0}=p_{r e f}+p+0.5 \rho|\boldsymbol{U}|^{2}
$$

- $\quad$ static pressure coefficient, $C_{p}$ :

$$
C p=\frac{p-p_{\text {inf }}}{0.5 \rho_{\text {inf }}\left|\boldsymbol{U}_{\text {inf }}\right|^{2}}
$$

- $\quad$ total pressure coefficient, $C p_{0}$ :

$$
C p_{0}=\frac{p_{0}-p_{i n f}}{0.5 \rho_{\text {inf }}\left|\boldsymbol{U}_{\text {inf }}\right|^{2}}
$$

Where

$\rho \quad=\quad$ Density $[\mathrm{kg} / \mathrm{m} 3]$ 


$$
\begin{array}{lll}
U & = & \text { Velocity }[\mathrm{m} / \mathrm{s}] \\
\rho_{\text {inf }} & = & \text { Freestream density }[\mathrm{kg} / \mathrm{m} 3] \\
p_{\text {inf }} & = & \text { Freestream pressure }[\mathrm{Pa}] \\
U_{\text {inf }} & = & \text { Freestream velocity }[\mathrm{m} / \mathrm{s}] \\
p_{k} & = & \text { Kinematic pressure }(\mathrm{p} / \mathrm{rho})[\mathrm{m} 2 / \mathrm{s} 2] \\
p & = & \text { Pressure }[\mathrm{Pa}] \\
p_{0} & = & \text { Total pressure }[\mathrm{Pa}] \\
p_{r e f} & = & \text { Reference pressure level }[\mathrm{Pa}] \\
C p & = & \text { Pressure coefficient } \\
C p_{0} & = & \text { Total pressure coefficient }
\end{array}
$$

The static pressure coefficient $C_{p}$ is calculated by the butterfly plugin of OpenFOAM.

\subsubsection{Model description}

\subsubsection{The wind tunnel experimental model}

To validate the wind pressure coefficient prediction by OpenFOAM, the prediction was compared with the results of wind tunnel experiment. According to Melbourne's paper, six centres conducted wind tunnel experiments on the CAARC Standard Tall Building Model (Melbourne, 1980). They compared different natural winds in different wind tunnels to help improve the technique. The CAARC Standard Tall Building Model consisted of a rectangular block $(30.5 \mathrm{~m} \times 45.7 \mathrm{~m} \times 182.9 \mathrm{~m})$ in the centre (Figure 35). The comparative experiment was carried out at the National Aeronautical Establishment. The inflow velocity at the height of $182.9 \mathrm{~m}$ was $15 \mathrm{~m} / \mathrm{s}$. Test points were at $2 / 3$ height of the block. The power-law exponent of the boundary layer of this research was around 0.28 (Melbourne, 1980). There was a range of wind directions between $0^{\circ}$ and $90^{\circ}$, at $15^{\circ}$ intervals. 


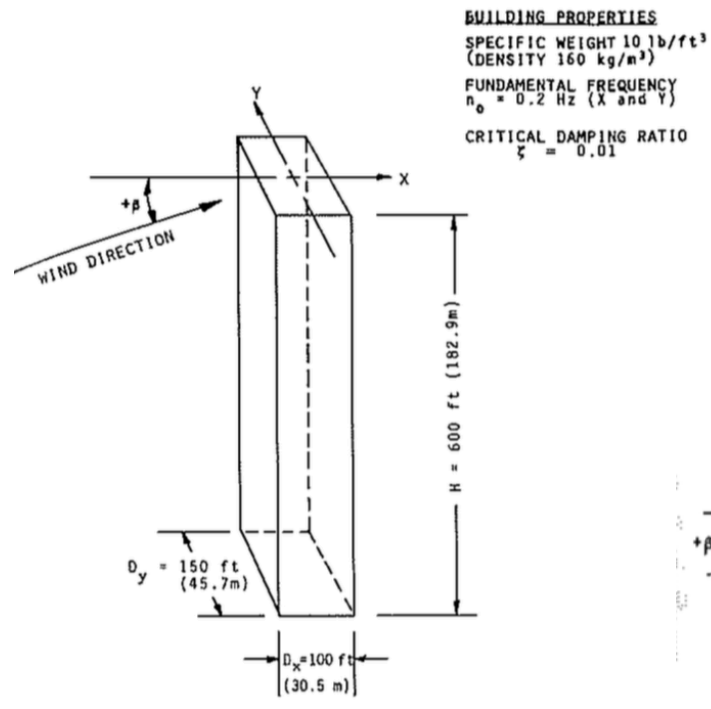

(a)

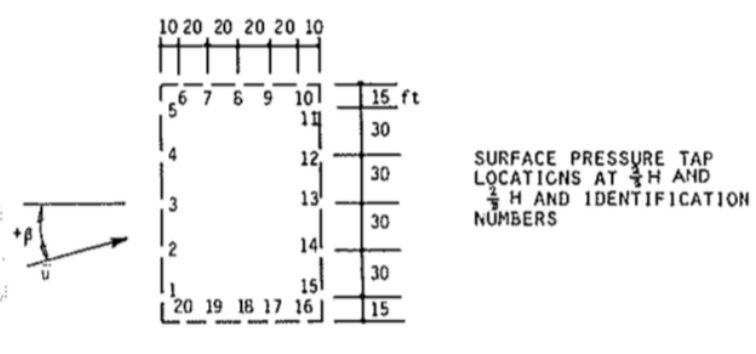

(b)

Figure 35: CAAR stand tall building: full-scale dimensions, dynamic properties and pressure tap location (Melbourne, 1980).

\subsubsection{The numerical CFD model}

In the OpenFOAM simulation, the model is in real size. The prototype model was based on the experimental condition of the CAARC Standard Tall Building Model (Melbourne, 1980). Table 15 gives the modelling condition parameters. A high-rise building (30.5m x $45.7 \mathrm{~m} \times 182.9 \mathrm{~m})$ was modelled, and the wind pressure coefficients of 20 test points at $2 / 3$ height of the building was measured. The wind speed was 15 $\mathrm{m} / \mathrm{s}$, and wind directions were from $0^{\circ}$ to $90^{\circ}$ in $15^{\circ}$ steps (Table 15 ). The OpenFOAM simulation results were compared with the wind tunnel measured data by the National Aeronautical Establishment and the maximum and minimum experimental values of the six wind tunnel experiment centres.

Table 15: Basic parameters of the simulation condition for wind pressure coefficients model

\begin{tabular}{l|l}
\hline $\begin{array}{l}\text { Basic condition for prototype } \\
\text { model }\end{array}$ & Values \\
\hline $\begin{array}{l}\text { Inflow velocity at } 182.88 \mathrm{~m}(600 \\
\text { ft) height (Building Height) }\end{array}$ & $15 \mathrm{~m} / \mathrm{s}$ \\
\hline Wind direction & $0^{\circ}, 15^{\circ}, 30^{\circ}, 45^{\circ}, 60^{\circ}, 75^{\circ}, 90^{\circ}$ \\
\hline Measurement points height $(\mathrm{z})$ & $121.92 \mathrm{~m}(2 / 3$ Building Height) \\
\hline $\begin{array}{l}\text { Landscape (Based } \\
\text { OpenFOAM standard) }\end{array}$ & $\begin{array}{l}4>^{\prime} 0.25^{\prime} \text { \# rough. Cultivated or natural area with high } \\
\text { crops or crops of varying height, and scattered obstacles } \\
\text { at relative distances of } 12-15 \text { obstacle heights for porous } \\
\text { objects (e.g. shelterbelts) or 8-12 obstacle heights for low } \\
\text { solid objects (e.g. buildings). }\end{array}$ \\
\hline Turbulence model & k-Epsilon model \\
\hline Meshing & $\begin{array}{l}\text { X axis percentage length }(20 \%, 10 \%, 70 \%) \\
\text { percentage cells (10\%, 70\%, 20\%) }\end{array}$ \\
\hline
\end{tabular}




\begin{tabular}{l|l}
\hline & $\begin{array}{l}\text { Y axis percentage length }(45 \%, 10 \%, 45 \%) \\
\text { percentage cells }(10 \%, 80 \%, 10 \%) \\
\text { Z axis percentage length }(60 \%, 40 \%) \\
\text { percentage cells }(90 \%, 10 \%)\end{array}$ \\
\hline The cell size & $(100,50,30)$ \\
\hline Refinement level & 2 \\
\hline Computational domain & $\begin{array}{l}\text { Windward extension: } 8 \text { times } \\
\text { Top extension: } 6 \text { times } \\
\text { Sides extension: } 8 \text { times } \\
\text { Leeward extension: } 25 \text { times }\end{array}$ \\
\hline
\end{tabular}

This computational domain (Table 15) is bigger than that for wind speed verification (Table 13) because this wind tunnel needs to obtain data of freestream pressure and freestream velocity. The freestream height expands the scope of the model. Figure 36 shows the meshing of the wind tunnel.

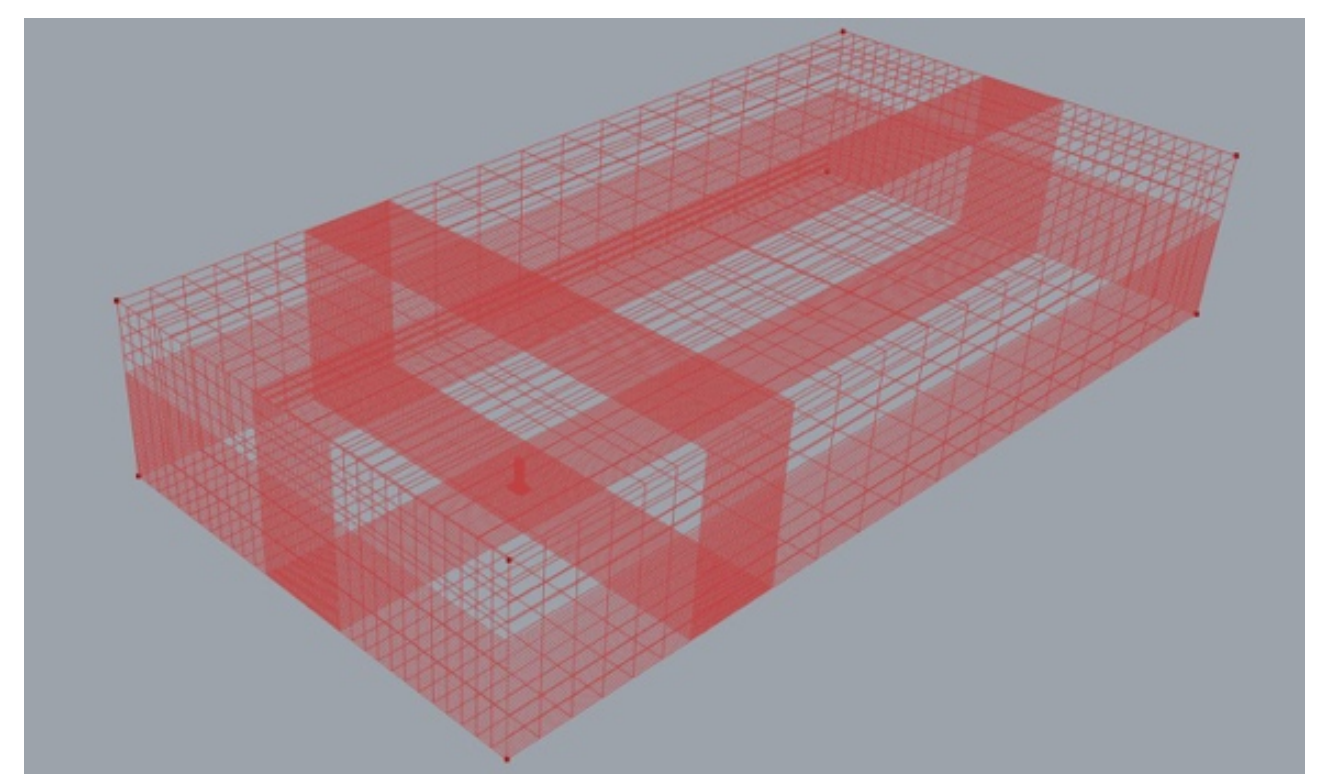

Figure 36: Meshing of the numerical wind tunnel of CAAR stand tall building using OpenFOAM

Figure 37 shows the CAARC standard tall building meshing and the locations of test points. The grids around the standard tall building and test points are denser than other areas. The density of grids decreases with distance away from central building and test points. 
Figure 37: Meshing of CAARC standard tall building and 20 test points

\subsubsection{The pressure coefficient strings for function objects set-up}

Before simulating the wind pressure coefficient, it is necessary to calculate the freestream pressure and freestream velocity. In this study, the freestream height is 1000 $\mathrm{m}$ (Sokhi, 2012), and the pressure and velocity of a point in windward direction was measured at the height of $1000 \mathrm{~m}$. The wind tunnel model was run without a function object set-up to get the freestream pressure and freestream velocity. The remaining settings for the freestream pressure and velocity simulation were the same as for the pressure coefficient simulation. The wind came from the X-axis, and the speed was 15 $\mathrm{m} / \mathrm{s}$ at $182.88 \mathrm{~m}$ height. The outputs of the wind tunnel simulation were wind speed (U) and wind pressure $(\mathrm{p})$.

According to the simulation results, the freestream velocity (UInf) is $33.43 \mathrm{~m} / \mathrm{s}$ (around $120 \mathrm{~km} / \mathrm{h}$ ) and the freestream pressure (pInf) is $26.77 \mathrm{~Pa} .1 .29 \mathrm{~kg} / \mathrm{m} 3$ was taken as the freestream density (rhoInf). These values were imported into the pressure coefficient calculation, and the additional string for the function object setting is shown in Figure 38. 


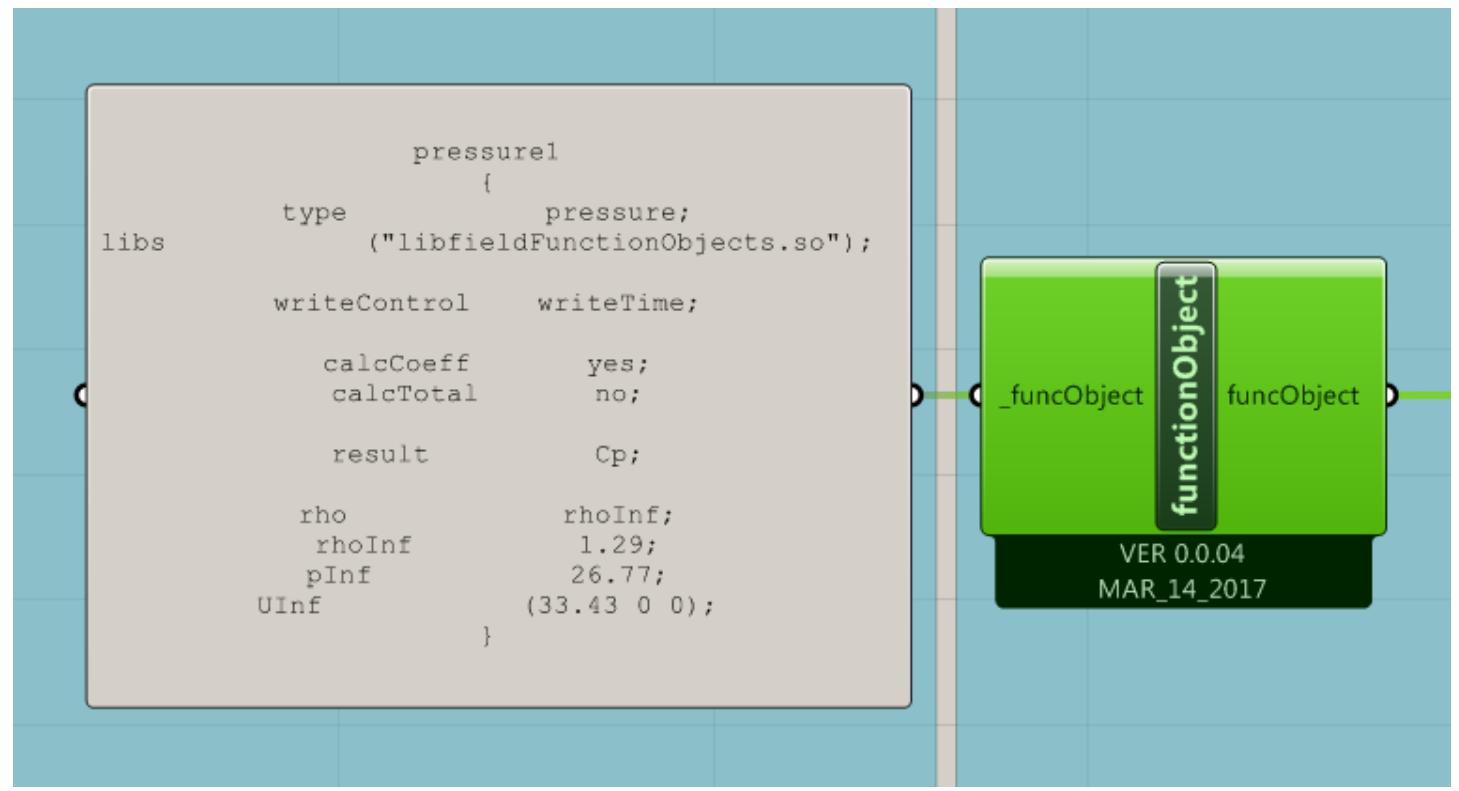

Figure 38: Pressure coefficient calculation strings for the function object

\subsubsection{The comparison of analysis results}

The wind pressure coefficients $(\mathrm{Cp})$ of the CAARC standard tall building were collected in seven directions. The measurement wind tunnel data of six research centres was collated. Red curves are the maximum absolute values and grey curves are minimum absolute values. The values from the OpenFOAM numerical simulation (green curves) were compared with the experimentally measured values from the National Aeronautical Establishment (blue curves). Figure 39 shows seven groups of data of seven wind directions. Experimental data and simulation results are curves of four colors respectively.

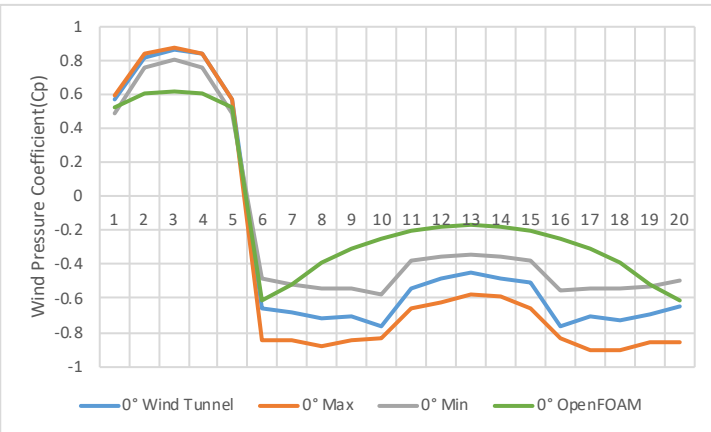

(a)

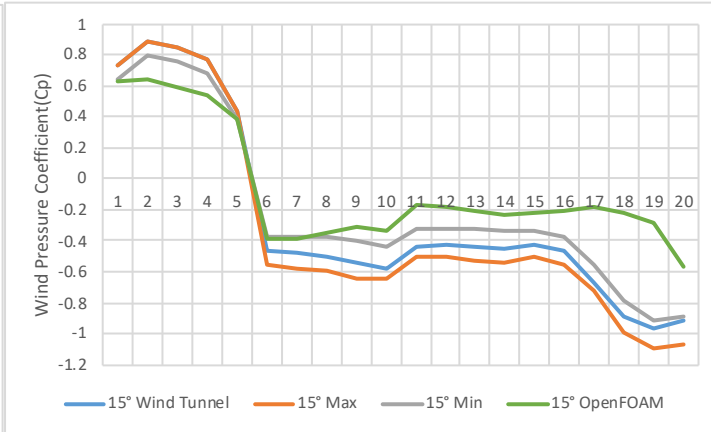

(b) 


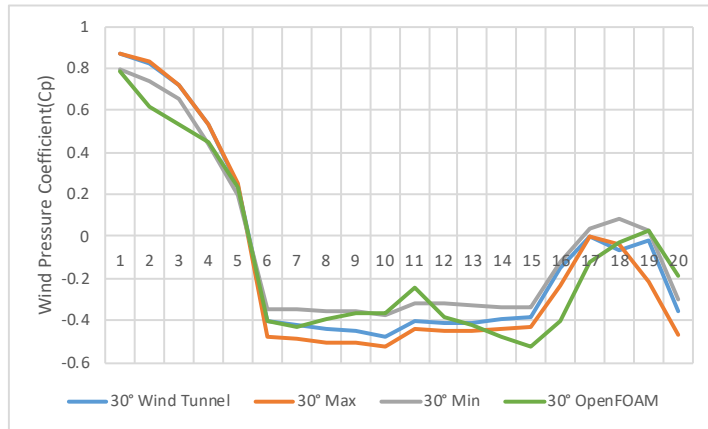

(c)

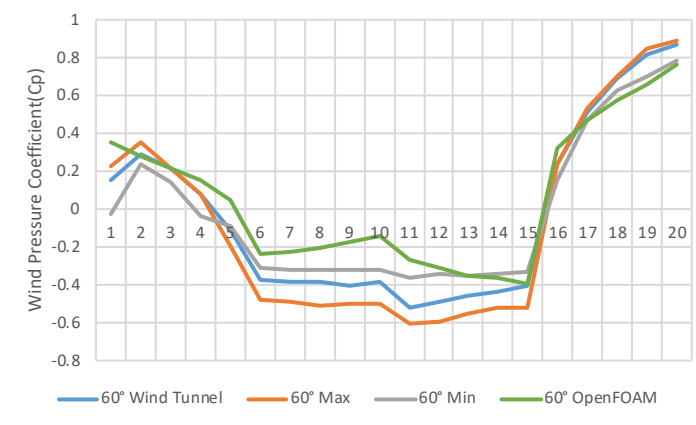

(e)

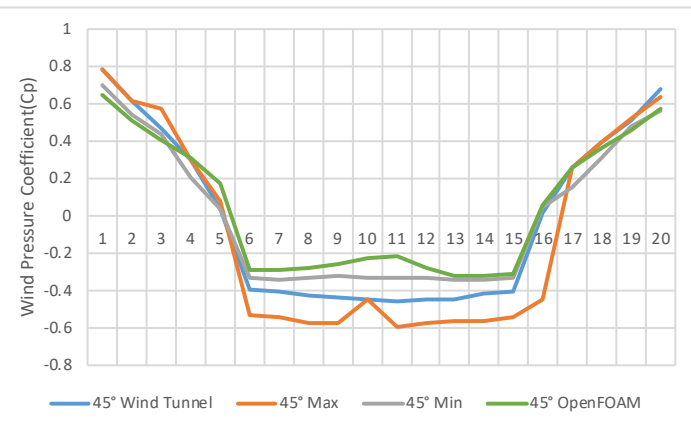

(d)

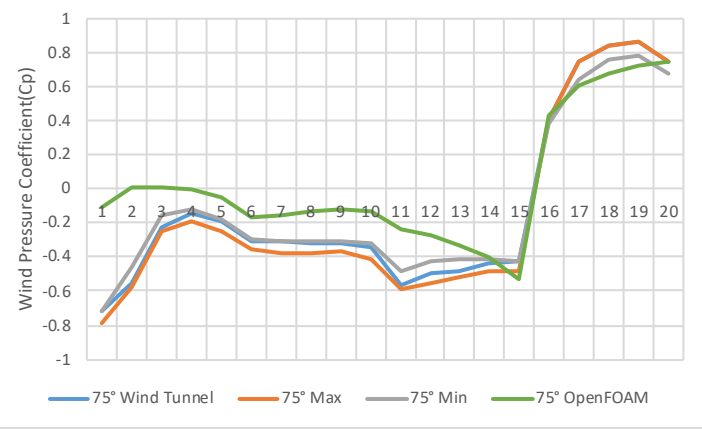

(f)

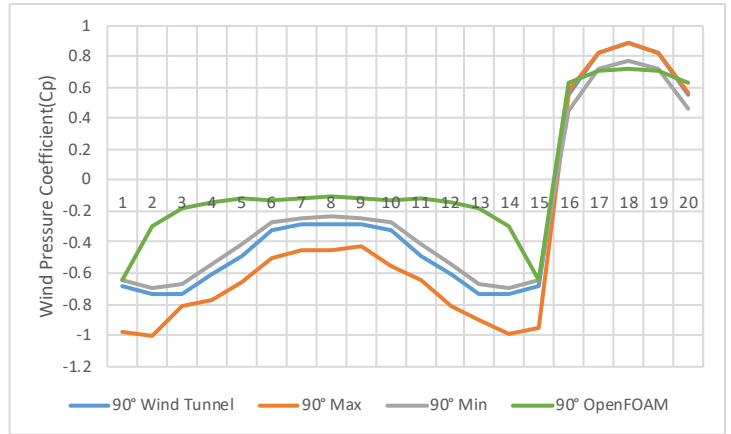

(g)

Figure 39: Comparison of wind pressure coefficients at different wind direction

Figure 39 shows that the overall trends of curves match each other, especially for (c) (d) and (e). In all seven figures from (a) to (g), the blue curves of wind tunnel measured data from National Aeronautical Establishment is between the red curves and grey curves, which means the absolute values are between the max and min values. The green curves are much closer to the 0 -horizontal line, which means the absolute values of OpenFOAM numerical results are smaller than experimental data.

In Figure 39 (a), when the wind blows from $0^{\circ}$ direction, the prediction is not good in the upwind side areas and shelter effects areas, because point 8 to point 18 values do not match well with the measured data. Figure $39(\mathrm{~g})$ is almost the mirror image of (a). Figure 39 (b) and (f) are mirror images of each other. When the wind blows from the direction of $15^{\circ}$ or $75^{\circ}$, the OpenFOAM curves match well in the upwind areas, but the values are underestimated in the other areas. Figure 39 (c) (d) and (e) show a perfect 
match, except point 11 . Point 11 is in the shelter effect area, and the gap of point 11 is small.

In Figure 40, the values of $\mathrm{R}^{2}$ are more than $87 \%$ and the trend lines are reliable. Wind pressure coefficients of OpenFOAM are $60 \%$ to $85 \%$ of wind tunnel values. The OpenFOAM at $30^{\circ}$ has the best consistency with the wind tunnel, and the worst at $15^{\circ}$.

The trends of the OpenFOAM simulation results are basically consistent with that of wind tunnel data. However, the absolute values of the simulation results are smaller than the experimental data.

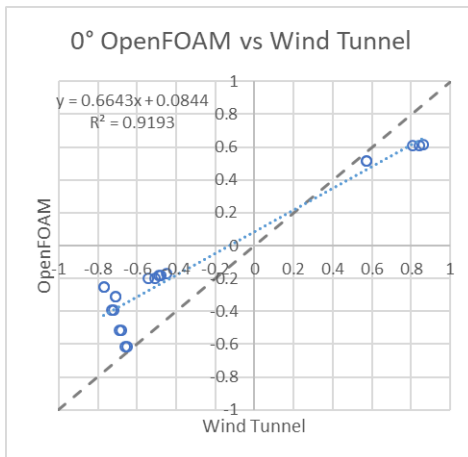

(a)

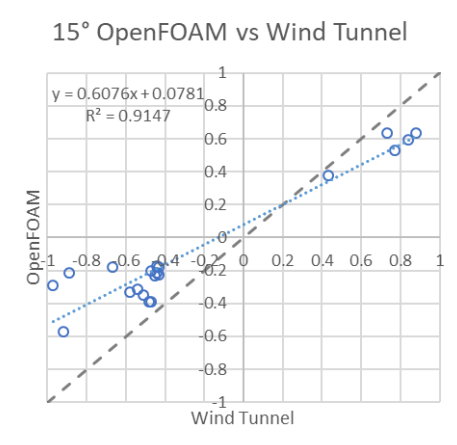

(b)

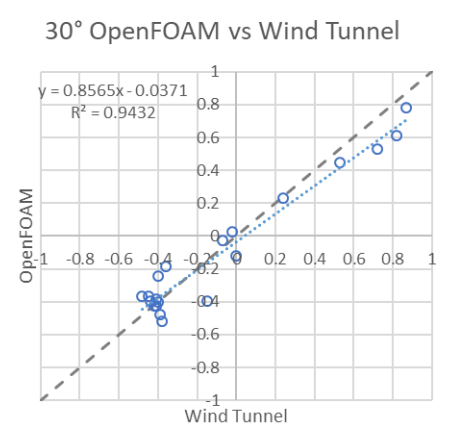

(c)

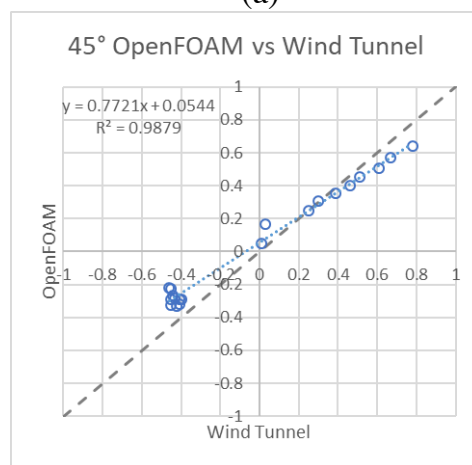

(d)

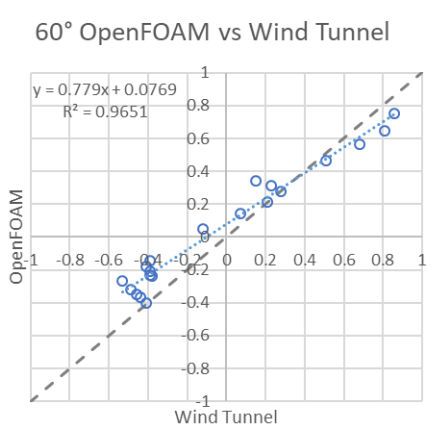

(e)

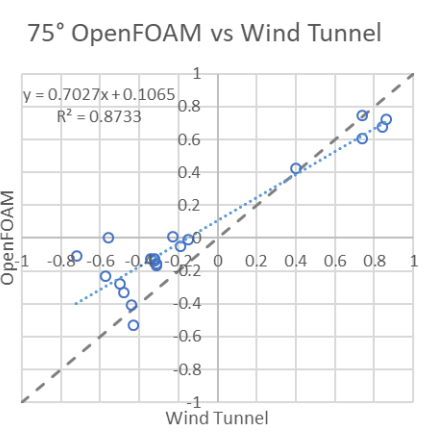

(f)

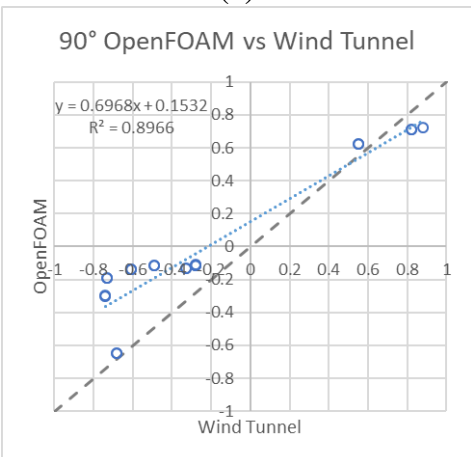

(g)

Figure 40: Wind pressure coefficients comparison between OpenFOAM and Wind Tunnel 


\subsection{Verification of Urban Heat Island Effects Modelling with Urban Weather Generator}

A building energy performance can be influenced by Urban Heat Island (UHI) effects. This influence is due to temperature changes in urban and rural areas. In Crawley's study, the impact of the UHI effect on a small office building is between $5 \%$ and $10 \%$ of energy consumption. Cooling energy consumption increases in summer and heating energy demand decreases in winter (Crawley, 2008).

\subsubsection{Methodology}

To test and verify the trustworthiness of Urban Weather Generator (UWG), the UHI effects of a large city modelled by UWG was compared with the real data. In this part of the research, London is used as a case study. London is a big city, with significant UHI effect that is well researched (Kolokotroni \& Giridharan, 2008; Watkins et al., 2002). Measured data on UHI effects are available for London and Geographic Information Systems (GIS) data of the City of London is available. GIS data of the City of London was made available by the UCL (University College London) Energy Institute. A three-dimensional model of a city is necessary for UHI modelling.

The modelled area was not Greater London, which spans more than $1500 \mathrm{~km}^{2}$. Most of the $1500 \mathrm{~km}^{2}$ is suburban and rural areas, and these areas do not have significant UHI effects. UHI effects increase with proximity to the city centre. The City of London was rebuilt and modelled to represent the urban form of London. Apart from having access to buildings data of the City of London, the City of London was chosen as the UHI modelling area because of its typical urban form. The buildings' heights cover a wide range in that region, from $20 \mathrm{~m}$ low-rise buildings to $200 \mathrm{~m}$ high-rise buildings. Furthermore, it is the centre of London where the UHI effects are much greater than in other areas. The red area in the middle of Figure 41 is the UHI modelling area, the City of London. 


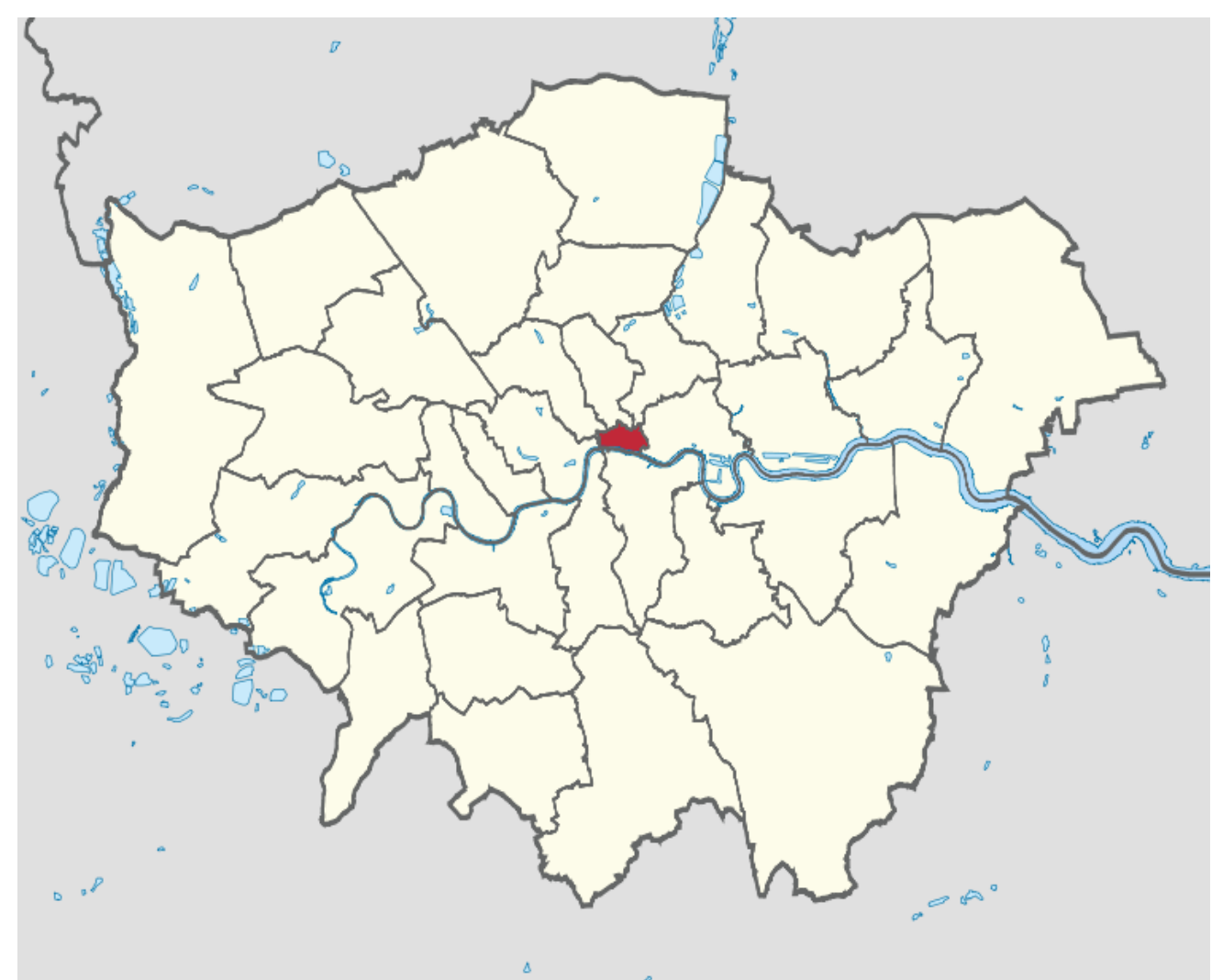

Figure 41: City of London (red area) in Greater London (TUBS, 2011)

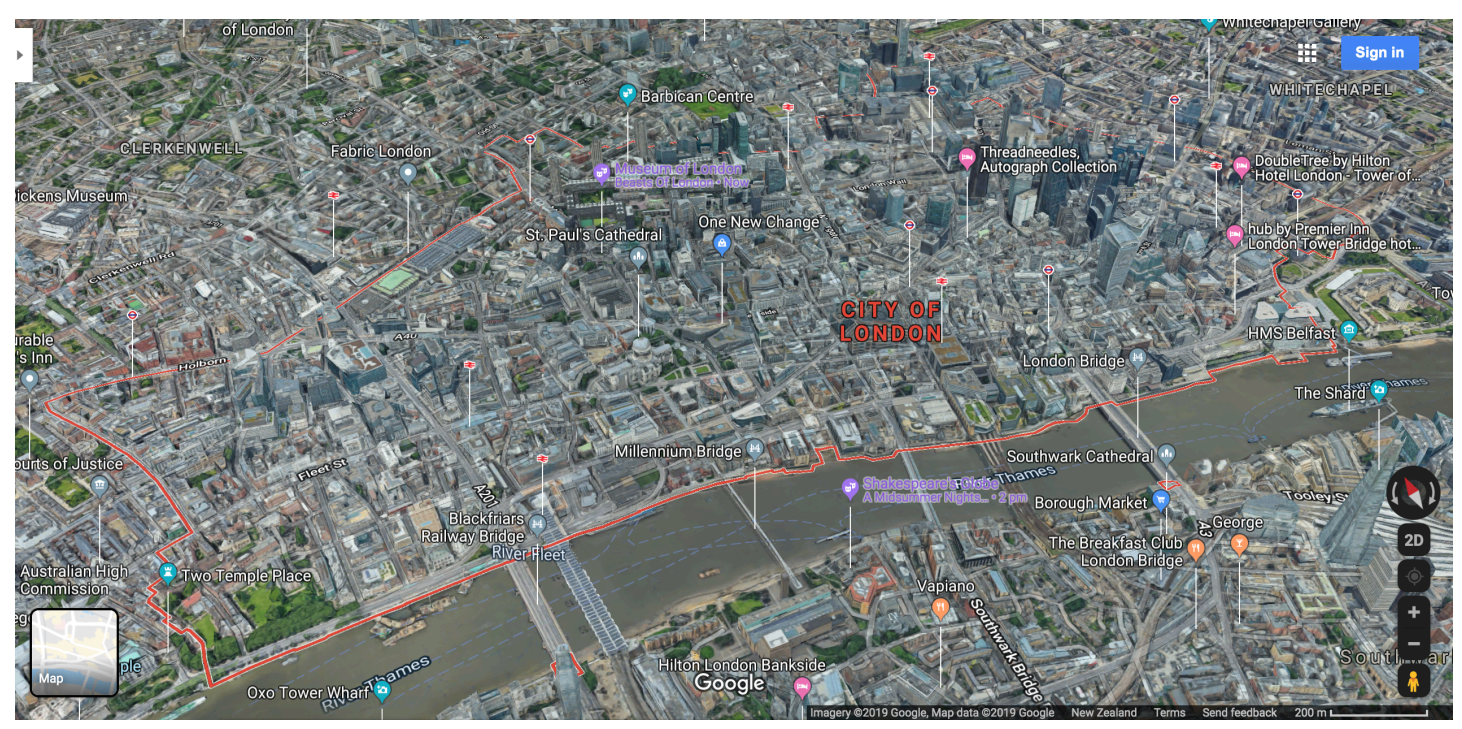

Figure 42: three-dimensional City of London from Google map (Google Maps, 2019)

From Figure 42, it can be seen that the City of London is densely populated with tall buildings. Figure 43 is a three-dimensional model of building blocks in City of London reconstructed using GIS data. GIS data of City of London is provided by the UCL (University College London) Energy Institute. The three-dimensional model is used for UHI calculation. 


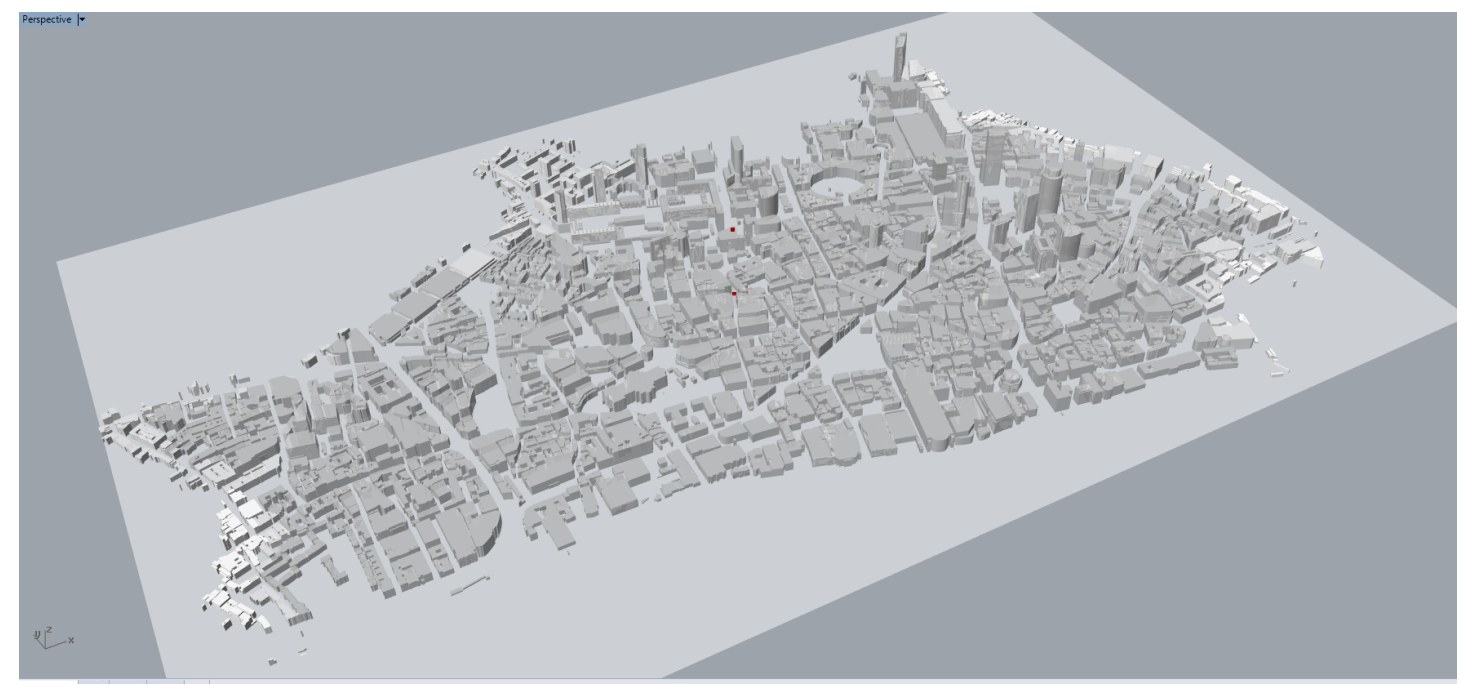

Figure 43: City of London from GIS model

\subsubsection{Model description}

To verify the reliability of Urban Weather Generator (UWG) modelling, the estimated simulation results from UWG were compared with measured London UHI. The key to model UHI with Urban Weather Generator is to define UWGCity. UWGCity is a city whose multi-parameter for UHI calculation is defined by Urban Weather Generator (UWG) program. In general, there are three methods to define UWGCity. The first method is to define the typology of each building, when the shape and typology information of each building are accessible, which is appropriate for small-scaled cities. The second method is to define UWGCity by the buildings' footprint. The footprint of buildings is 2-dimensional information, lacking the buildings' height. This method is suitable for the city with uniform building shape. Meanwhile, the typologies of buildings' footprint are accessible. The third method is using typological ratio to define UWGCity. This method is applicable to a big-scaled city whose three-dimensional information is available, and typology information is not. This study chose the third method because of not only the large urban size, but also because of the lack of typology information of each building.

To model the UHI in London with UWG, the parameters for the buildings of London are necessary. According to GIS data of the City of London, the three-dimensional blocks were generated. Firstly, building blocks were imported into the UWG. Secondly, urban typologies and the ratio of each typology in the urban area were used to define the UWGCity. In this section, there are two urban typologies, residential typology and commercial typology. The ratios of residential and commercial typology were set as 
0.4 and 0.6 , respectively. In addition to information on buildings, information on pavement, coverage of trees and grass, and traffic conditions was also included in the UWGCity. Finally, run the simulation and get the new weather file for London urban areas in EPW format.

\subsubsection{The comparison of analysis results}

After four hours of calculations, a new version of the London weather file, taking UHI effects into account, had been generated. The original air temperature was collected from the weather station at Gatwick airport, which is far from the urban area of London. The revised urban air temperature was compared with the original suburb air temperature. The UHI is the temperature difference between the City of London and Gatwick Airport. In Figure 44, the average air temperature in the city is always higher (around 10\%) than that in the rural areas, and the temperature gap is especially significant in July and August. The average values of every day's UHI in each month are between $0.8^{\circ} \mathrm{C}$ and $1.8^{\circ} \mathrm{C}$ and remains stable.

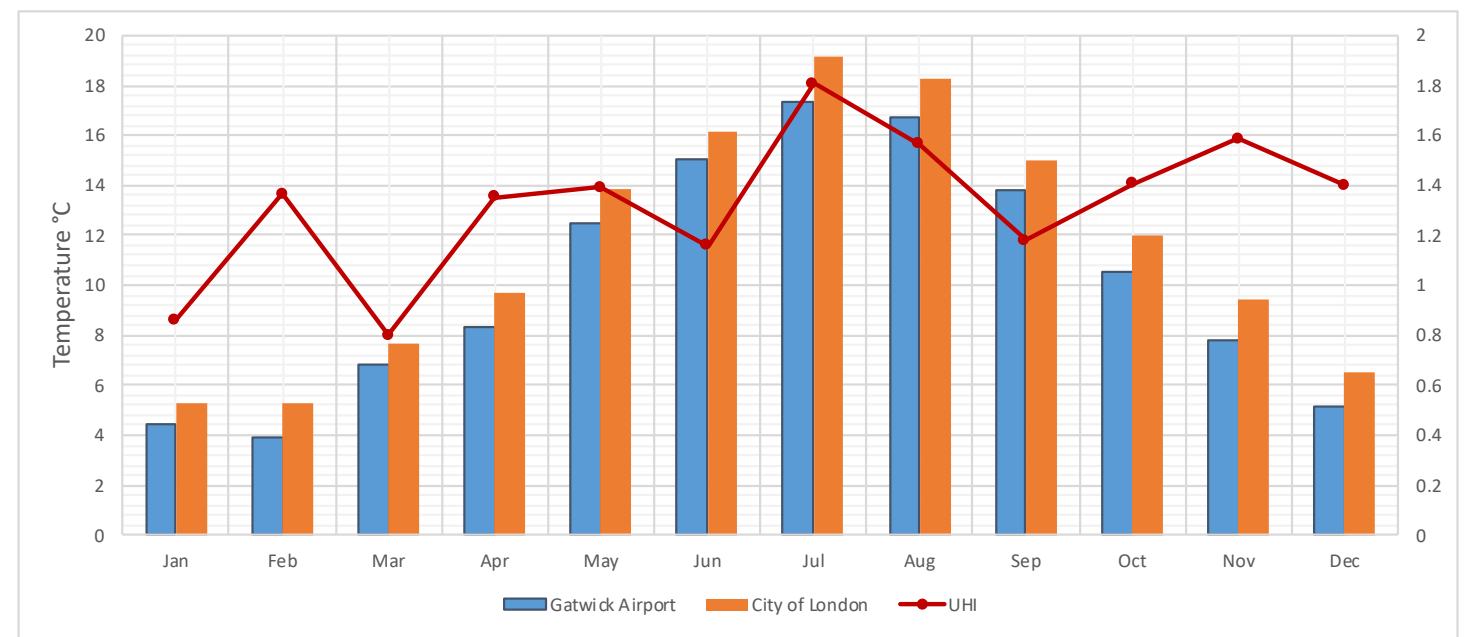

Figure 44: Average air temperature and UHI of London

The hottest week in London is August, and the highest UHI is also in August. Hence, taking August as an example, the maximum, minimum and average values of UHI effects in London are shown in Figure 45. The daily average and minimum UHI values are slightly different. The average UHI values range from $0{ }^{\circ} \mathrm{C}$ and $3.15^{\circ} \mathrm{C}$, and the minimum daily UHI values in August range from $-2.1{ }^{\circ} \mathrm{C}$ and $0.2^{\circ} \mathrm{C}$. While, the lowest $\mathrm{UHI}$ value is $0.8^{\circ} \mathrm{C}$ and the highest is $8.3^{\circ} \mathrm{C}$, with a difference of ten times. 


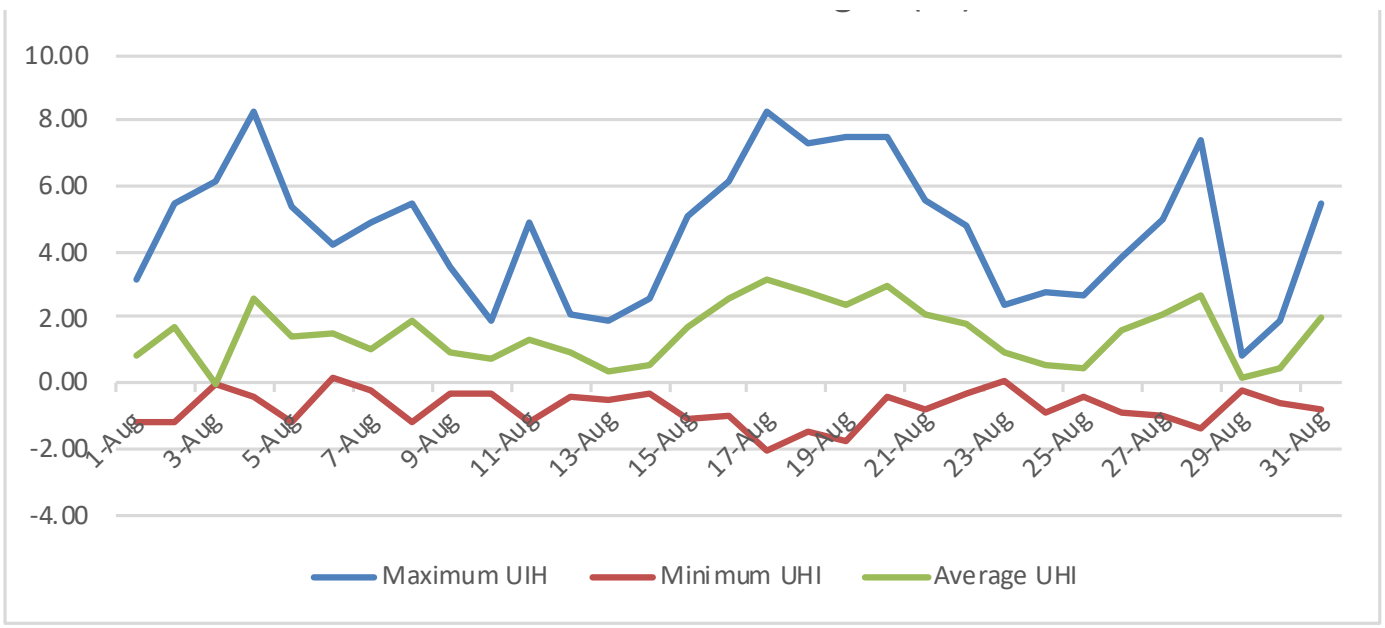

Figure 45: Maximum, minimum and average London UHI in August $\left({ }^{\circ} \mathrm{C}\right)$

Figure 45 shows the highest UHI happened twice in the whole year, on $4^{\text {th }}$ and $17^{\text {th }}$ August respectively. Taking $4^{\text {th }}$ and $17^{\text {th }}$ August as examples, the UHI hourly change is shown in Figure 46. The highest UHI on both days is $8.3^{\circ} \mathrm{C}$ at 5:00 am (Figure 46). UHI effects increase in the afternoon and peak in the early morning.

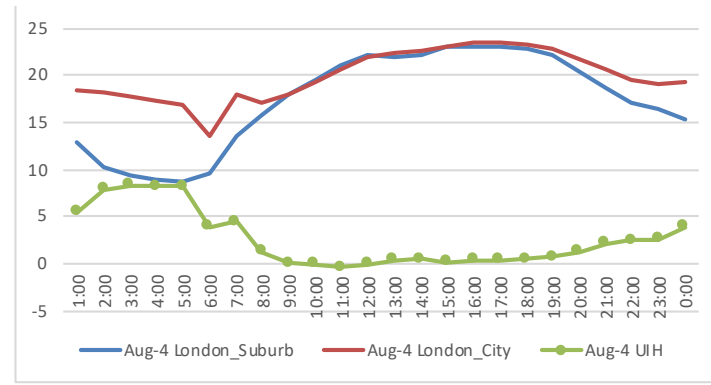

(a)

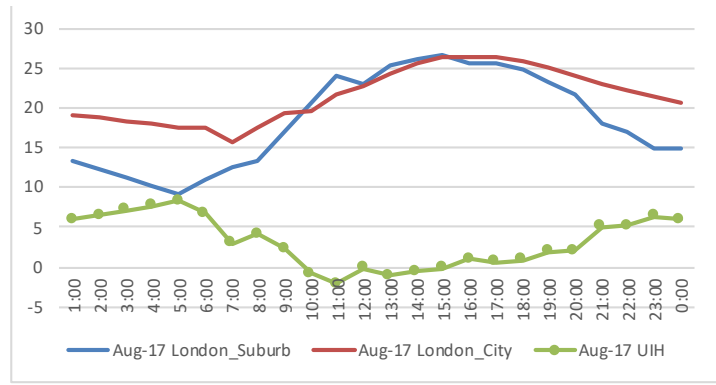

(b)

Figure 46: Air temperature of London suburb and city as well as UHI on Aug-4 and Aug-17

The research of Kolokotroni and Giridharan shows that the maximum UHI effects at night in London during the periods of clear-sky, partially-cloudy and cloudy are $8.6^{\circ} \mathrm{C}$, $7.3{ }^{\circ} \mathrm{C}$ and $6.6^{\circ} \mathrm{C}$ respectively (Kolokotroni \& Giridharan, 2008). The data was collected from 77 measurement stations during the summer from May to September. Another study monitored the summertime in London, with 68 measurement stations simultaneously recording air temperature (Watkins et al., 2002). According to Watkins' research, the UHI in London occasionally reached $7{ }^{\circ} \mathrm{C}$, mostly at night.

The annual average value of UHI in London simulated by Urban Weather Generator is $2.3^{\circ} \mathrm{C}$, and the maximum value is $8.3^{\circ} \mathrm{C}$. The UHI intensity of $8.3^{\circ} \mathrm{C}$ from the simulation is slightly lower than $8.6^{\circ} \mathrm{C}$ during clear-sky periods of measured data by 
Kolokotroni, and higher than the $7^{\circ} \mathrm{C}$ measured data by Watkins. The simulation result is within the range of measured data.

The measurement data is for Greater London and the simulation data is for City of London. It is acceptable that the simulation results are slightly different from the measurement data. The Urban Weather Generator program is a useful tool for UHI intensity modelling (Palme et al., 2017).

\subsection{Verification of Building Performance with EnergyPlus}

In addition to urban microclimate modelling, building performance simulation is also a significant part of this research. This research is to build a simulation system, and the reliability of the simulation system is based on the reliability of each part of the system. The EnergyPlus program is responsible for building performance modelling. This section demonstrates the reliability of building performance modelling program, EnergyPlus.

\subsubsection{Methodology}

The most straightforward way to verify the trustworthiness of EnergyPlus is to compare simulation results with an actual situation. This section takes the actual energy consumption data of a high-rise office building as an example and compares the data with the simulated results of electricity demand.

Cory explored the feasibility of converting New Zealand commercial building stock to be Net Zero Energy in his thesis (Cory, 2016). In Cory's PhD research, he collected the data on actual energy use of the office, retail and mixed commercial buildings in New Zealand. He followed through a process with careful systematic calibration. Each commercial building was given a building ID. In the research, a high-rise office building was studied. Of all the commercial buildings studied by Cory, ID R0198 is the most appropriate case study, because it is the highest of all the office buildings.

\subsubsection{Model description}

Cory studied 48 buildings selected from 101 BEES monitored building (Cory, 2016). These 48 buildings represented all the buildings in New Zealand. The highest office building in Cory's research, R0198, had 20 storeys. The 20-storeyed building was 
modelled to verify the reliability of EnergyPlus for modelling large office building performance.

In this section, R0198 is the prototype of the EnergyPlus verification modelling and Table 13 shows geometric information of R0198. According to Cory's research, R0198 as a large open office building with a Variable Air Volume (VAV) ventilation system, with a total floor area of $33636.4 \mathrm{~m}^{2}$ (Cory, 2016). The location of R0198 was in Auckland, and the monitoring time of R0198 was 2011.

Table 16: Geometric information of R0198

\begin{tabular}{|c|c|c|}
\hline \multicolumn{2}{|c|}{ HVAC System } & VAV \\
\hline \multicolumn{2}{|c|}{$\begin{array}{c}\text { Building Orientation } \\
\text { (Degrees-Clockwise from North, } 0=\text { North) }\end{array}$} & 18 \\
\hline \multicolumn{2}{|c|}{ Total Building Floor Area $\left(\mathrm{m}^{2}\right)$} & 33628 \\
\hline \multicolumn{2}{|c|}{ Total Number of Storeys } & 20 \\
\hline \multicolumn{2}{|c|}{ Building Height (m) } & 62.1 \\
\hline \multirow{4}{*}{ Glazing Percentage } & North & $90 \%$ \\
\hline & East & $30 \%$ \\
\hline & South & $70 \%$ \\
\hline & West & $30 \%$ \\
\hline
\end{tabular}

\subsubsection{The comparison of analysis results}

The EnergyPlus model for R0198 was built based on the building information of R0198. The original building was in Auckland, and its energy consumption data was collected in 2011. Therefore, the weather file for Auckland in 2011 was imported into the EnergyPlus model of R0198. The simulation results were compared with the actual monitoring data. The actual and model thermal loads were divided into weekday and weekend average hourly loads.

Figure 47 shows the average hourly loads of monitoring and simulation data on weekdays. The loads of EnergyPlus model is slightly higher than the monitoring loads, especially during the daytime. The overall trend of the thermal loads of EnergyPlus model is consistent with the actual energy consumption. The average difference of hourly loads between the simulation and monitoring data on weekdays is $10 \%$. 


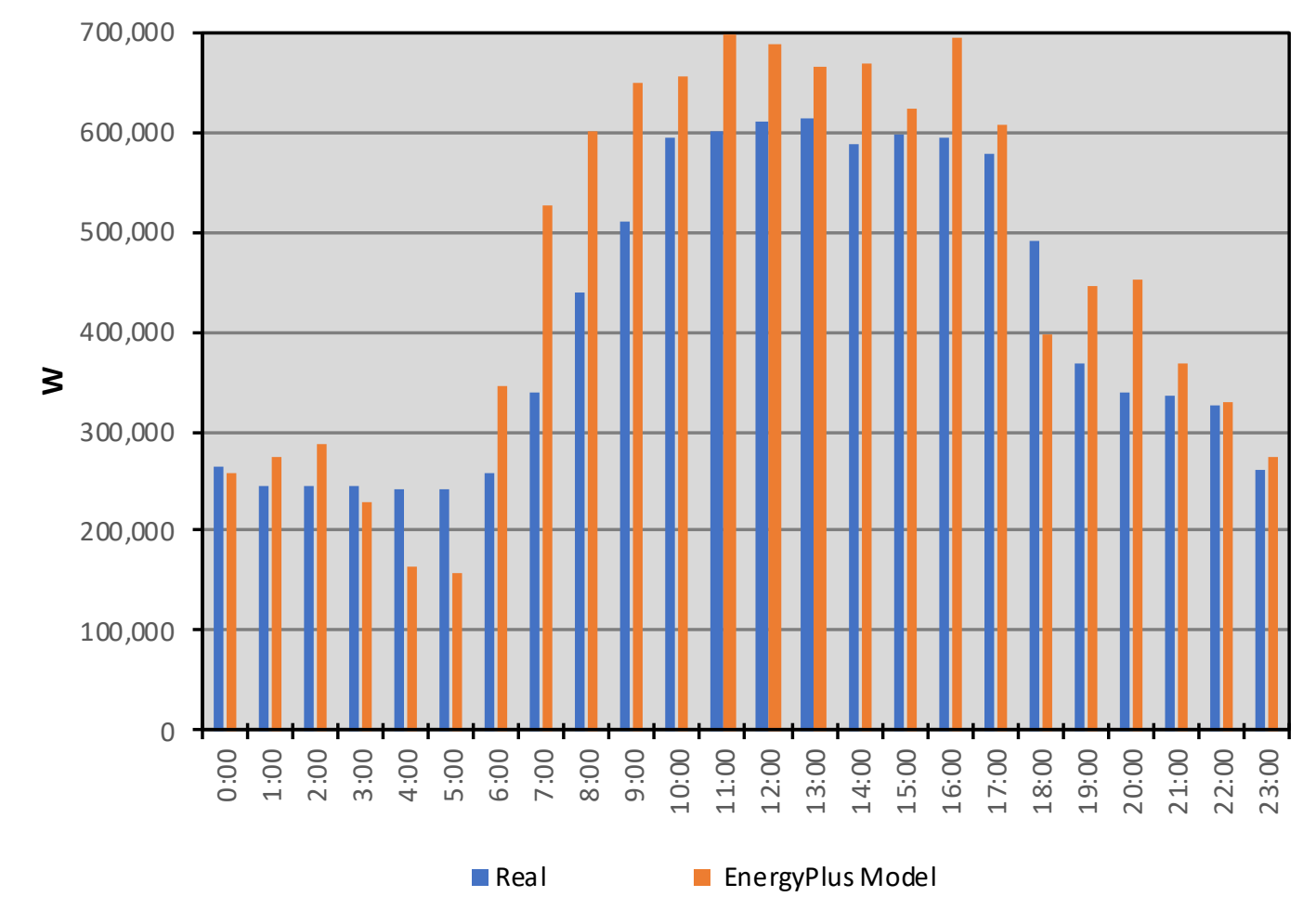

Figure 47: Weekday Average Hourly Loads

Figure 48 shows the average hourly loads of monitoring and simulation data over the weekend. The weekend loads of EnergyPlus model matches the actual data better than the weekday loads. The average difference of hourly loads between simulation and monitoring data over the weekend is $5 \%$.

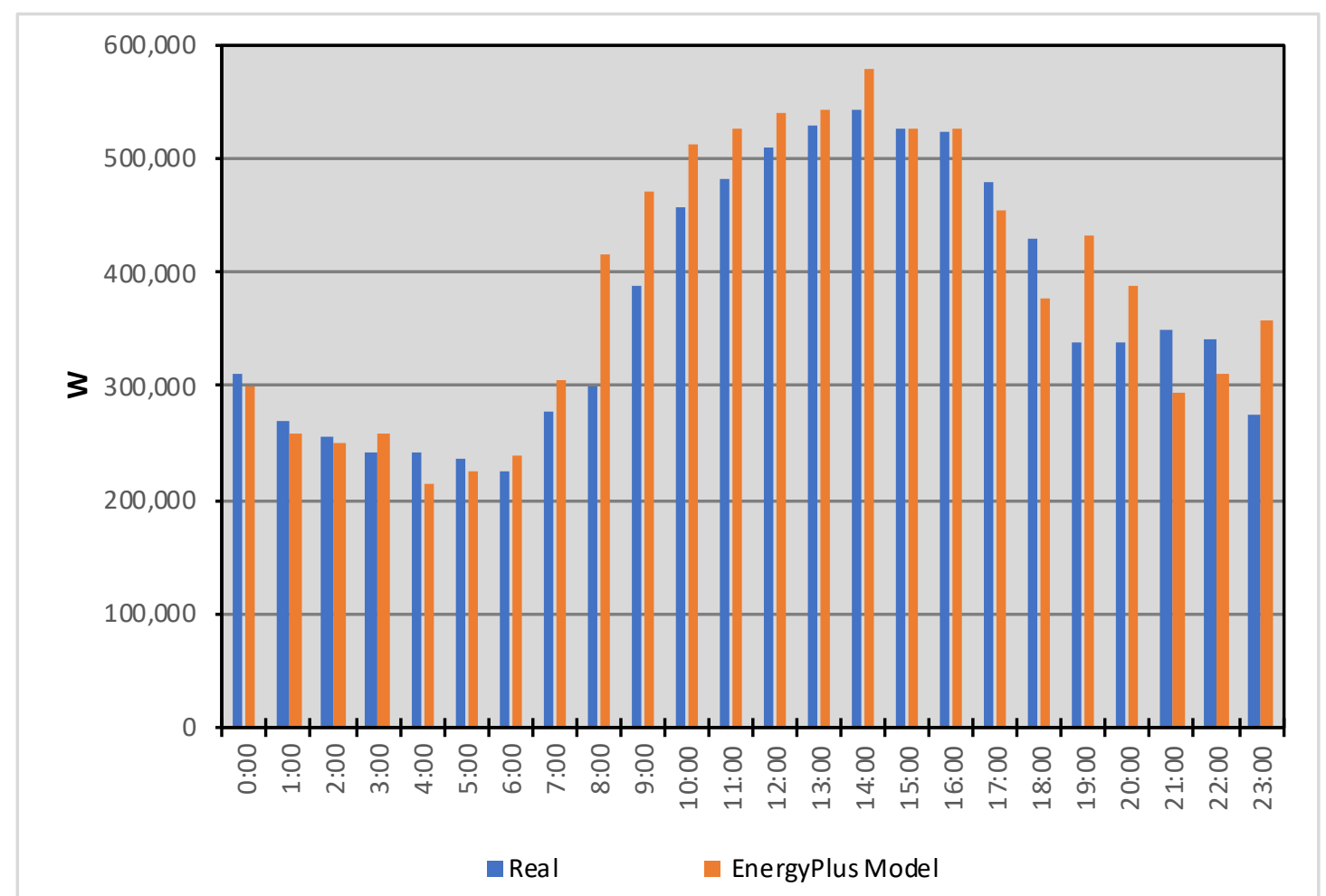

Figure 48: Weekend Average Hourly Loads 
In Figure 47 and Figure 48, it can be seen that the simulation results of the EnergyPlus model closely correlate the actual data. The reliability of EnergyPlus has been tested and verified.

\subsection{Chapter Summary}

In this chapter, the reliability of OpenFOAM, Urban Weather Generator, and EnergyPlus is tested and verified. The reliability verification of OpenFOAM consisted of the simulation of wind speeds and wind pressure coefficients. Hence, there were four sets of verifications.

- OpenFOAM-wind speed

The weakness is the wind speed simulation in the wake flow area. The wind speed calculated by OpenFOAM matches well with wind tunnel results in the non-wake areas, not well in the wake area. How this weakness affects the development of the simulation system is evaluated in the next chapters. Meshing of refinement level 2 and the kEpsilon turbulence model are highly recommended. The roughness length is associated with the wind profile, so the effects of the roughness length is discussed when exploring vertical variations of urban microclimates.

- OpenFOAM-wind pressure coefficients

The trends of the OpenFOAM simulation results are basically consistent with that of wind tunnel data, while the simulation results are slightly less than measurement data. In this research, the wind pressure coefficient simulation is carried out for modelling the detailed natural ventilation system. Hence, the underestimation of wind pressure coefficients by OpenFOAM maybe influence the building performance simulation using a detailed natural ventilation system.

\section{- Urban Weather Generator}

This study models the City of London not the Greater London, because Greater London is too massive to model. Hence, it is acceptable to have a slight difference between the simulation results and measurement data. The UHI of Urban Weather Generator numerical model is compared with measurement data of London collected from two papers: "Urban heat island intensity in London: An investigation of the impact of physical characteristics on changes in outdoor air temperature during summer (Kolokotroni \& Giridharan, 2008)" and "The London Heat Island: results from 
summertime monitoring (Watkins et al., 2002)". The simulation result is in the range of measurement data.

- EnergyPlus

Thermal loads of the EnergyPlus model are compared with the actual energy consumption data of a high-rise commercial building in Auckland, which is from Cory's PhD research (Cory, 2016). The simulation results of EnergyPlus model match the actual data.

Overall, the simulation results of these three programs are consistent with corresponding experiment data or measurement data. The reliability of the simulation tools used in this research has been verified. These tools can be used to develop the simulation system for urban microclimate detailed modelling. 


\section{CHAPTER 5. A REPRESENTATIVE SAMPLE OF PROTOTYPICAL OFFICE BUILDING IN A REAL CITY}

\subsection{Chapter Intent}

Chapter 4 demonstrated the reliability of simulation tools. The next three chapters are developing a simulation system step by step. Chapter 5 is to use these simulation tools to develop an initial model and ensure the model worked well.

The initial version of the model contained a prototypical high-rise building in a real city and a rough estimated urban microclimate. Rough urban weather data was converted from rural weather data. It takes the horizontal and vertical features of urban microclimates into account. The effects and importance of each horizontal feature, such as urban winds and the UHI, were discussed. Whether or not urban microclimate vertical variations influence building performance is briefly analysed in this chapter. The detailed analyses will be carried out in the next chapter.

In this chapter, the building performance of a prototypical office building with urban or rural weather data files is calculated to explore the influence of urban microclimate parameters. The first stage of modelling, Chapter 5, mostly focuses on horizontal variations of weather data. The second stage of modelling, Chapter 6, is about vertical variations of urban microclimates. This chapter discusses whether vertical variations influence building performance simulation. Then in the next chapter, how the vertical variations and height influence building performance will be discussed.

\subsection{Real City - London}

\subsubsection{Real city or ideal city?}

In general, a real city has a complex configuration with details and an ideal city is simplified. The urban planning of an ideal city is much easier to model. However, the configuration of an ideal city is non-existent, and it cannot represent the diversity of a city. Furthermore, the urban microclimate based on an ideal city is quite unrepresentative. A real city has individual urban microclimate and topography, and its weather data is from the local airport area. Both the weather data and the city configuration information are all real and reliable. The data can be used and compared. 
An ideal city does not have a unified standard, which means the results based on an ideal city might be far from the real one. In this research, the simulation system is intended to be applied in practice, and the evaluation based on a real city is much more appropriate.

\subsubsection{Why London?}

One of the issues discussed in this research is the difference between weather data in urban areas and rural areas. Urban Heat Island (UHI) is one of the causes of extreme differences in microclimates between urban and rural areas. London is one of the cities particularly affected by UHI in summer. Many studies on the UHI in London provide additional information that is readily available. The UHI effects and accessible data in London make it possible to verify the reliability of the UHI modelling program and explore differences between rural and urban areas in large cities. Figure 49 shows the relative position of Gatwick Airport and the City of London. The weather station is at Gatwick Airport and it is far away from the urban areas of London.

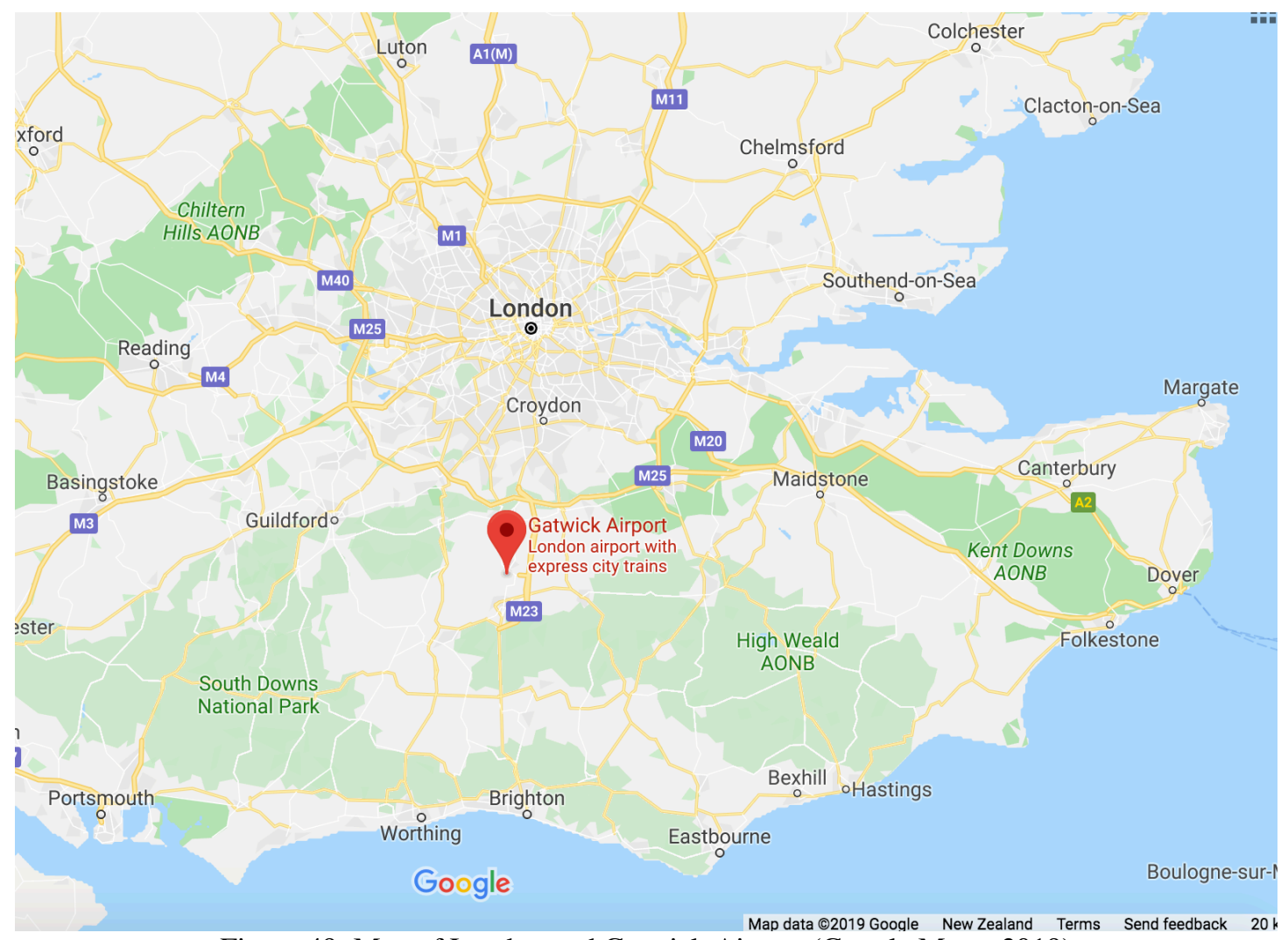

Figure 49: Map of London and Gatwick Airport (Google Maps, 2019)

Figure 50 shows the isotherm map of London UHI in mid-May with clear skies and light winds. The general pattern in the diagram shows the highest temperature is in the 
city core, reaching $11^{\circ} \mathrm{C}$, which contrasts with the rural fringe, where temperatures dropped to $5^{\circ} \mathrm{C}$ (Chandler, 1965).

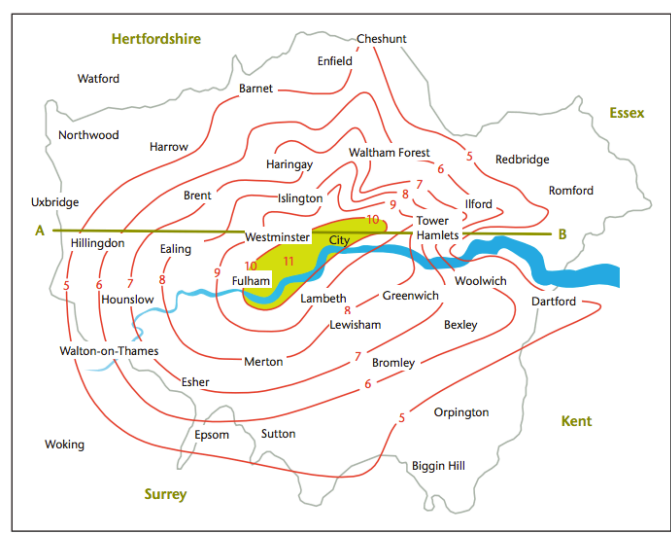

(a)

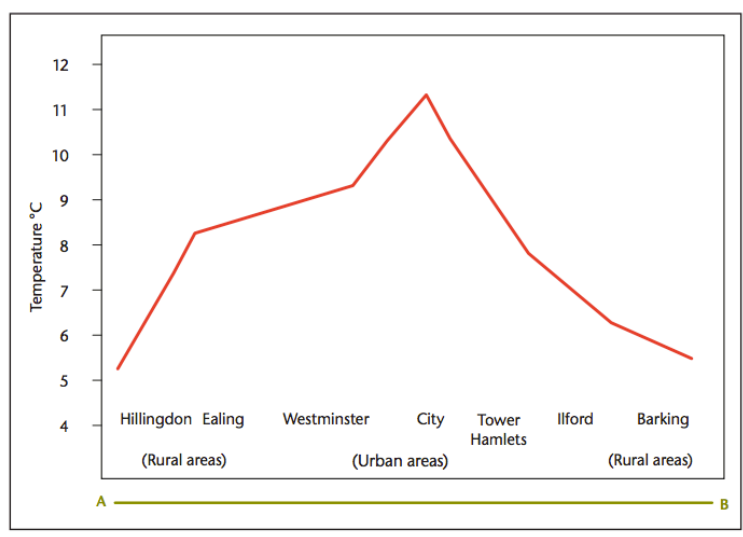

(b)

Figure 50: (a)London 'heat island' (minimum temperatures in ${ }^{\circ} \mathrm{C}$ ) (mid-May: clear skies and light winds) (b) Temperature profile of London (Jebson, 2008)

It has been reported that the temperature in the centre of large cities increases up by $7^{\circ} \mathrm{C}$ compared with the local weather station (Wilby, 2003). The UHI effects are greater in the City of London than in other urban areas of London.

\subsection{Prototypical Office Building}

\subsubsection{Why office buildings?}

Office buildings are energy-intensive, with HVAC systems consuming nearly $50 \%$ of total energy use (Pérez-Lombard et al., 2008). This research discussed how to model urban microclimate in detail. The urban microclimate model may provide a different design method of ventilation systems to get a high-performance building. Office buildings are usually located in urban areas. Large office buildings primarily adopt automatic centralized control through a building management system. The building performance of office buildings depends on their engineering design. If urban microclimate models can give engineers a different design strategy, the performance of office buildings can be significantly improved.

Office buildings have a relatively regular schedule and a stable indoor environment. Most office buildings operate much more standardized. Office building users cannot individually control their working environment. In general, workers need a comfortable work environment, and they should not be distracted by things outside of work. If part of HVAC system is replaced by natural ventilation systems, it can not only save lots of energy, but also provide fresh air and a thermal comfortable work environment. Hence, 
a high-performance office building is quite necessary. The possibility of modelling a high-performance office building was explored.

\subsubsection{Why high-rise office buildings?}

As the population increased with time during the last century (Figure 51a), higher density has reformed the urban configuration, and more and more high-rise buildings are continually built (Figure 51b). As high-rise buildings are more exposed to lower temperatures, stronger winds and more solar gains, there is a trend of increasing energy use with height (Godoy-Shimizu et al., 2018). Hence, the energy conservation of highrise office buildings is very important.

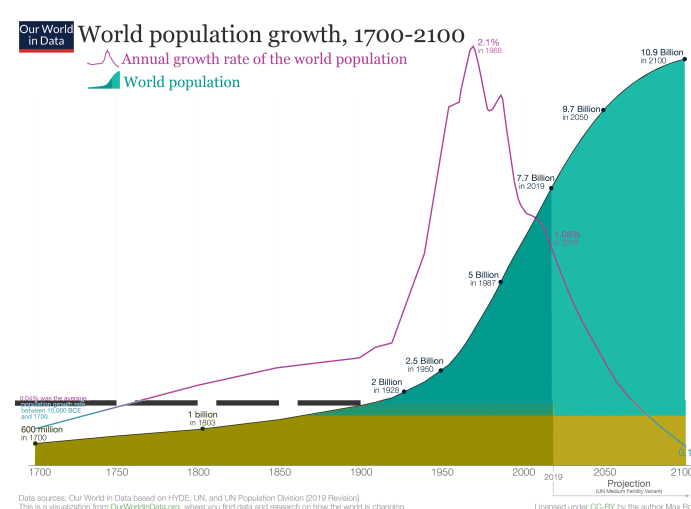

(a)

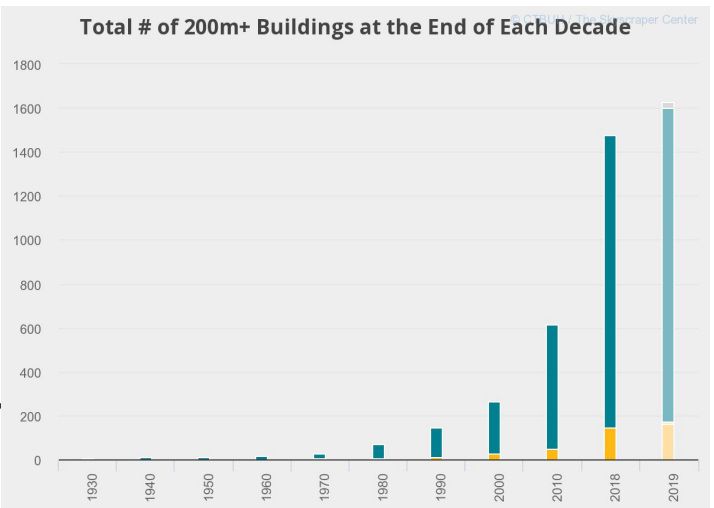

(b)

Figure 51: a) World population growth (Roser et al., 2013) b) Total number of 200-meter-plus buildings (blue) and 300-meter-plus (yellow) at the end of each decade (2018 Tall Building Year in Review, 2018)

High-rise office buildings are exposed to complex urban microclimates. Urban microclimate modelling is highly correlated with height, such as Urban Boundary Layer and Lapse Rate. High-rise office building make it possible to evaluate the influence of vertical variations of urban microclimates. For low-rise buildings, the increase of wind speed and the decrease of temperature caused by elevation is too small to be significant. Hence, the complex surrounding microclimate of high-rise office buildings is worth to analyse in order to build a high-performance office building.

\subsubsection{Prototypical office building based on highest office buildings in London}

Under normal circumstances, a real city has a unique urban environment and configuration. The prototypical high-rise office building was based on the tallest buildings in London, because the research looked into an extreme case study that could reveal differences between under and above the Urban Canopy layer and also could represent other high-rise buildings. Hence, the prototypical building was a very tall 
building but not an unrealistic building. Its height was set to the average height of buildings over $100 \mathrm{~m}$ in the City of London, rather than the height of the tallest building. The studied city was London and the prototypical building also referred high-rise buildings in London.

There were 32 office buildings in London that are $100 \mathrm{~m}$ or higher in 2016. The average height of the 32 tallest buildings in London was $153 \mathrm{~m}$; the average number of floors was 35 ; the average floor to floor height was $4.36 \mathrm{~m}$ (Table 17). The 32 buildings varied widely in floor area, from $640 \mathrm{~m}^{2}$ to $4900 \mathrm{~m}^{2}$. The height of the 6 buildings around median (ranked $13^{\text {th }}-18^{\text {th }}$ ) of 32 buildings are consistent and their average floor area is $3592 \mathrm{~m}^{2}$. Based on this information, the prototypical high-rise office building in this study was $72 \mathrm{~m}$ x $50 \mathrm{~m} \times 154 \mathrm{~m}$ high, with 35 storeys. Three typical floors (defined as top, middle, and bottom) were modelled to represent the performance near the top, near the bottom and around the middle of the building as a whole (Figure 52). Natural Renewable Energy Laboratory (NREL) has demonstrated that even simulating a single floor with a multiplier can give accurate results for an entire building, as long as the floor is near mid-height (Ellis \& Torcellini, 2005). A systematic study showed that these could also be combined to calculate the performance of the entire building (Ellis \& Torcellini, 2005).

Table 17: Top 32 tallest office building in London in 2016 ('List of Tallest Buildings and Structures in London', 2019)

\begin{tabular}{|c|c|c|c|c|c|c|c|c|c|}
\hline Rank & Name & Height(m) & Floors & $\begin{array}{l}\text { Floor to } \\
\text { Floor }\end{array}$ & $\begin{array}{c}\text { Floor } \\
\text { area(m2) }\end{array}$ & \begin{tabular}{|l} 
Average \\
floor \\
size(m2)
\end{tabular} & Year & $\begin{array}{c}\text { Primary } \\
\text { use }\end{array}$ & Location \\
\hline 1 & 22 Bishopsgate & 278 & 62 & 4.48387097 & 201863 & 3255.85 & 2019 & Office & City of London \\
\hline 2 & One Canada Square & 235 & 50 & $\begin{array}{r}4.7 \\
\end{array}$ & 162422 & 3248.44 & 1991 & Office & Isle of Dogs \\
\hline 3 & Heron Tower & 230 & 46 & 5 & 43000 & 934.78 & 2011 & Office & City of London \\
\hline 4 & 122 Leadenhall Street & 225 & 46 & 4.89130435 & 84424 & 1835.30 & 2014 & Office & City of London \\
\hline 5 & 8 Canada Square & 200 & 42 & 4.76190476 & 164410 & 3914.52 & 2002 & Office & Isle of Dogs \\
\hline 6 & 25 Canada Square & 200 & 42 & 4.76190476 & 170000 & 4047.62 & 2002 & Office & Isle of Dogs \\
\hline 7 & The Scalpel & 192 & 39 & 4.92307692 & 38545 & 988.33 & 2018 & Office & City of London \\
\hline 8 & Tower 42 & 183 & 47 & 3.89361702 & 30100 & 640.43 & 1980 & Office & City of London \\
\hline 9 & 30 St Mary Axe & 180 & 40 & 4.5 & 47950 & 1198.75 & 2003 & Office & City of London \\
\hline 10 & 100 Bishopsgate & 172 & 40 & 4.3 & 73000 & 1825.00 & 2018 & Office & City of London \\
\hline 11 & \begin{tabular}{|l|} 
Broadgate Tower \\
\end{tabular} & 164 & 35 & 4.68571429 & 37000.3 & 1057.15 & 2008 & Office & City of London \\
\hline 12 & 20 Fenchurch Street & 160 & 37 & 4.32432432 & 62100 & 1678.38 & 2014 & Office & City of London \\
\hline 13 & One Churchill Place & 156 & 32 & $\begin{array}{r}4.875 \\
\end{array}$ & 157164 & \begin{tabular}{ll|}
4911.38 \\
\end{tabular} & 2004 & Office & Isle of Dogs \\
\hline 14 & 25 Bank Street & 153 & 33 & 4.15 & 97546 & 2955.94 & 2003 & Office & Isle of Dogs \\
\hline 15 & 40 Bank Street & 153 & 33 & 4.63636364 & 84021 & 2546.09 & 2003 & Office & Isle of Dogs \\
\hline 16 & 10 Upper Bank Street & 151 & 32 & 4.71875 & 92251 & 2882.84 & 2003 & Office & Isle of Dogs \\
\hline 17 & Heron Quays West 2 & 147 & 28 & $\begin{array}{r}5.25 \\
\end{array}$ & 121789 & 4349.61 & 2019 & Office & Isle of Dogs \\
\hline 18 & 25 Churchill Place & 130 & 23 & 5.65217391 & 89800 & 3904.35 & 2014 & Office & Isle of Dogs \\
\hline 19 & CityPoint & 127 & 36 & 3.53 & 110000 & 3055.56 & 1967 & Office & City of London \\
\hline 20 & Willis Building & 125 & 26 & 4.81 & 50107 & 1927.19 & 2007 & Office & City of London \\
\hline 21 & Euston Tower & 124 & 36 & 3.44 & 37661 & 1046.14 & 1970 & Office & Euston \\
\hline 22 & Millbank Tower & 119 & 33 & 3.61 & & 0.00 & 1963 & Office & Westminster \\
\hline 23 & St. Helen's & 118 & 28 & 4.21 & 56097 & 2003.46 & 1969 & Office & City of London \\
\hline 24 & Centre Point & 117 & 35 & 3.34 & 27180 & 776.57 & 1967 & Office & West End \\
\hline 25 & \begin{tabular}{|l|} 
Empress State \\
Building \\
\end{tabular} & 117 & 31 & 3.77 & 43664 & 1408.52 & 1961 & Office & Earls Court \\
\hline 26 & 1 West India Quay & 108 & 36 & 3.00 & & & 2004 & Office & Isle of Dogs \\
\hline 27 & Shell Centre & 107 & 26 & 4.12 & 22761.24 & 875.43 & 1961 & Office & South Bank \\
\hline 28 & 33 Canada Square & 105 & 18 & 5.83 & & & 1999 & Office & Isle of Dogs \\
\hline 29 & 99 Bishopsgate & 104 & 26 & 4.00 & 30000 & 1153.85 & 1976 & Office & City of London \\
\hline 30 & Portland House & 101 & 29 & 3.48 & 29914.78 & 1031.54 & 1963 & Office & Westminster \\
\hline 31 & One Angel Court & 101 & 24 & 4.21 & 29357.36 & 1223.22 & 2017 & Office & City of London \\
\hline 32 & $\begin{array}{l}\text { Stock Exchange } \\
\text { Tower }\end{array}$ & 100 & 27 & 3.70 & 31000 & 1148.15 & 1970 & Office & City of London \\
\hline
\end{tabular}


The buildings may not be exactly representative of London, but this was to set up a system to test Urban Canopy. It would be fair to say if the Canopy is smaller, then the effects would be different but the overall importance of modelling all aspects of the UCL and UBL does not change.

If people want to look lower buildings, when reducing the height and it might get a different scale. If you are doing a tall building, it has been demonstrated that people definitely need to do all of the effectors.

Thermal loads of three typical floors represented the thermal loads of the building. The bottom floor was the one just above the ground floor ( $1^{\text {st }}$ floor $)$, the middle floor was the $17^{\text {th }}$ floor and the top floor was the one just under the highest floor (the $33^{\text {rd }}$ floor) (Figure 52). Note that the convention of calling the lowest floor above ground level the ground floor and the next the first floor was used here. The bottom floor was not the ground floor because the ground floor was adjacent to the ground so it had potential for heat gain or loss to the ground which was not typical of other lower floors. The top floor was not the roof floor because the roof floor was exposed to solar radiation and had potential for heat gain or loss through the ceiling to outside. Hence the topmost floor was not representative of higher floors. Therefore, the performance of $1^{\text {st }}, 17^{\text {th }}$ and $33^{\text {rd }}$ floor was calculated to predict whole building performance.

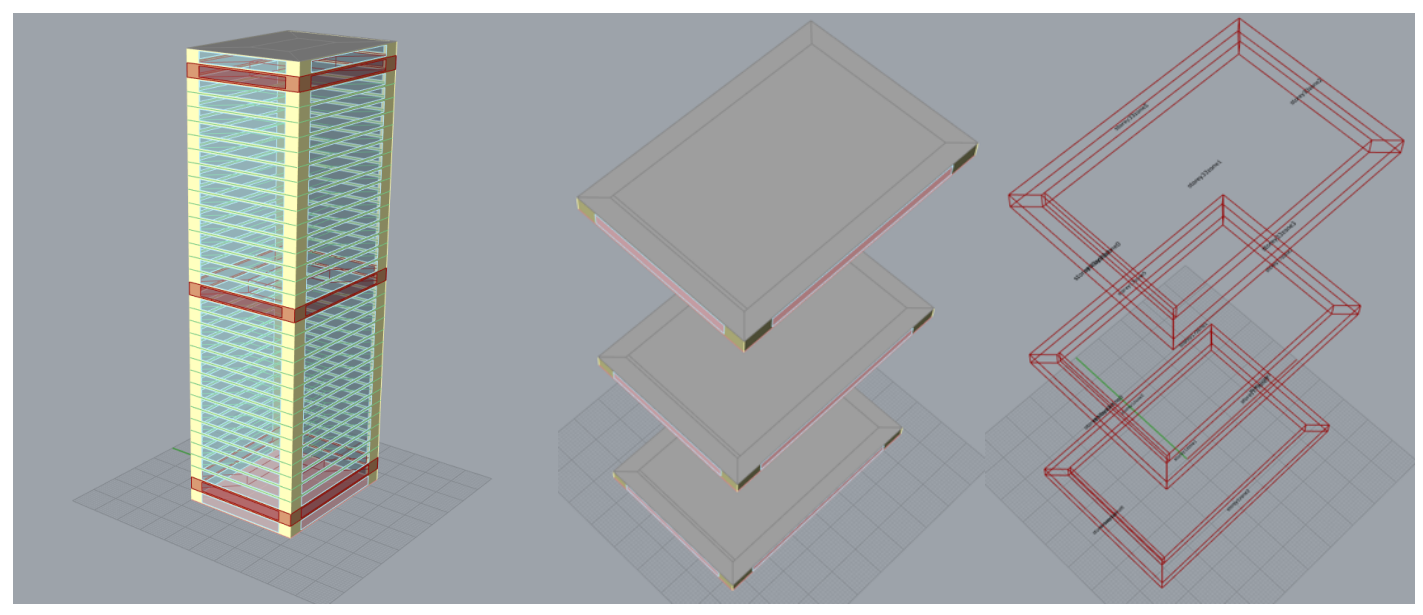

Figure 52: 3 floors of the prototypical high-rise office building

Each floor of the prototypical high-rise office building was divided into 5 zones, 4 perimeter zones and 1 core zone (Table 18). The thermal zones and perimeter zone depth $(5 \mathrm{~m})$ were set according to Pacific Northwest National Laboratory (PNNL) prototype office large (Commercial Prototype Building Models, 2016) and large office studies of Lawrence Berkeley National Laboratory (Huang et al., 1991). The perimeter 
zone is affected by daylighting. The daylighting zone depth depended on the height of ceiling and window percentage area. According to the study of Huang et al., the depth of the perimeter zone of large office buildings is 15 feet $(4.5 \mathrm{~m})$ when the wall is 10 feet $(3 \mathrm{~m})$. The floor to floor height of the typical high-rise office building was $4.4 \mathrm{~m}$, however, the floor to ceiling height was less than the floor to ceiling height. Assuming the ceiling height was $3.3 \mathrm{~m}$ and the depth of the perimeter zone was $5 \mathrm{~m}$ in this study.

Table 18: The percentage of each zone

\begin{tabular}{lll}
\hline Name & Function & \% on floor size \\
\hline Zone0 & Core Zone & $68.9 \%$ \\
Zone1-Zone4 & Perimeter zone & $31.1 \%$ \\
\hline
\end{tabular}

The loads (Table 19), working schedules (Table 20), and construction (Table 21) of the prototypical high-rise office building model were based on the large office model from Pacific Northwest National Laboratory. The glazing ratio was 0.6 (Juniwati, 2008). The HVAC system used in this research was a Variable Air Volume (VAV) system. The heating setpoint of the natural ventilation system used in this research was $18^{\circ} \mathrm{C}$, and the cooling $27^{\circ} \mathrm{C}$. The high-rise office building located in the City of London. Hence, the terrain was set as a city. The Wind Speed Exponent for a city was 0.33 , and the Wind Speed Profile Boundary Layer Thickness for a city was $460 \mathrm{~m}$. The default Air Temperature Gradient Coefficient was $0.0065 \mathrm{~K} / \mathrm{m}$.

Table 19: Loads set-up

\begin{tabular}{ll}
\hline Per Area & $\left(\mathrm{W} / \mathrm{m}^{2}\right)$ \\
\hline Equipment Load & $7.64 \mathrm{~W} / \mathrm{m}^{2}$ \\
Infiltration Rate & $0.000227 \mathrm{~m}^{3} / \mathrm{s}-\mathrm{m}^{2}$ \\
Lighting Density & $11.84 \mathrm{~W} / \mathrm{m}^{2}$ \\
Number of People & $0.056 \mathrm{ppl} / \mathrm{m}^{2}$ \\
Ventilation & $0.000305 \mathrm{~m}^{3} / \mathrm{s}-\mathrm{m}^{2}$ \\
\hline
\end{tabular}

Table 20: Schedules set-up

\begin{tabular}{ll}
\hline Schedules Type & EP Schedule Libraty \\
\hline Occupancy & Office Bldg Occ \\
Occupancy Activity & Office Activity \\
Heating Set Point & Office HtgSetp \\
Cooling Set Point & Office ClgSetp \\
Lighting & Office Bldg Light \\
Equipment & Office Bldg Equip \\
Infiltration & Office Infil Quarter On \\
\hline
\end{tabular}


Table 21: Construction set-up

\begin{tabular}{lll}
\hline Construction & Standard & Surface Type \\
\hline Wall & ASHRAE90.1-2010 & Exterior Wall Steel Frame \\
Window & ASHRAE90.1-2010 & Exterior Window Metal \\
Roof & ASHRAE90.1-2010 & Exterior Roof IEAD \\
Floor & ASHRAE90.1-2010 & Attic Floor \\
\hline
\end{tabular}

\subsection{Weather Data in Urban Areas Calibration}

According to the reference of EnergyPlus, air temperature is measured at approximately $1.5 \mathrm{~m}$ above ground and wind speed is measured at $10 \mathrm{~m}$ above ground (LBNL, 2018). Weather station is in a flat, open field with little protection from the wind. The weather station of London locates in Gatwick airport.

London is one of the cities which is significantly affected by UHI effects, especially in summer (Kotthaus \& Grimmond, 2014). The first step in this progress is to obtain the urban microclimate data for London.

\subsubsection{Urban Heat Island weather data}

Based on GIS information of London, the buildings of the City of London were modelled, and the UHI climate data was calculated by Urban Weather Generator (UWG) (Urban Weather Generator, n.d.). The predicted values of Dry Bulb Temperature $\left({ }^{\circ} \mathrm{C}\right)$, Dew Point Temperature $\left({ }^{\circ} \mathrm{C}\right)$ and Relative Humidity (\%) differ from the original Gatwick data. The difference between original and UHI daily averaged Dry Bulb Temperature is shown in Figure 53. The air temperature is between $-3^{\circ} \mathrm{C}$ and $10^{\circ} \mathrm{C}$ in winter and between $10^{\circ} \mathrm{C}$ and $25^{\circ} \mathrm{C}$ in summer. The maximum London UHI is $8.3^{\circ} \mathrm{C}$, the maximum daily average $\mathrm{UHI}$ is around $6^{\circ} \mathrm{C}$ and the average London $\mathrm{UHI}$ is $2.32^{\circ} \mathrm{C}$. 


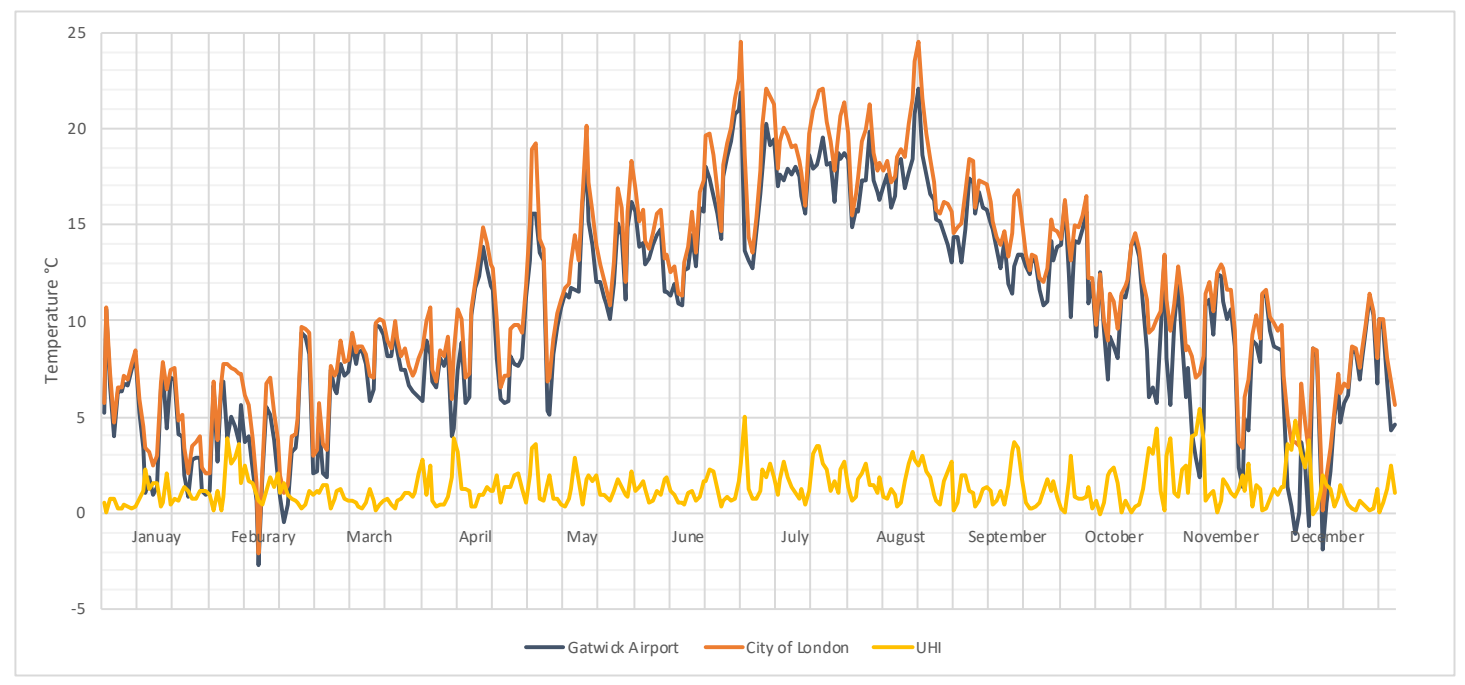

Figure 53: Daily averaged Dry Bulb Temperature and UHI

\subsubsection{Urban wind weather data}

The EPW (EnergyPlus Weather data file) file of London weather data was collected from Gatwick airport, $47.5 \mathrm{~km}$ south of Central London. The wind speed collected from airports is usually higher than that of the airflow in cities. To explore the accuracy of wind speed in urban areas, it is necessary to take the terrain into account and calculate the relative urban speed.

The Ladybug script, WindSpeedCalculator, calculated wind speed at a specific height for a given terrain type (Roudsari, n.d.). It generated an approximate wind speed and direction in an urban area, which was used to explore whether the air-flow movement has an impact on building performance. In terms of the terrain of city, the ratio of the wind Speed at $10 \mathrm{~m}$ in central London to the Wind Speed at $10 \mathrm{~m}$ at Gatwick Airport is around 0.45 .

\subsubsection{Four kinds of weather data}

On the basis of considering terrain, the weather data of central London with UHI and wind was predicted. In addition to the original EPW file of Gatwick Airport, a revised weather file considering urban wind, a revised weather file considering UHI and a revised weather file combining UHI and wind were created (Table 22). EPW weather files were transferred to csv format and CSV files were opened by excel. Temperature was adjusted according to the UHI data calculated by UWG and wind speed was adjusted according to urban wind produced by OpenFOAM. Temperature and wind speed data were revised in excel and saved as CSV files. At last, CSV files were 
transferred back to EPW format. These four weather data files were used to explore the impacts of horizontal parameters of urban microclimates on the simulation of building performance, such as the influence of UHI on cooling energy consumption and the influence of air-flow movement on natural ventilation.

Table 22: 4 kinds of weather data in London

\begin{tabular}{ll}
\hline No. & Weather data \\
\hline 1.epw & Gatwick airport weather file \\
2.epw & London city wind weather file \\
3.epw & London city UHI weather file \\
4.epw & London city UHI and wind weather file
\end{tabular}

\subsection{Analysis of the Prototypical Office Building Performance}

This case study reported the possible effects of three-dimensional variations of temperature and wind speed when modelling tall buildings in dense urban areas. In modelling these three-dimensional effects, the case study demonstrated the significant impact of the variances in temperatures and wind speeds between rural and urban areas on the performance of a high-rise office building. The possible impact on simulation results of modelling with and without vertical variations was also explored. The next chapter would study how each parameter of vertical variations, such as the wind profile exponent and the temperature gradient, influences energy simulation. The modelling flow of the case study is shown in Table 23.

Table 23: Modelling flow for heights, weather data, ventilation systems and height variations

\begin{tabular}{|c|c|c|c|c|c|c|c|c|}
\hline \multirow{2}{*}{$\begin{array}{c}\text { Height } \\
\text { Varations(HV) }\end{array}$} & \multirow{2}{*}{$\begin{array}{c}\text { Ventilation } \\
\text { Systems }\end{array}$} & \multirow{2}{*}{$\begin{array}{l}\text { Weather } \\
\text { data }\end{array}$} & \multirow{2}{*}{$\begin{array}{c}\text { Performance } \\
\text { Calculation } \\
\end{array}$} & \multicolumn{3}{|c|}{ Different Height } & Average & \multirow{2}{*}{$\begin{array}{c}\text { Modelling } \\
\text { steps }\end{array}$} \\
\hline & & & & 1st Floor & 17th Floor & 33rd Floor & $1 \& 17 \& 33$ Floors & \\
\hline \multirow{8}{*}{$\begin{array}{l}\text { With Height } \\
\text { Variations }\end{array}$} & \multirow{4}{*}{$\begin{array}{l}\text { HVAC } \\
\text { system }\end{array}$} & 1.epw & \begin{tabular}{|l} 
Thermal Loads \\
Cooling \\
Heating
\end{tabular} & $\begin{array}{l}\text { Performance(kWh } \\
\text { /m2.monthly) }\end{array}$ & $\begin{array}{l}\text { Performance(kW } \\
\text { h/m2.monthly) }\end{array}$ & $\begin{array}{l}\text { Performance }(\mathrm{kWh} / \\
\text { m2.monthly) }\end{array}$ & $\begin{array}{c}\text { Performance(kWh/ } \\
\text { m2.monthly) }\end{array}$ & \multirow{4}{*}{$\begin{array}{l}1 \text { st } \\
\text { Step }\end{array}$} \\
\hline & & 2.epw & \multirow{2}{*}{\multicolumn{5}{|c|}{$\begin{array}{l}\text { Repeat calculaton for 2.epw } \\
\text { Repeat calculaton for 3.epw }\end{array}$}} & \\
\hline & & 3.epw & & & & & & \\
\hline & & 4.epw & \multicolumn{5}{|c|}{ Repeat calculaton for 4.epw } & \\
\hline & \multirow{4}{*}{$\begin{array}{l}\text { Natural } \\
\text { Ventilation } \\
\text { stytem }\end{array}$} & 1.epw & \begin{tabular}{|l} 
Thermal Loads \\
Cooling \\
Heating
\end{tabular} & $\begin{array}{l}\text { Performance(kWh } \\
\text { /m2.monthly) }\end{array}$ & $\begin{array}{l}\text { Performance(kW } \\
\text { h/m2.monthly) }\end{array}$ & $\begin{array}{l}\text { Performance }(\mathrm{kWh} / \\
\text { m2.monthly) }\end{array}$ & $\begin{array}{c}\text { Performance }(\mathrm{kWh} / \\
\text { m2.monthly) }\end{array}$ & \multirow{4}{*}{ 2nd Step } \\
\hline & & 2.epw & \multirow{2}{*}{\multicolumn{5}{|c|}{$\begin{array}{l}\text { Repeat calculaton for 2.epw } \\
\text { Repeat calculaton for 3.epw }\end{array}$}} & \\
\hline & & 3.epw & & & & & & \\
\hline & & 4.epw & \multicolumn{5}{|c|}{ Repeat calculaton for 4.epw } & \\
\hline \multirow{8}{*}{$\begin{array}{c}\text { Without } \\
\text { Height } \\
\text { Variations }\end{array}$} & \multirow{4}{*}{$\begin{array}{l}\text { HVAC } \\
\text { system }\end{array}$} & 1.epw & $\begin{array}{l}\text { Thermal Loads } \\
\text { Cooling } \\
\end{array}$ & $\begin{array}{l}\text { Performance(kWh } \\
\text { /m2.monthly) }\end{array}$ & $\begin{array}{l}\text { Performance (kW } \\
\text { h/m2.monthly) }\end{array}$ & $\begin{array}{l}\text { Performance(kWh/ } \\
\text { m2.monthly) }\end{array}$ & \multirow[t]{2}{*}{$\begin{array}{l}\text { Performance }(\mathrm{kWh} / \\
\text { m2.monthly) }\end{array}$} & \multirow{8}{*}{ 3rd Step } \\
\hline & & 2.epw & & & oeat calculaton for & 2.epw & & \\
\hline & & 3.epw & \multirow{2}{*}{\multicolumn{5}{|c|}{$\begin{array}{l}\text { Repeat calculaton for 3.epw } \\
\text { Repeat calculaton for 4.epw }\end{array}$}} & \\
\hline & & 4.epw & & & & & & \\
\hline & \multirow{4}{*}{$\begin{array}{l}\text { Natural } \\
\text { Ventilation } \\
\text { stytem }\end{array}$} & 1.epw & \begin{tabular}{|l} 
Thermal Loads \\
Cooling \\
Heating
\end{tabular} & $\begin{array}{l}\text { Performance(kWh } \\
\text { /m2.monthly) }\end{array}$ & $\begin{array}{l}\text { Performance(kW } \\
\text { h/m2.monthly) }\end{array}$ & $\begin{array}{l}\text { Performance (kWh/ } \\
\text { m2.monthly) }\end{array}$ & $\begin{array}{l}\text { Performance (kWh/ } \\
\text { m2.monthly) }\end{array}$ & \\
\hline & & 2.epw & & & beat calculaton for & 2.epw & & \\
\hline & & 3.epw & & & beat calculaton for & 3.epw & & \\
\hline & & 4.epw & & & oeat calculaton for & 4.epw & & \\
\hline
\end{tabular}


In Table 23, in the first step, the buildings in the City of London were modelled, and the UHI climate data was calculated using the Urban Weather Generator (UWG). The UHI climate data was calibrated against published empirical data. The approximate urban wind speeds were also achieved through a Ladybug script, WindSpeedCalculator. A comparison was made of:

a) the performance of the typical high-rise office building based on climate data collected from a weather station in a rural area;

b) the performance of the same building using climate data of the adjusted urban wind;

c) the performance of the same building using climate data of the adjusted UHI calculated by UWG;

d) the performance of the same building using climate data of adjusted UHI and urban wind.

The performance calculation was based on an HVAC system, including thermal loads, cooling loads and heating loads at the $1^{\text {st }}$ floor, the $17^{\text {th }}$ floor and the $33^{\text {rd }}$ floor.

The second step modelled the performance of the same building based on a natural ventilation system and repeated the calculation with four kinds of weather data.

The third step was to model the typical building without vertical variations of urban microclimate, tested the effects of vertical variations, and repeated the performance calculation with four kinds of weather data, two kinds of ventilation systems, at different floors (refer to Table 23). Vertical variations of urban microclimates included the Wind Speed Profile Exponent, Wind Speed Profile Boundary Layer Thickness (m), and Air Temperature Gradient Coefficient $(\mathrm{K} / \mathrm{m})$. The previous model had an original height variation setting and changed the default values to 0 . Then the effects of UHI, urban winds, heights, ventilation systems and vertical variations of urban microclimates were compared and analysed.

\subsubsection{Urban microclimate weather data}

To explore the influence of UHI and wind in urban areas on the accuracy of modelling, the thermal loads, and cooling and heating performance using different weather data were compared with each other. A rural weather file (GatwickAirport) and three urban weather files taking the UHI (LondonCity_UHI), urban wind (LondonCity_Wind) and 
both the UHI and wind (LondonCity_UHI+Wind) into account were imported into the simulation. The ventilation system was an HVAC system. The black error bars in figures represent a $5 \%$ difference.

Figure 54 shows that thermal loads using rural weather data are higher than those using urban weather data for most of the year. In summer, the UHI increases cooling loads. The effects of urban wind on thermal loads are less than 5\% and the effects of the UHI are more than $10 \%$. This means the urban wind has fewer effects on building performance, while the UHI has greater effects on building performance.

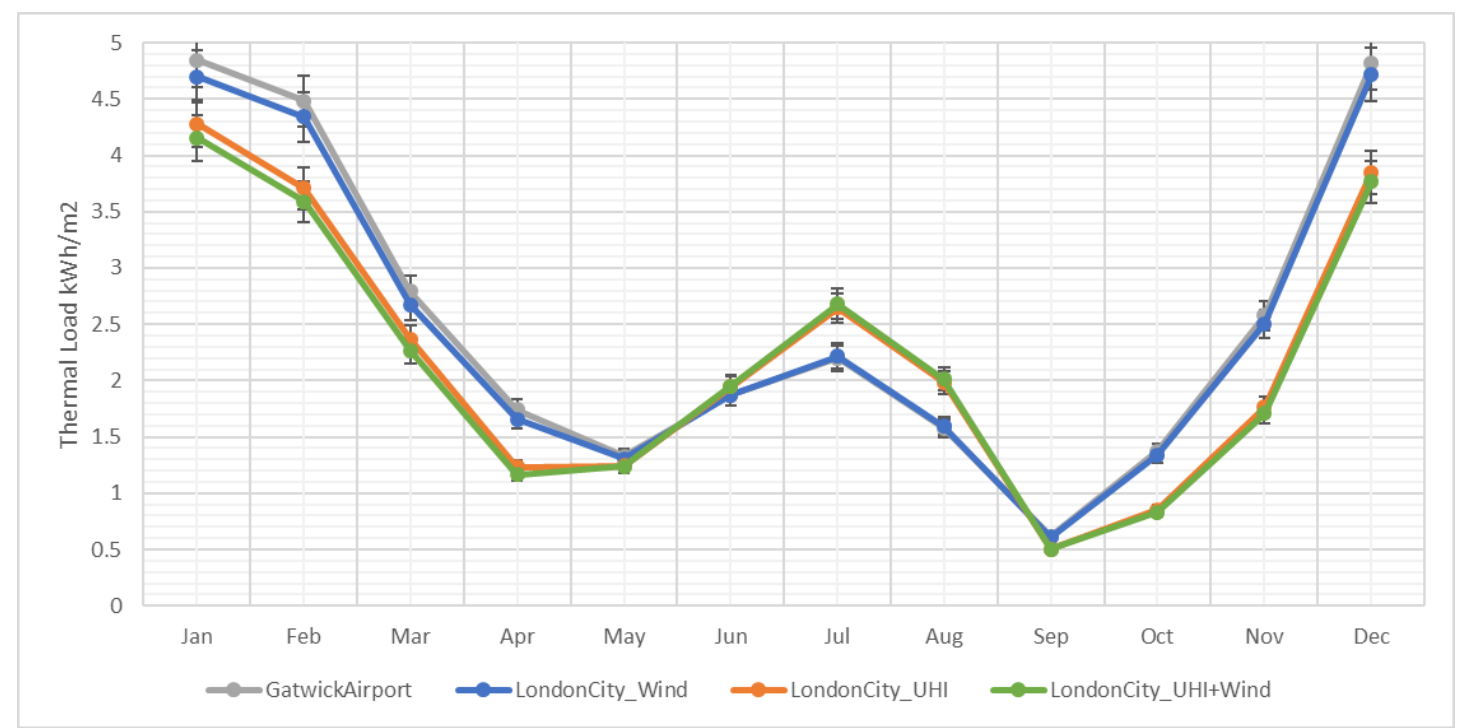

Figure 54: Thermal loads of the high-rise office building for 4 different weather data

Figure 55 shows that urban wind has very slight impacts on the cooling loads and the UHI has big impacts on the cooling loads in summer. Figure 56 shows the heating load using rural weather data is higher than that with urban weather data. Urban microclimates reduce heating loads. The decrease caused by the UHI is greater than that caused by wind. That means that UHI has a big impact on heating consumptions in winter. 


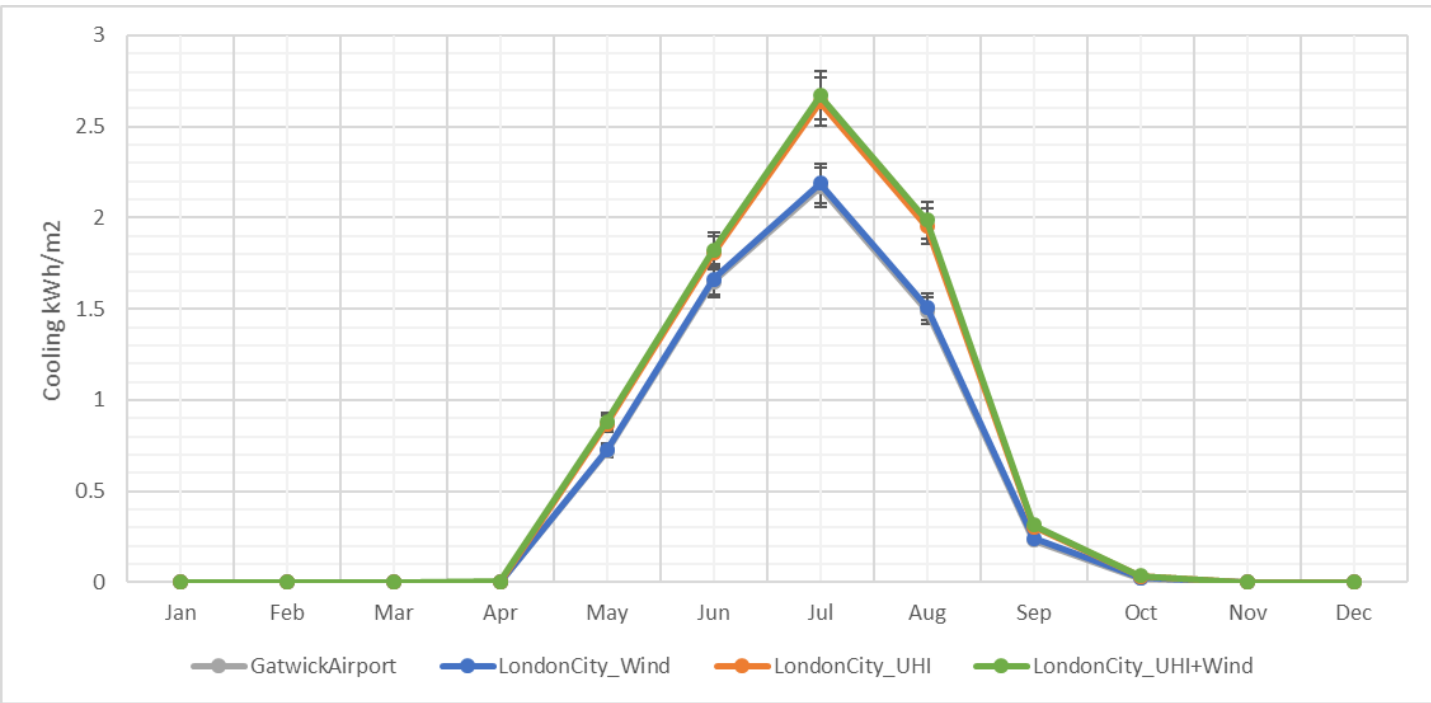

Figure 55: Cooling of the high-rise office building for 4 different weather data

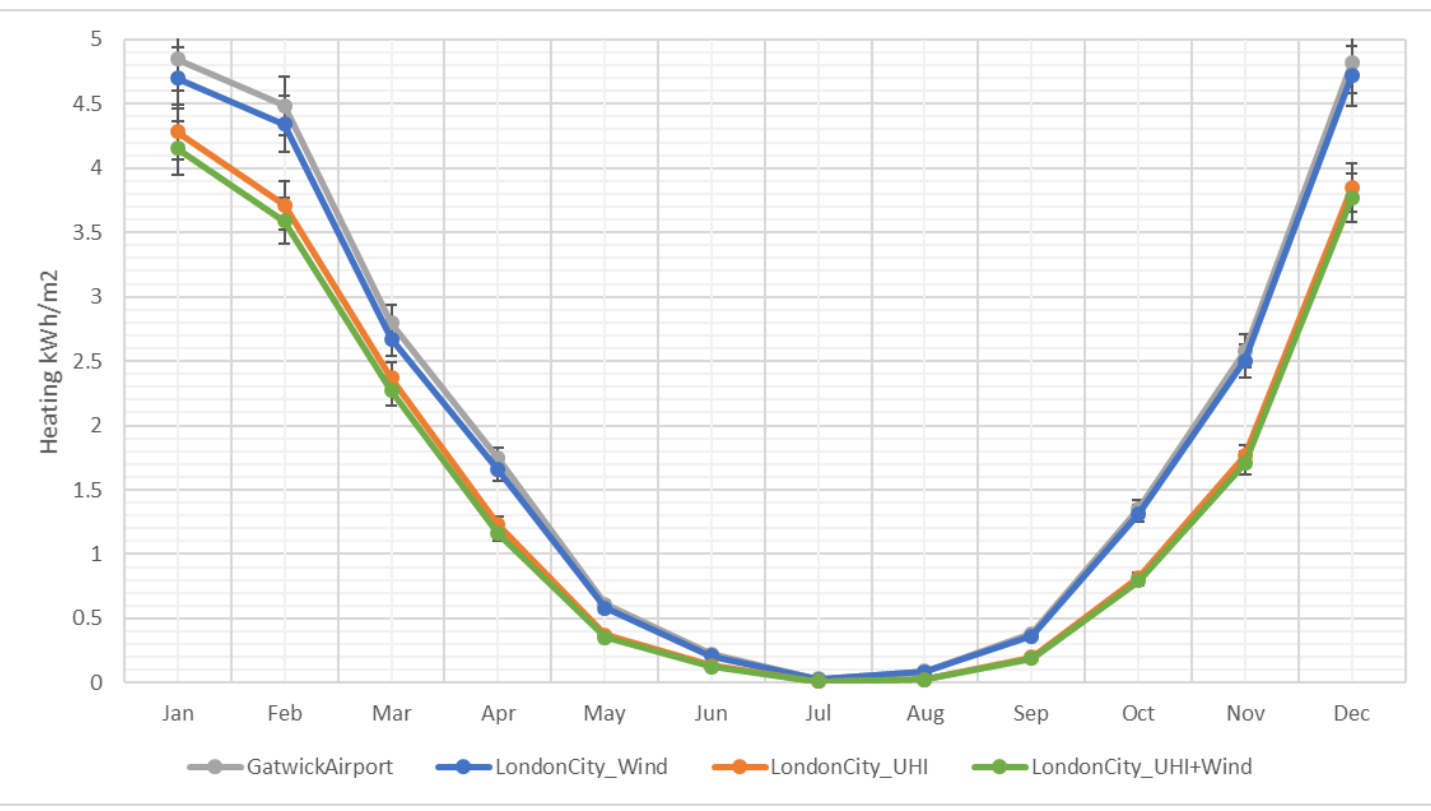

Figure 56: Heating of high-rise office building for 4 different weather data

As shown in Figure 54-Figure 56, the UHI has a big impact on building performance simulation. For most of the year, the difference in energy consumption between taking into account the UHI effects and using the original weather data is more than $10 \%$. Estimated wind speed in the urban area has a less than $5 \%$ effect on the energy performance modelling. The combined effects taking the UHI and wind into account are higher than that taking the UHI into account alone.

Therefore, in London, engineers should model the UHI first. If they need more accurate results, they could model both the UHI and the urban wind. At present, it is not clear whether the accurate air-flow movement has a bigger impact on the natural ventilation. The additive effect of the wind might be significant for the overall results. 


\subsubsection{Height}

Three typical floors $\left(1^{\text {st }}, 17^{\text {th }}\right.$ and $33^{\text {rd }}$ floors $)$ of the high-rise building were selected to explore the influence of height on building performance. A rural weather file (GatwickAirport) and an urban weather files taking the UHI and wind into account (LondonCity_UHI+Wind) were imported to investigate the effects of height on rural and urban weather data with an HVAC system.

Thermal loads using rural weather data and urban weather data at the $1^{\text {st }}, 17^{\text {th }}$ and $33^{\text {rd }}$ floors are shown in Figure 57. For most of the year, the thermal loads increase with height and the thermal loads of urban microclimates are fewer than those of rural microclimates. The difference of thermal loads between using rural and urban weather data increases with height. In summer, cooling loads using urban weather data are more than those using rural weather data, while, they are not affected by height a lot.

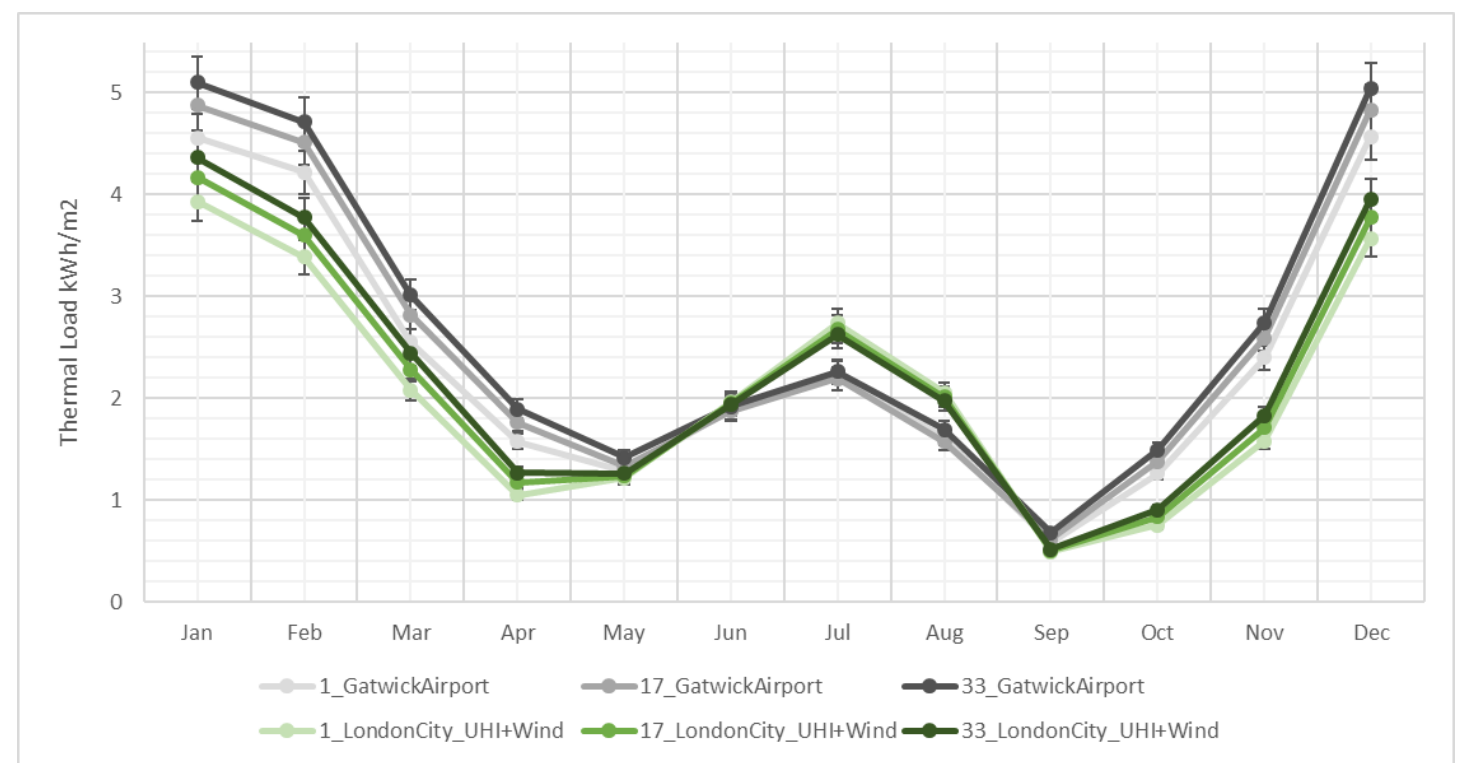

Figure 57: Thermal loads at the $1^{\text {st }}, 17^{\text {th }}$ and $33^{\text {rd }}$ floors for rural and urban weather files

Compared with the rural weather file, the urban weather file increases cooling load predictions more than $10 \%$ in July and August (Figure 58). The cooling loads using urban weather data decrease very slightly with height. 


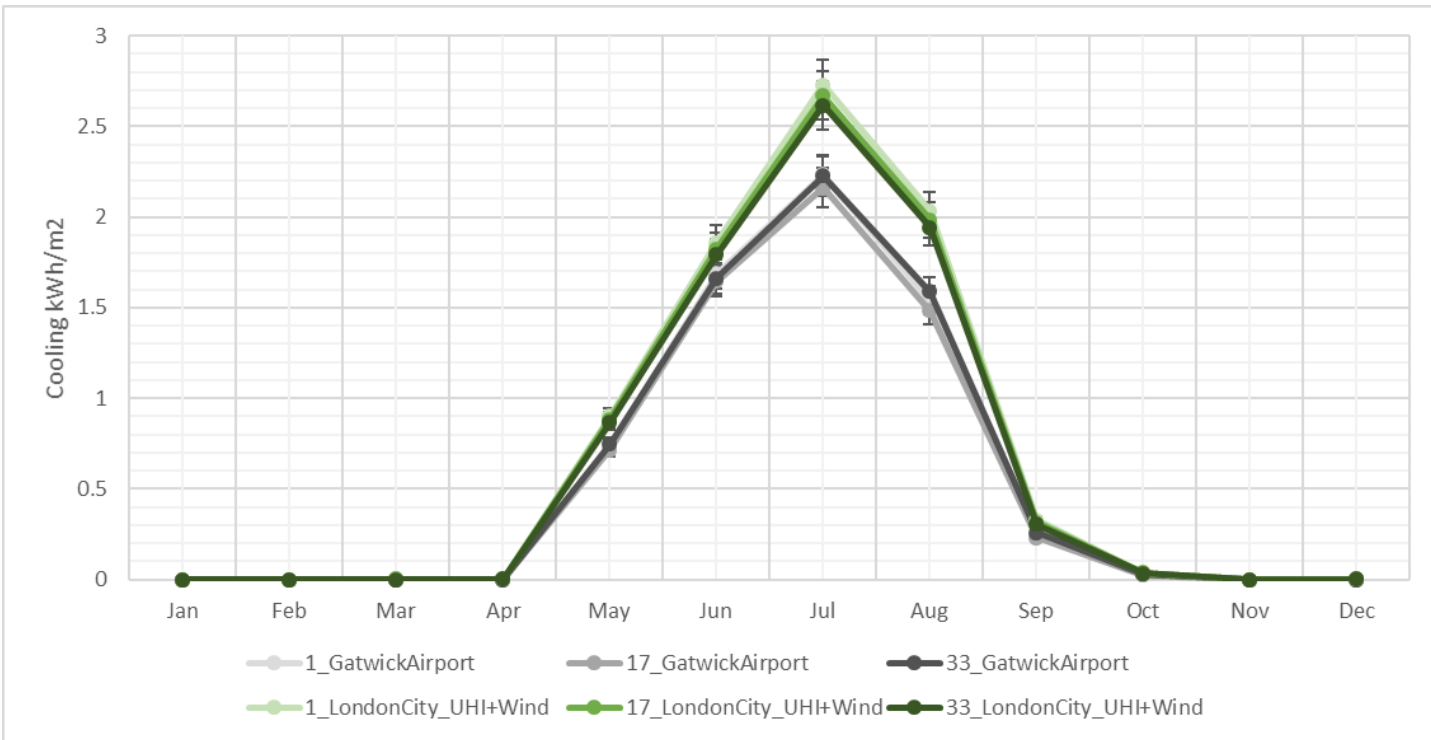

Figure 58: Cooling at the $1^{\text {st }}, 17^{\text {th }}$ and $33^{\text {rd }}$ floors for rural and urban weather files

The urban weather file decreases heating load predictions more than $10 \%$ in Winter, because the temperature in urban areas is higher than in rural areas (Figure 59). The reduction of heating load predictions due to urban weather file increases with height. The heating loads increase with height in both rural and urban areas.

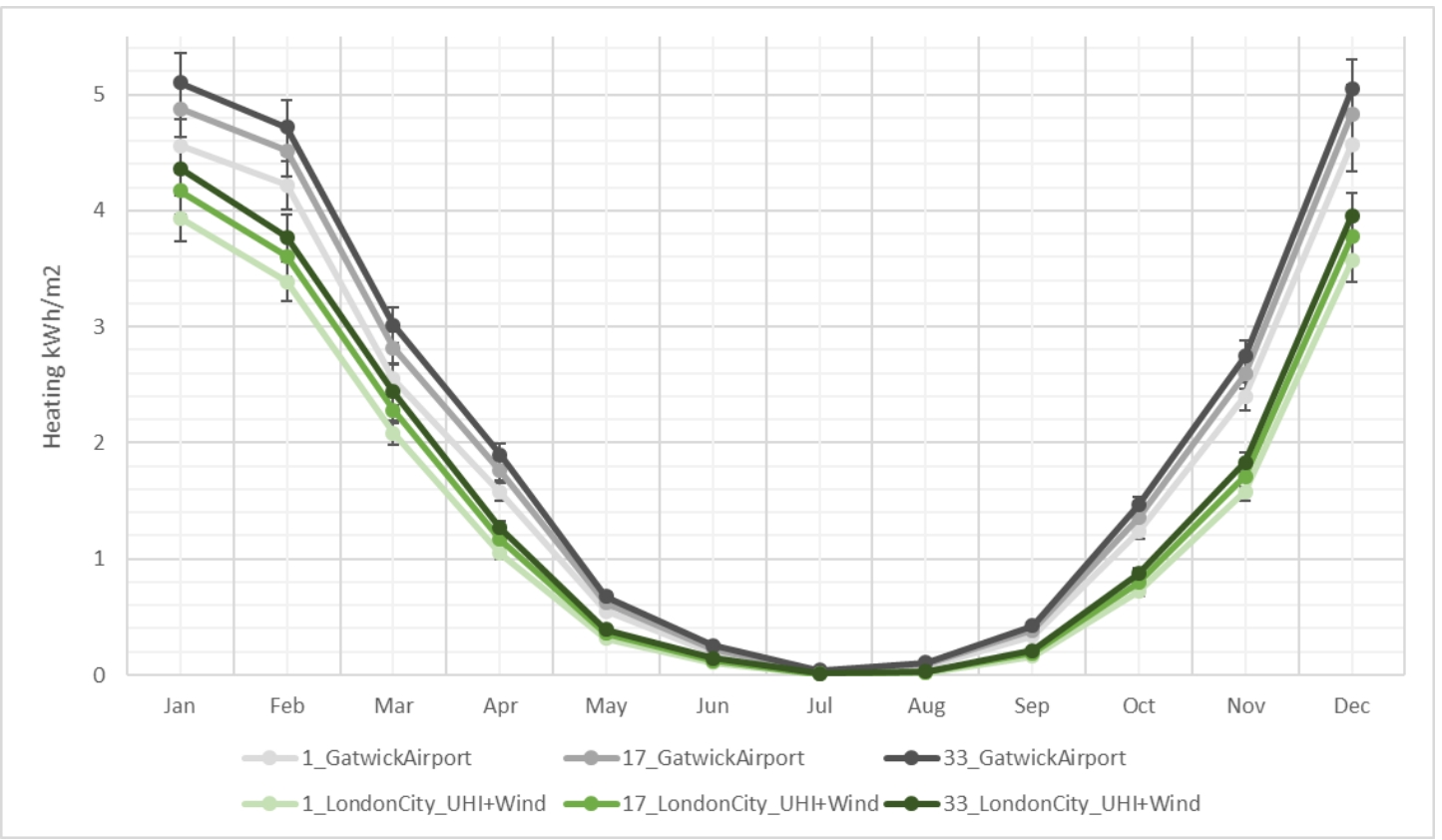

Figure 59: Heating at the $1^{\text {st }}, 17^{\text {th }}$ and $33^{\text {rd }}$ floors for rural and urban weather files

As shown in Figure 57-Figure 59, the higher floor has the higher thermal load for most of the year. Cooling loads at the higher floor are slightly lower than those at the lower floor in urban areas. In contrast, heating loads at the higher floor are higher than those at the lower floor. That is because of vertical change in wind and temperature. The urban microclimate considering the UHI and urban wind has a big influence on the cooling in summer and the heating in winter. The influence of height is also significant. 
The research discussed the combined effects of the UHI and urban winds. What are the respective effects of the UHI and urban winds? At different heights, will the significance of the UHI and urban winds be different? The thermal loads caused by the UHI (LondonCity_UHI) and the thermal Loads caused by urban winds (LondonCity_Wind) were compared with those using rural weather data (GatwickAirport). The thermal load percentage changes are shown in Figure 60. The cooling load percentage changes from May to October are shown in Figure 61 and the heating load percentage changes from November to April are shown in Figure 62.

At the $1^{\text {st }}, 17^{\text {th }}$ and $33^{\text {rd }}$ floors, the thermal load percentage change caused by urban winds is much smaller than that caused by the UHI (Figure 60). That means the influence of the UHI is much bigger than urban winds at different height. For engineers, they can model detailed urban microclimates according to their requirements for accuracy. When they don't have enough time to model a very detailed model, the UHI takes precedence over urban winds.

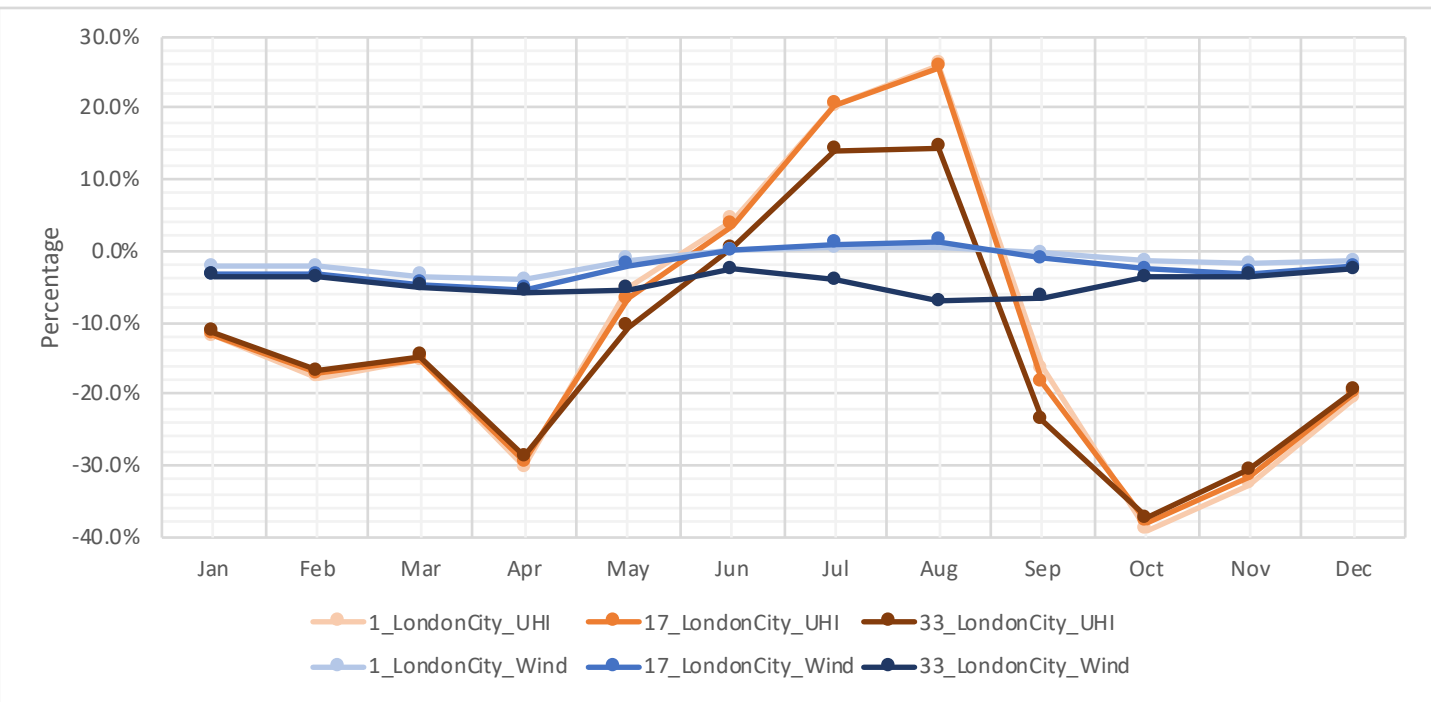

Figure 60: Thermal load percentage changes at the $1^{\text {st }}, 17^{\text {th }}$ and $33^{\text {rd }}$ floors for UHI and urban winds From May to October, the cooling load predictions change a lot when taking UHI into account (Figure 61). The cooling loads also change when taking urban winds into account. However, the changes caused by urban winds are smaller than those caused by the UHI. At the $1^{\text {st }}$ and $17^{\text {th }}$ floors, considering urban winds increases cooling loads, while, at the $33^{\text {rd }}$ floor, considering urban winds reduces cooling loads. 


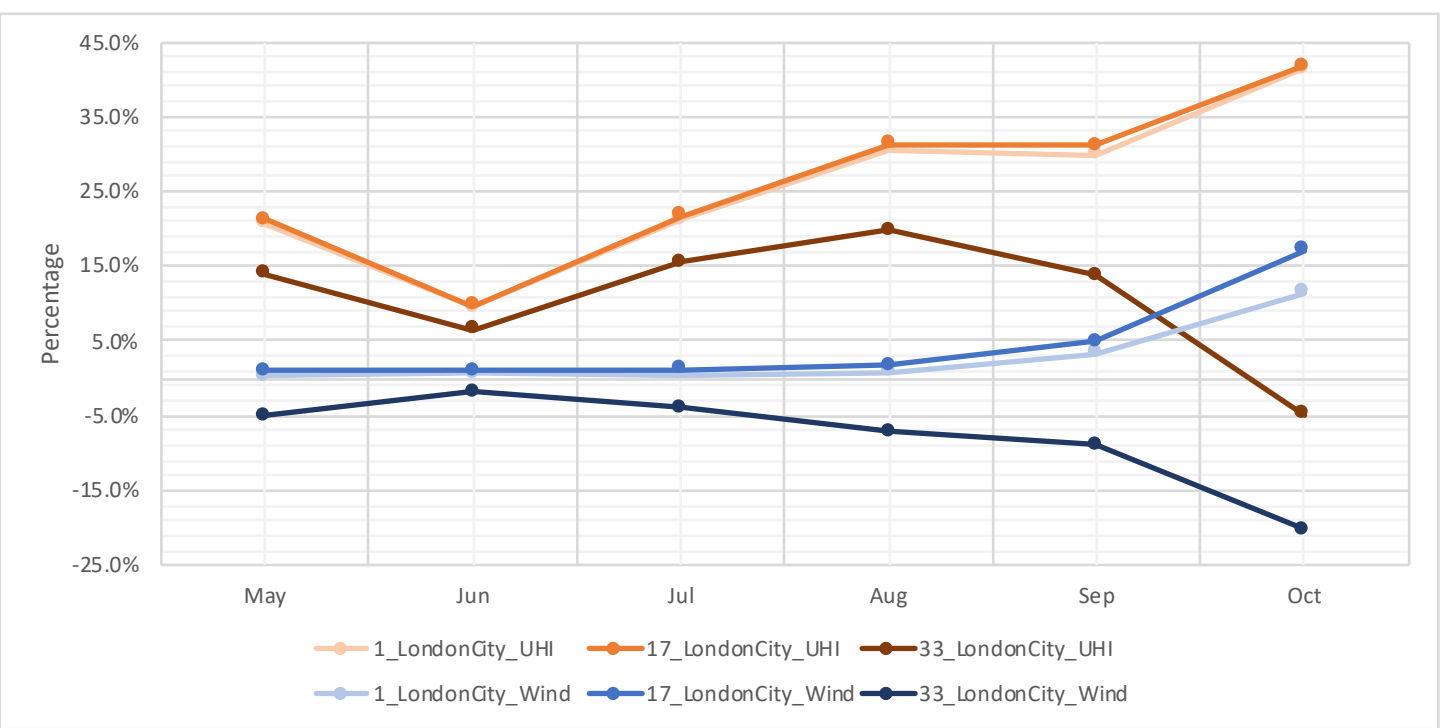

Figure 61: Cooling percentage changes at the $1^{\text {st }}, 17^{\text {th }}$ and $33^{\text {rd }}$ floors for UHI and urban winds (from May to October)

Taking the UHI into account reduces heating load predictions a lot (between 10\% and $33 \%$ ), while taking urban winds into account reduces heating load predictions by less than 5\% (Figure 62). The influence of the UHI slightly decreases with height and the influence of urban winds slightly increases with height.

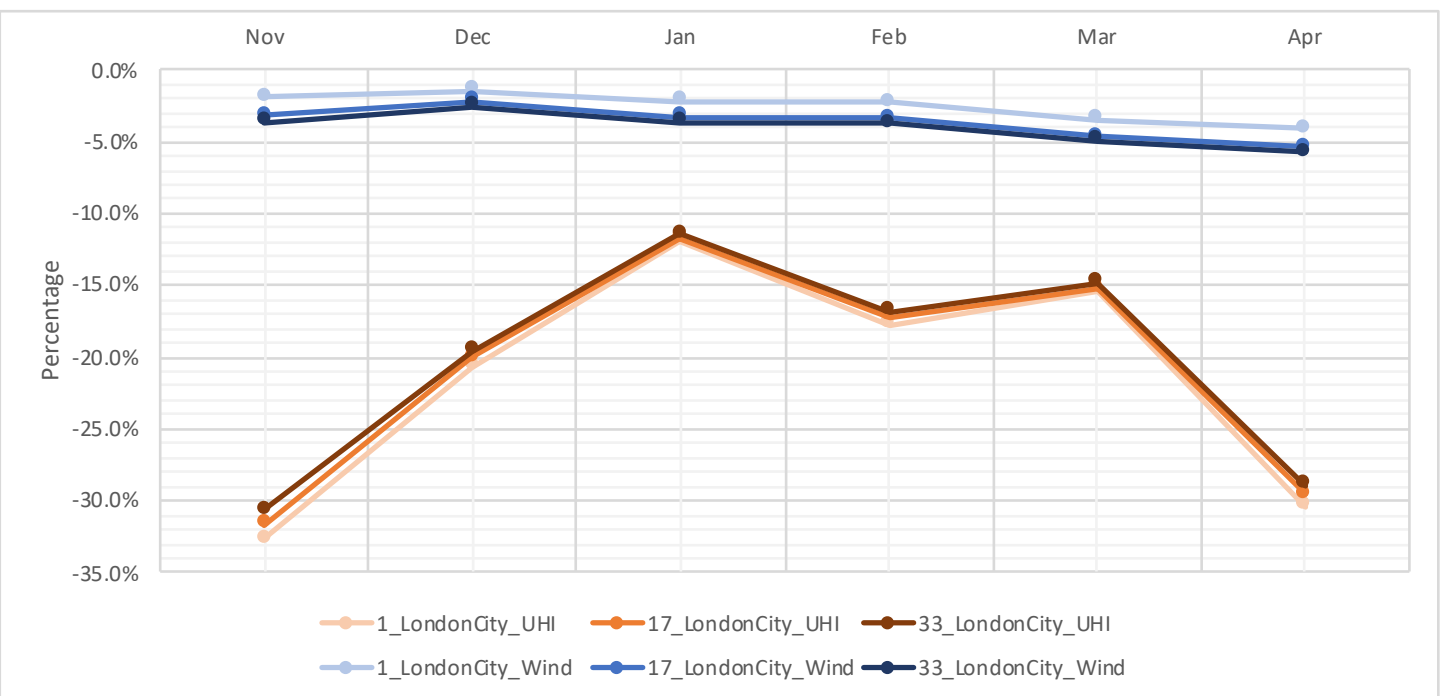

Figure 62: Heating percentage changes at the $1^{\text {st }}, 17^{\text {th }}$ and $33^{\text {rd }}$ floors for UHI and urban winds (from November to April)

As shown in Figure 60-Figure 62, at different heights, urban winds slightly influence thermal load predictions, cooling in summer and heating in winter. The effects of urban winds increase with height, while, the effects of the UHI decrease with height slightly. However, the effects of the UHI are much bigger than those of urban winds. The influence of height on the heating load is bigger than that on the cooling load. Hence, when engineers design the capacity of building equipment at different floors, it is 
necessary to consider the influence of height to simulate building performance and optimize the design.

\subsubsection{Natural ventilation}

Compared with HVAC systems, natural ventilation systems (NV) have a closer relationship with the outdoor environment. In this part of research, NV is short for natural ventilation. Whether or not urban microclimates have a bigger influence on natural ventilation systems (GatwickAirport_NV, LondonCity_NV, LondonCity_UHI_NV and LondonCity_UHI+Wind_NV) than on HVAC systems (GatwickAirport, LondonCity, LondonCity_UHI and LondonCity_UHI+Wind) were analysed. The effects of different weather data on different ventilation systems at different floors were also discussed.

The effects of different weather data on an HVAC system and a natural ventilation system are similar (Figure 63). The influence of the UHI is bigger than that of urban winds, using both HVAC systems and natural ventilation systems. Natural ventilation reduces thermal load predictions, especially in summer.

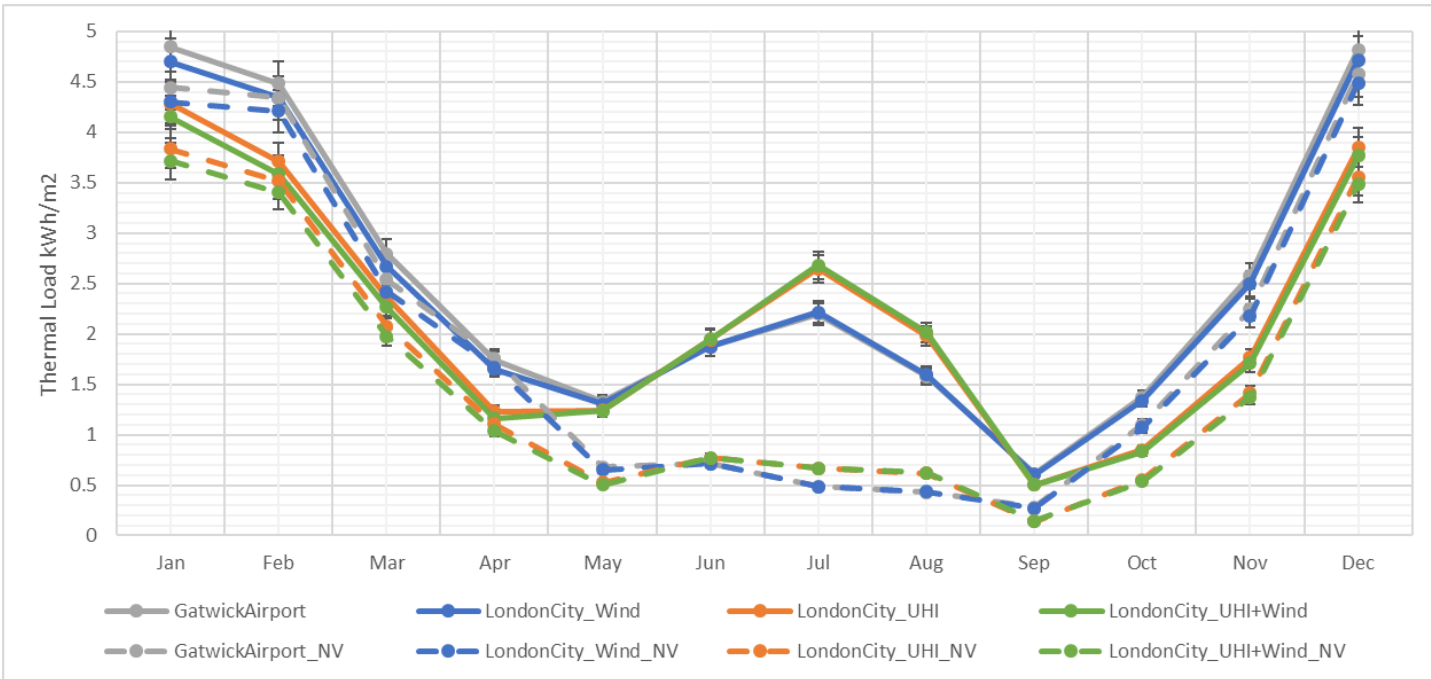

Figure 63: Thermal loads for 4 weather data with an HVAC system and with a natural ventilation system (NV)

In Figure 64, for an urban weather file considering both the UHI and urban winds, thermal loads of a natural ventilation system (LondonCity_UHI+Wind_NV) are compared with those of an HVAC system (LondonCity_UHI+Wind) at different floors. The impacts of height on natural ventilation are similar to those on HVAC systems. Thermal loads increase with height for most of the year while in summer they decrease slightly with height, when using an HVAC system and a natural ventilation system. 


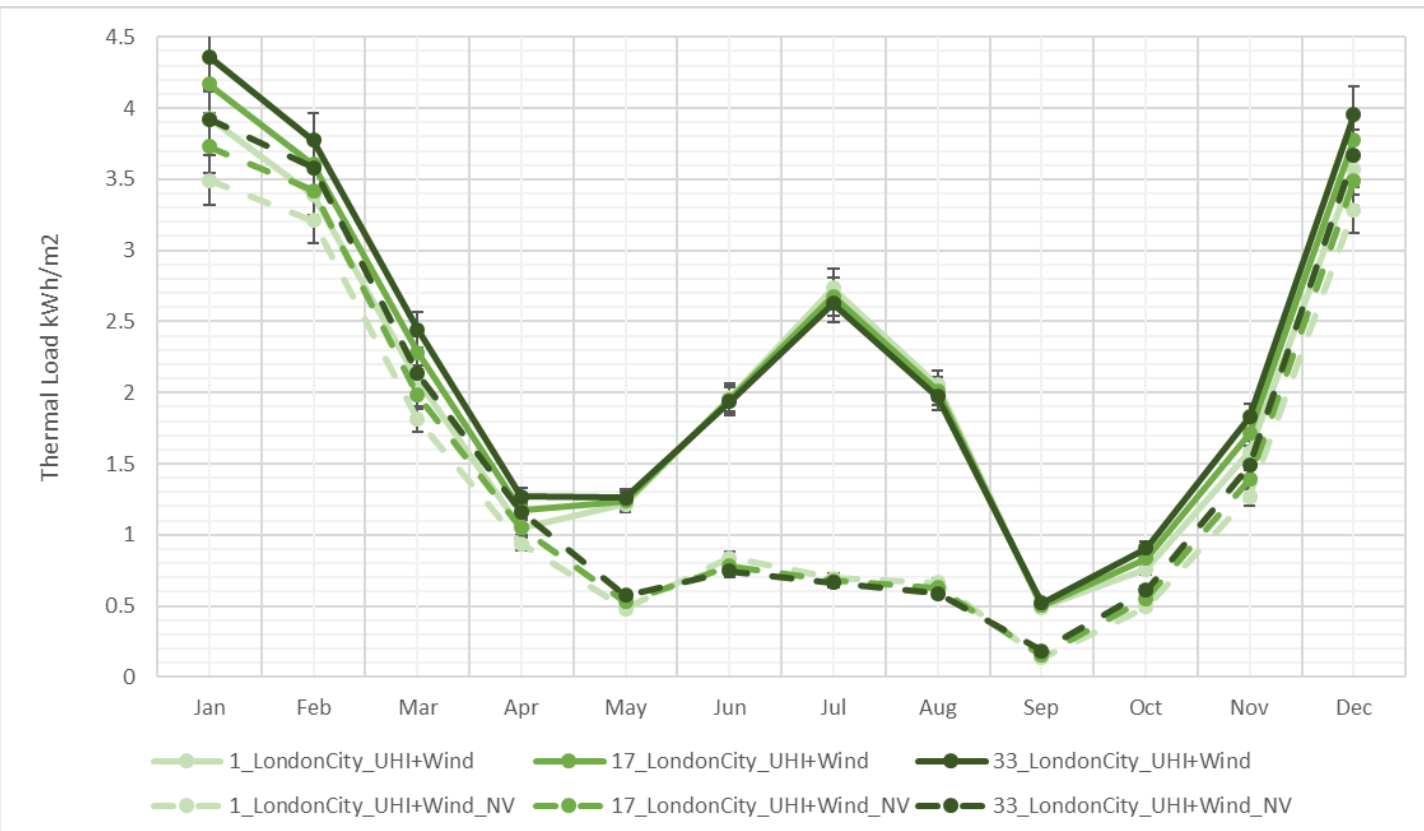

Figure 64: Thermal loads of urban weather data at the $1^{\text {st }}, 17^{\text {th }}$ and $33^{\text {rd }}$ floors with an HVAC system and with a natural ventilation system (NV)

The cooling change between an HVAC system and a natural ventilation system is cooling loads of an HVAC system minus cooling loads of a natural ventilation system (HVAC-NV). HVAC-NV is short for the change between those two systems. Figure 65 shows the reduction of cooling load predictions due to natural ventilation. The cooling changes at different heights are similar. natural ventilation reduces more cooling load predictions when considering the combined effect of the UHI and urban winds.

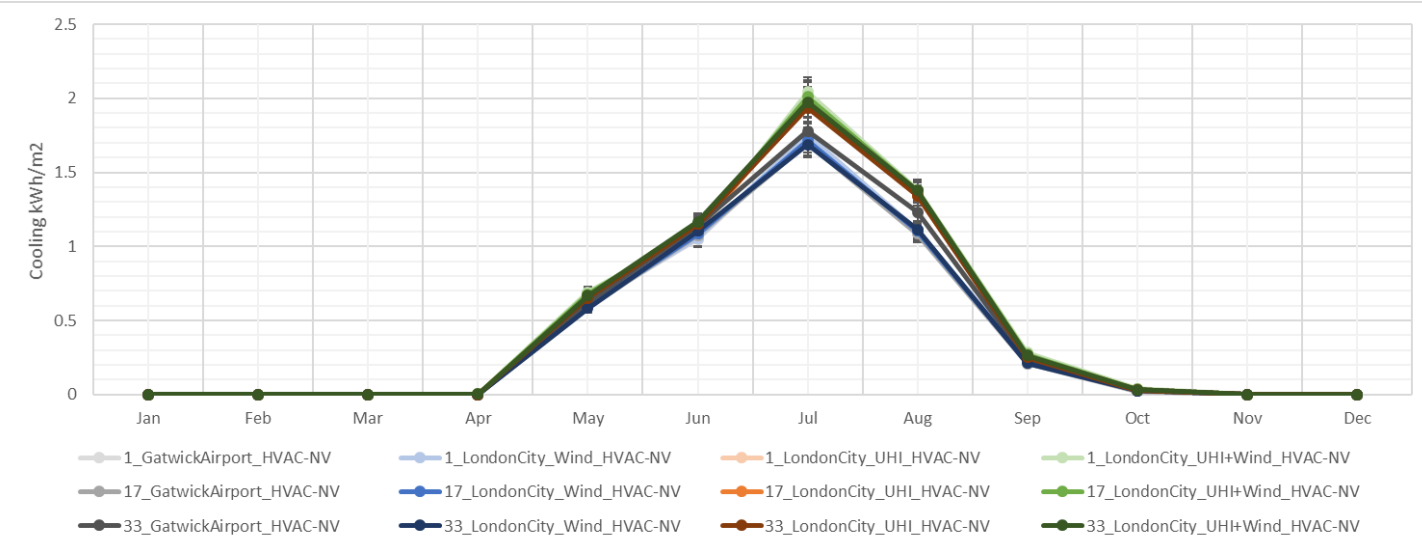

Figure 65: Cooling changes for 4 weather data at the $1^{\text {st }}, 17^{\text {th }}$ and $33^{\text {rd }}$ floors between an HVAC system and a natural ventilation system (HVAC-NV)

What are the respective effects of the UHI and urban winds on natural ventilation systems? Compared to an HVAC system (Figure 60), does the influence increase or not? The thermal loads considering the UHI (LondonCity_UHI_NV) and the thermal loads considering urban winds (LondonCity_Wind_NV) are compared to the thermal loads using rural weather data (GatwickAirport_NV). For a natural ventilation system, 
the thermal load percentage changes due to the UHI and urban winds are shown in Figure 66.

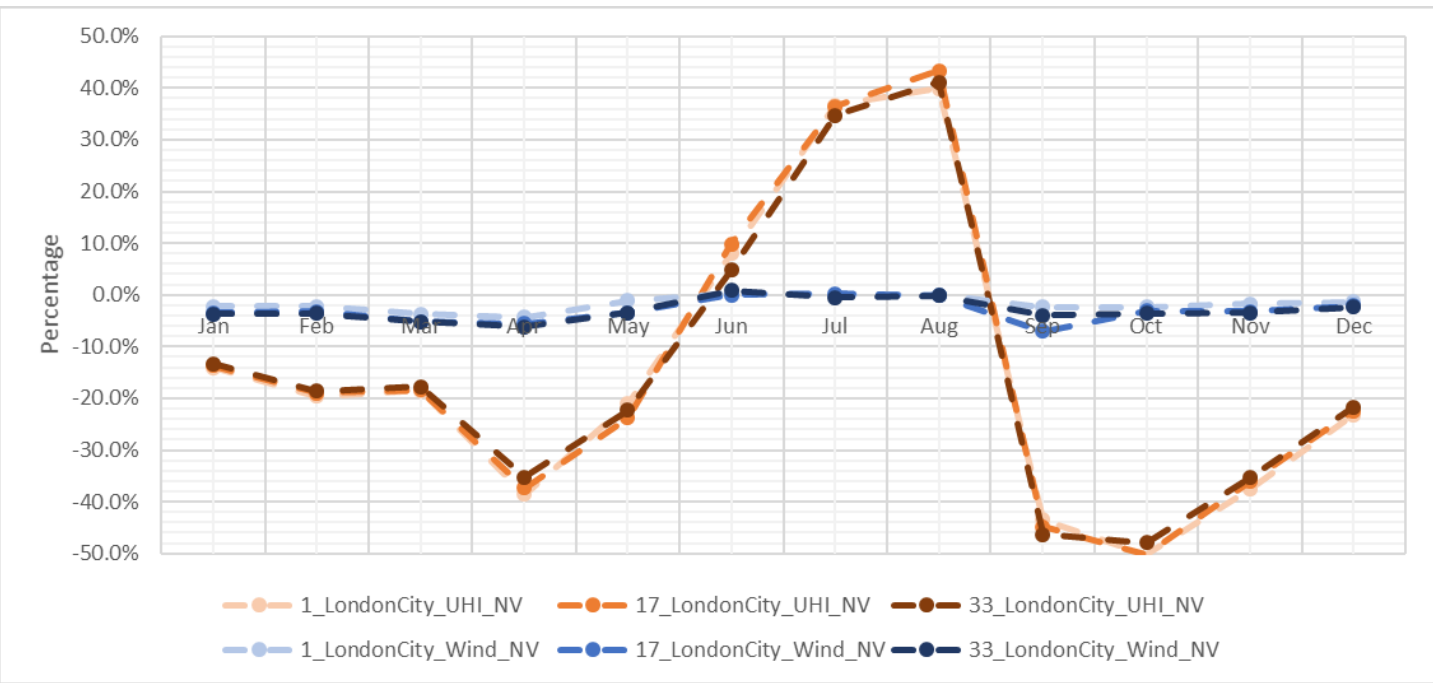

Figure 66: Thermal load percentage changes at the $1^{\text {st }}, 17^{\text {th }}$ and $33^{\text {rd }}$ floors of the UHI and urban winds with a natural ventilation system (NV) over an HVAC system

For natural ventilation systems, the effects of UHI are much bigger than urban winds (Figure 66). Compared with the effects on an HVAC system, Figure 60 and Figure 66 show that the effects of the UHI on natural ventilation systems are bigger than those on HVAC systems, and the effects of urban winds are similar. Therefore, when designing a natural ventilation system for a project, it is necessary to consider the influence of the $\mathrm{UHI}$ in the project site to optimize the design.

\subsubsection{Vertical variation}

When exploring the effect of height in Section 5.5.2, the research found cooling loads decrease with height, and heating loads increase with height. That is because of the vertical variations of urban microclimates. The wind speed increases with height, and temperature decreases with height. How these changes impact the simulation results was explored by adding the following additional variables into an EnergyPlus model. The terrain was set as a city. The additional variables were changed from the corresponding value of a city to zero, except that the boundary layer thickness which could not be zero. The Wind Speed Profile Exponent is a parameter to describe the wind profile using Power-law. The exponent corresponding to a city is 0.33 . The Wind Speed Profile Boundary Layer Thickness is the height reached the free stream velocity. The thickness corresponding to a city is $460 \mathrm{~m}$. The Air Temperature Gradient Coefficient is related to the Lapse Rate and the default value is $0.0065 \mathrm{~K} / \mathrm{m}$. Then the 
Wind Speed Profile Exponent and the Air Temperature Gradient Coefficient were changed to 0 (Table 24). The Wind Speed Profile Boundary Layer Thickness was changed to $200 \mathrm{~m}$, because it had to be more than 0 and the one corresponding to the ocean is $210 \mathrm{~m}$ and $200 \mathrm{~m}$ was taken as an approximate value. The Wind Speed Profile Boundary Layer Thickness was set to be slightly smaller than that of the ocean. HV is short for HeightVariation.

Table 24: With and without height variations

\begin{tabular}{llc}
\hline HeightVariation $(\mathbf{H V})$ & City & Without height variations \\
\hline Wind Speed Profile Exponent & 0.33 & 0 \\
Wind Speed Profile Boundary Layer Thickness $\{\mathrm{m}\}$ & 460 & 200 \\
Air Temperature Gradient Coefficient $\{\mathrm{K} / \mathrm{m}\}$ & 0.0065 & 0 \\
\hline
\end{tabular}

For an HVAC system, the thermal loads with height variations (HV) (GatwickAirport_HV, LondonCity_HV, LondonCity_UHI_HV and LondonCity_UHI+Wind_HV) were compared to the thermal loads without height variations (Figure 67).

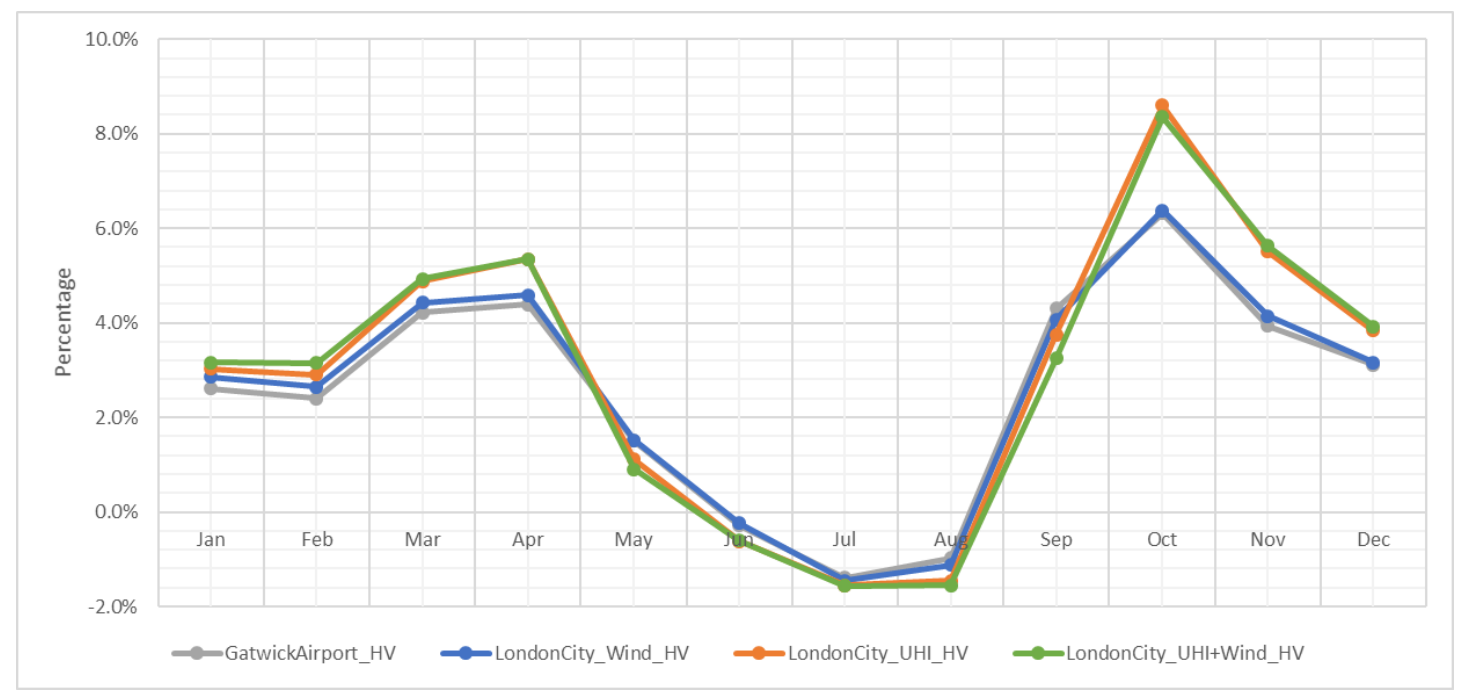

Figure 67: Thermal load percentage changes for 4 different weather data with height variations (HV) over without height variations for an HVAC system

Figure 67 shows the thermal load percentage changes between with and without height variations of microclimates. The effects of height variations are less than $9 \%$ for all 4 kinds of weather data. Height variations increase the heating load in winter and reduce the cooling load in summer because the percentage change in summer is negative and in winter is positive. 
For a natural ventilation system (NV), the thermal loads with height variations (HV) (GatwickAirport_NV_HV, LondonCity_NV_HV, LondonCity_UHI_NV_HV and LondonCity_UHI+Wind_NV_HV) were compared without the thermal loads with height variations (Figure 68).

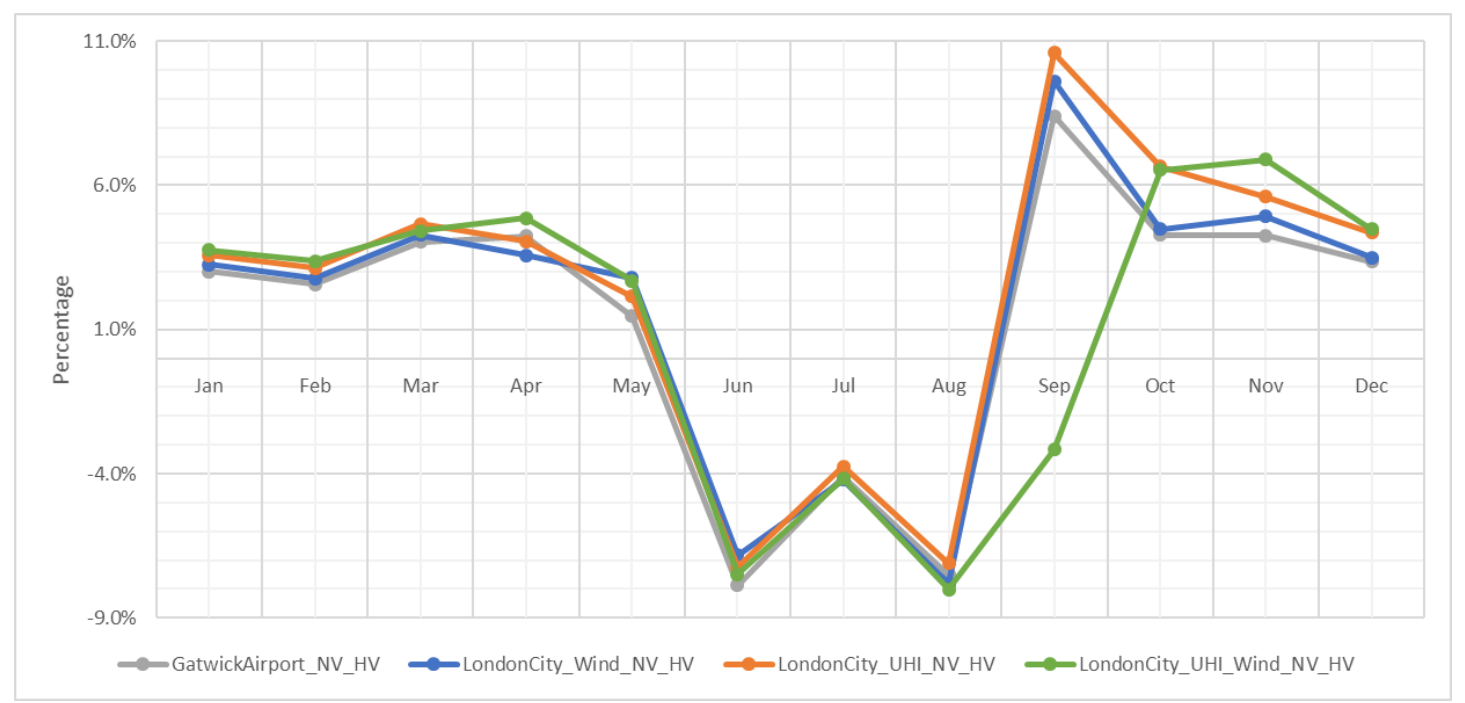

Figure 68: Thermal load percentage changes of 4 weather data with height variations (HV) over without height variations for a natural ventilation system $(\mathrm{NV})$

For a natural ventilation system, the effects of height variations are less than $11 \%$. Figure 68 shows the effects of height variations on a natural ventilation system are a little bigger than those on an HVAC system. The thermal load reduction due to height variations in summer on a natural ventilation system are much bigger than that on an HVAC system. The effects of height variations on using different weather data are similar, but on using different ventilation systems they are different.

Thermal load changes between with and without height variations at different floors are shown in Figure 69. It can be seen that the effects of height variations increase with height. 


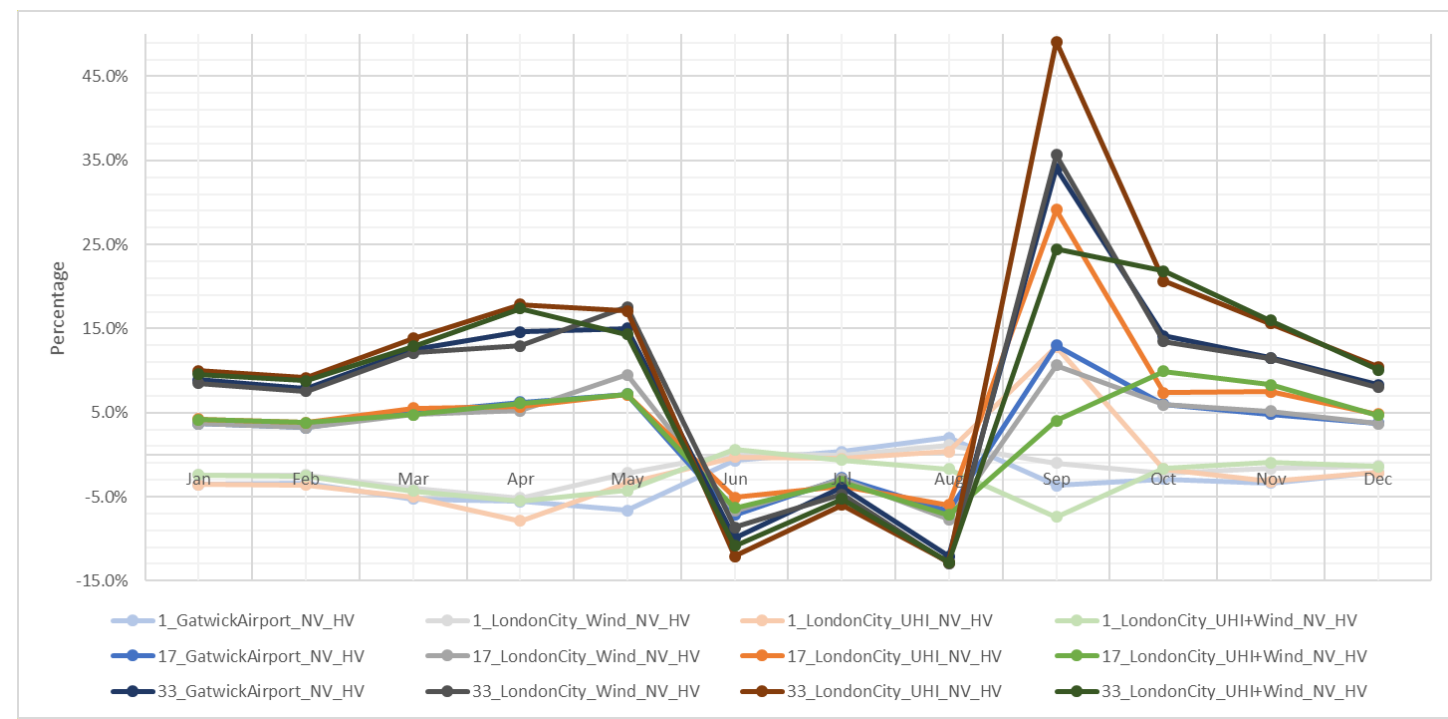

Figure 69: Thermal load changes of 4 weather data with height variations (HV) over without height variations for a natural ventilation system $(\mathrm{NV})$ at the $1^{\text {st }}, 17^{\text {th }}$ and $33^{\text {rd }}$ floors

This section demonstrates the necessity of exploring the influence of vertical variations of urban microclimates, because the influence of vertical variations is significant and it increases with height (Figure 67-Figure 69). Therefore, the next step is to investigate the influence of the precision of vertical variations. In designing high-rise buildings, engineers should consider the impact of vertical variations and the feasibility of using natural ventilation systems.

\subsection{Chapter Summary}

- Accounting for UHI effects results in a more than $10 \%$ variation in the performance simulation results.

- Accounting for the variation in winds between open field and urban environments results in a less than $5 \%$ variation in the performance simulation results, and its influence increases with height.

- Natural ventilation efficiency is affected by UHI effects and height.

- Vertical variation of microclimate has an around $10 \%$ impact on the performance simulation results and its influence increases with height a lot.

This chapter has confirmed that the urban microclimate effects on building performance can be modelled. This generic modelling has also confirmed that the effects are potentially of sufficient size that more detailed modelling is required.

At present, the wind model is a generic model, recognizing that the natural rate of increase of wind speed with height is much slower in cities than in rural areas, where 
weather files for building simulation are typically measured. These generic models are well-validated. This wind model needs to consider the specific aerodynamics of the real geometry of a city. The next stage of this research is to evaluate how the vertical variations of urban winds influence the building performance.

Similarly, the generic horizontal plane definition of the Urban Heat Island needs to be tested to determine how to make it specific to a particular urban geometry. Whether or not the vertical variation of temperature changes the building performance at different heights a lot will be explored in the next stage. 


\section{CHAPTER 6. VERTICAL VARIATION EFFECTS ON BUILDING PERFORMANCE AND NATURAL VENTILATION}

\subsection{Chapter Intent}

Chapter 5 confirmed that rough urban weather data and rough vertical variations of urban microclimates influence the simulation results of a prototypical high-rise building's performance. In this chapter, the urban microclimate profile is addressed, such as the wind profile and the temperature profile. The effects of vertical variations of urban microclimates on energy performance predictions were explored. How these vertical variations affect the natural ventilation at different heights was analysed as well.

\subsection{Urban Microclimate Profile}

Urban microclimate profile is different from rural microclimate profile due to the difference of topography between urban and rural areas. Compared with rural areas, dense buildings in urban areas change wind and temperature profiles. According to the research of Lee, the mean wind speed in city centre of London is always lower than the mean wind speed in the surrounding rural areas, with $20-30 \%$ due to the roughness of urban surface (Lee, 1979). The wind profile and wind profile depth are influenced by the high surface roughness caused by high-rise buildings in central London. Likewise, the UHI monthly averaged Dry Bulb Temperature was approximately 10\% higher than the temperature of surrounding rural areas (Section 4.4.3). Also, the lapse rate is much higher in urban areas than in the non-urban areas, especially in summer (Bokwa, 2015). The urban wind profile and the temperature profile of central London were reproduced based on the observed data in this chapter.

Urban microclimate data was not widely available, but weather data from airports is always accessible. A substitute for urban microclimate data converted from rural weather data and accounting for the UHI and the reduction of urban wind speed was used. The results of based on revised urban weather data were then compared with those from the original and common urban weather data to determine how the revised data influences the results. 


\subsubsection{Urban wind profile}

The Atmospheric Boundary Layer (ABL) is the air layer near the earth's surface which is influenced by the earth's surface. The ABL is characterized by the turbulence of airflow due to the roughness of earth's surface. The height of the boundary layer is based on the turbulence generated by the surface (Oke, 1978). The Urban Boundary Layer (UBL) is the boundary layer over a city, which is characterized by the turbulence caused by the roughness of urban areas. The roughness length of a city is bigger than that in rural areas, and the lower portion of UBL extends up to $10 \%$ of the depth of the boundary layer (Ricciardelli \& Polimeno, 2006). The urban wind profile described in this paper is the vertical distribution of wind speed within the lowest part of UBL. Generally, there are two mathematical models to represent the mean wind speed at different heights, namely the logarithmic law and the power-law (Manwell et al., 2010).

\subsubsection{Power-law}

The power-law model is more widely used because it is easy to use (Davenport, 1960). The power-law formula of wind profile is an empirical formula, not a theoretical formula. The exponent, $\alpha$, produces the best match of wind speed predictions and observations between two heights (Drew et al., 2013).

$$
\frac{U_{(z)}}{U_{\left(z_{r e f}\right)}}=\left(\frac{z}{z_{r e f}}\right)^{\alpha}
$$

The $U_{\left(z_{r e f}\right)}$ is the mean wind speed at the reference height $Z_{r e f}$; and $\alpha$ is the exponent which represents the ground roughness (Q. S. Li et al., 2010). The Wind Speed Profile Exponent in Section 5.5.4 was based on this power-law formula.

\subsubsection{2 $\underline{\text { Log law }}$}

The log law wind profile formula uses a logarithm to extrapolate the vertical distribution of mean wind speeds and is also empirical. The formula is given by (Davenport, 1960).

$$
U_{(z)}=\left(\frac{U_{0}^{*}}{\kappa}\right) \ln \left(\frac{Z}{Z_{0}}\right)
$$

Where $Z_{0}$ is the surface roughness length; $U_{0}^{*}$ is the surface friction velocity; $\kappa$ is von Karman's constant; $U_{(z)}$ is the mean wind speed at height z (Q. S. Li et al., 2010). The roughness length in open areas is generally smaller than that in areas with lots of 
obstacles such as buildings, which means that the magnitude $Z_{0}$ of rural areas is smaller than that of urban areas. The roughness length in Section 3.3.1.1.2 and Section 4.2 was based on this log law formula.

\subsubsection{Reliability of logarithmic and power-law wind profile}

In Johnson's research, an examination of the vertical wind profile in the lowest layer of the atmosphere was taken. The relative accuracy of the logarithmic and power-law wind profile was analysed, and compared with the logarithmic law, the power-law represented the data better (Johnson, 1959). In Drew et al.'s research, the log wind profile was addressed as valid in the inertial sublayer (Drew et al., 2013). Nicholas John Cook considered a log wind profile representation better than a power-law representation between $10 \mathrm{~m}$ and $20 \mathrm{~m}$ height (Nicholas John Cook, 1985). From $20 \mathrm{~m}$ to $100 \mathrm{~m}$, both can predict the realistic mean wind speed. However, over a height of $100 \mathrm{~m}$, the power-law estimated the more reliable mean wind speed within ABL (Nicholas John Cook, 1985). While Tieleman and Nicholas J. Cook considered the logarithmic law wind profile, it does not produce as reliable predictions of wind speed as power-law above around $200 \mathrm{~m}$ height (Nicholas J. Cook, 1997; Tieleman, 2008).

\subsubsection{Urban atmospheric boundary layer height/thickness}

Urban boundary layer (UBL) height or thickness is the atmospheric boundary layer (ABL) height over urban areas. Above the ABL is the free atmosphere. Under the free atmosphere, there is a mixed layer in the upper part of ABL, and the well mixed height is the ABL height. The UBL is often diagnosed from vertical profiles of temperature, humidity and wind (Liu \& Liang, 2010). These profiles can be retrieved from measured data from lidar, sodar, radiosonde, satellite and other remote-sensing instruments. Lidar uses light from a laser, sodar is an acoustic radar, and radiosonde uses radio to transmit measurements. Because the mixed layer is typically moister and contains more aerosols than the free atmosphere, lidar can easily detect the boundary between the two layers (Boers et al., 1984; Flamant \& Pelon, 1996; Kunkel et al., 1977; Stull \& Eloranta, 1984). The resolution of lidars is a few tens of meters, and their repetition rate is a few tens of hertz. These make lidar one of the most appropriate systems for analysing the ABL structure and height (Menut et al., 1999). The ABL structure are more complex over urban areas than over rural areas due to the dense buildings and thermal radiation. 
The UBL height varies from time to time. On $14^{\text {th }}$ March, the UBL in Paris slowly deepened from around $350 \mathrm{~m}$ at $0975 \mathrm{GMT}$ to $600 \mathrm{~m}$ at $1625 \mathrm{GMT}$. On $21^{\text {st }}$ May, 2008, the UBL of Xi' an city was $424 \mathrm{~m}$ in the morning, increased to $827 \mathrm{~m}$ in the noon, and decreases to $204 \mathrm{~m}$ at night (Du et al., 2013).

The UBL height also varies when different measurement or calculation methods are used. The difference between the radiosonde and the lidar ABL heights was within 100 $\mathrm{m}$ to $300 \mathrm{~m}$, or $10 \%$ (Cooper \& Eichinger, 1994). The ABL heights calculated by Nozaki method are generally higher than those calculated by Liu method (Du et al., 2013). The difference of the ABL heights between radiosonde and sodar data is around \pm 167 m (Liu \& Liang, 2010).

The UBL height changes with time and measured or calculation methods. How will the UBL height errors produced by these factors influence the urban microclimate modelling, and will the urban microclimate modelling impact the building performance simulation?

\subsubsection{Urban temperature profile}

The typical temperature profile for the vegetation canopy is not the same as that for the urban canopy, because urban surface geometries are more complex than the vegetation (Kanda et al., 2005). The lapse rate is the temperature falling rate with altitude (Jacobson, 2005). If the temperature increases with height, the phenomenon is called an inversion. N. J. Tapper found the dominance of nocturnal inversion conditions at both urban and rural sites of Christchurch (Tapper, 1990). Low building density and high vegetation coverage are partially responsible for the high rate of urban nocturnal inversions. According to the research of M. Kanda, R. Moriwaki and Y. Kimoto, the height of the maximum temperature with in and above the urban canopy of Tokyo varied with the season (Kanda et al., 2005). The maximum temperature was at the roof level in winter but near the ground in summer. Hence, there are inversion conditions in winter under the building height. In New York City, the inversion of urban surface temperature is not as strong as that of non-urban regions, and the inversion layer height of $310 \mathrm{~m}$ was observed over suburban areas (Bornstein, 1968). In Columbus, Ohio, there is a lapse rate when the wind is from the northwest and an inversion when the wind is from the southwest or southeast (Angell et al., 1971). 
Due to the UHI effects, the urban temperature is generally higher than the rural temperature. The urban temperature excess decreases with height (Bornstein, 1968). The urban temperature excess decreased to zero at $300 \mathrm{~m}$ in both the Christchurch and New York, and at $700 \mathrm{~m}$ in Montreal. In Christchurch, the diurnal mean rural lapse rate of $0.0043 \mathrm{~K} / \mathrm{m}$ was slightly larger than the urban lapse rate of $0.00375 \mathrm{~K} / \mathrm{m}$ (Tapper, 1990). In New York City, the urban lapse rate was around $0.0043 \mathrm{~K} / \mathrm{m}$ in the morning of $16^{\text {th }}$ July 1964 York (Bornstein, 1968). In Montreal, the urban lapse rate was around $0.0035 \mathrm{~K} / \mathrm{m}$, the suburban lapse rate $0.0041 \mathrm{~K} / \mathrm{m}$ and the rural lapse rate $0.0043 \mathrm{~K} / \mathrm{m}$ on February 22, 1968 at 0700 EST (Oke \& East, 1971).

The urban temperature profile varies with time, the season and the wind direction. How will the temperature gradient influence the building performance simulation? Is the precision of the urban temperature gradient important for urban microclimate modelling?

\subsection{Urban Microclimate Profile of London}

\subsubsection{Urban wind profile of London}

To improve the accuracy of simulation, measured values were collected to replace assumed or stipulated values because they could reduce biases (Guideline, 2002). The vertical distribution of urban wind in London was replicated according to the observed data (Drew et al., 2013). In Drew et al.'s research, a Dopplar lidar was used to obtain weather data for 8 months in London city centre. The wind data was used to develop the mean wind speed profile of central London (Figure 70). According to the sorted data, the exponent of the mean wind speed profile of central London for around 2500 $\mathrm{m}$ height was 0.4237 .

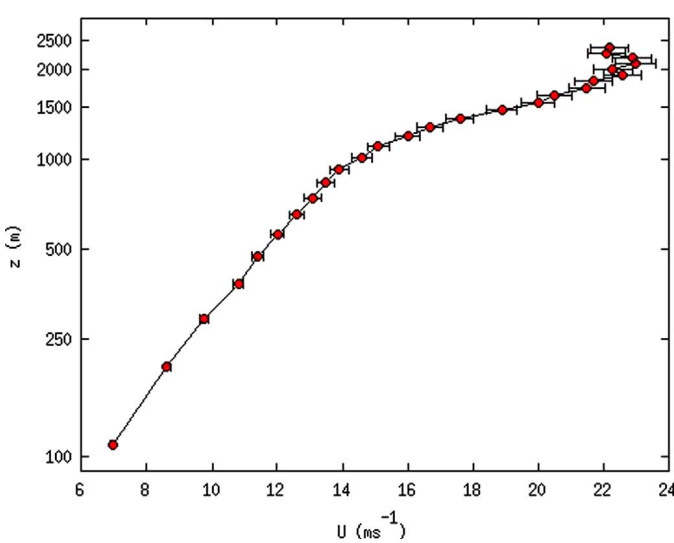

(a)

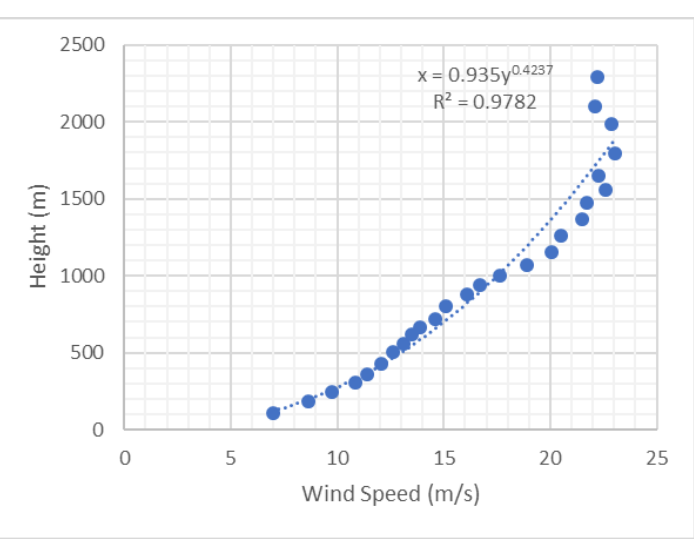

(b)

Figure 70: The mean wind speed profile averaged within $4578 \mathrm{~h}$ (Drew et al., 2013) and data sorted out 
In Figure 71, it can be seen that the end of the trendline does not match the observed data from $1000 \mathrm{~m}$ to $2500 \mathrm{~m}$. The trendlines for $1500 \mathrm{~m}, 1000 \mathrm{~m}$ and $500 \mathrm{~m}$ heights are then reproduced, and the value of the power-law exponents are $0.4383,0.3962,0.3996$. The exponents 0.3962 for $1000 \mathrm{~m}$ and 0.3996 for $500 \mathrm{~m}$ heights are incredibly similar, and trendlines match well with data. The exponents are very close to 0.4 . Hence, 0.4 was taken as the exponent of the London urban wind profile in this research.

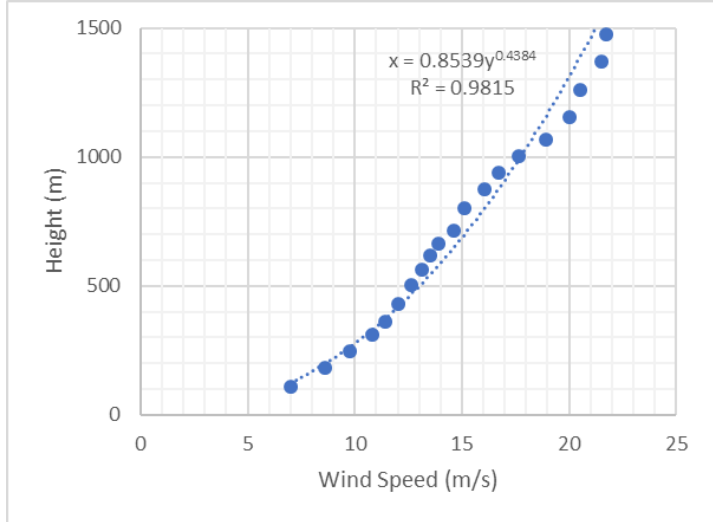

(a) $1500 \mathrm{~m}$

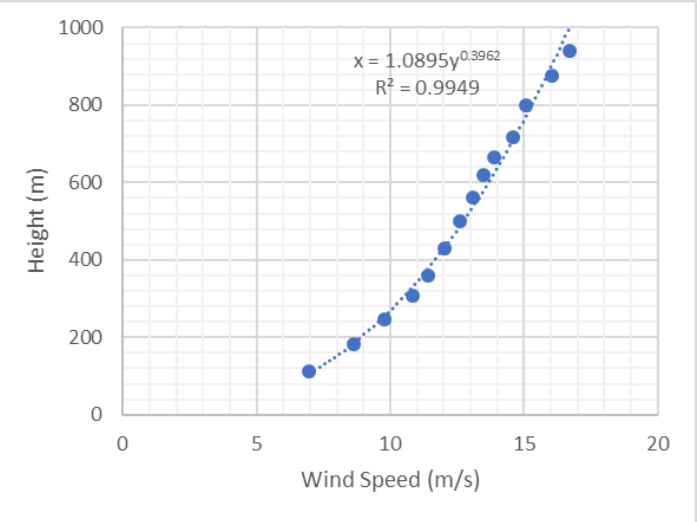

(b) $1000 \mathrm{~m}$

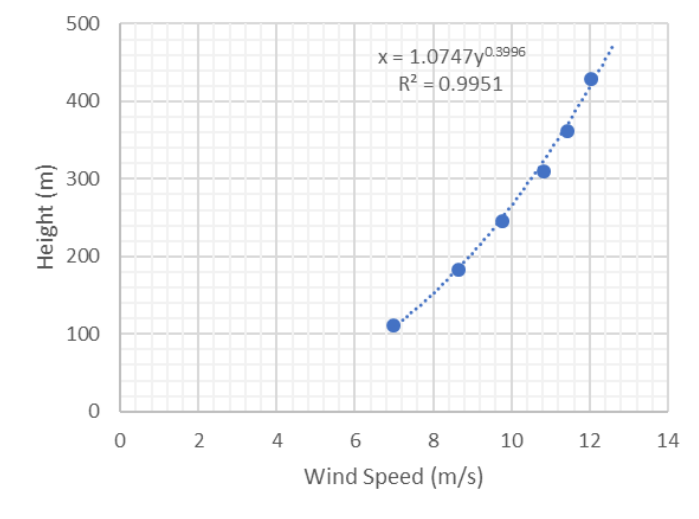

(b) $500 \mathrm{~m}$

Figure 71: Modified mean wind speed profile for the height of $1500 \mathrm{~m}, 1000 \mathrm{~m}$ and $500 \mathrm{~m}$

Table 25 shows the relative exponent values and boundary layer thickness of different terrain. The experimentally determined value 0.4 is quite different from the value of 0.33 recommended in the ASHRAE Fundamentals (Handbook-Fundamentals, 2009). It recommends caution in accepting such general guidance in design. 
Table 25: Wind Speed Profile Coefficients (Handbook-Fundamentals, 2009)

\begin{tabular}{cccc}
\hline Terrain & Terrain Description & Exponent & $\begin{array}{c}\text { Boundary Layer } \\
\text { Thickness(m) }\end{array}$ \\
\hline Country & Flat, open country & 0.14 & 270 \\
\hline Suburbs & Rough, wooded country & 0.22 & 370 \\
\hline City & Towns and cities & 0.33 & 460 \\
Ocean & Ocean & 0.10 & 210 \\
\hline & Urban, industrial, forest & 0.22 & 370 \\
\hline
\end{tabular}

\subsubsection{Urban atmospheric boundary layer thickness of London}

Due to the increased turbulence caused by higher terrain roughness, the boundary layer thickness in urban areas increases significantly compared with that in rural areas (Rigby \& Toumi, 2008). In 1988 it was found that the mixing height of central London was $50-100 \mathrm{~m}$ higher than that of rural areas $50 \mathrm{~km}$ away (Spanton \& Williams, 1988). According to Rigby and Toumi's study, compared to rural areas, the boundary layer depth of central London increased by around $100 \mathrm{~m}$ (Rigby \& Toumi, 2008). In the 20 years since then, hundreds of high-rise buildings have been built in London. As a result, the urban boundary layer thickness is expected to be even greater in parts of London. Bohnenstengel et al. determined the UBL of London be approximately $400 \mathrm{~m}$ to $500 \mathrm{~m}$ deep and relatively invariable (Bohnenstengel et al., 2014). The ASHRAE handbook of Fundamentals suggests a similar value: 460 m (Handbook-Fundamentals, 2009).

\subsubsection{Urban temperature profile of London}

Similar to the wind data, the original temperature data of London was also based on the weather data collected from weather stations in rural areas. To convert the temperature data from rural areas to urban areas, the first step was to consider the $10 \%$ increase in the monthly average due to the UHI (Chapter 5). The second step was to replicate the vertical distribution of the urban temperature. After two steps of conversion, the urban temperature profile of central London was reproduced based on data from a rural weather station.

Barlow et al. used radiosondes to measure potential temperature from 28 September to 2 October in rural areas (Barlow et al., 2015). To get the absolute temperature profile, it is necessary to convert the potential temperature to the absolute temperature. 


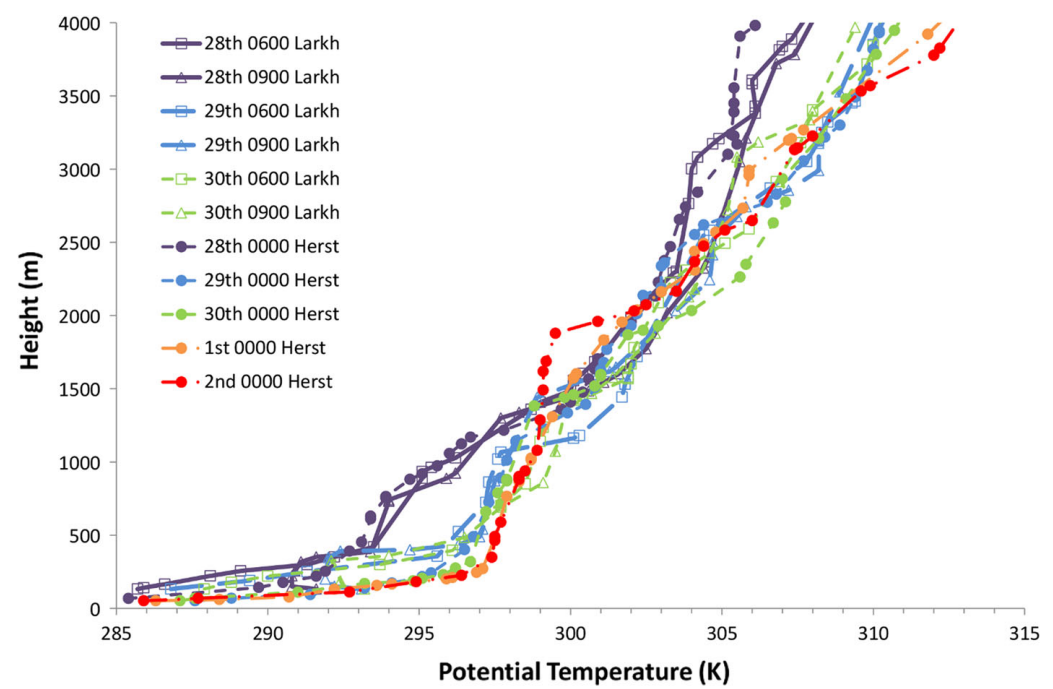

Figure 72:Potential temperature profile measured from Larkhill and Herstmonceux (Barlow et al., 2015)

Figure 72 shows the potential temperature values at different heights. At first, collect the data to get average potential temperature values. Then convert the height to air pressure according to the barometric formula.

$$
p=p_{0} \cdot\left(1-\frac{L \cdot h}{T_{0}}\right)^{\frac{g \cdot M}{R_{0} \cdot L}}
$$

Finally, use the known potential temperature $\theta$ and relative air pressure $\mathrm{P}$ to get absolute temperature $\mathrm{T}$ according to the following formula, and usually the reference pressure $P_{0}=1000 \mathrm{hPa}$ and $R / c_{p}=0.286$.

$$
\theta=T\left(\frac{P_{0}}{P}\right)^{R / c_{p}}
$$

After the previous calculation, absolute temperature values and relative heights are shown in Figure 73. Figure 73 also shows the relationship between temperature and height. The air temperature increase with height and then decreases with height. Overall, air temperature decreases by approximately $4.2 \mathrm{~K}$ every $1000 \mathrm{~m}$. 


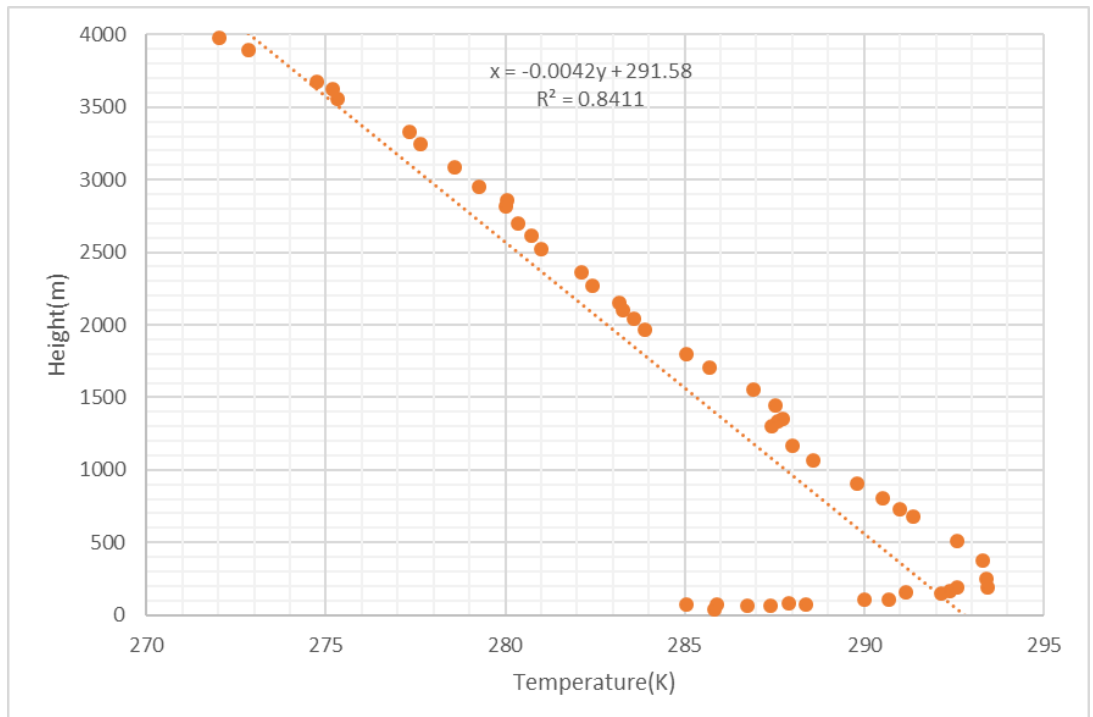

Figure 73: Absolute temperature profile converted from potential temperature profile

The trendline in Figure 73 is divided into two parts at the height of $200 \mathrm{~m}$. Figure 74 shows under $200 \mathrm{~m}$ the temperature has an upward trend. Near the ground, air temperature increases with height. At a certain height, the air temperature starts to decrease by around $5.5 \mathrm{~K}$ every $1000 \mathrm{~m}$.

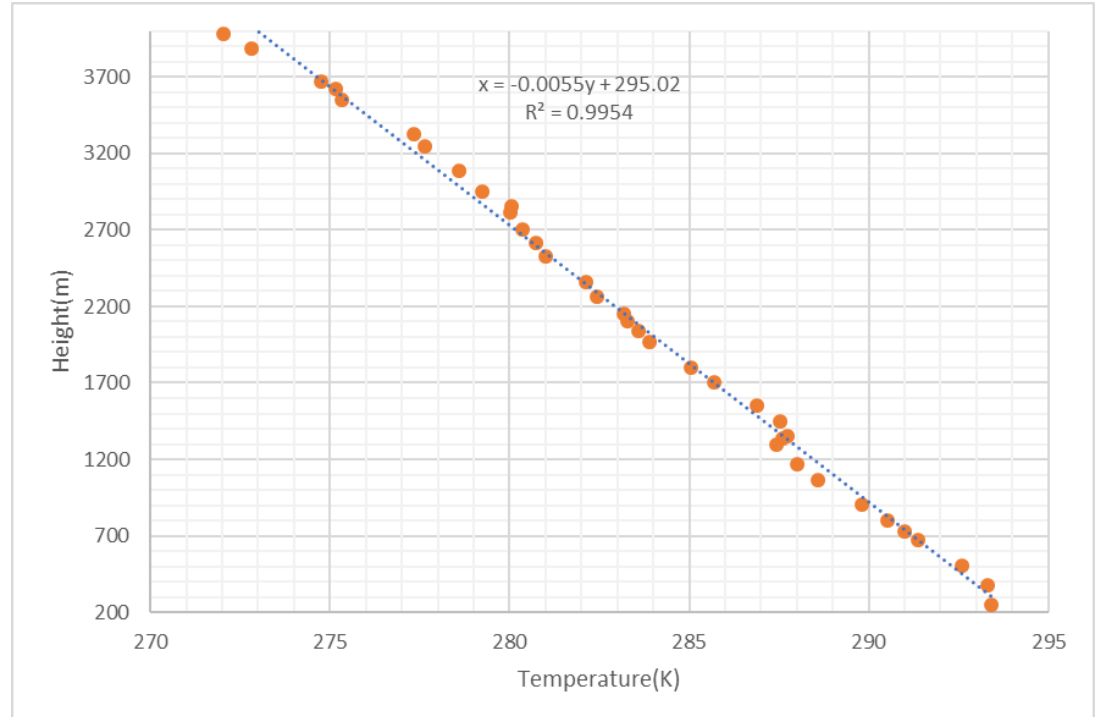

(a) $200-4000 \mathrm{~m}$

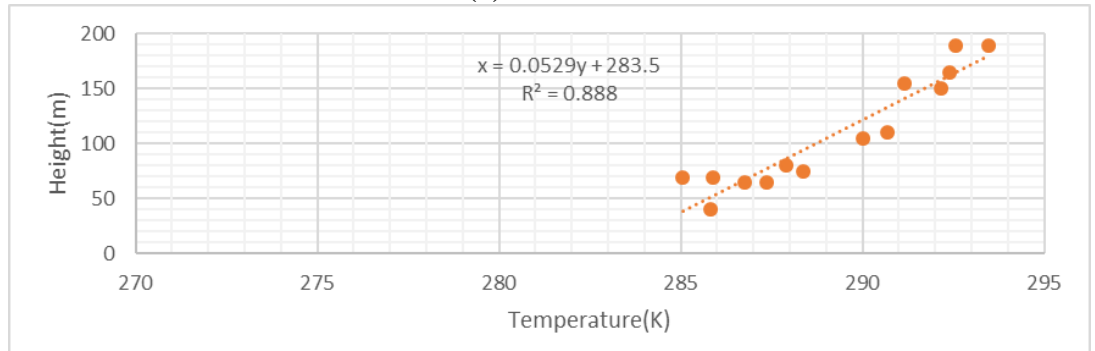

(b) $0-200 \mathrm{~m}$

Figure 74: Upward trend part and downward trend part of the absolute temperature profile 
In Kukkonen's research, they used a MM5 model, which is a mesoscale weather forecast model, to predict the temperature profiles of Herstmonceux, a suburban area of London, and the London Weather Centre(LWC), an urban area of London, (Kukkonen et al., 2005). Compared with the observational data from Herstmonceux, they predicted the structure of inversions fairly well, but they slightly under-predicted absolute values. In addition, the measured temperature profiles showed a slight groundbased temperature inversion under $200 \mathrm{~m}$. The predicted model for the LWC site in the centre of London shows the temperature profile from $17^{\text {th }}$ to $22^{\text {nd }}$ February 2003 (Kukkonen et al., 2005).

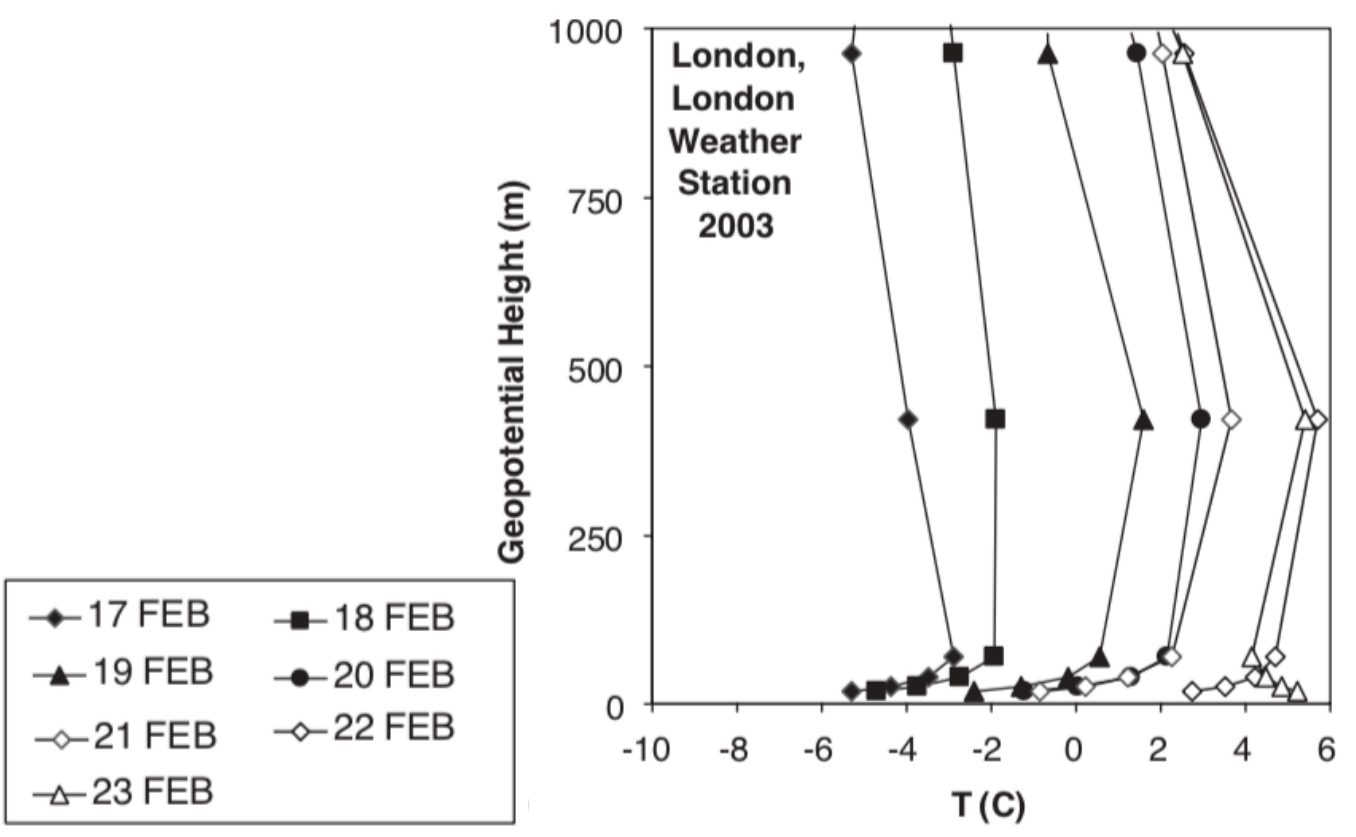

Figure 75: Predicted temperature profiles of LWC (Kukkonen et al., 2005)

Figure 75 shows the temperature gradient of LWC based on the data of Kukkonen's research and. The average temperature change rate with height is around 0.0002 , which means the air temperature increases by $0.2^{\circ} \mathrm{C}$ every $1000 \mathrm{~m}$. The temperature gradient indicates that the temperature decreases with height. Hence, it can be seen from Figure 76 that the temperature gradient of LWC is $-0.0002 \mathrm{~K} / \mathrm{m}$. 


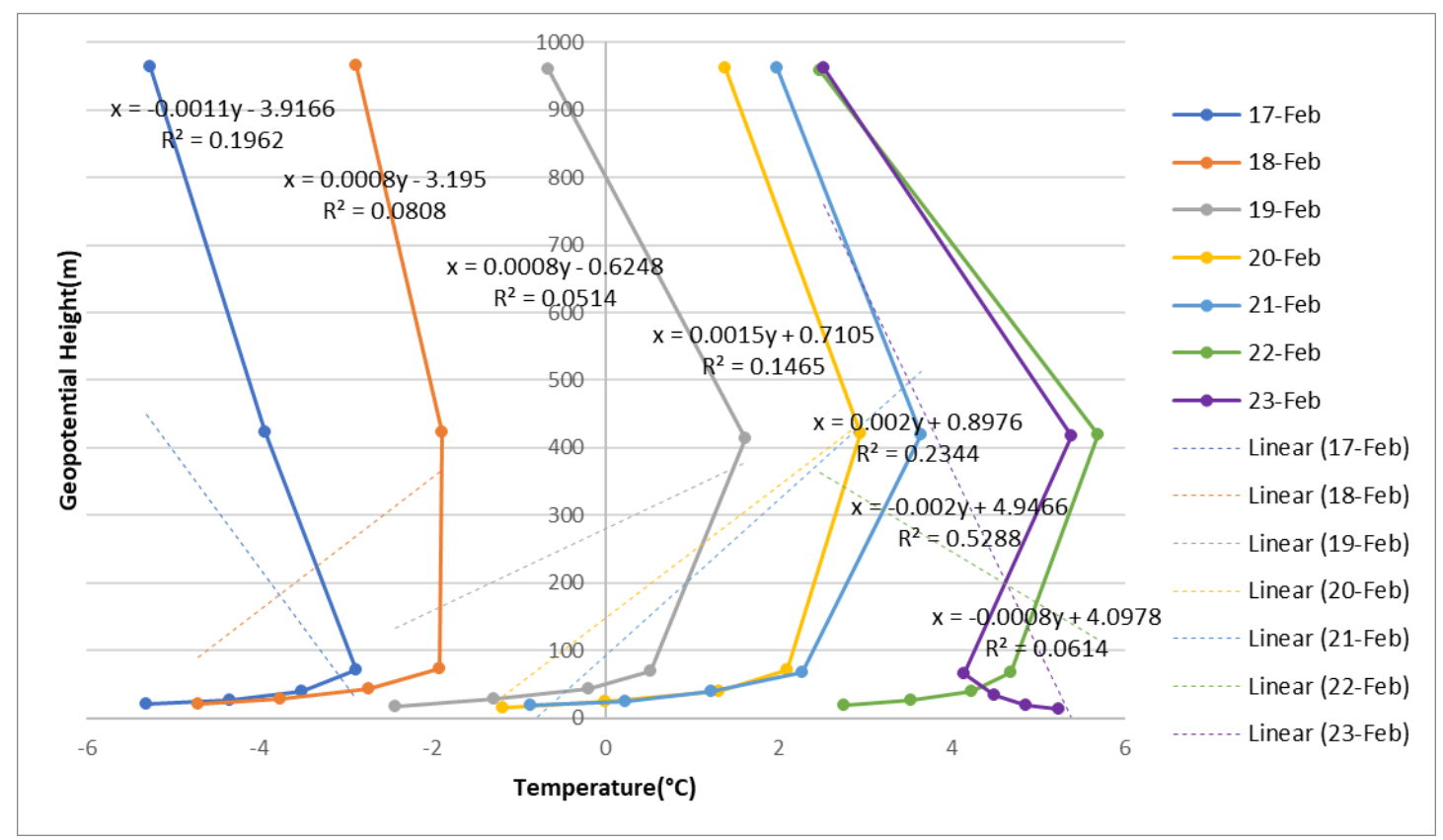

Figure 76: Temperature changes with the height of LWC

However, the minimum value of the temperature gradient set for EnergyPlus is $0 \mathrm{~K} / \mathrm{m}$ (Figure 77), and cannot be negative. If it is set -0.01 , the simulation will not run correctly because of this severe error:

Overall, the predicted temperature gradient of LWC from Kukkonen's research is very close to $0 \mathrm{~K} / \mathrm{m}$.

\begin{tabular}{|l|l|l|}
\hline Field & Units & \multicolumn{1}{|l|}{ 0bj1 } \\
\hline Wind Speed Profile Exponent & & \\
\hline Wind Speed Profile Boundary Layer Thickness & $\mathrm{m}$ & \\
\hline Air Temperature Gradient Coefficient & $\mathrm{K} / \mathrm{m}$ & 0 \\
\hline & & $\mathbf{0}$ \\
\hline & & $\mathbf{0 . 0 0 6 5}$ default \\
& & $\mathbf{0}$ minimum \\
\hline
\end{tabular}

Figure 77: Air temperature gradient coefficient minimum value of EnergyPlus

\subsubsection{Vertical variation Settings of London microclimate}

A set of parameters was analysed to explore their impacts on performance (Table 26). Two groups used rural weather data (R1-R2) and 11 groups used urban weather data (U1-U11). R was short for rural and U was short for urban. The settings of R1 and U1 were close to without vertical variations. Vertical variations of R2 was for terrain of open country. The parameters of U2-U4 were based on the Wind Speed Profile Exponent and the Wind Speed Profile Boundary Layer Thickness of different terrain (Table 25). U2-U4 could be used to explore the impact of the wind speed profile. U5U7 kept the Wind Speed Profile Exponent and the Air Temperature Gradient the same to explore the influence of the Wind Speed Profile Boundary Layer Thickness. U8-U11 
kept the Wind Speed Profile Exponent and the Wind Speed Profile Boundary Layer Thickness the same to explore the impact of the Air Temperature Gradient. Two ventilation systems were applied to calculations which are an HVAC system and a natural ventilation (NV) system.

Table 26:Vertical Variation Settings

\begin{tabular}{|c|c|c|c|c|}
\hline $\begin{array}{l}\text { Weather } \\
\text { Data } \\
\text { Location }\end{array}$ & $\begin{array}{c}\text { Wind Speed } \\
\text { Profile Exponent }\end{array}$ & $\begin{array}{c}\text { Wind Speed Profile } \\
\text { Boundary Layer Thickness } \\
(\mathrm{m})\end{array}$ & $\begin{array}{l}\text { Air Temperature Gradient } \\
\text { Coefficient }(\mathrm{K} / \mathrm{m})\end{array}$ & $\begin{array}{l}\text { Serial } \\
\text { Number }\end{array}$ \\
\hline \multirow{2}{*}{$\begin{array}{l}\text { Rural- } \\
\text { Gatwick } \\
\text { Airport }\end{array}$} & 0 & 200 & 0 & $\mathrm{R} 1$ \\
\hline & 0.14 & 270 & 0.0065 & $\mathrm{R} 2$ \\
\hline \multirow{11}{*}{$\begin{array}{c}\text { Urban- } \\
\text { London } \\
\text { City Centre }\end{array}$} & 0 & 200 & 0 & U1 \\
\hline & 0.14 & 270 & 0 & $\mathrm{U} 2$ \\
\hline & 0.22 & 370 & 0 & U3 \\
\hline & 0.33 & 460 & 0 & U4 \\
\hline & 0.4 & 400 & 0 & U5 \\
\hline & 0.4 & 460 & 0 & U6 \\
\hline & 0.4 & 500 & 0 & U7 \\
\hline & 0.4 & 500 & 0.002 & U8 \\
\hline & 0.4 & 500 & 0.004 & U9 \\
\hline & 0.4 & 500 & 0.0065 & U10 \\
\hline & 0.4 & 500 & 0.01 & U11 \\
\hline
\end{tabular}

\subsection{Urban Microclimate Vertical Variation Effects}

\subsubsection{Vertical variations effects on thermal loads in rural and urban areas}

To explore the effects of vertical variations in rural and urban areas, thermal load predictions with vertical variations (R2, U8) were compared to those without vertical variations $(\mathrm{R} 1, \mathrm{U} 1)$. The thermal load percentage changes at the $1^{\text {st }}, 17^{\text {th }}$ and $33^{\text {rd }}$ floors using an HVAC system are shown in Figure 78, and using a natural ventilation system are shown in Figure 79. The effects of vertical variations in rural and urban areas were compared, and the effects on different ventilation systems were also compared.

When using an HVAC system, the effects increase with height in rural areas (Figure 78). Compared with without vertical variations (R1), vertical variations (R2) in rural areas show a less than $20 \%$ thermal loads change at the $33^{\text {rd }}$ floor. However, in urban areas, the effects do not increase with height. Vertical variations have the greatest impact on the $1^{\text {st }}$ floor. At the $1^{\text {st }}$ floor, the effects of vertical variations are bigger in 
urban areas than those in rural areas. While, at the $17^{\text {th }}$ and $33^{\text {rd }}$ floors, the effects are smaller in urban areas than those in rural areas. The vertical variations of urban microclimates have an impact not only on high-rise buildings but also on low-rise buildings, when using an HVAC system.

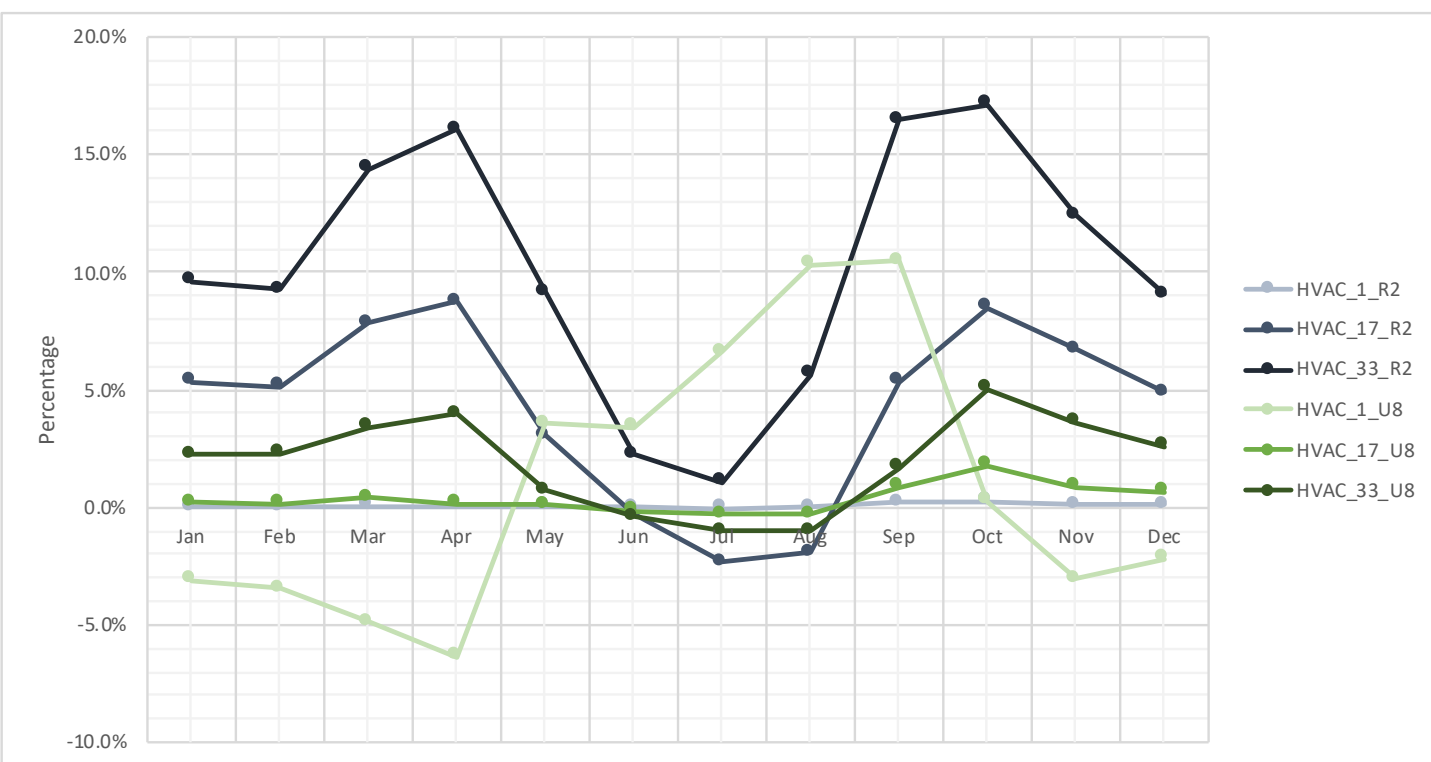

Figure 78: For an HVAC system thermal load percentage changes with vertical variations over without at the $1^{\text {st }}, 17^{\text {th }}$ and $33^{\text {rd }}$ floors in rural and urban areas of London.

When using a natural ventilation system, the effects of vertical variations increase with height in rural areas (Figure 79). In urban areas, vertical variations decrease thermal load predictions at the $1^{\text {st }}$ floor and increase thermal load predictions at the $33^{\text {rd }}$ floor for most of the year. The effects of vertical variations on a natural ventilation system are bigger than on an HVAC system.

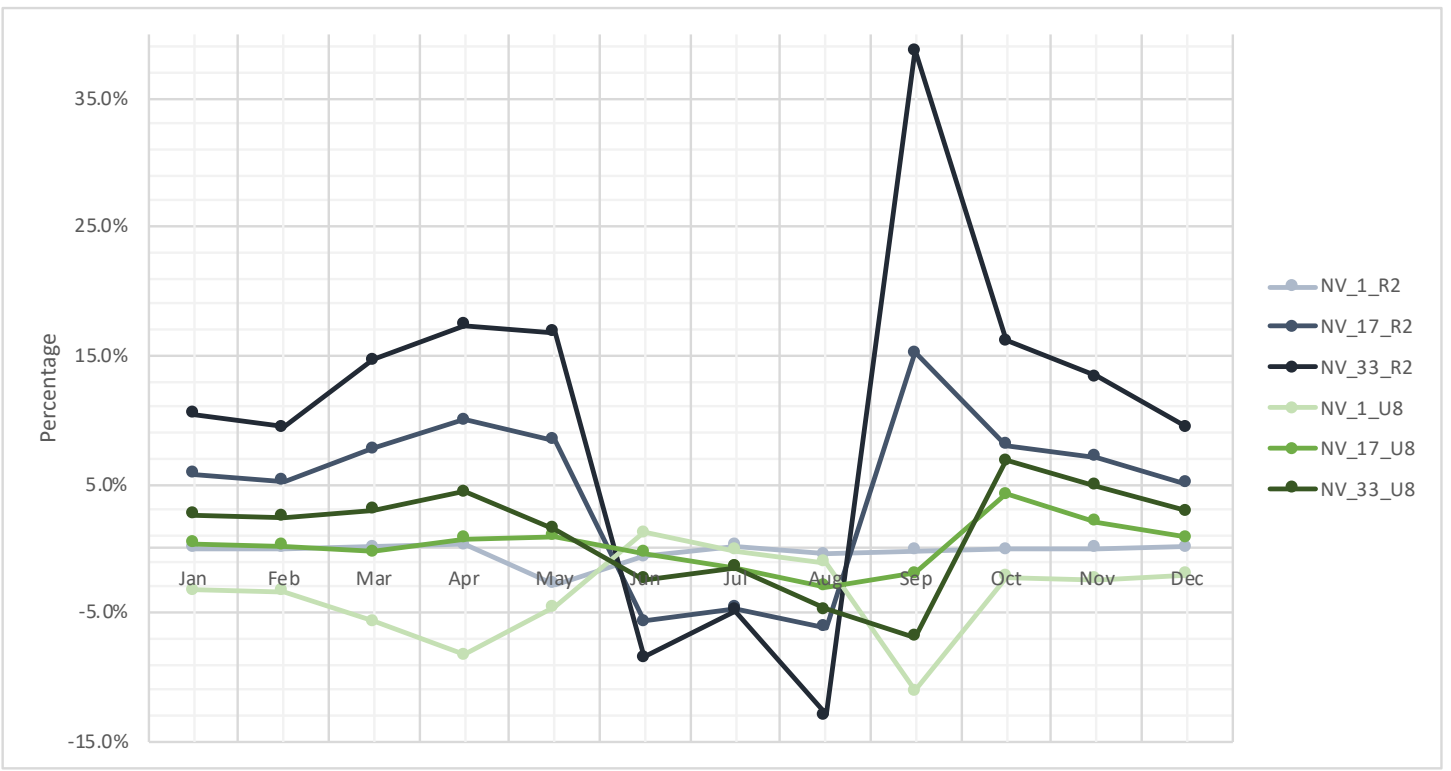


Figure 79: For the natural ventilation (NV) system thermal load changes with vertical variations over without at the $1^{\text {st }}, 17^{\text {th }}$ and $33^{\text {rd }}$ floors in rural and urban areas of London.

It can be seen from Figure 78 and Figure 79 that the vertical variations in rural areas have a greater impact than those in urban areas, whether using an HVAC system or a natural ventilation system. In urban areas, the impact of vertical variations on the near ground level is noteworthy. Engineers should consider the impact of vertical variations which is up to $10 \%$.

\subsubsection{Effects of wind speed profile parameters on thermal loads in urban areas}

The combined effects of vertical variations were discussed. This section explores the effects of wind speed profile parameters. The urban weather data in London without the Wind Speed Profile Exponent and the Wind Speed Profile Boundary Layer (U1) was taken as a compared group. The thermal load percentage changes between with (U2-U4, U7) and without (U1) the wind speed profile exponent and relative boundary layer thickness are shown in Figure 80 and Figure 81. Figure 80 shows the effects of wind vertical variations using an HVAC system, and Figure 81 using a natural ventilation system.

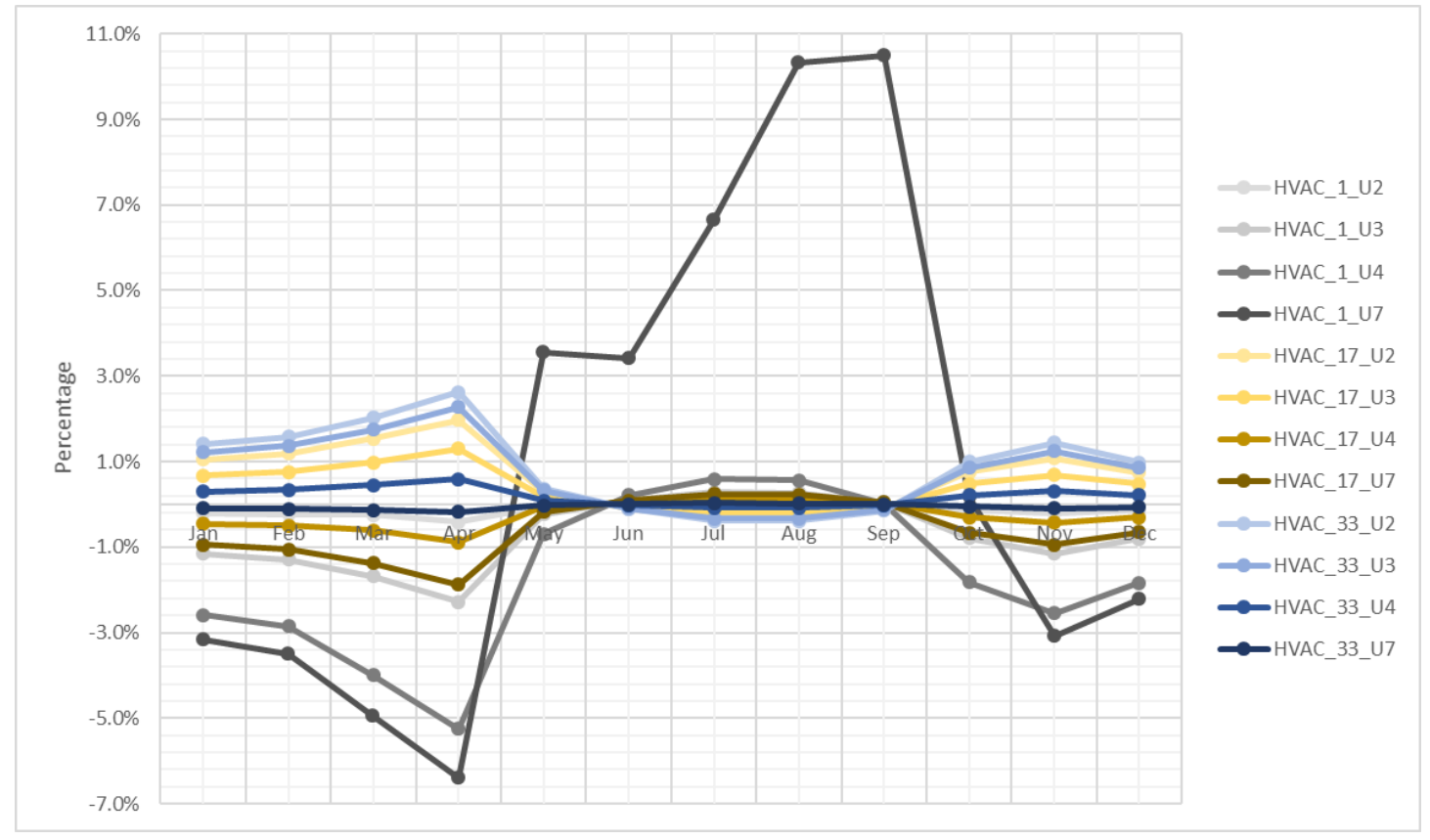

Figure 80: For an HVAC system effects of the wind speed profile exponent and relative boundary layer thickness on thermal load changes at the $1^{\text {st }}, 17^{\text {th }}$ and $33^{\text {rd }}$ floors.

When using an HVAC system, the differences of the thermal loads increase with the wind speed profile exponent and relative boundary layer thickness slightly (Figure 80). At the $1^{\text {st }}$ floor, the thermal load percentage changes increase with the exponent and 
relative boundary layer thickness. The vertical variations of the wind reduce thermal load predictions for most of the year. At the $17^{\text {th }}$ floor and $33^{\text {rd }}$ floor, the thermal load percentage changes between different variations are small, less than $3 \%$. At the $17^{\text {th }}$ floor, smaller vertical variations increase thermal load predictions, while larger vertical variations decrease thermal load predictions. At the $33^{\text {rd }}$ floor, the influence of wind vertical variations decreases with the exponent and relative boundary layer thickness. Vertical variations of the wind speed profile increase thermal loads for most of the year. When using an HVAC system, the influence of wind profiles at the $1^{\text {st }}$ floor is bigger than that at the $33^{\text {rd }}$ floor and the $17^{\text {th }}$ floor. Hence, at a lower floor, the influence of vertical variations of wind should be taken into consideration, using an HVAC system. Then the effects of wind profiles on a natural ventilation system were also discussed. In Figure 81, the effects of the wind speed profile exponent and relative boundary layer thickness using a natural ventilation system are slightly bigger than using an HVAC system. The effects don't increase with height and don't increase with the exponent and the boundary layer thickness. The vertical variations of the wind speed profile only have a less than 5\% impact for most of the year when using an HVAC system (Figure 80). When using a natural ventilation system, the impacts are less than $10 \%$ (Figure 81 ). When using a natural ventilation system, engineers also should consider the impacts of the vertical variations of the wind on lower floors.

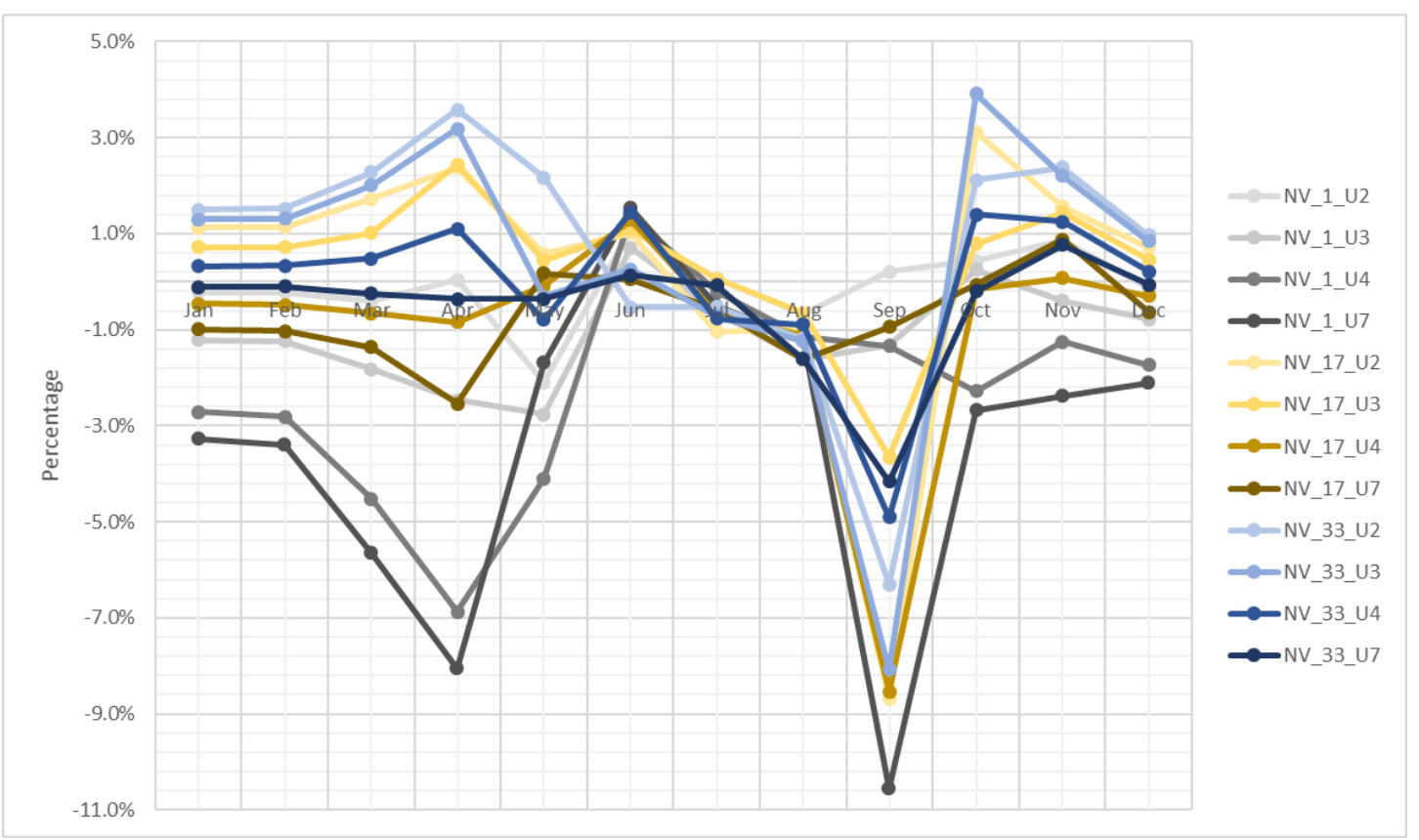

Figure 81: For the natural ventilation (NV) system effects of the wind speed exponent and relative boundary layer thicknesses on thermal load changes at the $1^{\text {st }}, 17^{\text {th }}$ and $33^{\text {rd }}$ floors. 
The combined effects of the wind speed profile exponent and relative boundary layer thickness were investigated. The individual effects of boundary layer thickness were then explored. The wind speed profile exponent of each group was 0.4 and the air temperature gradient was ignored. The impacts of the Wind Speed Profile Boundary Layer Thickness of $460 \mathrm{~m}$ (U6) and $500 \mathrm{~m}$ (U7) were compared to those of $400 \mathrm{~m}$ (U5). The effects on an HVAC system are shown in Figure 82 and on a natural ventilation system are shown in Figure 83.

When using an HVAC system, the effects of the wind speed profile boundary thickness on thermal loads are minimal, with a difference of less than $1 \%$ (Figure 82 ). Even if the difference is not big, the difference of thermal loads increases with boundary thickness, and it also increases with height. The effects of the precision of the boundary layer thickness are too small to be considered.

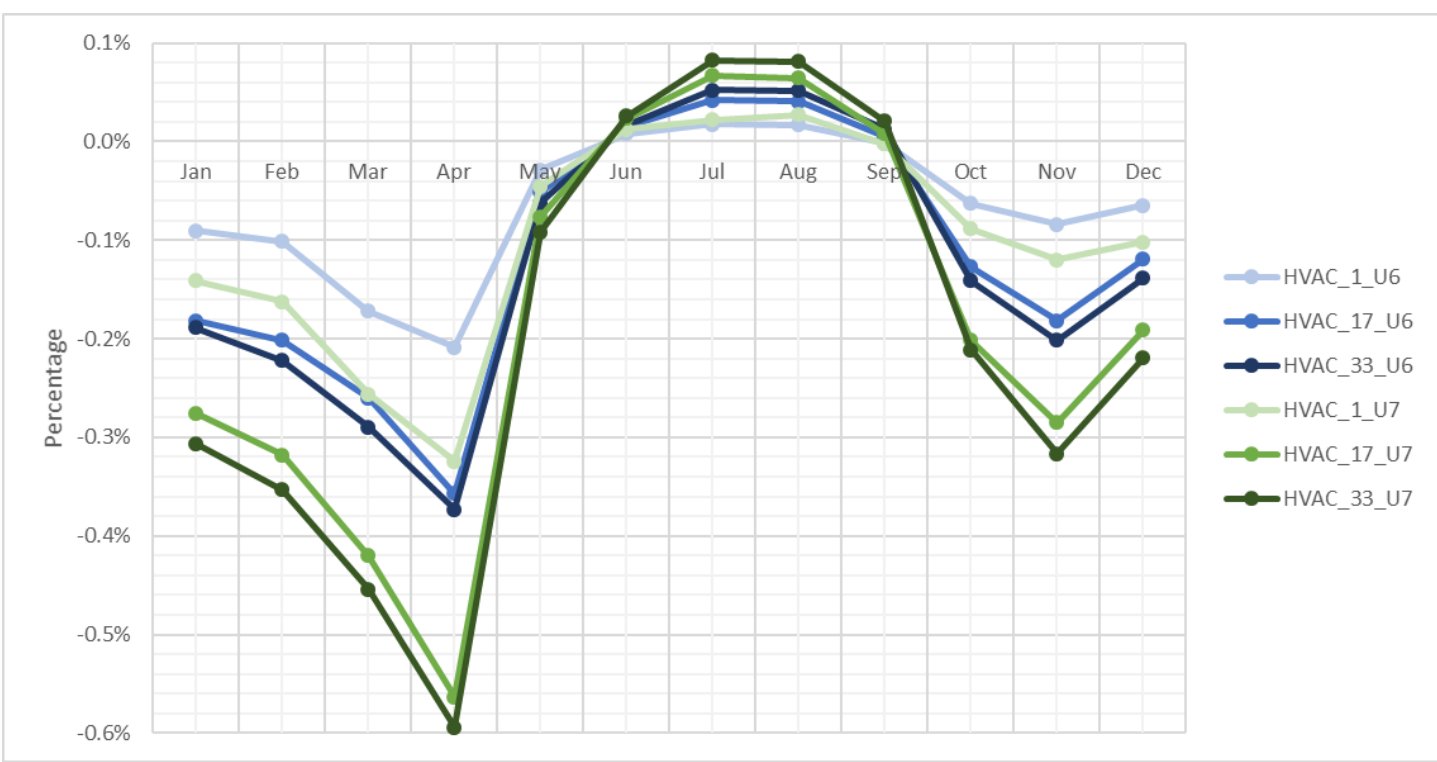

Figure 82: For an HVAC system effects of the boundary layer thickness on thermal load changes at the $1^{\text {st }}, 17^{\text {th }}$ and $33^{\text {rd }}$ floors.

The effects of the boundary layer thickness on a natural ventilation system are bigger than those on an HVAC system. However, the effects on a natural ventilation system are also very small, with a difference of less than $2 \%$ for most of the year (Figure 83 ). Engineers do not need to consider the precision of the Wind Speed Profile Boundary Layer Thickness. 


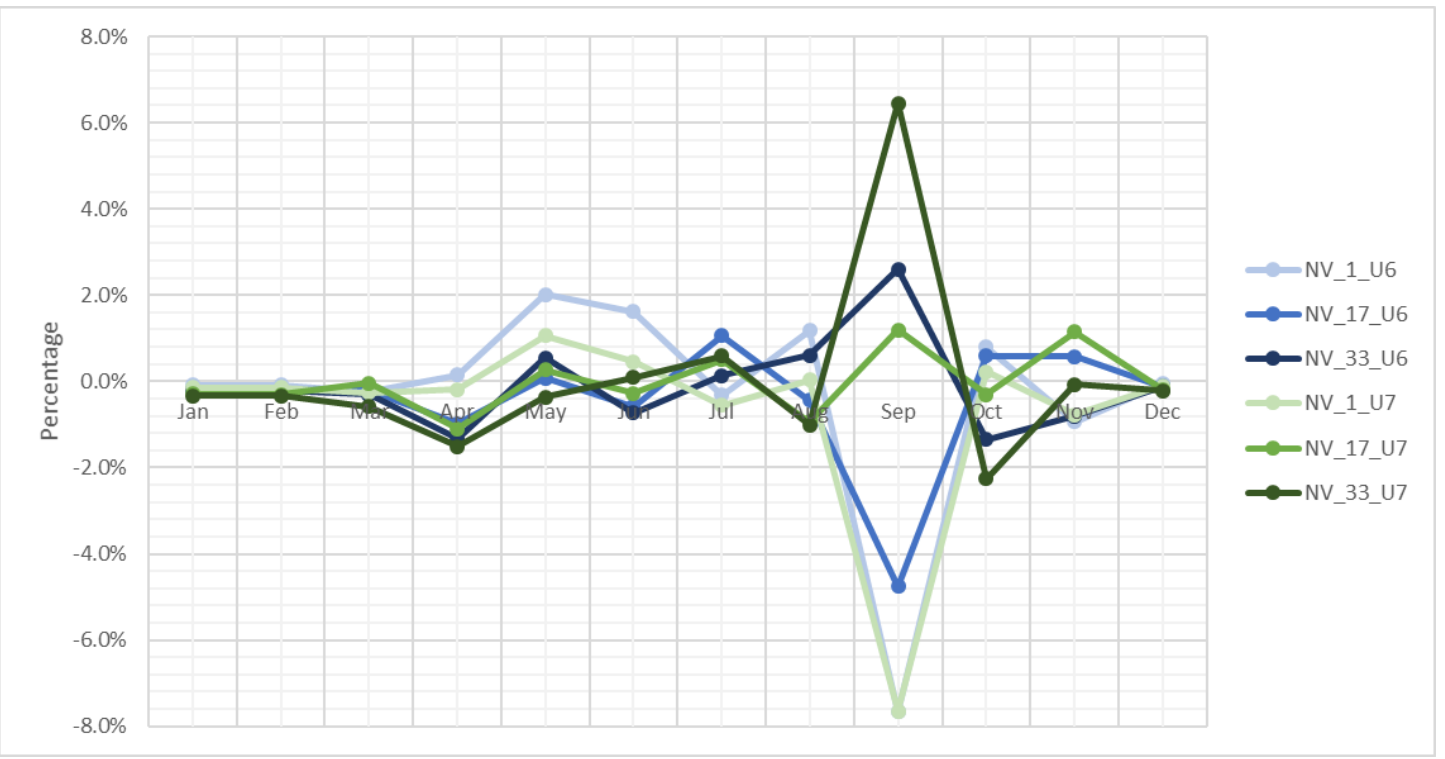

Figure 83: For the natural ventilation (NV) system effects of boundary layer thickness on thermal load changes at the $1^{\text {st }}, 17^{\text {th }}$ and $33^{\text {rd }}$ floors.

\subsubsection{Effects of temperature gradient coefficient on thermal loads in urban areas}

The effects of the Air Temperature Gradient Coefficient are explored in this section. The thermal load percentage changes between with (U8-U11) and without (U7) the temperature gradient coefficient are shown Figure 84 and Figure 85 . The results using an HVAC system are shown in Figure 84, and using a natural ventilation system are shown in Figure 85.

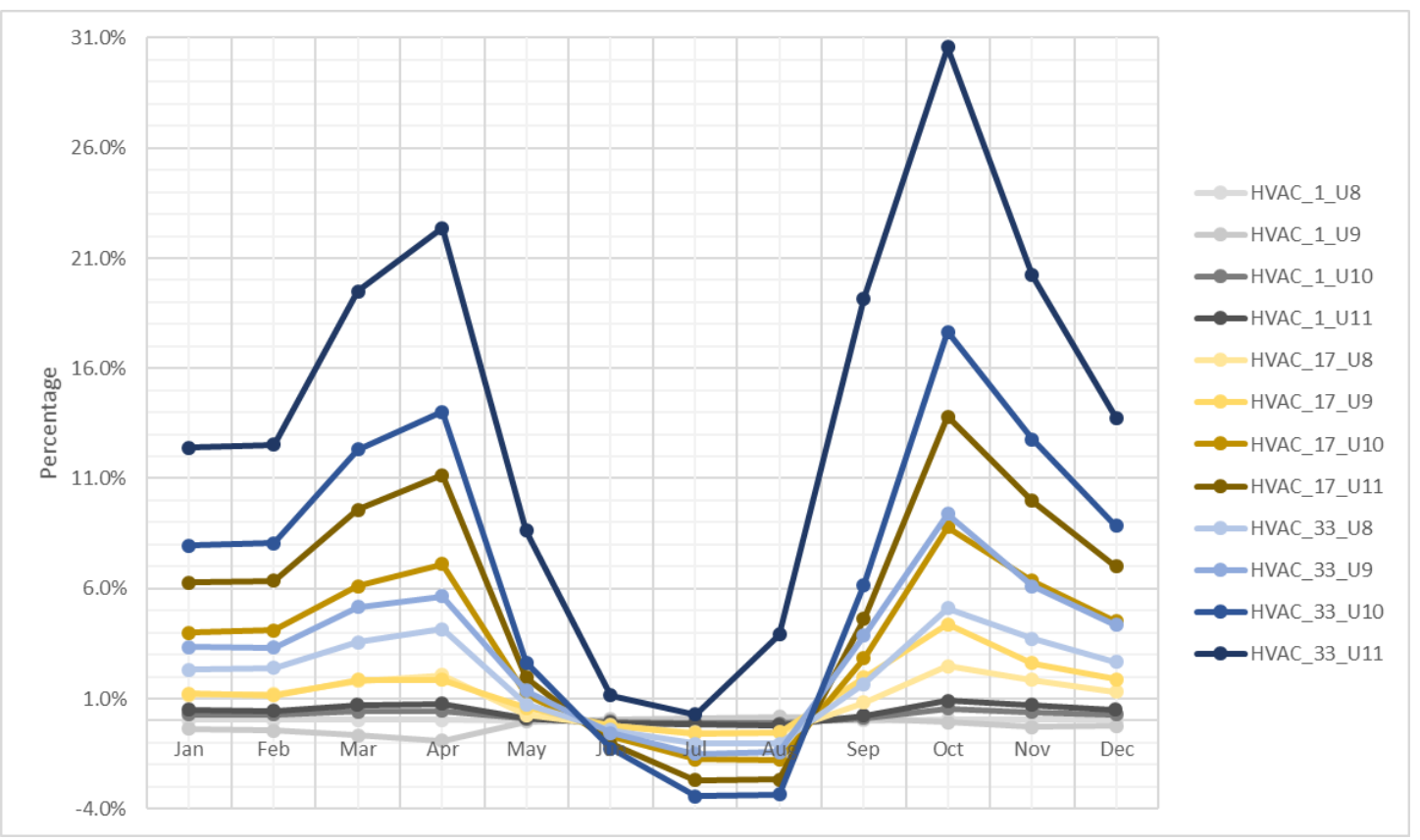

Figure 84: For an HVAC system effects of the temperature gradient coefficient on thermal load changes at the $1^{\text {st }}, 17^{\text {th }}$ and $33^{\text {rd }}$ floors. 
In Figure 84, no matter what the temperature gradient coefficient is, the differences increase with height. No matter at which floor, the differences increase with the temperature gradient coefficient. At the $1^{\text {st }}$ floor, the effects of the temperature gradient coefficient are less than $1 \%$. At the $33^{\text {rd }}$ floor, the temperature gradient coefficient can increase thermal loads by up to $30 \%$. In contrast to the wind speed exponent which has less influence at upper floors, the temperature gradient coefficient has more impacts at upper floors. The influence of temperature gradient and height can make a great difference to thermal loads, when using an HVAC system.

The effects of the temperature gradient coefficient on a natural ventilation system are bigger than those on an HVAC system (Figure 85). For a natural ventilation system, at the $1^{\text {st }}$ floor, thermal load changes are less than $5 \%$, and at the $33^{\text {rd }}$ floor, the thermal load changes produced by temperature gradient coefficient $0.01 \mathrm{~K} / \mathrm{m}(\mathrm{NV}$ 33_U11) can reach great values (up to $45 \%$ ). The precision of the Air Temperature Gradient Coefficient is very important for engineers to model.

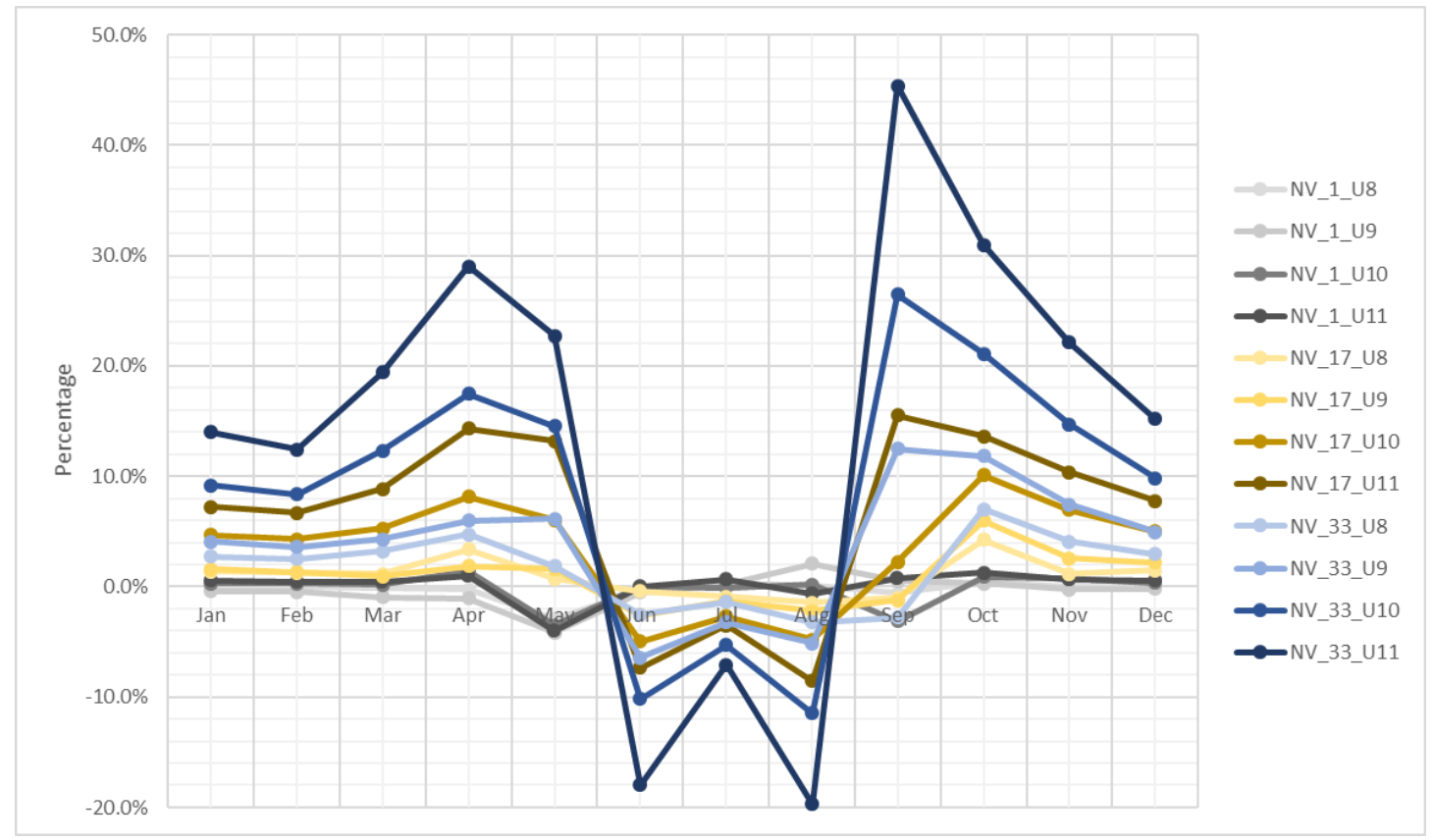

Figure 85: For the natural ventilation (NV) system effects of the temperature gradient coefficient on thermal load changes at the $1^{\text {st }}, 17^{\text {th }}$ and $33^{\text {rd }}$ floors.

\subsubsection{Effects of vertical variation on different ventilation systems in urban areas}

In this section, the effects of vertical variation on an HVAC system and a natural ventilation $(\mathrm{NV})$ system are compared with each other. U1 did not take vertical variations of urban microclimates into account, while U8 did. U1 was used to be compared with. The effects of vertical variations with the Wind Speed Profile Exponent 
of 0.4, the Wind Speed Profile Boundary Layer Thickness of $500 \mathrm{~m}$ and the Air Temperature Gradient of $0.002 \mathrm{~K} / \mathrm{m}$ (U8) are shown in Figure 86.

The effects of vertical variations on a natural ventilation system are bigger than those on an HVAC system (Figure 86). At the 1st floor, the effects on both an HVAC system and a natural ventilation system are big (up to $11 \%$ ). At the 17 th floor and the 33rd floor, the effects on a natural ventilation system are slightly bigger than those on an HVAC system (up to 7\%). For HVAC systems and natural ventilation systems, the effects of vertical variations of urban microclimates are relatively larger at upper floors than at lower floors, and they are larger in spring and autumn than in summer and winter.

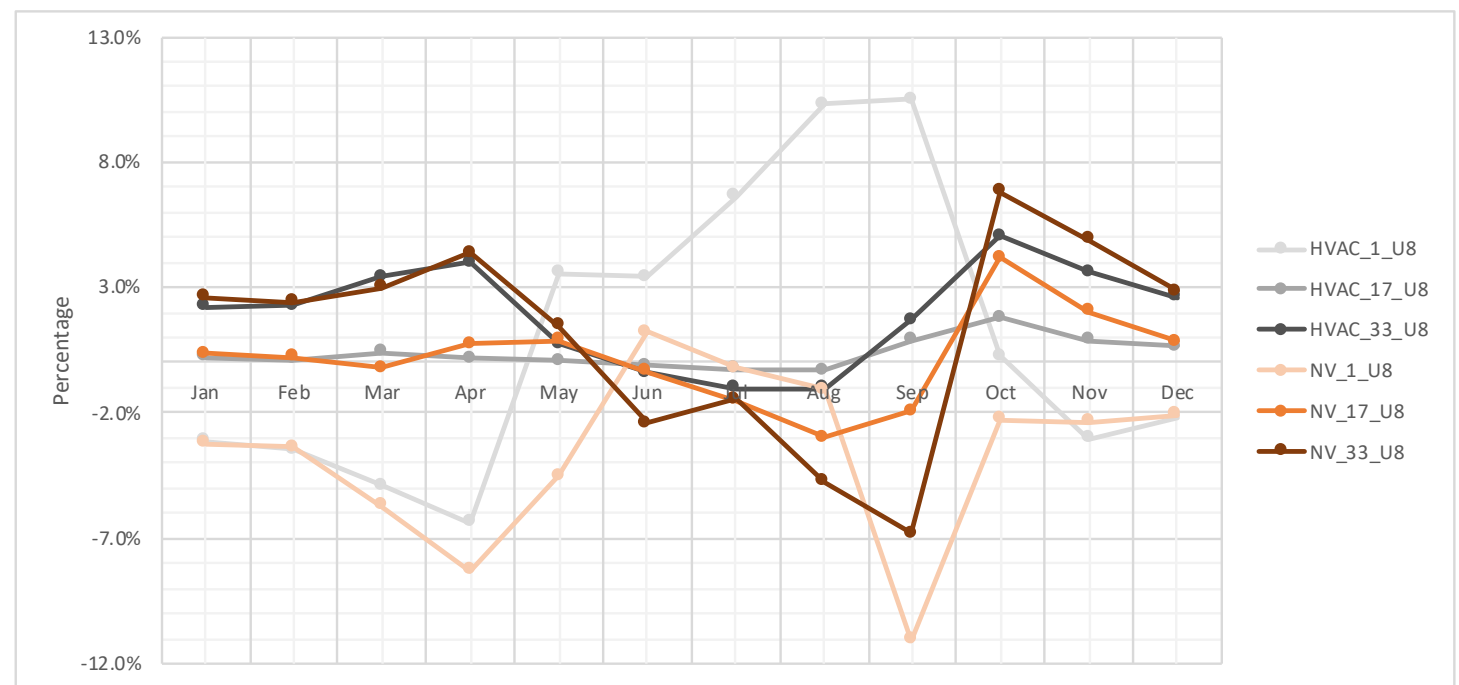

Figure 86: Effects of vertical variations on thermal load changes with an HVAC system and a natural ventilation system.

\subsection{Conclusions}

- Microclimate vertical variations have more effects on building performance in rural areas than in urban areas.

- The influence of wind speed exponent and relative boundary layer thickness on building performance simulation is significant at a lower floor. However, the accuracy of the exponent of wind speed profile does not give a significant influence on the results.

- The accuracy of boundary layer thickness also does not have a significant influence on building performance simulation.

- The temperature gradient coefficient has a big influence on the simulation results, especially at higher floors. The influence increases with height. 
- The effects of vertical variations on a natural ventilation system are bigger than that on an HVAC system.

It is necessary to model the urban microclimate vertical variation, as the effect of vertical variations is significant, and it increases with height. At a lower floor, the vertical variations of wind speed have a greater influence than those of temperature gradient. While at a higher floor, the air temperature gradient dominates. For high-rise buildings, it is necessary to model the vertical variation of air temperature. At a higher floor, the importance of the temperature gradient coefficient is greater than that of the wind speed profile exponent and boundary thickness. In the design of both low-rise and high-rise buildings, engineers are advised to consider the influence of wind vertical variations on lower floors. In the design of high-rise buildings, engineers should consider the impacts of the air temperature gradient. The accuracy of the boundary layer thickness has little impact, so engineers do not have to consider it when modelling. When using natural ventilation systems, engineers should consider more vertical variations of urban microclimates, because vertical variations have more impacts on a natural ventilation system than that an HVAC system. 


\section{CHAPTER 7. SIMULATION SYSTEM}

\subsection{Chapter Intent}

From Chapter 5 to Chapter 6, urban microclimates were gradually modelled in detail. In Chapter 5, the rural weather data was converted into the urban weather data. In Chapter 6, the 2-dimensional urban microclimate model was transformed into a threedimensional model.

This chapter explores a multilayer modelling method. In Chapter 6, the research found that the urban microclimate vertical variations influence building performance, especially at greater building heights. However, vertical variations in urban areas are not as constant as those in rural areas. In this chapter, the vertical variations in urban areas were divided into two layers. The lower portion is the Urban Canopy Layer (UCL) and the upper portion is the Urban Boundary Layer (UBL). The Urban boundary layer (UBL) is above roughness elements. Compared with the UCL, the UBL is open. This chapter develops a multilayer modelling method to explore the impact of the two-layer urban microclimate profile. Then, by modelling the horizontal (Chapter 5) and vertical parameters of urban microclimate modelling (Chapter 6) and using the multilayer modelling method (Chapter 7), an urban microclimate simulation system was established. The simulation system can model the urban microclimate in detail.

\subsection{Methodology}

The Urban Canopy Layer (UCL) lies between the two layers' (the UCL and the UBL) interface and the ground, which is the result of sophisticated energy and airflow exchanges (Mills, 1997). The Urban Canopy Layer (UCL) in this research focused on the layer covering the vast majority of urban buildings. In the UCL, the performance of high-rise buildings is affected by neighbouring buildings. The average height of the neighbouring buildings represents the height of UCL. The height is the dividing line with or without the influence surrounding urban buildings. The middle and upper floors in UBL are located in the open area with less complicated urban microclimate profiles. The lower floors beneath the average height of the UCL are influenced by the complex 
urban microclimate caused by neighbouring buildings. Hence, the model of urban microclimate in the UCL is different from that in the UBL. The corresponding building performance simulation in the UCL and UBL had to be modelled separately, because the influence due to inconsistent microclimate in the two layers is likely to be different. Figure 87 shows the wind and temperature profile and the two portions of the prototypical building in the UBL and the UCL.

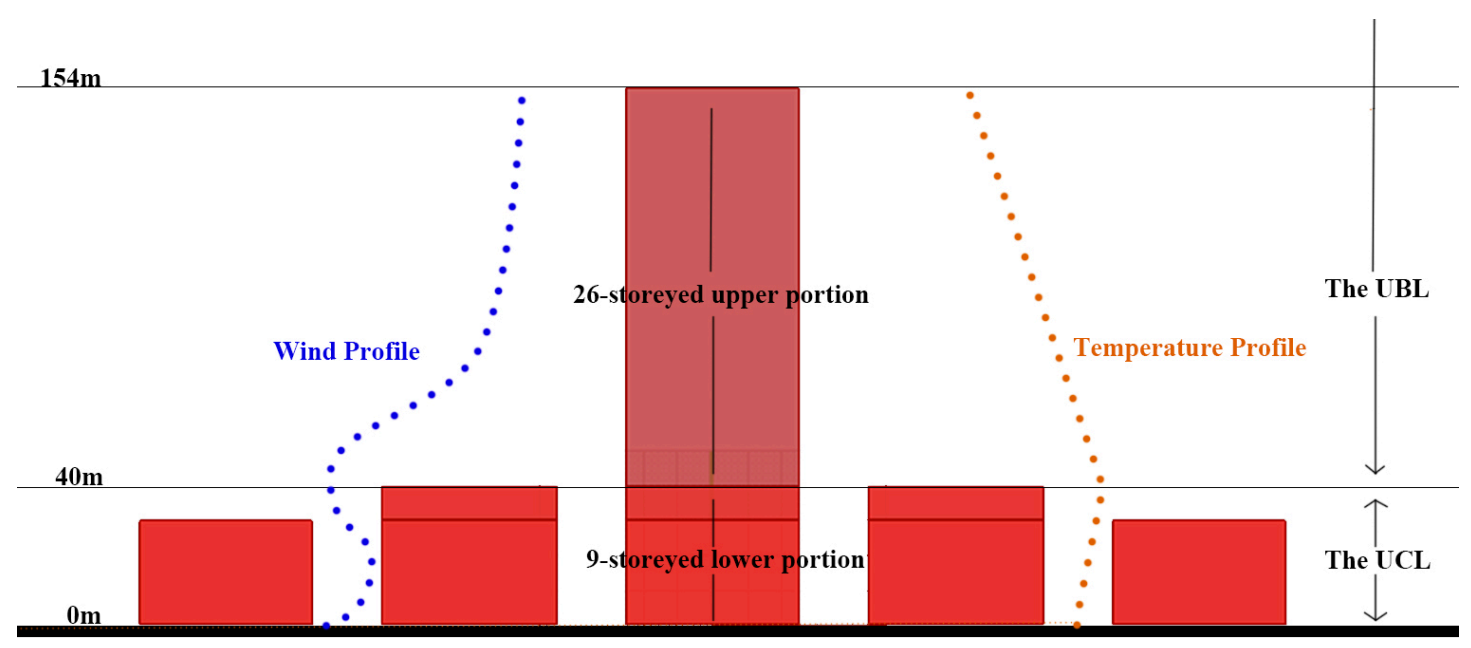

Figure 87: The urban microclimate and the building in the UCL and in the UBL

\subsubsection{Modelling two layers of urban microclimate and prototypical building}

Chapter 6 concluded that vertical variations of urban microclimates are worth investigating and modelling. Using EnergyPlus to model the vertical variations needs the additional data which is HeightVariation: Wind Speed Profile Exponent, Wind Speed Profile Boundary Layer Thickness (m) and Air Temperature Gradient Coefficient $(\mathrm{K} / \mathrm{m})$, mentioned in Section 5.5.4 and Section 6.3. The problem is that the actual Wind Speed Profile Exponent and Air Temperature Gradient Coefficient are not constant in urban areas. Hence, the urban microclimate and the prototypical building had to be divided into layers to get the trend for each layer.

\subsubsection{Urban microclimate in the UCL and UBL modelling}

The lower layer model of urban microclimate was composed of the wind profile in the UCL and the temperature profile in the UCL. Due to the large number of buildings in the UCL, the airflow model had to consider the impacts of surrounding buildings. Hence, the prototypical high-rise building and 24 surrounding buildings were modelled. Similar to the lower layer model, the upper layer model of urban microclimate also contained the wind and temperature profile model in the UBL. This part of urban 
microclimate is above the majority of the urban buildings, which is open. Hence, the upper layer urban microclimate is more like the rural microclimate profile.

The wind environment around urban buildings was modelled by OpenFOAM to get the wind speed profile in urban areas. In this section, firstly buildings of the City of London were imported into the CFD program, OpenFOAM. A list of test points was then generated in the middle of the windward city street, ranging in height from $1 \mathrm{~m}$ to 500 $\mathrm{m}$ at $1 \mathrm{~m}$ interval. Finally, the wind speed data and the wind speed profile in the UCL and UBL were collected. The temperature profile is determined based on information in literature (Barlow et al., 2015; Kukkonen et al., 2005).

\subsubsection{Prototypical building in the UCL and UBL modelling}

As the urban microclimate modelling system consisted of two layers, the prototypical building was divided into two parts to model the building performance respectively. One part of the building was in the UCL and the other part was in the UBL.

The prototypical high-rise office building for this study was $72 \mathrm{~m} \times 50 \mathrm{~m} \times 154 \mathrm{~m}$, with 35 floors (Section 5.3.3). According to GIS data of the City of London, more than $90 \%$ of buildings in the City of London were under $40 \mathrm{~m}$ in 2016. The average height of buildings was around $17 \mathrm{~m}$. In this section, the urban canopy was assumed to be the height covering the vast majority $(40 \mathrm{~m})$, not the average height, because the high-rise buildings were surrounded by higher buildings (Figure 88). In Figure 88, the buildings higher than $40 \mathrm{~m}$ were mostly surrounded by the buildings between $30 \mathrm{~m}$ and $40 \mathrm{~m}$. The buildings might not be exactly representative of the whole of the city of London, but this was to set up a system to test Urban Canopy. It would be fair to say if the Canopy is smaller, then the effects would be different but the overall importance of modelling all aspects of the UCL and UBL does not change. If people want to work with buildings, then reducing the height might be affected by these parameters to a lesser degree. If you are doing a tall building, it has been demonstrated that people definitely need to model using all of the effectors.

The prototypical building was then divided into 9 lower floors and 26 upper floors by the height of $40 \mathrm{~m}$. The multilayer modelling method was to model the lower layer of 9 floors with vertical variations of urban microclimates in the UCL and the upper layer of 26 floors with vertical variations in the UBL. This multilayer modelling method was 
to simulate the inconstant exponent of urban wind speed profile and inconstant urban temperature gradient.

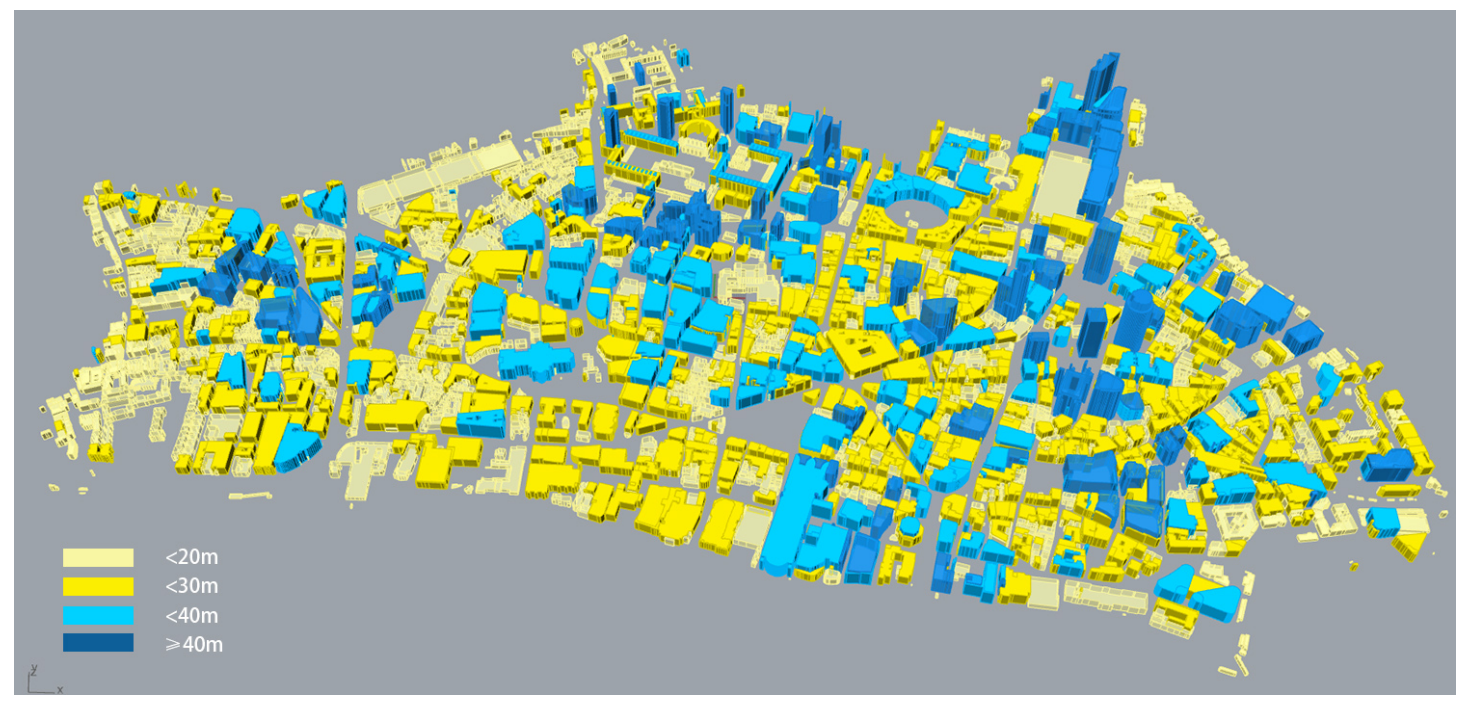

Figure 88: Distribution of building height in the City of London

\subsubsection{Urban wind speed and wind pressure coefficients}

\subsubsection{Urban wind speed coefficient}

In Section 5.4.2, the urban wind was adjusted by a Ladybug script, WindSpeedCalculator (Roudsari, n.d.). The type of terrain is city and the input and output of wind speed heights are both $10 \mathrm{~m}$. The wind profile is based on the powerlaw function. The ratio of the wind Speed of London City to the Wind Speed of Gatwick Airport was recommended to be 0.45 because of the terrain of the city. The ratio in Chapter 5 was a rough coefficient for cities, the adjusted ratio in this chapter is specific for London. In this section, the urban-rural wind speed ratio is modelled and calculated by OpenFOAM.

\subsubsection{Urban wind pressure coefficients}

In terms of wind, the weather data generally includes wind speed and wind direction. When calculating energy performance using EnergyPlus, the information about wind is always imported through weather data without reference to wind pressure coefficients. However, wind pressure coefficients are essential to model a detailed natural ventilation system. Wind pressure coefficients also can be calculated by OpenFOAM.

Another reason for calculating wind pressure coefficients is because they can be used to input a specified urban microclimate just around a high-rise building. The adjusted 
weather data and microclimate height variations in Chapter 5 and Chapter 6 represented a mesoscale urban microclimate, which could not accurately address the urban wind environment around a high-rise building.

A high-rise building is surrounded by middle-rise or low-rise buildings, and the urban wind around the high-rise buildings is turbulent. CFD programs can model complex microclimates and air movements. OpenFOAM was used to get the wind pressure coefficients on windows at each floor of the high-rise building. The wind pressure coefficients were then imported into the airflow network model of EnergyPlus, which further realize the vertical variation model and the detailed natural ventilation system (LBNL, 2018).

\subsubsection{Ventilation system}

In this research, there were two types of ventilation systems; they were mechanical ventilation systems and mixed-mode natural ventilation systems. The mechanical ventilation system used in the research was a basic HVAC system. There were two types of mixed-mode natural ventilation simulation used in this research: simplified natural ventilation (without wind pressure coefficient modelling) and detailed natural ventilation (with wind pressure coefficient modelling). The reason for exploring detailed natural ventilation model is that it can be used to study the influence of vertical variation of wind pressure on building performance.

The simplified natural ventilation model used the temperature of the heating and cooling setpoints in the simulation to switch between natural ventilation and mechanical ventilation. This model combined the effect of wind speed driven air flow and the thermal stack effect. The ventilation rate was related to the open area of the model and the rate can be controlled by a multiplier fraction schedule and the specification of minimum, maximum and the difference between indoor and outdoor temperatures. It is intended for simplified ventilation calculations where wind driven ventilation is just a function of wind speed and opening size as opposed to the more detailed ventilation investigations that can be performed with the AirflowNetwork model (LBNL, 2018).

Compared with simplified ventilation calculations, more detailed ventilation was performed with the AirflowNetwork model and was based on the influence of wind pressure coefficients that vary across each building surface making wind driven 
ventilation a function of wind speed, opening size, window orientation and window position in the facade. It specified the properties of air flow through windows and doors when they are closed or open. When the window or door is open, additional fields (opening type, opening dimensions, degree of opening, and opening schedule) are required to describe the air flow characteristics (LBNL, 2018). The additional field in this model was wind pressure data. The difference between these two natural ventilation systems was that one took wind pressure coefficients that could drive the rate of ventilation into consideration and the other did not. This detailed modelling of wind pressures enabled study of the effect of vertical variations of wind on natural ventilation. The ventilation systems analysed in Chapter 5 and Chapter 6 were a simplified natural ventilation system and a basic HVAC system. The basic HVAC system was the IdealLoadsAirSystem which was modelled as an ideal variable air volume (VAV) terminal unit.

In this chapter, wind pressure coefficients of each floor are calculated, and that makes it possible to introduce a detailed natural ventilation system. Hence, in this chapter, there are three ventilation systems: HVAC system, simplified natural ventilation system, and detailed natural ventilation system. These three systems are shown in different colours in figures: the HVAC system is grey, the simplified natural ventilation system is orange, and the detailed natural ventilation system is blue. The simplified and detailed natural ventilation system used in this research were mixed-mode ventilation systems. They did not just rely on natural ventilation. The systems automatically chose natural ventilation or mechanical ventilation based indoor and outdoor conditions. They were compared with each other to explore the efficiency of natural ventilation.

\subsection{Urban Microclimate Modelling}

\subsubsection{Urban-rural wind speed ratio of London}

The City of London is the financial district of London, and there are many high-rise office buildings in that area (Figure 89). All the buildings in the City of London were imported to the OpenFOAM program which encompasses more than 6000 blocks. The simulation area was around $2.9 \mathrm{~km}^{2}$, and the test points area was the central $0.04 \mathrm{~km}^{2}$. Because the computational domain was quite large, it took around 8 hours to obtain the wind speed of around 500 test points through more than 6000 blocks (Figure 90). The 
wind speed from the inflow side was $6 \mathrm{~m} / \mathrm{s}$, and the average wind speed in the central region was $1.85 \mathrm{~m} / \mathrm{s}$ at the height of $10 \mathrm{~m}$. According to the calculation, the ratio of urban wind speed to rural wind speed is approximately 0.31 , which is less than the rough value 0.45 used in Chapter 5 and Chapter 6.

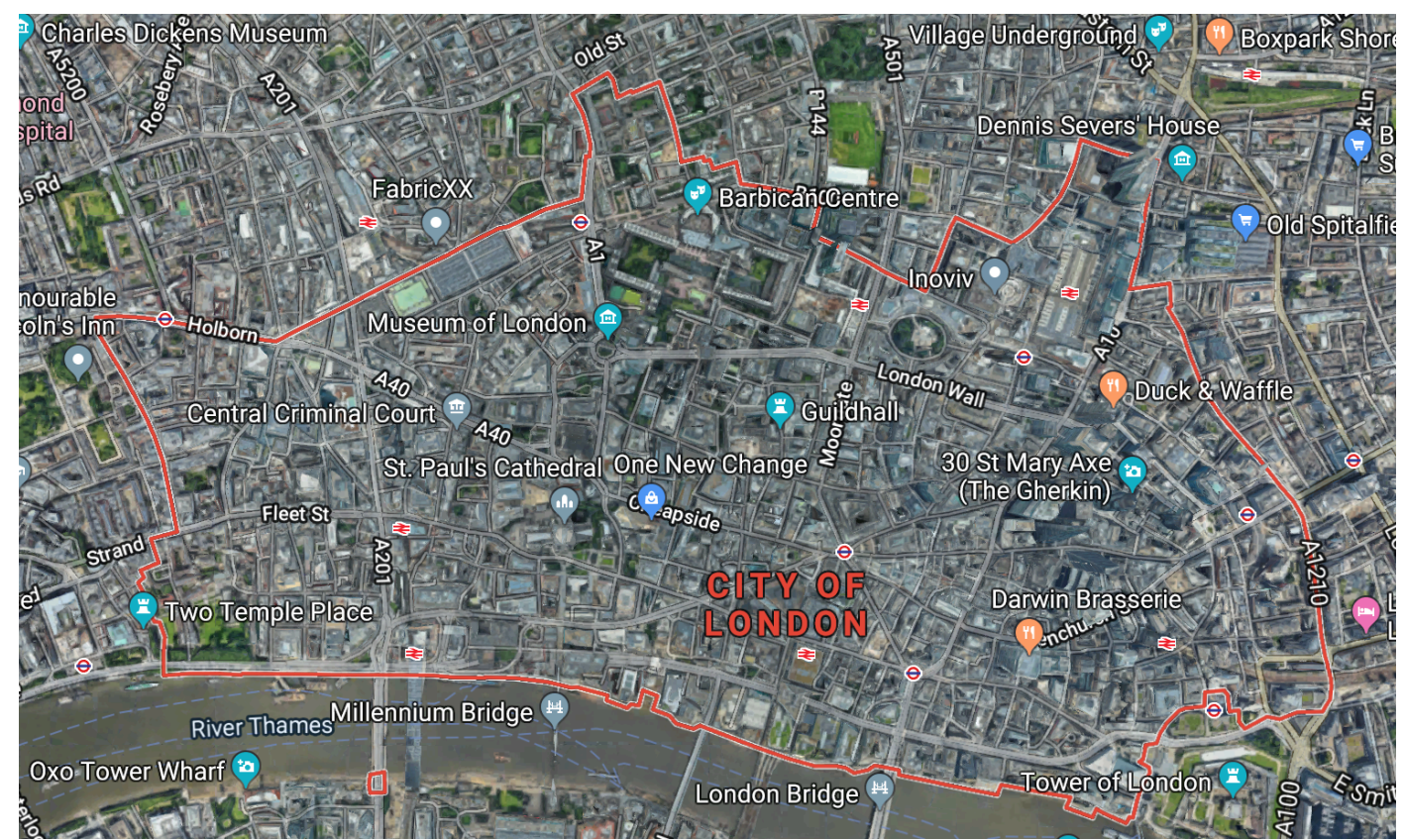

Figure 89: Outline of the City of London from Google map (Google Maps, 2019)

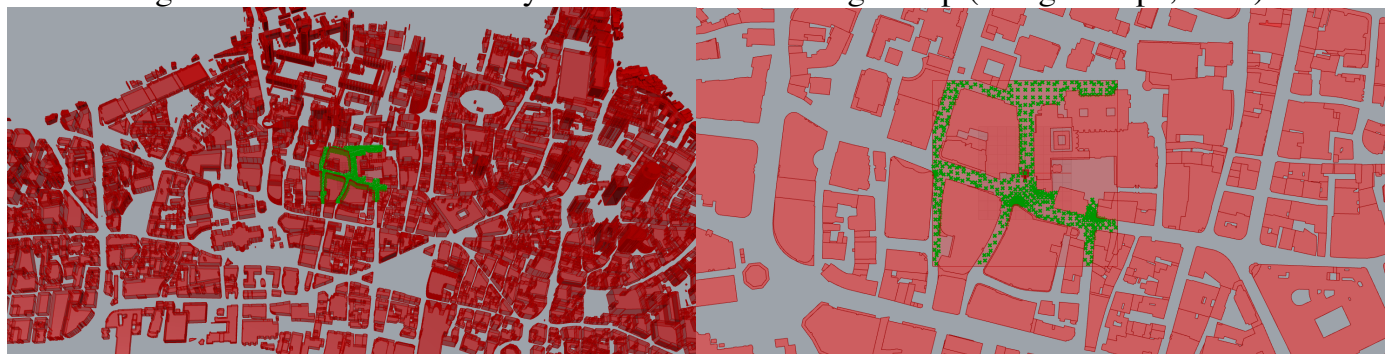

(a)

(b)

Figure 90: Building blocks and test points in City of London (a) blocks (b) test points

\subsubsection{Wind pressure coefficients at different height}

The central high-rise office building was the prototypical building in Chapter 5, which was $72 \mathrm{~m} \times 50 \mathrm{~m} \times 154 \mathrm{~m}$ with 35 floors. The 8 blocks of the first surrounding circle were $50 \mathrm{~m} \times 50 \mathrm{~m} \times 40 \mathrm{~m}$, because the vast majority of buildings in the City of London were under $40 \mathrm{~m}$, which was also the height of UCL. The 16 blocks of the second surrounding circle were $50 \mathrm{~m} \times 50 \mathrm{~m} \times 30 \mathrm{~m}$, because the second most common height was $30 \mathrm{~m}$ (Figure 91). This group of buildings was imported into OpenFOAM, and the wind pressure coefficients on the surfaces of the high-rise building were calculated with 12 wind direction at $30^{\circ}$ intervals (Figure 92). 


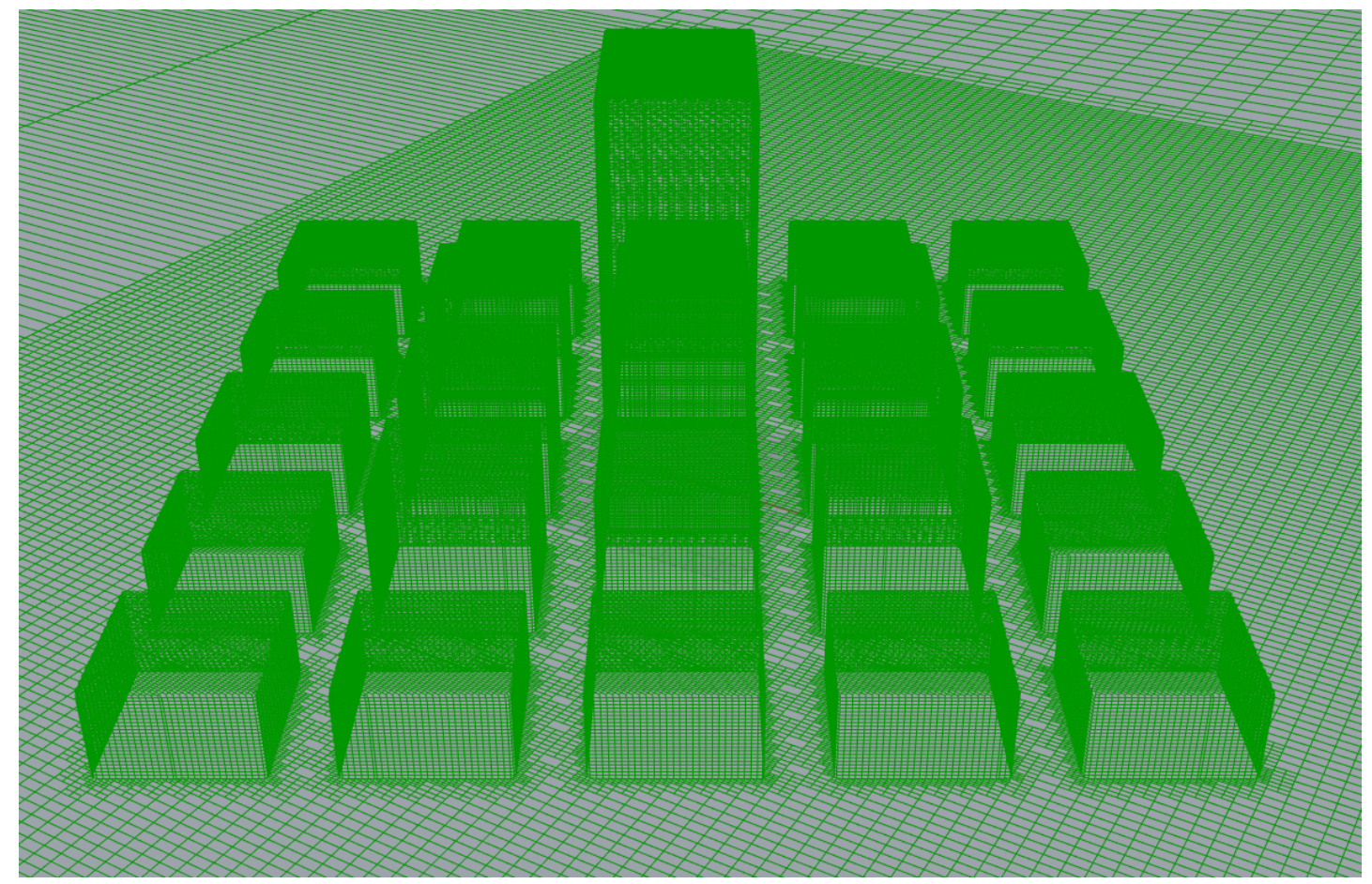

Figure 91: Prototypical building with surroundings

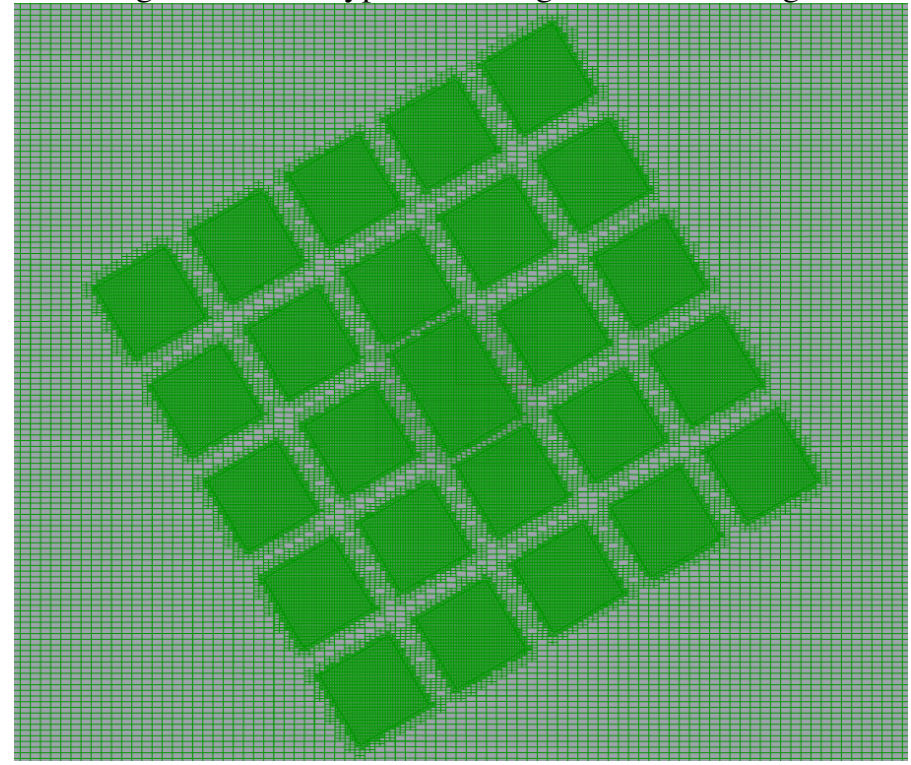

Figure 92: Rotated blocks according to wind directions

Test points of the 35-storeyed prototypical high-rise office building were set at the $1^{\text {st }}$, $17^{\text {th }}$ and $33^{\text {rd }}$ floor. There were 26 test points on each floor, and the average wind pressure coefficients of north, east, south, and west windows on each floor from 12 wind directions were achieved through wind tunnel simulations (Figure 93). 


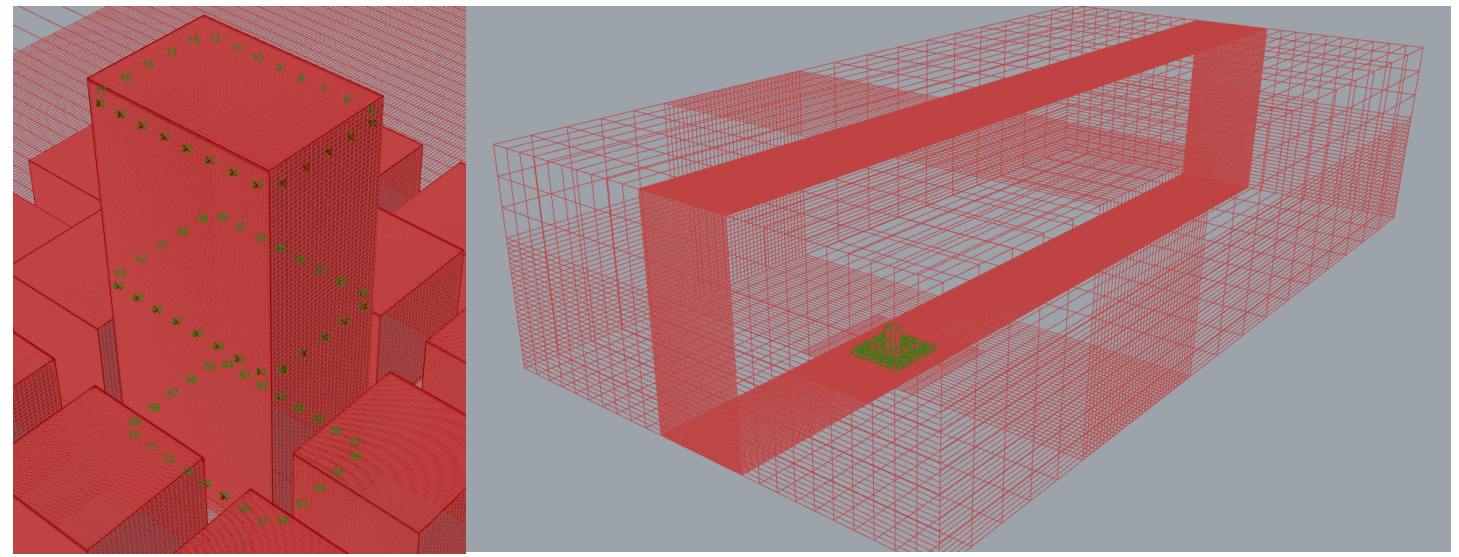

(a)

(b)

Figure 93: Test points around the prototypical building and its wind tunnel meshing

\subsubsection{Vertical variations of two layers respectively}

\subsubsection{Vertical variations of wind speed in the UCL and UBL}

In Section 6.3.1, according to the study of Drew et al., the exponent of the urban wind speed profile of London was approximately 0.4 . However, the wind speed experimental data was taken from around $100 \mathrm{~m}$ to $2000 \mathrm{~m}$ (Drew et al., 2013). It did not show the wind speed profile under $100 \mathrm{~m}$.

To get the wind speed profile in the UCL, the wind speeds at intervals of $1 \mathrm{~m}$ height were calculated through OpenFOAM. Inlet wind speed was $6 \mathrm{~m} / \mathrm{s}$, and the results of 500 test points are shown in Figure 94.

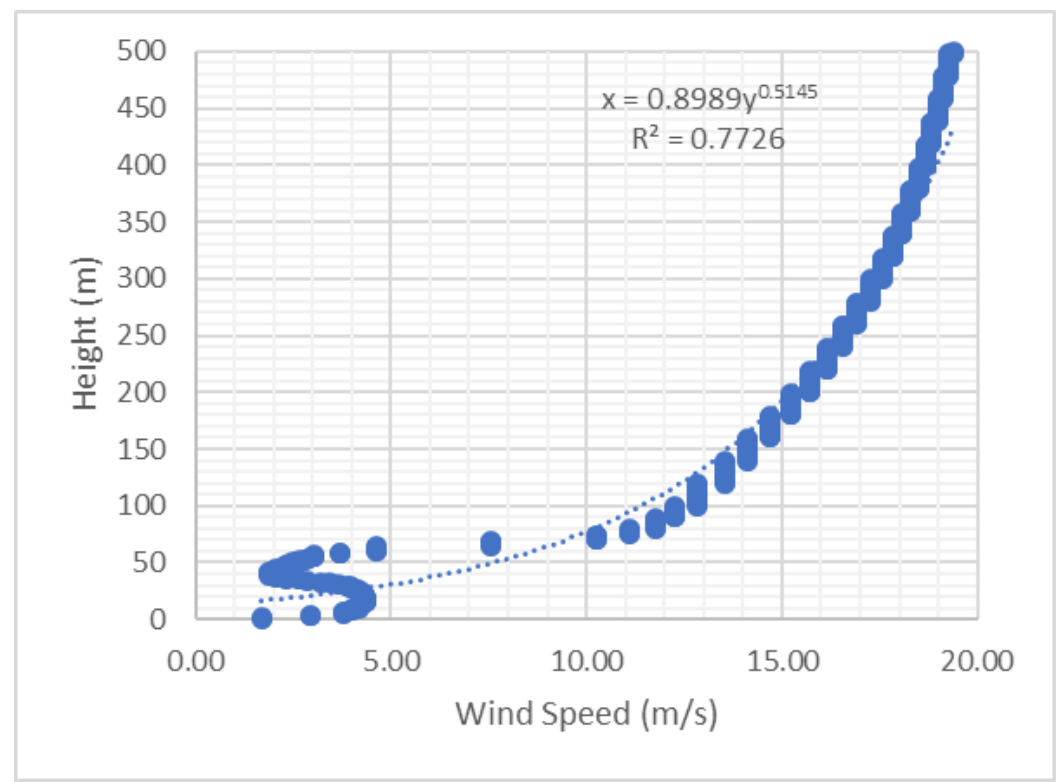

Figure 94: Urban wind speed profile of London (simulated by OpenFOAM)

Figure 94 shows that the urban wind speed increases at first with height then decreases with height, and finally increases with height again. In this section, the profile is split 
into two layers by the UCL, the lower layer under $40 \mathrm{~m}$ in the UCL (Figure 96) and the upper layer above $40 \mathrm{~m}$ in the UBL (Figure 95).

\subsection{Wind speed profile in the UBL}

In Figure 95, the wind speed profile in the UBL is shown as power-law formula, and the exponent of the wind profile is approximately 0.41 . The experimental data of the exponent of London wind profile is 0.4 (Drew et al., 2013). They are quite close to each other, and the exponent value of the wind profile is predicted relatively well.

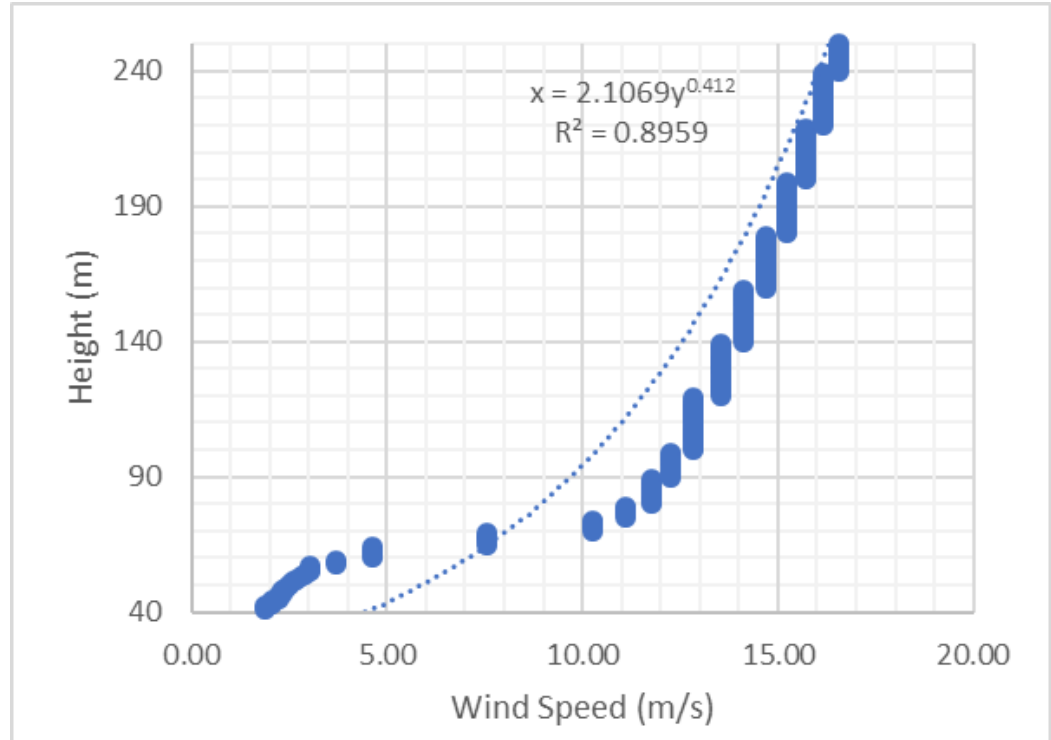

Figure 95: Urban wind speed profile of London in the UBL (simulated by OpenFOAM) 7.3.3.1.2 Wind speed profile in the UCL

In Figure 96, the urban wind speed trend in the UCL layer is not consistent. It increases at first and then decreases. The standard wind speed profile formulas, power-law (Section 6.3.1.1) and log law (Section 6.3.1.2), cannot show the wind speed profile trends. The exponent of power-law is 0.02 , very close to 0 .

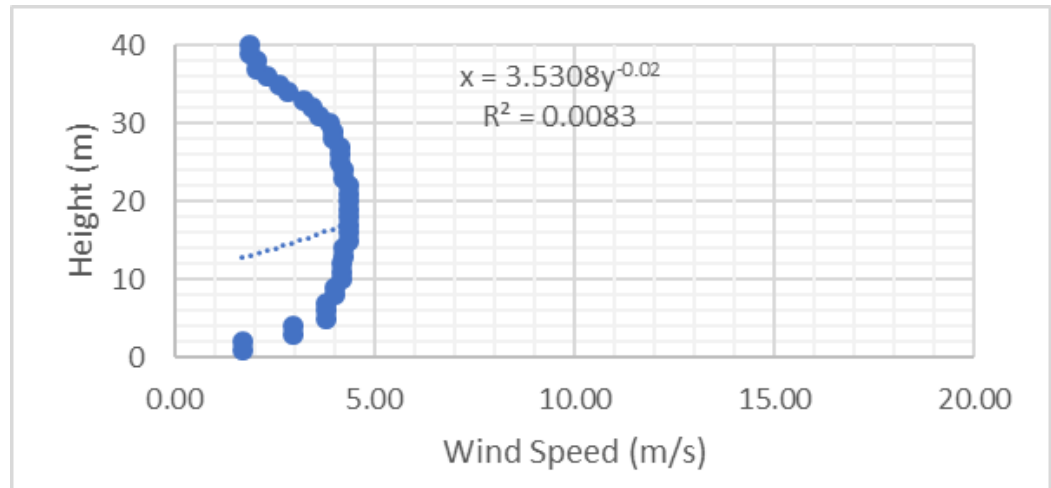

Figure 96: Urban wind speed profile of London in the UCL layer (simulated by OpenFOAM) 


\subsubsection{Vertical variations of temperature in the UCL and UBL}

In Section 6.3.3, Kukkonen et al. used MM5 model to predict the temperature profile of London Weather Centre(LWC) in the urban area of London (Kukkonen et al., 2005). The predicted model for the LWC site in the centre of London showed a temperature profile between $0 \mathrm{~m}$ to $1000 \mathrm{~m}$ from $17^{\text {th }}$ to $22^{\text {nd }}$ February. Overall, the average predicted temperature gradient was $-0.0002 \mathrm{~K} / \mathrm{m}$, close to $0 \mathrm{~K} / \mathrm{m}$ (Section 6.3.3). The two parts of the trendlines cancel each other out, as the first parts of the trendlines mostly increase with height and the second part decreases with height (Figure 97).

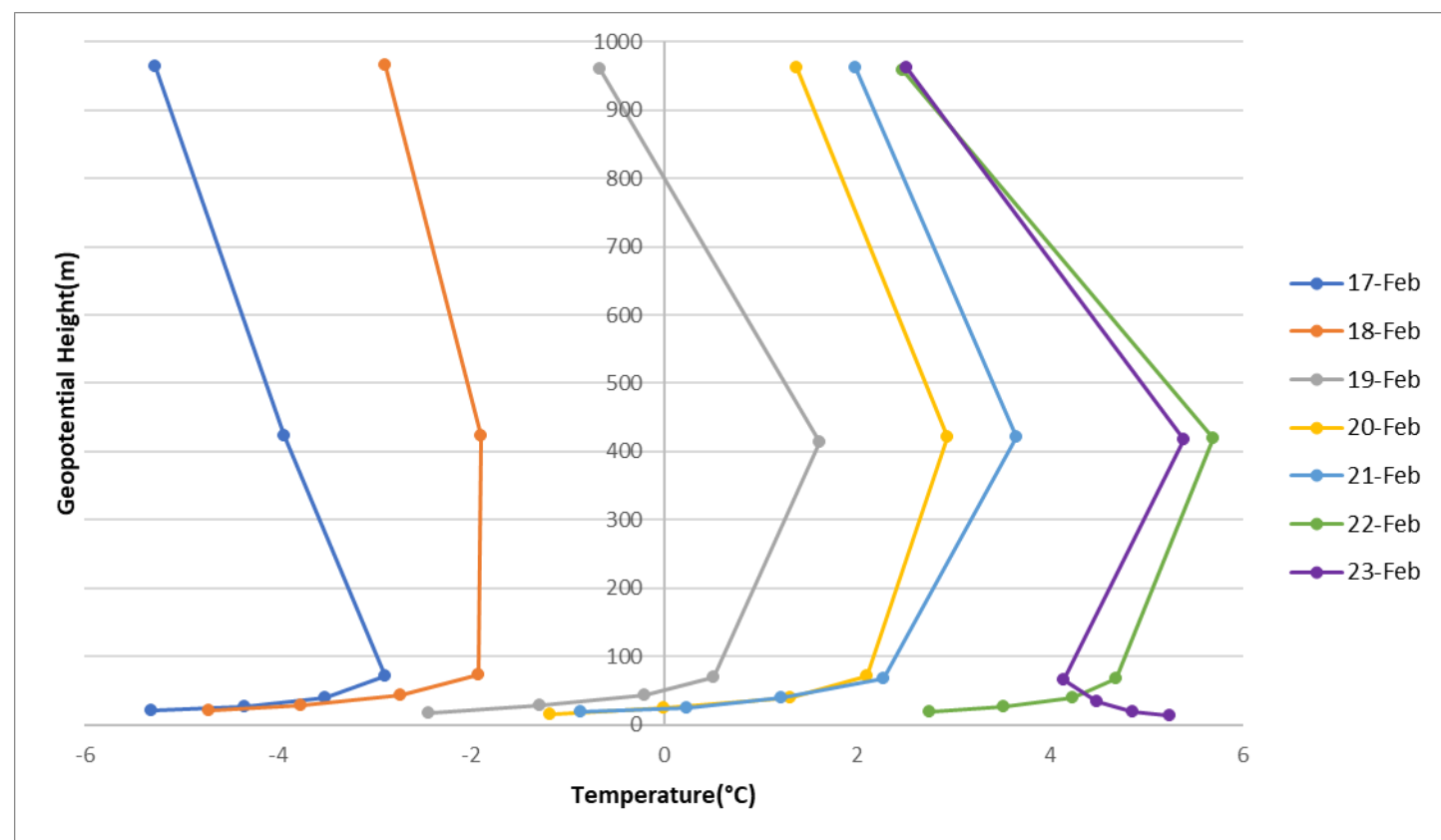

Figure 97: Trendlines of the predicted temperature of London Weather Centre (LWC) (Kukkonen et al., 2005)

\subsection{Temperature profile in the UBL}

Figure 98 shows the temperature profile between $40 \mathrm{~m}$ to $1000 \mathrm{~m}$ and the average temperature gradient coefficient is approximately $0.002 \mathrm{~K} / \mathrm{m}$. In this section, the air temperature gradient coefficient in the UBL layer is set as $0.002 \mathrm{~K} / \mathrm{m}$. 


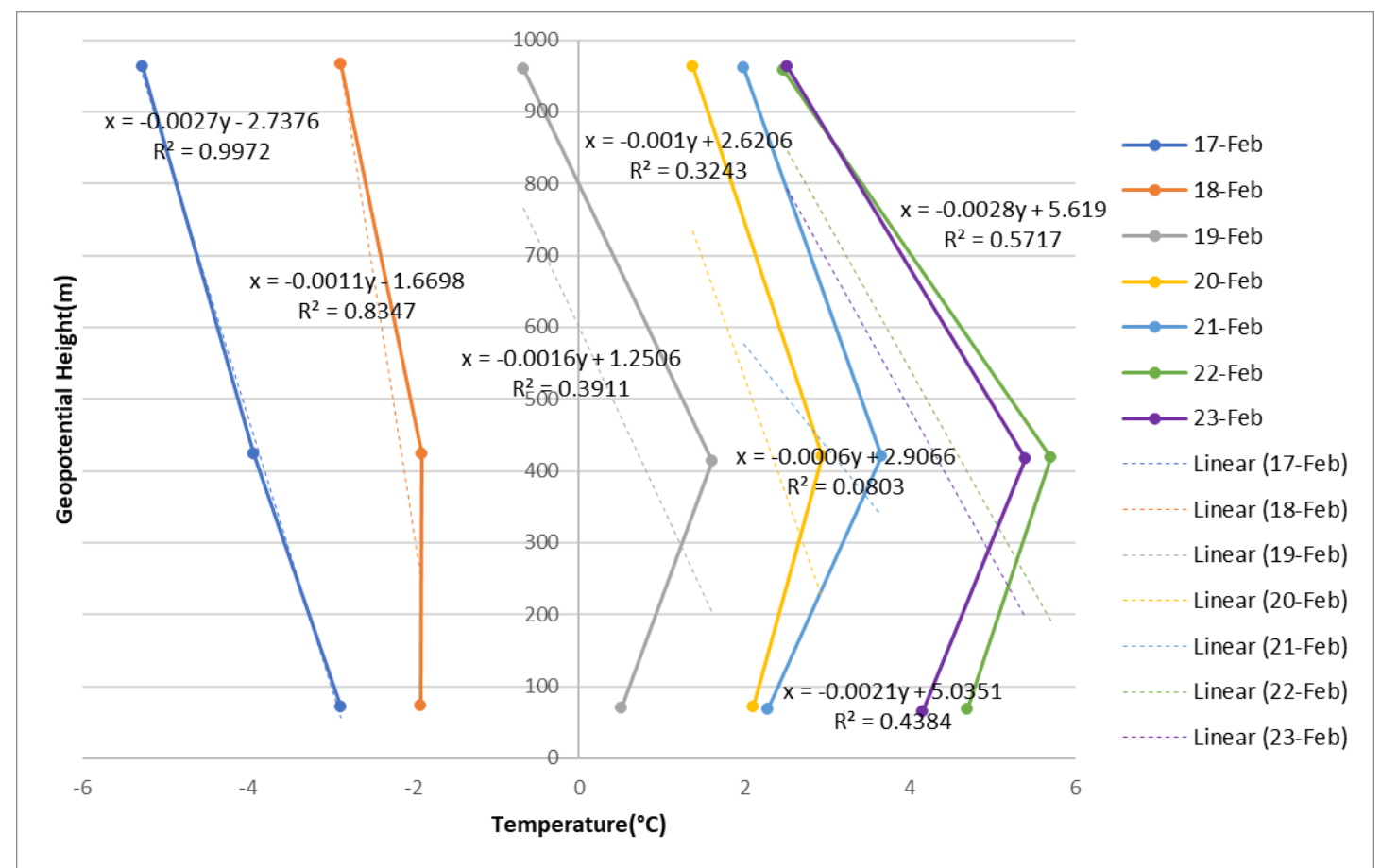

Figure 98: Predicted temperature profile in the UBL (Kukkonen et al., 2005)

\subsection{Temperature profile in the UCL}

Figure 99 shows the temperature profile between $0 \mathrm{~m}$ to $40 \mathrm{~m}$, and the average temperature gradient is $-0.0726 \mathrm{~K} / \mathrm{m}$. If the temperature increases with height, the temperature gradient coefficient is negative. The minimum air temperature gradient coefficient value of EnergyPlus is $0 \mathrm{~K} / \mathrm{m}$ (Section 6.3.3 and Figure 77). In this section, the air temperature gradient coefficient in the UCL is set as $0 \mathrm{~K} / \mathrm{m}$.

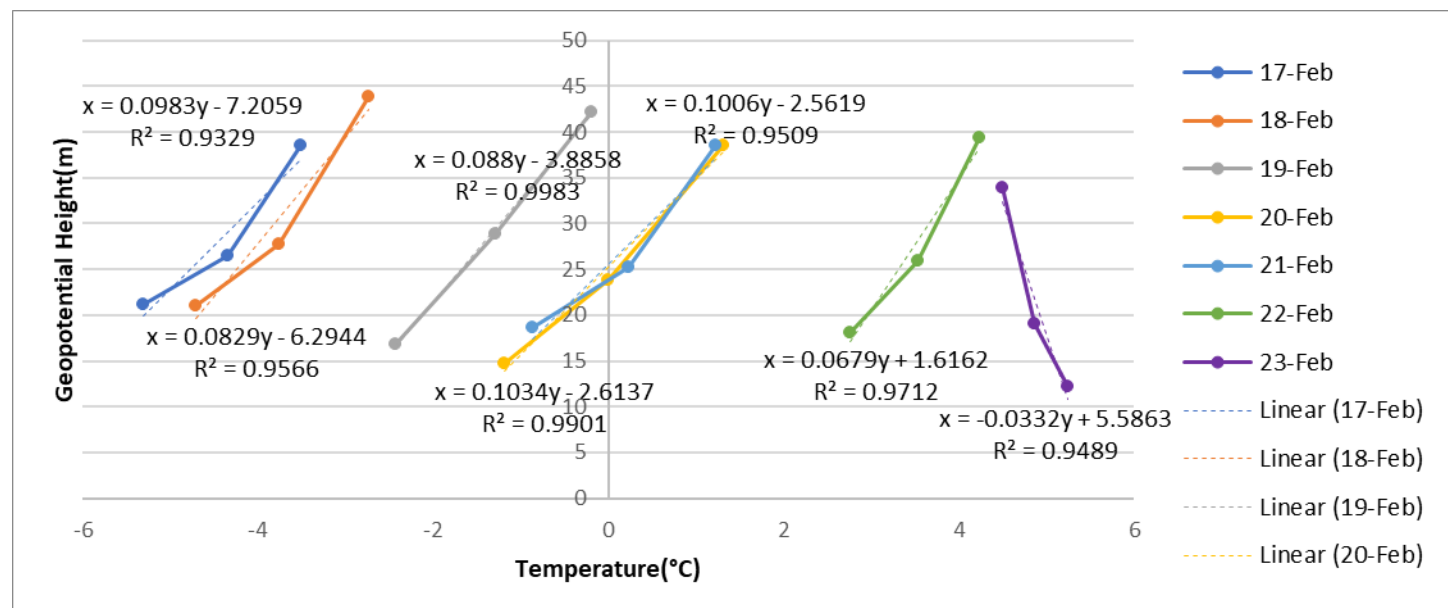

Figure 99: Predicted temperature profile in the UCL (Kukkonen et al., 2005)

\subsection{Necessity of Modelling Wind Pressure Coefficients}

The basic natural ventilation system was simplified natural ventilation. Wind pressure coefficients were also introduced to model the detailed natural ventilation. The detailed 
natural ventilation system was compared with the simplified natural ventilation system to explore the effects of different urban microclimate features on different natural ventilation systems. Does the temperature gradient have a greater impact on simplified natural ventilation than on detailed natural ventilation? Does the wind speed profile exponent have a greater impact on detailed natural ventilation than on simplified natural ventilation? Is the detailed natural ventilation system more susceptible to altitude than simplified natural ventilation? The necessity of getting wind pressure coefficients and modelling detailed natural ventilation was explored.

\subsubsection{Wind pressure coefficients at the $1^{\text {st }}, 17^{\text {th }}$ and $33^{\text {rd }}$ floors}

The wind pressure coefficients on the east $(\mathrm{E})$, north $(\mathrm{N})$, west $(\mathrm{W})$ and south $(\mathrm{S})$ windows of the low (1), middle (17) and high (33) floors of the prototypical 35-storeyed high-rise office building were generated by OpenFOAM and they are shown in Figure 100. Each of the wind pressure coefficients calculations could only give a set of results in one direction, and it takes about 4-5 hours. This simulation had 12 directions $\left(0^{\circ}\right.$ $330^{\circ}$ at an interval of $30^{\circ}$ ) and took around 4 days to complete the entire calculation. In Figure 100, red represents positive pressure, and green represents suction. Both dark red and dark green indicate higher absolute value of the wind pressure coefficients. The absolute value of the wind pressure coefficient increases with height.

\begin{tabular}{|r|rlll|lllll|lllll|}
\hline & $1 \mathrm{E}$ & $1 \mathrm{~N}$ & $1 \mathrm{~W}$ & $1 \mathrm{~S}$ & \multicolumn{1}{l}{$17 \mathrm{E}$} & $17 \mathrm{~N}$ & $17 \mathrm{~W}$ & $17 \mathrm{~S}$ & $33 \mathrm{E}$ & $33 \mathrm{~N}$ & $33 \mathrm{~W}$ & $33 \mathrm{~S}$ \\
\hline 0.00 & -0.09 & -0.12 & -0.09 & 0.17 & -0.26 & -0.12 & -0.26 & 0.38 & -0.31 & -0.13 & -0.31 & 0.77 \\
30.00 & -0.15 & -0.16 & -0.01 & 0.14 & -0.28 & -0.18 & 0.04 & 0.31 & -0.24 & -0.16 & 0.18 & 0.63 \\
60.00 & -0.14 & -0.16 & 0.04 & 0.05 & -0.20 & -0.29 & 0.31 & 0.10 & -0.15 & -0.23 & 0.66 & 0.22 \\
90.00 & -0.07 & -0.06 & 0.11 & -0.06 & -0.11 & -0.20 & 0.42 & -0.20 & -0.14 & -0.23 & 0.84 & -0.24 \\
120.00 & -0.14 & 0.05 & 0.04 & -0.16 & -0.21 & 0.09 & 0.31 & -0.29 & -0.15 & 0.22 & 0.66 & -0.23 \\
150.00 & -0.15 & 0.14 & -0.01 & -0.16 & -0.28 & 0.31 & 0.04 & -0.18 & -0.24 & 0.63 & 0.18 & -0.16 \\
180.00 & -0.09 & 0.17 & -0.09 & -0.12 & -0.26 & 0.38 & -0.26 & -0.12 & -0.31 & 0.77 & -0.31 & -0.13 \\
210.00 & -0.01 & 0.14 & -0.15 & -0.16 & 0.04 & 0.31 & -0.28 & -0.18 & 0.18 & 0.63 & -0.24 & -0.16 \\
240.00 & 0.04 & 0.05 & -0.14 & -0.16 & 0.31 & 0.10 & -0.20 & -0.29 & 0.66 & 0.22 & -0.15 & -0.23 \\
270.00 & 0.11 & -0.06 & -0.07 & -0.06 & 0.42 & -0.20 & -0.11 & -0.20 & 0.84 & -0.24 & -0.14 & -0.23 \\
300.00 & 0.04 & -0.16 & -0.14 & 0.05 & 0.31 & -0.29 & -0.21 & 0.09 & 0.66 & -0.23 & -0.15 & 0.22 \\
330.00 & -0.01 & -0.16 & -0.15 & 0.14 & 0.04 & -0.18 & -0.28 & 0.31 & 0.18 & -0.16 & -0.24 & 0.63 \\
\hline
\end{tabular}

Figure 100: Wind pressure coefficients from 12 directions at the $1^{\text {st }}, 17^{\text {th }}$ and $33^{\text {rd }}$ floors

\subsubsection{Wind pressure coefficients effects on natural ventilation}

In this research, several programs such as OpenFOAM, Urban Weather Generator and EnergyPlus were strung together by grasshopper plugins such as Butterfly, Dragonfly, Ladybug and Honeybee. However, Ladybug and Honeybee could not import wind 
pressure coefficients data directly. Hence, unlike previous building performance simulations, the wind pressure coefficients had to be imported into the EnergyPlus. The EnergyPlus Honeybee interface did not have a way of running the airflow network model, so there was some manual editing and analysis required.

There were two groups of comparison, one using original height variations (HandbookFundamentals, 2009), and the other one using adjusted height variations with an abbreviation of HV (Section 6.3). The original height variations were rough for cities while the adjusted height variations were specific for London. The original and adjusted height variations (HV) of London are shown in Table 27.

Table 27: Original and adjusted height variations for the City of London

\begin{tabular}{llc} 
Height Variation & Original & Adjusted (HV) \\
\hline Wind Speed Profile Exponent & 0.33 & 0.4 \\
Wind Speed Profile Boundary Layer Thickness $\{\mathrm{m}\}$ & 460 & 500 \\
Air Temperature Gradient Coefficient $\{\mathrm{K} / \mathrm{m}\}$ & 0.0065 & 0.002 \\
\hline
\end{tabular}

The thermal loads of detailed natural ventilation and HVAC system are compared with the simplified natural ventilation. The thermal load ratio in Figure 101 is the ratio of the thermal load of three systems to the thermal load of the simplified natural ventilation. It can be seen that an HVAC system has higher thermal loads than the two natural ventilation systems, especially in summer. Detailed natural ventilation has lower thermal loads in spring and autumn and higher thermal loads in summer than simplified natural ventilation. In summer, detailed natural ventilation has a higher cooling load than simplified natural ventilation. The influence of adjusted height variations (HV) on an HVAC system is greater than that on the detailed natural ventilation system. Figure 102 shows that adjusted height variations have fewer thermal loads than original height variations for most of the year. The thermal load reduction due to adjusted height variations increases with height, which means the influence of height variations increases with the height of the building. 


\begin{tabular}{|c|c|c|c|c|c|c|c|c|c|}
\hline & NV Simplified & 1_HVAC & 1_Detailed NV & $\begin{array}{l}\text { 17__Simplified } \\
\text { NV }\end{array}$ & 17_HVAC & $\begin{array}{l}\text { 17__Detailed } \\
\text { NV }\end{array}$ & $\begin{array}{l}\text { 33__simplified } \\
\text { NV }\end{array}$ & 33_HVAC & $\begin{array}{l}\text { 33_Detailed } \\
\text { NV }\end{array}$ \\
\hline Jan & 1.00 & 1.13 & 1.03 & 1.00 & 1.12 & 1.02 & 1.00 & 1.11 & 1.02 \\
\hline Feb & 1.00 & 1.06 & 0.97 & 1.00 & 1.05 & 0.97 & 1.00 & 1.05 & 0.97 \\
\hline Mar & 1.00 & 1.15 & 0.95 & 1.00 & 1.15 & 0.97 & 1.00 & 1.15 & 0.98 \\
\hline Apr & 1.00 & 1.13 & 0.86 & 1.00 & 1.12 & 0.89 & 1.00 & 1.09 & 0.89 \\
\hline May & 1.00 & 2.48 & 1.07 & 1.00 & 2.30 & 1.01 & 1.00 & 2.17 & 0.97 \\
\hline Jun & 1.00 & 2.32 & 1.44 & 1.00 & 2.43 & 1.49 & 1.00 & 2.64 & 1.61 \\
\hline Jul & 1.00 & 3.93 & 2.03 & 1.00 & 3.95 & 2.03 & 1.00 & 3.98 & 2.03 \\
\hline Aug & 1.00 & 3.08 & 1.81 & 1.00 & 3.20 & 1.87 & 1.00 & 3.39 & 1.96 \\
\hline Sep & 1.00 & 3.69 & 1.35 & 1.00 & 3.32 & 1.18 & 1.00 & 2.95 & 1.03 \\
\hline Oct & 1.00 & 1.51 & 0.82 & 1.00 & 1.52 & 0.88 & 1.00 & 1.51 & 0.92 \\
\hline Nov & 1.00 & 1.24 & 0.94 & 1.00 & 1.24 & 0.96 & 1.00 & 1.23 & 0.97 \\
\hline Dec & 1.00 & 1.09 & 1.00 & 1.00 & 1.08 & 1.00 & 1.00 & 1.08 & 1.00 \\
\hline
\end{tabular}

(a)

\begin{tabular}{|c|c|c|c|c|c|c|c|c|c|}
\hline & $\begin{array}{l}1 \_ \\
\text {Simplified } \\
\text { NV_HV }\end{array}$ & 1_HVAC_HV & $\begin{array}{l}1 \_ \text {Detailed } \\
\mathrm{NV} \_\mathrm{HV}\end{array}$ & $\begin{array}{l}17 \_ \\
\text {Simplified } \\
\text { NV_HV }\end{array}$ & 17_HVAC_HV & $\begin{array}{l}\text { 17_Detailed } \\
\text { NV_HV }\end{array}$ & $\begin{array}{l}33 \_ \\
\text {Simplified } \\
\text { NV_HV }\end{array}$ & 33_HVAC_HV & $\begin{array}{l}\text { 33_Detailed } \\
\text { NV_HV }\end{array}$ \\
\hline Jan & 1.00 & 1.13 & 1.03 & 1.00 & 1.12 & 1.02 & 1.00 & 1.12 & 1.02 \\
\hline Feb & 1.00 & 1.06 & 0.97 & 1.00 & 1.05 & 0.97 & 1.00 & 1.05 & 0.97 \\
\hline Mar & 1.00 & 1.15 & 0.95 & 1.00 & 1.15 & 0.96 & 1.00 & 1.15 & 0.97 \\
\hline Apr & 1.00 & 1.14 & 0.86 & 1.00 & 1.12 & 0.87 & 1.00 & 1.12 & 0.88 \\
\hline May & 1.00 & 2.71 & 1.12 & 1.00 & 2.49 & 1.09 & 1.00 & 2.44 & 1.07 \\
\hline Jun & 1.00 & 2.43 & 1.46 & 1.00 & 2.35 & 1.45 & 1.00 & 2.39 & 1.47 \\
\hline Jul & 1.00 & 4.17 & 2.03 & 1.00 & 3.95 & 2.04 & 1.00 & 3.93 & 2.03 \\
\hline Aug & 1.00 & 3.39 & 1.82 & 1.00 & 3.11 & 1.82 & 1.00 & 3.13 & 1.83 \\
\hline Sep & 1.00 & 4.07 & 1.35 & 1.00 & 3.60 & 1.30 & 1.00 & 3.41 & 1.22 \\
\hline Oct & 1.00 & 1.59 & 0.84 & 1.00 & 1.51 & 0.84 & 1.00 & 1.51 & 0.86 \\
\hline Nov & 1.00 & 1.24 & 0.94 & 1.00 & 1.25 & 0.95 & 1.00 & 1.24 & 0.96 \\
\hline Dec & 1.00 & 1.09 & 1.00 & 1.00 & 1.09 & 1.00 & 1.00 & 1.08 & 1.00 \\
\hline
\end{tabular}

(b)

Figure 101: Thermal load ratio of detailed natural ventilation, HVAC system over simplified natural ventilation a) with original height variations b) with adjusted height variations (HV)

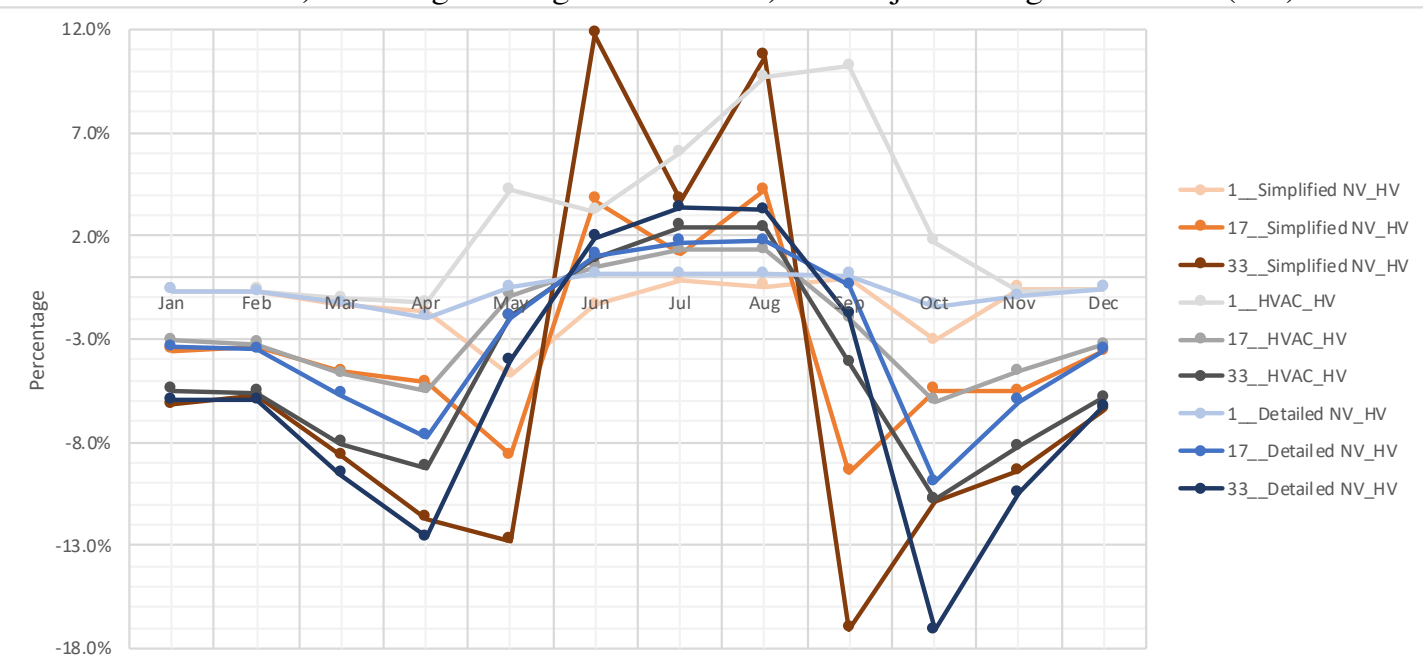

Figure 102 Thermal load percentage change with adjusted height variations (HV) over original height variations for simplified natural ventilation, HVAC system and detailed natural ventilation

The thermal load of detailed natural ventilation is quite different from that of simplified natural ventilation. The comparison of thermal load between different ventilation systems shows that it is necessary to model detailed natural ventilation and wind pressure coefficients, because urban microclimate parameters have different influence on detailed natural ventilation, especially in spring and autumn. 


\subsubsection{Effects of urban microclimate parameters on detailed natural ventilation system}

Chapter 5 and Chapter 6 discussed the effects of urban microclimate parameters on simplified natural ventilation and an HVAC system. The UHI has a greater effect on the building performance than the urban wind, and the temperature gradient coefficient has a greater effect than wind speed exponent. Temperature-related parameters strongly influence the temperature-related ventilation system. When taking wind pressure coefficients into consideration, whether or not wind-related parameters have a stronger impact is discussed in this chapter. The effects of horizontal and vertical wind-related and temperature-related parameters on the detailed natural ventilation system were compared.

Four kinds of weather data were imported into the building performance simulation using the detailed natural ventilation system. The four kinds of weather data contained rural weather data, urban weather data considering urban wind, urban weather data considering the UHI, and urban weather data considering both urban wind and the UHI. In Figure 103, thermal loads considering urban winds are slightly lower than those using rural weather data, and thermal loads considering the UHI is much lower than those using rural weather data for most of the year. Hence, for detailed natural ventilation system the UHI still has a greater impact than urban winds.

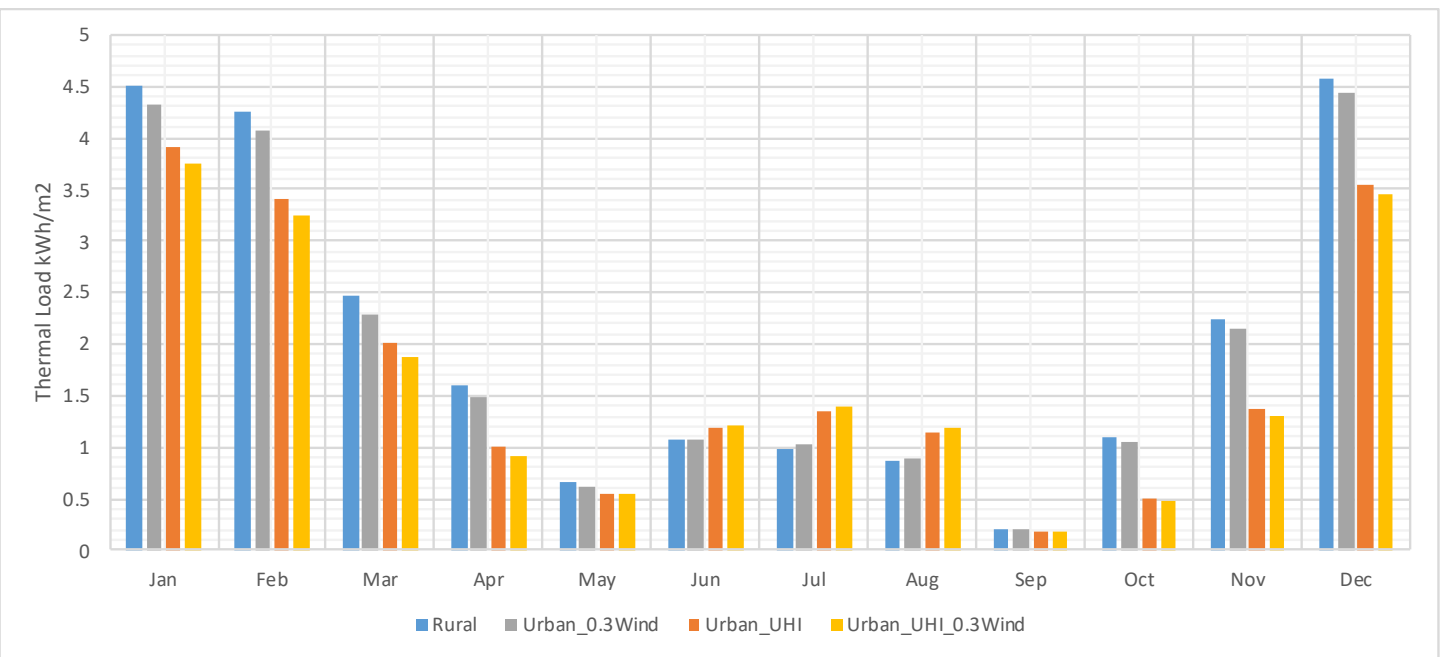

Figure 103: Thermal loads for detailed natural ventilation with four kinds of weather data

The effects of vertical variations on the detailed natural ventilation system were compared through changing variables (Table 28) to explore the importance of vertical variation precision. Wind speed profile exponent of 0.33 was compared with 0.4 , wind 
speed profile boundary layer thickness of $400 \mathrm{~m}$ was compared with $500 \mathrm{~m}$, and air temperature gradient coefficient of $0.004 \mathrm{~K} / \mathrm{m}$ was compared with $0.002 \mathrm{~K} / \mathrm{m}$.

Table 28: Vertical Variation Settings of detailed natural ventilation system

\begin{tabular}{l|c|c|c}
\hline & $\begin{array}{c}\text { Wind Speed } \\
\text { Profile Exponent }\end{array}$ & $\begin{array}{c}\text { Wind Speed Profile } \\
\text { Boundary Layer Thickness } \\
(\mathrm{m})\end{array}$ & $\begin{array}{c}\text { Air Temperature Gradient } \\
\text { Coefficient }(\mathrm{K} / \mathrm{m})\end{array}$ \\
\hline $\begin{array}{l}\text { Control } \\
\text { Group }\end{array}$ & 0.4 & 500 & 0.002 \\
\hline $\begin{array}{c}\text { Experimental } \\
\text { Group }\end{array}$ & $\mathbf{0 . 3 3}$ & 500 & 0.002 \\
\cline { 2 - 4 } & 0.4 & $\mathbf{4 0 0}$ & 0.002 \\
\hline
\end{tabular}

In Figure 104, the air temperature gradient coefficient has a greater impact on detailed natural ventilation than the wind speed profile exponent, and the wind speed profile exponent has a greater impact than the wind speed profile boundary layer thickness. The influence of air temperature gradient increases with height, however, the influence of wind speed profile exponent decreases with height. The influence of the wind speed profile boundary layer thickness is quite small (less than 1\%). Two wind-related parameters, such as the wind speed profile exponent and the wind speed profile boundary layer thickness, have little influence on the building performance using a detailed natural ventilation system.

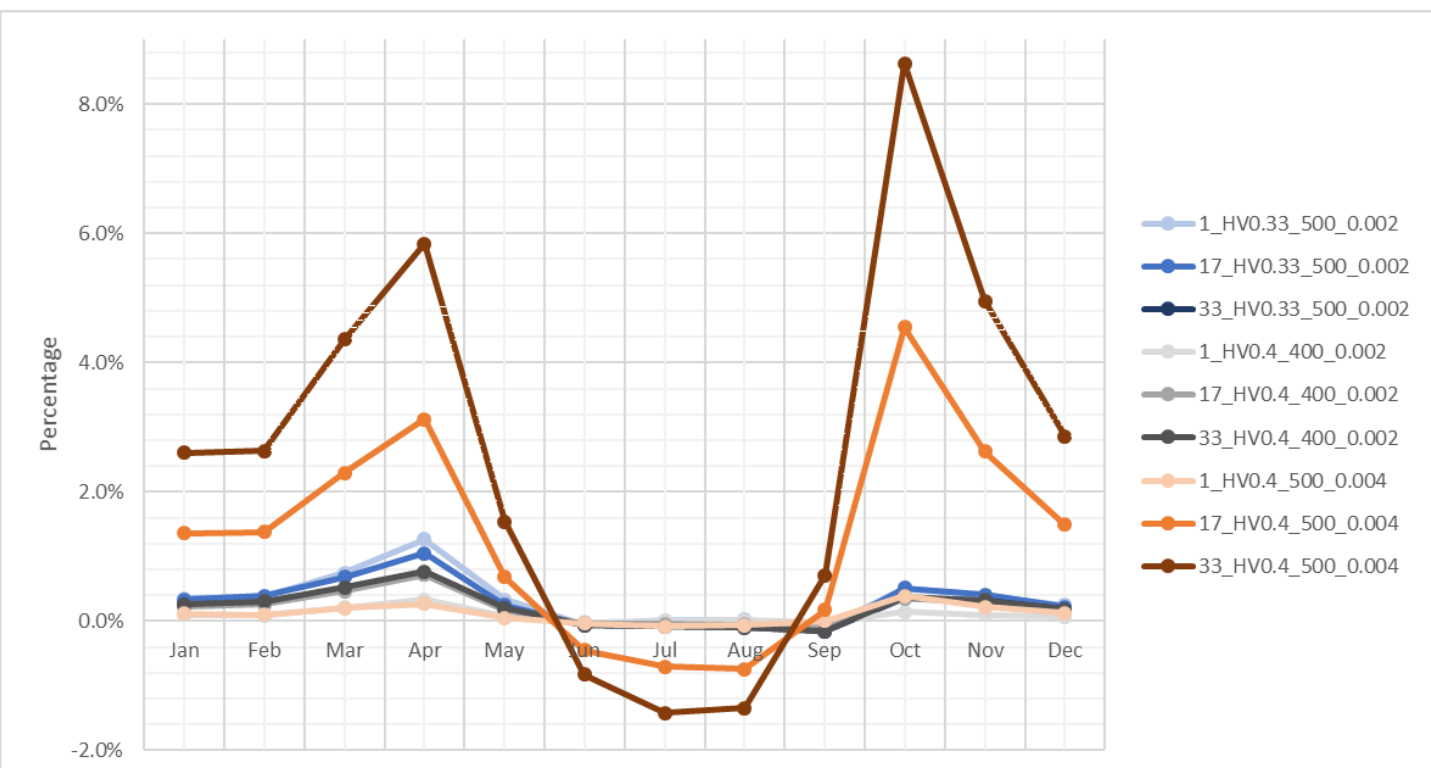

Figure 104: Thermal load percentage change for detailed natural ventilation with different height variations (HV) over control group (HV0.4_500_0.002) at the $1^{\text {st }}, 17^{\text {th }}$ and $33^{\text {rd }}$ floors

Overall, for the three systems, HVAC, the simplified natural ventilation and the detailed natural ventilation, temperature-related parameters play a more important role than wind-related parameters. Wind-related parameters do not strongly influence the 
ventilation system taking wind pressure coefficients into consideration. Therefore, engineers should pay more attention to temperature-related parameters.

\subsection{Urban Microclimate Multilayer Modelling Method}

The urban microclimate was divided into a lower layer in the UCL and an upper layer in the UBL. They were simulated respectively to explore the necessity of modelling with a multilayer modelling method. When using a single-layer modelling method, vertical variations of urban microclimate have a great impact on the building performance simulation. However, vertical variations in urban areas are not constant and they had an upper layer and a lower layer, respectively. Hence, if using a multilayer modelling method, will it make a big difference? The 35-storeyed prototypical building was divided into a 9-storeyed portion and another 26-storeyed portion.

\subsubsection{Wind pressure coefficients in the UCL and UBL}

In this section, the wind pressure coefficients of the 9-storeyed lower section of the building in the UCL and the 26-storeyed upper section of the building in the UBL are generated. The process was similar to Section 7.3.2. The test points for the wind pressure coefficients of the 9 -storeyed portion were set at the $1^{\text {st }}, 4^{\text {th }}$ and $7^{\text {th }}$ floors and those of the 26 -storeyed portion were set at the $10^{\text {th }}, 22^{\text {nd }}$ and $33^{\text {rd }}$ floors.

Figure 105 and Figure 106 show the wind pressure coefficients on the east (E), north $(\mathrm{N})$, west $(\mathrm{W})$ and south $(\mathrm{S})$ windows of three floors from 12 directions $\left(0^{\circ}-330^{\circ}\right.$ at an interval of $30^{\circ}$ ) in the UCL and in the UBL. The wind pressure coefficients in the UCL are lower than those in the UBL. In the UCL, they increase with height slightly, because the movement of the air flow is disturbed by surrounding buildings. The wind pressure coefficients in the UBL increase significantly with height. These coefficients are then imported into IDF files. 


\begin{tabular}{|c|c|c|c|c|c|c|c|c|c|c|c|c|}
\hline & & & & $1 \mathrm{~S}$ & & $4 \mathrm{~N}$ & $N$ & $4 S$ & $7 \mathrm{E}$ & $7 \mathrm{~N}$ & $7 \mathrm{~W}$ & $7 S$ \\
\hline & & & & & & & & & & & -0.16 & \\
\hline & & & & & & & & & & & & \\
\hline & & & & & & & & & & & & \\
\hline 90 & -0. & -0. & & & & & & & -0.09 & -0. & 03 & -0.0 \\
\hline & & & & & & & & & & & & \\
\hline & & & & & & & & & & & & \\
\hline 180.00 & -0.09 & & & -0.12 & & & & & -0.16 & & & -0 \\
\hline 210.00 & -0.01 & & & & & & & & & & & \\
\hline & & & & & & & & & & & & \\
\hline & & & & -0. & & & & & & & & \\
\hline & & & & & & & & & & & & \\
\hline 30.00 & -0.01 & -0.16 & -0.15 & 0.14 & -0.02 & -0.17 & -0.18 & 0.12 & -0.03 & -0.18 & -0.24 & 0.1 \\
\hline
\end{tabular}

Figure 105: Wind pressure coefficients from 12 directions at the $1^{\text {st }}, 4^{\text {th }}$ and $7^{\text {th }}$ floors

\begin{tabular}{|c|c|c|c|c|c|c|c|c|c|c|c|c|}
\hline & & $\mathrm{N}$ & W & OS & $\mathrm{E}$ & $2 \mathrm{~N}$ & $2 W$ & $22 \mathrm{~S}$ & $33 \mathrm{E}$ & $33 N$ & $33 \mathrm{~W}$ & $33 \mathrm{~S}$ \\
\hline 0.00 & 21 & & & & & .12 & & 53 & & & 0.31 & \\
\hline & & & & & & & & & & & & \\
\hline $6 c$ & -0.2 & -0 . & & & & & & 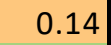 & -0.15 & & 66 & 0.2 \\
\hline & & & & & & & & & & & & \\
\hline & & & & & & & & & & & & \\
\hline 0.00 & -0.3 & & $-0 .($ & & & & & & & & 18 & \\
\hline 18 & -0.2 & & & & & & & & & & & \\
\hline & & & & & & & & & & & & \\
\hline & & & & & & & & & & & & \\
\hline & & & & & & & & & & & & \\
\hline & & & & & & & & & & & -0.15 & 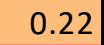 \\
\hline 30.00 & .05 & -0.19 & -0.30 & 0.12 & 0.08 & -0.16 & -0.23 & 0.43 & 0.18 & -0.16 & -0.24 & 0.63 \\
\hline
\end{tabular}

Figure 106: Wind pressure coefficients from 12 directions at the $10^{\text {th }}, 22^{\text {nd }}$ and $33^{\text {rd }}$ floors

\subsubsection{Urban microclimate setting in the UCL and UBL}

The urban wind speed profile and the temperature profile were divided into two parts because of the inconstant wind speed exponent and air temperature gradient in urban areas. The lower layer in the UCL used urban weather data considering urban winds and the UHI. The wind environment of the upper layer in the UBL was close to rural wind. The temperature gradient in UCL was $0 \mathrm{~K} / \mathrm{m}$ (Section 7.3.3.2.2), so the temperature at the lowest floor in the UBL was close to the temperature in the UCL. Hence, the upper layer in the UBL introduced rural wind data and the UHI data into its model. Vertical variations of the multilayer model were explained in Section 7.3.3 and shown in Table 29. The original height variations in the UCL and the UBL were the same. The adjusted height variations in the UCL and the UBL were different, and they were based on the split wind profile in Section 7.3.3.1 and the split temperature profile in Section 7.3.3.2. 
Table 29: Height variations of multilayer model

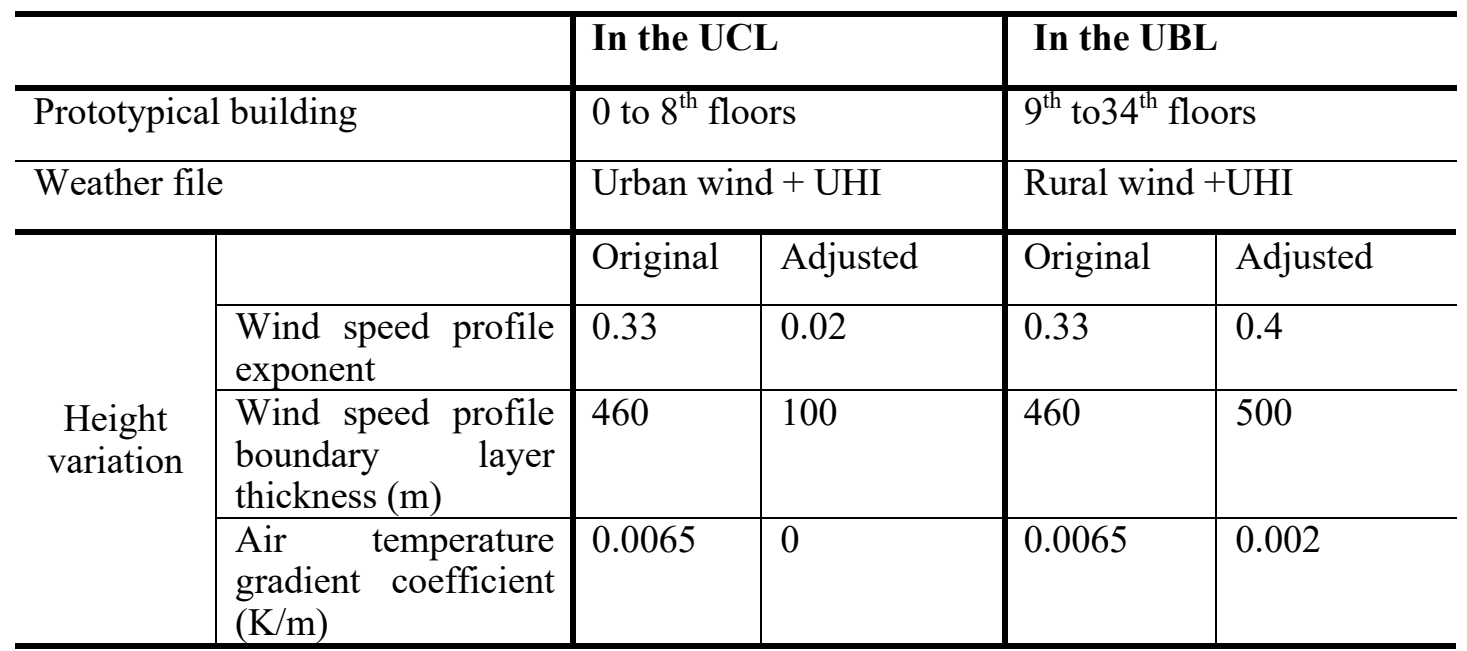

The effects of the multilayer modelling method on detailed natural ventilation, and simplified natural ventilation, as well as an HVAC system were compared. The effects of height variations on multilayer urban microclimate model were also discussed in this section.

\subsubsection{Analysis and results}

Firstly, the effects of the multilayer modelling method and the effects of vertical variations on three different ventilation systems were analysed: a simplified natural ventilation system (orange), an HVAC system (grey) and a detailed natural ventilation system (blue). Secondly, the importance of detailed natural ventilation was discussed by comparing natural ventilation systems with an HVAC system. Lastly, the multilayer modelling method was compared with the original one-layer modelling method, which assumes the vertical variations are constant within the prototypical building height.

\subsubsection{Simplified natural ventilation system}

This section explores the effects of the multilayer modelling method on a simplified natural ventilation system. Figure 107 shows that thermal loads in the UCL using original height variations (Figure 107a) are smaller than those using adjusted height variations (Figure 107b) for most of the year. In contrast, thermal loads in the UBL using original height variations (Figure 107a) are bigger than those using adjusted height variations (Figure 107b). The adjusted height variations in the UCL increase thermal load predictions, while the adjusted height variations in the UBL decrease thermal load predictions for most of the year. In the UCL and the UBL, cooling loads in summer decrease with height. 


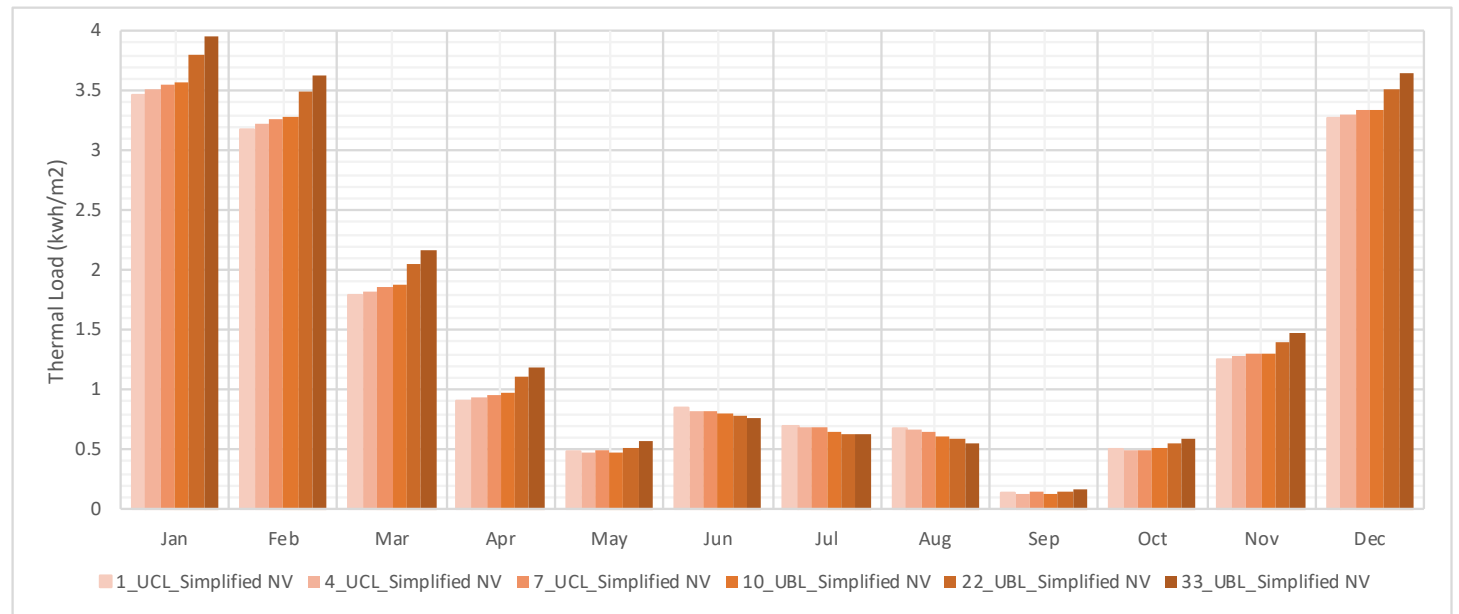

(a)

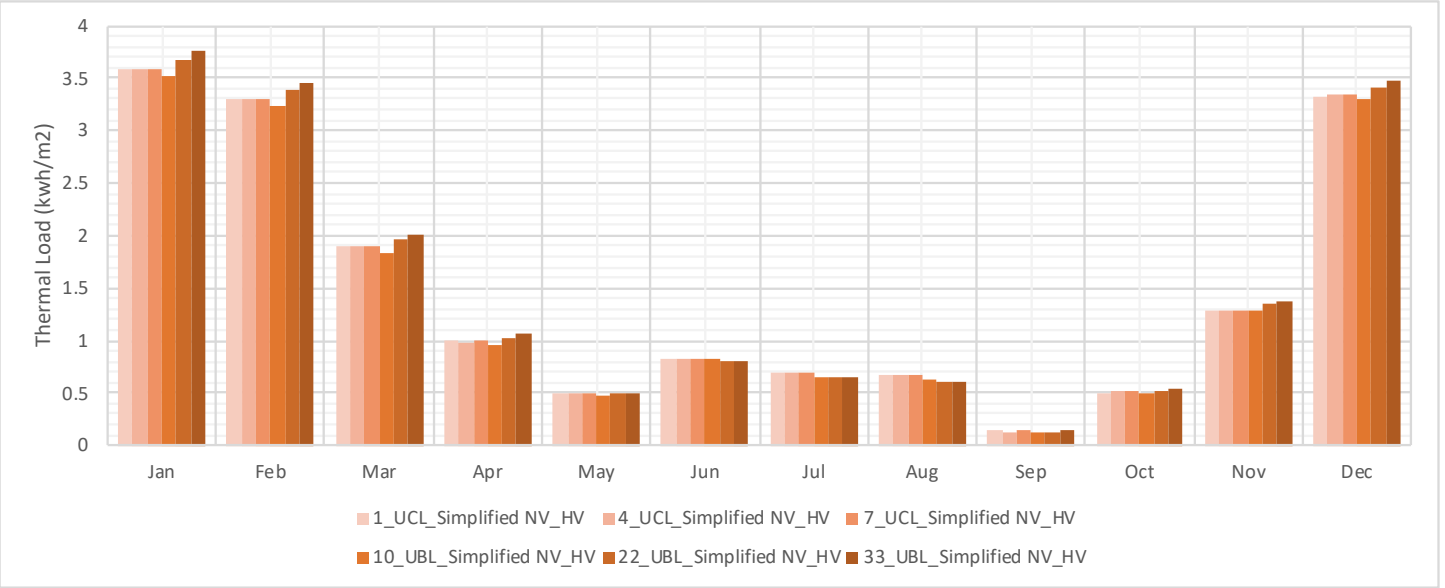

(b)

Figure 107: Thermal loads of six floors in the UCL and UBL for simplified natural ventilation a) with original height variations b) with adjusted height variations (HV)

In Figure 108, in the UCL, the increase of thermal load predictions due to adjusted height variations is less than $9 \%$. The thermal loads of the lower floor increase more than those of the higher floor. In the UCL, the increase due to adjusted height variations decreases with height. However, thermal loads in the UBL decrease for most of the year and the decrease can reach $21 \%$ at the $33^{\text {rd }}$ floor. The reduction due to adjusted height variations in the UBL increases with height. The multilayer modelling method has a big impact at a lower or a higher floor on building performance predictions using a simplified natural ventilation system. 


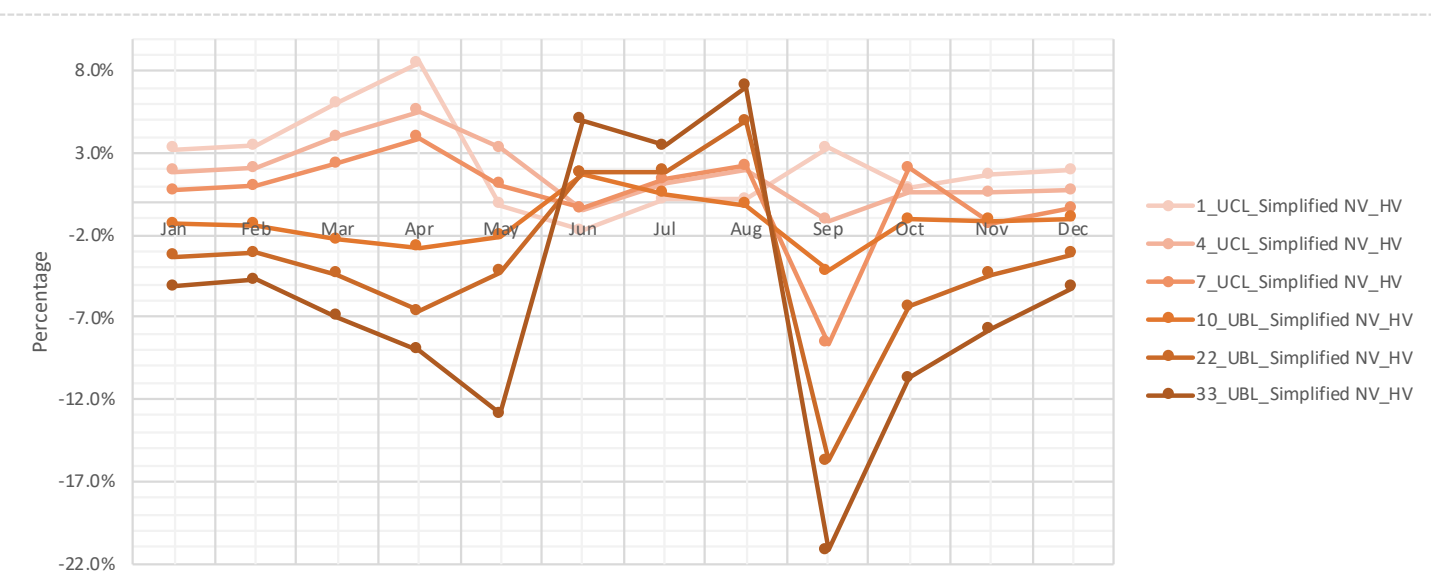

Figure 108: Thermal load percentage change with adjusted height variations (HV) over original height variations for simplified natural ventilation of six floors in the UCL and UBL

For the simplified natural ventilation system, the effects of adjusted height variation on the thermal load change increase with the distance between the floor and the height of the UCL. The multilayer modelling method reduces the differences of thermal loads at different floors, because it increases the lower thermal load at a lower floor and it decreases the higher thermal load at a higher floor.

\subsubsection{HVAC system}

The scale of effects of the multilayer modelling method on an HVAC system in the UCL and the UBL are similar, but the effects are opposite. When using an HVAC system, thermal loads of summer grows dramatically (up to $2.8 \mathrm{kWh} / \mathrm{m}^{2}$ ), and the thermal loads at $10^{\text {th }}$ floor are higher than at other floors in summer (Figure 109). When using original height variations, thermal loads increase with height in winter, spring and autumn. When using adjusted height variations, thermal loads are similar in the UCL. In the UBL, thermal loads decrease with height in summer and increase with height for the rest of the year. For both original and adjusted height variations cooling loads at the $10^{\text {th }}$ floor are the highest in summer. When using adjusted height variations, heating loads at the $10^{\text {th }}$ floor are lower than at other floors. 


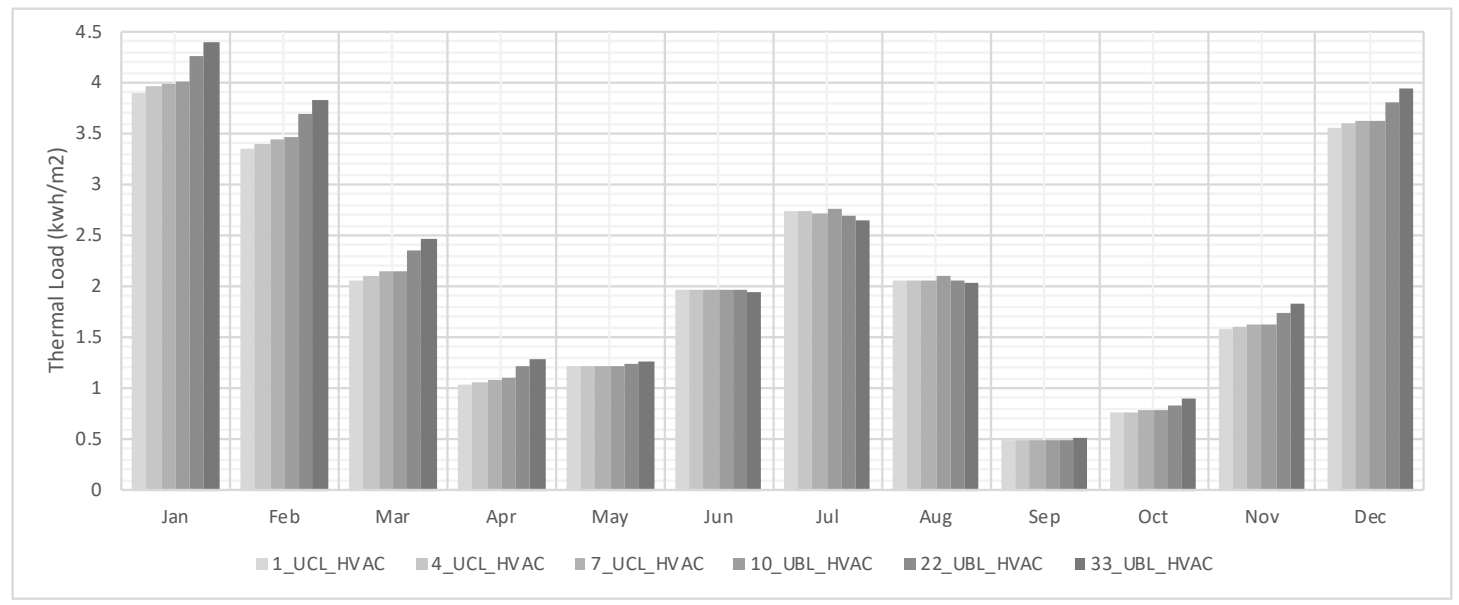

(a)

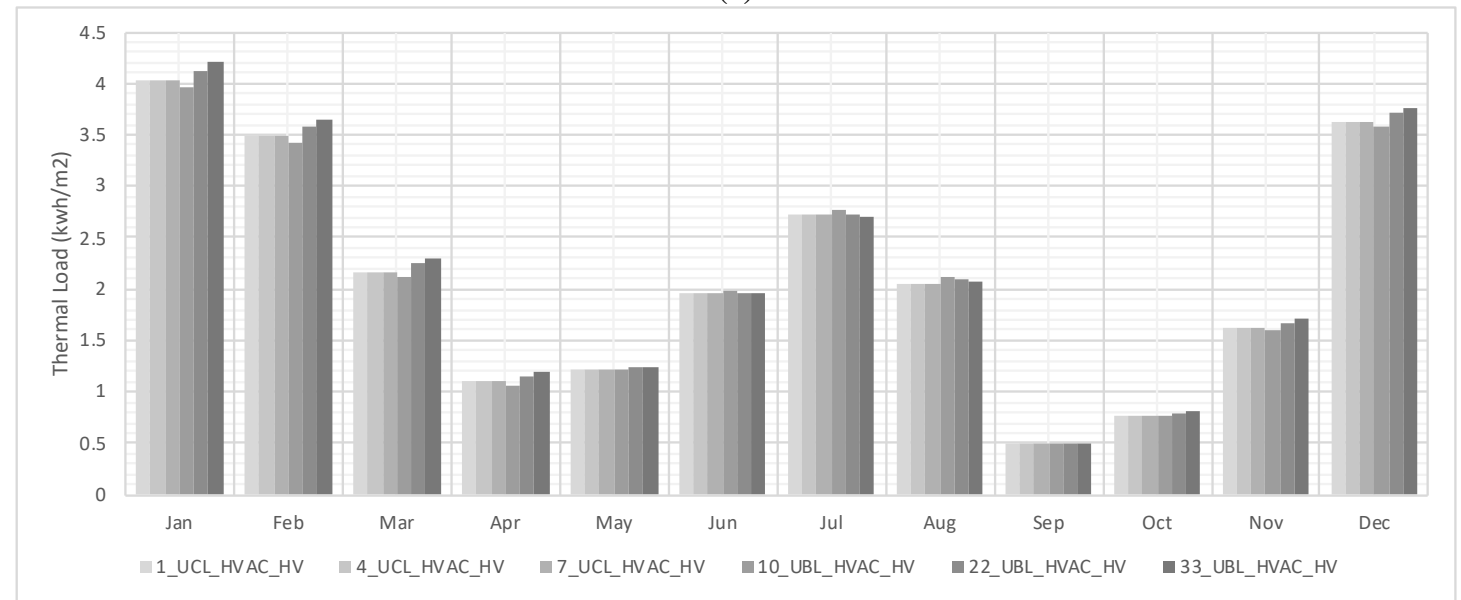

(b)

Figure 109: Thermal loads of six floors in the UCL and UBL for an HVAC system a) with original height variations b) with adjusted height variations (HV)

Figure 110 shows for an HVAC system the effects of adjusted height variations during spring and autumn are more than that in summer. In the UCL, adjusted height variations increase thermal load predictions (less than 7\%) for most of the year. In the UBL, adjusted height variations increase thermal load predictions in summer and decrease thermal loads (less than 9\%) for the rest of the year. 


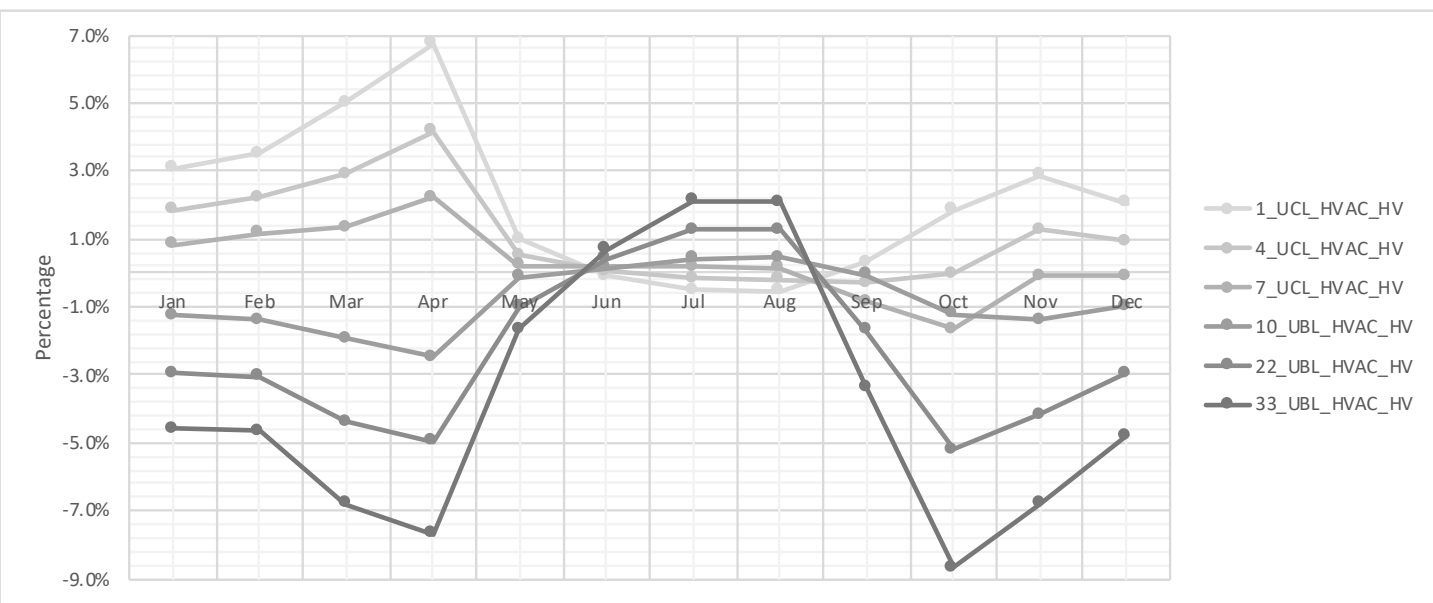

Figure 110: Thermal load percentage change with adjusted height variations (HV) over original height variations for an HVAC system of six floors in the UCL and UBL

The effects of adjusted height variation on an HVAC system increase with the distance to the UCL height. The effects of adjusted height variation on an HVAC system (less than $10 \%$ ) are smaller than those on the simplified natural ventilation (less than $22 \%$ ). The multilayer modelling method has a certain impact on the heating load of an HVAC system (less than 9\%) but has a small impact on the cooling load (less than $3 \%$ ).

\subsubsection{Detailed natural ventilation system}

The effects of adjusted height variations on a detailed natural ventilation system are similar to the simplified natural ventilation system. In Figure 111, thermal loads decrease with height slightly in summer, while they increase with height in the UCL and the UBL separately for most of the year. When using adjusted height variations, thermal loads at $10^{\text {th }}$ floor are the lowest for most of the year.

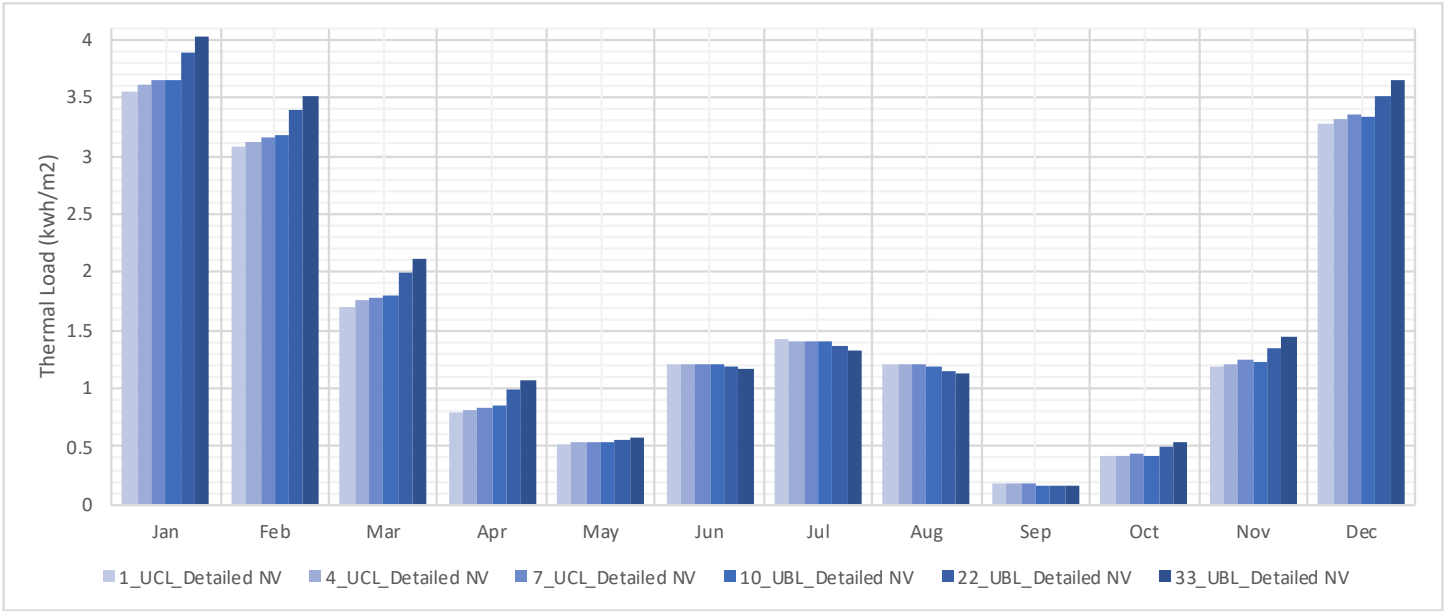

(a) 


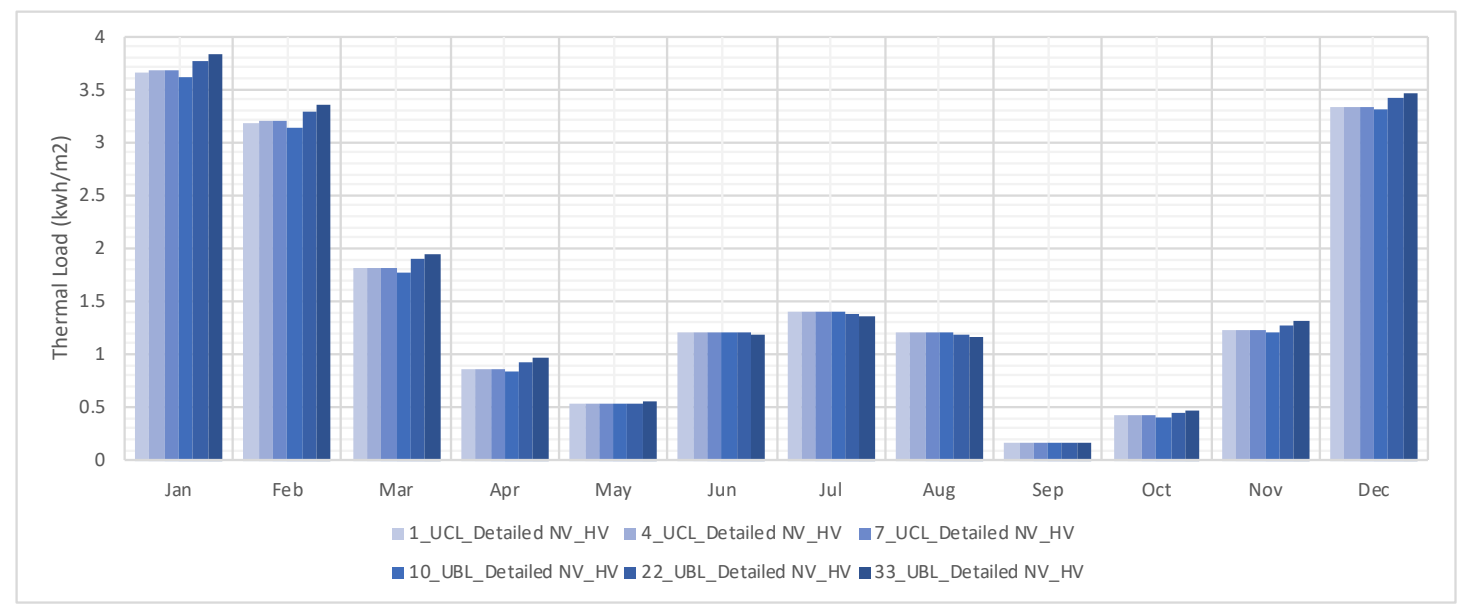

(b)

Figure 111: Thermal loads of six floors in the UCL and UBL for detailed natural ventilation a) with original height variations $b$ ) with adjusted height variations (HV)

The effects of adjusted height variations on detailed natural ventilation during spring and autumn are more than that in summer and winter (Figure 112). In the UCL adjusted height variations increase thermal loads for most of the year less than $10 \%$. In the UBL adjusted height variations decrease thermal loads for most of the year less than $15 \%$.

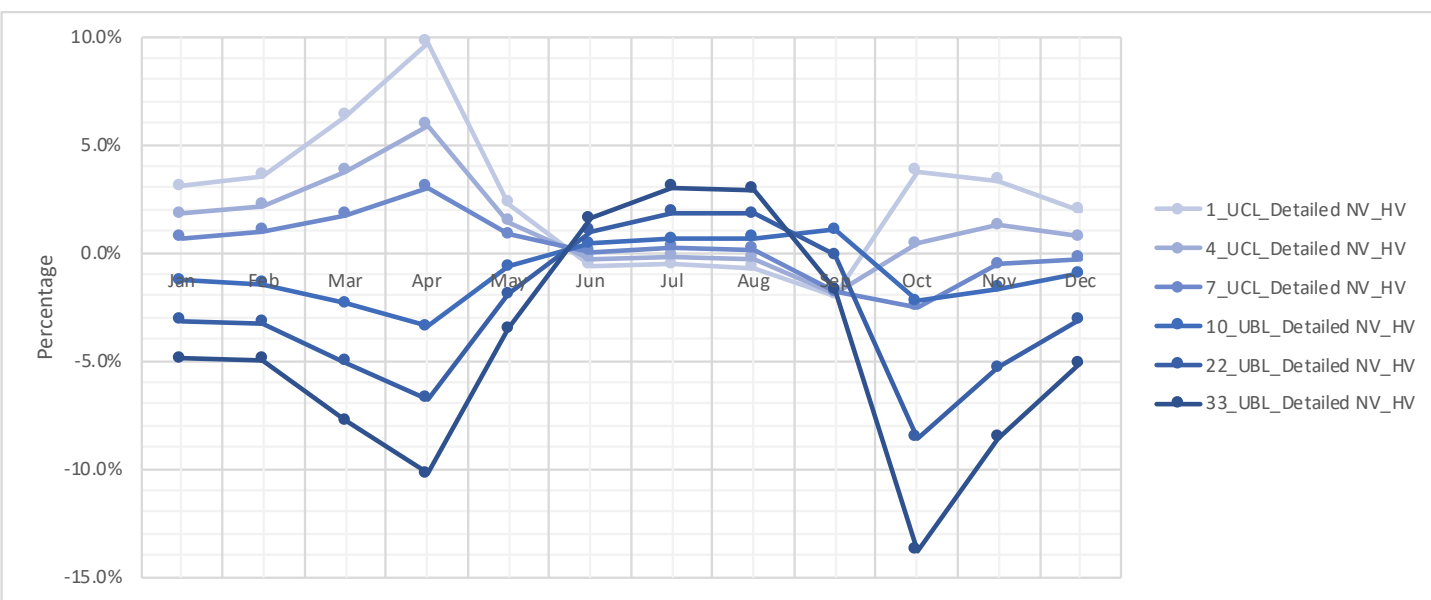

Figure 112: Thermal load percentage change with adjusted height variations (HV) over original height variations for detailed natural ventilation of six floors in the UCL and UBL

The effects of adjusted height variation for detailed natural ventilation increase with the distance to the UCL height. In the UBL, the effects of adjusted height variation on detailed natural ventilation (less than 14\%) are smaller than those on the simplified natural ventilation (less than 22\%). In the UCL, the effects on detailed natural ventilation (less than 10\%) are bigger than those on the simplified natural ventilation (less than $8 \%$ ). The multilayer modelling method has a big impact on the heating load of the detailed natural ventilation system (less than 14\%) but has a small impact on the cooling load (less than 3\%). 
The comparison of adjusted vertical variation effects on different ventilation systems at different floors from January to December is shown in Figure 113. In Figure 113, the orange bar means a positive percentage change and the green bar means a negative percentage change. Positive percentage changes mean that thermal load predictions caused by adjusted height variations (HV) are bigger than those caused by original height variations. Negative percentage changes mean that thermal load predictions caused by adjusted height variations (HV) are smaller than those caused by original height variations.

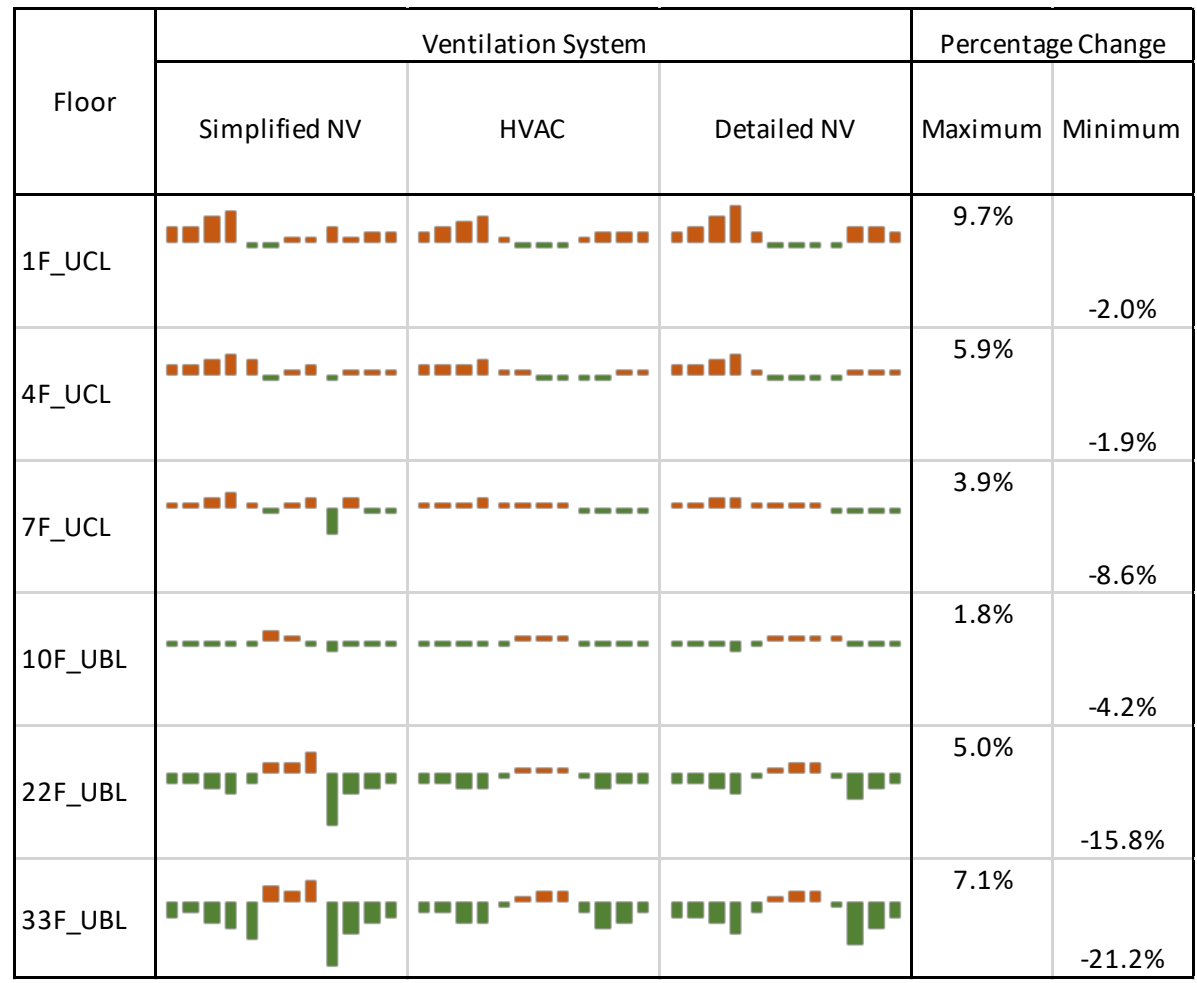

Figure 113: Effects of adjusted height variations (HV) on simplified natural ventilation, HVAC system, and detailed natural ventilation of six floors in the UCL and UBL

Figure 113 shows the thermal load percentage change due to adjusted height variation using simplified natural ventilation is bigger than that using detailed natural ventilation, and using detailed natural ventilation is bigger than using an HVAC system. In the UCL, the multilayer modelling method increases thermal load predictions, while in the UBL, it decreases thermal load predictions for most of the year. The multilayer modelling method reduces the differences of thermal load predictions at different floors. It has a big impact on the heating load but a small impact on the cooling load. The influence of the multilayer modelling method on natural ventilation systems is bigger than on HVAC systems.

\subsubsection{Natural ventilation efficiency}


Section 7.4.2 compared simplified natural ventilation with detailed natural ventilation when using a single-layer modelling method. In this section, they are compared to explore the natural ventilation efficiency using a multilayer modelling method. Figure 114 shows the comparison between detailed and simplified natural ventilation over an HVAC system.

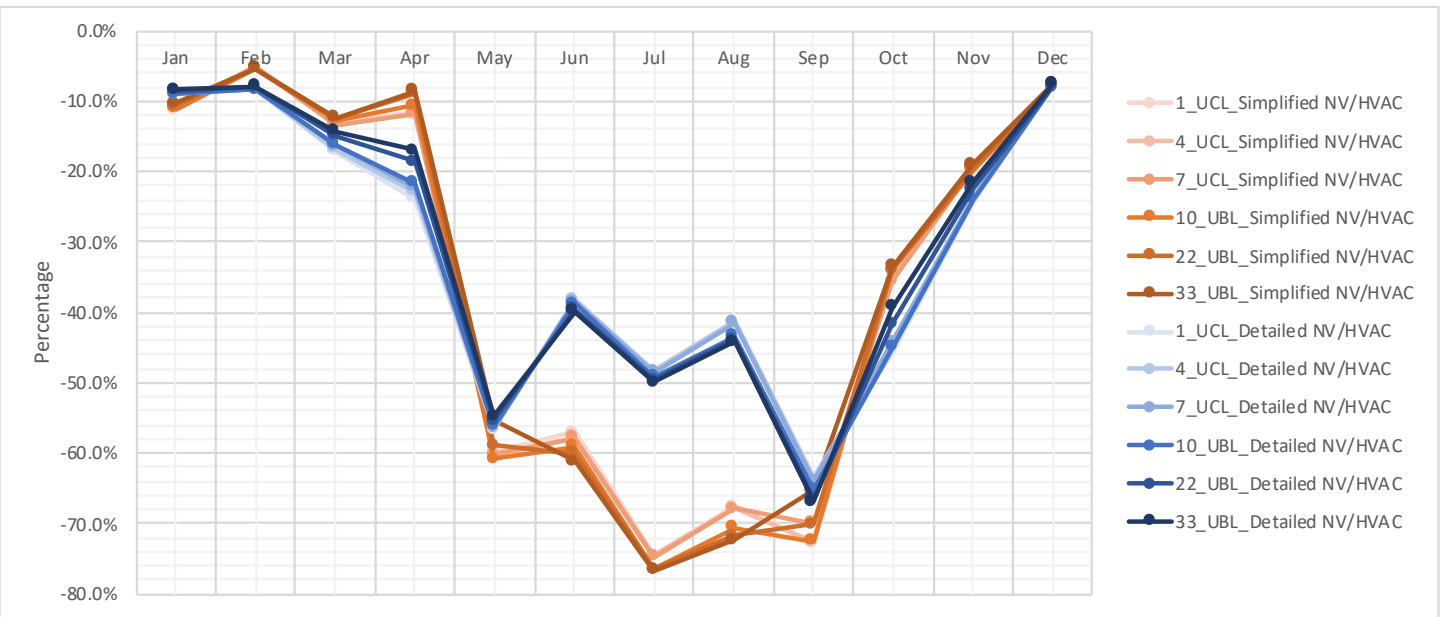

(a)

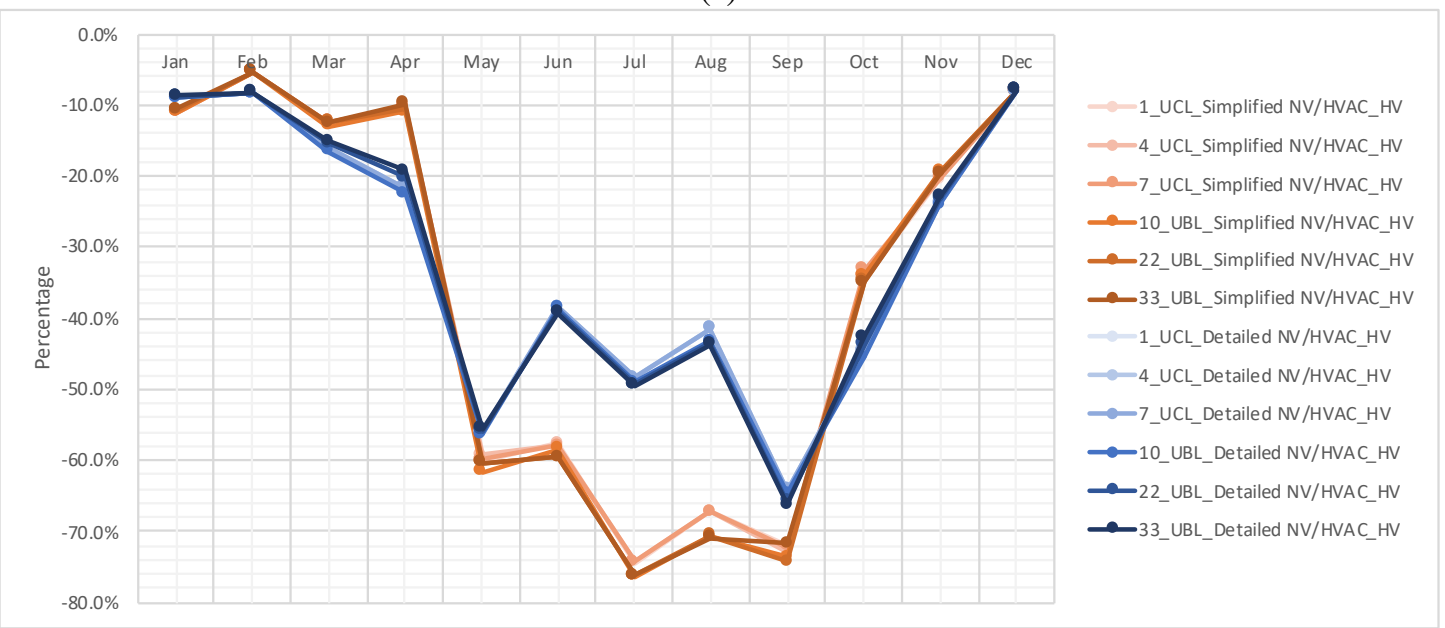

(b)

Figure 114: Thermal load percentage change of simplified natural ventilation and detailed natural ventilation over an HVAC system of six floors a) with original height variations b) with adjusted height variations $(\mathrm{HV})$

Compared with an HVAC system, natural ventilation systems have fewer thermal loads (Figure 114). Simplified natural ventilation can save up to $78 \%$ thermal loads in summer and detailed natural ventilation can save $45 \%$ thermal loads in autumn. In summer simplified natural ventilation saves more energy than detailed natural ventilation. For the rest of the year detailed natural ventilation has fewer thermal loads. At different heights, thermal load percentage changes of natural ventilation systems over an HVAC system are similar. They are not influenced by height and height variations of urban microclimates a lot. 


\subsubsection{Comparison of single-layer and multilayer urban microclimate modelling}

The difference in the energy efficiency between simplified natural ventilation and detailed natural ventilation was explained. In this section, the multilayer modelling method is compared with the original single-layer urban microclimate modelling method. The original single-layer modelling method was used in Chapter 5 and Chapter 6 , assuming that the vertical variation of urban microclimates is constant. Thermal loads at the $1^{\text {st }}, 17^{\text {th }}$ and $33^{\text {rd }}$ floors using the single-layer method were compared with those using the multilayer method. The $1^{\text {st }}$ floor is in the UCL and the $17^{\text {th }}$ and $33^{\text {rd }}$ floors were in the UBL. The set-up of single-layer model and multilayer model are shown in Table 30. The original height variations were constant and for normal cities (Table 25) and the adjusted height variations were based on the inconstant wind and temperature profile (Section 7.3.3). In the UCL, the adjusted height variations of the multilayer model are different from those of the single-layer model. In the UBL, the weather file of the multilayer model is different from that of the single-layer model.

Table 30: Weather data and height variations of single-layer and multilayer model

\begin{tabular}{|c|c|c|c|c|c|c|c|}
\hline \multirow{2}{*}{\multicolumn{2}{|c|}{$\frac{\text { Modelling Method }}{\text { Prototypical building }}$}} & \multirow{2}{*}{\multicolumn{2}{|c|}{$\frac{\text { Single-layer Model }}{1^{\text {st }} 17^{\text {th }} 33^{\text {rd }} \text { floors }}$}} & \multicolumn{4}{|c|}{ Multilayer Model } \\
\hline & & & & $\mathrm{UCL}$ & ${ }^{\text {st }}$ floor & $\begin{array}{l}\mathrm{UBL}^{-1} \\
\mathrm{UBL}^{-3}\end{array}$ & $\begin{array}{l}7^{\text {th }} \text { floor } \\
3^{\text {rd }} \text { floor } \\
\end{array}$ \\
\hline \multicolumn{2}{|c|}{ Weather file } & \multicolumn{2}{|c|}{ Urban wind + UHI } & \multicolumn{2}{|c|}{ Urban wind + UHI } & \multicolumn{2}{|c|}{ Rural wind $+\mathrm{UHI}$} \\
\hline \multirow{4}{*}{$\begin{array}{l}\text { Height } \\
\text { variation }\end{array}$} & & Original & $\begin{array}{c}\text { Adjusted } \\
(\mathrm{HV})\end{array}$ & Original & $\begin{array}{c}\text { Adjusted } \\
(\mathrm{HV})\end{array}$ & Original & $\begin{array}{c}\text { Adjusted } \\
(\mathrm{HV})\end{array}$ \\
\hline & $\begin{array}{l}\text { Wind speed } \\
\text { profile } \\
\text { exponent }\end{array}$ & 0.33 & 0.4 & 0.33 & 0.02 & 0.33 & 0.4 \\
\hline & $\begin{array}{l}\text { Wind speed } \\
\text { profile } \\
\text { boundary } \\
\text { layer } \\
\text { thickness } \\
(\mathrm{m})\end{array}$ & 460 & 500 & 460 & 100 & 460 & 500 \\
\hline & $\begin{array}{c}\text { Air } \\
\text { temperature } \\
\text { gradient } \\
\text { coefficient } \\
(\mathrm{K} / \mathrm{m}) \\
\end{array}$ & 0.0065 & 0.002 & 0.0065 & 0 & 0.0065 & 0.002 \\
\hline
\end{tabular}

In Figure 115, the influence of the multilayer modelling method on a natural ventilation system is bigger than that on an HVAC system. The adjusted height variations amplify the influence of the multilayer modelling method, because the influence of the multilayer modelling method on the original height variations is smaller (between $-5 \%$ and 3\%) than the adjusted height variations (between $-5 \%$ and $8 \%$ ). 


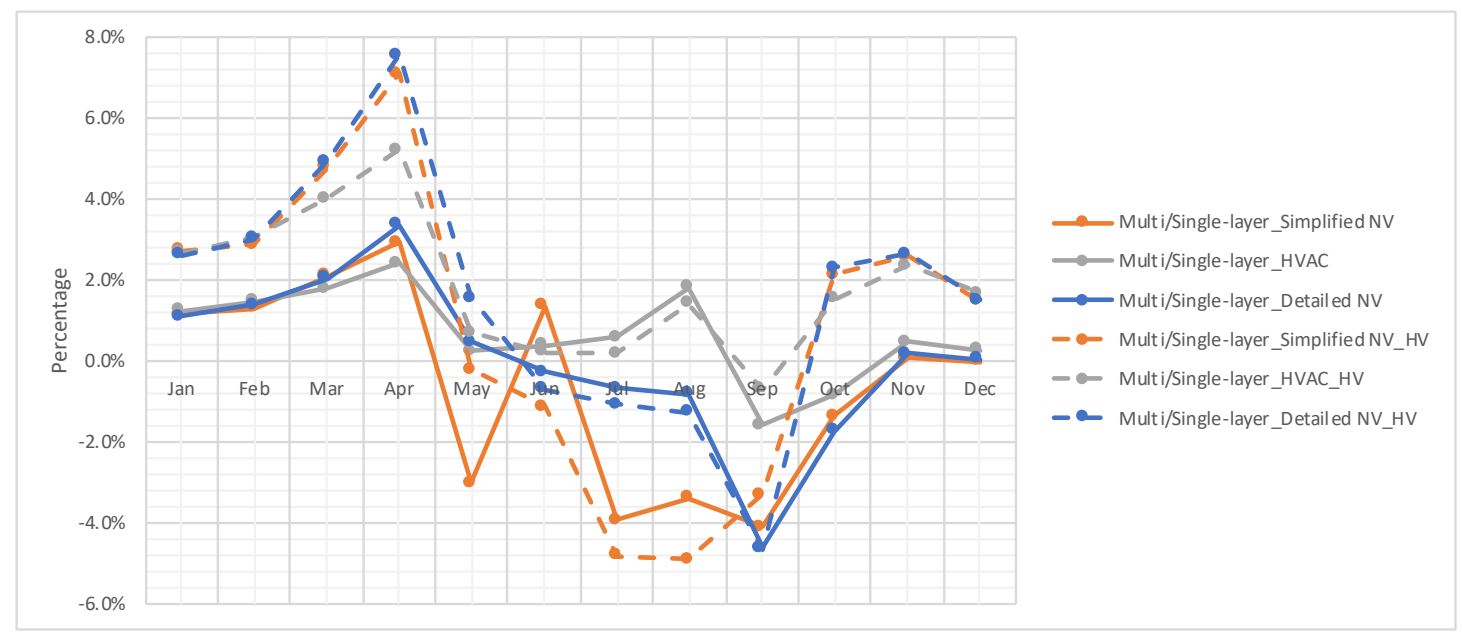

Figure 115: Thermal load percentage change of multilayer model over single-layer model for simplified natural ventilation, an HVAC system and detailed natural ventilation with original height variations and adjusted height variations (HV)

At different heights, the influence of the multilayer modelling method was compared with the original single-layer urban microclimate modelling method. This part is about original height variations which are constant at different floors. In Figure 116a, for original height variations, predicted thermal loads using the multilayer modelling method are the same as using the single-layer modelling method at the $1^{\text {st }}$ floor. Figure $116 \mathrm{~b}$ and Figure 116 show thermal loads of the multilayer model are more than that of the single-layer model at $17^{\text {th }}$ and $33^{\text {rd }}$ floors from January to April. Figure $116 \mathrm{~d}$ shows the multilayer modelling method has a bigger effect on the simplified natural ventilation than detailed natural ventilation in summer. If modelling fully airconditioned buildings, the differences between the single-layer and multilayer model are small. If modelling natural ventilation, modelling with the multilayer method seems very important. The effects of the multilayer model on detailed natural ventilation increase with height. The effects on simplified natural ventilation at the $17^{\text {th }}$ floor are higher than at the $1^{\text {st }}$ and $33^{\text {rd }}$ floors. In summer thermal loads of the multilayer model are less than that of single-layer model when using natural ventilation systems. For an HVAC system the multilayer model has more thermal loads than the single-layer model at $17^{\text {th }}$ and $33^{\text {rd }}$ floors except in September and October. The multilayer model increases thermal load predictions for most of the year when using an HVAC system. These differences are caused by rural wind in the UBL. 


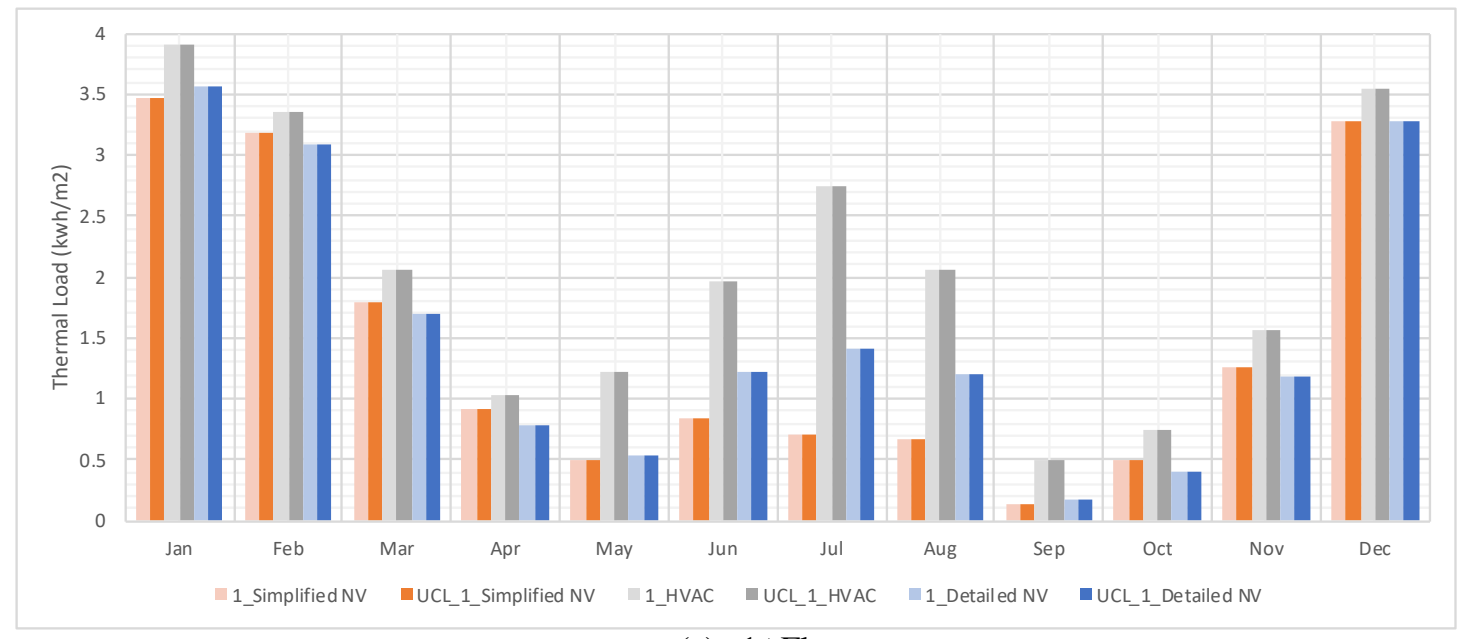

(a) $1^{\text {st }}$ Floor

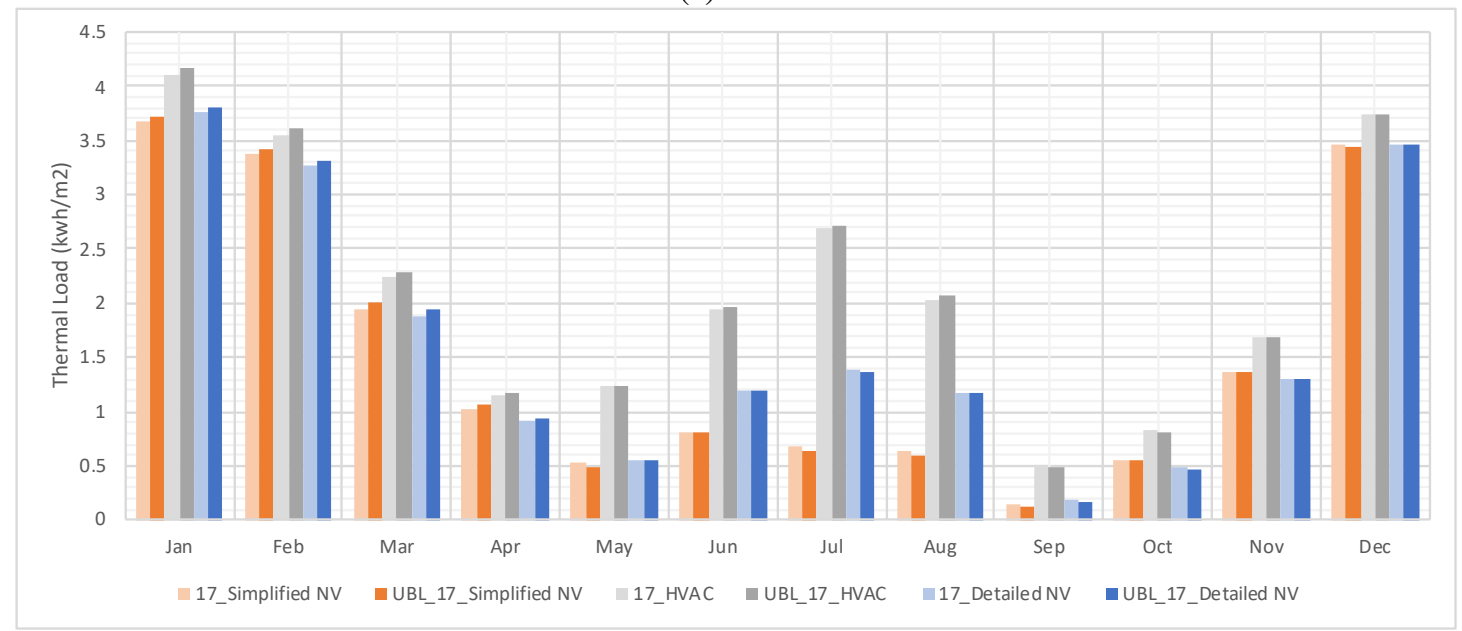

(b) $17^{\text {th }}$ Floor

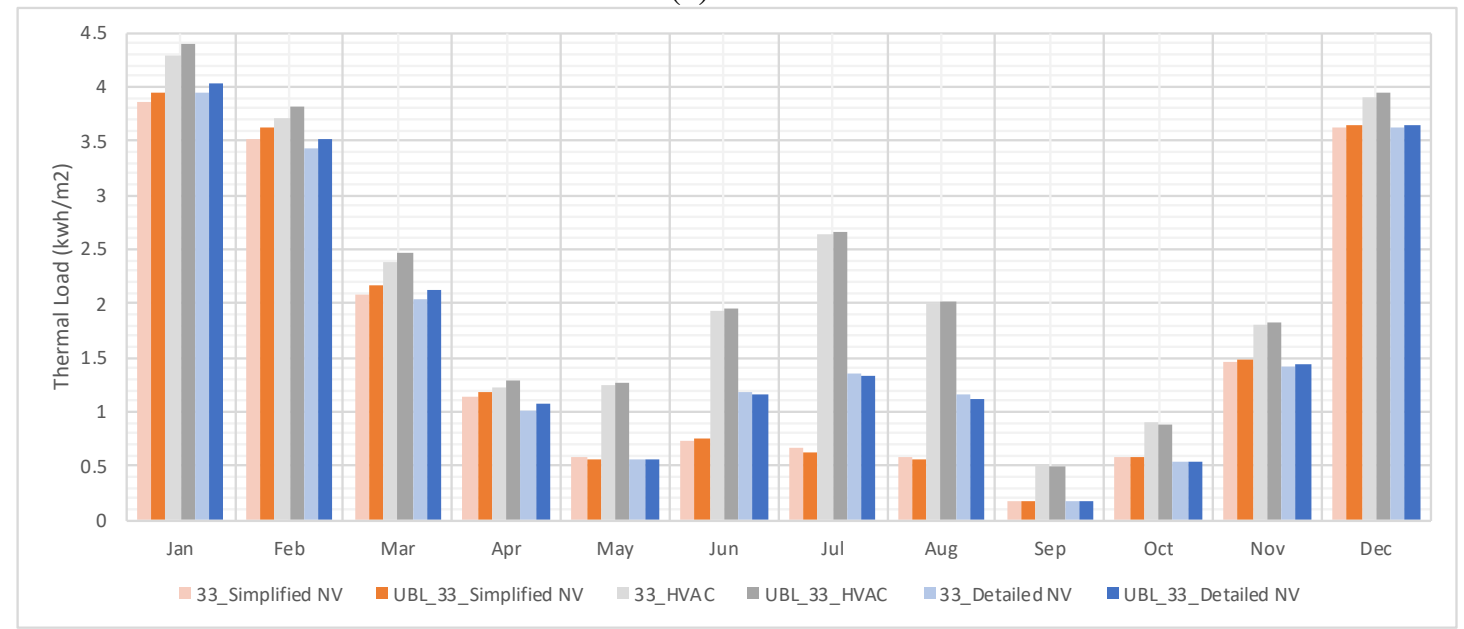

(c) $33^{\text {rd }}$ Floor 


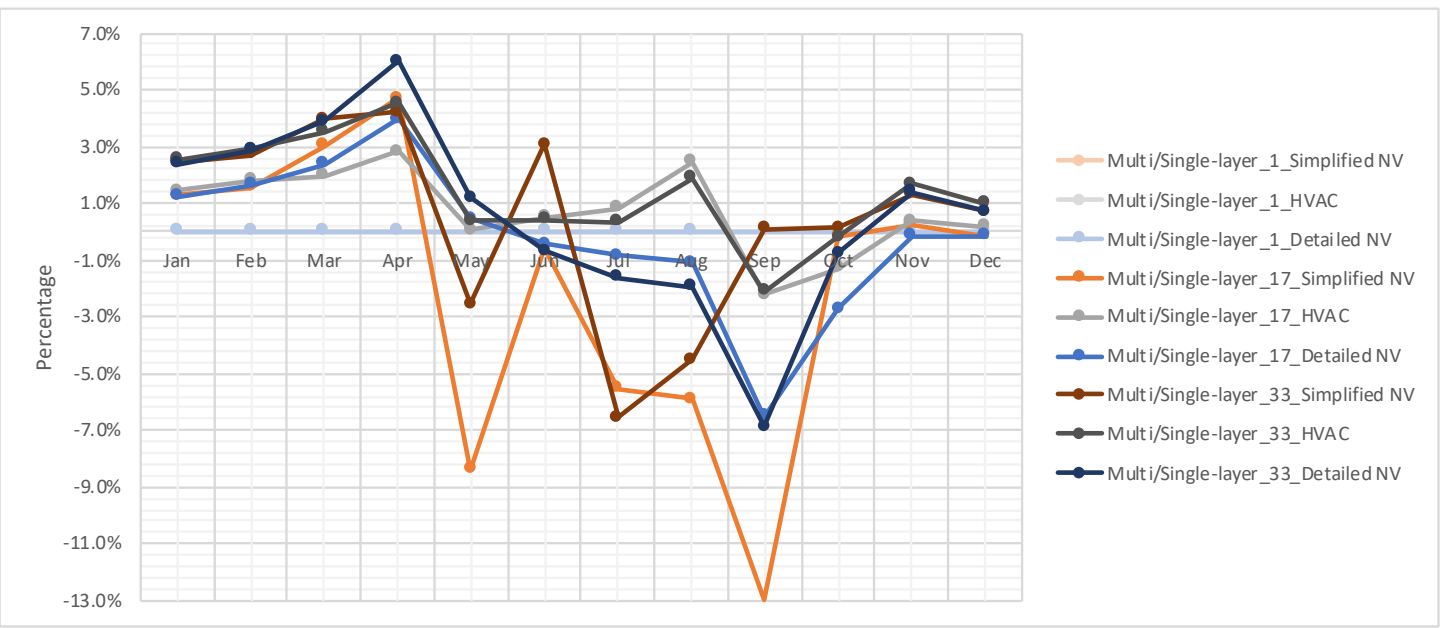

(d) $1^{\text {st }} 17^{\text {th }} 33^{\text {rd }}$ Floor

Figure 116: Thermal loads of multilayer model and single-layer model for simplified natural ventilation, an HVAC system and detailed natural ventilation at a) $1^{\text {st }}$ floor b) $17^{\text {th }}$ floor c) $33^{\text {rd }}$ floor, and percentage change of multilayer model over single-layer model at d) $1^{\text {st }}, 17^{\text {th }}$ and $33^{\text {rd }}$ floors with original height variations

This part is about adjusted height variations which are different in the UCL and in the UBL. In Figure 117, the adjusted height variations extend the influence of the multilayer model. For most of the year, the multilayer model has more thermal load predictions than the single-layer model. In summer, the multilayer model has fewer thermal load predictions than the single-layer model except for an HVAC system at $17^{\text {th }}$ and $33^{\text {rd }}$ floors and the simplified natural ventilation at the $1^{\text {st }}$ floor. In summer the effects of multilayer model on natural ventilation increase with height.

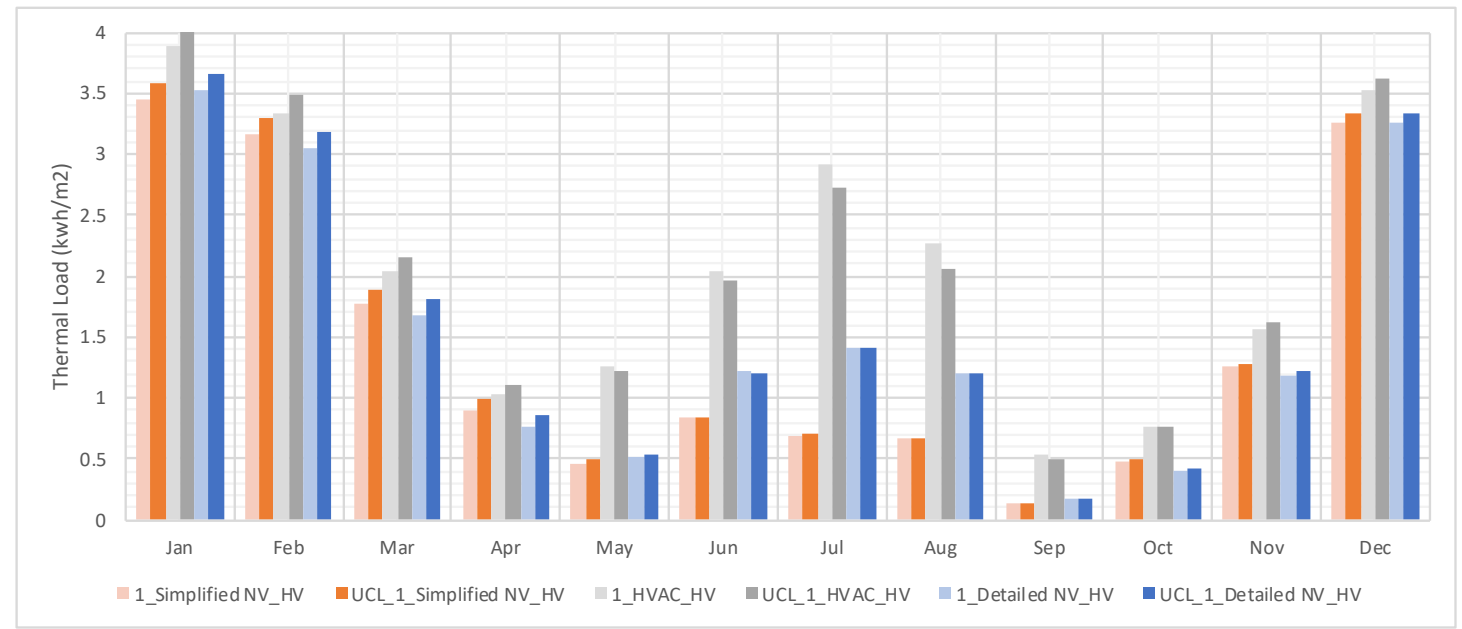

(a) $1^{\text {st }}$ Floor 


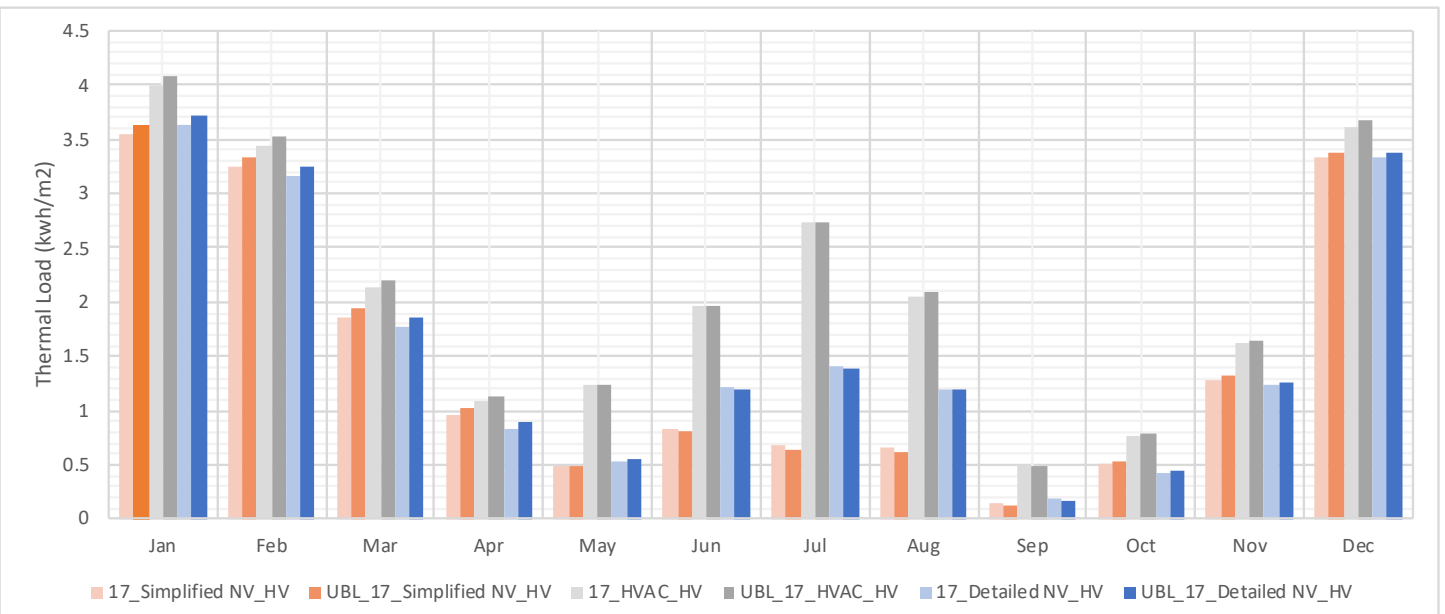

(b) $17^{\text {th }}$ Floor

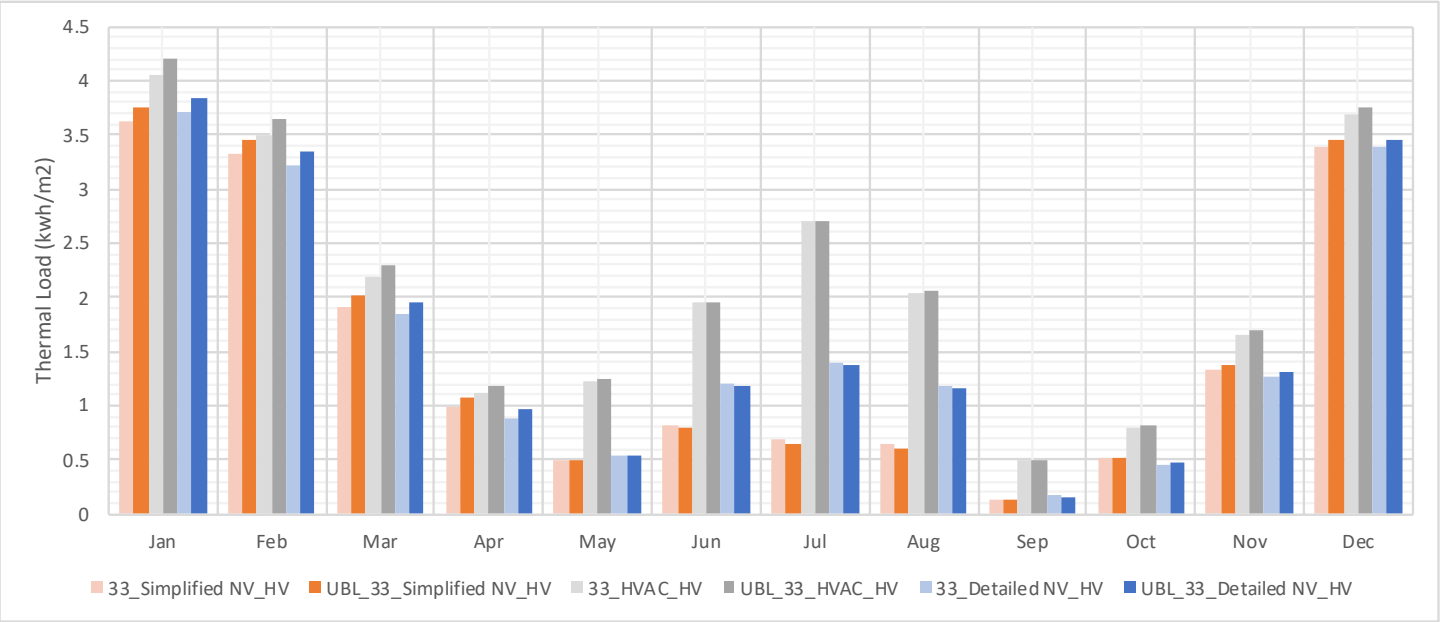

(c) $33^{\text {rd }}$ Floor

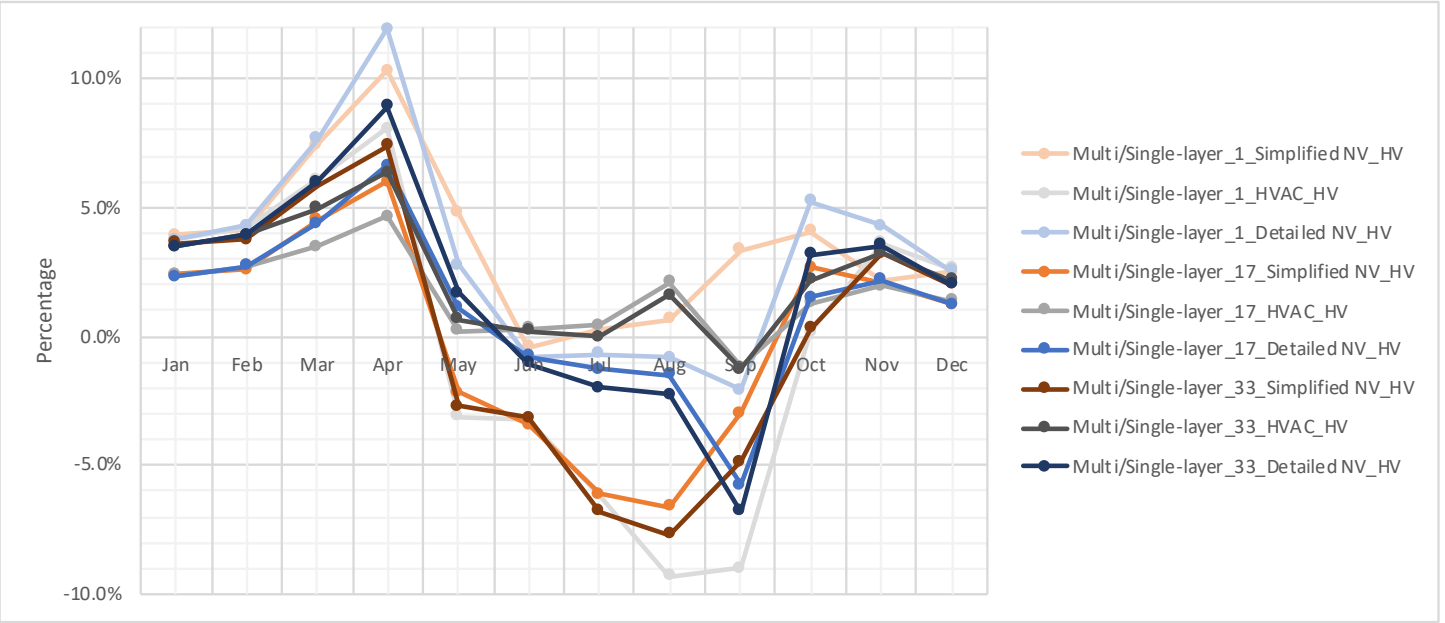

(d) $1^{\text {st }}, 17^{\text {th }}$ and $33^{\text {rd }}$ Floors

Figure 117: Thermal loads of multilayer model and single-layer model for simplified natural ventilation, an HVAC system and detailed natural ventilation at a) $1^{\text {st }}$ floor b) $17^{\text {th }}$ floor c) $33^{\text {rd }}$ floor, and percentage change of multilayer model over single-layer model at d) $1^{\text {st }}, 17^{\text {th }}$ and $33^{\text {rd }}$ floors with adjusted height variations (HV)

Compared with the single-layer modelling method, the multilayer modelling method increases thermal loads in winter and decreases that in summer. In Figure 117d the thermal load percentage change due to multilayer model is up to $12 \%$ in April. However, 
the multilayer model shows an increase in thermal load predictions in spring and autumn and decrease thermal loads in summer. That makes a less change in the annual thermal loads. In Figure 118 the annual thermal load change due to the multilayer model is less than $4 \%$. The effects of multilayer model on natural ventilation systems at a lower floor are more than at a higher floor. For an HVAC system, the annual thermal load change due to the multilayer modelling method increases with height.

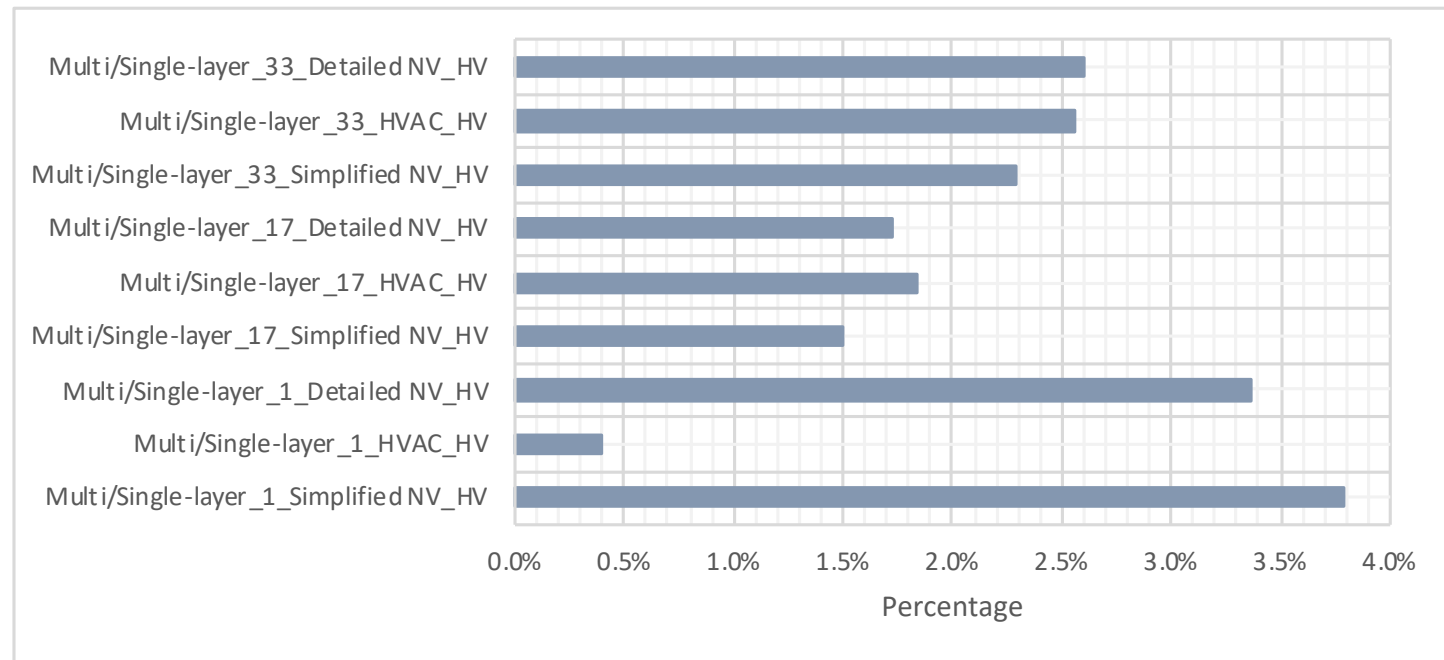

Figure 118: Annual total thermal load percentage change of multilayer model over single-layer model for simplified natural ventilation, an HVAC system and detailed natural ventilation model at the $1^{\text {st }}$, $17^{\text {th }}$ and $33^{\text {rd }}$ floors with adjusted height variations $(\mathrm{HV})$

Therefore, if engineers only need the annual data on thermal loads, a difference of up to $4 \%$ might not be worth the effort. However, if engineers need the monthly data on thermal loads and optimize building performance according to the data, it is worthwhile to build a multilayer model and explore its impact on the cooling and heating load.

\subsection{Conclusion}

The primary conclusion of this research is that it is feasible to generate a multilayer urban microclimate simulation system.

- It is necessary to model wind pressure coefficients for detailed natural ventilation because taking wind pressure coefficients into consideration has a bigger impact on the heating load and a smaller impact on the cooling load than simplified natural ventilation.

- Taking wind pressure coefficients into consideration or not, temperature-related parameters play a more important role than wind-related parameters. 
- In the UCL, the multilayer modelling method increases thermal loads, while in the UBL, it reduces thermal loads. Adjusted vertical variations amplify the influence of the multilayer modelling method.

- The multilayer modelling method reduces the differences of thermal loads at different floors.

- The effects of the multilayer modelling method increase with the distance to the height of the UCL. It has a certain impact on the heating load but has a small impact on the cooling load.

- The multilayer modelling method has a significant impact on the monthly thermal loads, while a small impact on the annual thermal loads.

Overall, the multilayer urban microclimate modelling method has a bigger effect on the simulation of natural ventilation systems than that of an HVAC system. The adjusted height variations are important for the multilayer modelling method. The distance between the floor and the UCL height influence the simulation results of the multilayer model. The annual thermal load change due to the multilayer modelling method is quite small, because the increase in thermal load in the UCL and the decrease in the UBL due to the multilayer modelling method cancel each other out. Therefore, if there is not enough time to building a multilayer model, a difference of up to $4 \%$ might not be worth the effort. If there is enough time, engineers can build a multilayer urban microclimate model to help them predict and improve building performance for different floors, especially when using natural ventilation systems. 


\section{CHAPTER 8. EFFECTS OF DIFFERENT CLIMATES}

\subsection{Chapter Intent}

In the last three chapters, an urban microclimate simulation system was gradually developed to model urban microclimates in detail. The modelling of horizontal parameters, vertical variations and the multilayer method have effects on the prediction of building performance. The feasibility and the necessity of developing a simulation system were demonstrated. Previous simulations were based on the moderate climate of London. Is it still necessary to build a simulation system in other different climates? Is the primary parameter affecting building performance predictions in other climates the same as in a moderate climate? In this chapter, the same prototypical building and the same urban configuration are modelled in three other climate regions. Then the effects of different climates are compared with each other. This chapter discusses the parameters that should be given priority when modelling urban microclimate under different climates. It is also discussed whether the simulation system is worth developing under different climatic conditions.

\subsection{Methodology}

In this chapter, the influence of urban microclimate detailed modelling on different climates is explored. London has a moderate climate. What if the climate is moderate and windy, will it change the importance of developing a simulation system? How about an extremely hot and cold climate or a hot and wet climate? Hence, the research also studied the effects on windy, continental, and tropical climates. Wellington is moderate and windy, Beijing has a continental climate, and the climate of Singapore is tropical (Figure 119). London, Wellington, Beijing and Singapore are case studies in this chapter.

In Figure 119, according to Köppen classification, the climate type of London is "Cfb", Welllington is "Csb", Beijing is "Dwa", and Singapore is "Af" (Kottek et al., 2006). According to the weather data in STAT format, London is marine west coastal (warm summer, mild winter, rain all year), Wellington is a Mediterranean climate (dry warm 
summer, mild winter), Beijing is humid continental (hot summer, cold dry winter), and Singapore is tropical wet (no dry season, rainforest, hot all year) (Weather Data EnergyPlus, n.d.).

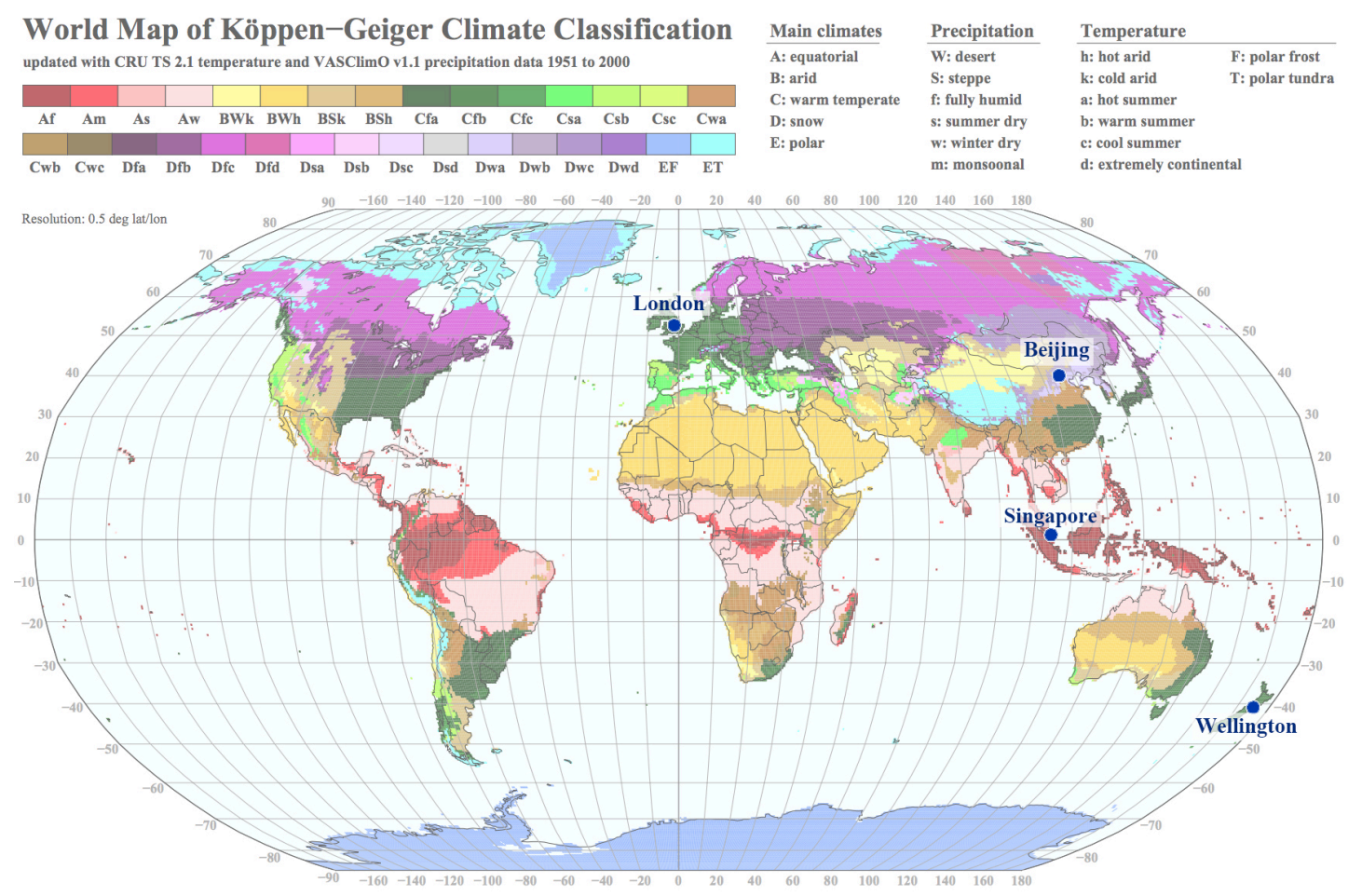

Figure 119: London, Beijing Singapore and Wellington four different climates (Kottek et al., 2006) Figure 120 shows the Heating Degree Days (HDD) and the Cooling Degree Hours $(\mathrm{CDH})$ of the four cities. The HDD and $\mathrm{CDH}$ can reflect their climatic features. The HDD and CDH information is from weather data in STAT format (Weather Data EnergyPlus, n.d.). The base temperature of the HDD is $18^{\circ} \mathrm{C}$ and the $\mathrm{HDD}$ is $18^{\circ} \mathrm{C}$ minus the daily average temperature. The $\mathrm{CDH}$ base $27^{\circ} \mathrm{C}$ is the hourly average temperature minus $27^{\circ} \mathrm{C}$. That is because the heating setpoint of a natural ventilation system is $18^{\circ} \mathrm{C}$ and the cooling setpoint $27^{\circ} \mathrm{C}$. In Figure 120, the HDD in London is less than 450 and that in Wellington is less than 300. The CDH in London is quite small and 0 in Wellington. Beijing is very different from London and Wellington. London and Wellington are both near the sea, so the climates there are classified as maritime and temperate, with the heat sink effect of the sea moderating temperature extremes. Their climates are neither very hot nor very cold. Beijing is far away from the sea and its climate is continental and more extreme. In Beijing, it is cold in winter, and hot in summer. In Figure 120, the HDD in Beijing is less than 700 and the $\mathrm{CDH}$ in Beijing is less than 700. The heating and cooling loads in Beijing are relatively large. However, 
London and Wellington have large heating loads and small cooling loads. Unlike the extreme hot and cold in Beijing, Singapore is another kind of extreme. Singapore is close to the equator and has a tropical climate. Singapore is hot all year round, so there is no need for heating. In Figure 120, the HDD of Singapore is 0 and the CDH is between 400 and 1240. All four cities represent one type of climate, such as moderate, windy, continental and tropical.

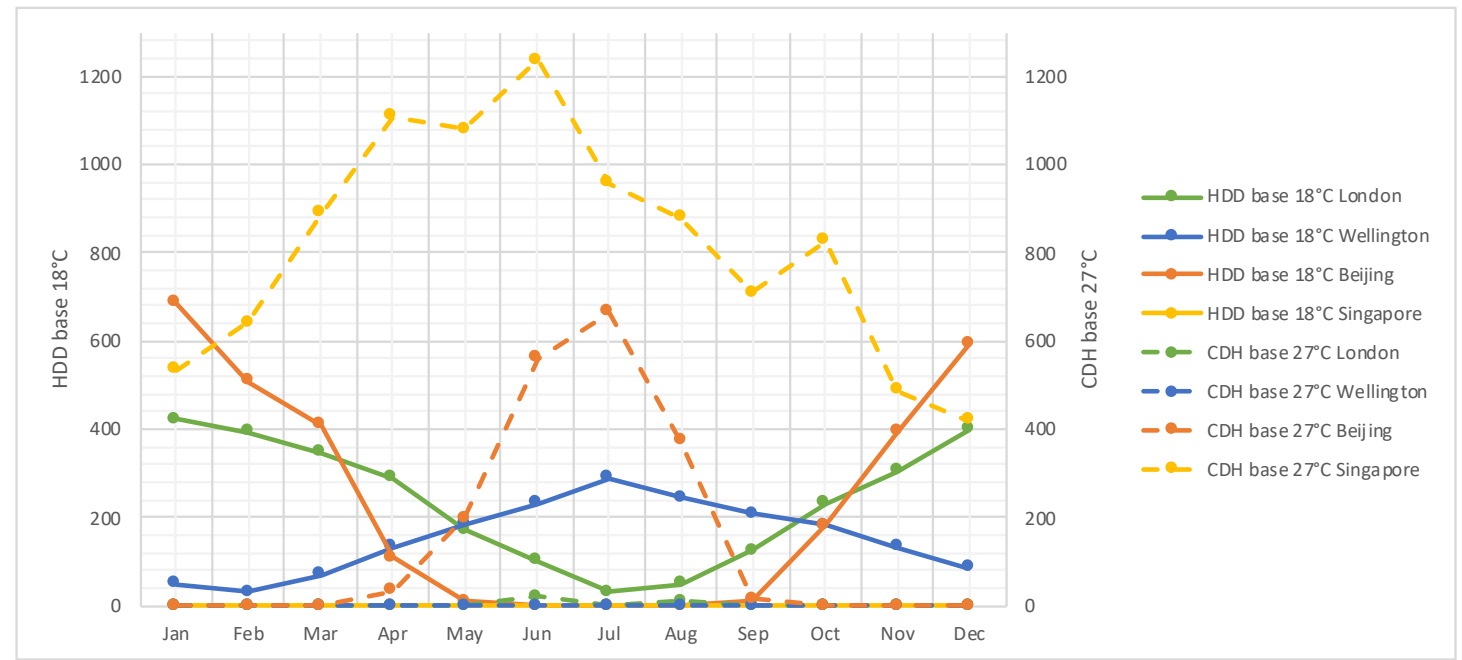

Figure 120: Heating Degree Days (HDD) base $18^{\circ} \mathrm{C}$ and Cooling Degree Hours (CDH) base $27^{\circ} \mathrm{C}$ in different cities

There are four climate regions and three ventilation systems in this chapter. The simulation system of urban microclimate detailed modelling was applied in the four climate regions. The effects of different urban microclimate parameters on various ventilation systems and various climate regions were explored. Also, the likely scale of the effects on the building performance predictions was evaluated. Table 31 shows the process of comparison. The comparison includes three parts:

1) urban microclimate modelling precision, such as considering urban wind, UHI, adjusted urban height variations (HV) and using multilayer modelling method;

2) height variation precision for a city, such as the effects of tiny difference of urban microclimate vertical parameters;

3) height variations of terrain, such as the effects of suburban microclimate vertical parameters.

The reason for studying the influence of height variation precision of a city is the inaccessibility of accurate height variations of urban microclimates. Hence, the importance of height variation precision of a city was explored. The reason for studying the influence of suburban height variations is the uneven urban density. The density 
rates within a city are not uniform (Aquino \& Gainza, 2014). If a high-rise building is located near a large park in a city, its vertical variation parameters are close to those of suburbs. Therefore, the influence of height variations of suburban terrain was discussed. The comparison includes a control group and several experiment groups (Table 31). In terms of urban microclimate modelling precision, the control group used the original weather file from rural areas, and the experiment groups used detailed urban microclimate models with a gradual process. In terms of height variation precision for a city and height variation of terrain, the control group was the prototypical building performance with an urban weather file considering the UHI, urban wind and adjusted height variations. To explore the effects of precision, the urban vertical parameters were slightly changed. To explore the effects of terrain, the urban height variations were replaced with suburban vertical parameters. Vertical variations include wind speed profile exponent, wind speed profile boundary layer thickness and air temperature gradient coefficient.

Table 31: 4 climate regions, 3 ventilation systems and 15 urban microclimate parameters

\begin{tabular}{|c|c|c|c|c|c|c|c|}
\hline \multirow{2}{*}{ No. } & \multirow{2}{*}{ Comparision } & \multirow{2}{*}{$\begin{array}{l}\text { Urban microclimate } \\
\text { parameter }\end{array}$} & \multirow{2}{*}{ Ventilation system } & \multicolumn{4}{|c|}{ City } \\
\hline & & & & London & Wellinton & Beijing & Singapore \\
\hline \multirow{8}{*}{$\begin{array}{c}\text { (1) Urban } \\
\text { microclim } \\
\text { ate } \\
\text { modelling } \\
\text { precision }\end{array}$} & \multirow{3}{*}{$\begin{array}{l}\text { Control } \\
\text { group }\end{array}$} & \multirow{3}{*}{ Surburban } & HVAC & \multirow{3}{*}{$\begin{array}{l}\text { Thermal loads } \\
\text { (kWh/m2.mo } \\
\text { nthly) }\end{array}$} & \multirow{3}{*}{$\begin{array}{l}\text { Thermal loads } \\
\text { (kWh/m2.mo } \\
\text { nthly) }\end{array}$} & \multirow{3}{*}{$\begin{array}{l}\text { Thermal loads } \\
\text { (kWh/m2.mo } \\
\text { nthly) }\end{array}$} & \multirow{3}{*}{$\begin{array}{l}\text { Thermal loads } \\
\text { (kWh/m2.mo } \\
\text { nthly) }\end{array}$} \\
\hline & & & Simplified NV & & & & \\
\hline & & & Detailed NV & & & & \\
\hline & \multirow{5}{*}{$\begin{array}{l}\text { Experiment } \\
\text { group }\end{array}$} & Wind & \multicolumn{5}{|c|}{ Compare urban wind with rural weather file } \\
\hline & & UHI & \multicolumn{5}{|c|}{ Compare UHI with rural weather file } \\
\hline & & UHI+Wind & \multicolumn{5}{|c|}{ Compare UHI+Wind with rural weather file } \\
\hline & & $\mathrm{UHI}+\mathrm{Wind}+\mathrm{HV}$ & \multicolumn{5}{|c|}{ Compare UHI+Wind+HV with rural weather file } \\
\hline & & $\mathrm{UHI}+$ Wind+HV+Multilayer & \multicolumn{5}{|c|}{ Compare $\mathrm{UHI}+\mathrm{Wind}+\mathrm{HV}+$ Multilayer with rural weather file } \\
\hline \multirow{6}{*}{$\begin{array}{l}\text { (2) Height } \\
\text { variation } \\
\text { precision } \\
\text { for a city }\end{array}$} & \multirow{3}{*}{$\begin{array}{l}\text { Control } \\
\text { group }\end{array}$} & \multirow{3}{*}{$\begin{array}{c}\text { UHI+Wind }+H V(0.4500 \mathrm{~m} \\
0.002 \mathrm{~K} / \mathrm{m})\end{array}$} & HVAC & \multirow{3}{*}{$\begin{array}{l}\text { Thermal loads } \\
\text { (kWh/m2.mo } \\
\text { nthly) }\end{array}$} & \multirow{3}{*}{$\begin{array}{l}\text { Thermal loads } \\
\text { (kWh/m2.mo } \\
\text { nthly) }\end{array}$} & \multirow{3}{*}{$\begin{array}{l}\text { Thermal loads } \\
\text { (kWh/m2.mo } \\
\text { nthly) }\end{array}$} & \multirow{3}{*}{$\begin{array}{l}\text { Thermal loads } \\
\text { (kWh/m2.mo } \\
\text { nthly) }\end{array}$} \\
\hline & & & Simplified NV & & & & \\
\hline & & & Detailed NV & & & & \\
\hline & \multirow{3}{*}{$\begin{array}{l}\text { Experiment } \\
\text { group }\end{array}$} & $\begin{array}{l}\text { Wind speed profile } \\
\text { exponent }(0.33)\end{array}$ & \multicolumn{5}{|c|}{ Compare wind speed profile exponent 0.33 with $0.4(\mathrm{UHI}+\mathrm{Wind}+\mathrm{HV})$} \\
\hline & & $\begin{array}{l}\text { Wind speed profile } \\
\text { boundary layer thickness } \\
(400 \mathrm{~m})\end{array}$ & \multicolumn{5}{|c|}{ Compare wind speed profile boundary layer thickness $400 \mathrm{~m}$ with $500 \mathrm{~m}(\mathrm{UHI}+\mathrm{Wind}+\mathrm{HV})$} \\
\hline & & $\begin{array}{l}\text { Air temperature gradient } \\
\text { coefficient }(0.004 \mathrm{~K} / \mathrm{m})\end{array}$ & \multicolumn{5}{|c|}{ Compare air temperature gradient coefficient $0.004 \mathrm{~K} / \mathrm{m}$ with $0.002 \mathrm{~K} / \mathrm{m}(\mathrm{UHI}+\mathrm{Wind}+\mathrm{HV})$} \\
\hline \multirow{7}{*}{$\begin{array}{l}\text { (3) Height } \\
\text { variation } \\
\text { of terrain }\end{array}$} & \multirow{3}{*}{$\begin{array}{l}\text { Control } \\
\text { group }\end{array}$} & \multirow{3}{*}{$\begin{array}{c}\text { UHI+Wind }+H V(0.4500 \mathrm{~m} \\
0.002 \mathrm{~K} / \mathrm{m})\end{array}$} & HVAC & \multirow{3}{*}{$\begin{array}{l}\text { Thermal loads } \\
\text { (kWh/m2.mo } \\
\text { nthly) }\end{array}$} & \multirow{3}{*}{$\begin{array}{l}\text { Thermal loads } \\
\text { (kWh/m2.mo } \\
\text { nthly) }\end{array}$} & Thermal loads & Thermal loads \\
\hline & & & Simplified NV & & & $(\mathrm{kWh} / \mathrm{m} 2 . \mathrm{mo}$ & $(\mathrm{kWh} / \mathrm{m} 2 . \mathrm{mo}$ \\
\hline & & & Detailed NV & & & nthly) & nthly) \\
\hline & & $\begin{array}{l}\text { Wind speed profile } \\
\text { exponent }(0.22)\end{array}$ & Compare win & oeed profile exp & onent 0.22 with & 0.4 (UHI+Wind+ & $+\mathrm{HV}$ ) \\
\hline & $\begin{array}{l}\text { Experiment } \\
\text { group }\end{array}$ & $\begin{array}{l}\text { Wind speed profile } \\
\text { boundary layer thickness } \\
(370 \mathrm{~m})\end{array}$ & Compare wind speed $p$ & le boundarylay & er thickness 370 & $m$ with $500 \mathrm{~m}(\mathrm{U}$ & $\mathrm{JH}+$ Wind $+\mathrm{HV}$ ) \\
\hline & & $\begin{array}{l}\text { Air temperature gradient } \\
\text { coefficient }(0.0065 \mathrm{~K} / \mathrm{m})\end{array}$ & Compare air temperatu & radient coefficie & ent $0.0065 \mathrm{~K} / \mathrm{m} \mathrm{v}$ & vith $0.002 \mathrm{~K} / \mathrm{m}(\mathrm{L}$ & $\mathrm{UHI}+\mathrm{Wind}+\mathrm{HV}$ ) \\
\hline & & $\begin{array}{l}\text { UHI+Wind+SurburbanHV } \\
(0.22370 \mathrm{~m} 0.0065 \mathrm{~K} / \mathrm{m})\end{array}$ & Compare suburban heig & $\begin{array}{r}\text { ariations }(0.333 \\
0.4500 \mathrm{r} \\
\end{array}$ & $\begin{array}{l}370 \mathrm{~m} 0.0065 \mathrm{~K} / \mathrm{n} \\
\mathrm{m} 0.002 \mathrm{~K} / \mathrm{m})\end{array}$ & n) with urban he & eight variations \\
\hline
\end{tabular}

This part of the research explores the effects of climates, not including the configuration of cities. The prototypical high-rise office building and the urban configuration in this 
chapter are the same as the model in London. The weather data of UHI and urban wind of Wellington's climate, Beijing's climate and Singapore's climate were simulated using the urban configuration of the City of London not their own urban configuration.

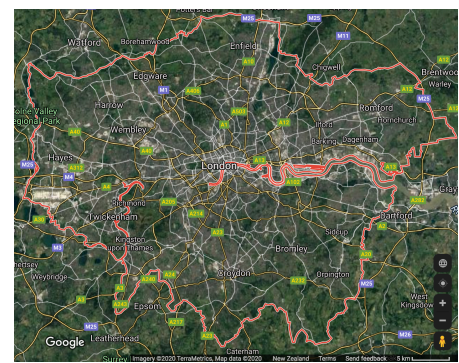

(a) London

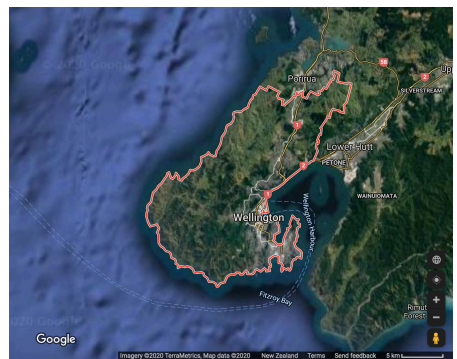

(b) Wellington

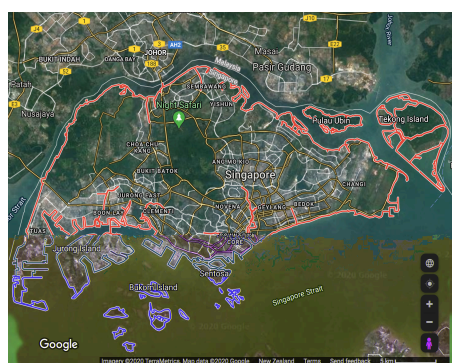

(c) Singapore

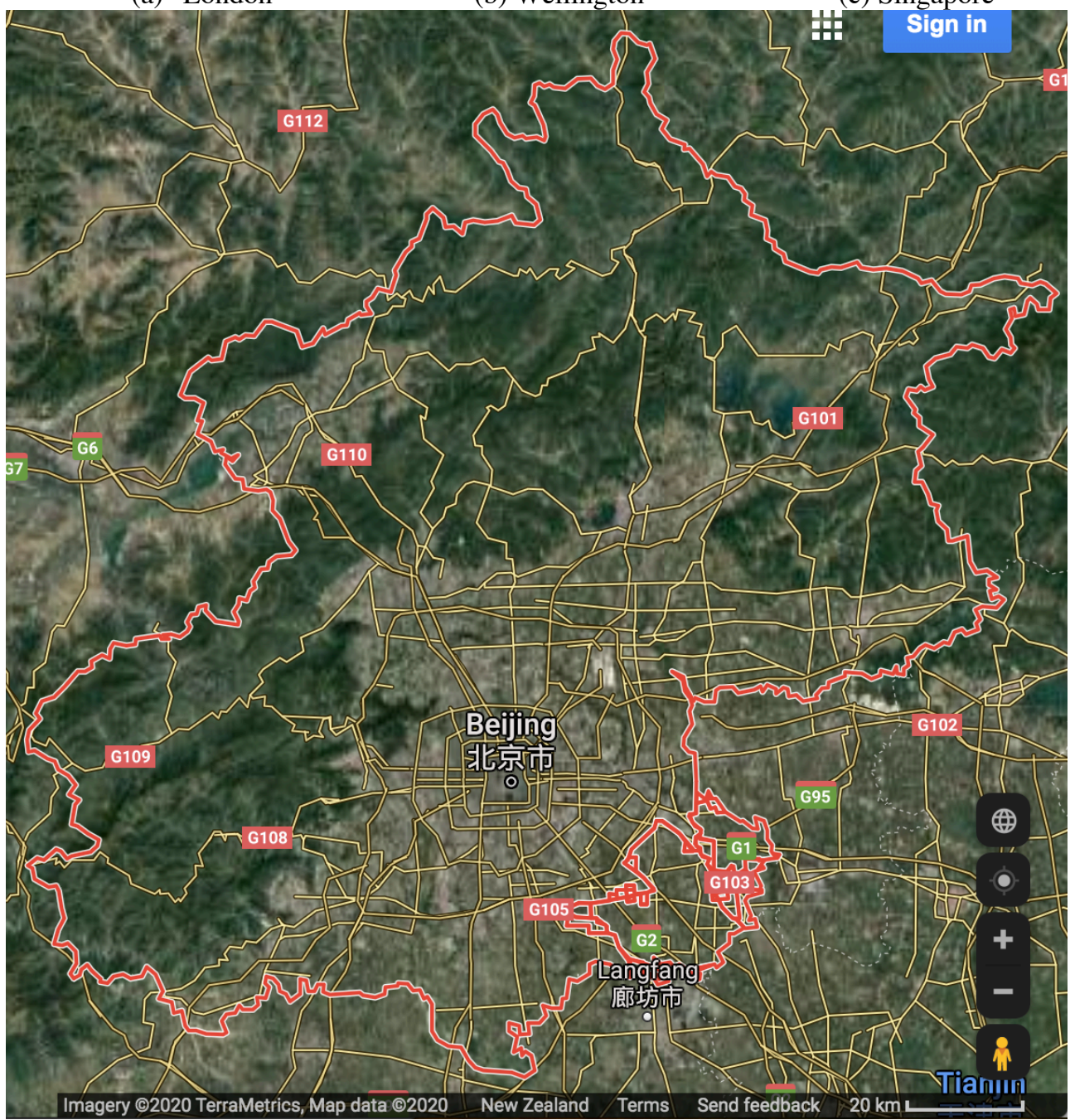

(d) Beijing

Figure 121: Size and outlines of cities (Google Maps, 2019)

This part research is to explore the effects of climate regions, hence, other factors are kept the same. The climate effects are not the effects of real cities. For example, the UHI of Wellington is based on the urban configuration of the City of London. In reality, there is almost no UHI in Wellington because it is too windy and the UHI is reduced in windy climates (Gedzelman et al., 2003). Beijing has the largest area, several times the 
size of London (Figure 121). London is denser than Singapore. The actual UHI of Beijing and Singapore is different from the calculated UHI because the calculation is based on the urban configuration of the City of London. This part of the research focuses on climates, not actual cities.

\subsection{Urban Microclimate Parameters}

In order to evaluate the likely scale of the influence of urban microclimate parameters on building performance predictions, figures about thermal load percentage changes and thermal load absolute changes are shown in this chapter. For thermal load percentage change figures, boxes and whiskers show the minimum, 1 quarter, median, 3 quarters and maximum value of the monthly percentage change for 12 months. The dark dot of the dot-line is the percentage change of the whole year. The percentage change is equal to the thermal loads of experiment groups minus the thermal loads of the control group, and then the difference is divided by the thermal load of the control group. For thermal load change figures, the thermal load change equals the thermal loads of experiment groups minus the thermal loads of the control group. Boxes and whiskers (primary axis) show the minimum, 1 quarter, median, 3 quarters and maximum value of monthly change of 12 months, and the dark dot of the dot-line (secondary axis) is the change of the whole year. If the value is positive, it means the value of the experiment group is bigger than that of the control group. It also means the corresponding parameter increases the thermal load prediction. If the value is negative, it means the value of the experiment group is smaller than that of the control group. Therefore, the corresponding parameter decreases the thermal load prediction.

\subsubsection{Urban microclimate modelling precision}

\subsubsection{Urban wind}

The impacts of urban wind on building performance predictions are shown in Figure 122. In Figure 122a, the thermal load percentage changes of urban wind in Wellington's climate are bigger than those in other cities. The maximum month is more than $20 \%$ with an HVAC system. However, the annual percentage change with an HVAC system in Wellington's climate is close to $0 \%$. The annual percentage change with simplified natural ventilation is less than $10 \%$. The percentage changes of urban wind in London's climate and Beijing's climate with different ventilation systems are similar. Taking 
urban wind into account in London's climate and Beijing's climate reduces a less than $5 \%$ thermal load. The effects of urban wind in Singapore's climate are very small. In Figure 122b, the thermal load monthly changes due to urban wind in Beijing's climate are bigger than in other cities. The percentage changes in Wellington's climate are the biggest, but the absolute changes in Beijing's climate are the biggest. The annual changes in Beijing's climate and London's climate are bigger than in Wellington's climate and Singapore's climate. The urban wind slightly increases thermal loads in Singapore's climate. The effects of urban wind on natural ventilation systems are bigger than on an HVAC system.

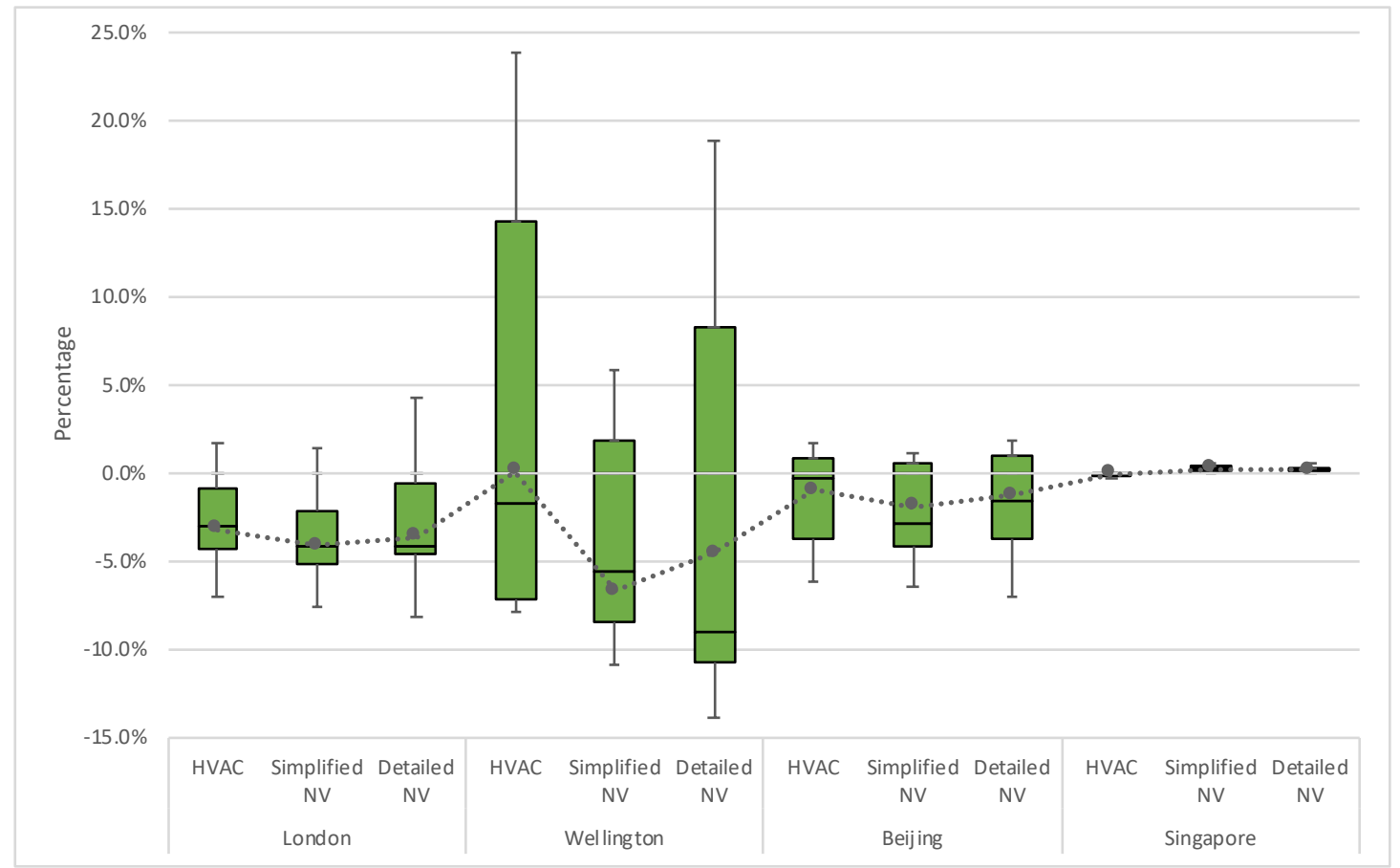

(a) 


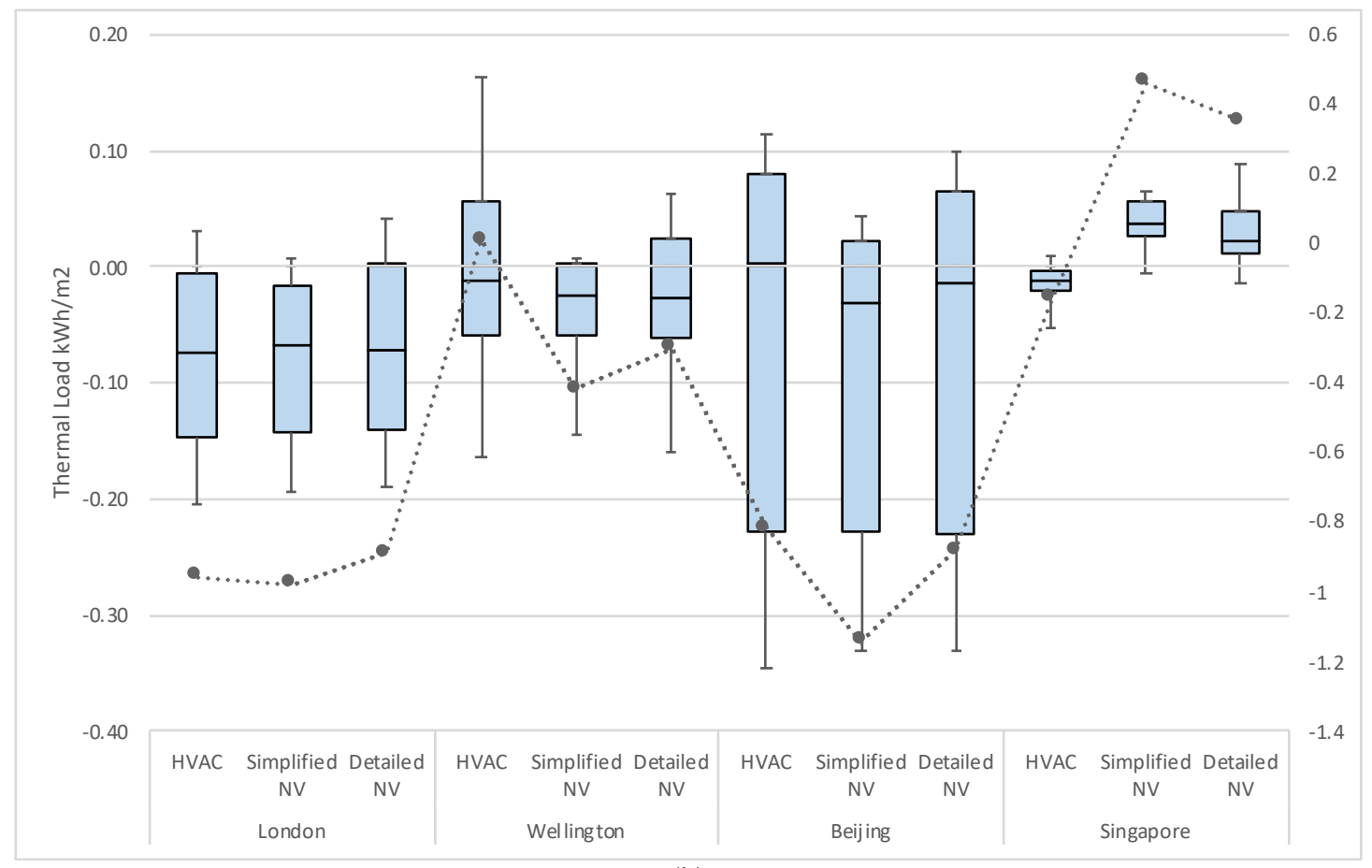

(b)

Figure 122: a) thermal load percentage change b) thermal load change of urban wind over rural weather file with different ventilation systems in the climate of different cities

Modelling urban wind is recommended in a windy climate, and not recommended in a tropical climate. As for in a moderate climate and a continental climate, it depends on the engineer's requirements, because the urban wind has a small impact on the percentage changes, but the absolute changes are greater than those in a windy climate.

\subsubsection{UHI}

The effects of the UHI are bigger than those of urban wind on building performance predictions, because the percentage changes and absolute changes in Figure 123 are around 3 times as large as in Figure 122. In Figure 123a, the monthly percentage changes are between $-55 \%$ and $65 \%$. The annual percentage change in London's climate using natural ventilation systems is more than $15 \%$. The thermal load percentage changes due to the UHI in London's climate are greater than those in Wellington's climate and Beijing's climate. The percentage changes in Singapore's climate are the smallest, less than 5\%. However, the absolute changes of thermal loads in Singapore are not the smallest (Figure 123b). The thermal load absolute changes due to the UHI in Wellington's climate are the smallest, and the annual percentage changes in Wellington's climate are less than around 15\%. 


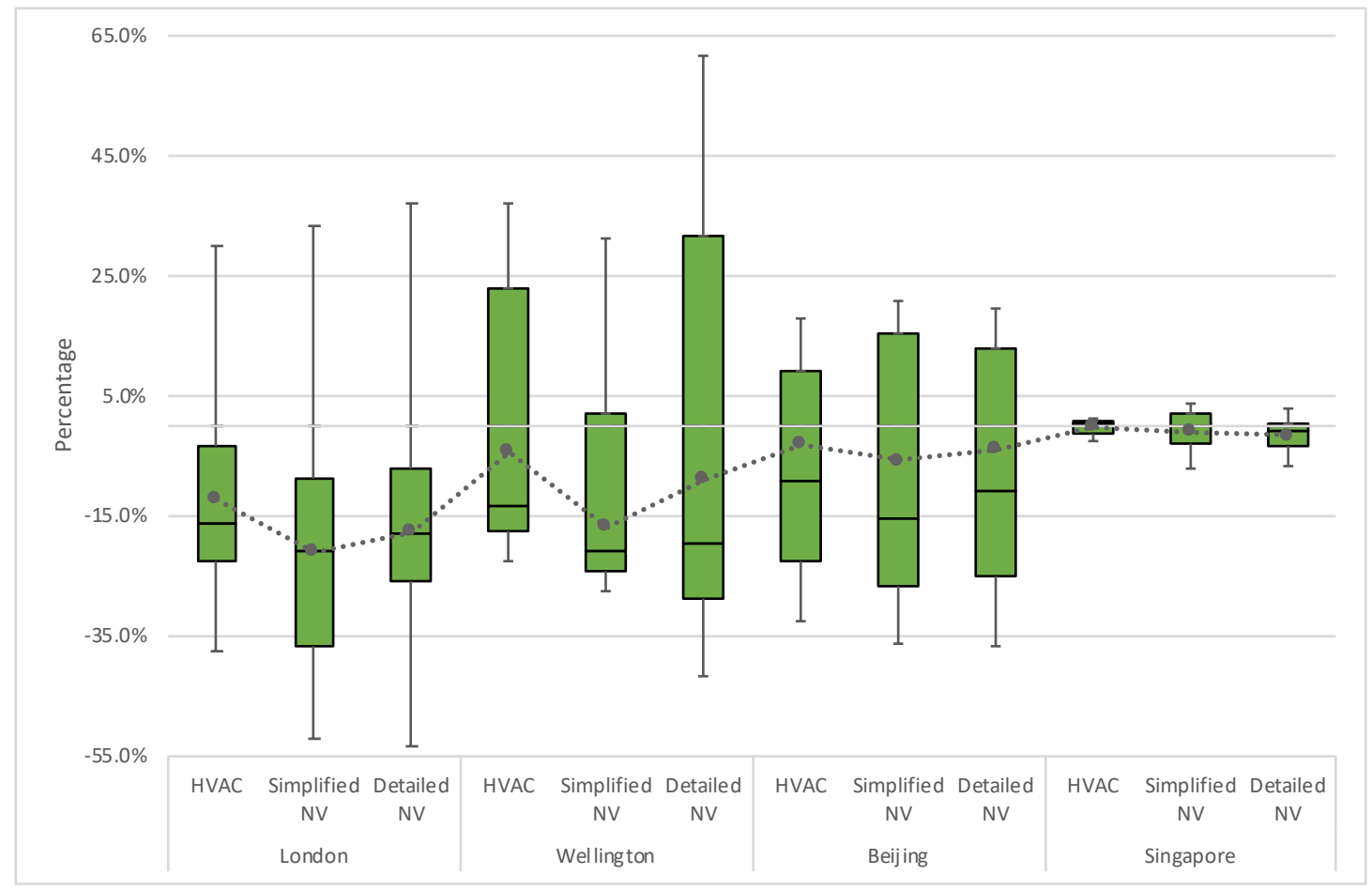

(a)

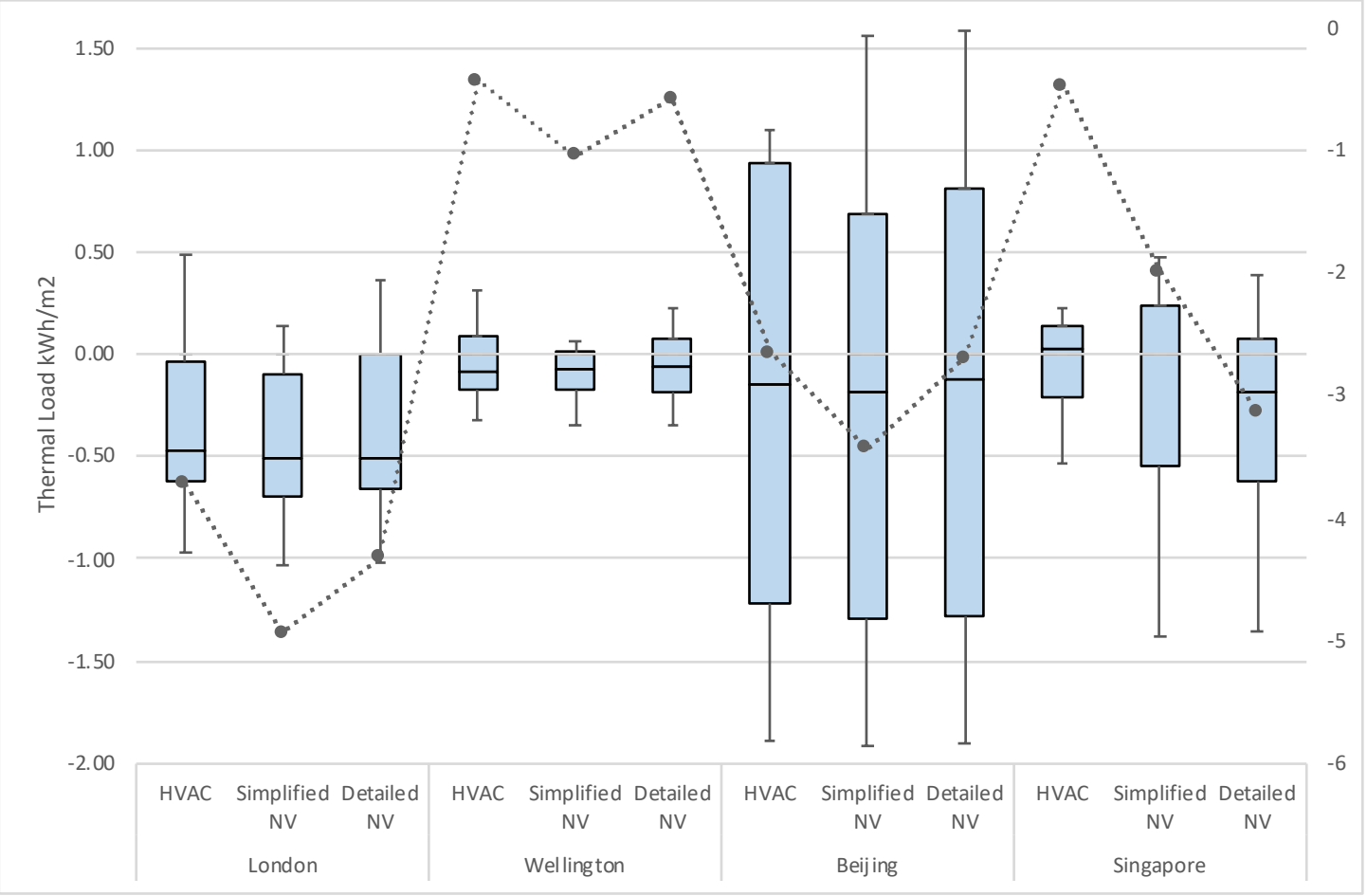

(b)

Figure 123: a) thermal load percentage change b) thermal load change of UHI over rural weather file with different ventilation systems in the climate of different cities

Hence, modelling the UHI is recommended in moderate climates. It is also recommended in a continental climate, because the UHI has a less 5\% impact on the annual percentage changes, but the impact on the monthly percentage changes and the absolute changes are great. As for in a tropical climate, it depends on the ventilation systems. For an HVAC system, modelling the UHI is not recommended, but for natural 
ventilation systems, it is recommended. Although the UHI has a less 5\% impact on the percentage changes, the absolute changes are greater than those in Wellington's climate.

\subsubsection{UHI and urban wind}

The individual effects of the UHI and urban wind were explored. On this basis, the combined effects of the UHI and urban wind are analysed in this section. The combined effects are bigger than the individual effects.

The percentage changes and absolute changes in Figure 124 are bigger than those in Figure 123. In Figure 124a, the percentage changes due to combined effects of the UHI and urban wind in London's climate, Wellington's climate and Beijing's climate are very big. The monthly percentage changes are between $-60 \%$ and $80 \%$, and the annual percentage change in London's climate with simplified natural ventilation is more than 20\%. The percentage changes in Singapore's climate are the smallest (Figure 124a), while the absolute changes in Wellington's climate are the smallest (Figure 124b). In Wellington's climate, the annual percentage changes due to the combined effects are big, especially with simplified natural ventilation which can reach $20 \%$. However, the absolute changes in Wellington's climate are smaller than those in the other three cities. The monthly changes in Beijing's climate are the biggest and the annual changes in London's climate are the biggest.

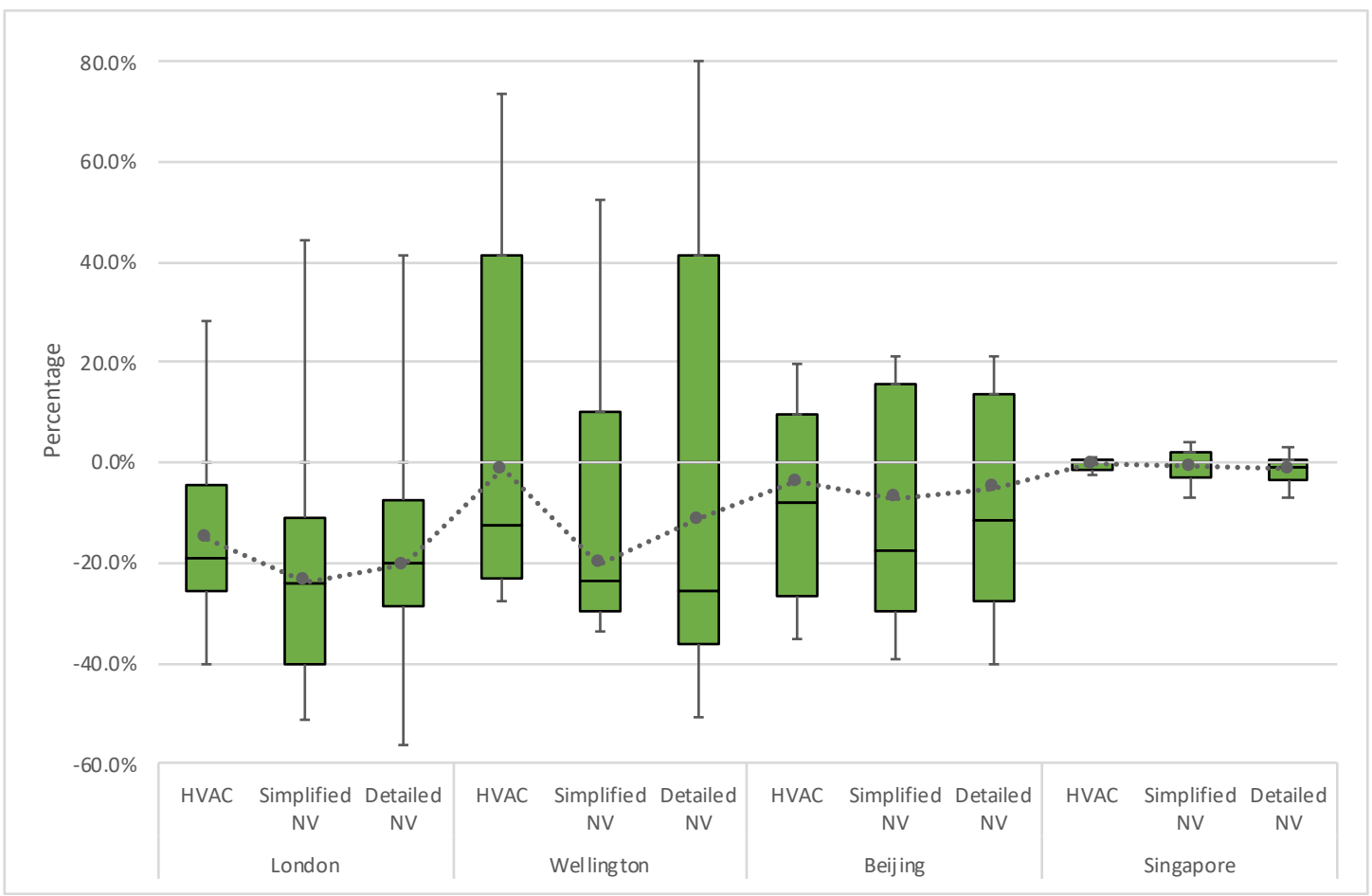

(a) 


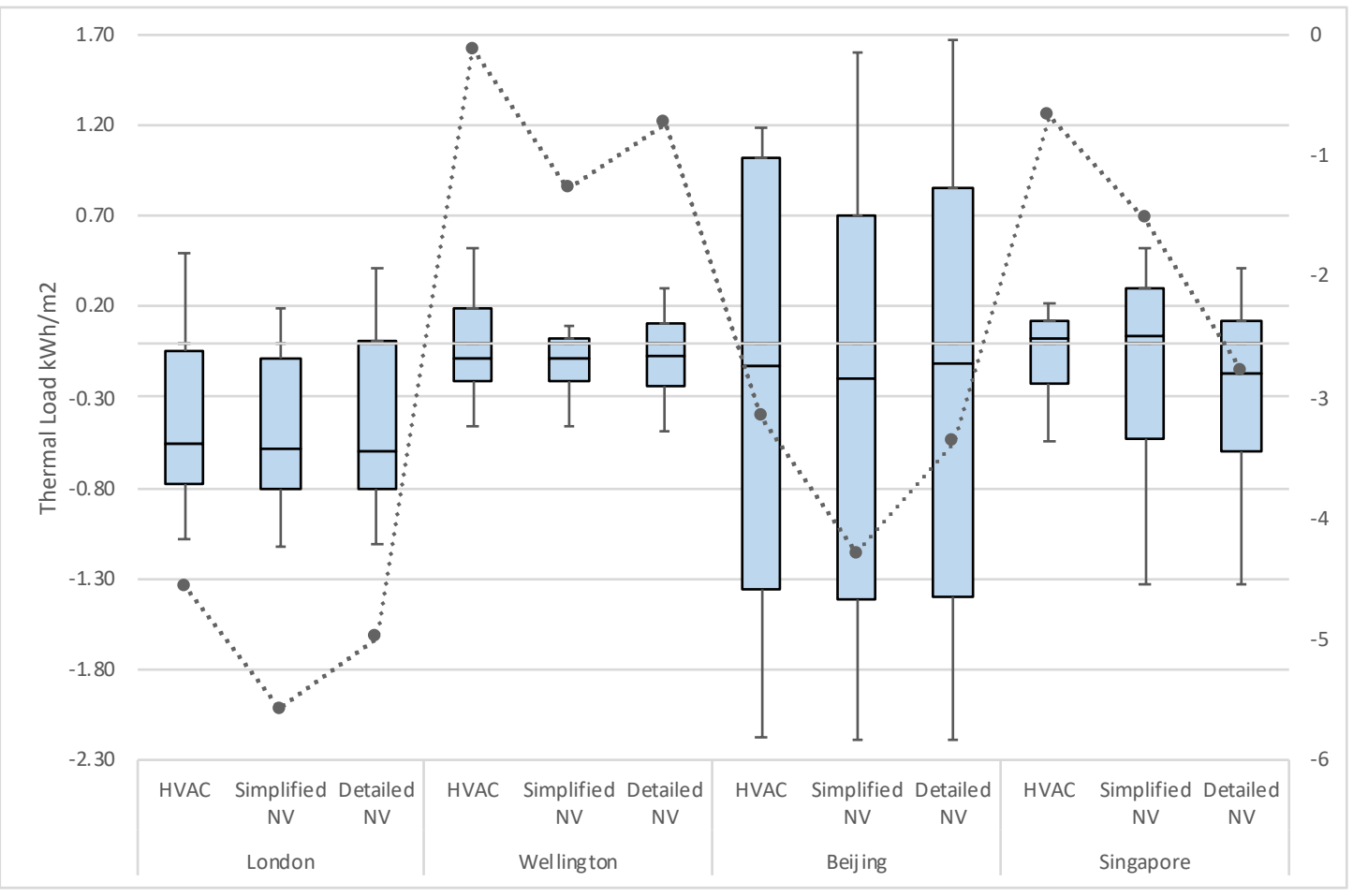

(b)

Figure 124: a) thermal load percentage change b) thermal load change of UHI and urban wind over rural weather file with different ventilation systems in the climate of different cities

Modelling the combined effects of the UHI and urban wind is recommended in moderate climates and a continental climate, because the combined effects enlarge the scale of influence. As for in a tropical climate, the combined effects are small. Modelling the combined effects is not recommended when using an HVAC system, but it is recommended when using a natural ventilation system.

\subsubsection{UHI, urban wind and adjusted height variations}

The information of original height variations and adjusted height variations is from Section 7.4.2 and Table 27. The original height variations are rough data and the adjusted height variations are relatively accurate data. This section explores the combined effects of the UHI, urban wind and adjusted height variations.

The adjusted height variations increase the effects of urban microclimate modelling on the building performance prediction because the percentage changes and absolute changes in Figure 125 are bigger than those in Figure 124. In Figure 125a, the annual percentage change due to the UHI, urban wind and adjusted height variations in London's climate and Wellington's climate with simplified natural ventilation reaches $25 \%$. The annual percentage change due to the UHI and urban wind is less than around $20 \%$ (Figure 124a), due to the UHI is less than around 15\% (Figure 123a) and due to 
the urban wind is less than around 7\% (Figure 123a). Detailed urban microclimate modelling enlarges the difference in building performance predictions.

The monthly percentage changes are between $-65 \%$ and $90 \%$. The monthly percentage changes in London's climate and Wellington's climate are very big and those in Wellington's climate are greater than those in London's climate. However, the absolute changes of thermal loads in Wellington's climate are the smallest (Figure 125b). In Beijing's climate, the monthly percentage changes are between $-45 \%$ and $30 \%$, and the monthly absolute changes are the biggest (between $-2.5 \mathrm{kWh} / \mathrm{m}^{2}$ and $2 \mathrm{kWh} / \mathrm{m}^{2}$ ).

The adjusted height variations increase the prediction of thermal loads a lot in Singapore's climate. The annual absolute changes in the climate of Singapore are negative in Figure 124b, but they are positive in Figure 125b. In Singapore's climate, the percentage changes are the smallest among the four cities. However, the thermal load changes in Singapore's climate are bigger than in Wellington's climate.

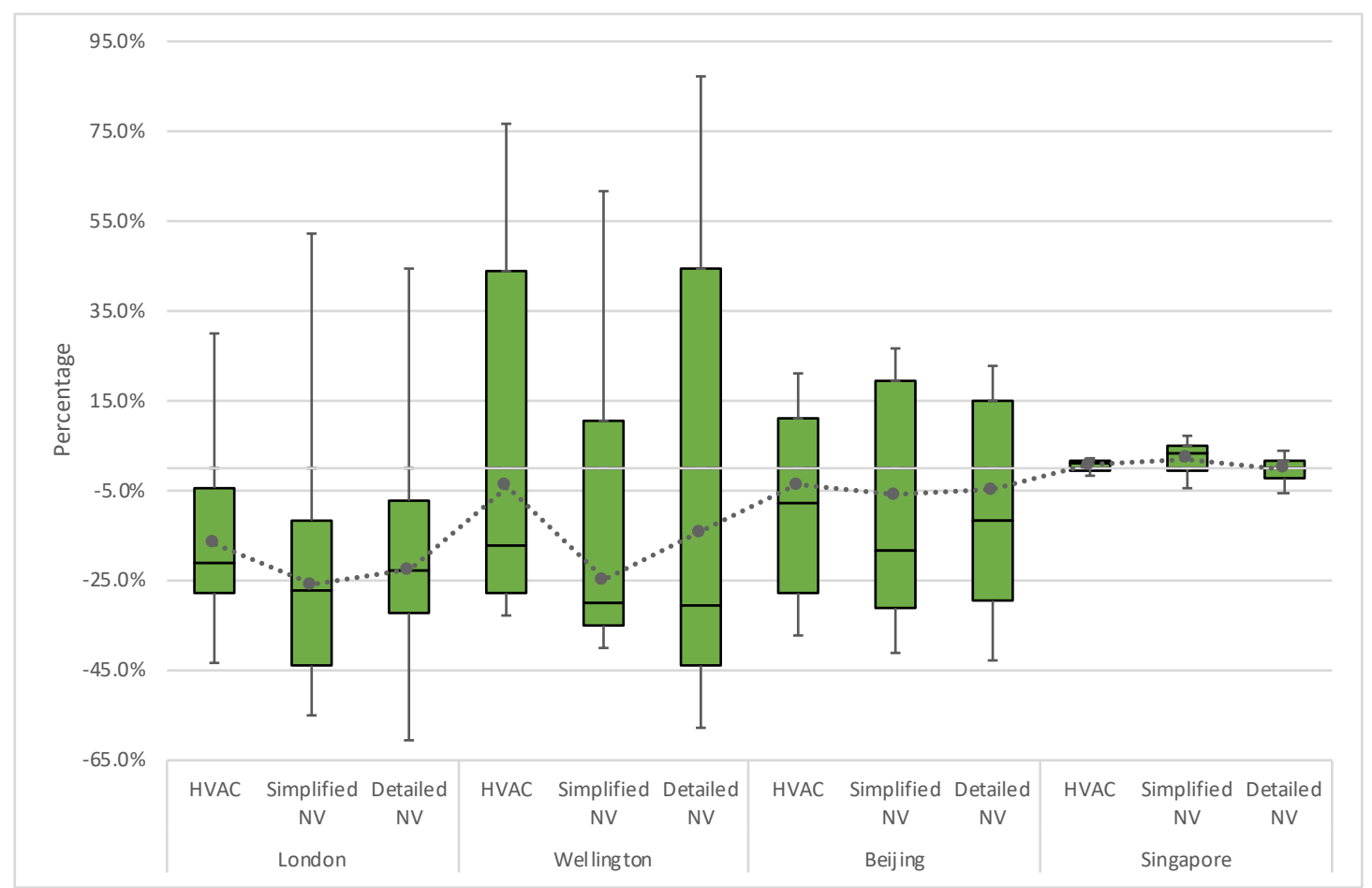

(a) 


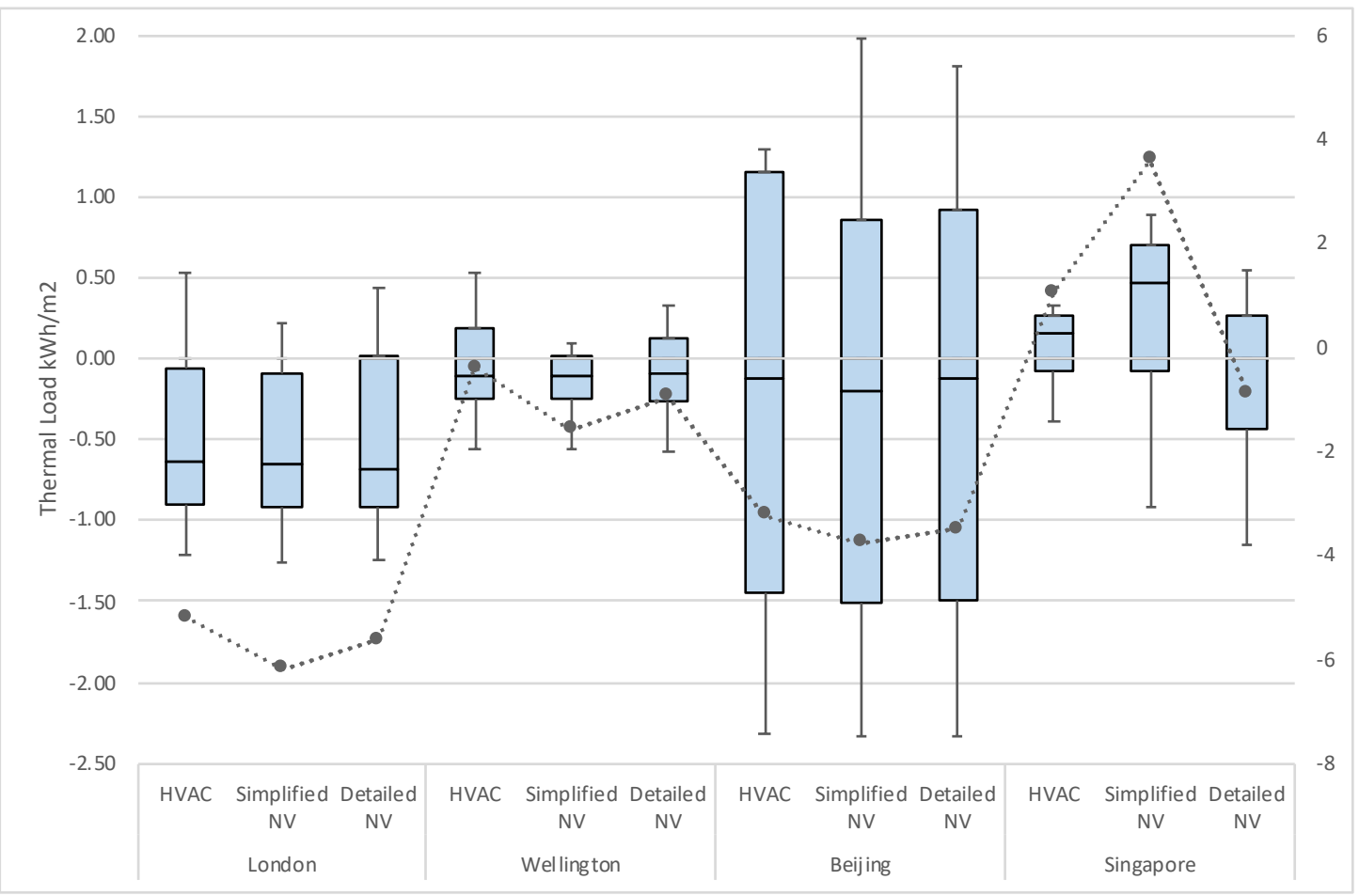

(b)

Figure 125: a) thermal load percentage change b) thermal load change of UHI, urban wind and adjusted height variations over rural weather file with different ventilation systems in the climate of different cities

Compared with the combined effects of the UHI and urban wind, the combined effects of the UHI, urban wind and adjusted height variations enlarge the difference in building performance predictions. The combined effects of the UHI and urban wind reduce the thermal load predictions. However, in a tropical climate, the adjusted height variations increase thermal load predictions, but in other climate regions they decrease thermal load predictions.

\subsubsection{UHI, urban wind, adjusted height variations and multilayer modelling method}

The multilayer modelling method is based on Section 7.5. In this section, the combined effects of the UHI, urban wind, adjusted height variations and multilayer modelling method are explored.

The multilayer modelling method slightly decreases the difference in building performance predictions. The UHI, urban wind and adjusted height variations mostly decrease thermal load predictions, but because the multilayer modelling method has an opposite effect which increases thermal load predictions slightly. The percentage changes and absolute changes in Figure 126 are smaller than those in Figure 125.

In Figure 126a, the percentage changes in Wellington's climate and London's climate are bigger than in Beijing's climate and Singapore's climate. In Singapore's climate, 
the percentage changes are the smallest which are less than 5\%. However, the absolute changes in Singapore's climate are bigger than those in Wellington's climate (Figure 126b). The annual changes in London's climate are bigger those than in Beijing's climate, but the monthly changes in London's climate are smaller than those in Beijing's climate. The percentage changes in Wellington's climate are the biggest, but the absolute changes in Wellington's climate are the smallest.
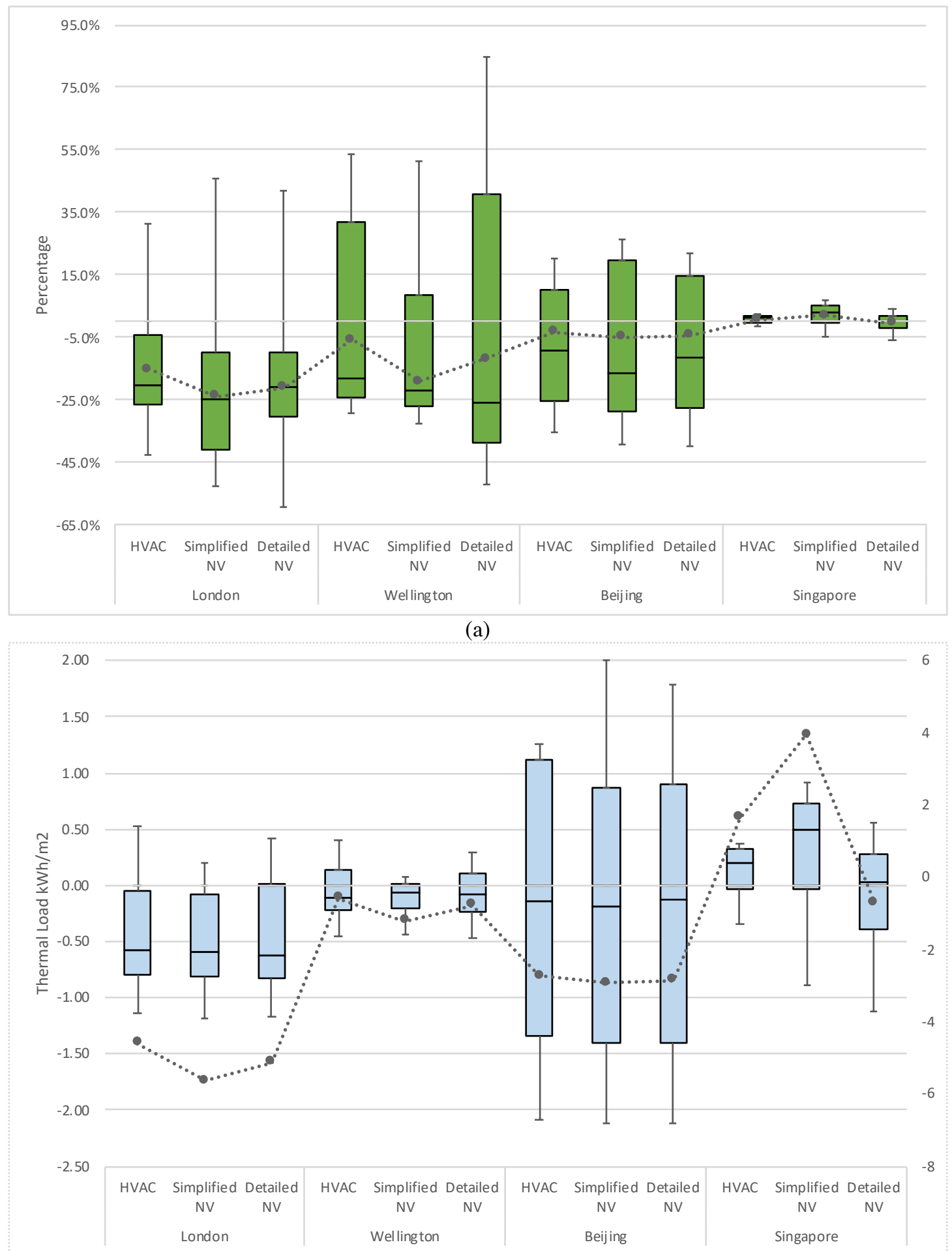

(b) 
Figure 126: a) thermal load percentage change b) thermal load change of UHI, urban wind, adjusted height variations and multilayer modelling method over rural weather file with different ventilation systems in the climate of different cities

The combined effects of the UHI, urban wind, adjusted height variations and the multilayer modelling method are smaller than the combined effects of the UHI and urban wind and adjusted height variations, because the multilayer modelling method reduces the difference in building performance predictions. Modelling the combined effects of the UHI, urban wind, adjusted height variations and multilayer modelling method is recommended in a moderate climate and a continental climate. As for in a tropical climate, it depends on the ventilation systems and the engineer's requirements.

In summary, developing a simulation system of urban microclimate is recommended in a moderate climate. It is also recommended in a windy climate because it influences the percentage changes in thermal load prediction a lot. In a continental climate, it is recommended, as it has a big impact on the monthly percentage changes and the absolute changes in thermal load prediction. It has a greater impact on the monthly percentage changes and a smaller impact on the annual percentage changes, because modelling horizontal parameters increases the thermal load prediction in some months and decreases the prediction in other months. Based on these increases and decreases, engineers can optimize design to improve building performance. In a tropical climate, developing a simulation system has a very small impact on the percentage changes in thermal load prediction. However, when using different ventilation systems, the absolute changes in a tropical climate are sometimes greater than those in a windy climate. In a tropical climate, the level of detailed modelling depends on the engineer's requirements and the ventilation systems.

\subsubsection{Height variation precision for cities}

In this section, the importance of the precision of height variations of urban microclimate is studied. The vertical variations of the control group are the adjusted height variations for the terrain of a city. In the control group, the wind speed profile exponent is 0.4 , the wind speed profile boundary layer thickness is $500 \mathrm{~m}$, and the air temperature gradient coefficient is $0.002 \mathrm{~K} / \mathrm{m}$ (Table 31 ). Then, the wind speed profile exponent 0.33 is compared with 0.4 , The wind speed profile boundary layer thickness $400 \mathrm{~m}$ is compared with $500 \mathrm{~m}$, and the air temperature gradient coefficient $0.004 \mathrm{~K} / \mathrm{m}$ 
is compared with $0.002 \mathrm{~K} / \mathrm{m}$. How these slight changes of height variations for cities influence the prediction of building performance is discussed.

\subsubsection{Wind speed profile exponent $(0.33)$}

The slight change of the wind speed profile exponent for cities has a very small influence on the building performance. The thermal load percentage changes are less than $1 \%$ except in Wellington's climate with simplified natural ventilation (Figure 127a). In Singapore's climate, the percentage changes are close to $0 \%$ and the monthly absolute changes are less than $0.006 \mathrm{kWh} / \mathrm{m}^{2}$ (Figure 127b). The influence of the wind speed profile exponent precision is negligible.

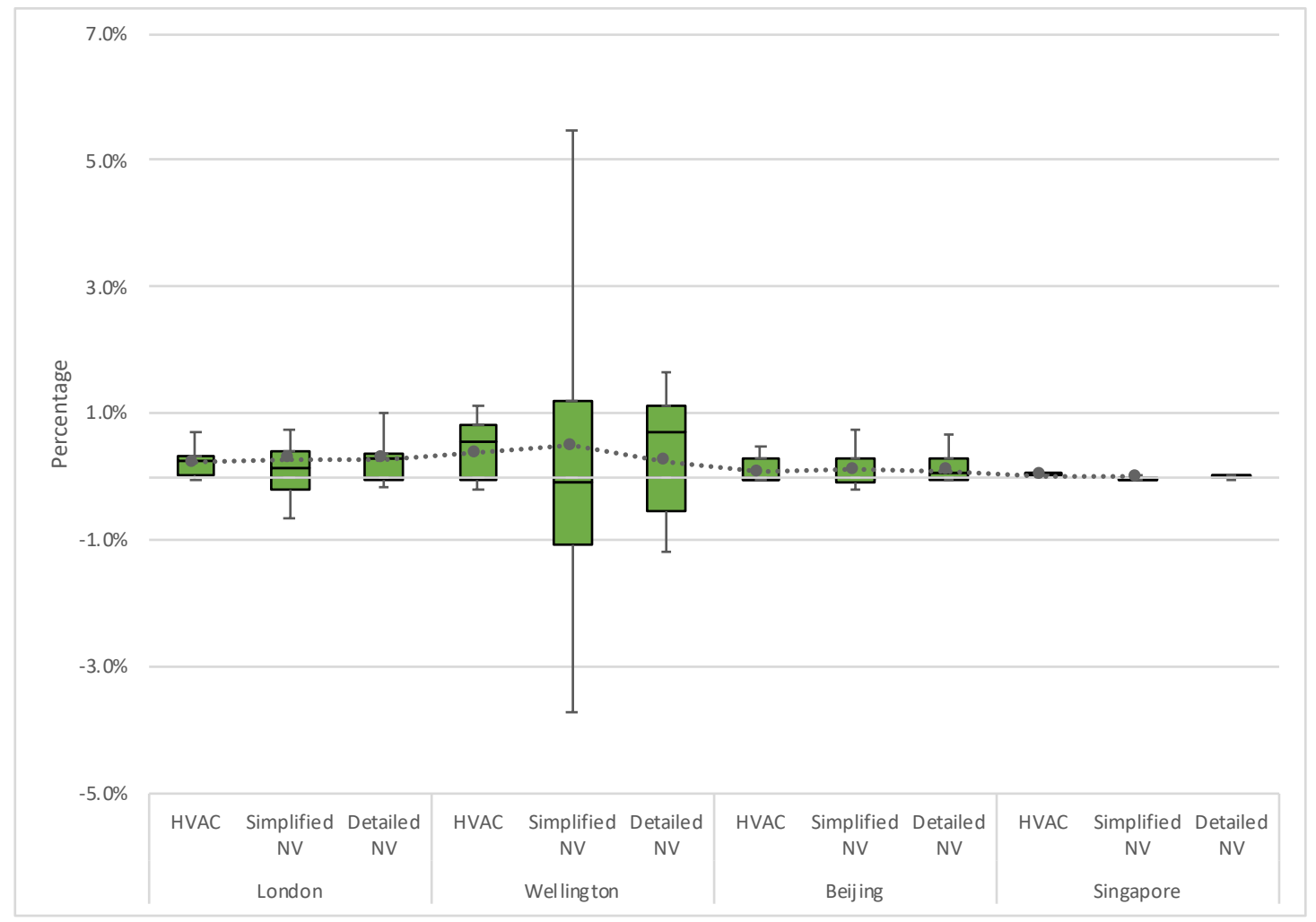

(a) 


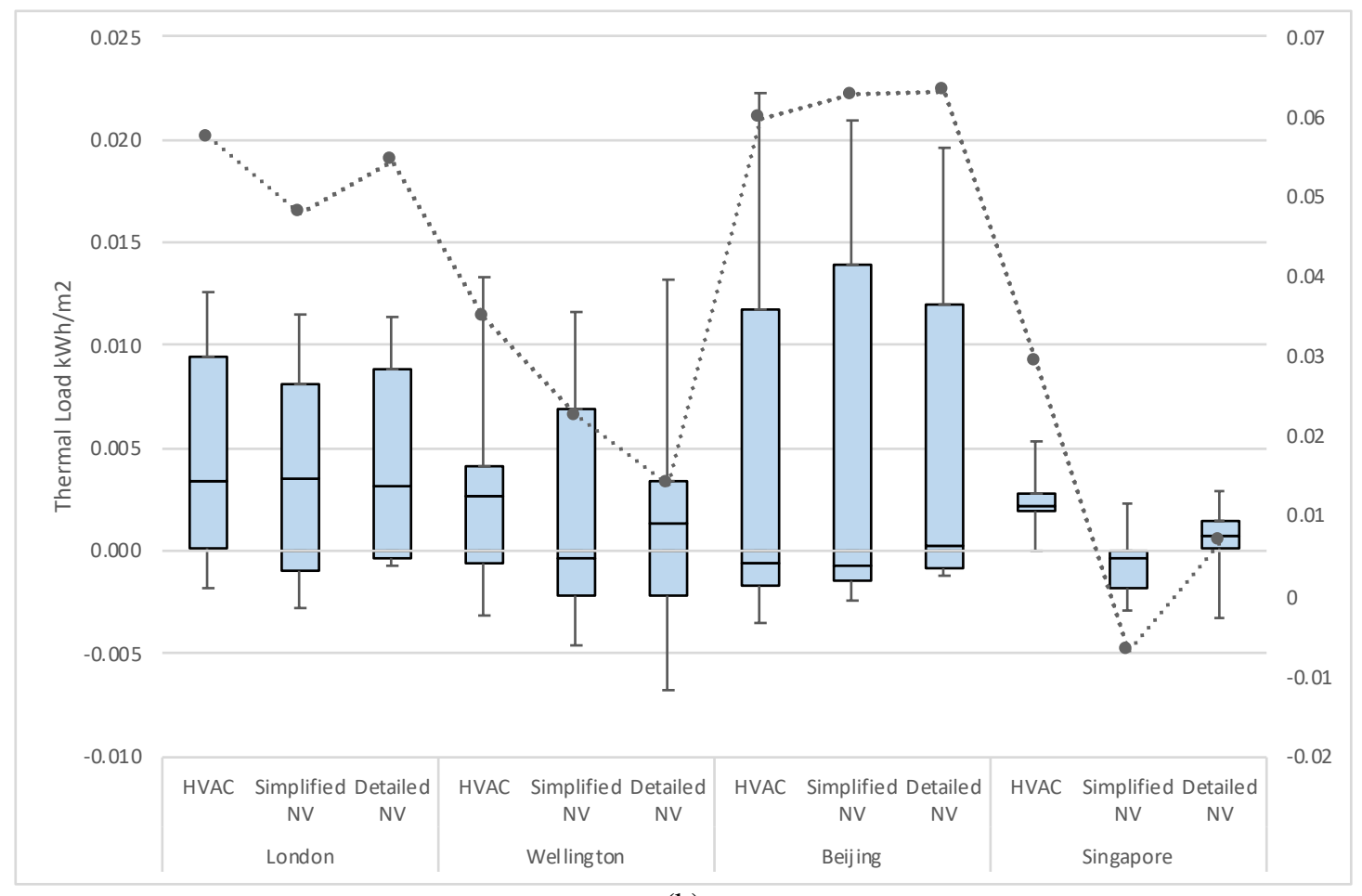

(b)

Figure 127: a) thermal load percentage change b) thermal load change of wind speed profile exponent 0.33 over 0.4 with different ventilation systems in the climate of different cities

\subsubsection{Wind speed profile boundary layer thickness $(400 \mathrm{~m})$}

The slight change of the wind speed profile boundary layer thickness for cities has little influence on the building performance which is smaller than that of the wind speed profile exponent. In Figure 128a, the percentage changes are less than 1\% except in London's climate and Wellington's climate with simplified natural ventilation. The percentage changes of the wind speed profile boundary layer thickness in Singapore's climate is close to $0 \%$ (Figure 128a) and monthly absolute changes are less than 0.004 $\mathrm{kWh} / \mathrm{m}^{2}$ (Figure 128b). The influence of the wind speed profile boundary layer thickness precision is also negligible. 

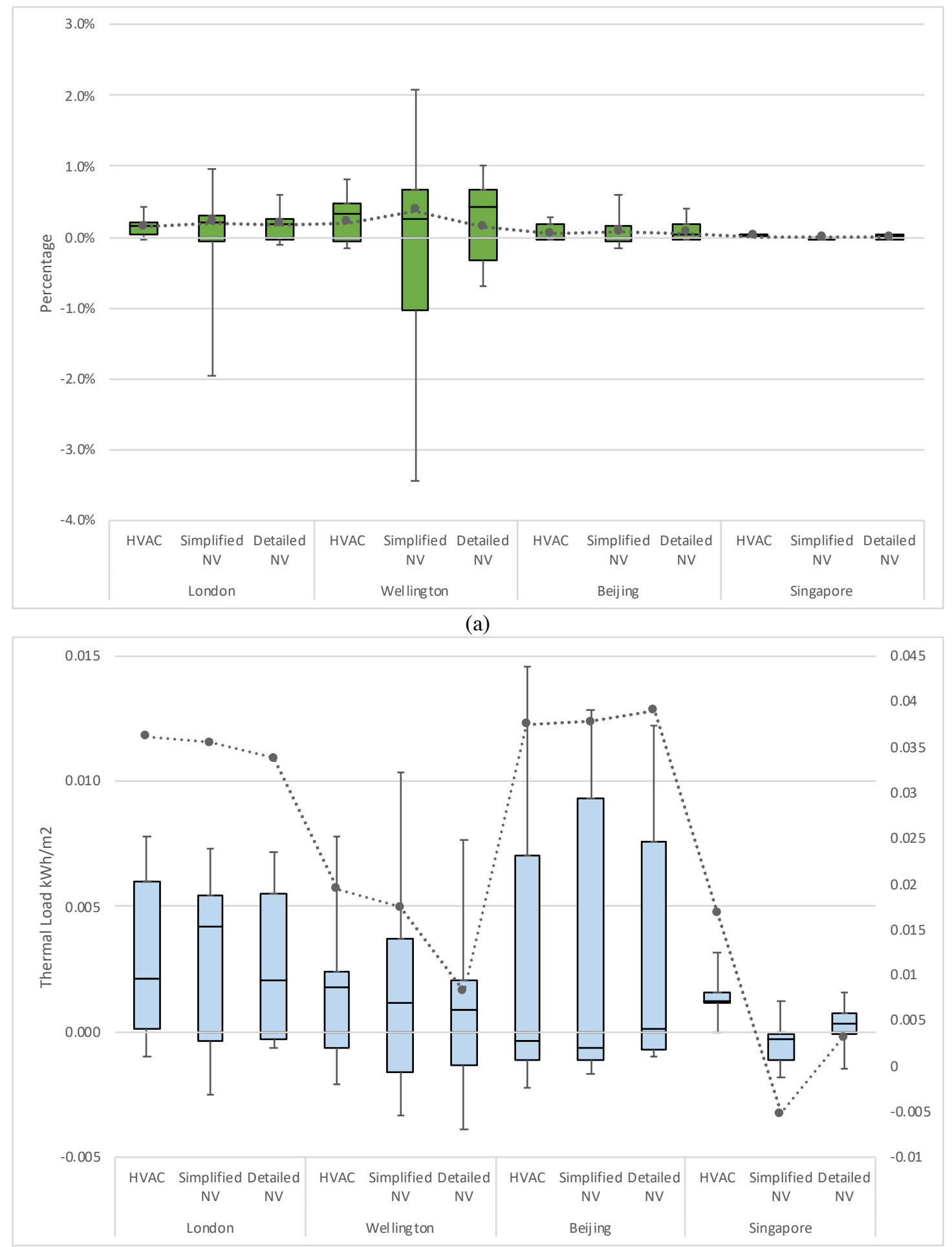

(b)

Figure 128: a) thermal load percentage change b) thermal load change of wind speed profile boundary layer thickness $400 \mathrm{~m}$ over $500 \mathrm{~m}$ with different ventilation systems in the climate of different cities

The effects of the precision of the wind speed profile exponent and the wind speed profile boundary layer thickness are very small. The influence of the precision of the wind speed profile exponent is slightly bigger than that of the wind speed profile boundary layer thickness. In the four climate regions, it is not worth the effort to model a more accurate urban wind profile. 


\subsubsection{Air temperature gradient coefficient $(0.004 \mathrm{~K} / \mathrm{m})$}

The slight change of the air temperature gradient coefficient for cities has bigger effects than the wind speed profile exponent and the wind speed profile boundary layer thickness. In Figure 129a, the monthly percentage changes in Wellington's climate are between $-6 \%$ and $8 \%$, in London's climate between $-2 \%$ and $5 \%$, in Beijing's climate between $-3 \%$ and $2 \%$, and in Singapore's climate between $-2 \%$ and $0 \%$. The annual percentage changes in the climate of the four cities are small (less than 3\%). The percentage changes in Singapore's climate are the smallest, however, the absolute changes in Singapore's climate are the biggest due to vary large cooling loads yearround in Singapore (Figure 129b). The precision of the air temperature gradient coefficient is more important than that of the wind speed profile exponent and the wind speed profile boundary layer thickness. However, the precision of the urban vertical variations is not important, as it usually gives a less than $2 \%$ change.

An accurate urban air temperature gradient coefficient in a windy climate is more important than that in a moderate climate and a continental climate. In a tropical climate, although it has very small influence on the percentage changes, the absolute changes are the biggest. The absolute changes in the building performance prediction may change the capacity design of building equipment. Whether or not modelling a more accurate urban air temperature gradient coefficient in a tropical climate depends on the requirements of the engineer. 


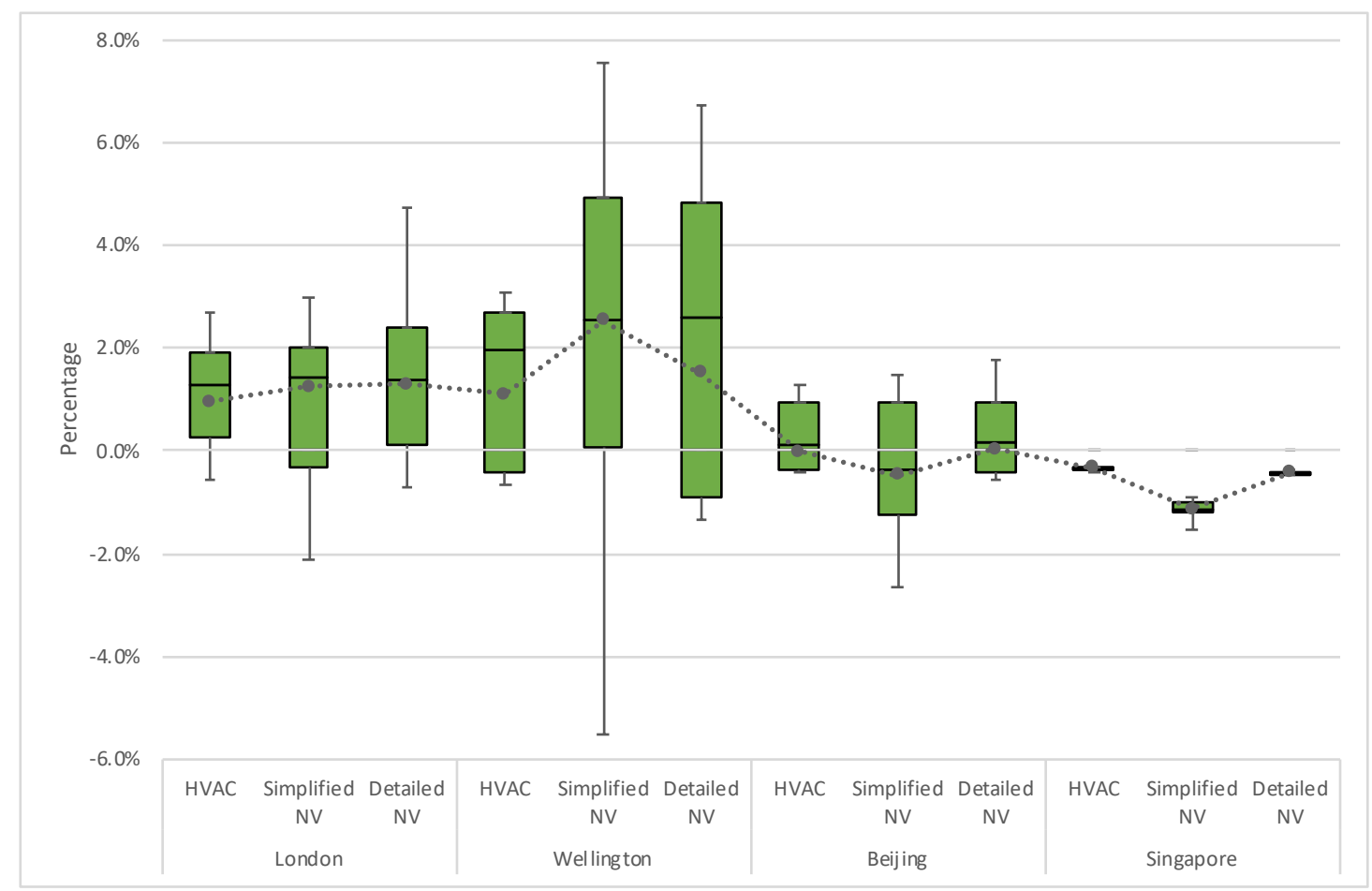

(a)

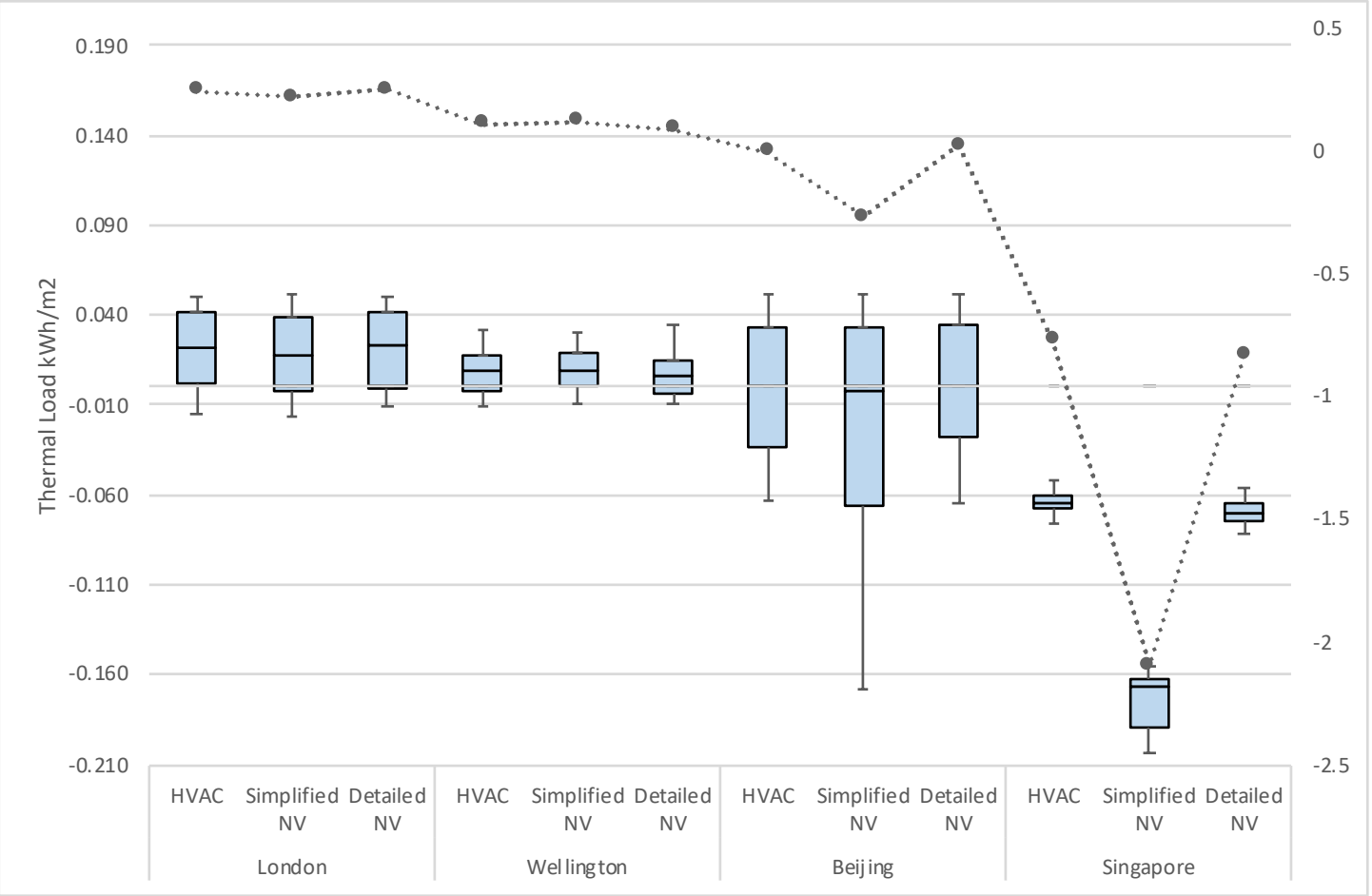

(b)

Figure 129: a) thermal load percentage change b) thermal load change of air temperature gradient coefficient $0.004 \mathrm{~K} / \mathrm{m}$ over $0.002 \mathrm{~K} / \mathrm{m}$ with different ventilation systems in the climate of different cities

\subsubsection{Height variations of terrain}

The previous section studied whether the accuracy of height variations for a city influences thermal load prediction. The slight change of urban height variations has little influence on building performance predictions. What if a building is in urban areas, 
but its surrounding terrain is more like suburbs? The difference between urban and suburban height variations is bigger than the slight change. This section discusses how the height variations of suburban terrain influence building performance simulation. The control group in this section is the same as that in previous section (Table 31). Then, the wind speed profile exponent 0.22 is compared with 0.4 , The wind speed profile boundary layer thickness $370 \mathrm{~m}$ is compared with $500 \mathrm{~m}$, and the air temperature gradient coefficient $0.0065 \mathrm{~K} / \mathrm{m}$ is compared with $0.002 \mathrm{~K} / \mathrm{m}$. The influence of suburban height variations $(0.22370 \mathrm{~m} 0.0065 \mathrm{~K} / \mathrm{m})$ is compared with that of the urban height variations $(0.4500 \mathrm{~m} 0.002 \mathrm{~K} / \mathrm{m})$.

\subsubsection{Wind speed profile exponent $(0.22)$}

The influence of suburban wind speed profile exponent is bigger than the slight change of urban wind speed profile exponent. The annual percentage changes due to suburban terrain (less than 2\% in Figure 130a) are bigger than those due to the precision of urban wind speed profile exponent (less than 1\% Figure 127a). In Wellington's climate the monthly percentage changes are between $-3 \%$ and $5 \%$. The percentage changes in Wellington's climate are bigger than those in London's climate, Beijing's climate and Singapore's climate. However, the absolute changes in Beijing's climate are the biggest, and in Singapore's climate are the smallest. The suburban wind speed profile exponent has a very low impact on the prediction of building performance. Considering the influence of suburban wind speed profile exponent is recommended in a windy climate, while not recommended in a tropical climate. 


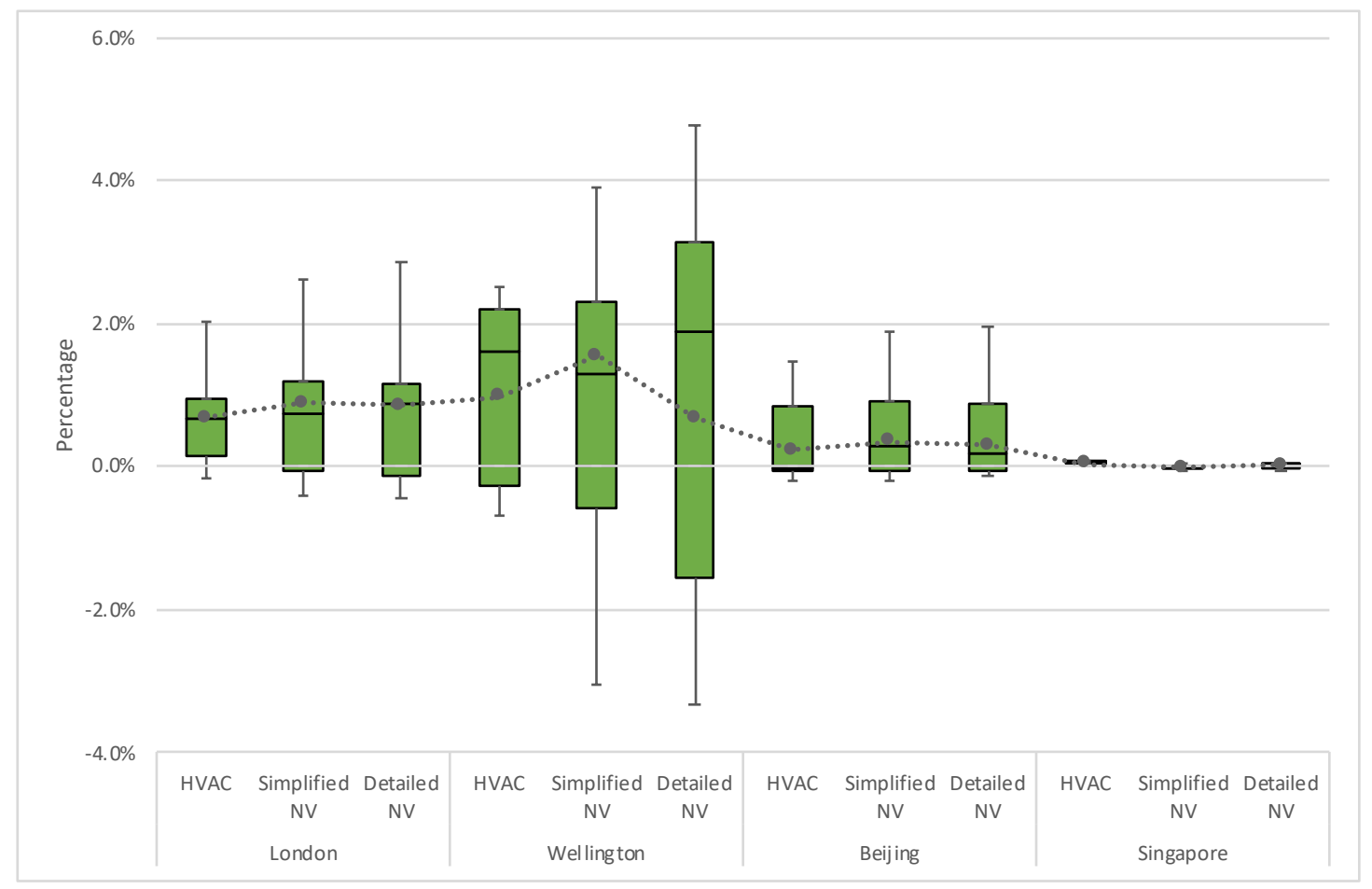

(a)

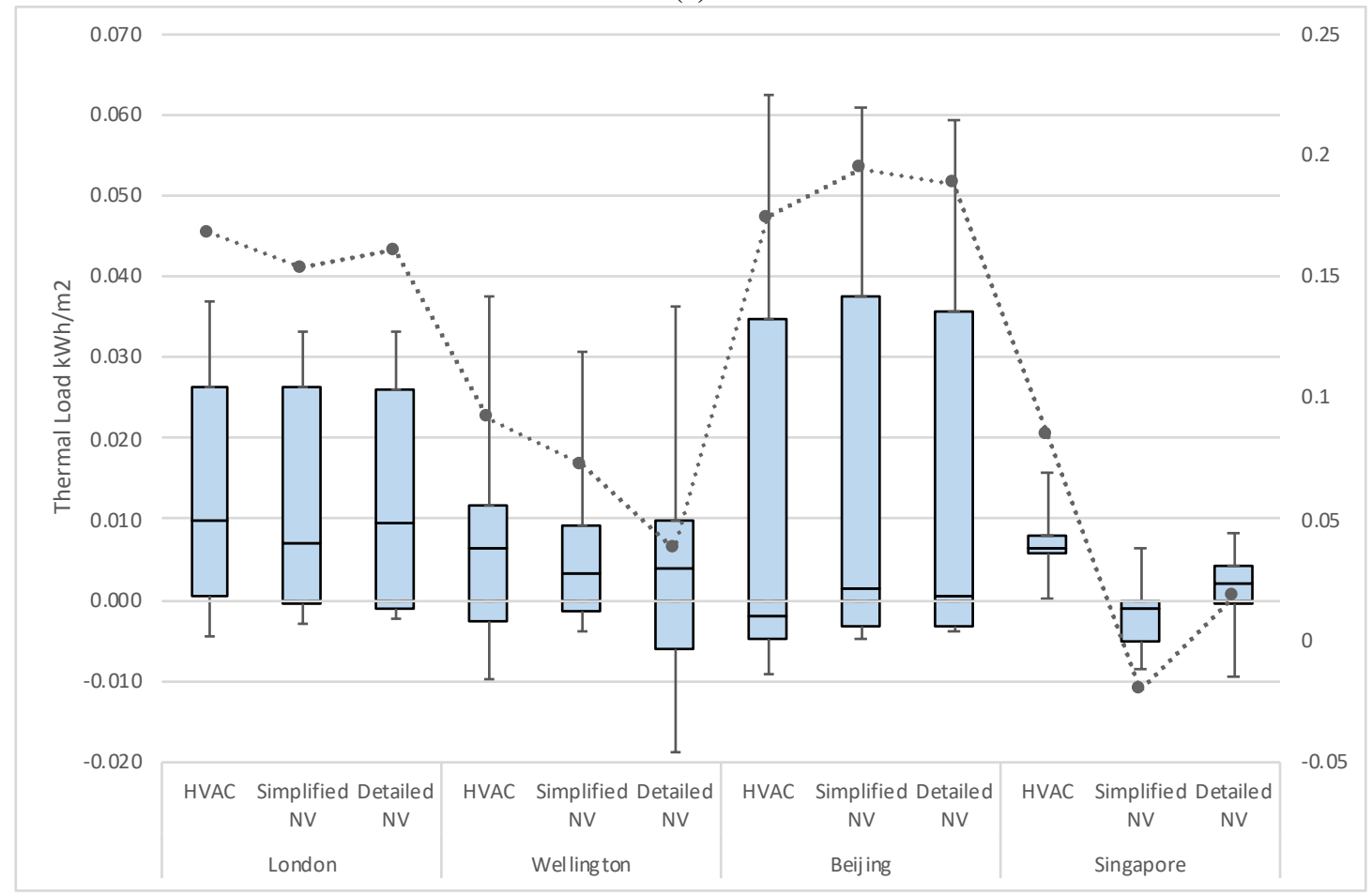

(b)

Figure 130: a) thermal load percentage change b) thermal load change of wind speed profile exponent 0.22 over 0.4 with different ventilation systems in the climate of different cities

\subsubsection{Wind speed profile boundary layer thickness $(370 \mathrm{~m})$}

The influence of suburban wind speed profile boundary layer thickness is very small (Figure 131). The effects of suburban thickness are a little bigger than those of the slight change of urban thickness (Figure 128). The percentage changes in Wellington's climate are the biggest (Figure 131a). The absolute changes in Beijing's climate are the 
biggest (Figure 131b). Both the percentage changes and the absolute changes in Singapore's climate are the smallest. In the four climate regions, the influence of the wind speed profile boundary layer thickness due to precision and terrain is not important.

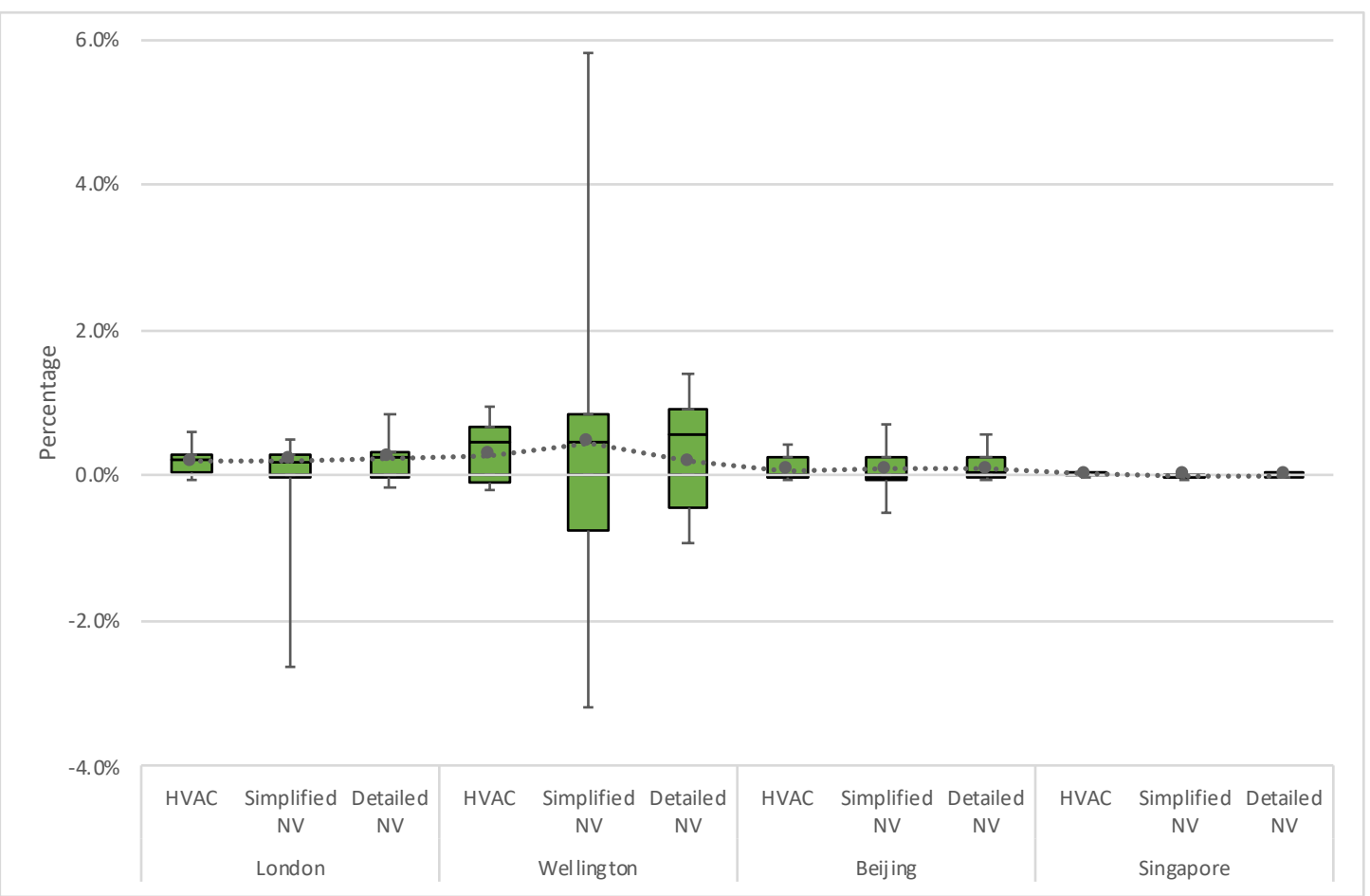

(a)

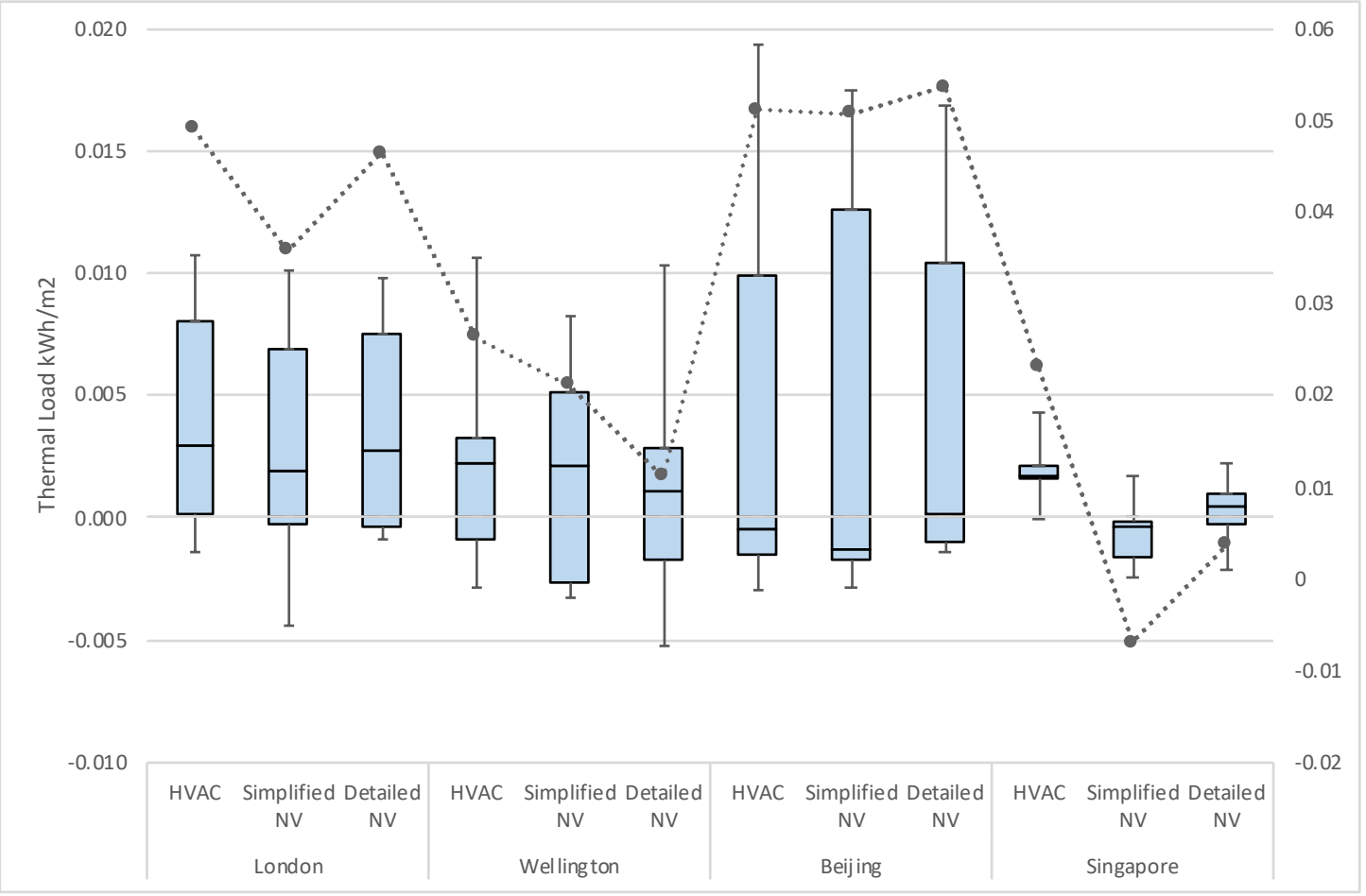

(b)

Figure 131: a) thermal load percentage change b) thermal load change of wind speed profile boundary layer thickness $370 \mathrm{~m}$ over $500 \mathrm{~m}$ with different ventilation systems in the climate of different cities

\subsubsection{Air temperature gradient coefficient $(0.0065 \mathrm{~K} / \mathrm{m})$}


The influence of suburban air temperature gradient coefficient is much bigger than that of suburban wind speed profile exponent and suburban wind speed profile boundary layer thickness, and it is also bigger than that of the precision of urban air temperature gradient coefficient. In Figure 132a, the percentage changes in Wellington's climate are between $-5 \%$ and 19\% which are bigger than those in London's climate, Beijing's climate and Singapore's climate. However, in Figure 132b, the absolute changes in Singapore's climate are the biggest, followed by in Beijing's climate. Wellington's climate is the smallest.

Considering suburban air temperature gradient coefficient is recommended in moderate climates, and not recommended in a continental climate. In a tropical climate, it is recommended. Although it has a less $4 \%$ impact on the percentage changes, the absolute changes are the biggest.

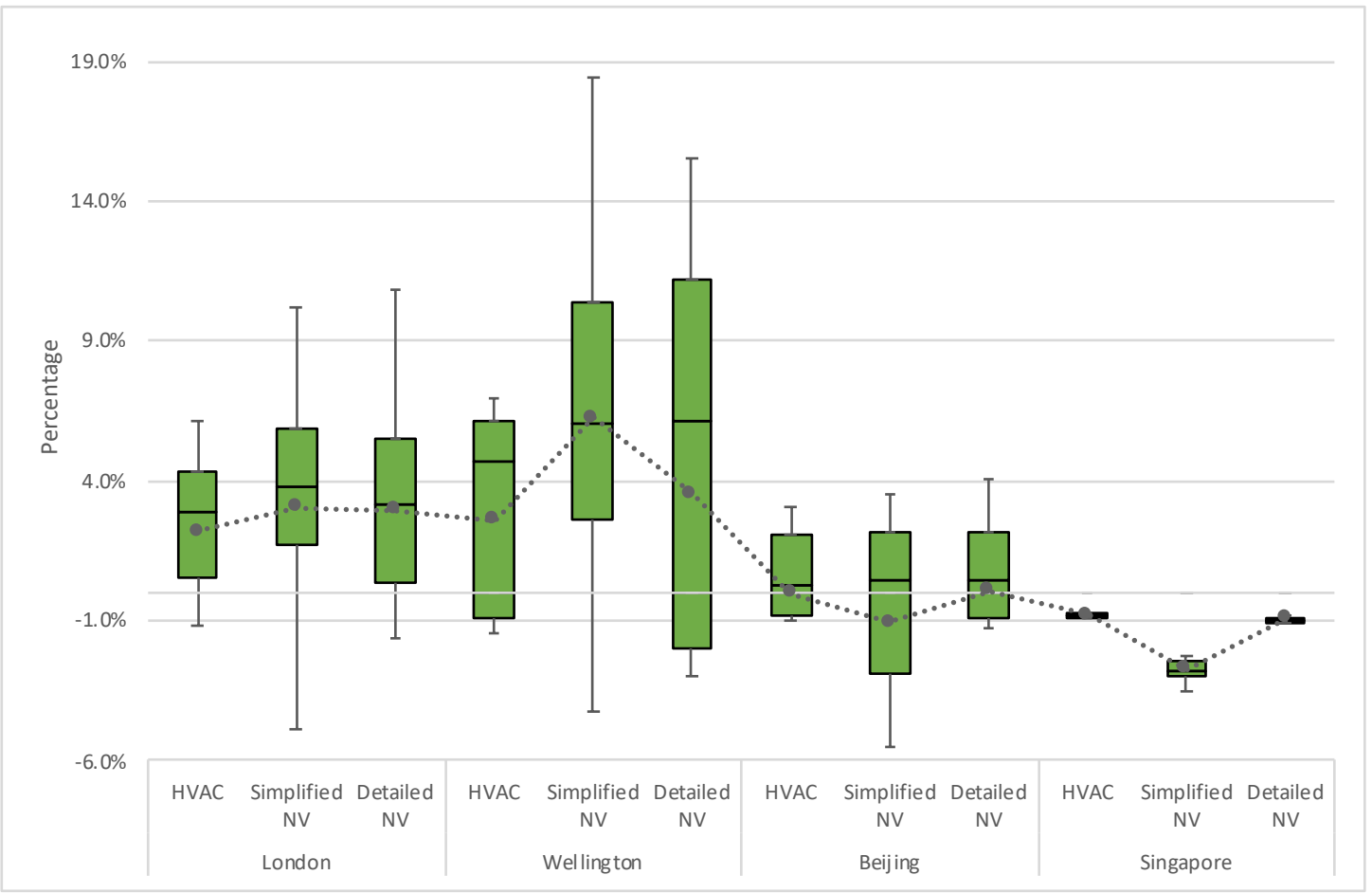

(a) 


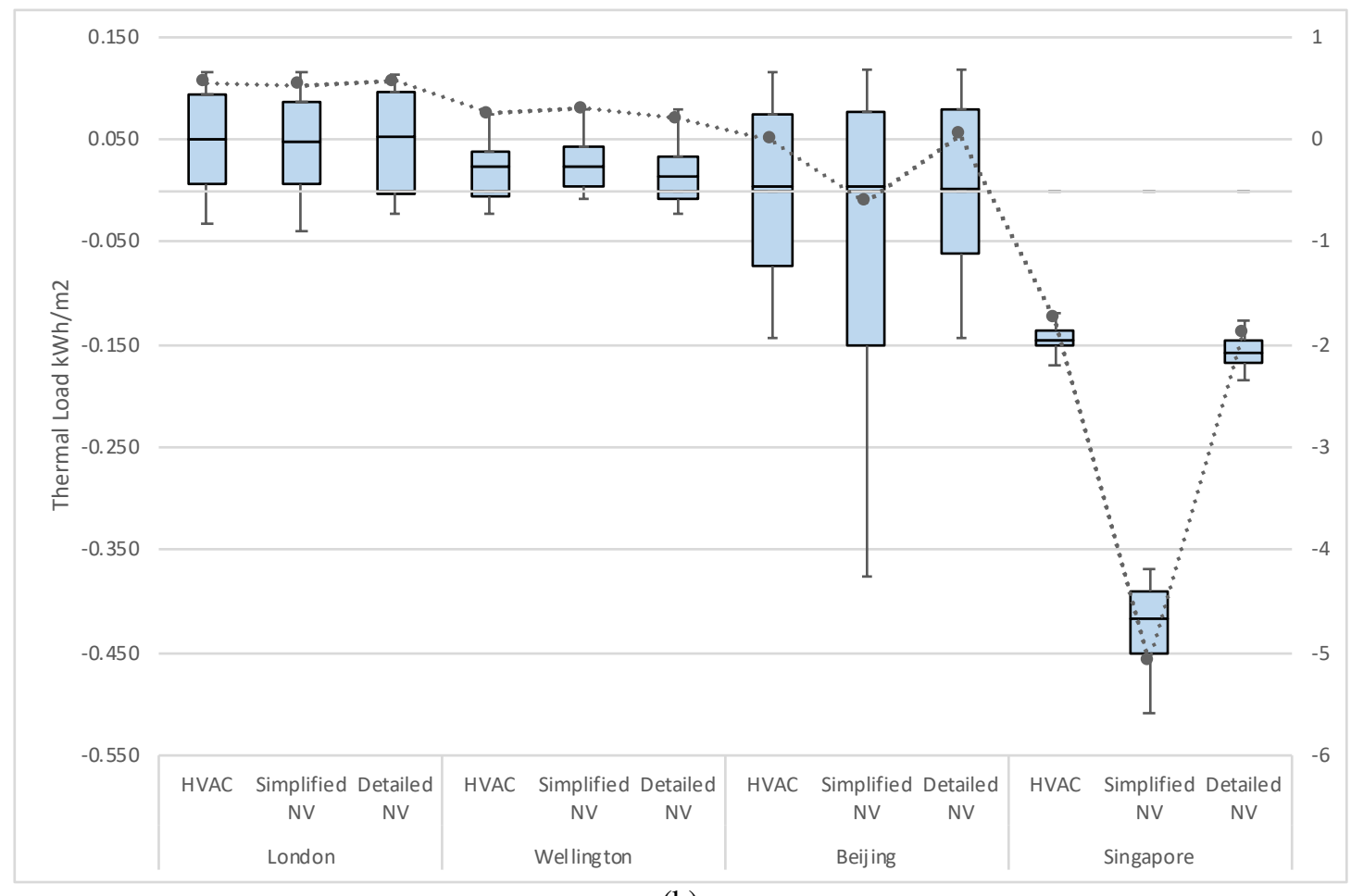

Figure 132: a) thermal load percentage change b) thermal load change of air temperature gradient coefficient $0.0065 \mathrm{~K} / \mathrm{m}$ over $0.002 \mathrm{~K} / \mathrm{m}$ with different ventilation systems in the climate of different cities

\subsubsection{Suburban height variations $(0.22370 \mathrm{~m} 0.0065 \mathrm{~K} / \mathrm{m})$}

The combined effects of suburban height variations are significant. The percentage changes in Wellington's climate are between $-7 \%$ and 22\%, followed by London's climate (Figure 133a). The annual percentage changes in Wellington's climate and London's climate are positive, but in Singapore's climate those are negative. In Singapore's climate, the percentage changes are the smallest, however, the absolute changes are the biggest (Figure 133b).

Considering the terrain of suburbs is recommended in moderate climates. In a continental climate, it is also recommended when engineers need the information of monthly thermal load changes to optimize building performance. As for in a tropical climate, it is recommended as well. Although it has a less 3\% impact on the percentage changes, the absolute changes are the biggest. Hence, the influence of height variations of suburban terrain is important to the climate of these four cities. 


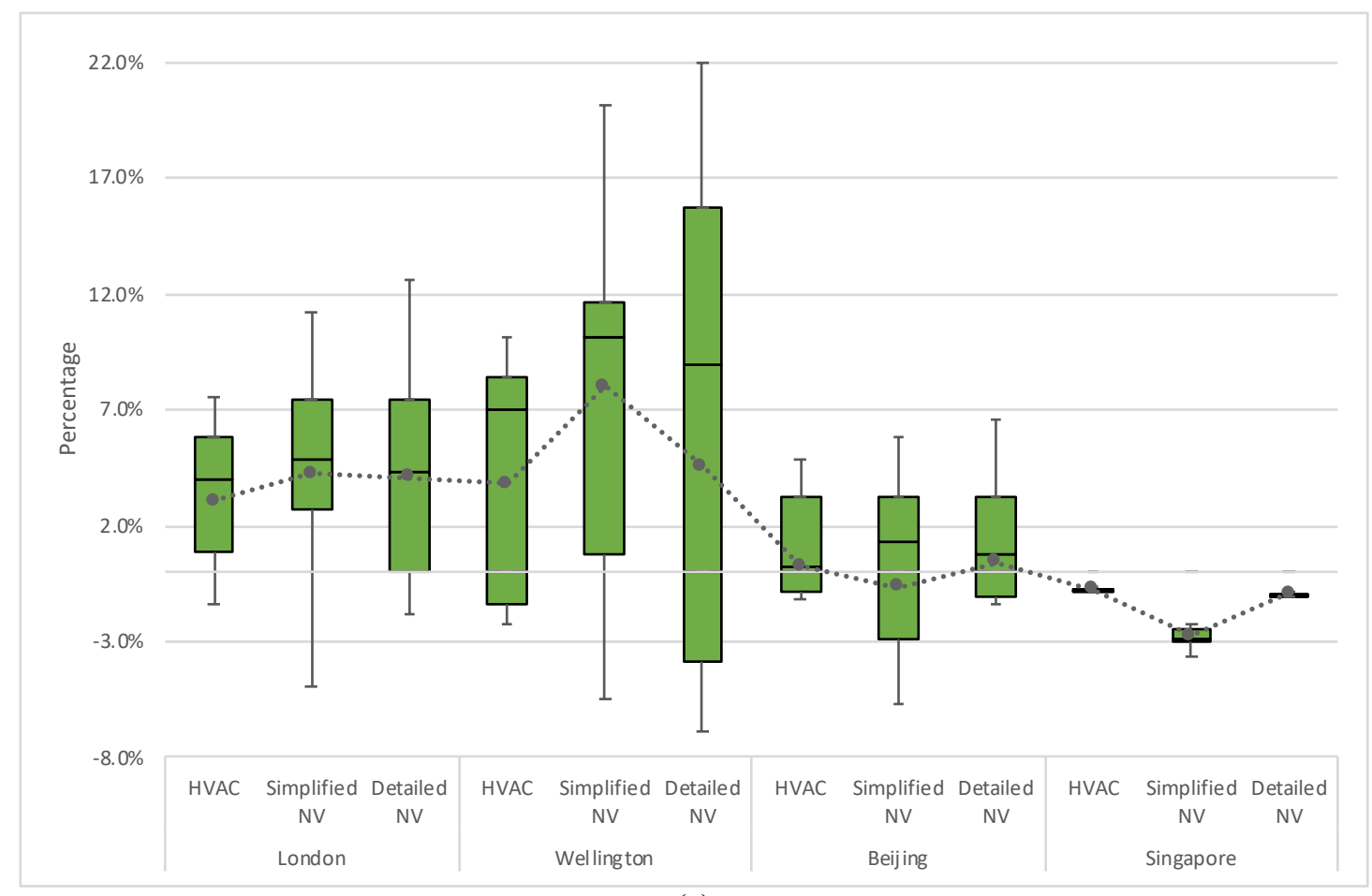

(a)

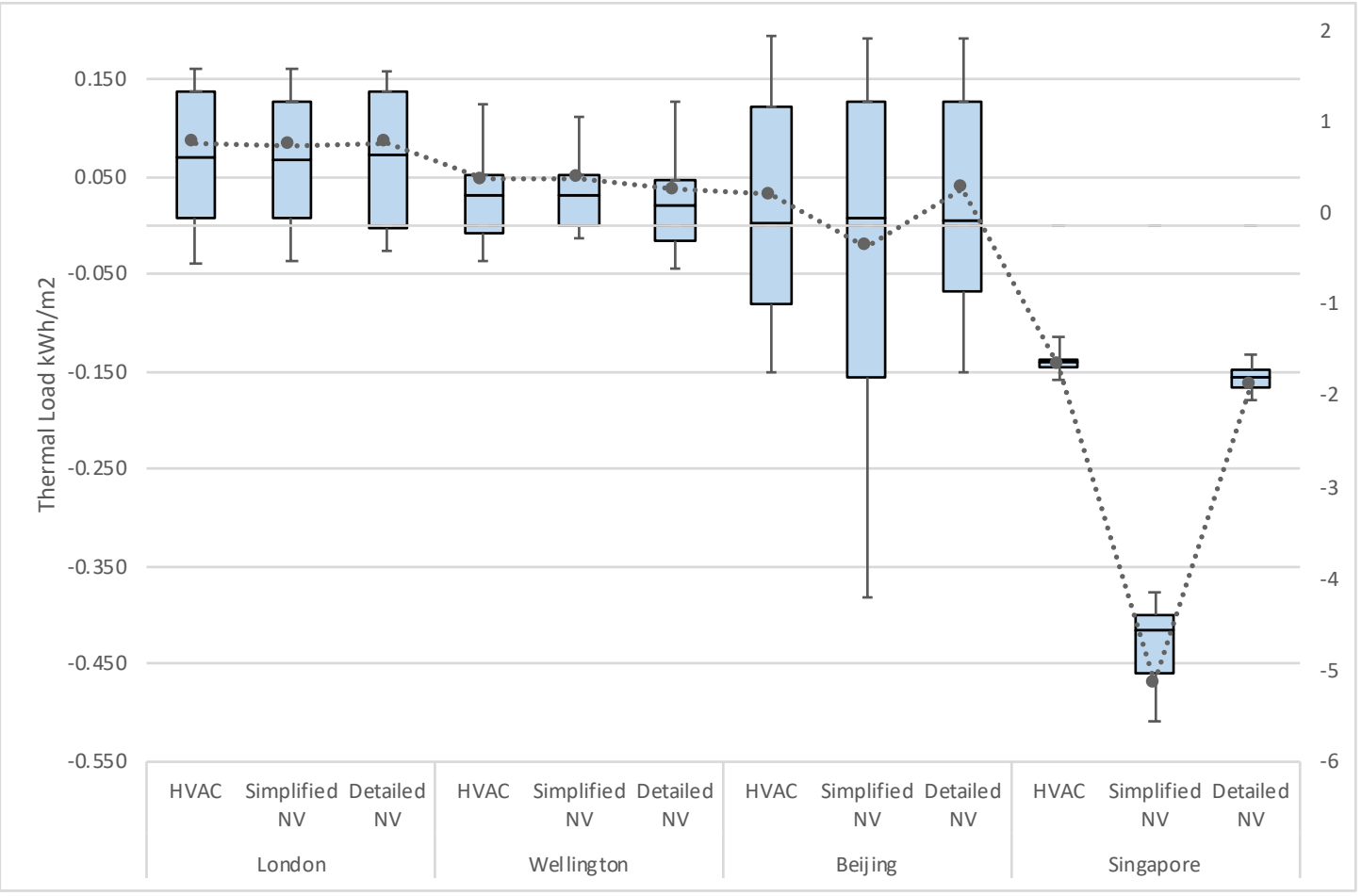

(b)

Figure 133: a) thermal load percentage change b) thermal load change of suburban height variations $(0.22370 \mathrm{~m} 0.0065 \mathrm{~K} / \mathrm{m})$ over urban height variations $(0.4500 \mathrm{~m} 0.004 \mathrm{~K} / \mathrm{m})$ with different ventilation systems in the climate of different cities 


\subsection{Effects of Urban Microclimate Detailed Modelling on Cities with Different Climate}

The last section explained the effects of each parameter separately in detail. This section compares these effects together. Monthly percentage changes in thermal loads due to urban microclimate modelling precision in four cities with three ventilation systems are shown in the same figure. It shows the thermal load percentage changes over 12 months. In that figure, the orange bar means an increase in thermal load and the green bar means a decrease in thermal load. From left to right is January to December in London, Beijing and Singapore. Wellington is in the southern hemisphere. In Wellington, from left to right is July to June to keep the order of the seasons. Annual absolute changes in thermal loads due to each urban microclimate parameter in four cities with three ventilation systems are also shown in one figure. A negative value means a decrease in thermal load prediction and a positive value means an increase in thermal load prediction.

\subsubsection{Effects of Urban microclimate modelling precision}

The combined effects of urban microclimate parameters increase with the urban microclimate modelling precision. In Figure 134, the combined effects increase cooling loads in summer and decrease heating loads in winter in London's climate, Wellington's climate and Beijing's climate. The effects in Singapore's climate are different from those in the climate of other three cities, because there are only cooling loads in Singapore's climate. The parameters increase cooling load prediction in winter and decrease cooling load prediction in summer. The percentage changes in Wellington's climate (between -58\% and 87\%), London's climate (between $-61 \%$ and $52 \%$ ) and Beijing's climate (between $-43 \%$ and 26\%) are bigger than in Singapore's climate (between $-7 \%$ and $7 \%$ ). The percentage changes with simplified natural ventilation and detailed natural ventilation are bigger than those with an HVAC system. The effects of urban wind are very small in London's climate, Beijing's climate and Singapore's climate, except in Wellington's climate.

According to the monthly percentage changes, developing a simulation system of urban microclimate is recommended in moderate, windy and continental climates. 


\begin{tabular}{|c|c|c|c|c|c|c|c|c|}
\hline \multirow{3}{*}{ City } & \multirow{3}{*}{$\begin{array}{l}\text { Ventilaiton } \\
\text { System }\end{array}$} & \multicolumn{7}{|c|}{ Urban microclimate modelling precision } \\
\hline & & \multirow[t]{2}{*}{ Urban Wind } & \multirow[t]{2}{*}{ UHI } & \multirow[t]{2}{*}{ UrbanWind+UHI } & \begin{tabular}{|c|} 
Urban \\
Wind+UHI+adjuste \\
d Height \\
\end{tabular} & \multirow{2}{*}{\begin{tabular}{|c|} 
Urban \\
Wind+UHI+adjuste \\
$\mathrm{d}$ Height \\
$\begin{array}{c}\text { Variations+Multilay } \\
\text { er }\end{array}$ \\
\end{tabular}} & \multirow{2}{*}{ MAX } & \multirow[t]{2}{*}{ MIN } \\
\hline & & & & & $0.4500 \mathrm{~m} 0.002 \mathrm{~K} / \mathrm{m}$ & & & \\
\hline \multirow{3}{*}{ London } & HVAC & ---------- & 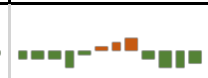 & 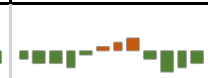 & 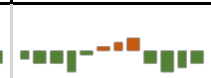 & 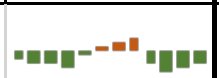 & $30 \%$ & \\
\hline & Simplified NV & ------------ & 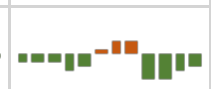 & 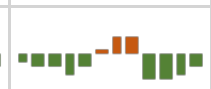 & 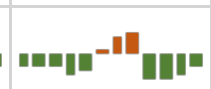 & 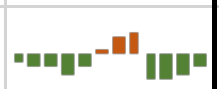 & $52 \%$ & $-55 \%$ \\
\hline & Detailed NV & --------.- & 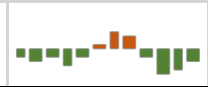 & "Iח-" & . & " & $44 \%$ & $-61^{\circ}$ \\
\hline \multirow{3}{*}{ Wellingtor } & HVAC & 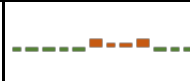 & แோแ & man- & m| & 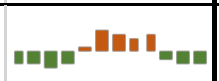 & $77 \%$ & $-33^{\circ}$ \\
\hline & Simplified NV & 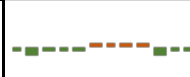 & 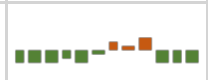 & 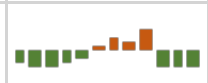 & 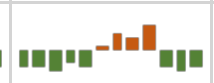 & 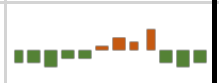 & $62 \%$ & \\
\hline & Detailed NV & 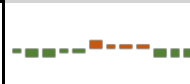 & 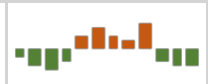 & 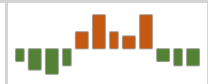 & 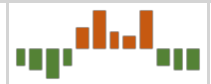 & 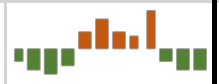 & $87 \%$ & $-58 \%$ \\
\hline \multirow{3}{*}{ Beijing } & HVAC & 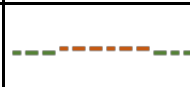 & 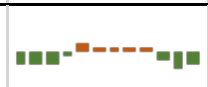 & 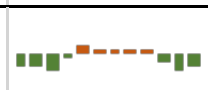 & | & 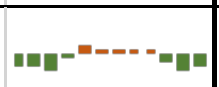 & $21 \%$ & $-37^{\circ}$ \\
\hline & Simplified NV & |---------_-- & 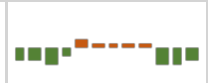 & 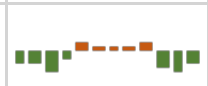 & שום"-"=-"ם & | & $26 \%$ & $-41 \%$ \\
\hline & Detailed NV & ---------- & 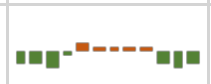 & 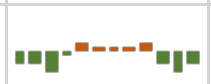 & שום"---"םسי & 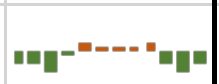 & $23 \%$ & $-43^{\circ}$ \\
\hline \multirow{3}{*}{ Singapore } & HVAC & |---------- & --ー--ー--ー--" & ----- & & -ーーー-ー- & $2 \%$ & \\
\hline & Simplified NV & 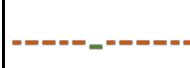 & -----ー--ー-"- & 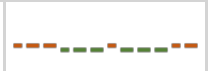 & ------_--- & -------- ----- & $7 \%$ & \\
\hline & Detailed NV & -- & .-- & .---- & --- & --- & $T^{70}$ & \\
\hline
\end{tabular}

Figure 134: Monthly percentage changes due to urban microclimate modelling precision in four cities with three ventilation systems

Figure 134 shows the gradual change of combined effects and Figure 135 shows each individual effect of urban microclimate parameters. UHI has big effects in the climate of the four cities. In London's climate, Wellington's climate and Beijing's climate the UHI has the biggest influence, but in Singapore's climate adjusted height variations have the biggest influence. In London's climate urban wind has the second biggest influence. The effects of adjusted height variation and multilayer modelling method are similar, but one is negative the other is positive. In Beijing's climate the effects of urban wind (negative) and multilayer modelling method (positive) are similar. Adjusted height variations have the smallest influence. In Wellington's climate the parameters except the UHI have a similar influence. The thermal load changes due to the multilayer modelling method are similar in London's climate, Beijing's climate and Singapore's climate.

In Figure 135, urban wind decreases thermal load prediction except in Wellington's climate with an HVAC system and in Singapore's climate with natural ventilation 
systems. The UHI decreases annual thermal load prediction in the climates of four cities with three ventilation systems. The adjusted height variations of urban microclimates increase thermal load prediction in Singapore dramatically. They decrease thermal load prediction in the climates of other cities, except in Beijing's climate with simplified natural ventilation. The multilayer modelling method increases thermal load prediction, except in Wellington's climate with an HVAC system.

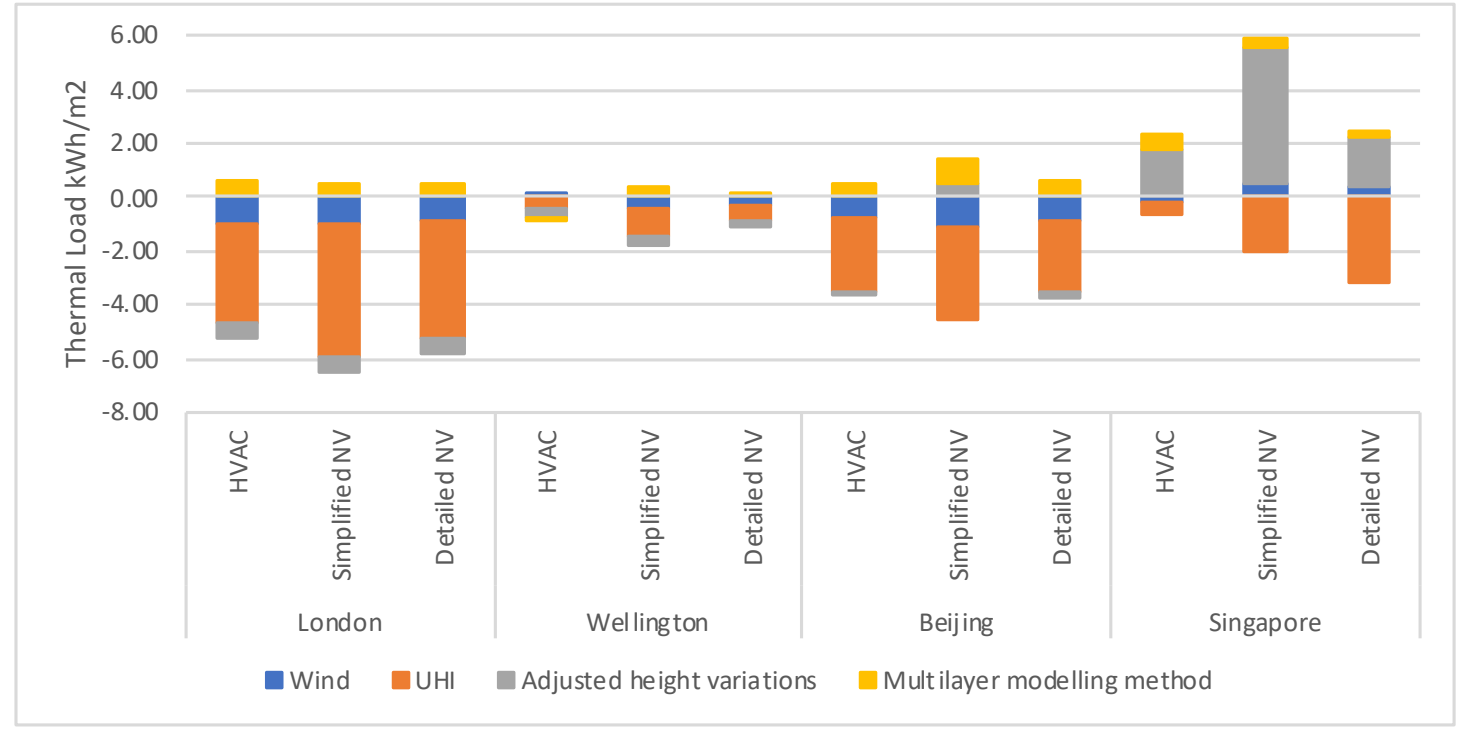

Figure 135: Annual absolute changes of thermal load due to urban microclimate parameters in four cities with three ventilation systems

The percentage changes in Singapore's climate are very small, but the absolute changes are significant. The parameters except the UHI increase thermal load prediction in Singapore's climate. In the climates of other cities most of the parameters decrease thermal load prediction.

According to the annual absolute changes, developing a simulation system of urban microclimate is recommended in moderate, continental and tropical climates. In the climate of Wellington, although the absolute changes are small, the percentage changes are big. In the climate of Singapore, although the percentage changes are small, the absolute changes are big. Hence, according to the percentage and absolute changes, developing a simulation system of urban microclimate is recommended in the four climate regions.

\subsubsection{Height variation precision and terrain}

The influence of height variations of different terrain is bigger than that of height variation precision. In Figure 136, the monthly percentage changes of thermal loads 
due to height variation precision are less than $8 \%$. The monthly percentage changes due to suburban height variations can reach $22 \%$. The suburban terrain decreases cooling load prediction in summer and increases heating load prediction in winter in London's climate, Wellington's climate and Beijing's climate. In Singapore's climate, the wind speed profile exponent and the wind speed profile boundary layer thickness increase and the air temperature gradient coefficient decreases cooling load prediction for most of the year.

In Figure 137, the influence of the air temperature gradient coefficient is bigger than that of the wind speed profile exponent and the wind speed profile boundary layer thickness. The thermal load changes due to the wind speed profile exponent and the wind speed profile boundary layer thickness are very small.

The influence of height variations in the climate of Singapore is different from that in the climate of other cities. In Figure 136 the percentage changes in Singapore's climate are the smallest, however, the absolute changes in Singapore's climate are the biggest (Figure 137). The suburban air temperature gradient coefficient increases thermal loads in London and Wellington. In Beijing's climate and Singapore's climate, it decreases thermal loads except with detailed natural ventilation in Beijing's climate.

The influence of terrain is bigger than that of height variation precision. Considering the influence of terrain type is recommended in moderate climates. In a tropical climate, modelling a more accurate urban air temperature gradient coefficient and considering the influence of suburban air temperature gradient coefficient are recommended. The air temperature gradient coefficient has a great impact on thermal load prediction in a tropical climate. Height variation precision and suburban height variations have a small impact on thermal load prediction in a continental climate. 


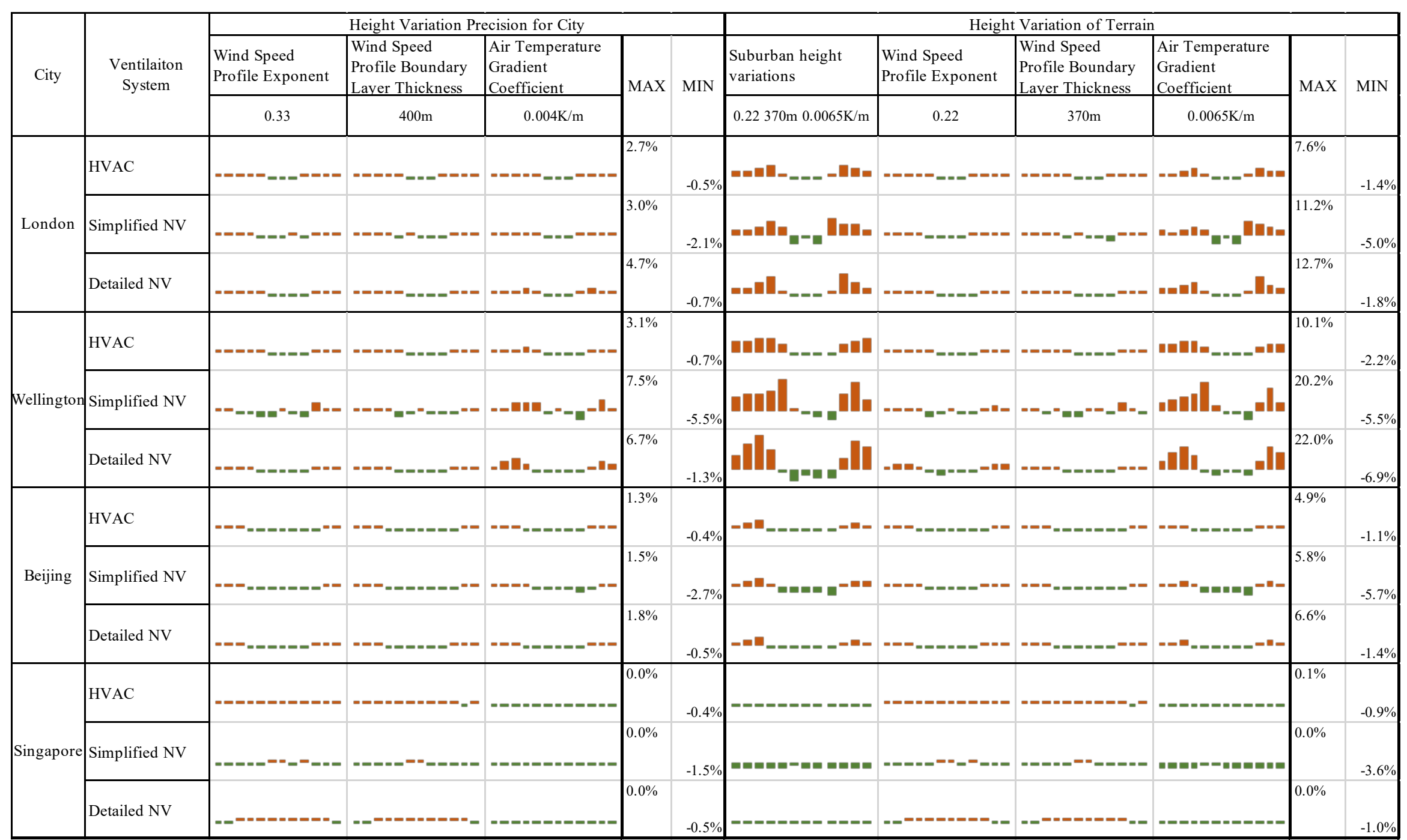

Figure 136: Monthly percentage changes due to height variation precision and terrain in four cities with three ventilation systems 


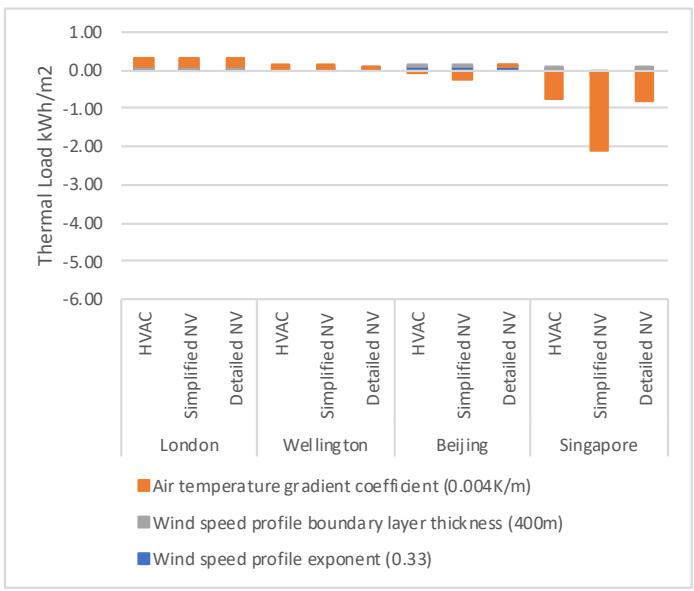

(a)

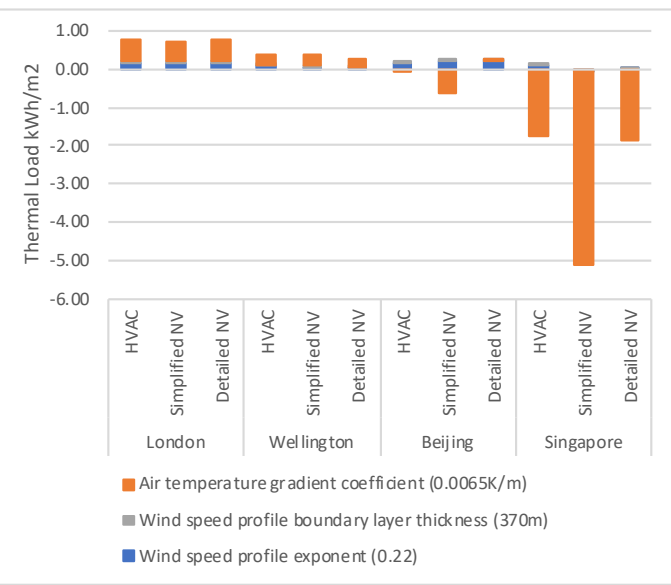

(b)

Figure 137: Annual absolute changes due to (a) height variation precision and (b) height variation of terrain in four cities with three ventilation systems

\subsubsection{Effects of Height variation precision and terrain at different height}

Height variations of urban microclimates have different impacts at different floors. At the $1^{\text {st }}$ floor, the effects of the wind speed profile exponent are bigger than the wind speed profile boundary layer thickness and the air temperature gradient coefficient. In London's climate and Wellington's climate, the monthly changes due to the wind speed profile exponent can reach 9\%. In Beijing's climate the changes are less than 3.4\% and in Singapore's climate are less than $0.3 \%$ (Figure 138). At the 17th and 33rd floors, the air temperature gradient coefficient plays a more important role than the wind speed profile exponent and the wind speed profile boundary layer thickness. The influence of the height variations increases with height. At the 17th floor, the monthly changes due to the terrain in London's climate are less than 12.2\% (Figure 139). At the 33rd floor, they are less than $25.4 \%$ (Figure 140). In Wellington's climate, the monthly changes are less than $23.4 \%$ at the 17 th floor and $33.2 \%$ at the $33 \mathrm{rd}$ floor.

At a lower floor, modelling a more accurate urban wind speed profile exponent and considering the impact of suburban wind speed profile exponent are recommended in moderate climates. At an upper floor, modelling a more accurate urban air temperature gradient coefficient and considering the impact of suburban air temperature gradient coefficient are recommended in moderate climates.

At the 1st floor, in London's climate, the effects of height variations on an HVAC system are bigger than natural ventilation systems. In the other three cities the effects on natural ventilation systems are bigger than an HVAC system. 


\begin{tabular}{|c|c|c|c|c|c|c|c|c|c|c|c|c|}
\hline \multirow[b]{2}{*}{ City } & \multirow[b]{2}{*}{$\begin{array}{l}\text { Ventilaiton } \\
\text { System }\end{array}$} & \multicolumn{5}{|c|}{ Height Variation Precision for City } & \multicolumn{6}{|c|}{ Height Variation of Terrain } \\
\hline & & $\begin{array}{c}\text { Wind Speed } \\
\text { Profile Exponent }\end{array}$ & $\begin{array}{l}\text { Wind Speed } \\
\text { Profile Boundary } \\
\text { Layer Thickness }\end{array}$ & $\begin{array}{c}\text { Air Temperature } \\
\text { Gradient } \\
\text { Coefficient }\end{array}$ & MAX & MIN & $\begin{array}{c}\text { Suburban height } \\
\text { variations }\end{array}$ & $\begin{array}{c}\text { Wind Speed } \\
\text { Profile Exponent }\end{array}$ & $\begin{array}{l}\text { Wind Speed } \\
\text { Profile Boundary } \\
\text { Layer Thickness }\end{array}$ & $\begin{array}{c}\text { Air Temperature } \\
\text { Gradient } \\
\text { Coefficient }\end{array}$ & MAX & MIN \\
\hline \multirow{3}{*}{ London } & HVAC & "---"매| & --- & 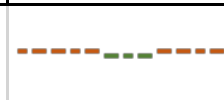 & $0.8 \%$ & $-9.4 \%$ & 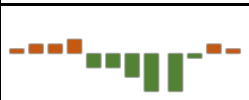 & |--"'-घㅁ| & --- & & $3.4 \%$ & $-9.4 \%$ \\
\hline & Simplified NV & 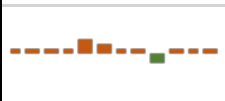 & ------_-_-_- & 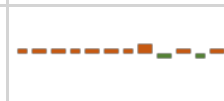 & $2.8 \%$ & $-3.0 \%$ & 붐ㅁ-_ー & 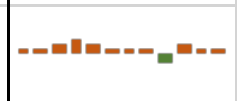 & 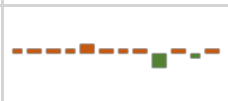 & 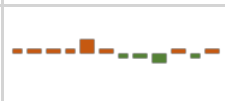 & $4.3 \%$ & $-4.1 \%$ \\
\hline & Detailed NV & 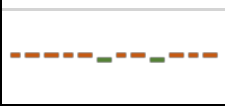 & --- & -----------" & $1.3 \%$ & $-0.1 \%$ & 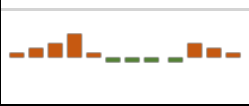 & 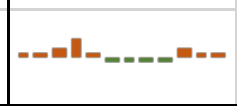 & 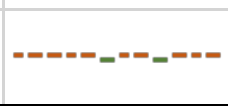 & ---- & $5.2 \%$ & $-0.4 \%$ \\
\hline \multirow{3}{*}{ Wellington } & HVAC & 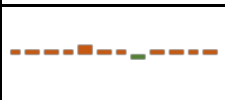 & ------ & ------------ & $1.6 \%$ & $-0.2 \%$ & 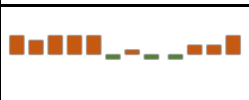 & | & 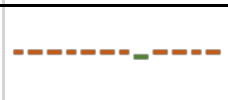 & 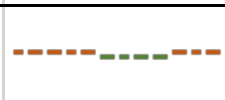 & $4.6 \%$ & $-0.9 \%$ \\
\hline & Simplified NV & $a^{2}=-2$ & ---1. & 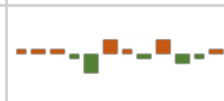 & $7.5 \%$ & $-9.0 \%$ & 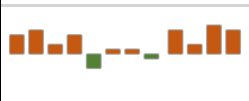 & 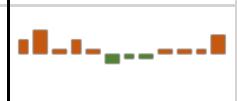 & 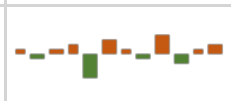 & 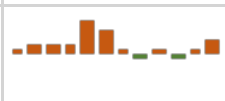 & $8.3 \%$ & $-5.6 \%$ \\
\hline & Detailed NV & 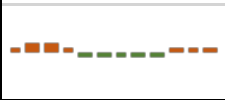 & 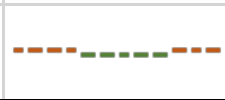 & 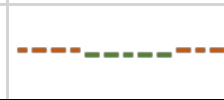 & $2.2 \%$ & $-1.4 \%$ & G| & | & 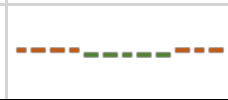 & ---------- & $9.1 \%$ & $-5.2 \%$ \\
\hline \multirow{3}{*}{ Beijing } & HVAC & 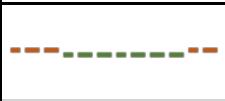 & 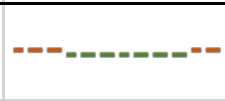 & 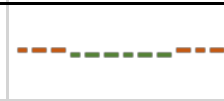 & $0.6 \%$ & $-0.1 \%$ & ーツッーーーーーーーーー & 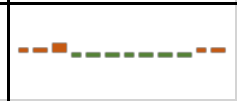 & 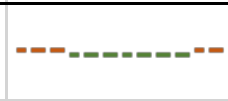 & 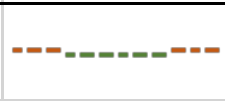 & $2.5 \%$ & $-0.3 \%$ \\
\hline & Simplified NV & |---_-ー-ロ-ー-- & 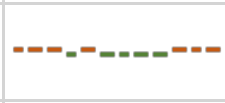 & 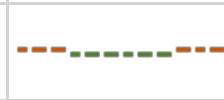 & $0.9 \%$ & $-0.8 \%$ & -ோ-ーーーーーロேー & |--日---------- & 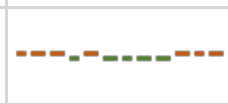 & 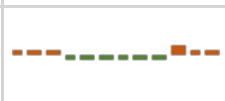 & $3.4 \%$ & $-0.9 \%$ \\
\hline & Detailed NV & 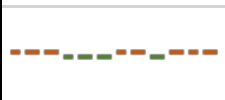 & 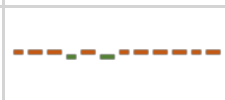 & 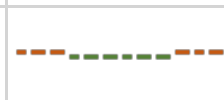 & $0.8 \%$ & $0.0 \%$ & 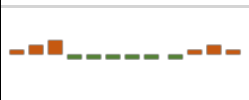 & 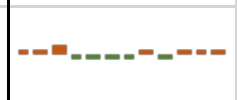 & 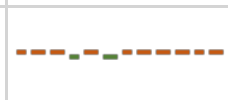 & ------------ & $3.3 \%$ & $-0.2 \%$ \\
\hline \multirow{3}{*}{ Singapore } & HVAC & --- & ----- & --- & $0.0 \%$ & $0.0 \%$ & 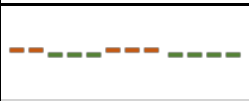 & & & & $0.1 \%$ & $-0.1 \%$ \\
\hline & Simplified NV & 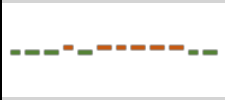 & --- ------- & 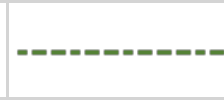 & $0.0 \%$ & $-0.1 \%$ & |ーーーーーーーーーーーー & ----_---ー--- & --- -------. & 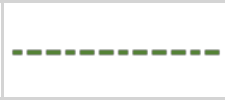 & $0.1 \%$ & $-0.3 \%$ \\
\hline & Detailed NV & 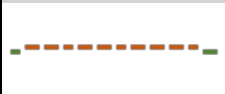 & -- & ----------- & $0.0 \%$ & $0.0 \%$ & --ー-ー-ー- ---- & -- & & & $0.1 \%$ & $-0.2 \%$ \\
\hline
\end{tabular}

Figure 138: Monthly percentage changes at the $1^{\text {st }}$ Floor due to height variation precision and terrain in four cities with three ventilation systems 


\begin{tabular}{|c|c|c|c|c|c|c|c|c|c|c|c|c|}
\hline \multirow[b]{2}{*}{ City } & \multirow[b]{2}{*}{$\begin{array}{l}\text { Ventilaiton } \\
\text { System }\end{array}$} & \multicolumn{5}{|c|}{ Height Variation Precision for City } & \multicolumn{6}{|c|}{ Height Variation of Terrain } \\
\hline & & $\begin{array}{l}\text { Wind Speed } \\
\text { Profile Exponent }\end{array}$ & $\begin{array}{l}\text { Wind Speed } \\
\text { Profile Boundary } \\
\text { Layer Thickness }\end{array}$ & $\begin{array}{c}\text { Air Temperature } \\
\text { Gradient } \\
\text { Coefficient }\end{array}$ & MAX & MIN & $\begin{array}{c}\text { Suburban height } \\
\text { variations }\end{array}$ & $\begin{array}{l}\text { Wind Speed } \\
\text { Profile Exponent }\end{array}$ & $\begin{array}{l}\text { Wind Speed } \\
\text { Profile Boundary } \\
\text { Layer Thickness }\end{array}$ & $\begin{array}{c}\text { Air Temperature } \\
\text { Gradient } \\
\text { Coefficient }\end{array}$ & MAX & MIN \\
\hline \multirow{6}{*}{ London } & & & & & $2.6 \%$ & & & & & & $7.5 \%$ & \\
\hline & HVAC & ------- & -----ー------ & 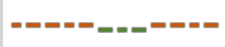 & & $-0.5 \%$ & 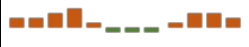 & --- & & 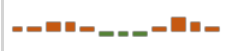 & & $-1.5 \%$ \\
\hline & & & & & $4.7 \%$ & & & & & & $12.2 \%$ & \\
\hline & Simplified NV & --- & ------- & $=-=--$ & & $-2.6 \%$ & 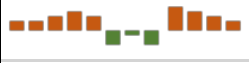 & -._-_-- & ----- & - & & $-4.3 \%$ \\
\hline & Detailed NV & & & & $4.5 \%$ & & & & & & $12.2 \%$ & \\
\hline & Detanted in v & & --- & --- & & $-0.7 \%$ & & & & In & & $-2.0 \%$ \\
\hline \multirow{4}{*}{ Wellington } & & & & & $2.8 \%$ & & & & & & $9.3 \%$ & \\
\hline & HVAC & $=---\infty$ & -----ー------ & $=----$ & & $-0.7 \%$ & 口n & --- & --- & $=m$ & & $-2.6 \%$ \\
\hline & Simplified NV & & & & $18.2 \%$ & & & & & & $23.4 \%$ & \\
\hline & & & & & & $-5.1 \%$ & & & & & & $-6.6 \%$ \\
\hline \multirow{6}{*}{ Beijing } & & & & & $1.3 \%$ & & & & & & $4.8 \%$ & \\
\hline & HVAC & 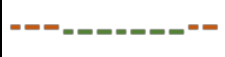 & ------------ & 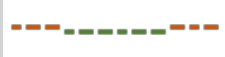 & & $-0.4 \%$ & -ோ-ーーーーーーツー & |-ーー-ーー-ー & 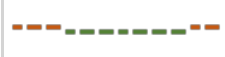 & 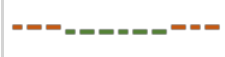 & & $-1.1 \%$ \\
\hline & & & & & $2.0 \%$ & & & & & & $5.4 \%$ & \\
\hline & Simplified NV & 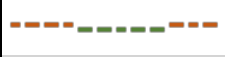 & 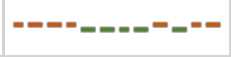 & 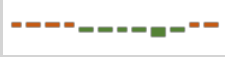 & & $-2.7 \%$ & 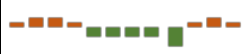 & 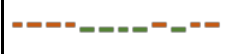 & 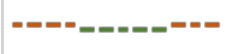 & 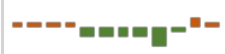 & & $-6.1 \%$ \\
\hline & & & & & $1.8 \%$ & & & & & & $6.6 \%$ & \\
\hline & Detailed NV & 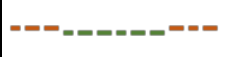 & ----------- & 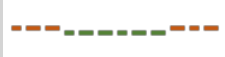 & & $-0.6 \%$ & 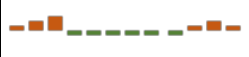 & 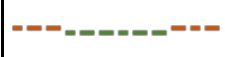 & 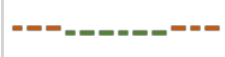 & 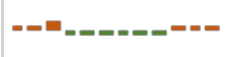 & & $-1.4 \%$ \\
\hline \multirow{6}{*}{ Singapore } & HVAC & & & & $0.0 \%$ & & & & & & $0.1 \%$ & \\
\hline & HVAC & -_- & --ー-ー-ー-ー - & 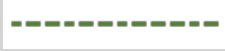 & & $-0.4 \%$ & |------------ & |------ & & --- & & $-0.9 \%$ \\
\hline & & & & & $0.0 \%$ & & & & & & $0.0 \%$ & \\
\hline & Simplified NV & |-----ーー-_-ー-- & 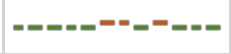 & ----------- & & $-1.5 \%$ & 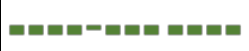 & |-------_---- & 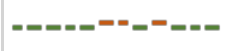 & 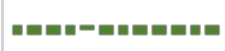 & & $-3.5 \%$ \\
\hline & & & & & $0.0 \%$ & & & & & & $0.0 \%$ & \\
\hline & Detalled NV & 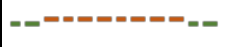 & 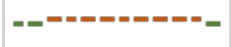 & > & & $-0.4 \%$ & $-\boldsymbol{-}-\boldsymbol{-}$ & ----- & --- & & & $-1.0 \%$ \\
\hline
\end{tabular}

Figure 139: Monthly percentage changes at the 17th Floor due to height variation precision and terrain in four cities with three ventilation systems 


\begin{tabular}{|c|c|c|c|c|c|c|c|c|c|c|c|c|}
\hline \multirow{3}{*}{ City } & \multirow{3}{*}{$\begin{array}{l}\text { Ventilaiton } \\
\text { System }\end{array}$} & \multicolumn{5}{|c|}{ Height Variation Precision for City } & \multicolumn{6}{|c|}{ Height Variation of Terrain } \\
\hline & & $\begin{array}{c}\text { Wind Speed } \\
\text { Profile Exponent }\end{array}$ & $\begin{array}{c}\text { Wind Speed } \\
\text { Profile Boundary } \\
\text { Layer Thickness }\end{array}$ & $\begin{array}{c}\text { Air Temperature } \\
\text { Gradient } \\
\text { Coefficient }\end{array}$ & MAX & MIN & $\begin{array}{c}\text { Suburban height } \\
\text { variations }\end{array}$ & $\begin{array}{l}\text { Wind Speed } \\
\text { Profile Exponent }\end{array}$ & $\begin{array}{c}\text { Wind Speed } \\
\text { Profile Boundary } \\
\text { Layer Thickness }\end{array}$ & $\begin{array}{c}\text { Air Temperature } \\
\text { Gradient } \\
\text { Coefficient }\end{array}$ & MAX & MIN \\
\hline & & 0.33 & $400 \mathrm{~m}$ & $0.004 \mathrm{~K} / \mathrm{m}$ & & & $0.22370 \mathrm{~m} 0.0065 \mathrm{~K} / \mathrm{m}$ & 0.22 & $370 \mathrm{~m}$ & $0.0065 \mathrm{~K} / \mathrm{m}$ & & \\
\hline \multirow{3}{*}{ London } & HVAC & & & & $5.1 \%$ & 1001 & 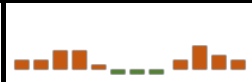 & & & - & $12.7 \%$ & \\
\hline & Simplified NV & ---- & --- & 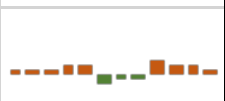 & $8.5 \%$ & $-5.5 \%$ & | & ---"--- & 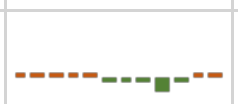 & 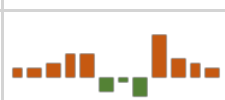 & $25.4 \%$ & $-10.8 \%$ \\
\hline & Detailed NV & --- & & $--\infty$ & $8.6 \%$ & $-1.4 \%$ & ---1 & & & --_-DE= & $21.7 \%$ & $-3.5 \%$ \\
\hline \multirow{3}{*}{ Wellington } & HVAC & |------------- & 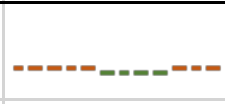 & 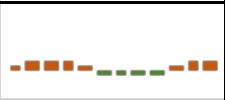 & $5.7 \%$ & $-1.2 \%$ & 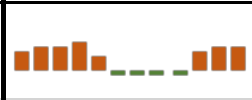 & --- & ------------ & 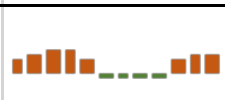 & $15.9 \%$ & $-3.4 \%$ \\
\hline & Simplified NV & 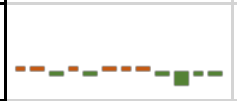 & ------ & 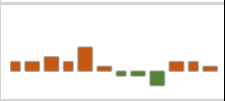 & $14.0 \%$ & $-7.7 \%$ & اله_-n & & -----10----- & 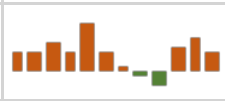 & $28.2 \%$ & $-8.3 \%$ \\
\hline & Detailed NV & |----_-------- & ーーーーーーーー & 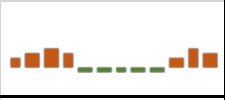 & $11.9 \%$ & $-2.6 \%$ & & & & II & $33.2 \%$ & $-8.7 \%$ \\
\hline \multirow{3}{*}{ Beijing } & HVAC & 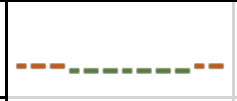 & 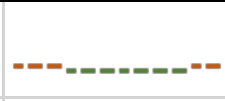 & ---- & $2.5 \%$ & $-0.8 \%$ & $-=-1---$ & $---=---$ & ------------ & $--=--$ & $7.3 \%$ & $-2.0 \%$ \\
\hline & Simplified NV & 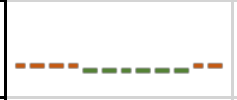 & -ーーー-ー-ー & 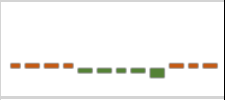 & $2.7 \%$ & $-5.1 \%$ & 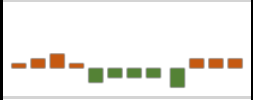 & ---------- & ----------- & |- & $7.6 \%$ & $-10.4 \%$ \\
\hline & Detailed NV & 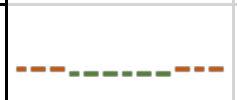 & 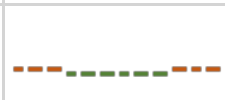 & ------ー-ー-ー-- & $3.4 \%$ & $-1.1 \%$ & 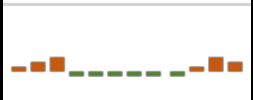 & |-ー-ー-ー--ーー-- & ------------ & 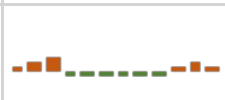 & $9.7 \%$ & $-2.5 \%$ \\
\hline \multirow{3}{*}{ Singapore } & HVAC & |-------ー--_-" & 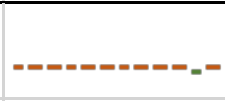 & 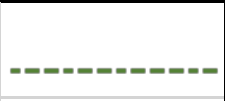 & $0.0 \%$ & $-0.7 \%$ & ---- ---- & 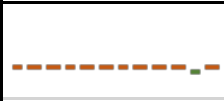 & -------- & -- & $0.1 \%$ & $-1.7 \%$ \\
\hline & Simplified NV & 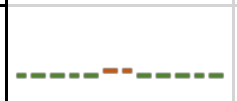 & ---------- & ----- & $0.0 \%$ & $-3.1 \%$ & 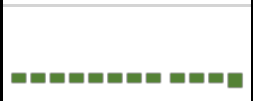 & 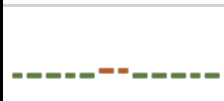 & 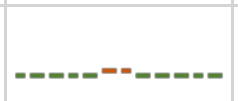 & 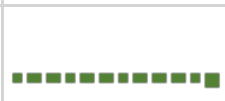 & $0.0 \%$ & $-7.0 \%$ \\
\hline & Detailed NV & |----_-ー-ー-ー-- & 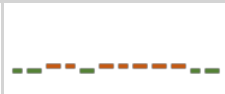 & $-=--$ & $0.0 \%$ & $-0.9 \%$ & --- & 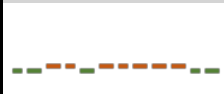 & ----_----ー-- & $=-$ & $0.0 \%$ & $-2.0 \%$ \\
\hline
\end{tabular}

Figure 140: Monthly percentage changes at the $33^{\text {rd }}$ Floor due to height variation precision and terrain in four cities with three ventilation systems 
At the $1^{\text {st }}$ floor, the annual absolute changes are very small. In London's climate, Wellington's climate and Beijing's climate, the influence of the wind speed profile exponent due to terrain is bigger than the air temperature gradient coefficient. In Singapore's climate the air temperature gradient coefficient plays an important role than the wind speed profile exponent. The influence of the wind speed profile boundary layer thickness is the smallest (Figure 141).

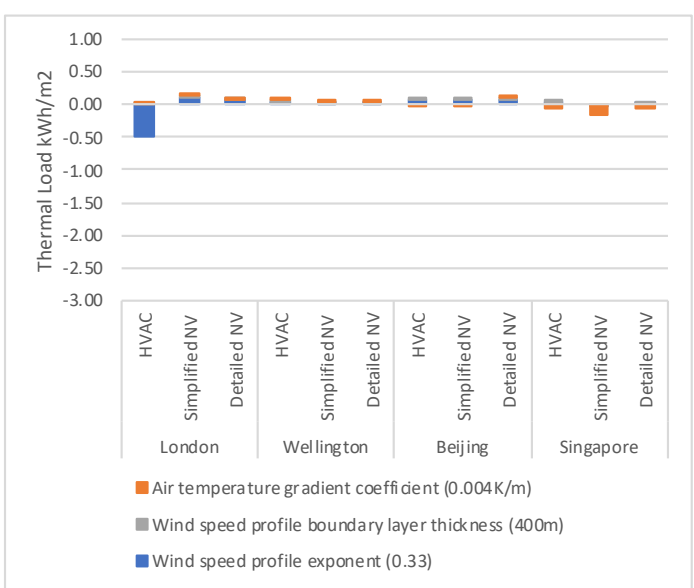

(a)

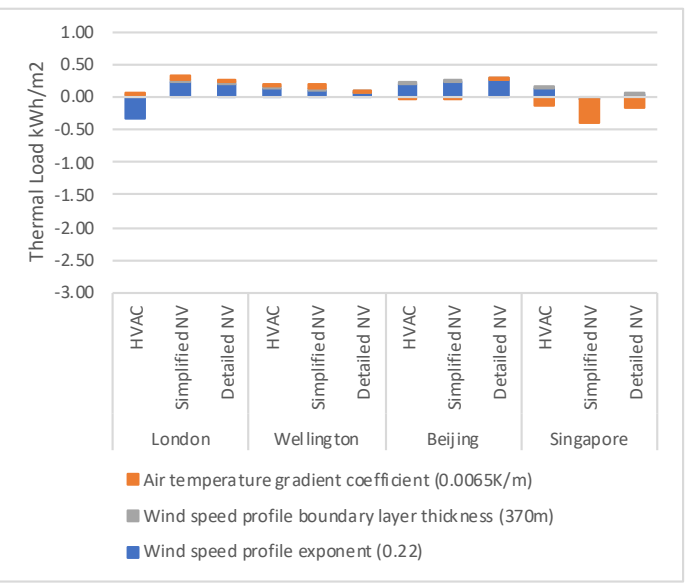

(b)

Figure 141: Annual absolute changes at the $1^{\text {st }}$ floor due to (a) height variation precision and (b) height variation of terrain in four cities with three ventilation systems

At the 17th and 33rd floors, the absolute changes of thermal loads due to the air temperature gradient coefficient are significant in Singapore's climate (Figure 142 and Figure 143). They increase with height. However, the percentage changes in Singapore's climate are less than 7\% (Figure 140), because the basic thermal load prediction in Singapore's climate are extremely high.

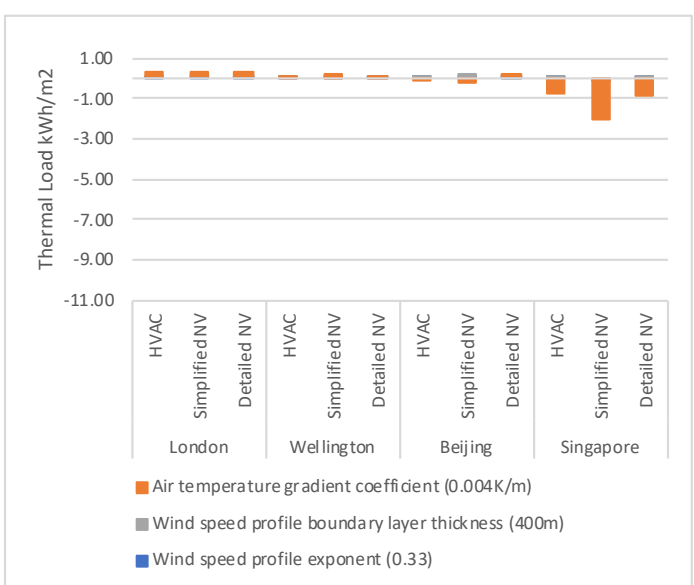

(a)

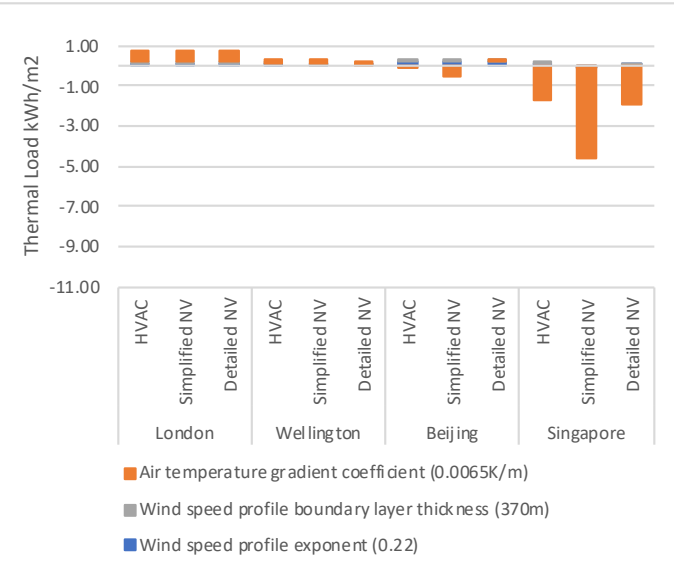

(b)

Figure 142: Annual absolute changes at the $17^{\text {th }}$ floor due to (a) height variation precision and (b) height variation of terrain in four cities with three ventilation systems 


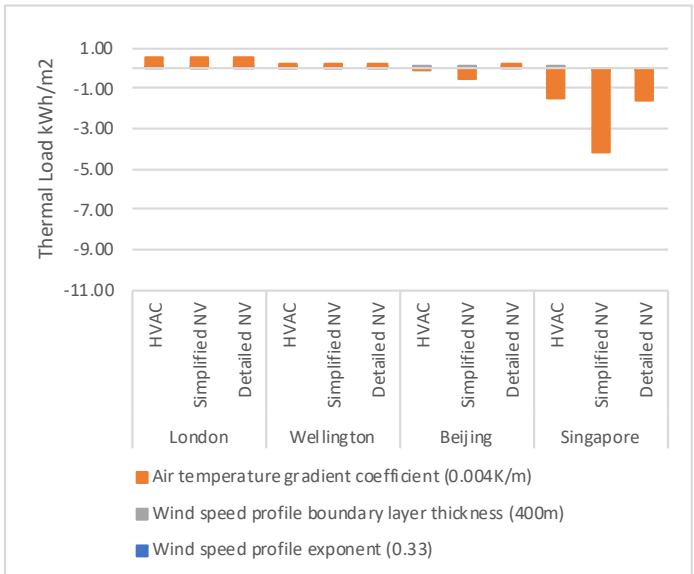

(a)

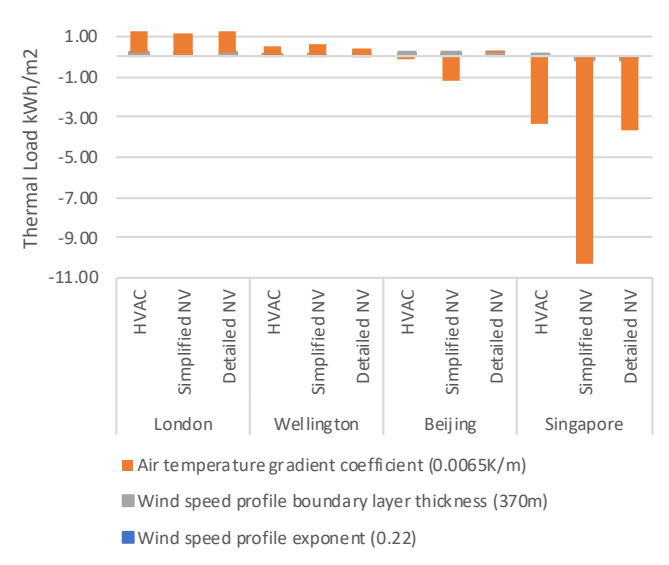

(b)

Figure 143: Annual absolute changes at the $33^{\text {rd }}$ floor due to (a) height variation precision and (b) height variation of terrain in four cities with three ventilation systems

At the lower floor the influence of the wind speed profile exponent is bigger than the air temperature gradient coefficient. At the higher floor the influence of the air temperature gradient coefficient is bigger than the wind speed profile exponent. The influence of the wind speed profile boundary layer thickness is negligible.

\subsection{Priority of Urban Microclimate Parameters in Different Climates}

This section analyses the priority of parameters under different climatic conditions. Figure 144 shows the annual thermal load changes due to modelling parameters in the climate of four cities and the HDD and CDH of the four cities. From left to right is January to December in London, Beijing and Singapore. In Wellington from left to right is July to June to keep the order of the seasons.

In London main thermal loads are heating loads in winter. The UHI reduces heating load prediction through raising the environmental temperature. In London's climate the most important parameter of urban microclimate modelling is the UHI. The second one is urban wind. Then the importance of adjusted height variations, multilayer modelling method, and suburban air temperature gradient coefficient are similar. The influence of other parameters is very small.

The climate in Wellington is similar to that in London. Main thermal loads are also heating loads in Wellington. However, heating loads in Wellington are less than in London. In Wellington's climate, the UHI has the biggest effects on the thermal load prediction. The second one is urban wind. Then the importance of adjusted height variations, multilayer modelling method, and suburban air temperature gradient coefficient are similar. The influence of other parameters is very small. 


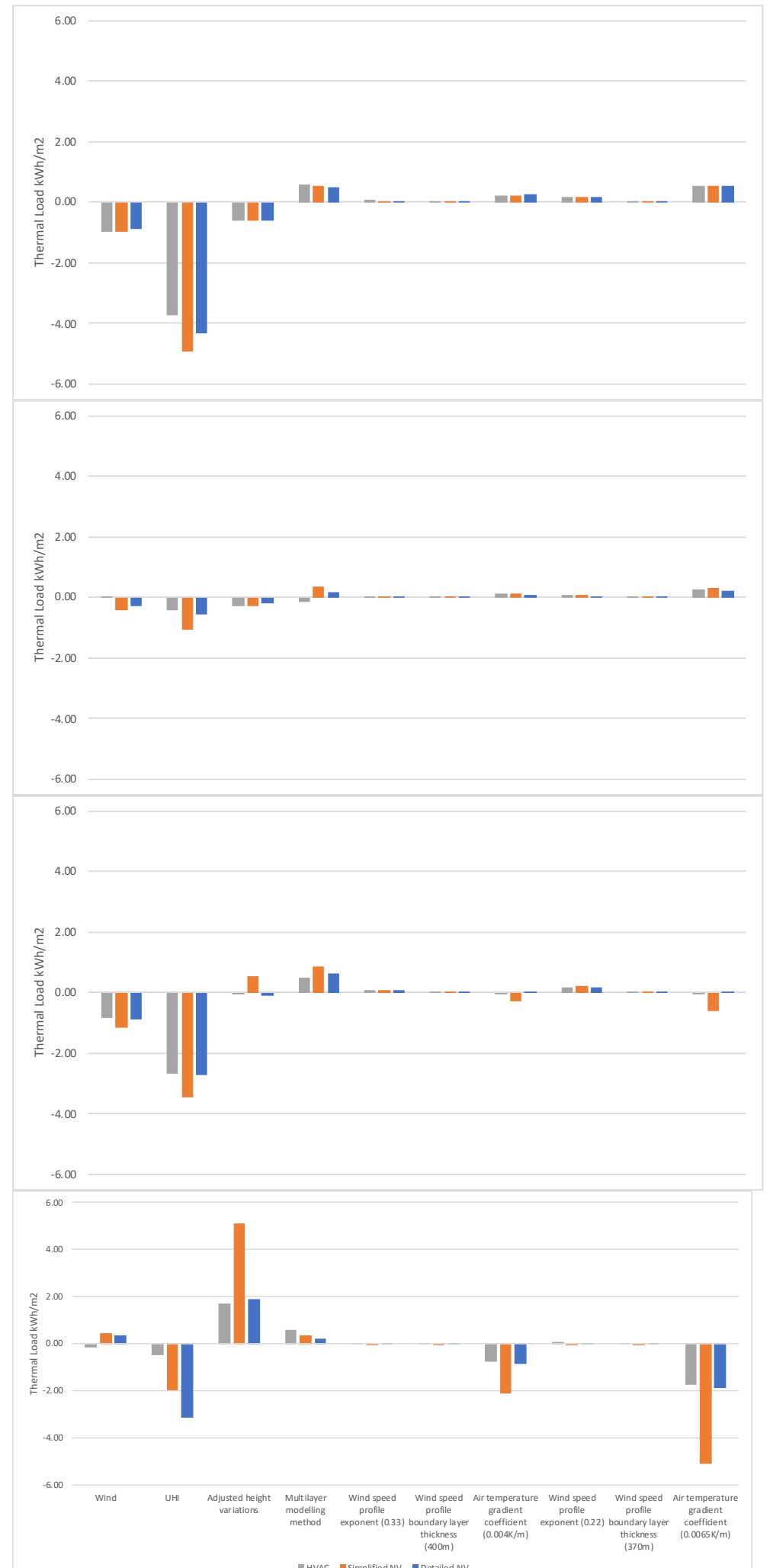

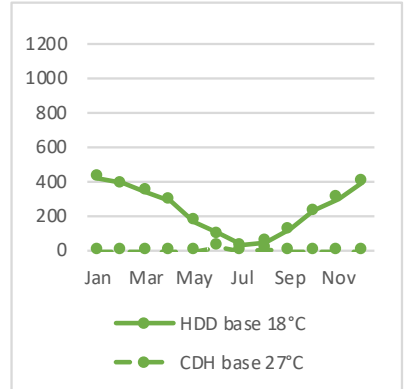

London climate

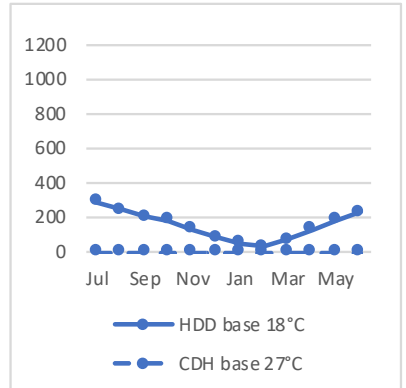

Wellington climate

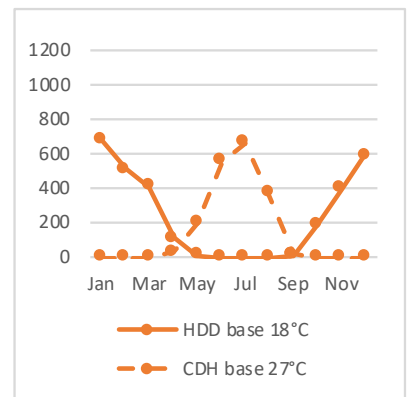

Beijing climate

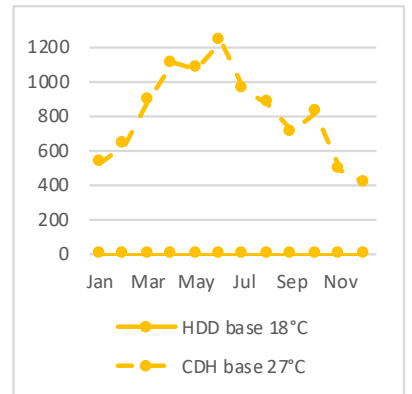

Singapore climate

Figure 144: Annual thermal load changes due to urban microclimate parameters and relative climates $\mathrm{HDD}$ and $\mathrm{CDH}$

The climate of Beijing is different from that of London and Wellington. It has high cooling loads in summer and high heating loads in winter. Heating loads in Beijing are higher than in London. In Beijing's climate, the most important parameter is the UHI. 
However, the annual thermal load changes due to the UHI in Beijing's climate are less than in London's climate. The UHI reduces heating loads in winter, but it increases cooling loads in summer. In Beijing's climate the heating load reduction and the cooling load increase in prediction cancel each other out. Hence, the annual thermal load changes in Beijing are not as high as in London. The second one is urban wind and the third one is the multilayer modelling method. The influence of other parameters is very limited.

In Singapore there are only cooling loads and the cooling loads are extremely high. In Singapore's climate the most important parameters are adjusted height variations and suburban air temperature gradient coefficient. The second one is the UHI and the third one is the precision of urban air temperature gradient coefficient.

\begin{tabular}{|c|c|c|c|c|c|c|c|c|c|c|c|c|}
\hline \multirow{2}{*}{$\begin{array}{l}\text { Thermal load changes } \\
\left(\mathrm{kWh} / \mathrm{m}^{2)}\right.\end{array}$} & \multicolumn{3}{|c|}{ London } & \multicolumn{3}{|c|}{ Wellington } & \multicolumn{3}{|c|}{ Beijing } & \multicolumn{3}{|c|}{ Singapore } \\
\hline & HVAC & $\begin{array}{l}\text { Simplified } \\
\text { NV }\end{array}$ & Detailed NV & HVAC & $\begin{array}{l}\text { Simplified } \\
\text { NV }\end{array}$ & Detailed NV & HVAC & $\begin{array}{l}\text { Simplified } \\
\text { NV }\end{array}$ & Detailed NV & HVAC & $\begin{array}{l}\text { Simplified } \\
\text { NV }\end{array}$ & Detailed NV \\
\hline Wind & \begin{tabular}{l|l|}
-0.96 \\
\end{tabular} & \begin{tabular}{l|l|l|}
6 & -0.98 \\
\end{tabular} & \begin{tabular}{|l|l|l|} 
& -0.89 \\
\end{tabular} & 0.01 & \begin{tabular}{l|l|l|}
1 & -0.42 \\
\end{tabular} & \begin{tabular}{|l|l|} 
& -0.30 \\
\end{tabular} & -0.82 & \begin{tabular}{|l|l|}
2 & -1.14 \\
\end{tabular} & \begin{tabular}{|l|l|} 
& -0.88 \\
\end{tabular} & -0.16 & \begin{tabular}{l|l|}
5 & 0.46 \\
\end{tabular} & \begin{tabular}{|l|l|}
5 & 0.35 \\
\end{tabular} \\
\hline \begin{tabular}{|l|l}
$\mathrm{HI}$ \\
\end{tabular} & -3.72 & -4.94 & -4.33 & -0.43 & -1.06 & -0.58 & -2.66 & -3.44 & -2.70 & -0.48 & -1.99 & -3.14 \\
\hline \begin{tabular}{|l|} 
Adjusted height variations \\
\end{tabular} & -0.62 & -0.60 & -0.63 & -0.29 & -0.31 & -0.22 & -0.06 & 0.53 & -0.12 & 1.72 & 5.11 & $1.8 \mathrm{~s}$ \\
\hline Multilayer modelling method & 0.59 & 0.54 & 0.48 & -0.16 & 0.38 & 0.18 & 0.50 & 0.85 & 0.62 & 0.60 & 0.37 & 0.20 \\
\hline $\begin{array}{l}\text { Wind speed profile exponent } \\
(0.33)\end{array}$ & 0.06 & 0.05 & 0.05 & 0.03 & 0.02 & 0.01 & 0.06 & 0.06 & 0.06 & 0.03 & -0.01 & 0.01 \\
\hline $\begin{array}{l}\text { Wind speed profile boundary } \\
\text { layer thickness }(400 \mathrm{~m})\end{array}$ & 0.04 & 0.04 & 0.03 & 0.02 & 0.02 & 0.01 & 0.04 & 0.04 & 0.04 & 0.02 & -0.01 & 0.00 \\
\hline $\begin{array}{l}\text { Air temperature gradient } \\
\text { coefficient }(0.004 \mathrm{~K} / \mathrm{m})\end{array}$ & 0.24 & 0.22 & 0.25 & 0.11 & 0.12 & 0.08 & -0.01 & -0.27 & 0.02 & -0.78 & -2.10 & -0.8 \\
\hline $\begin{array}{l}\text { Wind speed profile exponent } \\
(0.22)\end{array}$ & 0.17 & 0.15 & 0.16 & 0.09 & 0.07 & 0.04 & 0.17 & 0.19 & 0.19 & 0.08 & -0.02 & 0.02 \\
\hline $\begin{array}{l}\text { Wind speed profile boundary } \\
\text { layer thickness }(370 \mathrm{~m})\end{array}$ & 0.05 & 0.04 & 0.05 & 0.03 & 0.02 & 0.01 & 0.05 & 0.05 & 0.05 & 0.02 & -0.01 & 0.00 \\
\hline \begin{tabular}{|l} 
Air temperature gradient \\
coefficient $(0.0065 \mathrm{~K} / \mathrm{m})$
\end{tabular} & 0.55 & 0.53 & 0.56 & 0.24 & 0.29 & 0.20 & -0.01 & -0.61 & 0.04 & -1.75 & -5.09 & -1.89 \\
\hline
\end{tabular}

(a)

\begin{tabular}{|c|c|c|c|c|c|c|c|c|c|c|c|c|}
\hline \multirow[b]{2}{*}{ Percentage changes (\%) } & \multicolumn{3}{|c|}{ London } & \multicolumn{3}{|c|}{ Wellington } & \multicolumn{3}{|c|}{ Beijing } & \multicolumn{3}{|c|}{ Singapore } \\
\hline & HVAC & $\begin{array}{l}\text { Simplified } \\
\text { NV }\end{array}$ & Detailed NV & HVAC & $\begin{array}{l}\text { Simplified } \\
\text { NV }\end{array}$ & Detailed NV & HVAC & $\begin{array}{l}\text { Simplified } \\
\text { NV }\end{array}$ & Detailed NV & HVAC & $\begin{array}{l}\text { Simplified } \\
\text { NV }\end{array}$ & Detailed NV \\
\hline Wind & $-3.2 \%$ & $6 \quad-4.2 \%$ & $-3.6 \%$ & $0.4 \%$ & 6 $-6.7 \%$ & $-4.6 \%$ & $-1, b \%$ & $-1.1 .9 \%$ & $-11 \%$ & $-0.1 \% \%$ & $0 . \dot{\beta} \%$ & $0.2 \%$ \\
\hline \begin{tabular}{|l|l|}
$U H I$ \\
\end{tabular} & $-12.3 \%$ & $-20.8 \%$ & $-17 . \%$ & $-4.4 \%$ & $-16.8 \%$ & $-8.9 \%$ & $-3.2 \%$ & $5.7 \%$ & $-4.6 \%$ & $-0.2 \%$ & $-1, \frac{1}{2} \%$ & $-1,6 \%$ \\
\hline \begin{tabular}{|l|} 
Adjusted height variations \\
\end{tabular} & $-2,4 \%$ & $-2.6 \%$ & $-2.6 \%$ & $-2.9 \%$ & $-4.9 \%$ & $-3.3 \%$ & $-0.1 \%$ & $0.0 \%$ & $-0.2 \%$ & $0.8 \%$ & $2.8 \%$ & $0.9 \%$ \\
\hline Multilayer modelling method & $2.0 \%$ & $2.3 \%$ & $2.0 \%$ & $-1 \% \%$ & $6.0 \%$ & $2.7 \%$ & $0.6 \%$ & 1. $\%$ & $0.9 \%$ & $0 . \beta \%$ & $0.2 \%$ & $0.1 \%$ \\
\hline $\begin{array}{l}\text { Wind speed profile exponent } \\
(0.33)\end{array}$ & $0.2 \%$ & $0.2 \%$ & $0.2 \%$ & $0.4 \%$ & $0.4 \%$ & $0.2 \%$ & $0.1 \%$ & $0.1 \%$ & $0.1 \%$ & $0 . p \%$ & $0 . p \%$ & $0.0 \%$ \\
\hline $\begin{array}{l}\text { Wind speed profile boundary } \\
\text { layer thickness }(400 \mathrm{~m}) \\
\end{array}$ & $0 . h \%$ & $0.2 \%$ & $0.1 \%$ & $0 . p \%$ & $0.3 \%$ & $0.4 \%$ & $0.0 \%$ & $0.1 \%$ & $0.1 \%$ & $0 . p \%$ & $0.0 \%$ & $0 . p \%$ \\
\hline $\begin{array}{l}\text { Air temperature gradient } \\
\text { coefficient }(0.004 \mathrm{~K} / \mathrm{m})\end{array}$ & $0.8 \%$ & $0.9 \%$ & 1. $6 \%$ & 1. $\%$ & $1.9 \%$ & $1.3 \%$ & $0.6 \%$ & $-0.5 \%$ & $0.0 \%$ & $-0.8 \%$ & $-1,2 \%$ & $-0.4 \%$ \\
\hline $\begin{array}{l}\text { Wind speed profile exponent } \\
(0.22)\end{array}$ & $0.6 \%$ & $0.6 \%$ & $0.7 \%$ & $0.6 \%$ & $1.2 \%$ & $0.6 \%$ & $0.2 \%$ & $0.3 \%$ & $0 . \beta \%$ & $0 . p \%$ & $0.0 \%$ & $0.6 \%$ \\
\hline $\begin{array}{l}\text { Wind speed profile boundary } \\
\text { layer thickness }(370 \mathrm{~m})\end{array}$ & $0.2 \%$ & $0.2 \%$ & $0.2 \%$ & $0.8 \%$ & $0.3 \%$ & $0 .+\%$ & $0.1 \%$ & $0.1 \%$ & $0.1 \%$ & $0 . p \%$ & $0.0 \%$ & $0.6 \%$ \\
\hline \begin{tabular}{|l|} 
Air temperature gradient \\
coefficient $(0.0065 \mathrm{~K} / \mathrm{m})$
\end{tabular} & $1.8 \%$ & $2.2 \%$ & $2.8 \%$ & $2.5 \%$ & $4.7 \%$ & $3.6 \%$ & $0.0 \%$ & $-1 . b \%$ & $0.1 \%$ & $-0.8 \%$ & $-2.8 \%$ & $-0 . p \%$ \\
\hline
\end{tabular}

(b)

Figure 145: a) annual thermal load absolute changes b) annual thermal load percentage changes in different climate regions due to individual urban microclimate parameters

Figure 145 shows the annual absolute and percentage changes due to individual urban microclimate parameters. In London's climate and Beijing's climate, their annual absolute changes are similar. However, the percentage changes in London's climate are much bigger than those in Beijing's climate (Figure 145a). The UHI makes a more than $10 \%$ changes in London's climate, and in Wellington's climate when using the simplified natural ventilation system. The UHI should be modelled in London. In reality, 
Wellington doesn't have the UHI effects. Urban winds in Wellington should be taken into consideration because there is an around 5\% change due to urban winds with natural ventilation systems (Figure 145b).

\begin{tabular}{|c|c|c|c|c|c|c|c|c|c|c|c|c|}
\hline \multirow{2}{*}{$\begin{array}{l}\text { Thermal load changes } \\
\left(\mathrm{kWh} / \mathrm{m}^{2}\right)\end{array}$} & \multicolumn{3}{|c|}{ London } & \multicolumn{3}{|c|}{ Wellington } & \multicolumn{3}{|c|}{ Beijing } & \multicolumn{3}{|c|}{ Singapore } \\
\hline & HVAC & $\begin{array}{l}\text { Simplified } \\
\text { NV }\end{array}$ & Detailed NV & HVAC & $\begin{array}{l}\text { Simplified } \\
\text { NV }\end{array}$ & Detailed NV & HVAC & $\begin{array}{l}\text { Simplified } \\
\text { NV }\end{array}$ & Detailed NV & HVAC & $\begin{array}{l}\text { Simplified } \\
\text { NV }\end{array}$ & Detailed NV \\
\hline $\mathrm{UHI}$ & 3.72 & \begin{tabular}{|l|l|l|} 
& -4.94 \\
\end{tabular} & \begin{tabular}{l|l}
-4.33 \\
\end{tabular} & \begin{tabular}{|l|l|l|l|l|} 
& -0.43 \\
\end{tabular} & -1.06 & -0.58 & -2.66 & -3.44 & -2.70 & -0.48 & $\begin{array}{l:l} & -1.99 \\
\end{array}$ & -3.14 \\
\hline UHI+Wind & 4.57 & -5.58 & 4.99 & -0.12 & -1.27 & -0.74 & -3.16 & -4.29 & -3.37 & -0.68 & -1.52 & -2.79 \\
\hline UHI+Wind+HV & 5.09 & -6.54 & -6.07 & 0.64 & -1.58 & -1.08 & -3.46 & -3.77 & -3.78 & 1.62 & 5.34 & -0.18 \\
\hline UHI+Wind+HV+Multilayer modelling method & 4.60 & -5.64 & -5.14 & -0.57 & -1.20 & -0.78 & -2.73 & -2.92 & -2.87 & 1.64 & 3.96 & -0.70 \\
\hline
\end{tabular}

\begin{tabular}{|c|c|c|c|c|c|c|c|c|c|c|c|c|}
\hline \multirow[b]{2}{*}{ Percentage changes $(\%)$} & \multicolumn{3}{|c|}{ London } & \multicolumn{3}{|c|}{ Wellington } & \multicolumn{3}{|c|}{ Beijing } & \multicolumn{3}{|c|}{ Singapore } \\
\hline & HVAC & $\begin{array}{l}\text { Simplified } \\
\text { NV }\end{array}$ & Detailed NV & HVAC & $\begin{array}{l}\text { Simplified } \\
\text { NV }\end{array}$ & Detailed NV & HVAC & $\begin{array}{l}\text { Simplified } \\
\text { NV }\end{array}$ & Detailed NV & J HVAC & Simplified & Detailed NV \\
\hline $\mathrm{UHI}$ & $-12.3 \%$ & $-20.9 \%$ & $-17.7 \%$ & $-4.4 \%$ & $-16.8 \%$ & $-8.9 \%$ & $-3.2 \%$ & $-5.7 \%$ & $-4.0 \%$ & $-0.2 \%$ & $-1.1 \%$ & -1.6\% \\
\hline UHI+Wind & $-15.1 \%$ & $-23.6 \%$ & $-20.4 \%$ & -1.2 㻤 & $-20.2 \%$ & $-11.3 \%$ & $-3.8 \%$ & $-7.2 \%$ & $-5.0 \%$ & $-0.3 \%$ & $-0.8 \%$ & $-1.4 \%$ \\
\hline UHI+Wind+HV & $-17.2 \%$ & $-26.2 \%$ & $-22.9 \%$ & $-4.1 \%$ & $-25.2 \%$ & $-14.6 \%$ & $-3.92 \%$ & $-6.3 \%$ & $-5.2 \%$ & $0.5 \%$ & $2.0 \%$ & $-0.4 \%$ \\
\hline UHI+Wind+HV+Multilayer modelling method & $-15.2 \%$ & $-23.9 \%$ & $-21.0 \%$ & $-5.8 \%$ & $-19.2 \%$ & $-11.9 \%$ & $-3.3 \%$ & $-4.9 \%$ & $-4.2 \%$ & $0.7 \%$ & $2.2 \%$ & $-0.3 \%$ \\
\hline
\end{tabular}

(b)

Figure 146: a) annual thermal load absolute changes b) annual thermal load percentage changes in different climate regions due to combined effects

Figure 146 shows the annual absolute and percentage changes due to the combined effects of urban microclimate parameters. The combined effects in London's climate and in Wellington's climate are notable (up to 20\%). In London and Wellington, detailed urban microclimates should be modelled. However, in Beijing's climate and Singapore's climate, the combined effects are negligible using an HVAC system (Beijing less than 5\%, Singapore less than 1\%) and small using natural ventilation systems (Beijing less than 7.5\%, Singapore less than 2.5\%). Figure 146 only shows the annual results, and the relative smaller annual data does not mean that the monthly data is small In Beijing and Singapore, the level of detailed modelling should depend on the requirements of engineers and their monthly information. If they have time and require accurate results, detailed modelling is recommended.

The priority of parameters in London's climate and Wellington's climate are similar, because they both have a moderate climate. The biggest influence is from the UHI and the second one is urban wind. In a windy climate, the effects of urban winds are bigger than in other climates. In moderate climates, the adjusted height variations and multilayer modelling method, as well as suburban air temperature gradient coefficient have a similar effect on the building performance simulation.

In a continental climate, the UHI plays the most important role. The second one is urban wind and the third one is the multilayer modelling method. Other parameters have very small annual changes. However, the monthly changes in Beijing are big. Height variations of urban microclimates have opposite effects in summer and winter. Hence, they cancel each other out and annual changes are very small. 
In a tropical climate, the percentage changes of thermal loads are usually very small because the basic thermal loads are extremely high. The most important parameters in Singapore are the adjusted height variations and suburban air temperature gradient coefficient. The second one is the UHI. Urban winds have a very small influence in Singapore's climate.

Overall, it is worthwhile to develop a simulation system to model urban microclimate in detail under different climate conditions. The importance of each parameter varies in different climatic conditions. The effects of detailed modelling of urban microclimates also vary from season to season and are related with height. According to simulation results, engineers can use different strategies in different climates. In a moderate, developing the simulation system is recommended. In a windy climate, the effects of urban winds are bigger than in other climates. In a continental climate, there is a big difference in the monthly thermal load prediction. It helps engineers optimize the design of heating in winter and cooling in summer. In a tropical climate, air temperature gradient should be modelled. Developing the simulation system of urban microclimate helps engineers understand the effects of each parameters. The priority of parameters is not the same in different climates. Therefore, it is necessary to develop the simulation system in different climates. 


\section{CHAPTER 9. CONCLUSIONS}

\subsection{Research Conclusions}

This research aimed to explore the necessity of urban microclimate detailed modelling. The necessity is based on the size of the impact of urban microclimate detailed modelling on building performance simulation. Two goals have been achieved to address this research question:

1) Build a simulation system that can be used to report the likely impact of microclimates;

2) Make an estimate of the likely scale of the microclimate effects, based on annual simulations and accounting for the three-dimensional effects of urban environments on wind and temperature.

The research had three Phases: Phases A and B built the simulation system for the first goal; Phase $\mathrm{C}$ estimated the microclimate effects for the second goal.

Phase A - Review urban microclimates and modelling techniques.

Phase B - Develop a trustworthy simulation system to model the effect of urban microclimates on building performance.

Phase $\mathrm{C}$ - Analyse the impacts of urban microclimates on high-rise office buildings Before developing the urban microclimate simulation system, Phase A illustrated urban microclimate parameters and prepared the appropriate modelling techniques for Phase B. Phase B modelled each urban microclimate parameter, strung the individual programs together, and then developed the simulation system. Phase $\mathrm{C}$ estimated the scale of urban microclimate detailed modelling effects in different climates and demonstrated the necessity of developing a simulation system to model urban microclimate in detail.

Phase A-Review urban microclimates and modelling techniques.

- What are the features of a three-dimensional urban microclimate model?

- What are the requirements for selecting appropriate modelling techniques?

- Are the modelling techniques reliable? 
A systematic literature review revealed that few studies had comprehensively considered such factors as UHI, urban wind, Lapse Rate, and urban wind profile. A large number of studies focused on the influence of individual features, and some studies focused on the combined effects of two features. This research built a threedimensional model of urban microclimates, and explored wind and temperature related features. The features were modelled together by developing a simulation system.

Urban Heat Island (UHI) and urban winds are the horizontal difference between urban and rural areas. Lapse Rate and urban wind profile are the vertical variations of urban microclimates. The UHI and Lapse Rate determine the three-dimensional temperature field in urban areas. Urban winds and urban wind profile determine the threedimensional wind field in urban areas. UHI, urban winds, Lapse Rate and urban wind profile are the features of the three-dimensional urban microclimate model studied in this research.

The research linked individual tools to develop a simulation system for comprehensive urban microclimate modelling. One reason for the lack of comprehensive studies on urban microclimates is the lack of available simulation tools. Modelling programs typically described one or two features of urban microclimate. There were only independent simulation tools, and none of them were comprehensive.

Urban Weather Generator (UWG) and ENVI-met can model urban temperature. OpenFOAM, Autodesk CFD and UrbaWind can model urban winds. UWG was used to model the UHI effects because it can predict the UHI for a whole year at hourly intervals. The outputs of UWG were the inputs of energy simulation programs. ENVImet could not meet these requirements. OpenFOAM was used instead of Autodesk CFD and UrbaWind because the difference between OpenFOAM and the wind tunnel data was smaller than that between the other two programs and the wind tunnel data. In addition to minor differences, OpenFOAM is capable of setting up flexible conditions for a wind tunnel. Defining the location of measurement points was necessary because, for detailed natural ventilation, the wind pressure coefficients on windows should be measured. However, Autodesk CFD could not be configured to define the location of measurement points. Wind profile modelling is carried out for the three-dimensional wind field. UrbaWind could not be configured to input selected inlet wind speed and turbulence profiles. Compared with Autodesk CFD and UrbaWind, OpenFOAM can 
define the meshing methodology and turbulence model, which is appropriate for this research.

UWG and OpenFOAM met the requirement of modelling the UHI and urban winds. Besides, they should have the compatibility. These individual programs can be linked up by the Visual Programming Language, Grasshopper. That is because Grasshopper, a plugin of Rhino which is a three-dimensional model program, provided a platform for UWG, OpenFOAM, and EnergyPlus. The three programs had corresponding Grasshopper plugins, UWG with Dragonfly, OpenFOAM with Butterfly, EnergyPlus with Ladybug and Honeybee. The platform of Grasshopper linked the three programs through their plugins. The platform made it possible to share the information among the three programs. For example, the output of UWG was the input of EnergyPlus.

UWG and OpenFOAM were picked to model urban microclimates, and EnergyPlus to predict building performance, because they could be linked via Grasshopper plugins. The reliability of these programs was verified by comparing simulation results with experimental data. The reliability of individual programs determined the feasibility of establishing urban microclimate models in a way that produced reliable predictions.

The UHI predicted by UWG is within the range of measurement data of London. Therefore, this established a level of trust of the predictions of UWG model in this study. The verification of OpenFOAM was divided into two parts: wind speeds and wind pressure coefficients. Wind speeds were associated with urban microclimate modelling, and wind pressure coefficients were associated with the detailed natural ventilation system. The weakness of wind speed modelling was the wake flow simulation. In this research, the average wind speed was taken as the urban wind speed, and the wind profile was the windward profile. Therefore, the influence of inaccurate wake flow calculation was limited. The wind pressure coefficients were related to detailed natural ventilation. Compared with wind tunnel data, the simulation results of the wind pressure coefficient were slightly underestimated. Thermal loads of the EnergyPlus model were compared with measurement data from a high-rise commercial building in Auckland. The simulation results of EnergyPlus model matched the real data well.

The research verified the reliability of the three programs. UWG and OpenFOAM were used for urban microclimate modelling. EnergyPlus was used for building performance 
calculations. Dragonfly, butterfly, honeybee and ladybug are interfaces to UWG, OpenFOAM, and EnergyPlus (Section 2.3). They enabled the modelling programs to be linked together in a single system. Individual tools were prepared, and they were used as components to build the simulation system.

Phase B - Develop a trustworthy simulation system to model the effect of urban microclimates on building performance.

- What is the case study used in this research?

- How do the horizontal parameters, vertical variations of urban microclimate and a multilayer modelling method influence the building performance prediction?

- How does urban microclimate detailed modelling influence natural ventilation systems?

The research took a real city and a prototypical high-rise office building as a case study. Taking a real city as the case study was because the weather information about a real city was exhaustive. Taking a prototypical high-rise office building as the case study was because it could represent common high-rise office buildings. A real high-rise office building was not used as the case study because it contains details that are too specific to be generalisable such as specific materials and irregular geometry. A real building with detailed data could not represent common high-rise office buildings. The City of London is a borough at the centre of the Greater London Metropolitan area. It was used as the case study city. The geometric data of the prototypical high-rise office building was based on the top 32 London's tallest office buildings over $100 \mathrm{~m}$ in 2016. The basic building performance model of the prototypical high-rise office building was based on the large office of Pacific Northwest National Laboratory.

The rural weather data collected from Gatwick Airport was the baseline. The UHI was calculated by the UWG based on the urban configuration of the City of London. This is because the Greater London is too large and most of the area is rural, and the City of London is densely populated. The City of London is in the central area and there are many high-rise office buildings there. The prototypical high-rise office building was modelled by selecting three representative floors following the NREL modelling recommendations developed for the Freedom Tower (Ellis \& Torcellini, 2005). 
The first stage demonstrated the importance of horizontal parameters of urban microclimate modelling. The research found that compared with rural weather data, UHI effects generated a more than $10 \%$ difference in building performance prediction, while urban winds generated a less than $5 \%$ difference. The difference expanded to around 15\% when putting UHI effects and urban winds together. The influence increased with modelling precision and with height in London. The thermal load difference between rural and urban weather data for upper floors was more obvious than that for lower floors. Even a very slight influence due to urban winds increased from $2 \%$ at the bottom floor to $4 \%$ at the top floor. Compared with HVAC systems, the thermal loads with both rural and urban weather data decreased dramatically when natural ventilation systems are used. Natural ventilation efficiency was affected by urban microclimates and height. The influence of the UHI, urban winds and height on natural ventilation systems is greater than that on HVAC systems. Although the effects on HVAC systems were less than on natural ventilation systems. They were large enough that urban microclimates should be modelled in detail when using HVAC systems and natural ventilation systems.

The second stage demonstrated the necessity of modelling the vertical variations of urban microclimate. The building performance varied with height, and microclimate changed with height as well. In this research the height variations of microclimate were addressed by Wind Speed Profile Exponent, Wind Speed Profile Boundary Layer Thickness and Air Temperature Gradient Coefficient (Section 5.5.4). The effects of vertical variations were worth investigating because the results changed when importing those parameters into building performance simulation, especially at higher floors.

The research found that vertical variations had a greater impact on building performance in urban areas than in rural areas. Vertical variations of rural microclimates increased thermal load predictions slightly. However, vertical variations of urban microclimates reduced thermal load predictions. At a lower floor, the vertical variations of wind speed had a greater influence than those of temperature gradient. While at a higher floor, the air temperature gradient had a big influence on the simulation results, and the influence increases with height. The accuracy of boundary layer thickness also did not have a significant influence on building performance predictions. Hence, engineers should pay more attention the wind speed profile 
exponent and the boundary layer thickness when simulating building performance of a low-rise building. However, for a high-rise building, vertical variations of urban microclimates should be considered, especially the temperature gradient coefficient.

The process of analysing parameters of urban microclimate three-dimensional model was also the process of developing the simulation system. The research found that the simulation system was capable of modelling the effects of UHI, urban wind, microclimatic vertical variations, natural ventilation system and height on building performance simulation. This natural ventilation system was simplified natural ventilation and the vertical variations of microclimate were constant.

To model a specified urban microclimate just around a high-rise building, wind pressure coefficients were introduced, and they were imported into a detailed natural ventilation system. Both temperature and detailed natural ventilation were mixed-mode ventilation systems. The detailed natural ventilation system improved natural ventilation efficiency in spring and autumn, by approximately $10 \%$ to $30 \%$. The influence of wind related features on detailed natural ventilation system was smaller than that of temperature related features.

The third stage developed a multilayer modelling method. In rural areas vertical variations of microclimates are constant. Vertical variations of urban microclimates are not constant. The inconsistent vertical variation in urban areas was divided into two layers by the urban canopy, a lower portion in the Urban Canopy Layer (UCL) and an upper portion in the Urban Boundary Layer (UBL). It is because the UBL portion is more like rural microclimates. The prototypical high-rise office building was split at the height of UCL. The portion in the UCL was around 1/4 the height of the high-rise office building, and the portion in the UBL was around 3/4 the height.

The research found microclimatic vertical variations increase thermal load predictions in the UCL and decrease thermal load predictions in the UBL. Detailed natural ventilation was more efficient in the UBL than that in the UCL. In the UCL, the multilayer modelling method had similar results to the single-layer modelling method. In the UBL, the thermal loads of the multilayer modelling method were higher than those of the single-layer modelling method in most of the year.

The multilayer urban microclimate modelling method had a bigger effect on the simulation using natural ventilation systems than that using an HVAC system. The 
annual thermal load change due to the multilayer modelling method was quite small, because the increase in the UCL and the decrease in the UBL canceled each other out. It is not recommended to build a multilayer model when considering annual thermal load changes which is less than $4 \%$. Only if there is enough time, engineers can build a multilayer urban microclimate model to help them predict and improve building performance for different floors, especially when using natural ventilation systems.

In this research, an urban microclimate simulation system was successfully developed. The goal was to determine what is the scale of the likely microclimate effects on energy performance and study the necessity of detailed modelling of each urban microclimate effect, not to present a system that precisely predicts how microclimate varies. The system was developed to study the relative effect on tall building performance of the detailed modelling of each urban microclimate effect. The goal was not to predict absolute values that could be compared to real measurements. Having identified those microclimate effects that have a significant effect on building performance in this study, a follow-on study will be needed to validate the predictions of the combined system against real measurements. The research started with modelling the UHI, urban winds, and vertical variations, then the multilayer modelling method. The comprehensive simulation system was built step by step and the urban microclimate effects on building performance were illustrated piece by piece. The urban microclimate simulation system was developed using the geometry and climate of the City of London. Then the research evaluated the case by testing the case study conclusions in the climate of other cities.

\section{Phase C-Analyse the impacts of urban microclimates on high-rise office buildings}

- Is the impact of urban microclimate detailed modelling on building performance prediction important enough to develop a simulation system?

- What is the priority of urban microclimate parameters in different climates?

The necessity of urban microclimate detailed modelling has been proved in the climate of London. London has a moderate climate. The simulation system worked well in a moderate climate. Whether the London conclusions are robust in other climates was studied. The research also studied the effects of urban microclimate detailed modelling on windy, continental, and tropical climates. Wellington is windy and moderate. Beijing has a continental climate, and Singapore has a tropical climate. The study added case study climates for Wellington, Beijing and Singapore to the existing London case 
study. The weather data of the four cities were imported. The urban configuration was based on the City of London, and since the research studied the influence of climates rather than specific cities, other conditions, such as the prototypical high-rise office building and the height variations of urban microclimates were the same.

The corresponding urban microclimates of the four climate regions were modelled. The analysis of the effects of urban microclimate detailed modelling in different climates contained three parts: 1) the urban microclimate modelling precision; 2) height variation precision for a city; 3 ) height variations of terrain. The reason of studying the influence of suburban height variations was the uneven urban density. It was found that, in addition to the urban microclimate modelling precision, the height variations of terrain are more important than the height variation precision for the city.

The annual and monthly percentage and absolute changes in building performance predictions under different climatic conditions were compared. The combined effects produced around $-25 \%$ annual change in London's climate and Wellington' climate at most. In Beijing's climate the change was around $-6 \%$ and in Singapore's climate was $2.2 \%$ at most. The annual percentage changes under a moderate climate were great. Under a continental climate, the annual percentage changes were not great, but the monthly percentage changes were great. That is because urban microclimate parameters had opposite effects in summer and winter, they cancelled each other out. The monthly data is helpful for engineers to design heating and cooling strategies. Under a tropical climate, the annual percentage changes were very small, but the absolute changes were great which are useful for the capacity design of building equipment. It is necessary to model urban microclimate in detail in different climates because the effects were different and significant.

In a moderate climate and a continental climate, the biggest influence was from the UHI and the second one was urban winds. In a moderate climate, the adjusted height variations and multilayer modelling method, as well as suburban air temperature gradient coefficient had a similar effect on the building performance simulation. In a continental climate, third one was the multilayer modelling method. Other parameters have very small annual changes. The most important parameters in a tropical climate were adjusted height variations and suburban air temperature gradient coefficient. The second one was the UHI. Urban winds had very small influence on a tropical climate. 
The priority of parameters was different in different climates. Hence, it is necessary to model urban microclimate in detail in different climates. Here is the second reason.

The combined effects due to several parameters were significant, while individual effects due to each parameter were small. Only the annual percentage changes due to the effects of the UHI in moderate climates were more than $10 \%$. The effects of urban winds and multilayer modelling method in a windy climate with simplified natural ventilation were more than $5 \%$. The effects due to urban winds in a windy climate were higher than in other climates. In moderate climates, adjusted height variations and multilayer modelling method had opposite effects. The absolute changes due to these two parameters were close, hence, they could be left out when the simulation period is limited. In a continental climate, height variations were not important when only considering annual thermal loads. In a tropical climate, the important parameters were height variations and the air temperature gradient coefficient was the most important parameter among the height variations. The microclimate modelling cannot be done systematically by simple rule of thumb adjustment, because each climate is different.

In moderate climates, urban microclimates should be modelled in detail. In windy climates, urban winds should be modelled. In continental climates, the monthly change data helps engineers optimize the design of heating in winter and cooling in summer. In tropical climate, the air temperature gradient coefficient should be modelled firstly. Developing the simulation system of urban microclimate helps engineers understand the effects of each parameters. The parameters' priorities in different climate regions are different.

In this research, an urban microclimate simulation system was developed, and the necessity of urban microclimate detailed modelling was proved. The research found that in different climates urban microclimate should be model in detail, because detailed modelling has a significant impact on building performance predictions and the priority of urban microclimates in each climate is inconsistent. The level of detailed modelling depends on the requirements of engineers. Detailed modelling is important for both mechanical and natural ventilation, and it is more important for natural ventilation systems than for an HVAC system. 


\subsection{Limitations and Future Studies}

1) The temperature gradient set in EnergyPlus can only be positive (air temperature decreases with height), however, in reality it sometimes can be negative (air temperature increases with height). In this study, the negative value cannot be explored due to the limitation of simulation tools. In the future, when EnergyPlus allows for a negative temperature gradient, its influence can be explored.

2) This research explored the influence of wind and temperature and the EnergyPlus contained the model of shading from nearby buildings on solar radiation. However, due to urban pollution, solar radiation in urban areas is different from that in rural areas. The influence of the difference in solar radiation due to urban pollution could be explored in the future.

3) This research demonstrated the necessity of modelling in detail. It does not necessarily demonstrate that the system makes a precise estimate, but it could be explored in the future.

In this research, the effects of detailed modelling in four climate regions are explored. The four climates are moderate, windy, extremely hot and cold, and tropical climates. The effects are different in different climates. In the future more climate regions could be explored, such as humid subtropical climate.

In Chapter 6, the research found the influence of wind speed exponent and relative boundary layer thickness on building performance simulation is significant at a lower floor. Are the vertical variations worth modelling for a middle-rise or low-rise building? What height is worth modelling? This research studied high-rise office buildings and used a 35 storied building (154 m) as a case study. The height of $154 \mathrm{~m}$ is high enough to be affected by vertical variations of urban microclimates. However, we do not know if a 20 storied building should model vertical variations and whether the height affected by vertical variations of urban microclimates is correlated with the height of Urban Canopy Layer. In the future, the minimum height that is affected by vertical variations could be studied. 


\section{CHAPTER 10. BIBLIOGRAPHY}

2018 Tall Building Year in Review. (2018). Skyscraper Center. http://www.skyscrapercenter.com/year-in-review/2018

2019 Tall Building Year in Review. (2019). Skyscraper Center. https://www.skyscrapercenter.com/year-in-review/2019

Act, E. P. (2005). Energy policy act of 2005. Public Law 109-58 109th Congress. https://www.govinfo.gov/content/pkg/PLAW-109publ58/html/PLAW109publ58.htm

Ai, Z. T., \& Mak, C. M. (2013). CFD simulation of flow and dispersion around an isolated building: Effect of inhomogeneous $\mathrm{ABL}$ and near-wall treatment. $\begin{array}{lll}\text { Atmospheric } & \text { Environment, } & \text { 56, }\end{array}$ https://doi.org/10.1016/j.atmosenv.2013.05.034

Ali-Toudert, F., \& Mayer, H. (2006). Numerical study on the effects of aspect ratio and orientation of an urban street canyon on outdoor thermal comfort in hot and dry climate. Building and Environment, 41(2), 94-108. https://doi.org/10.1016/j.buildenv.2005.01.013

Allegrini, J., \& Carmeliet, J. (2017). Coupled CFD and building energy simulations for studying the impacts of building height topology and buoyancy on local urban microclimates. Urban $\quad$ Climate, 21, 278-305. https://doi.org/10.1016/j.uclim.2017.07.005

Angell, J. K., Pack, D. H., Dickson, C. R., \& Hoecker, W. H. (1971). Urban Influence on Nighttime Airflow Estimated from Tetroon Flights. Journal of Applied 
Meteorology, $\quad$ 10(2), 194-204. https://doi.org/10.1175/15200450(1971)010<0194:UIONAE $>2.0 . \mathrm{CO} ; 2$

Aquino, F. L., \& Gainza, X. (2014). Understanding Density in an Uneven City, Santiago de Chile: Implications for Social and Environmental Sustainability. Sustainability, 6(9), 5876-5897. https://doi.org/10.3390/su6095876

Arnfield, A. J. (2003). Two decades of urban climate research: A review of turbulence, exchanges of energy and water, and the urban heat island. International Journal of Climatology, 23(1), 1-26. https://doi.org/10.1002/joc.859

Aude, L., \& Valery, M. (2001). Simulation of a Summer Urban Breeze Over Paris.

Barlow, J. F., Halios, C. H., Lane, S. E., \& Wood, C. R. (2015). Observations of urban boundary layer structure during a strong urban heat island event. Environmental Fluid Mechanics, 15, 1567-7419.

Boers, R., Eloranta, E. W., \& Coulter, R. L. (1984). Lidar Observations of Mixed Layer Dynamics: Tests of Parameterized Entrainment Models of Mixed Layer Growth Rate. Journal of Climate and Applied Meteorology, 23(2), 247-266. https://doi.org/10.1175/1520-0450(1984)023<0247:LOOMLD>2.0.CO;2

Bohnenstengel, S. I., Hamilton, I., Davies, M., \& Belcher, S. E. (2014). Impact of anthropogenic heat emissions on London's temperatures. Quarterly Journal of the Royal Meteorological Society, 140(679), 687-698. https://doi.org/10.1002/qj.2144

Bokwa, A. (2015). Temperature Lapse Rates in the air near the Ground in Urban and Rural Areas. Institute of Geography and Spatial Management, Jagiellonian University. 
Bornstein, R. D. (1968). Observations of the Urban Heat Island Effect in New York City. Journal of Applied Meteorology, 7(4), 575-582. https://doi.org/10.1175/1520-0450(1968)007<0575:OOTUHI>2.0.CO;2

Bourbia, F., \& Boucheriba, F. (2010). Impact of street design on urban microclimate for semi arid climate (Constantine). Renewable Energy, 35(2), 343-347. https://doi.org/10.1016/j.renene.2009.07.017

Boyano, A., Hernandez, P., \& Wolf, O. (2013). Energy demands and potential savings in European office buildings: Case studies based on EnergyPlus simulations. Energy and Buildings, 65, 19-28. https://doi.org/10.1016/j.enbuild.2013.05.039

Bozonnet, E., Musy, M., Calmet, I., \& Rodriguez, F. (2015). Modeling methods to assess urban fluxes and heat island mitigation measures from street to city scale. International Journal of Low-Carbon Technologies, 10(1), 62-77. https://doi.org/10.1093/ijlct/ctt049

Bruno, B., Leslie, N., \& Julia, H. (2012). The urban weather generator.

Brunt, D. (1933). The adiabatic lapse-rate for dry and saturated air. Quarterly Journal of the Royal Meteorological Society, 59(252), 351-360. https://doi.org/10.1002/qj.49705925204

Bruse, M., \& Fleer, H. (1998). Simulating surface-plant-air interactions inside urban environments with a three dimensional numerical model. Environmental Modelling \& Software, 13(3), 373-384. https://doi.org/10.1016/S13648152(98)00042-5

Bueno, B., Hidalgo, J., Pigeon, G., Norford, L., \& Masson, V. (2012). Calculation of Air Temperatures above the Urban Canopy Layer from Measurements at a 
Rural Operational Weather Station. Journal of Applied Meteorology and Climatology, 52(2), 472-483. https://doi.org/10.1175/JAMC-D-12-083.1

Bueno, B., Norford, L., Hidalgo, J., \& Pigeon, G. (2013). The urban weather generator. Journal of Building Performance Simulation, 6(4), 269-281. https://doi.org/10.1080/19401493.2012.718797

Building height restrictions. (2017, July 26). JAPAN PROPERTY CENTRAL. http://japanpropertycentral.com/real-estate-faq/building-height-restrictions/

Calis, H. P. A., Nijenhuis, J., Paikert, B. C., Dautzenberg, F. M., \& van den Bleek, C. M. (2001). CFD modelling and experimental validation of pressure drop and flow profile in a novel structured catalytic reactor packing. Chemical Engineering Science, 56(4), 1713-1720. https://doi.org/10.1016/S00092509(00)00400-0

Caniot, G., Li, W., \& Dupont, G. (2011). Validations and applications of a CFD tool dedicated to wind assessment in urban areas. 13th International Conference on Wind Engineering. https://www.scribd.com/document/216735662/Validationsand-applications-of-a-CFD-tool-dedicated-to-wind-assessment-in-urban-areas

Cao, A., Li, Q., \& Meng, Q. (2015). Effects of Orientation of Urban Roads on the Local Thermal Environment in Guangzhou City. Procedia Engineering, 121, 20752082. https://doi.org/10.1016/j.proeng.2015.09.209

Chandler, T. J. (1965). The climate of London. Hutchinson. https://www.abebooks.com/CLIMATE-LONDON-CHANDLER-Thutchinson-1965/65397009/bd

Chang, C.-H., \& Meroney, R. N. (2001). Numerical and physical modeling of bluff body flow and dispersion in urban street canyons. Journal of Wind Engineering 
and Industrial Aerodynamics, $\quad$ 89(14), 1325-1334.

https://doi.org/10.1016/S0167-6105(01)00129-5

Code for fire protection design of buildings, GB 50016-2014 (2014). http://www.gbstandards.org/China_standards/GB/GB\%2050016-2014.htm

Christian, J., \& Pandeya, A. (1997). Cost Predictions of Facilities. Journal of Management in Engineering, 13(1), 52-61. https://doi.org/10.1061/(ASCE)0742-597X(1997)13:1(52)

CIBSE - Weather Data. (2019). https://www.cibse.org/weatherdata

Cook, Nicholas J. (1997). The Deaves and Harris ABL model applied to heterogeneous terrain. Journal of Wind Engineering and Industrial Aerodynamics, 66(3), 197214. https://doi.org/10.1016/S0167-6105(97)00034-2

Cook, Nicholas John. (1985). The Designer's Guide to Wind Loading of Building Structures, Background, Damage Survey, Wind Data and Structural Classification. Building Research Establishment, Department of the Environment.

Cooper, D. I., \& Eichinger, W. E. (1994). Structure of the atmosphere in an urban planetary boundary layer from lidar and radiosonde observations. Journal of Geophysical Research: Atmospheres, 99(D11), 22937-22948. https://doi.org/10.1029/94JD01944

Cory, S. (2016). An Exploration of the Feasibility of Converting the New Zealand Commercial Building Stock to be Net Zero Energy: A Thesis Submitted to the Victoria University of Wellington in Fulfilment of the Requirements for the Degree of Doctor of Philosophy in Architecture (Building Science) [PhD Thesis]. Victoria University of Wellington. 
Craighead, G. (2009). High-Rise Security and Fire Life Safety (3rd ed.). ButterworthHeinemann. https://www.elsevier.com/books/high-rise-security-and-fire-lifesafety/craighead/978-1-85617-555-5

Crawley, D. B. (2008). Estimating the impacts of climate change and urbanization on building performance. Journal of Building Performance Simulation:, 1, 91-115.

Crawley, D. B., Hand, J. W., Kummert, M., \& Griffith, B. T. (2008). Contrasting the capabilities of building energy performance simulation programs. Building and Environment, 43(4), 661-673. https://doi.org/10.1016/j.buildenv.2006.10.027

CTBUH Journal Tall Buildings in Numbers.

http://www.ctbuh.org/Publications/CTBUHJournal/InNumbers/tabid/1 108/lan guage/en-GB/Default.aspx

Davenport, A. G. (1960). Rationale for determining design wind velocities. NATIONAL RESEARCH COUNCIL OF CANADA OTTAWA (ONTARIO) DIV OF BUILDING RESEARCH. https://apps.dtic.mil/docs/citations/AD0675580

Dimoudi, A., Kantzioura, A., Zoras, S., Pallas, C., \& Kosmopoulos, P. (2013). Investigation of urban microclimate parameters in an urban center. Energy and Buildings, 64, 1-9. https://doi.org/10.1016/j.enbuild.2013.04.014

Commercial Prototype Building Models, Building Energy Codes Program (2016). https://www.energycodes.gov/development/commercial/prototype_models

Drew, D. R., Barlow, J. F., \& Lane, S. E. (2013). Observations of wind speed profiles over Greater London, UK, using a Doppler lidar. Journal of Wind Engineering and Industrial Aerodynamics, 121, 98-105. https://doi.org/10.1016/j.jweia.2013.07.019 
Du, C., Liu, S., Yu, X., Li, X., Chen, C., Peng, Y., Dong, Y., Dong, Z., \& Wang, F. (2013). Urban Boundary Layer Height Characteristics and Relationship with Particulate Matter Mass Concentrations in Xi'an, Central China. Aerosol and Air Quality Research, 13(5), 1598-1607. https://doi.org/10.4209/aaqr.2012.10.0274

Ellis, P., \& Torcellini, P. (2005). Simulating Tall Buildings Using EnergyPlus (No. NREL/CP-550-38133; p. 12). National Renewable Energy Lab.

Emmanuel, R., Rosenlund, H., \& Johansson, E. (2007). Urban shading - a design option for the tropics? A study in Colombo, Sri Lanka. International Journal of Climatology, 27(14), 1995-2004. https://doi.org/10.1002/joc.1609

Emmanuel, Rohinton, \& Steemers, K. (2018). Connecting the realms of urban form, density and microclimate. Building Research \& Information, 46(8), 804-808. https://doi.org/10.1080/09613218.2018.1507078

EMPORIS. (n.d.). Emporis Standards: High-rise building [Building standards and information]. EMPORIS. Retrieved 22 September 2018, from https://www.emporis.com/building/standard/3/high-rise-building

Erell, E., Pearlmutter, D., \& Williamson, T. (2012). Urban Microclimate: Designing the Spaces Between Buildings. Routledge.

Flamant, C., \& Pelon, J. (1996). Atmospheric boundary-layer structure over the Mediterranean during a Tramontane event. Quarterly Journal of the Royal Meteorological Society, 122(536), 1741-1778. https://doi.org/10.1002/qj.49712253602 
Fumo, N., Mago, P., \& Luck, R. (2010). Methodology to estimate building energy consumption using EnergyPlus Benchmark Models. Energy and Buildings, 42(12), 2331-2337. https://doi.org/10.1016/j.enbuild.2010.07.027

Gedzelman, S. D., Austin, S., Cermak, R., Stefano, N., Partridge, S., Quesenberry, S., \& Robinson, D. A. (2003). Mesoscale aspects of the Urban Heat Island around New York City. Theoretical and Applied Climatology, 75(1), 29-42. https://doi.org/10.1007/s00704-002-0724-2

Giovannini, L., Zardi, D., \& de Franceschi, M. (2011). Analysis of the urban thermal fingerprint of the city of Trento in the Alps. Journal of Applied Meteorology and Climatology, 50(5), 1145-1162. Scopus. https://doi.org/10.1175/2010JAMC2613.1

Godoy-Shimizu, D., Steadman, P., Hamilton, I., Donn, M., Evans, S., Moreno, G., \& Shayesteh, H. (2018). Energy use and height in office buildings. Building Research \& Information, 46(8), 845-863. https://doi.org/10.1080/09613218.2018.1479927

Google $\quad$ Maps. $\quad$ (2019). Google $\quad$ Maps. https://www.google.co.nz/maps/place/City+of+London,+London,+UK/@51.5 $15069,-$ $0.1107947,14 \mathrm{z} /$ data $=! 3 \mathrm{~m} 1 ! 4 \mathrm{~b} 1 ! 4 \mathrm{~m} 5 ! 3 \mathrm{~m} 4 ! 1 \mathrm{~s} 0 \mathrm{x} 487603554 \mathrm{edf} 855 \mathrm{f}: 0 \mathrm{xa} 1185 \mathrm{c} 8$ $\mathrm{d} 19184 \mathrm{c} 0 ! 8 \mathrm{~m} 2 ! 3 \mathrm{~d} 51.5123443 ! 4 \mathrm{~d}-0.0909852$

Gowreesunker, B. L., \& Tassou, S. A. (2013). Effectiveness of CFD simulation for the performance prediction of phase change building boards in the thermal environment control of indoor spaces. Building and Environment, 59, 612-625. https://doi.org/10.1016/j.buildenv.2012.10.004 
Gracik, S., Heidarinejad, M., Liu, J., \& Srebric, J. (2015). Effect of urban neighborhoods on the performance of building cooling systems. Building and Environment, 90, 15-29. https://doi.org/10.1016/j.buildenv.2015.02.037

Grimmond, C. S. B., \& Oke, T. R. (2002). Turbulent heat fluxes in urban areas: Observations and a local-scale urban meteorological parameterization scheme (LUMPS). Journal of Applied Meteorology, 41(7), 792-810. Scopus.

Gromke, C., \& Blocken, B. (2015). Influence of avenue-trees on air quality at the urban neighborhood scale. Part I: Quality assurance studies and turbulent Schmidt number analysis for RANS CFD simulations. Environmental Pollution, 196, 214-223. https://doi.org/10.1016/j.envpol.2014.10.016

Guideline, A. S. H. R. A. E. (2002). Guideline 14-2002, Measurement of energy and demand savings. American Society of Heating, Ventilating, and Air Conditioning Engineers.

Gutiérrez, E., González, J. E., Martilli, A., Bornstein, R., \& Arend, M. (2015). Simulations of a heat-wave event in New York City using a multilayer urban parameterization. Journal of Applied Meteorology and Climatology, 54(2), 283-301. Scopus. https://doi.org/10.1175/JAMC-D-14-0028.1

Hafner, J., \& Kidder, S. Q. (1999). Urban Heat Island Modeling in Conjunction with Satellite-Derived Surface/Soil Parameters. Journal of Applied Meteorology, 38(4), $\quad 448-465 . \quad$ https://doi.org/10.1175/15200450(1999)038<0448:UHIMIC >2.0.CO;2

Hammond, D. S., Chapman, L., \& Thornes, J. E. (2012). Roughness length estimation along road transects using airborne LIDAR data. Meteorological Applications, 19(4), 420-426. https://doi.org/10.1002/met.273 
Handbook-Fundamentals, A. S. H. R. A. E. (2009). American society of Heating. Refrigerating and Air Conditioning Engineers.

Hemidi, A., Henry, F., Leclaire, S., Seynhaeve, J.-M., \& Bartosiewicz, Y. (2009). CFD analysis of a supersonic air ejector. Part II: Relation between global operation and local flow features. Applied Thermal Engineering, 29(14), 2990-2998. https://doi.org/10.1016/j.applthermaleng.2009.03.019

Hensen, J. L. M., \& Lamberts, R. (2012). Building Performance Simulation for Design and Operation. Routledge.

Hewitt, C. N., \& Jackson, A. V. (2020). Atmospheric Science for Environmental Scientists (2nd Edition). John Wiley \& Sons. https://www.wiley.com/ennz/Atmospheric + Science+for + Environmental + Scientists $\% 2 C+2 n d+E d i t i o n-p-$ 9781119515272

Holt, T., \& Pullen, J. (2007). Urban Canopy Modeling of the New York City Metropolitan Area: A Comparison and Validation of Single- and Multilayer Parameterizations. Monthly Weather Review, 135(5), 1906-1930. https://doi.org/10.1175/MWR3372.1

Huang, J., Akbari, H., Rainer, L., \& Ritschard, R. (1991). 481 Prototypical commercial buildings for 20 urban market areas.

Hummel, J. R., \& Kuhn, W. R. (1981). Comparison of radiative-convective models with constant and pressure-dependent lapse rates. Tellus, 33(3), 254-261. https://doi.org/10.1111/j.2153-3490.1981.tb01749.x

Irwin, J. S. (1979). A theoretical variation of the wind profile power-law exponent as a function of surface roughness and stability. Atmospheric Environment (1967), 13(1), 191-194. https://doi.org/10.1016/0004-6981(79)90260-9 
ISO, E. (2005). 7730:2005. Ergonomics of the Thermal Environment - Analytical Determination and Interpretation of Thermal Comfort Using Calculation of the $P M V$ and PPD Indices and Local Thermal Comfort Criteria. http://www.iso.org/cms/render/live/en/sites/isoorg/contents/data/standard/03/9 1/39155.html

Jacobson, M. Z. (2005). Fundamentals of atmospheric modeling. Cambridge university press.

Jebson, S. (2008). Fact sheet 14-Microclimates. The National Meteorological Library and Archive.

Johnson, O. (1959). An examination of the vertical wind profile in the lowest layers of the atmosphere. Journal of Meteorology, 16(2), 144-148. https://doi.org/10.1175/1520-0469(1959)016<0144:AEOTVW>2.0.CO;2

Juniwati, A. (2008). Optimum Facade Design for Energy Efficient High-rise Office Building in Hot Humid Tropics.

Kanda, M., Moriwaki, R., \& Kimoto, Y. (2005). Temperature Profiles Within and Above an Urban Canopy. Boundary-Layer Meteorology, 115(3), 499-506. https://doi.org/10.1007/s 10546-004-5644-5

Kleiven, T. (2003). Natural ventilation in buildings: Architectural concepts, consequences and possibilities. Institutt for byggekunst, historie og teknologi. https://brage.bibsys.no/xmlui/handle/11250/231090

Kolokotroni, M., \& Aronis, A. (1999). Cooling-energy reduction in air-conditioned offices by using night ventilation. Applied Energy, 63(4), 241-253. https://doi.org/10.1016/S0306-2619(99)00031-8 
Kolokotroni, M., \& Giridharan, R. (2008). Urban heat island intensity in London: An investigation of the impact of physical characteristics on changes in outdoor air temperature during summer. Solar Energy, 82(11), 986-998. https://doi.org/10.1016/j.solener.2008.05.004

Kong, F., Sun, C., Liu, F., Yin, H., Jiang, F., Pu, Y., Cavan, G., Skelhorn, C., Middel, A., \& Dronova, I. (2016). Energy saving potential of fragmented green spaces due to their temperature regulating ecosystem services in the summer. Applied Energy, 183, 1428-1440. https://doi.org/10.1016/j.apenergy.2016.09.070

Kottek, M., Grieser, J., Beck, C., Rudolf, B., \& Rubel, F. (2006). World Map of the Köppen-Geiger climate classification updated. Meteorologische Zeitschrift, 15(3), 259-263. https://doi.org/10.1127/0941-2948/2006/0130

Kotthaus, S., \& Grimmond, C. S. B. (2014). Energy exchange in a dense urban environment - Part II: Impact of spatial heterogeneity of the surface. Urban Climate, 10, 281-307. https://doi.org/10.1016/j.uclim.2013.10.001

Kukkonen, J., Pohjola, M., Sokhi, R. S., \& Luhana, L. (2005). Analysis and evaluation of selected local-scale PM10 air pollution episodes in four European cities: Helsinki, London, Milan and Oslo. Atmospheric Environment, 39(15), 27592773.

Kunkel, K. E., Eloranta, E. W., \& Shipley, S. T. (1977). Lidar Observations of the Convective Boundary Layer. Journal of Applied Meteorology, 16(12), 13061311. https://doi.org/10.1175/1520-0450(1977)016<1306:LOOTCB $>2.0 . C O ; 2$

Lam, J. C., \& Hui, S. C. M. (1996). Sensitivity analysis of energy performance of office buildings. Building and Environment, 31(1), 27-39. https://doi.org/10.1016/0360-1323(95)00031-3 
LBNL, E. (2018). EnergyPlus Version 9.0.1 Documentation: Input Output Reference. U.S. Department of Energy. https://bigladdersoftware.com/epx/docs/9-1/inputoutput-reference/group-location-climate-weather-file-access.html

Lee, D. O. (1979). The influence of atmospheric stability and the urban heat island on urban-rural wind speed differences. Atmospheric Environment (1967), 13(8), 1175-1180. https://doi.org/10.1016/0004-6981(79)90042-8

Lewis, A., Riley, D., \& Elmualim, A. (2010). Defining high performance buildings for operations and maintenance. International Journal of Facility Management, $1(2), 1-16$.

Li, J., Delmas, A., Donn, M., \& Willis, R. (2018). Validation and Comparison of Different CFD Simulation Software Predictions of Urban Wind Environment Based on AIJ Wind Tunnel Benchmarks. The 9th Annual Symposium on Simulation for Architecture and Urban Design, 263. http://dx.doi.org/10.22360/simaud.2018.simaud.027

Li, J., \& Donn, M. (2017). The influence of building height variability on natural ventilation and neighbor buildings in dense urban areas. 2398-2406.

Li, J., Donn, M., \& Thomas, G. (2018). Influence of Office Building Height in Urban Areas on Surrounding Microclimate and Building Performance. The 34th International Conference on Passive and Low Energy Architecture, 1, 359.

Li, Q. S., Zhi, L., \& Hu, F. (2010). Boundary layer wind structure from observations on a $325 \mathrm{~m}$ tower. Journal of Wind Engineering and Industrial Aerodynamics, 98(12), 818-832. https://doi.org/10.1016/j.jweia.2010.08.001 
Li, X., Bi, B., \& Li, Z. (2005). Numerical study of winter urban boundary layer structure over Beijing area. Journal of Meteorological Research, 19(3), 317-320,322$328,330-331$.

List of tallest buildings and structures in London. (2018). In Wikipedia. https://en.wikipedia.org/w/index.php?title=List_of_tallest_buildings_and_stru ctures_in_London\&oldid $=857501234$

List of tallest buildings and structures in London. (2019). In Wikipedia. https://en.wikipedia.org/w/index.php?title=List_of_tallest_buildings_and_stru ctures_in_London\&oldid $=922934183$

Liu, S., \& Liang, X.-Z. (2010). Observed Diurnal Cycle Climatology of Planetary Boundary Layer Height. Journal of Climate, 23(21), 5790-5809. https://doi.org/10.1175/2010JCLI3552.1

Manwell, J. F., McGowan, J. G., \& Rogers, A. L. (2010). Wind energy explained: Theory, design and application. John Wiley \& Sons. https://epdf.tips/windenergy-explained-theory-design-and-application.html

Melbourne, W. H. (1980). Comparison of measurements on the CAARC standard tall building model in simulated model wind flows. Journal of Wind Engineering and Industrial Aerodynamics, 6(1), 73-88. https://doi.org/10.1016/01676105(80)90023-9

Memon, R. A., Leung, D. Y. C., \& Liu, C.-H. (2010). Effects of building aspect ratio and wind speed on air temperatures in urban-like street canyons. Building and Environment, 45(1), 176-188. https://doi.org/10.1016/j.buildenv.2009.05.015 
Menut, L., Flamant, C., Pelon, J., \& Flamant, P. H. (1999). Urban boundary-layer height determination from lidar measurements over the Paris area. Applied Optics, 38(6), 945-954. https://doi.org/10.1364/AO.38.000945

Mills, G. (1997). An urban canopy-layer model. Theoretical and Applied Climatology, 57(3-4), 229-244. https://doi.org/10.1007/BF00863615

Modak, P., Jiemian, Y., Hongyuan, Y., \& Mohanty, C. (2012). Shanghai Manual: A Guide for Sustainable Urban Development in the 21st Century. United Nations Department of Economic and Social Affairs (UNDESA). https://sustainabledevelopment.un.org/index.php?page=view\&type $=400 \& n r=6$ $33 \& \operatorname{menu}=35$

Mohammed A., B., \& Jae D., C. (2015). The Influence of Heightwidth Ratio on Urban Heat Island in Hot-arid Climates.

Montazeri, H., Blocken, B., \& Hensen, J. L. M. (2015). Evaporative cooling by water spray systems: CFD simulation, experimental validation and sensitivity analysis. Building and Environment, 83, 129-141. https://doi.org/10.1016/j.buildenv.2014.03.022

Nagle, G., \& Cooke, B. (2017). Oxford IB Diploma Programme: Geography Course Companion. Oxford University Press - Children.

Nazarian, N., \& Kleissl, J. (2015). CFD simulation of an idealized urban environment: Thermal effects of geometrical characteristics and surface materials. Urban Climate, 12, 141-159. https://doi.org/10.1016/j.uclim.2015.03.002

Nkemdirim, Lawrence C. (1979). A Test of a Lapse Rate/Wind Speed Model for Estimating Heat Island Magnitude in an Urban Airshed. Journal of Applied 
Meteorology, $\quad$ 19(6), $\quad$ 748-756. https://doi.org/10.1175/15200450(1980)019<0748:ATOALR>2.0.CO;2

Nkemdirim, L.C. (1980). A test of a lapse rate/wind speed model for estimating heat island magnitude in an urban airshed ( Calgary). Journal of Applied Meteorology, 19(6), 748-756. Scopus.

Oke, T. R. (1973). City size and the urban heat island. Atmospheric Environment (1967), 7(8), 769-779. https://doi.org/10.1016/0004-6981(73)90140-6

Oke, T. R. (1976). The distinction between canopy and boundary-layer urban heat Islands. $\quad$ Atmosphere, $\quad$ 268-277. $\quad$ Scopus. https://doi.org/10.1080/00046973.1976.9648422

Oke, T. R. (1978). Boundary layer climates. Methuen; Wiley.

Oke, T. R., \& East, C. (1971). The urban boundary layer in Montreal. Boundary-Layer Meteorology, 1(4), 411-437. https://doi.org/10.1007/BF00184781

Oleson, K. W., Bonan, G. B., Feddema, J., \& Vertenstein, M. (2008). An urban parameterization for a global climate model. Part II: Sensitivity to input parameters and the simulated urban heat island in offline simulations. Journal of Applied Meteorology and Climatology, 47(4), 1061-1076. https://doi.org/10.1175/2007JAMC1598.1

OpenFOAM Introduction. (2018). https://www.openfoam.com/documentation/userguide/userch1.php

Padmanabhamurty, B., \& Hirt, M. S. (1974). The Toronto heat island and pollution distribution. Water, Air, and Soil Pollution, 3(1), 81-89. Scopus. https://doi.org/10.1007/BF00282729 
Pal, S., Xueref-Remy, I., Ammoura, L., Chazette, P., Gibert, F., Royer, P., Dieudonné, E., Dupont, J.-C., Haeffelin, M., Lac, C., Lopez, M., Morille, Y., \& Ravetta, F. (2012). Spatio-temporal variability of the atmospheric boundary layer depth over the Paris agglomeration: An assessment of the impact of the urban heat island intensity. Atmospheric Environment, 63, 261-275. https://doi.org/10.1016/j.atmosenv.2012.09.046

Palme, M., Inostroza, L., Villacreses, G., Lobato, A., \& Carrasco, C. (2017). Urban weather data and building models for the inclusion of the urban heat island effect in building performance simulation. Data in Brief, 14, 671-675. https://doi.org/10.1016/j.dib.2017.08.035

Park, K., Choi, C., \& Park, H. (2013). Analysis of micro-climate for the scheme of green infrastructure regeneration in Jeonju. WIT Transactions on Ecology and the Environment, 175, 77-85. Scopus. https://doi.org/10.2495/ECO130071

Pérez-Lombard, L., Ortiz, J., \& Pout, C. (2008). A review on buildings energy consumption information. Energy and Buildings, 40(3), 394-398. https://doi.org/10.1016/j.enbuild.2007.03.007

Perini, K., \& Magliocco, A. (2014). Effects of vegetation, urban density, building height, and atmospheric conditions on local temperatures and thermal comfort. Urban Forestry \& Urban Greening, 13(3), 495-506. https://doi.org/10.1016/j.ufug.2014.03.003

P.J.C, S., H.J.J, J., S., K., \& S.R. de, R. (2015). Breakdown of the night time urban heat island energy budget.pdf. 
Qaid, A., \& Ossen, D. R. (2015). Effect of asymmetrical street aspect ratios on microclimates in hot, humid regions. International Journal of Biometeorology, 59(6), 657-677. https://doi.org/10.1007/s00484-014-0878-5

Rafieian, M., Rad, H. R., \& Sharifi, A. (2014). The necessity of using Sky View Factor in urban planning: A case study of Narmak neighborhood, Tehran. 1-5.

Real Climate Science. (n.d.). Retrieved 1 December 2019, from https://realclimatescience.com/2015/09/the-extreme-stupidity-of-thescientific-consensus/

Ricciardelli, F., \& Polimeno, S. (2006). Some characteristics of the wind flow in the lower Urban Boundary Layer. Journal of Wind Engineering and Industrial Aerodynamics, 94(11), 815-832. https://doi.org/10.1016/j.jweia.2006.06.003

Rigby, M., \& Toumi, R. (2008). London air pollution climatology: Indirect evidence for urban boundary layer height and wind speed enhancement. Atmospheric Environment, $\quad$ 42(20), 4932-4947. https://doi.org/10.1016/j.atmosenv.2008.02.031

Riley, D. R., Magent, C. S., \& Horman, M. J. (2004). Sustainable metrics: A design process model for high performance buildings. 2-7.

Roser, M., Ritchie, H., \& Ortiz-Ospina, E. (2013). World Population Growth. Our World in Data. https://ourworldindata.org/world-population-growth

Roudsari, M. S. (n.d.). Ladybug Tools. Retrieved 1 September 2018, from https://www.ladybug.tools/

Rusly, E., Aye, L., Charters, W. W. S., \& Ooi, A. (2005). CFD analysis of ejector in a combined ejector cooling system. International Journal of Refrigeration, 28(7), 1092-1101. https://doi.org/10.1016/j.ijrefrig.2005.02.005 
Satwiko, P., Locke, N., \& Donn, M. (1998). Reproducing the real pressure coefficient using a computational fluid dynamics program How close is close enough? 1517. http://anzasca.net/paper/reproducing-the-real-pressure-coefficient-using-acomputational-fluid-dynamics-program-how-close-is-close-enough/

Sivaraja Subramania, P., \& Ryuichiro, Y. (2012). Experimental and numerical studies on convective heat transfer from various urban canopy configurations.

Sokhi, R. S. (2012). Urban Air Quality: Monitoring and Modelling: Proceedings of the First International Conference on Urban Air Quality: Monitoring and Modelling University of Hertfordshire, Hatfield, U.K. 11-12 July 1996. Springer Science \& Business Media.

Solecki, W. D., Rosenzweig, C., Parshall, L., Pope, G., Clark, M., Cox, J., \& Wiencke, M. (2005). Mitigation of the heat island effect in urban New Jersey. Global Environmental Change Part B: Environmental Hazards, 6(1), 39-49. https://doi.org/10.1016/j.hazards.2004.12.002

Spanton, A. M., \& Williams, M. L. (1988). A comparison of the structure of the atmospheric boundary layers in Central London and a rural/suburban site using acoustic sounding. Atmospheric Environment (1967), 22(2), 211-223. https://doi.org/10.1016/0004-6981(88)90029-7

Standard, A. S. H. R. A. E. (2010). Standard 55-2010, Thermal environmental conditions for human occupancy. American Society of Heating, Refrigerating and Air Conditioning Engineers.

Stewart, I. D., Oke, T. R., \& Krayenhoff, E. S. (2014). Evaluation of the 'local climate zone' scheme using temperature observations and model simulations. 
International Journal of Climatology, 34(4), 1062-1080. https://doi.org/10.1002/joc.3746

Street, M., Reinhart, C., Norford, L., \& Ochsendorf, J. (2013). Urban heat island in Boston-An evaluation of urban air-temperature models for predicting building energy use. 1022-1029. http://www.ibpsa.org/proceedings/BS2013/p_1492.pdf

Stull, R. B., \& Eloranta, E. W. (1984). Boundary Layer Experiment-1983. Bulletin of the American Meteorological Society, 65(5), 450-456. https://doi.org/10.1175/1520-0477(1984)065<0450:BLE>2.0.CO;2

Subramania Pillai, S., \& Yoshie, R. (2012). Experimental and numerical studies on convective heat transfer from various urban canopy configurations. Journal of Wind Engineering and Industrial Aerodynamics, 104-106, 447-454. https://doi.org/10.1016/j.jweia.2012.03.010

Tall buildings past and present trends. (2018). https://www.aurecongroup.com/thinking/thinking-papers/tall-buildings-pastand-present-trends

Tapper, N. J. (1990). Urban influences on boundary layer temperature and humidity: Results from Christchurch, New Zealand. Atmospheric Environment. Part B. Urban Atmosphere, 24(1), 19-27. https://doi.org/10.1016/09571272(90)90005-F

The blueCFD-Core project. (n.d.). Retrieved 25 May 2020, from http://bluecfd.github.io/Core/About/

Theeuwes, N. E., Steeneveld, G.-J., Ronda, R. J., Rotach, M. W., \& Holtslag, A. A. M. (2015). Cool city mornings by urban heat. Environmental Research Letters, 10(11), 114022. https://doi.org/10.1088/1748-9326/10/11/114022 
Theurer, W., Baechlin, W., \& Plate, E. J. (1992). Model study of the development of boundary layers above urban areas. Journal of Wind Engineering and Industrial Aerodynamics, 41(1), 437-448. https://doi.org/10.1016/0167-6105(92)90443-E

Tieleman, H. W. (2008). Strong wind observations in the atmospheric surface layer. Journal of Wind Engineering and Industrial Aerodynamics, 96(1), 41-77. https://doi.org/10.1016/j.jweia.2007.03.003

Tominaga, Y., \& Mochida, A. (2016). AIJ Benchmarks for Validation of CFD Simulations Applied to Pedestrian Wind Environment around Buildings. Architectural Institute of Japan.

Tominaga, Y., Mochida, A., Yoshie, R., Kataoka, H., Nozu, T., Yoshikawa, M., \& Shirasawa, T. (2008). AIJ guidelines for practical applications of CFD to pedestrian wind environment around buildings. Journal of Wind Engineering and Industrial Aerodynamics, 96(10), 1749-1761. https://doi.org/10.1016/j.jweia.2008.02.058

TUBS. (2011). City of London in Greater London. https://commons.wikimedia.org/wiki/File:City_of_London_in_Greater_Londo n.svg

United Nations Department of Economic and Social Affairs. (2018). 2018 Revision of World Urbanization Prospects. United Nations Department of Economic and Social Affairs. https://www.un.org/development/desa/publications/2018revision-of-world-urbanization-prospects.html

Urban Weather Generator. (n.d.). the Building Technology Program at MIT. Retrieved 1 September 2018, from http://urbanmicroclimate.scripts.mit.edu/ 
US EPA, O. (2014, June 23). Heat Island Compendium [Reports and Assessments]. US EPA. https://www.epa.gov/heat-islands/heat-island-compendium

Varga, S., Oliveira, A. C., Ma, X., Omer, S. A., Zhang, W., \& Riffat, S. B. (2011). Comparison of CFD and experimental performance results of a variable area ratio steam ejector. International Journal of Low-Carbon Technologies, 6(2), 119-124. https://doi.org/10.1093/ijlct/ctq048

Vijek. (2013). Velocity and Temperature boundary layer similarity. Created using Microsoft Powerpoint based Previously published: N/A. https://commons.wikimedia.org/wiki/File:Velocity_and_Temperature_bounda ry_layer_similarity.png

Wang, B., \& Malkawi, A. (2019). Design-based natural ventilation evaluation in early stage for high performance buildings. Sustainable Cities and Society, 45, 2537. https://doi.org/10.1016/j.scs.2018.11.024

Wang, L., Mathew, P., \& Pang, X. (2012). Uncertainties in energy consumption introduced by building operations and weather for a medium-size office building. Energy and Buildings, 53, 152-158. https://doi.org/10.1016/j.enbuild.2012.06.017

Wang, Y., Berardi, U., \& Akbari, H. (2015). The Urban Heat Island Effect in the City of Toronto. Procedia Engineering, 118, 137-144. https://doi.org/10.1016/j.proeng.2015.08.412

Watkins, R., Palmer, J., Kolokotroni, M., \& Littefair, P. (2002). The London Heat Island: Results from summertime monitoring. Building Services Engineering Research and Technology, 23(2), 97-106. 
Weather Data | EnergyPlus. (n.d.). Retrieved 20 April 2020, from https://energyplus.net/weather

Wei, R., Song, D., Wong, N. H., \& Martin, M. (2016). Impact of Urban Morphology Parameters on Microclimate. Procedia Engineering, 169, 142-149. https://doi.org/10.1016/j.proeng.2016.10.017

Wilby, R. L. (2003). Past and projected trends in London's urban heat island. Weather, 58(7), 251-260. https://doi.org/10.1256/wea.183.02

Wilcox, S., \& Marion, W. (2008). Users Manual for TMY3 Data Sets.

Wong, P. P.-Y., Lai, P.-C., Low, C.-T., Chen, S., \& Hart, M. (2016). The impact of environmental and human factors on urban heat and microclimate variability. Building and Environment, 95, 199-208. https://doi.org/10.1016/j.buildenv.2015.09.024

Yang, C., Wang, R., Zhang, S., Ji, C., \& Fu, X. (2019). Characterizing the Hourly Variation of Urban Heat Islands in a Snowy Climate City during Summer. International Journal of Environmental Research and Public Health, 16(14). https://doi.org/10.3390/ijerph16142467

Yoshie, R., Mochida, A., Tominaga, Y., Kataoka, H., Harimoto, K., Nozu, T., \& Shirasawa, T. (2007). Cooperative project for CFD prediction of pedestrian wind environment in the Architectural Institute of Japan. Journal of Wind Engineering and Industrial Aerodynamics, 95(9), 1551-1578. https://doi.org/10.1016/j.jweia.2007.02.023

Yuan, C. (2018). Urban Wind Environment: Integrated Climate-Sensitive Planning and Design. Springer Singapore. https://doi.org/10.1007/978-981-10-5451-8 
Yuan, C., Adelia, A. S., Mei, S., He, W., Li, X.-X., \& Norford, L. (2020). Mitigating intensity of urban heat island by better understanding on urban morphology and anthropogenic heat dispersion. Building and Environment, 176, 106876. https://doi.org/10.1016/j.buildenv.2020.106876

Zhang, W., Mak, C. M., Ai, Z. T., \& Siu, W. M. (2012). A Study of the Ventilation and Thermal Comfort of the Environment Surrounding a New University Building under Construction. Indoor and Built Environment, 21(4), 568-582. https://doi.org/10.1177/1420326X11419871 


\section{APPENDIX A. WORKFLOW}

This appendix illustrates the workflow of urban microclimate simulation system.

\section{A.1 Building Thermal Loads Simulation}

\section{A.1.1 Geometry and thermal zones}

- Step1: Geometry of the building

Floor plan: $72 \mathrm{~m} \times 50 \mathrm{~m}$

Storeys: 35

Height: $154 \mathrm{~m}$

Floor to floor: $4.4 \mathrm{~m}$

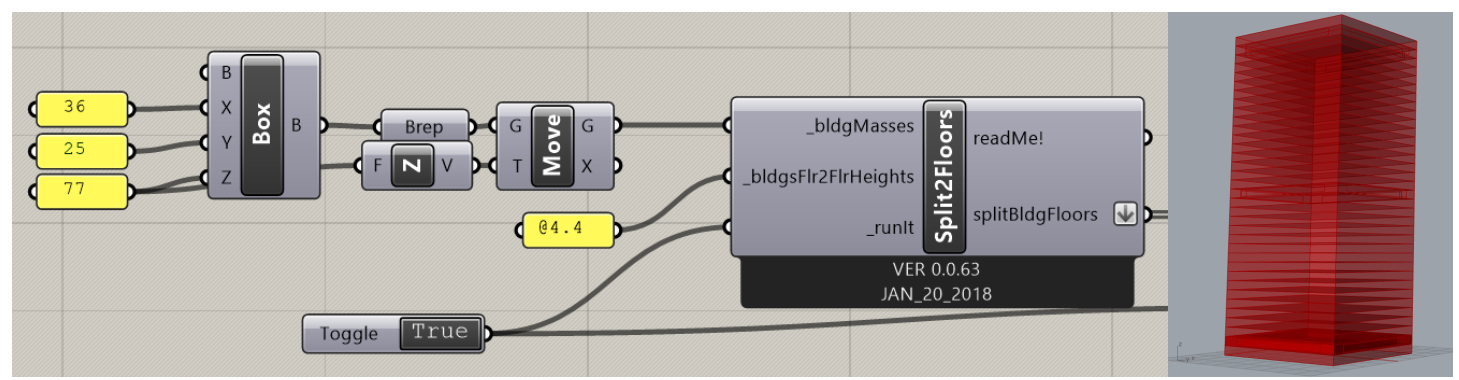

Figure A. 1 Set-up of the building geometry

- Step2: Split each floor into 5 zones

Perimeter zone depth: $5 \mathrm{~m}$

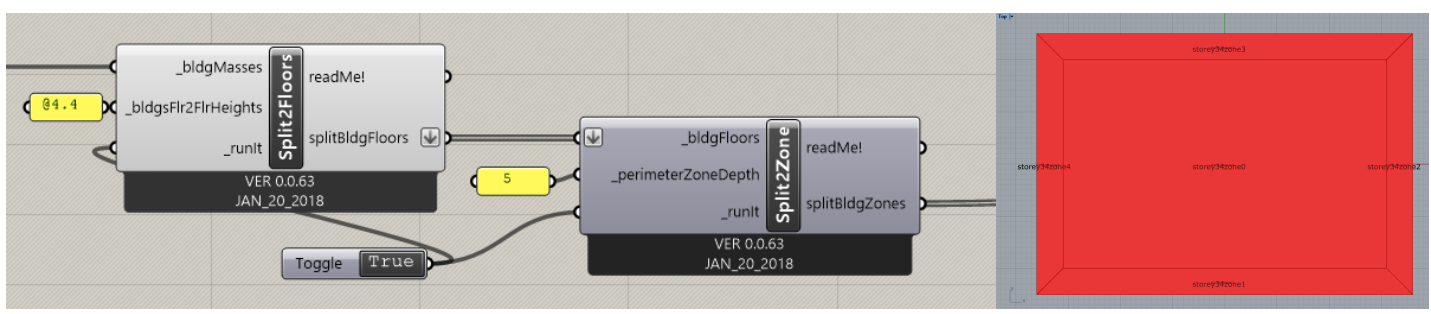

Figure A. 2 Set-up of the thermal zones

- Step3: Name each zones

Storey: 0-34

Zone: 0-4 


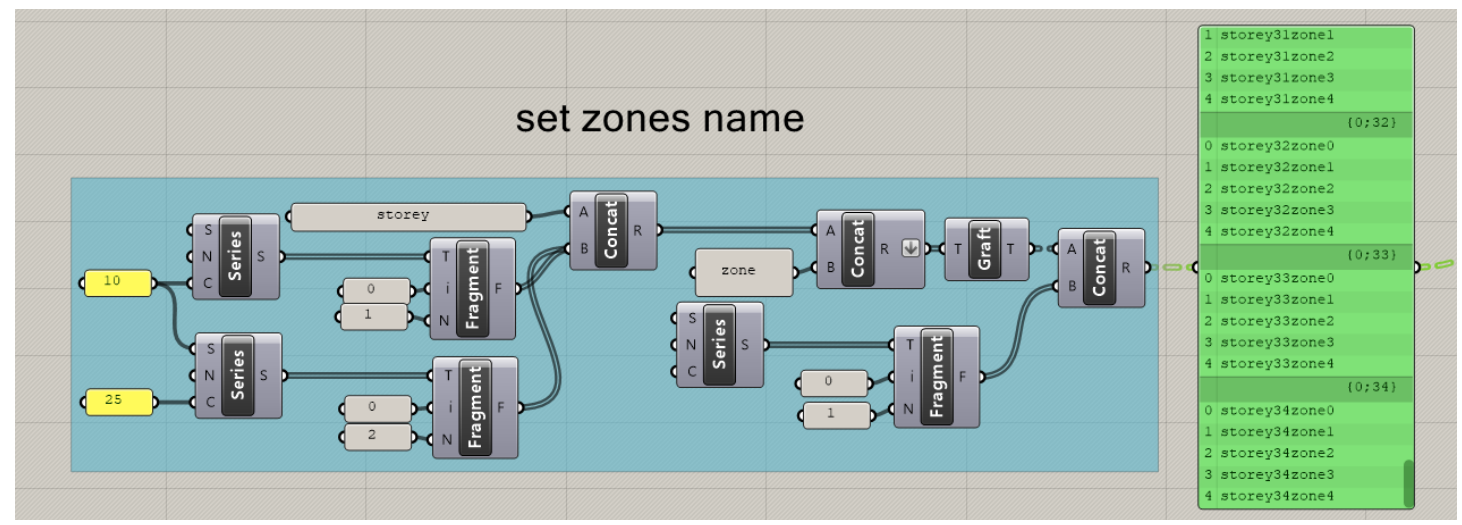

Figure A. 3 Set zones name

- Step4: Turn geometry into Honeybee Zones

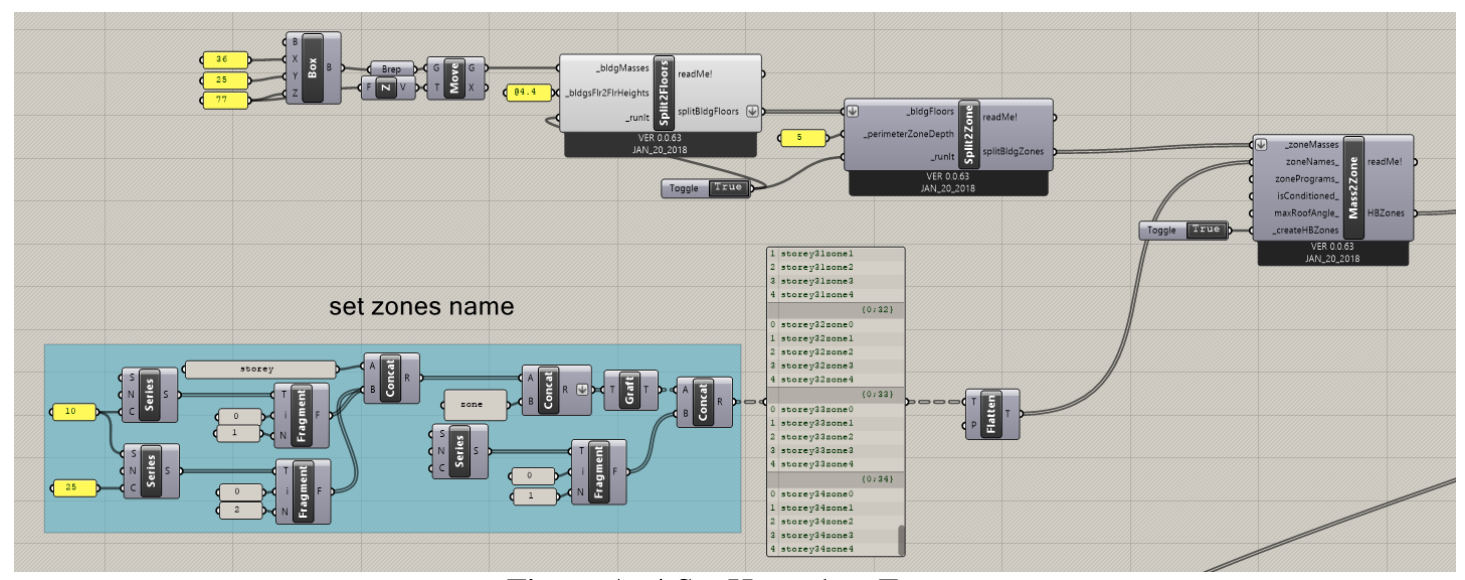

Figure A. 4 Set Honeybee Zones

- Step5: Take 3 floors 15 zones as template

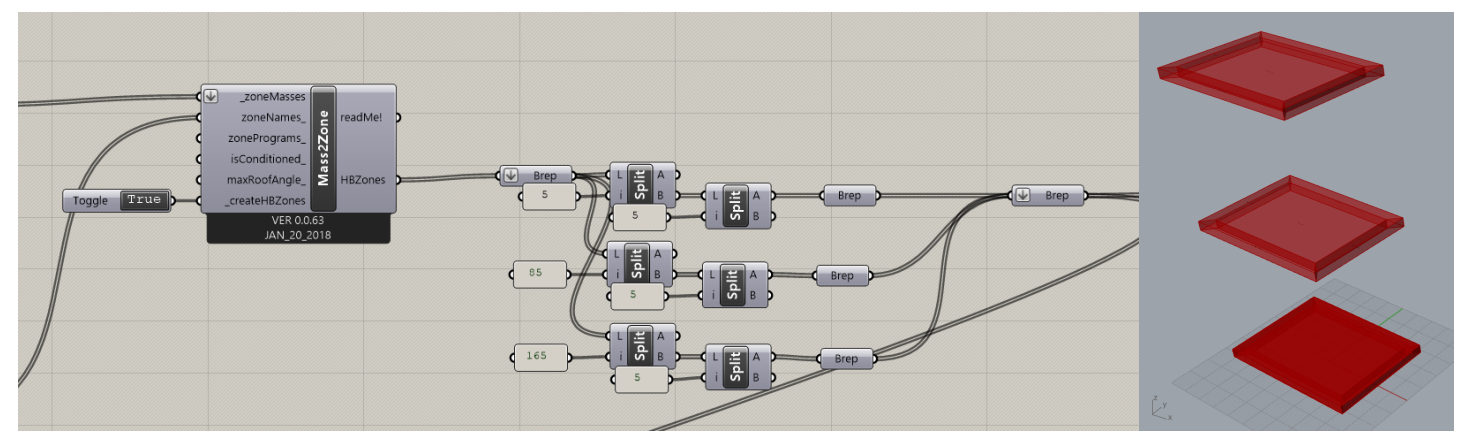

Figure A. 5 Set typical 3 floors with 15 zones

A blank line above the subheading has already been built into this template so it is not necessary to leave another blank line before headings so long as you are using the proscribed heading and subheading styles. Styles were discussed in Chapter 1 of this document.

\section{A.1.2 Loads, Schedule and Constructions}

- Step6: Set office buildings loads and schedules 


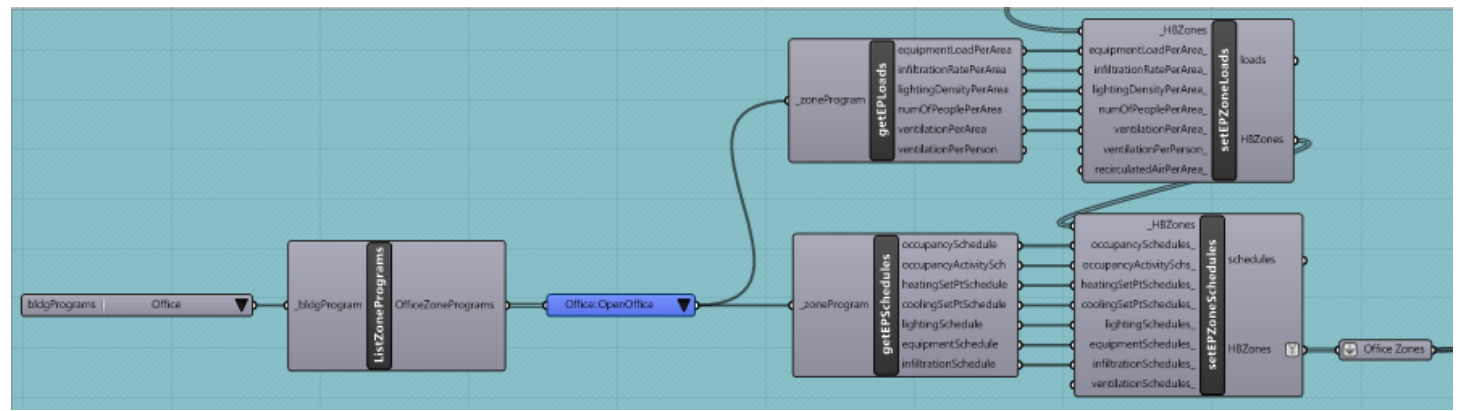

Figure A. 6 Set-up of loads and schedules

- Step7: Set glazing ratio

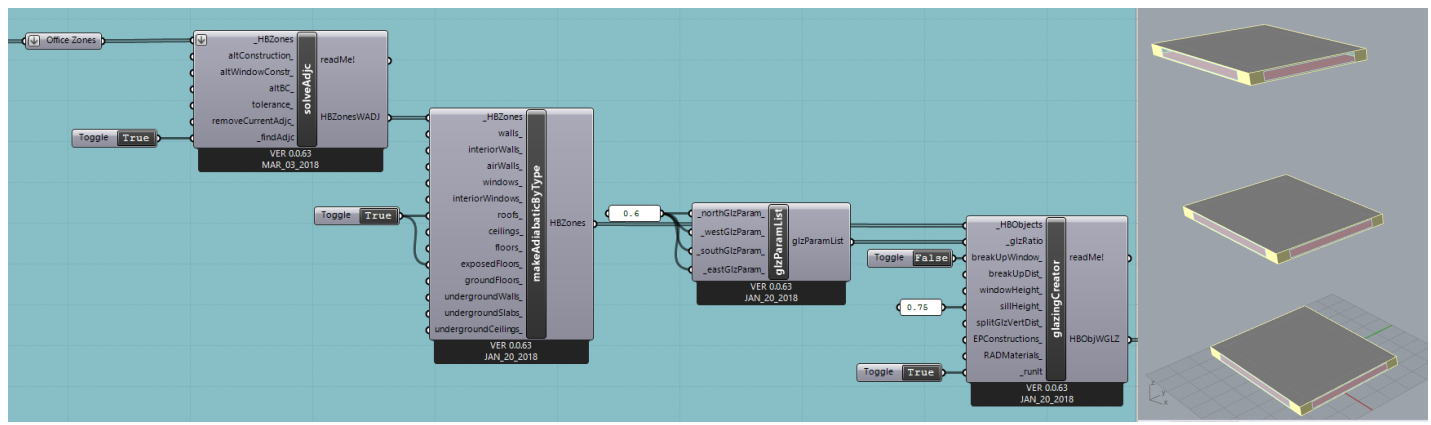

Figure A. 7 Set-up of windows

- Step8: Assign office building constructions

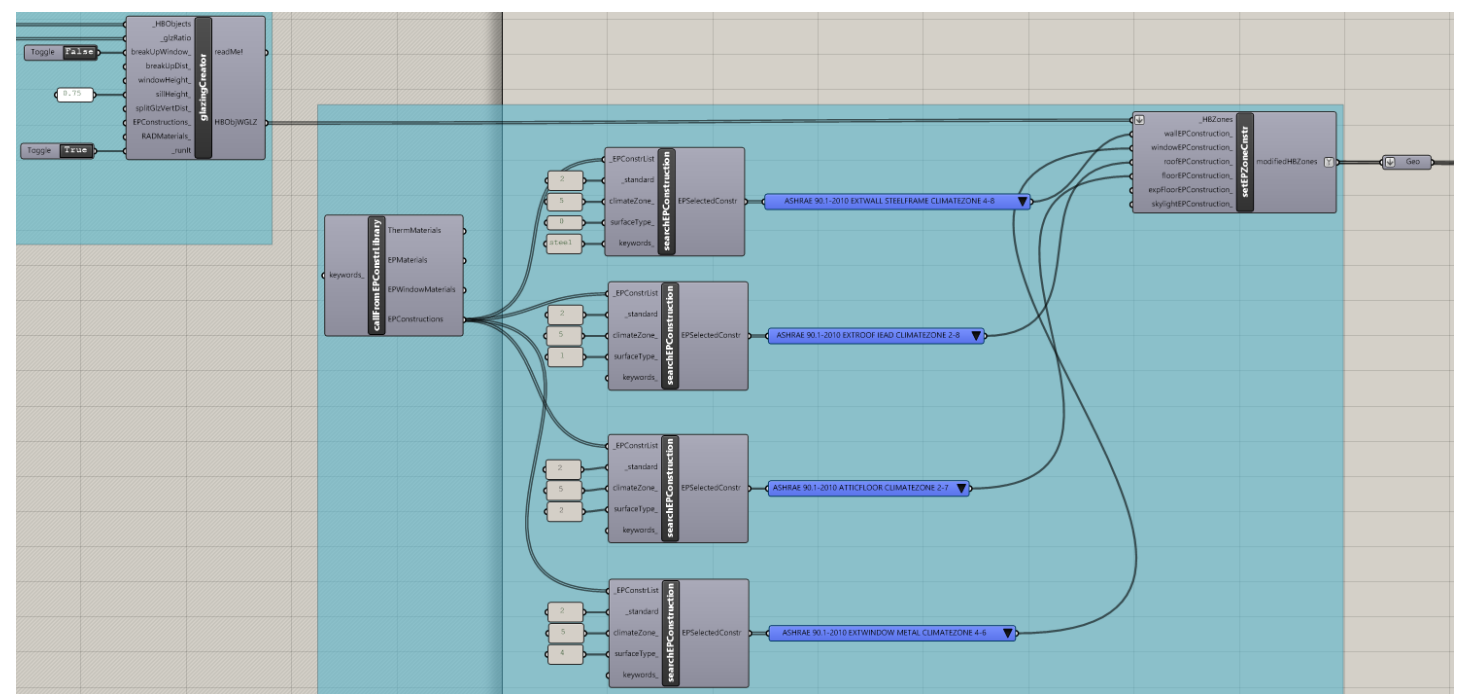

Figure A. 8 Set-up of constructions

\section{A.1.3 Thermal Loads}

- Step9: Import weather data and vertical variations

- Step10: Run the simulation and calculate thermal loads 


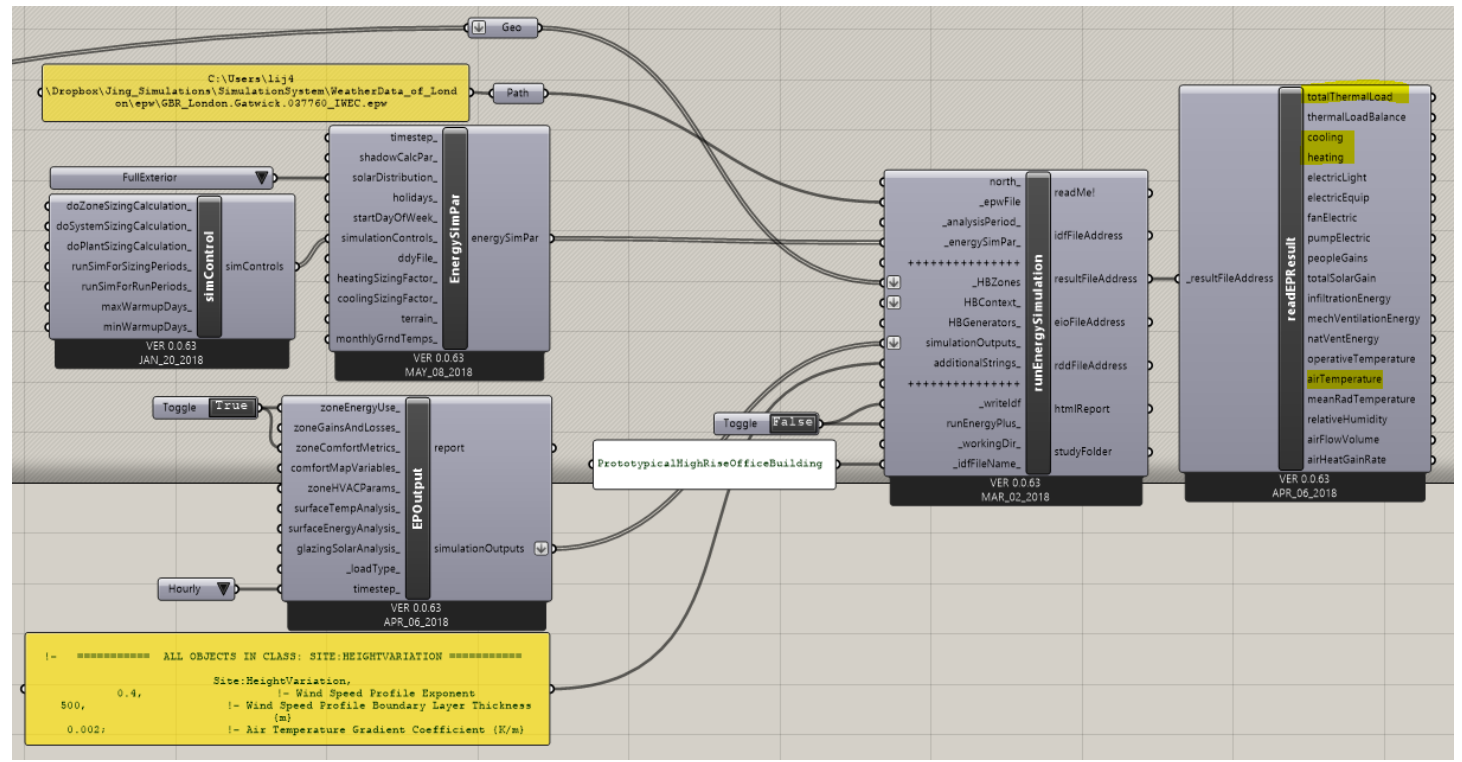

Figure A. 9 Import weather data and simulate the building performance

\section{A.2 Urban Microclimate Simulation}

\section{A.2.1 Urban wind}

- Step1: Geometries of the city

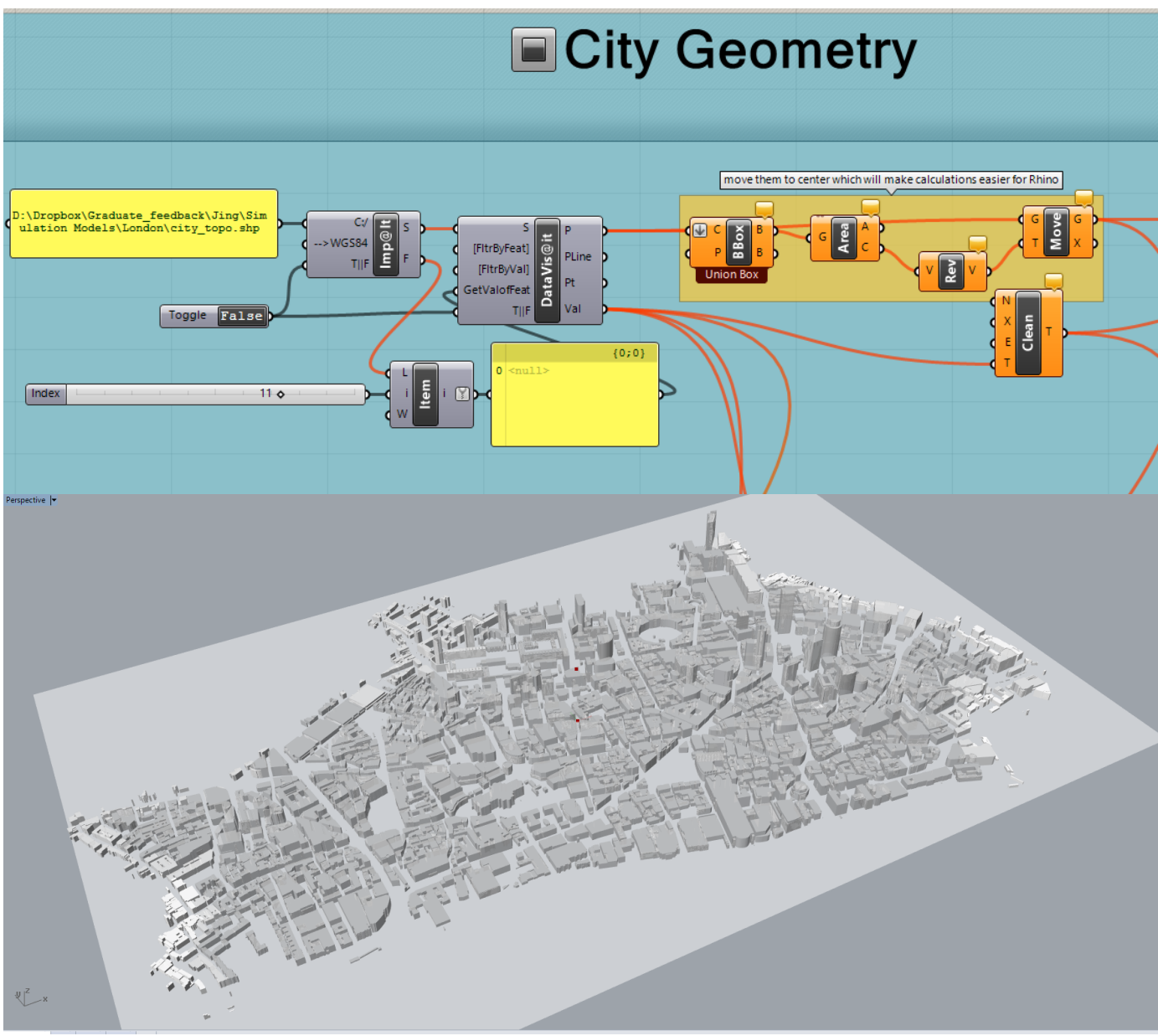

Figure A. 10 Rebuild three-dimensional model of the city 
- Step2: Build wind tunnel box

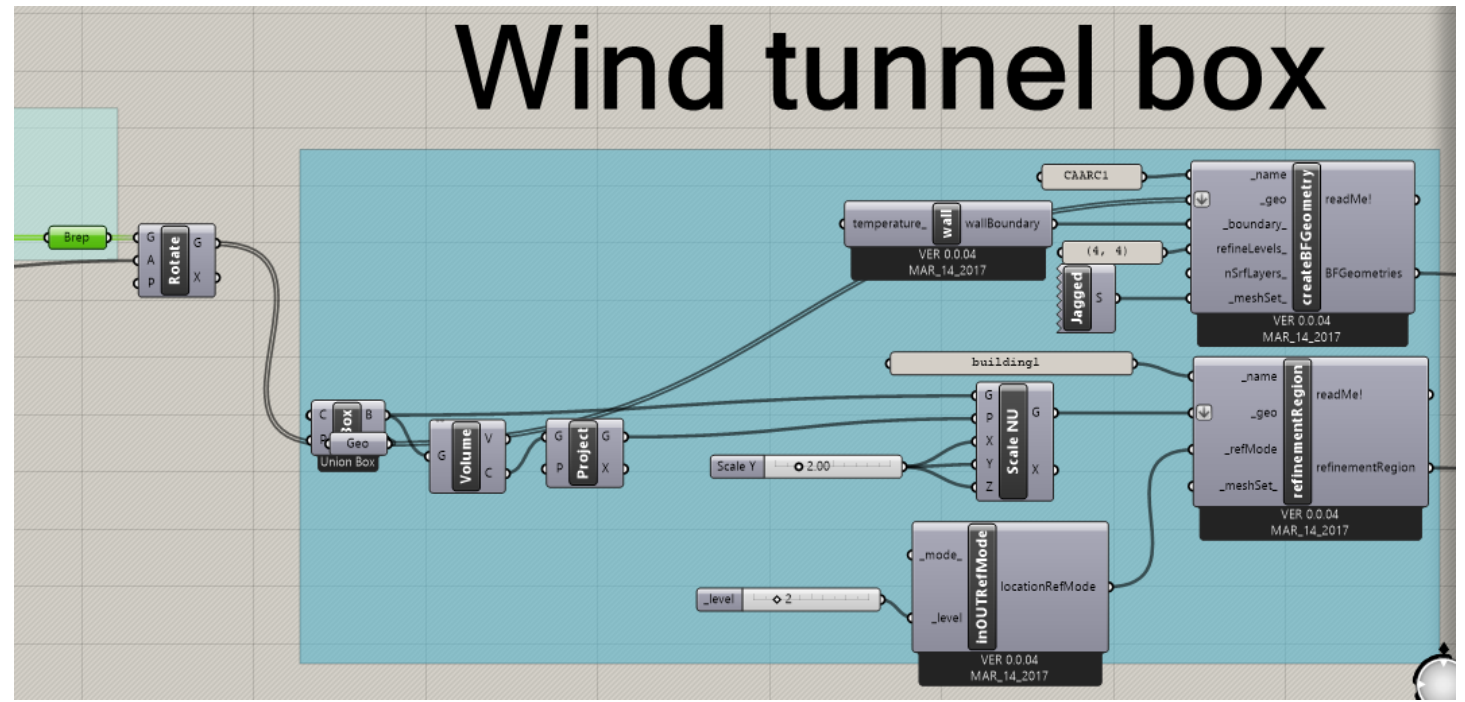

Figure A. 11 Set-up of wind tunnel box

- Step3: Grid and mesh

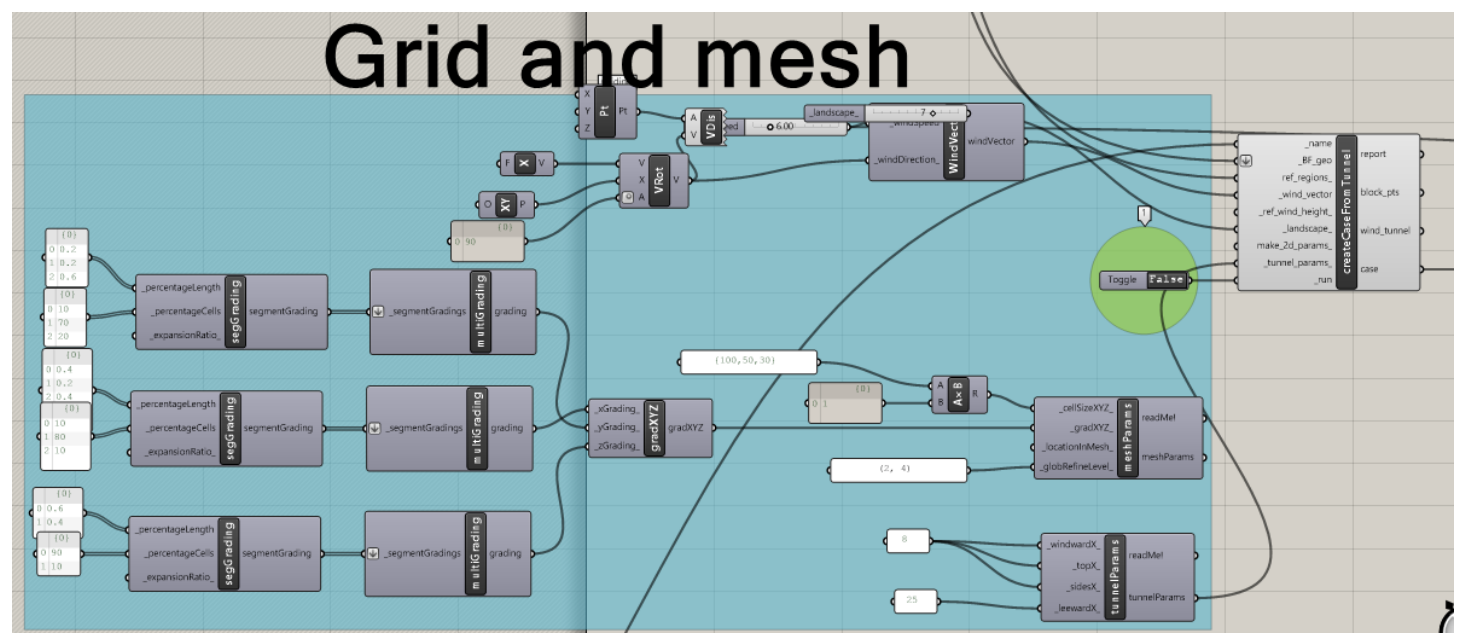

Figure A. 12 Set-up of grid and mesh

- Step4: Set test points

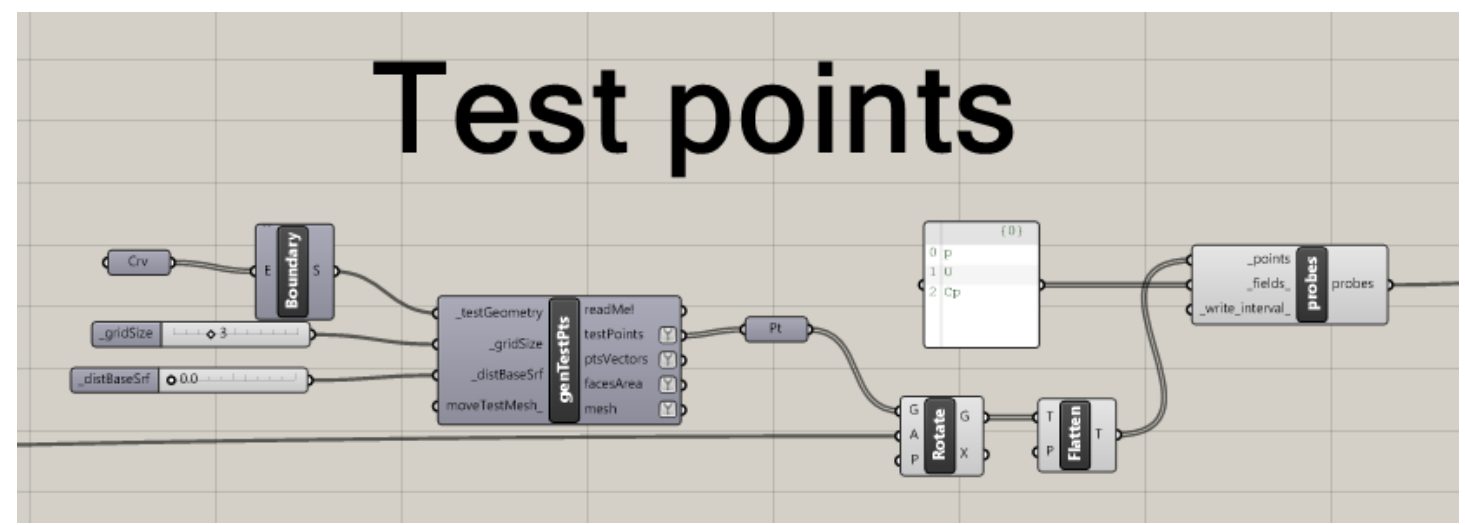

Figure A. 13 Set-up of test points

- Step5: Run the simulation and calculate urban wind speed 


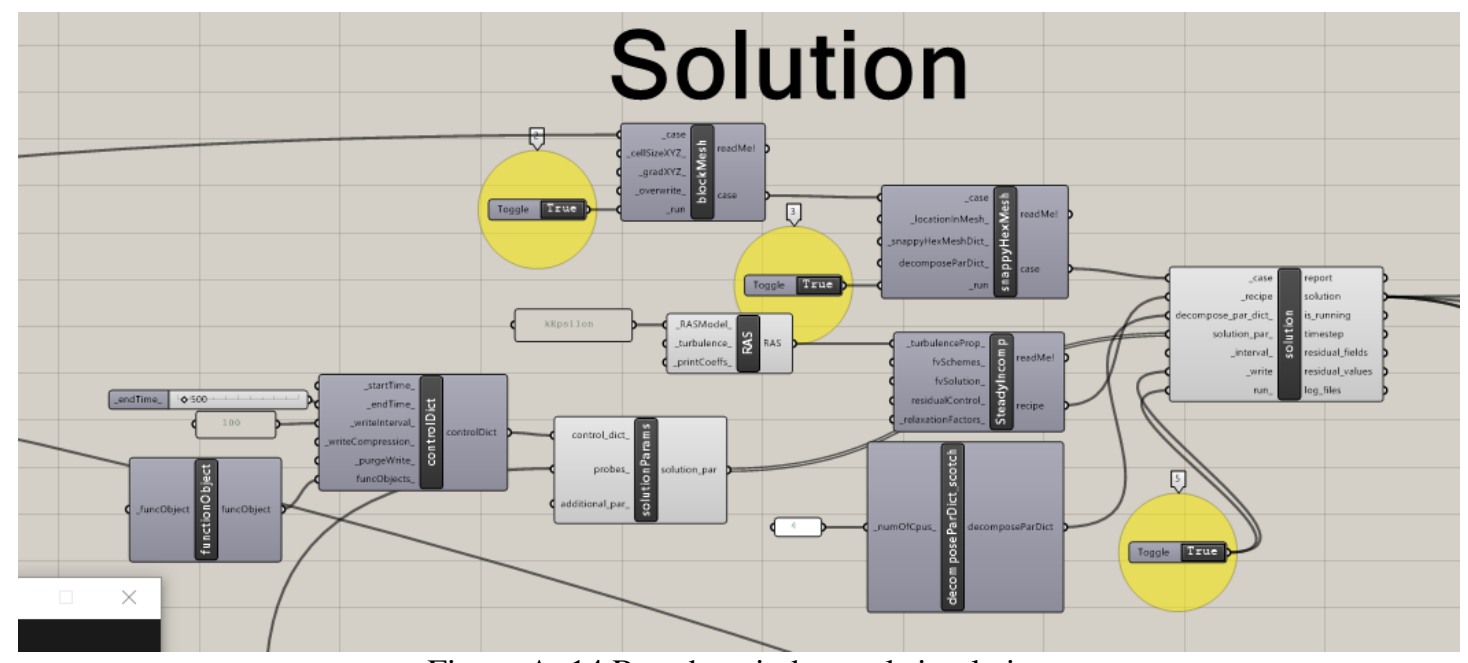

Figure A. 14 Run the wind tunnel simulation

\section{A.2.2 Urban Heat Island}

- Step1: Geometry of the city (same as A.2.1)

- Step2: Import geometries of the city and weather file

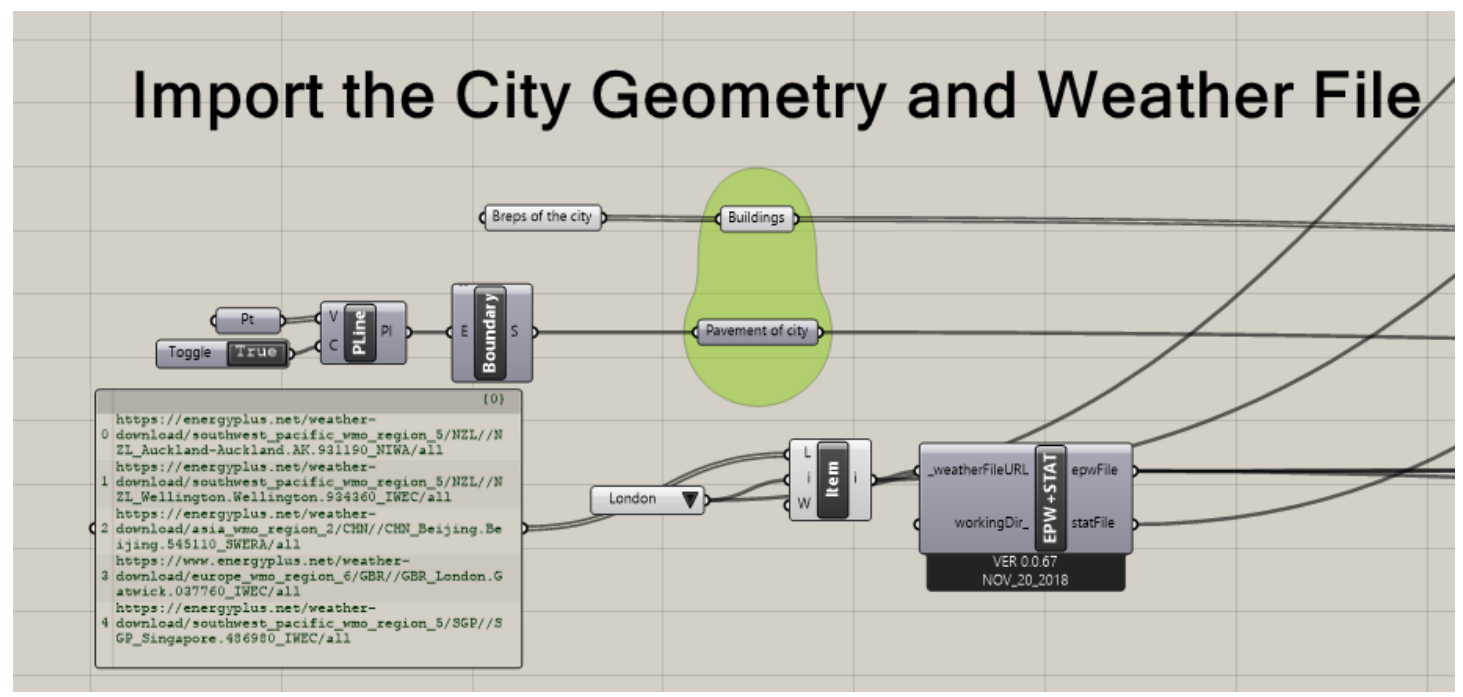

Figure A. 15 Set-up of weather data and urban configuration

- Step3: Define typologies and the city 


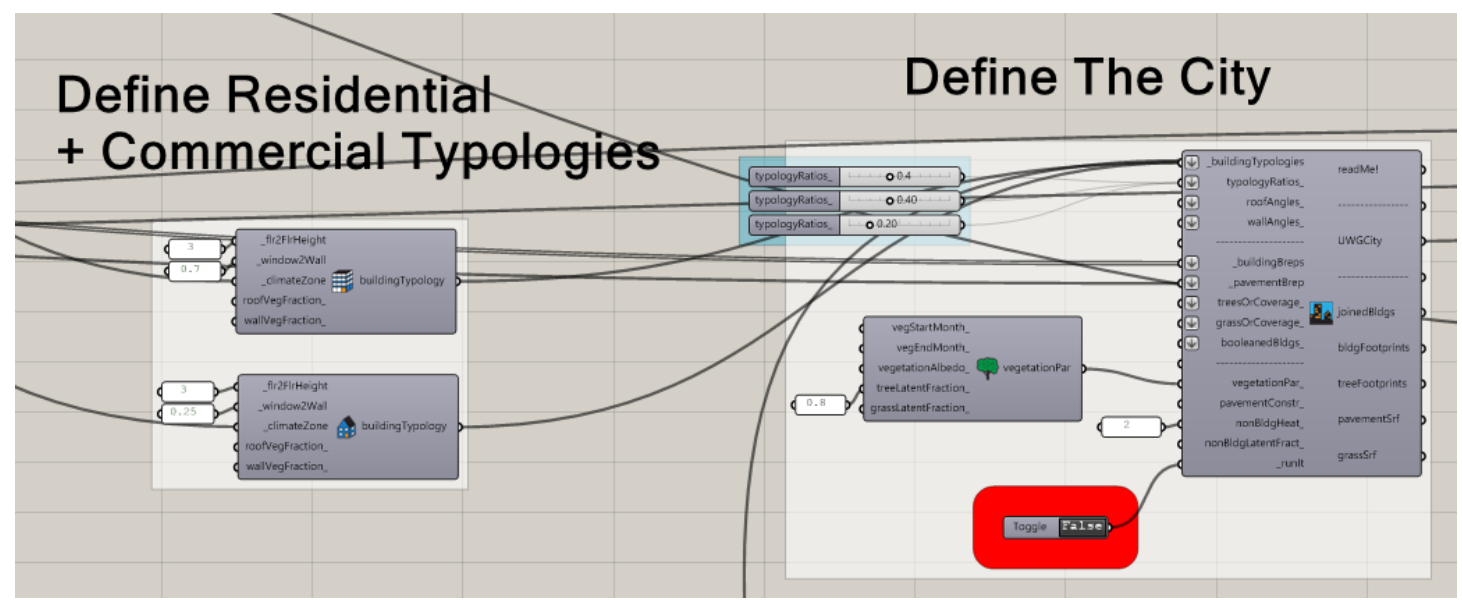

Figure A. 16 Define the parameters of the city

- Step4: Run the UWG and get the UHI weather file with epw format

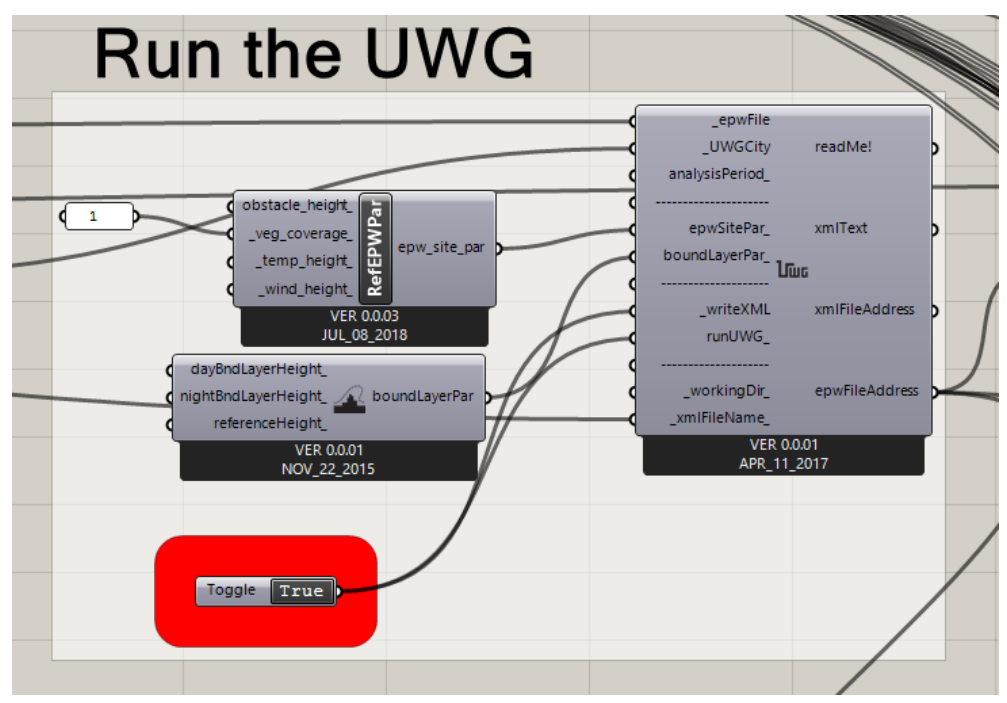

Figure A. 17 Simulate the UHI effects

\section{A.3 Detailed natural ventilation system}

- Step1: Get wind pressure coefficients around the prototypical building (wind tunnel model similar to A.2.1)

- Step2: Import wind pressure coefficients into EnergyPlus model 


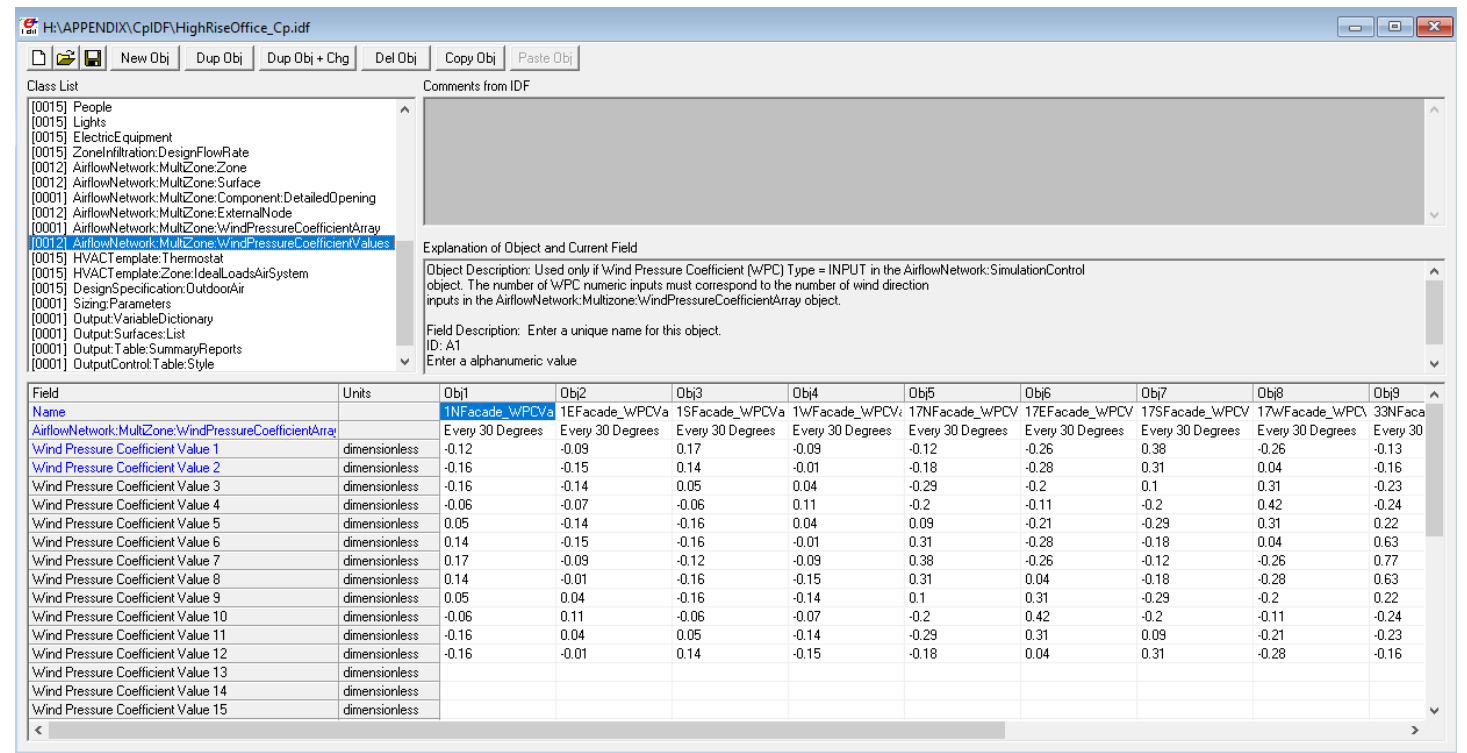

Figure A. 18 Set-up of the wind pressure coefficients of AirflowNetwork

- Step3: Simulate the building performance and calculate thermal loads (same as A.1)

\section{A.4 Versions of programs and plugins used in the simulation system}

Table A. 1 Programs and plugins for the urban microclimate simulation system

\begin{tabular}{c|c|c|c|c}
\hline & OpenFOAM & $\begin{array}{c}\text { Urban Weather } \\
\text { Generator }\end{array}$ & \multicolumn{2}{|c}{ EnergyPlus } \\
\hline Version & v1812 & 4.1 & \multicolumn{2}{|c}{9.1 .0} \\
\hline Plugin & Butterfly & Dragonfly & Ladybug & Honeybee \\
\hline Version & $\begin{array}{c}\text { VER 0.0.04 } \\
\text { Oct_06_2018 }\end{array}$ & $\begin{array}{c}\text { VER 0.0.01 } \\
\text { APR_29_2016 }\end{array}$ & $\begin{array}{c}\text { VER 0.0.66 } \\
\text { Mar_03_2018 }\end{array}$ & $\begin{array}{c}\text { VER 0.0.63 } \\
\text { May_18_2018 }\end{array}$ \\
\hline
\end{tabular}

